Lac du Flambeau Band of Lake Superior Chippewa Indians

\title{
Strategic Energy Plan
}

November 16th, 2009 


\section{Introduction}

The energy situation for the Lac du Flambeau Band of Lake Superior Chippewa Indians and the Lac du Flambeau Reservation has many areas of concern. The Tribe has recently seen significant increases in the financial costs of its energy and will likely see these costs continue to rise in the future. There are also significant environmental costs associated with the energy sources used by the Tribe. The reservation is supplied with electricity by a private electric utility that largely utilizes fossil fuels to produce its power. A majority of the thermal energy used on the reservation also is fossil fuel derived. Not only are these sources expensive and polluting, these sources are not produced locally, which therefore leaves the Tribe almost completely reliant upon others for its energy.

This plan discusses the current energy use on the Lac du Flambeau Reservation, the current status of the Tribe's energy program, as well as the issues and concerns with energy on the reservation. This plan also identifies and outlines energy opportunities, goals, and objectives for the Tribe to accomplish. The overall goal of this plan is to address the energy situation of the reservation in a holistic manner for the maximum benefit to the Tribe. This plan is an evolving document that will be re-evaluated as the Tribe's energy situation changes.

The Tribe aims to address its energy situation with the following vision:

"The Lac du Flambeau Tribe will commit to utilize local energy resources that reduce the environmental and financial costs of energy use to ultimately gain Tribal energy independence."

\section{Current Energy Use on the Reservation}

\section{Electric Energy}

The commercial facilities and housing of the Lac du Flambeau Band of Lake Superior Chippewa Indian Reservation are located within the electric service territory of Wisconsin Public Service Corporation (WPS), a private electric utility which operates under the jurisdiction of the Public Service Commission of Wisconsin. The utility provides retail electricity sales through electric distribution lines to Tribal and non-Tribal commercial facilities on the reservation, as well as tribal and non-tribal housing on the reservation. WPS's electricity is not produced on or near the Lac du Flambeau Reservation. The electricity is transferred from power plants scattered throughout and around the WPS service territory through a series of electrical transmission lines, then through distribution lines, ultimately leading to the reservation. The Tribe is completely reliant upon WPS as a provider and distributor of electricity for its facilities, businesses, and residents. Although, some tribal facilities do have diesel-fueled back-up generators for emergency electricity use during WPS power outages.

The majority of the WPS electricity comes from coal-fired power plants located in and around the utility's service territory (66\%), followed by nuclear power (24\%), hydroelectric (5\%), Gas $(4 \%)$, and renewable energy (wind, solar, biomass) only comprising $1 \%$ of the utility's power supply and therefore only $1 \%$ of the Tribe's electricity. (See Figure1) 


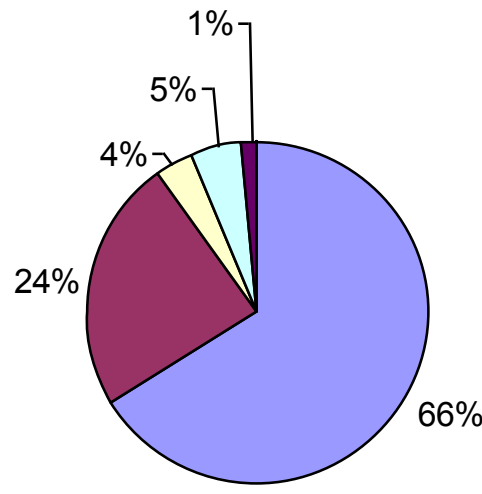

$$
\begin{aligned}
& \square \text { Coal } \\
& \square \text { Nuclear } \\
& \square \text { Gas } \\
& \square \text { Hydroelectric } \\
& \square \text { Renewables }
\end{aligned}
$$

\section{Thermal Energy}

All Tribal facilities on the reservation gain the majority of their thermal energy (heating) from propane (LP) as there are no natural gas lines on the reservation. The Tribe does not own or operate an LP distribution utility, so this energy source is also purchased from private LP distributors, one of which is located within the reservation boundaries and several others located off of the reservation in nearby communities. Tribal facilities usually solicit for bids annually for LP and contract with a distributor for the heating season. The LP is delivered by the distributors and stored in bulk storage tanks outside and adjacent to Tribal facilities. Tribally-owned facilities are completely reliant on the LP distributors for thermal energy.

The majority of tribal residences also heat with LP, although many residences on the reservation also supplement their LP heat by burning cordwood in woodstoves and fireplaces, while some residences primarily heat their homes with cordwood in outdoor wood boilers, as well as indoor woodstoves. The cordwood can be obtained by gathering on and off the reservation, as well as by purchase. It is estimated that between 25 and 50 percent of residences burn wood for a portion of their heat. Some residences also use wood pellets as a thermal energy source for their homes in pellet stoves and furnaces. Currently there is no local production of wood pellets in the Lac du Flambeau area although pellets can be delivered or purchased at businesses near the reservation.

Many Tribal office facilities and homes also supplement their thermal energy with electric space heaters.

\section{$\underline{\text { Renewable Energy }}$}

Currently, the aerators at the Tribal wastewater treatment facility and the Bear River gauging station located at $3^{\text {rd }}$ Bridge are powered by solar photovoltaic (PV) systems. Residences on the reservation utilize some renewable energy in their use of cordwood and wood pellets for thermal 
heating. Otherwise, there is currently no other utilization of renewable energy on the reservation by the Lac du Flambeau Tribe.

\section{$\underline{\text { Tribal Energy Loads and Costs }}$}

The Tribal Natural Resources Department, in collaboration with Seventh Generation Energy Systems, Wisconsin Public Service, Petroleum Heat and Power, and Ritchie Oil completed an analysis of recent Tribal energy use in 2008. This analysis included the compilation of annual energy use totals, energy price rates, evaluation of use and price trends, environmental impacts, and projections into the future. This energy analysis covered the years 2003 through 2007, and the future projections were analyzed through the year 2017. (See Addendum 1 - Executive Summary, Task One, and Task Two for detailed information and findings)

In 2007, the Tribe (excluding residential, Chippewa Housing Authority (CHA), and elder utilities) held 138 electric accounts with Wisconsin Public Service powering 92 facilities, which included all Tribal gaming, business, government, natural resources, and water/sewer operations on the reservation, as well as the Lac du Flambeau Public School. The actual price rates for a facility's electricity vary significantly depending on account type, the average demand, or the amount of electricity used each month. Typically, the more electricity a facility uses, the cheaper the cost per kilowatt hour (kWh) of electricity. (See Addendum 1 - Task 1-1.4.1, and Task 2-1.2 for more information on WPS electricity rates)

In 2007, Tribal facilities used 11.8 million $\mathrm{kWh}$ of electricity and 407,000 gallons of LP. Eighty-six percent of the overall electricity use was consumed by the 10 Tribal facilities with the highest electricity use, and $83 \%$ of the overall propane use was consumed by the 10 Tribal facilities with the highest LP use. The overall use of electricity by the Tribe increased by $10 \%$ from 2003 to 2007, while during this same five year period, the amount of money the Tribe spent on electricity increased by $46 \%$, for a 2007 electricity price of $\$ 826,026$. Also during that time period, the overall LP use by the Tribe increased by $47 \%$, while LP expenditures increased by $173 \%$. It is estimated that if these price trends continue, the energy bill for the Tribe could be near $\$ 5$ million by the year 2017. (See Figure 2 and Table 1 below, and Addendum 1 - Task 1 and Task 2 for more information)

Figure 2: Annual Lac du Flambeau Energy Costs, 2003-2007

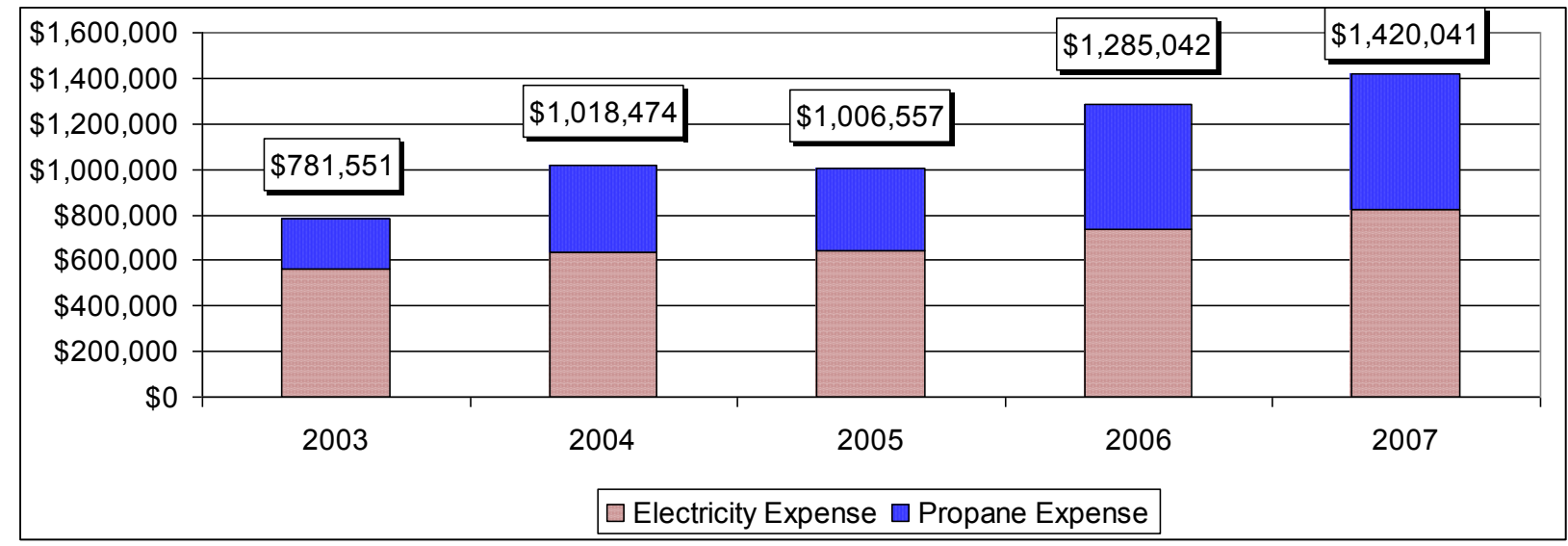


Table 1: Annual Electricity and Propane Consumption and Cost, 2003 to 2007

\begin{tabular}{|l|c|c|c|c|}
\hline Year & Electricity $(\mathrm{kWh})$ & Electricity Expenses (dollars) & Propane (gallons) & Propane Expenses (dollars) \\
\hline 2003 & $10,758,223$ & $\$ 564,603$ & 274,292 & $\$ 216,948$ \\
\hline 2004 & $11,050,869$ & $\$ 638,091$ & 388,589 & $\$ 380,383$ \\
\hline 2005 & $10,297,054$ & $\$ 640,596$ & 292,825 & $\$ 365,961$ \\
\hline 2006 & $11,634,594$ & $\$ 733,593$ & 397,817 & $\$ 551,449$ \\
\hline 2007 & $11,870,059$ & $\$ 826,026$ & 407,476 & $\$ 594,014$ \\
\hline TOTAL & $\mathbf{5 5 , 6 1 0 , 7 9 9}$ & $\mathbf{\$ 3 , 4 0 2 , 9 0 9}$ & $\mathbf{1 , 7 6 0 , 9 9 9}$ & $\mathbf{\$ 2 , 1 0 8 , 7 5 5}$ \\
\hline
\end{tabular}

The costs of this energy use are not limited to the financial costs outlined above. There is a significant environmental cost associated with the Tribe's energy use, largely in part to the fact that a majority of the Tribe's energy sources comes from the burning of fossil fuels. The WPS power supply mix is largely from burning coal, a fossil fuel, and LP gas, which is also fossil fuel derived. Table 2 below shows the quantified air emissions associated with the Tribal facilities energy use in 2007.

\begin{tabular}{|r|l|c|c|c|c|}
\hline & $\begin{array}{c}\text { Equivalent metric } \\
\text { description (lbs) }\end{array}$ & $\begin{array}{c}2007 \\
\text { electricity } \\
(\mathrm{kWh})\end{array}$ & $\begin{array}{c}\text { 2007 propane } \\
\text { (gallons) }\end{array}$ \\
\hline $31,331,860$ & Pounds of CO2 & are released from & $11,870,059$ & and the & 407,476 \\
\hline 73,364 & Pounds of NOx & are released from & $11,870,059$ & and the & 407,476 \\
\hline 144,831 & Pounds of SOx & are released from & $11,870,059$ & and the & 407,476 \\
\hline 1 & Pounds of mercury (HG) & are released from & $11,870,059$ & and the & 407,476 \\
\hline
\end{tabular}

\section{Current Status of the Tribe's Energy Program}

In October of 2007, The Tribe secured funding from the U.S. Department of Energy - Tribal Energy Program to assess and evaluate the current use and cost of energy on the reservation by Tribal facilities, as well as to assess and evaluate the potential for utilizing renewable or alternative energy on the reservation. The funding provided for a part-time staff person to coordinate the activities of the project, and for the contracting of a consultant to perform the technical analysis of the Tribe's current energy use, and the assessments of the Tribe's renewable energy resources. The consultant also analyzed the opportunities to retrofit Tribal facilities with 
renewable energy systems for electricity as well as heating and cooling. The Tribe would then identify issues, concerns, and goals, and compile these ideas into a Strategic Energy Plan to guide the Tribe towards energy conservation, renewable energy deployment, and energy independence.

During this project period, the project coordinator, with the assistance of Wisconsin's Focus on Energy program conducted walk-thru energy audits of the larger Tribal facilities to identify opportunities for energy savings through conservation and efficiency upgrades. The reports for each facility that was audited are currently available to Tribal staff for review. (See Addendum 1 - Task 3) Also, during the project period the Tribe hosted a training "Practical Energy Management for Schools and Government" in which tribal staff learned about typical energy issues with commercial facilities, maintenance of equipment for energy efficiency, opportunities for incentives and savings through Focus on Energy program, efficiency upgrade energy savings calculations, among many other energy related topics.

Tribal staff also coordinated with the hired energy consultant, Seventh Generation Energy Systems of Madison, WI as well as other energy professionals and groups to complete an assessment of the Tribes potential to use renewable energy such as wind, solar, geothermal, hydro, and biomass on the reservation. The Tribe now has technical reports on the findings of these assessments, with recommendations for deployment of systems that utilize these renewable and alternative energy technologies. Individual tribal facilities were analyzed for their potential to retro-fitted with these renewable energy systems, as well as the analysis of the financial return on investment for the individual systems. (See Addendum 1 - Task 1through Task 8)

Also during this time period, the Tribal Council has publicly supported pursuing the development of a $25 \times 25$ plan, in which the Tribe would work to obtain $25 \%$ of its energy from renewable sources by the year 2025 .

The funding for the Tribe's Energy Program has been limited to just this current project. The Tribal Natural Resources Department has continued to seek additional resources, although a majority of funding sources require a significant match from the Tribe for energy projects, which currently has left the program with limited opportunities.

\section{$\underline{\text { Issues and Concerns }}$}

\section{Energy Conservation and Energy Efficiency}

- Many Tribal facilities (government and business) are largely energy inefficient due to deterioration with age, poor insulation/weatherization, and inefficient HVAC systems, appliances, and lighting

- Tribal electricity use (commercial facilities) has increased at an average of $10 \%$ from 2003 to 2007

- Tribal LP use (commercial facilities) has increased at an average of $47 \%$ from 2003 to 2007

- Many Tribal residences are not properly weatherized for the local climate and are not energy efficient

- Many Tribal residential woodstoves are out-dated and burn inefficiently 
Energy Resources and Energy Independence

- The Tribe is entirely dependent on acquiring electricity from an outside private, forprofit, utility whose energy is produced off of the Reservation, mainly from coal-fired power plants

- Tribal commercial facilities are entirely dependent on acquiring LP fuel from local, private distributors for thermal energy (heating).

- Tribal residences are largely dependent on acquiring their thermal energy (heating) from local, private distributors of LP fuel

- Tribal forestry and logging operations offer options for utilization of woody biomass (logging residue, cordwood, sawlogs, etc) for thermal and/or electrical fuel, but currently are not utilized locally within the Tribe for either of these purposes

- The Tribe does not own and operate its own utility for electricity distribution or thermal energy/fuel distribution to Tribal facilities, businesses, or to Tribal members or community members residences, and is therefore largely dependent on other entities for its energy

- Currently there are no electrical transmission lines on the reservation, through which wholesale power could be supplied to the reservation, or in which the Tribe could supply large quantities of power to be sold to other users

\section{Financial and Environmental Costs}

- Tribal expenditures on electricity (commercial facilities) have increased $46 \%$ from 2003 to 2007

- Tribal expenditures on LP (commercial facilities) has increased at a rate of $173 \%$ from 2003 to 2007

- The majority of funds spent on local energy costs do not stay in the Lac du Flambeau community

- Existing Tribal energy use poses threats to the local, regional, and global environment; specifically by energy sources contributing to air pollution, and the unnatural release of greenhouse gases

- The opportunity to take advantage of federal tax credits/incentives for utilization of renewable energy systems is currently unavailable for the Tribe

- Many Tribal residential woodstoves are out-dated and release significant emissions that are potentially harmful to indoor and outdoor air environments

\section{Education and Capacity Development}

- Lack of educational resources available to the community regarding local, regional, and global energy issues

- Tribal staff, CHA staff, and local contractors/tradesman are currently not trained professionally in energy efficiency, renewable energy system site assessments, or system installations 


\section{Opportunities}

Energy Conservation and Energy Efficiency

- Energy efficiency retrofit projects on Tribal facilities can be deployed for significant energy savings (See Addendum - Task 3)

- Develop a wood-stove change out program for Tribal residences to replace old inefficient woodstoves with new, more efficient models

\section{Energy Resources and Energy Independence}

- The Tribe can gain "Energy Independence" by deploying Tribally owned and operated renewable energy systems on the reservation that produce clean energy from local resources (See Addendum 1 - Task 4 through Task 8)

- Build a model "green" office complex designed for low energy use and the utilization of alternative/renewable energy technologies

- Build model residence(s) designed for low energy use and the utilization of alternative/renewable energy technologies

\section{Financial and Environmental Costs}

- Economic development by keeping energy dollars in the community

- Utilize locally produced renewable electric and thermal energy resources to reduce the financial and environmental costs that are currently associated with local energy use

- Assess and evaluate energy efficiency and renewable energy projects as a long-term financial investments that immediately reduce environmental costs, rather than only pursuing projects with quick financial returns

\section{Education and Capacity Development}

- Explore new markets or assess feasibility for manufacturing energy or smart-grid related materials or supplies (Simpson Electric)

- Pursue tribal staff training on energy efficiency as well as renewable energy systems, building site assessments, and system installations

- Educate the community on opportunities for energy efficiency and renewable energy through presentations, publications, classes, and trainings

\section{Goals and Objectives}

- "To improve efficiency of energy use in Lac du Flambeau"

Deploy energy efficiency retrofits to Tribal facilities systems for lighting, HVAC, or other systems where possible, with priority given to systems over 20 years old 
$>$ Develop building codes for Tribal buildings and housing that addresses energy efficiency and conservation as well as opportunities for easily retrofitting with renewable energy systems

$>$ To develop a Tribal transportation energy plan that addresses energy efficiency of local transportation

$>$ To develop a Tribal woodstove change out program to replace older inefficient woodstoves with newer clean burning models with increased efficiency

- "To increase Lac du Flambeau energy independence by utilizing local, renewable energy resources"

$>$ Deploy renewable energy technologies on Tribal facilities (see Addendum 1 Task 4 through Task 8)

$>$ Pursue further feasibility assessments of micro-scale to commercial-scale energy development utilizing renewable resources such as biomass, solar, wind, municipal and residential waste, algal, and other renewable energy technologies (See Addendum 1 - Task 4 through Task 8)

$>$ Prioritize green building techniques with new construction and remodeling of Tribal facilities and housing

$>$ Achieve Tribal energy independence through development and deployment of locally produced renewable/alternative energy technologies

$>$ To obtain $25 \%$ of LdF energy sources from renewable resources by 2025 and develop a " 25 x 25 " plan

$>$ Develop a Forestry wood chip program that creates jobs and enhances biomass resources by removing usable biomass from forest from timber sales, timber stand improvement projects, or other sources

$>$ Coordinate with other agencies to evaluate other potential local resources of biomass such as State and Federal lands, as well as private forests.

$>$ Utilize local biomass for development of a pellet mill to provide a clean and efficient resource to heat Tribal facilities and homes

$>$ Develop a centrally located combined heat and power plant that utilizes biomass for electricity production and distribution of heat in to Tribal facilities and homes

$>$ Assess feasibility of developing a Tribal-owned utility for electricity distribution and/or LP distribution

$>$ Develop a Tribal transportation energy plan for utilizing alternative and/or renewable fuels for Tribal fleet vehicles and Tribal member vehicles

- "To reduce the financial and environmental costs of energy use in Lac du Flambeau"

Deploy renewable energy systems that significantly reduce the use of conventional, non-renewable energy sources for the most financial and environmental benefit to the Tribe

$>$ Seek Federal, State, or other funding sources to leverage with Tribal resources for deployment of energy efficiency improvements and renewable energy systems that reduce energy costs and negative environmental impacts 
Coordinate with local electrical utility to take advantage of available financial benefits offered through deployment of renewable energy systems

$>$ Research and pursue opportunities for the Tribe to take advantage of Federal tax credits for renewable energy system deployment

- "Education of the Lac du Flambeau Community and Lac du Flambeau Tribal Staff on energy issues, energy technologies, and local energy opportunities"

$>$ To educate the public on issues with current status of energy in Lac du Flambeau, the region, the nation, and the World (air pollution, global climate change, dependence on outside resources, fossil fuels, etc)

$>$ To educate the public on energy conservation, efficiency, and local renewable technology opportunities for Lac du Flambeau

$>$ To train Tribal staff in energy efficiency and renewable energy technologies

$>$ To build a model "green" office complex for the Tribal Natural Resources Department, which can be used as a demonstration facility for education the public on sustainable design and renewable energy technologies

$>$ To build a model residence or group of residences that utilize renewable energy technologies for electricity and thermal energy to educate the public of these options

\section{Alternative I: (No change)}

This alternative would result in the Tribe continuing to purchase all electricity from the local electric utility, currently Wisconsin Public Service Corporation, at retail electricity prices. Tribal facilities would continue to obtain thermal energy from LP, purchased through local distributors. Tribal residences would also continue to purchase their electricity from the local utility, and obtain thermal energy through purchasing LP for furnaces and purchasing or gathering wood for woodstoves.

Under this alternative, the Tribe would not employ staff to operate an Energy Program. Any energy improvements for Tribal facilities would be done through existing building maintenance activities or remodeling projects. The Tribe would not seek development of local renewable energy technologies for electric or thermal energy. The Tribe would not further pursue developing educational opportunities regarding energy issues or technologies for the public or Tribal staff. The estimated annual budget for this alternative would be $\$ 0$.

\section{$\underline{\text { Effects of Alternative I: }}$}

Under this alternative, the Tribe would remain entirely dependent on the private, electrical utility to obtain electricity by purchase. The Tribe would also remain entirely dependent on private LP distributors for thermal energy, except where residences can burn cordwood for heat. The Tribe would experience an entire lack of energy independence and energy sovereignty.

The financial costs for Tribal facilities' energy could very likely become close to $\mathbf{\$ 5}$ million annually by the year 2017. The environmental costs of the Tribe's electricity use would 
continue to be determined by the private distribution utility, and will be under no control of the Tribe. Tribal residences will also continue to experience increased financial costs for their electricity and thermal energy.

Energy education opportunities for Tribal members and Tribal staff would be limited to those offered from outside agencies. Tribal capacity to develop and carryout energy efficiency or renewable energy projects would also be limited as there will not be trained Tribal staff dedicated to pursuing these opportunities

\section{Alternative II: (preferred)}

Under this alternative, the Tribe would focus on addressing the energy issues of the Tribe and community as a whole. This would involve executing energy efficiency and renewable energy deployment projects, utilizing recommendations in Addendum 1 - Tasks 1 through Task 8. The Tribe would also pursue further feasibility studies and analysis of local renewable energy resources like biomass, and micro to commercial scale renewable energy technology opportunities, especially as those technologies continue to develop.

The Tribe would work closely with the utilities and other agencies to examine opportunities for saving on the financial and environmental costs of the Tribe's energy use. The Tribe would also aggressively pursue Federal and State grant-funded opportunities for energy projects, and leverage Tribal resources on these projects wherever possible.

The Tribe would also host community-based activities and collaborative initiatives to help accomplish the energy goals of the Tribe, and educate the community on energy-related issues and opportunities. Technical training for staff and community members on energy efficiency and renewable energy technologies would be provided to build capacity within the Tribe and the community.

The Tribe would also pursue further planning where necessary to address all energy issues that may arise or be identified.

Under this alternative, it would be necessary to expand the Tribe's Energy program to employ at least one full-time staff to carry out these duties. The estimated annual budget would be $\$ 200,000$, plus additional funds for potentially larger deployment projects.

\section{Effects of Alternative II:}

Under Alternative II, the energy issues facing the Tribe would be addressed in a holistic manner. The Tribe would work to deploy projects that solve energy inefficiencies, and install energy systems that utilize local, renewable, and clean energy sources. The Tribe would gain independence from energy providers by utilizing these energy resources and technologies.

Tribal forestry management will be enhanced as the Tribe pursues further utilization of the local woody biomass resource. As a result, tribal members will also have more opportunities for residential thermal energy savings by utilizing this enhanced local resource. 
The Tribe would experience significant financial savings in its energy use, as well as lessen the environmental impacts of using conventional energy resources like fossil fuels. More of the money spent on energy would stay in the Lac du Flambeau community, thus providing opportunities for economic development and job creation in the community.

Tribal sovereignty and self-determination will be enhanced as the Lac du Flambeau Tribe becomes less dependent on outside sources for energy.

\section{Alternative III:}

Under this alternative, the Tribe would aggressively pursue the development of a utility for the distribution of electrical and thermal energy. The Tribe would attempt to negotiate the purchase of the energy distribution infrastructure which currently exists on the Reservation, or would purchase and deploy or erect its own infrastructure. The Tribe would then pursue the extension of an electrical transmission line onto the reservation in order to purchase electricity from power plants and the transmission company, or build a commercial power production facility on its own.

This alternative would require a very significant investment by the Tribe financially for the research, legal processes, and purchasing of the infrastructure and operational facilities.

Effects of Alternative III:

Under this alternative, the Tribe would be able to purchase energy at wholesale rates, cheaper than what it currently pays, but would then be responsible for the distribution of the energy to Tribal facilities, businesses, and residences. Also, unless the Tribe built a power plant on the Reservation, it would continue to be largely dependent on outside private sources for its energy.

Some effects that may result from this alternative would include legal and jurisdictional issues, regional utility and environmental regulations, maintenance of infrastructure, and bill collection issues.

This alternative could give the Tribe energy independence, but not without a significant added responsibility associated with this type of development. 


\section{Energy Matrix}

O Alternative does not meet this goal

/ Alternative partially meets this goal

$\mathbf{X} \quad$ Alternative fully meets this goal

\section{Goals $\underline{\text { Alternative I }} \underline{\text { Alternative II }}$ Alternative III}

To improve efficiency of energy use in Lac du Flambeau

To increase Lac du Flambeau energy independence by utilizing local, renewable energy resources

To reduce the financial and environmental costs of energy use in Lac du Flambeau

Education of the Lac du Flambeau Community and Lac du Flambeau Tribal Staff on energy issues, energy technologies, and local energy opportunities 


\section{RESOLUTION NO. 227(09)}

WHEREAS, the Tribe's vision statement reads, "The Lac du Flambeau Tribal Council has the responsibility to create a sustainable community for Tribal Members, descendents and the seventh generation"; and

WHEREAS, the Lac du Flambeau Band of Lake Superior Chippewa Indians vision for the environment is to protect, conserve and enhance the resources of the Lac du Flambeau Reservation for the present and future generations; and

WHEREAS, the Tribe has established an Energy Program within the Tribal Natural Resources Department in October of 2007 through U.S. Department of Energy's Tribal Energy Program Grant \#DE-FG36--07G017085 with a goal to complete an audit of Tribal Facilities' energy use to establish a baseline of Tribal energy use, assess the potential for utilizing renewable energy on the reservation and to create Strategic Energy Plan for the Reservation; and

WHEREAS, the activities for this project are complete and the Tribe's Natural Resources Planning Departments have drafted Strategic Energy Plan for the Tribe to be included as a chapter to the Tribe's Integrated Resource Management Plan with Alternative II as the recommended and preferred alternative; and

WHEREAS, the Strategic Energy Plan was publicly available for comment from Tribal members and Tribal Staff from October $5^{\text {th }}, 2009$ to October $16^{\text {th }}, 2009$; and

WHEREAS, the comments received from the public overwhelmingly support the Tribal Strategic Energy Plan and Alternative II; now therefore be it

RESOLVED, by this Council in Regular Session assembled, hereby approves and supports the Lac du Flambeau Tribal Strategic Energy Plan dated November 16, 2009 with Alternative II as the Preferred Alternative; and be it further

RESOLVED, to approve that the Lac du Flambeau Tribal Strategic Energy Plan be included as a chapter to the Tribe's Integrated Resource Management Plan; and be it further

RESOLVED, to adopt the following as the Lac du Flambeau Tribal Energy Vision Statement: "The Lac du Flambeau Tribe will commit to utilize local energy resources that reduce the environmental and financial costs of energy use to ultimately gain Tribal energy independence."

\section{CERTIFICATION}

I, the undersigned, as Secretary of the Lac du Flambeau Band of Lake Superior Chippewa Indians, a tribal government operating under a Constitution adopted pursuant to Section 16 of the Indian Reorganization Act, 25 U.S.C., s. 476, do hereby certify that the Tribal Council of the Band is composed of twelve members, of whom eleven constituting a quorum, were present at a Regular Meeting, duly called, noticed, convened, and held on the 23rd Day of November, 2009, and that the foregoing resolution was duly adopted at said meeting by an affirmative vote of nine members, one against ( $E$. Risingsun). none abstaining, and that the said resolution has not been rescinded or amended in any way.

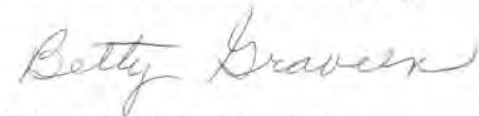

Betty Jo Graveen, Secretary

Lac du Flambeau Band of Lake

Superior Chippewa Indians 


\section{Renewable Energy and Conservation Planning}

Submitted to:

\section{Lac du Flambeau Band of Lake Superior}

Chippewa Indians

Tribal Natural Resources Department

Lac du Flambeau, WI 54538

(715) 588-3303

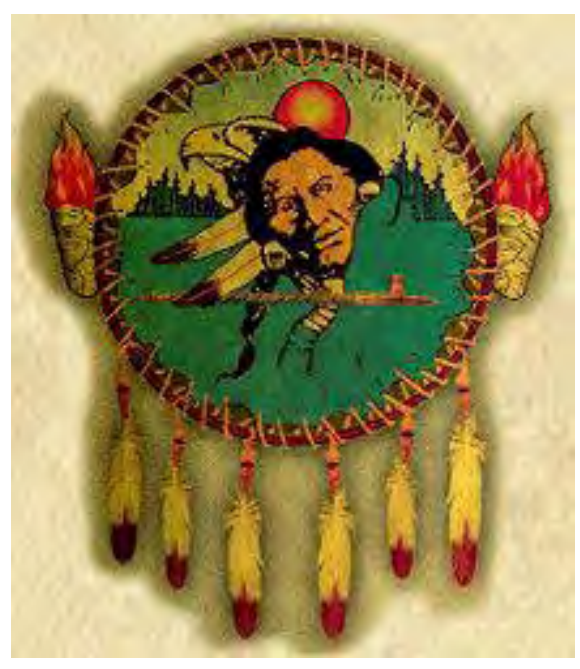

\section{SEVENTH}

GENERAT I ON

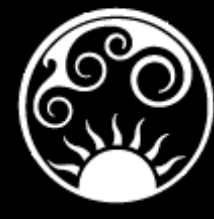

ENERGY

SYSTEMS

Submitted by:

Seventh Generation Energy Systems, Inc.

100 South Baldwin Street, Suite 304

Madison, WI 53703

www.seventhGenergy.org

info@seventhGenergy.org

Phone: (877) 222-9201

Fax: (866) 762-7496

February 2, 2009

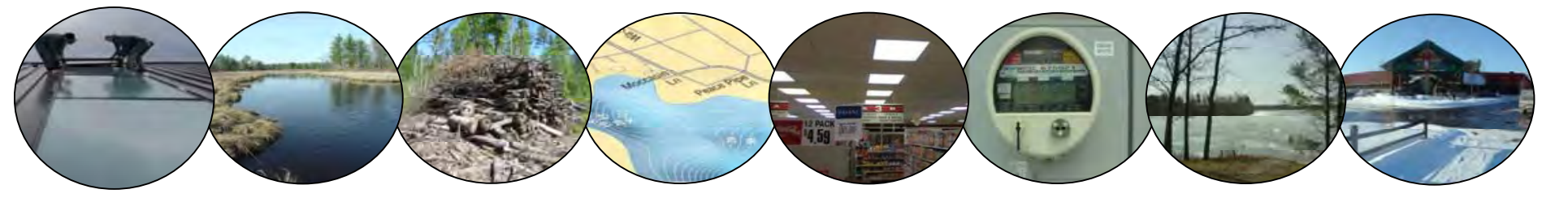




\section{Acknowledgements}

Seventh Generation Energy Systems, Inc., (SGES) is pleased to present this report for renewable energy and conservation planning to the Lac du Flambeau Band of Lake Superior Chippewa Indians. The project could not have been completed without the invaluable guidance and support of Tribal staff, and we are thankful for the staff's engaged participation and their continued enthusiasm and commitment to sustainable energy planning.

\section{Executive Summary}

In November 2007, the Lac du Flambeau Tribe sought consultant services to conduct a renewable energy and conservation study. The Tribe received funding for this project under the Department of Energy's First Steps Towards Developing Renewable Energy and Energy Efficiency on Tribal Lands. The goal of the consultant for the renewable energy and conservation study was to provide technical assistance in the development of a Strategic Energy Plan for the Tribe.

The proposal for the Renewable Energy and Energy Efficiency Planning project identified five subject areas, including:

1. Understanding the Tribal energy consumption, costs, trends and future impacts.

2. The potential for wind, solar and ground source heat pump technologies to be integrated into current and planned Tribal buildings.

3. The potential of water resources on Tribal land to generate small-scale electrical power for Tribal operations or for sale to the grid.

4. The potential for biomass resources to produce power, heat or other products for use within Tribal buildings, or for export.

5. The viability of retrofitting existing buildings to incorporate energy efficiency and clean energy technologies.

Seventh Generation Energy Systems, a non-profit renewable energy planning and development firm based in Madison, was awarded the project in February 2008. A kick-off meeting at Lac du Flambeau in February allowed the Tribal Energy Team to meet SGES and for SGES to understand the objectives of the technical investigation and the over-arching goals of the Tribe.

While working with Tribal staff, Seventh Generation completed the majority of the components for this project, however, several sub-consultants were contracted to complete various task. A summary of the work completed by the principle consultant, as well as the key findings and major recommendations, is presented below. 
The Tasks are presented as follows:

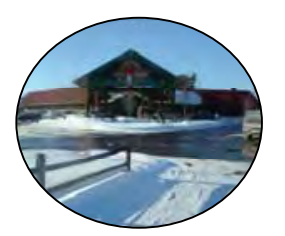

Task One. Current Tribal Load Assessment.

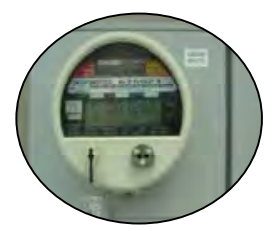

Task Two. Electricity Rate and Energy Intensity Analysis.

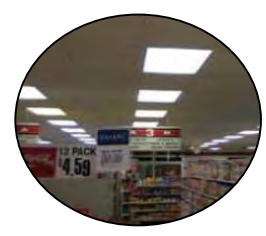

Task Three. Tribal Energy Audits.

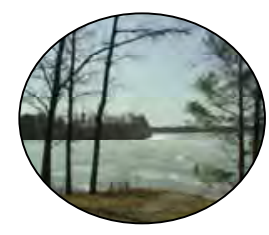

Task Four. Wind and Solar Technologies.

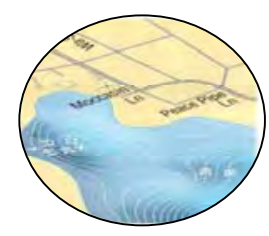

Task Five. Geothermal Systems.

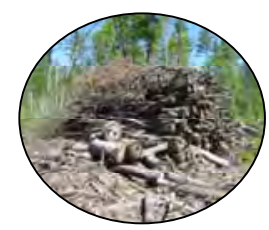

Task Six. Biomass Opportunity Assessment

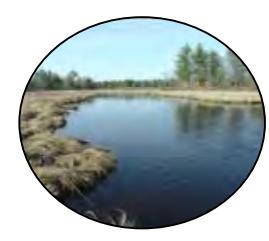

Task Seven. Micro-hydro.

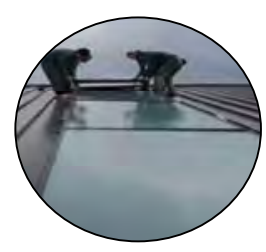

Task Eight. Integration of Renewables into Existing Facilities 


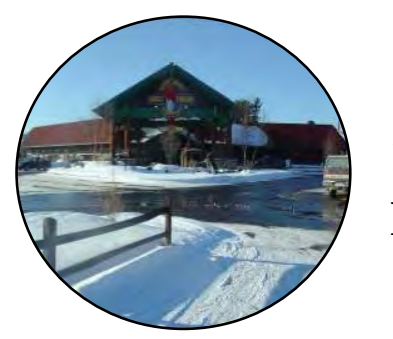

\section{Task One. Current Tribal Load Assessment} Prepared by: Seventh Generation Energy Systems

Work components. SGES completed the following:

- Analyzed five years of electricity and propane use (from 2003 to 2007) for 92 Tribal facilities (excluding Tribal Housing) to understand how much energy is consumed, if the total energy use is increasing, and how much money the Tribe spends to purchase energy.

- Presented historical energy prices, future energy price projections and Tribal consumption projections.

Findings:

- In 2007, Tribal facilities used 11.8 million kilowatt hours of electricity and 407,000 gallons of propane, at a price of \$1.4 million dollars and 31 million pounds of carbon dioxide emissions.

- The ten facilities that used the most electricity accounted for $86 \%$ of the tribe's total electricity consumption.

- The top ten propane users were responsible for $83 \%$ of the Tribe's total.

- From 2003 to 2007, electricity use increased by $10 \%$ and propane by $47 \%$. The amount of money spent on electricity increased $46 \%$ while propane increased $173 \%$.

- During the five year period, the price for one kWh of electricity increased $7.3 \%$ each year. The price for a gallon of propane rose $14.5 \%$ each year.

- If consumption continues to increase as quickly as it has over the past five years, the Tribe can expect their annual energy bill in 2017 to be $\$ 5$ million dollars.

- If significant conservation measures and renewable energy technologies are implemented, in ten years spending will remain close to 2007 spending at \$1.8 million dollars.

Recommended Actions:

- Evaluate the energy consumption and price of energy for Tribal Housing.

- Investigate utility manager software to continue monitoring the Tribal energy use.

Strategic Energy Plan Recommendations:

- Consider the energy consumption and pricing scenarios presented to help determine appropriate goals for energy management strategy. 


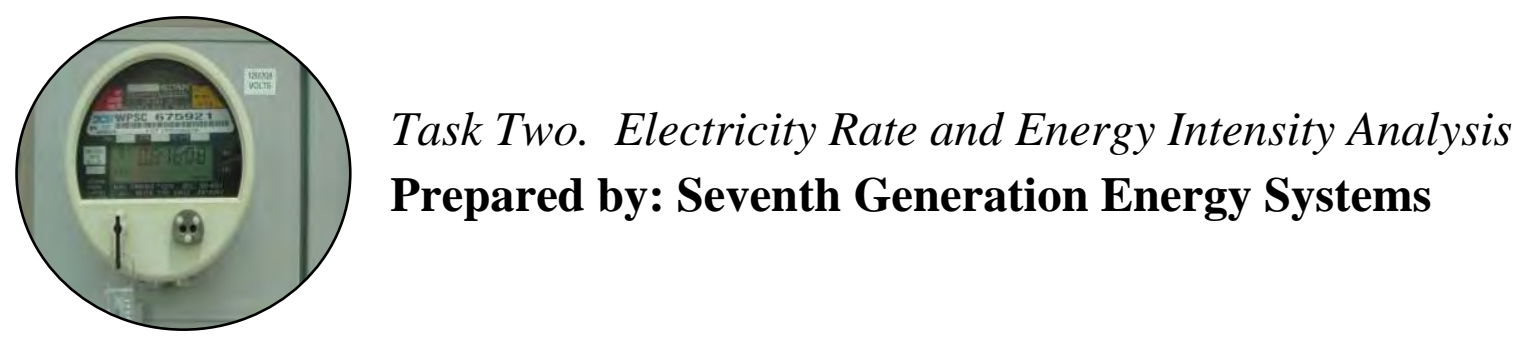

Work components. Seventh Generation completed the following:

- Researched the basic Tribal utility energy and demand charges for electricity.

- Analyzed the demand metered Tribal facilities.

- Computed the 'energy intensity' and 'energy cost intensity’ of Tribal facilities.

Findings:

- The Tribe pays $\$ 0.06$ to $\$ 0.11$ per kilowatt-hour of electricity depending on the utility rate.

- Six Tribal buildings are demand metered and charged \$10.67 per kW.

- Of these six Tribal buildings, most peak annually in summer, except for the Casino Hotel which peaks in winter due to the electric heating.

- The Casino Hotel peaks between 10am and 2pm, meaning that a solar electric system on this facility can be expected to help lower peak demand.

- The Gas Station had the greatest energy use intensity of $476 \mathrm{kBTU}$ per square foot.

Recommended Actions:

- Energy use intensity provides a first level look at a building's performance, therefore conduct thorough energy efficiency audits of the buildings that may not be relatively large energy consumers, but have a large energy use intensity, such as Bath House \#1, Deer Registration Station, Round House, Casino Engineering Building, and Bath House \#2.

- For more detailed analysis, compare the Tribal energy use intensities to regional averages.

Strategic Energy Plan Recommendations:

- Incorporate LEED standards into new buildings, as LEED buildings can cut their 'energy use intensity' levels in half. 


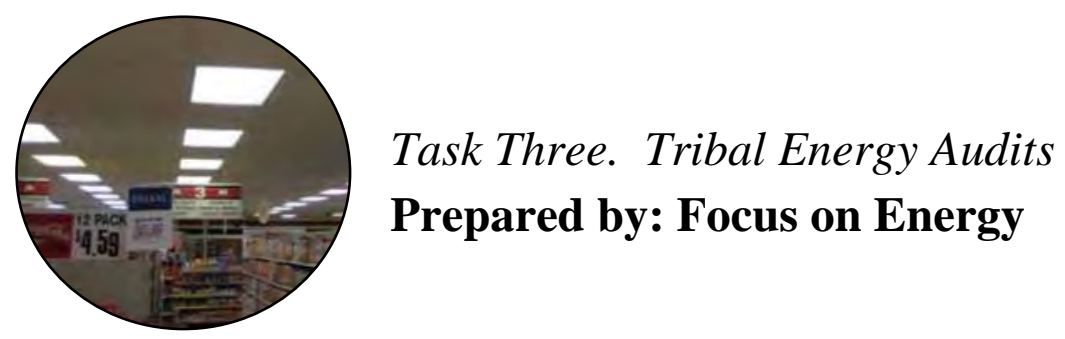

Work components. Bobbi Rongstad of Focus on Energy completed the following:

- $\quad$ Conducted basic energy efficiency audits of 16 Tribal buildings.

- Provided summary of priority energy efficiency options.

Findings:

- The buildings surveyed showed many low-cost opportunities for energy efficiency improvements on lighting, building shell, heating and cooling options.

Recommended Actions:

- Assign an Energy/Facilities Manager to assure continuity of energy-related policies and procedures as well as manage HVAC tuning, cleaning, repairs and service calls.

- Insulate Simpson's Plastic Plant and conduct professional review of compressed air system.

- Upgrade lighting and install lighting occupancy sensing controls specifically in the Bingo Hall, Grocery Store, Simpson facilities, Convenience Store, Community Center/Health Clinic, Court/Law Enforcement, Roads Garage, Dental Clinic, Community Center, Downtown 'Torches', and Casino.

- Continue to take advantage of Focus on Energy's free auditing services as well as their incentives and special promotions.

Strategic Energy Plan Recommendations:

- Develop procedures that direct all staff to make energy-efficient decisions, i.e. require an Energy Star rating for all new appliances, install lighting/heating/cooling controls, require T8/LED lighting in all current and new facilities.

- Educate all facility managers on their building energy use and how to determine energy efficiency options.

- Include a 'Long-range Plan’ to address any heating system upgrade greater than 20 years old. 


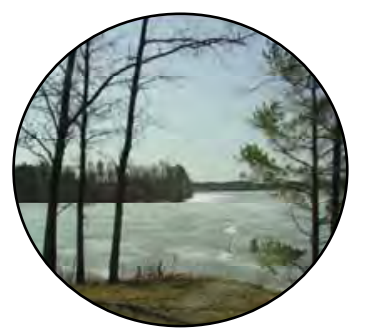

\section{Task Four. Wind and Solar Technologies Prepared by: Seventh Generation Energy Systems}

Work components. Seventh Generation completed the following:

- Provided a summary of financial factors and incentives for wind and solar systems.

- Evaluated existing resource assessment data on solar and wind resources.

- Evaluated the technical potential of using wind, solar electric and solar thermal on Tribal buildings.

Solar Electric Findings:

- The Tribe can expect a solar radiation of 4.4 kilowatt hours per square meter per day.

- A total of 15 buildings have been recommended as potential roof mounted solar electric sites.

- Twelve sites have been identified for small pole-mounted PV systems to serve as education and advocacy projects.

- A total of 13 locations have been identified for solar hot water applications.

- An estimated $12 \%$ of the Tribal energy use could be offset by solar electric systems and $2 \%$ of the Tribe's solar hot water and space heating requirements could be offset by solar thermal.

Wind Findings:

- The average wind speed at 40 meters at the lake edges is $11.2-12.3 \mathrm{mph}$, which is sufficient for small scale wind systems, but not utility scale wind systems.

- The most appropriate locations for wind systems are on the north and northeast shores of the larger Tribal lakes.

- Eight possible locations for a wind system were identified.

- Wind systems could provide an estimated 3-7\% of the Tribal energy needs, depending on the size and model of turbines installed.

Recommended Actions:

- Solar Electric Systems

o Prioritize buildings that can hold medium sized systems $(10-35 \mathrm{~kW})$ and are on the Cg 1 tariff: Judicial Building, Casino*, Gas Station, Water Resources Office, Simpson’s Plastic Plant, Elks Point Elder Housing, Planned Natural Resources Office.

o Install smaller solar electric systems $(1.5-2 \mathrm{~kW})$ to offset the casino billboards, as high visibility, educational projects.

o Connect the solar systems under the WPS Advanced Renewable Tariff, which pays 25c per kWh.

- Solar Thermal Systems

o Prioritize buildings that have consistent daily hot water needs, inefficient hot water systems and very good solar access: Bingo Hall, Hall of Nations, Lac du Flambeau School, Hotel Laundry, and Elks Point Elder Housing.

o Investigate the opportunity to space heat using solar thermal systems.

- Wind Systems

o Prioritize locations that are located on the north and northeastern location of the Tribal lakes and will most likely be charged the higher utility rates: Planned Natural Resource building, Elder Housing, Bearskin Circle apartments.

Strategic Energy Plan Recommendations:

- Require all future buildings to be built as solar ready. 


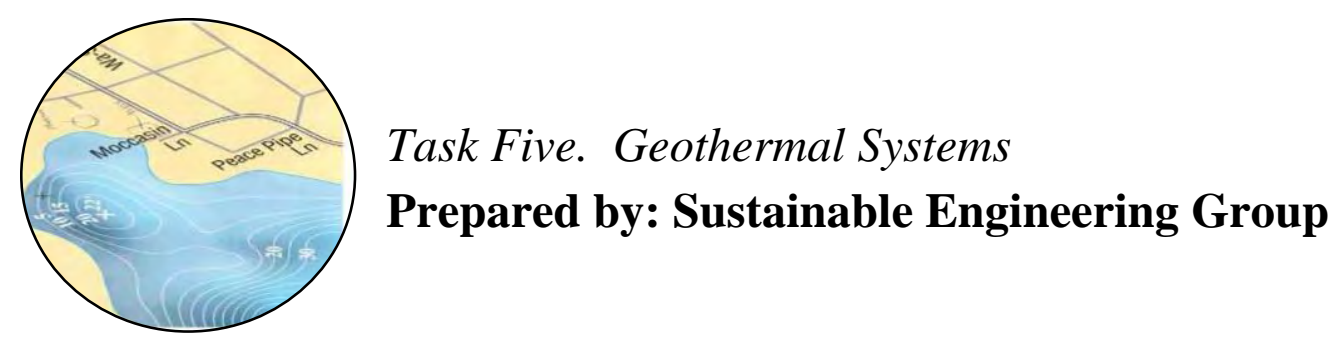

Work components. Sustainable Engineering Group completed the following:

- Reviewed DNR well water database for geothermal resource data.

- Evaluated the technical and financial potential of using geothermal systems on 16 Tribal buildings. The buildings were prioritized based on: Energy Efficiency, Environmental Stewardship, Life Cycle Analysis, Maintenance and Reliability

Findings:

- Vertical Bore Systems: The Lac Du Flambeau area has a high static water table, therefore the sand, clay, and gravel layers will have high moisture content, which increases geothermal potential. The performance estimates of vertical bore systems are presented for 12 Tribal buildings.

- Lake Geothermal Systems: The Judicial Building, Indian Bowl, Casino/Hotel, and Museum (and eventually the planned Natural Resources building) are located adjacent to lakes which make them ideal to be considered for geothermal.

- The reservation has the potential to offset $864,000 \mathrm{kWh}$ of electric use and 176,000 gallons of propane use if geothermal systems are installed in the 16 buildings.

- In general, paybacks range from 4 to 8 years for the buildings, with an expected 95\% savings in propane and $10 \%$ savings in electricity.

- Compared to the conventional heating and cooling systems, the geothermal systems could reduce carbon emissions by an estimated $40 \%$ for the Reservation.

Recommended Actions:

- Prioritize medium sized buildings with lake geothermal systems. Geothermal lake systems will be the most cost effective and easiest to retrofit, including the Indian Bowl, The Judicial Building, Museum, and the Planned Natural Resources Building.

- Secondary geothermal systems include medium and large sized buildings located proximate to each other that can share a vertical bore geothermal system. A shared borefield can take advantage of diversity from each of the buildings and be constructed at a reduced size and cost. In combination, The Youth Center, Bingo Hall, and Community Center are good candidates for a shared geothermal vertical bore system. The Simpson Assembly Plant in combination with Adaawae Place is also a good candidate for a shared geothermal vertical bore system.

Strategic Energy Plan Recommendations:

- Consider geothermal systems for all existing buildings slated for retrofit, and new construction. 


\section{Task Six. Biomass Opportunity Assessment Prepared by: Kaurich Energy Services}

Work components. Josh Kaurich of Kaurich Energy Services completed the following:

- Estimated the quantity and cost of biomass produced on the reservation through Tribal forest management activities, and within a 75 mile radius of the reservation.

- Evaluated the competing markets for biomass and local wood pellet markets.

- Evaluated the technical and economic feasibility of biomass power generation.

- Evaluated the feasibility of using biomass to heat current and planned Tribal buildings.

Findings:

- $\quad$ An estimated 11,929 dry tons of residue, cordwood, and saw timber were available from 20062007 harvest on Tribal land.

- Residue and cordwood volumes within a 25 mile radius of Lac du Flambeau total 79,270 and 307,021 dry-tons, respectively.

- Sawlog, cordwood, and residue prices are \$9.60, \$4.18, and \$3.84 per MMBtu delivered, respectively. LP prices are $\$ 19.02$ per MMBtu delivered.

- Biomass has the potential of saving the tribe over $\$ 600,000$ annually in heating fuel costs.

- Enough residues are available on tribal lands to offset casino and school heating loads.

- There are resources within a 25 mile radius of Lac du Flambeau to economically operate a large scale pellet mill facility.

Recommended Actions:

- Develop a timber harvest species and residue inventory to help determine current and future residue volumes available from harvest practices and assist in redeveloping any new forestry expansion plans.

- Reevaluate the priority, responsibility, and funding of tribal forest practice. The potential to expand timber harvest practices exists within tribal land. However, additional staff, support, and resources must be allocated to fully expand operations and utilize these value resources to their fullest potential.

- Conduct a detailed feasibility study for a biomass boiler in the Lac du Flambeau School and community center. In both locations, preliminary numbers indicate that a biomass combustion system would result in a quick payback. Also, analyze the potential for a pellet heating system at the new natural resource facility.

- Conduct a case study of chipping cordwood for thermal purposes. This will require weighing cordwood mass and comparing the value to cordwood prices. This should then be compared with residue and LP prices for an economic evaluation.

- Research residue prices in regard to local stumpage value and consider establishing a value price structure. Talk with local timber agents about residue removal, chipping, and transport cost for use at tribal facilities.

- Continue to further analyze the Wisconsin wood pellet market and the potential use of residue and cordwood for pellet production on tribal lands. Talk with current and future pellet plants within 75 miles of Lac du Flambeau about supplying residues for production. Conduct a more detailed feasibility study to determine pellet mill potentials in Lac du Flambeau.

- Further research should be conducted on the amount of residue available within different tree species harvested on tribal lands. Residues values were assumed to be sixteen percent of above ground biomass, however; this will vary by species and calendar harvest time.

- Further research should examine historical trends in harvest totals on tribal lands and attempt to evaluate future sales or anticipated sales total based upon annual allowable cut. With the newly 
explored area of cellulosic fuels, such as the Flambeau River Biofuels, it would be prudent to examine current or future plans for biofuel facilities in northern Wisconsin.

- Investigate biomass for space heat at the new Natural Resources building.

Strategic Energy Plan Recommendations:

- $\mathrm{n} / \mathrm{a}$ 


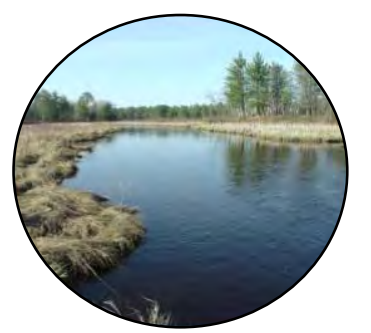

\section{Task Seven. Micro-hydro}

\section{Prepared by: Seventh Generation Energy Systems}

Work components. Seventh Generation completed the following:

- Assessed existing stream flow data from USGS gauging stations for Bear and Trout River.

- Evaluated river elevation drops, land use and siting considerations for hydroelectric development.

- Reviewed flow rates and site layout of the fish hatchery to determine technical feasibility of micro-hydro.

- Reviewed regulatory frameworks of state and federal agencies.

- Screened micro-hydro technologies.

Findings:

- In general the Lac du Flambeau water resources on the Trout and Bear Rivers are not well suited for hydropower development if the primary goal is to provide the community with an economical source of clean power.

- The fish hatchery may be able to construct a very small hydro electric generator for the primary purpose of community education and demonstration of the Tribe's commitment to renewable energy, however, building a system at the fish hatchery would not be without challenges.

- The power produced at the hatchery may be useful as a battery charging "source" for the local community's fishing boat batteries.

Recommended Actions:

- The Tribe should further investigate the option to install a $1 \mathrm{~kW}$ commercially available microhydro turbine at the Fish Hatchery.

- If the Tribe decides to invest in a micro-hydro system at the fish hatchery, then the micro-hydro system construction would be best undertaken as part of the planned renovation at the hatchery.

- Further investigate how to modify the existing raceway overflow/drain pipe network to divert a steady amount of flow (900 gal/min or $2060 \mathrm{gal} / \mathrm{min}$ depending on the turbine) through a channel to the hydro unit located at the right height above the top of the Trout Pond's water level.

- Assuming the existing physical plant can be readily modified for a hydropower unit, the Tribe will need to decide if an AC or DC generator best meets its needs.

Strategic Energy Plan Recommendations:

- $\mathrm{n} / \mathrm{a}$ 


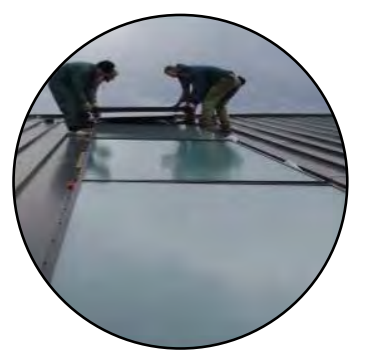

\section{Task Eight. Integration of Renewables into Existing} Facilities

\section{Prepared by: Seventh Generation Energy Systems}

Work components. Seventh Generation completed the following:

- Described economic variables that affect renewable energy financial performance, including incentives, equipment and maintenance costs and energy price escalation.

- Performed comparative financial analysis of solar PV, solar hot water, wind and geothermal heat pump technologies based on two different economic scenarios.

- Provided facility profiles that describe key building characteristics, 2007 energy use, electric account information, energy efficiency recommendations and detailed summaries of renewable energy system performance.

Findings:

- In both economic scenarios, solar hot water systems provide the greatest return on investment due to the relatively low equipment cost, minor maintenance costs and the significant savings that can be achieved by offsetting a high-cost fuel such as propane.

- In both scenarios, geothermal heat pump systems show favorable economic returns. In the baseline scenario, the benefits of geothermal appear greater, relative to other technologies, because the systems are cost effective without major financial incentives

- PV systems perform significantly better in the optimistic scenario when federal tax benefits can be utilized and when the system is connected to a facility that pays higher electric rates. Solar PV is scalable and can supply as large of a share of the Tribe's electricity consumption as is economically feasible.

- Two of the four locations analyzed show that wind speeds and electric rates are high enough that a wind turbine would provide a moderate return on investment in both economic scenarios.

- If all of the evaluated renewable energy systems were implemented, the energy production and savings potential would be 1,375,784 kWhs of electricity and 174,804 gallons of propane. This would provide $11.6 \%$ of the Tribe's 2007 electricity use and $29.4 \%$ of the Tribe's 2007 propane use.

Recommended Actions:

- Energy efficiency first. Efficiency improvements will reduce the amount of renewable energy that is needed. For every dollar spent on energy efficiency, three to five dollars can be saved on renewable energy systems.

- "Bite sized" investments in renewable energy can begin immediately and solar hot water systems provide a range of options that offer the quickest payback and high return on investment.

- Geothermal heat pumps are a cost-effective solution to provide a facility's entire heating and cooling needs. Their large upfront cost will require more careful planning and a more detailed economic feasibility study.

- Solar PV systems are a scalable technology and small systems on high-profile buildings or standalone structures should be considered immediately. If the Tribe finds a way to receive federal solar tax benefits, larger scale systems will become quite appealing. Also, while solar PV may be a relatively expensive technology today, we expect its cost to decline quickly over the next five years.

- The Tribe should begin researching the availability of federal tax credits. Federal business tax credits and accelerated depreciation can reduce the cost of solar hot water and solar PV by up to $50 \%$. If the Lac du Flambeau government isn't eligible directly, the Tribe may look into forming or partnering with other legal entities that do qualify for a desired incentive. 
- Once a direction is decided by the Tribe, current pricing and performance of smaller systems can be obtained through low-cost site assessments or by requesting bids from installers. As larger systems are pursued, economic feasibility studies may be necessary to obtain accurate equipment pricing, negotiate power purchase rates, and determine financing costs, applicable grants and tax benefits.

Strategic Energy Plan Recommendations:

- Lead by example by installing low-cost, highly visible renewable energy systems on tribal facilities immediately.

- Set achievable targets that require a certain percentage of Tribal energy to be supplied by renewable energy. 


\section{Task One: Current tribal load assessment}

\section{Table of Contents}

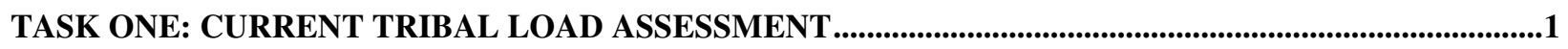

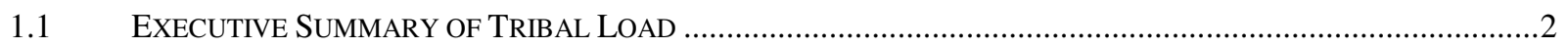

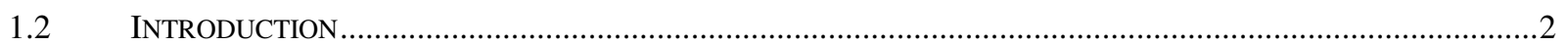

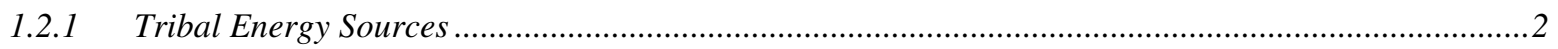

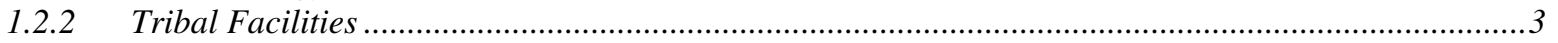

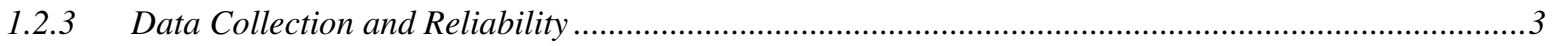

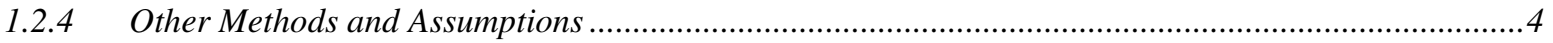

1.3 TRIBAL ENERGY USE - CONSUMPTION, EXPENSES, TRENDS ……...........................................................

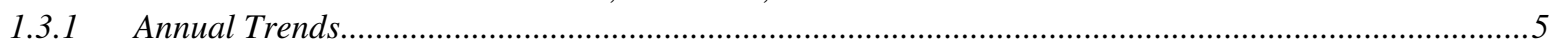

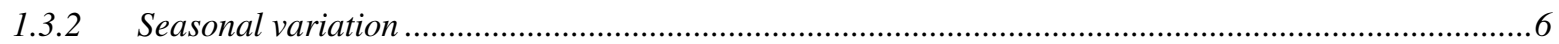

1.4 ENERGY CONSUMPTION AND COST DISCUSSION ............................................................................

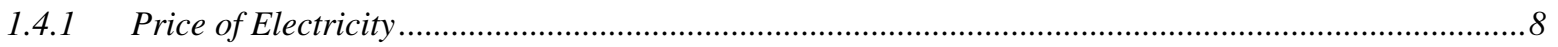

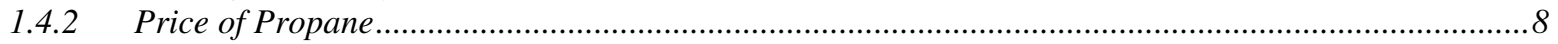

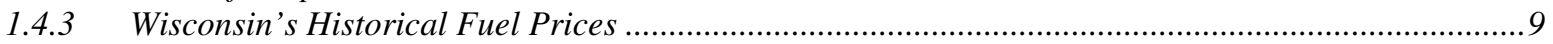

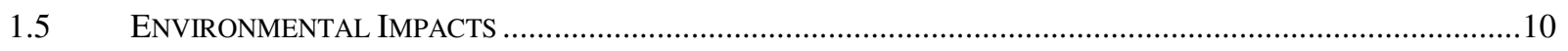

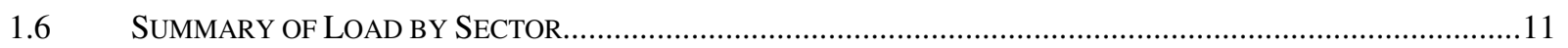

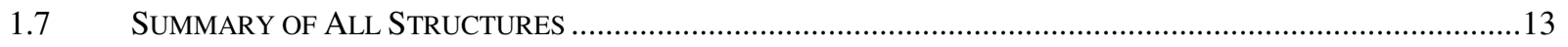

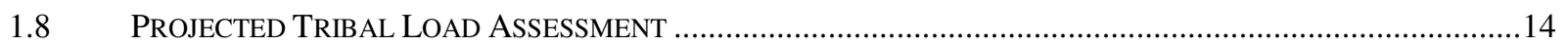

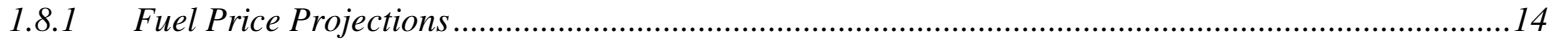

1.8.2 Tribal Energy Use Projections .............................................................................................. 15

1.8.3 Future Energy Consumption and Expense Scenarios ...................................................................16

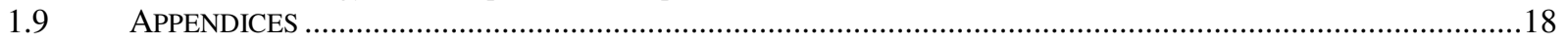

\section{List of Appendices}

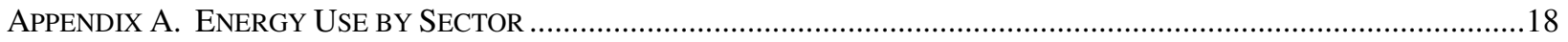

APPENDIX B. LIST OF FACILITIES, GROUPED BY SECTOR .................................................................................19

APPENDIX C. ENERGY CONSUMPTION FOR ALL FACILITIES (GROUPED BY SECTOR, ORDERED BY FIVE-YEAR

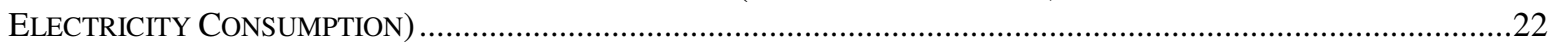

APPENDIX D. ASSUMED EMISSION FACTORS FOR ELECTRICITY AND PROPANE...............................................................29 


\subsection{Executive Summary of Tribal Load}

In 2007, Lac du Flambeau Tribal facilities used 11.8 million kilowatt hours of electricity and 407,000 gallons of propane. The consumption of this energy came at a price of $\$ 1.4$ million dollars and created 31 million pounds of carbon dioxide emissions.

Of the 92 facilities included in this report, a minority of facilities are responsible for the majority of the Tribe's energy consumption. In 2007, the 10 facilities that used the most electricity accounted for $88 \%$ of the Tribe's total electricity consumption. The top ten propane users were responsible for $83 \%$ of the Tribe's total. Complete five year energy consumption and expenditure records for all 92 facilities are presented in the Appendix of this report.

Between 2003 and 2007 Tribal energy use has increased steadily while energy expenditures have increased dramatically. Over this five year period, electricity use increased by a total of $10 \%$ and propane by a total of $47 \%$. Over this same five year period, the amount of money spent on electricity increased a total of $46 \%$ while propane expenditures increased by $173 \%$.

This dramatic rise in energy expenditures is a result of a sharp increase in the price of energy. Between 2003 and 2007 the price that the Tribe paid for one kWh of electricity increased on average $7.3 \%$ each year. The price for a gallon of propane rose $14.5 \%$ each year. These price increases experienced by the Tribe are similar to, but slightly higher than the Wisconsin state average during this time period. Compared to longer-term trends, the 2003 to 2007 period shows that prices increased at an unusually rapid rate. The 12-year trend (1995-2006) in Wisconsin shows annual electricity rate increases of $3.7 \%$ and propane increases of $8 \%$.

As the Tribe plans to manage their energy use and expenses over the next ten years, several potential scenarios should be considered. Assuming that energy prices over the next 10 years increase similar to the 12-year trends in Wisconsin, the Tribe can expect their future energy spending to depend significantly on their decisions to manage energy consumption. If consumption continues to increase as quickly as it has over the past five years, the Tribe can expect their annual energy bill in 2017 to be $\$ 5$ million dollars. If energy consumption is held constant from one year to the next, 2017 energy expenditures are projected to be $\$ 2.5$ million dollars. Finally, if significant conservation measures and renewable energy technologies are implemented, in 10 years spending will remain close to 2007 spending at $\$ 1.8$ million dollars.

\subsection{Introduction}

\subsubsection{Tribal Energy Sources}

Lac du Flambeau has two primary sources of energy: electricity, which is purchased from Wisconsin Public Service (WPS); and propane, which is purchased from local suppliers. WPS provides natural gas service, but their distribution pipeline does not extend to the Lac du Flambeau Reservation. 


\subsubsection{Tribal Facilities}

Working with Tribal staff, 92 facilities were identified for inclusion in this report. These facilities include all tribal office buildings, gaming facilities, and urban service infrastructure such as water towers and pump houses.

The Lac du Flambeau School, the Tribe's second largest energy user, was included in this report, but it is important to note that the Tribe pays for a small portion of the school's energy bill. From June 2007 onward the Tribe paid for 15\% of the school's energy budget and before June 2007, the Tribe's share was $10 \%$. In this report we did not account for this shared billing arrangement. As such, figures in this report show 100\% of the Lac du Flambeau School's energy consumption and costs.

One group of facilities that was not included in this report is Tribal housing. Tribal-owned housing, Chippewa Housing Authority owned housing, and Elder utility expenses were excluded. The combined energy consumption of this housing could be significant and we recommend that these facilities be evaluated in the future as part of Tribal energy conservation efforts. Private households of tribal members were also not included in this report. Their combined energy use is unknown but an estimate could be calculated by multiplying the number of homes by average Wisconsin household energy use statistics. Alternatively, a representative sample of energy usage data could be gathered from actual households on the reservation and the consumption of all private households could be estimated from this sample. The Chippewa Housing Authority has energy cost information for a certain number of single family units that they rent which could be used in such an analysis.

\subsubsection{Data Collection and Reliability}

The electricity consumption and expense data used in this report was collected from Wisconsin Public Service. The data was provided in electronic format and analyzed directly by SGES. Several redundant files were detected and removed but otherwise the electricity data was of very high quality. The only information that was sometimes unclear was which facility a particular electric account should be associated with. Tribal staff worked with WPS to resolve the proper identification of electric accounts.

Propane consumption data was obtained from the Tribal accounting department. Expense information was not provided by Tribal accounting and an annual "pre-buy bulk" rate had to be obtained from the seller of propane. This average annual price was used to estimate the amount of money spent to purchase propane.

Two issues with the propane data make it less reliable than the electricity data. First, because propane consumption records represent the date of deliveries, and not the actual fuel use, monthly consumption figures in this report may vary slightly from actual usage. Second, some facilities share a single propane tank and there is no exact way to determine how much propane was consumed by each facility. In these cases, a shared propane tank was associated with a single facility. 


\subsubsection{Other Methods and Assumptions}

All financial figures in this report are in nominal dollars, unadjusted for inflation. For example, the amount of money spent on electricity purchases in 2003 are shown in 2003 dollars and the amount of money spent on electricity in 2007 are shown in 2007 dollars. This method of accounting was decided on after discussions with tribal staff indicated that it would be more useful in budgeting discussions.

\subsection{Tribal energy use - consumption, expenses, trends}

This subsection presents the Tribe's total energy load in terms of total energy use, energy expenditures, energy prices, and greenhouse gas emissions.

Historical trends from 2003 through 2007 show that energy use by Lac du Flambeau Tribal facilities is increasing steadily and expenditures for this energy are increasing dramatically. The total amount of money spent on energy, including propane and electricity, in 2007 was nearly $\$ 1.5$ million. This is nearly double the amount spent just five years prior. Figure 1 shows the five year trend, including the relative shares that propane and electricity contribute to Lac du Flambeau's annual energy bill.

Figure 1. Annual Energy Expense, 2003 to 2007

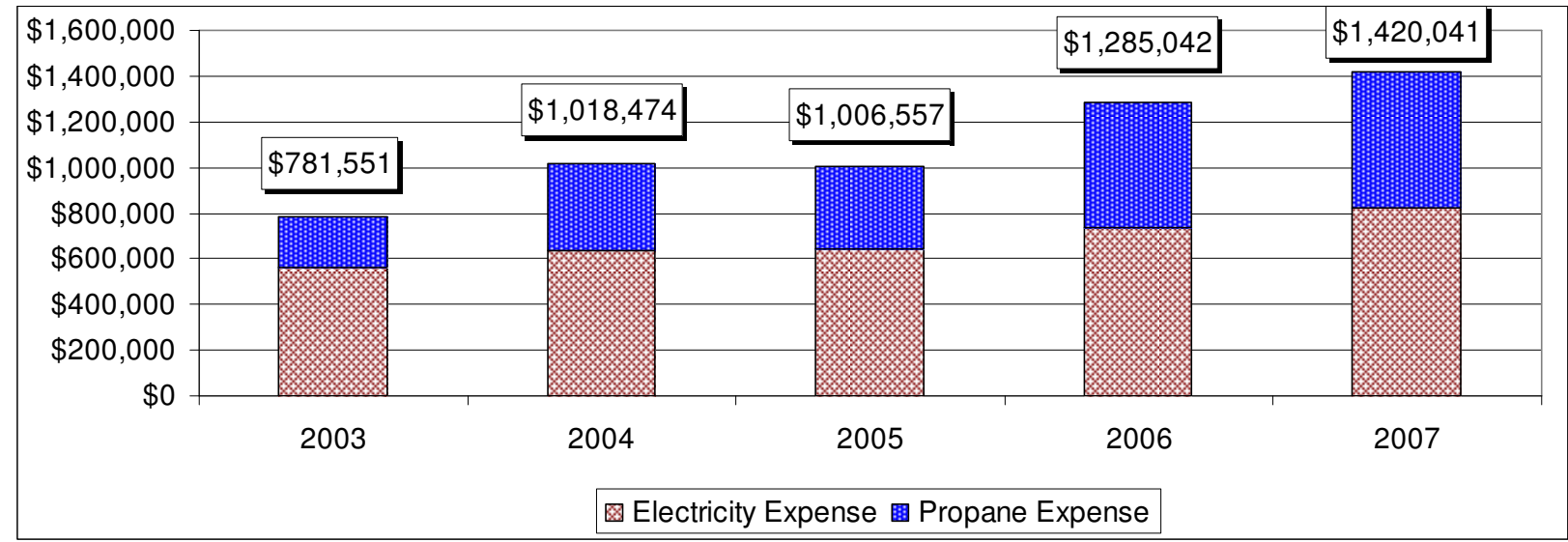

The specific annual expense and amount of electricity and propane consumed over the five year period is displayed in Table 1.

Error! Reference source not found.

Table 1. Annual Electricity and Propane Consumption and Cost, 2003 to 2007

\begin{tabular}{|c|c|c|c|c|}
\hline Year & $\begin{array}{l}\text { Electricity } \\
(\mathrm{kWh})\end{array}$ & $\begin{array}{c}\text { Electricity } \\
\text { Expenses (dollars) }\end{array}$ & $\begin{array}{l}\text { Propane } \\
\text { (gallons) }\end{array}$ & $\begin{array}{c}\text { Propane Expenses } \\
\text { (dollars) }\end{array}$ \\
\hline 2003 & $10,758,223$ & $\$ 564,603$ & 274,292 & $\$ 216,948$ \\
\hline 2004 & $11,050,869$ & $\$ 638,091$ & 388,589 & $\$ 380,383$ \\
\hline 2005 & $10,297,054$ & $\$ 640,596$ & 292,825 & $\$ 365,961$ \\
\hline 2006 & $11,634,594$ & $\$ 733,593$ & 397,817 & $\$ 551,449$ \\
\hline 2007 & $11,870,059$ & $\$ 826,026$ & 407,476 & $\$ 594,014$ \\
\hline TOTAL & $55,610,799$ & $\$ 3,402,909$ & $1,760,999$ & $\$ 2,108,755$ \\
\hline
\end{tabular}


The raw numbers in Table 1 reveal the year-to-year changes in tribal consumption of energy and energy expenditures.

\subsubsection{Annual Trends}

Electricity consumption increased at a modest rate while the associated expenses increased sharply. Over the five-year period the amount of electricity consumed by the Tribe increased by an average of $2.5 \%$ each year while the money the Tribe spent on electricity purchases increased on average 10.0\% each year. A comparison of 2003 numbers to 2007 numbers shows a total increase in annual electricity consumption of $10.3 \%$ and a total increase in money spent on electricity of $46.3 \%$. These trends are presented in Figure 2.

Figure 2. Change in Tribe's Electricity Consumption and Spending Relative to 2003

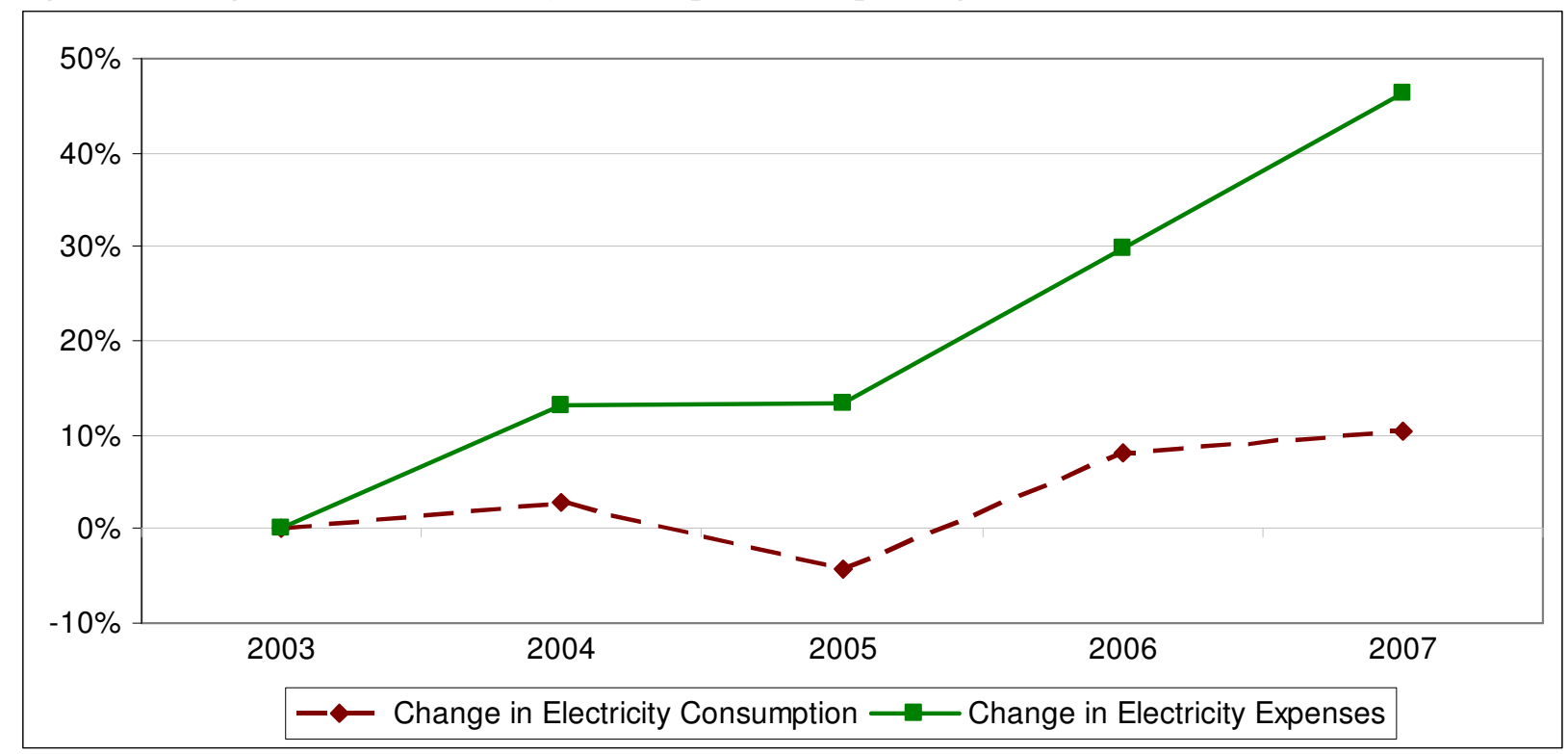

Increases in propane use are even more dramatic than that of electricity. Propane consumption has increased steadily and expenses have nearly tripled over the five year period. The amount of propane consumed by the Tribe increased by an average of $10.4 \%$ each year while the money the Tribe spent on propane purchases increased, on average, $28.6 \%$ each year. A comparison of 2003 numbers to 2007 numbers shows a total increase in annual propane consumption of $46.9 \%$ and a total increase in money spent on propane of $173.8 \%$. These trends are presented in Figure 3 . 
Figure 3. Change in Tribe's Propane Consumption and Spending Relative to 2003

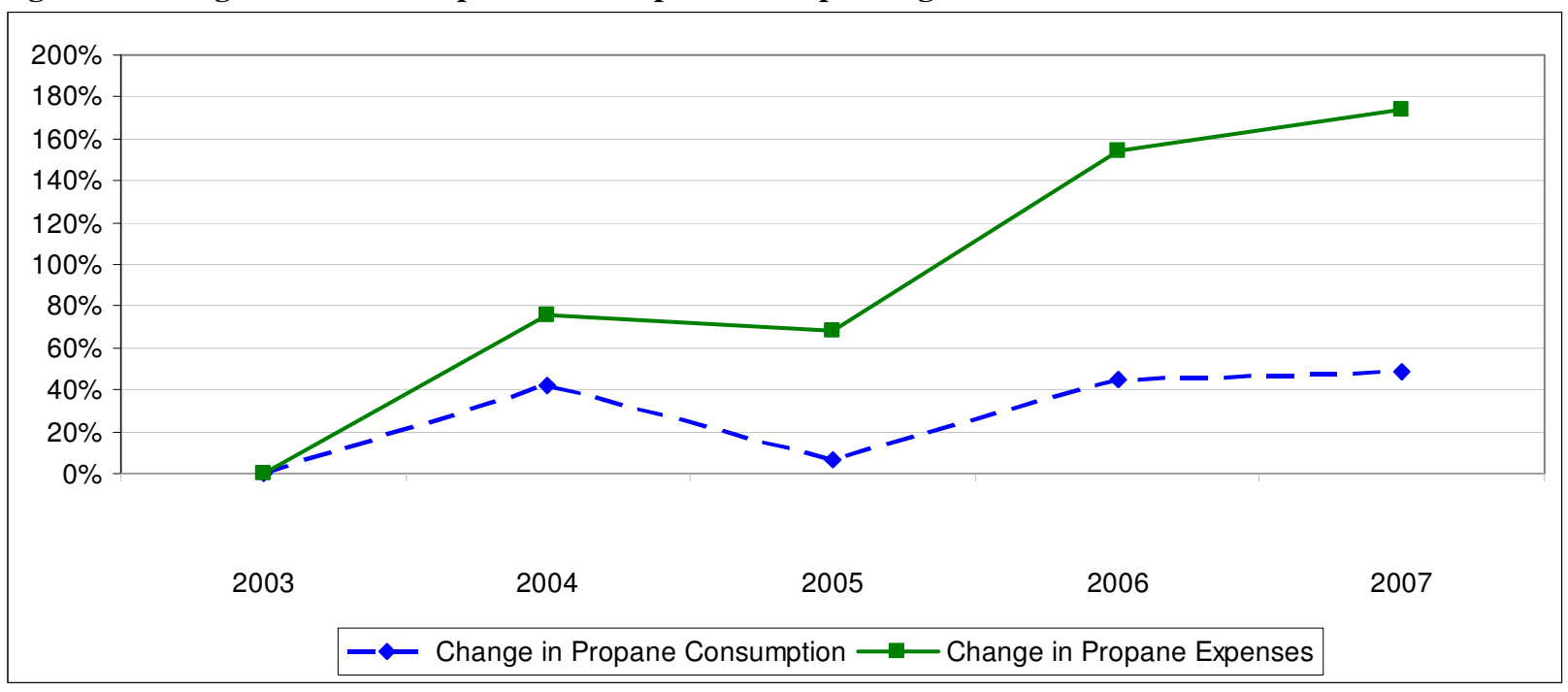

\subsubsection{Seasonal variation}

One revealing summary of energy use is an annual profile, which shows how energy is consumed from one month to the next. Figure 4 shows the average monthly energy use patterns over the years 2003 to 2007 . The bars show normalized data, which is calculated by dividing the value of each month by the monthly average. This allows us to see how energy use during any particular month is either greater, equal to or less than the average month. For example, propane use in January is about $50 \%$ greater than the average month, while in July propane use is about $50 \%$ less than the average month.

Figure 4. Normalized Energy Use by Month, 2003 to 2007

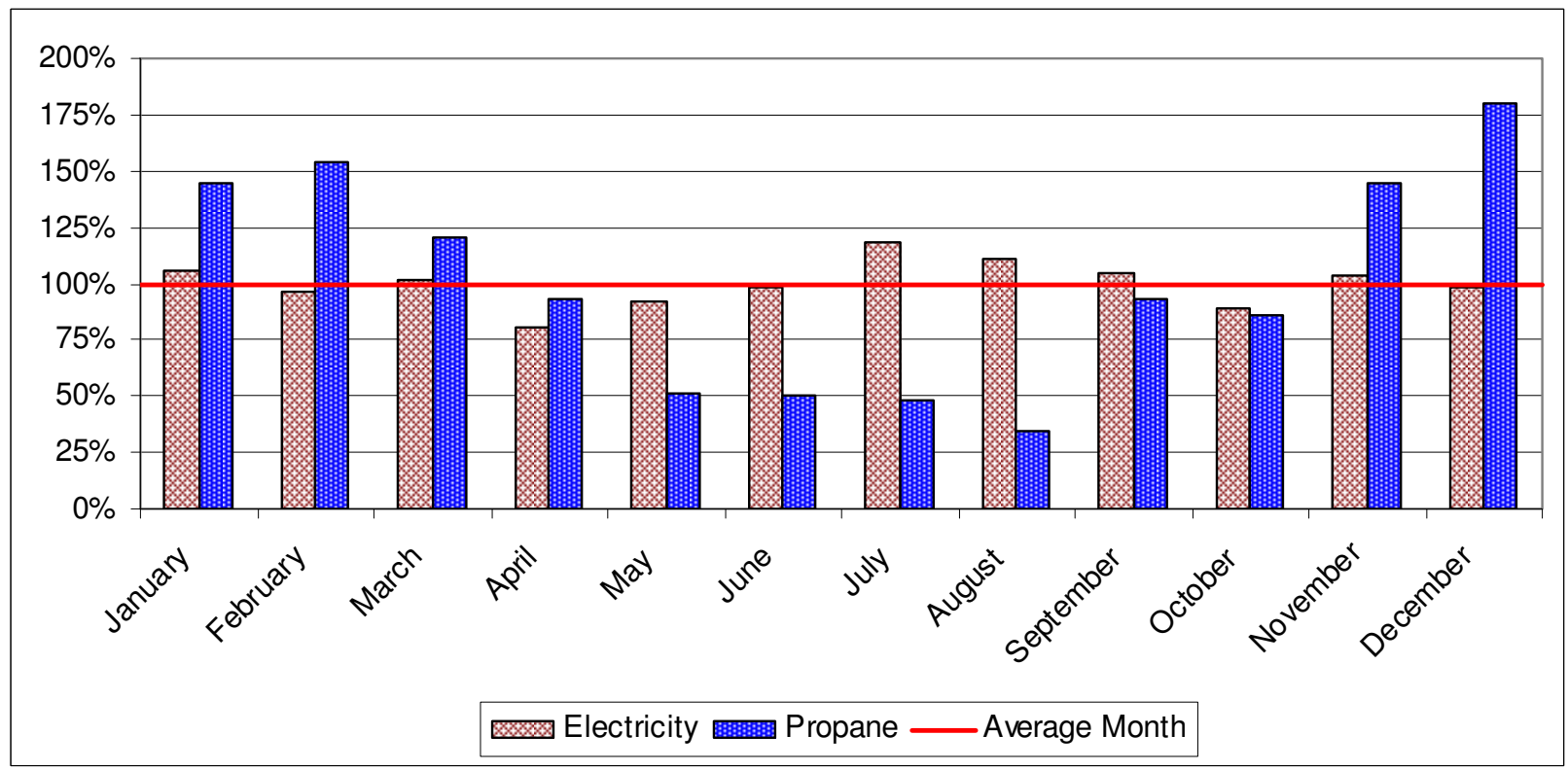


* Because propane consumption records are created on the date of purchase and not on the date of use, monthly consumption figures may vary slightly from the actual usage.

A similar view of monthly trends appears in Figure 5, which shows total monthly spending on electricity and propane during 2007.

Figure 5. Energy Expenditures by Month, 2007

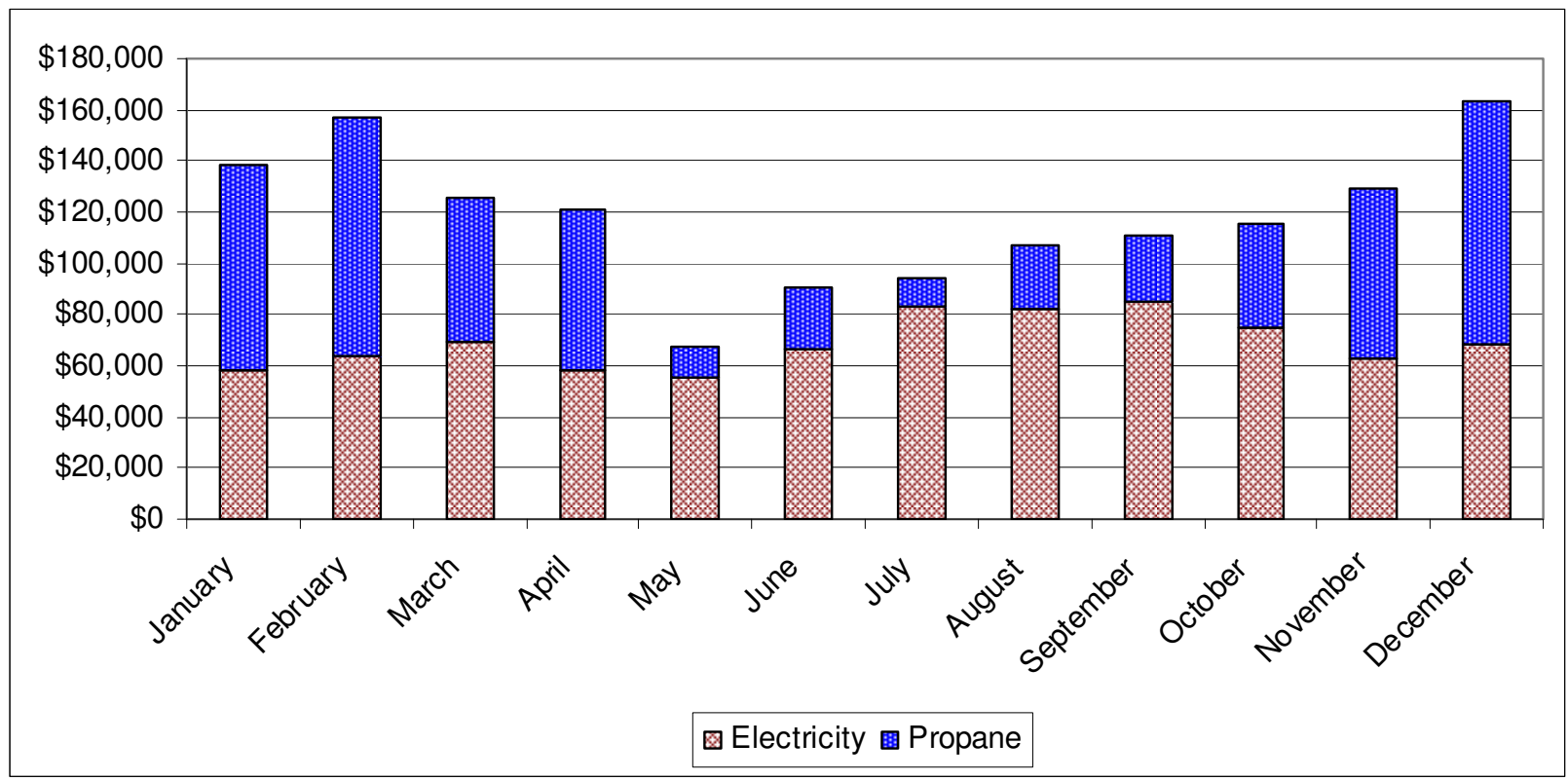

* Because propane consumption records are created on the date of purchase and not on the date of use, monthly consumption figures may vary slightly from the actual usage.

As expected, propane use is significantly greater in winter months when it is used for space heating, and electricity use peaks in summer months when air conditioner use is greatest.

Other factors that can influence monthly trends from one year to the next include the number of severely cold days (cooling degree days) and the number of severely hot days (heating degree days). Over the years, broad changes in behavior or policies may also have an affect, such as the increased use of air-conditioning or the adoption of incentives to switch from electric heating to propane heating.

\subsection{Energy Consumption and Cost Discussion}

As demonstrated in the section on annual energy use trends, tribal energy use is increasing moderately each year while the amount of money spent to purchase energy is increasingly dramatically. The reason expenditures are increasing faster than consumption is because the "cost of energy" (that is, the amount of money required to buy one unit of energy) is rapidly increasing. The following tables and figures demonstrate the five year trends. 


\section{Price of Electricity}

Table 2. Aggregate Electricity Rate

\begin{tabular}{|c|c|}
\hline Year & $\begin{array}{c}\text { Price per } \\
\mathrm{kWh}\end{array}$ \\
\hline 2003 & $\$ 0.05248$ \\
\hline 2004 & $\$ 0.05774$ \\
\hline 2005 & $\$ 0.06221$ \\
\hline 2006 & $\$ 0.06305$ \\
\hline 2007 & $\$ 0.06959$ \\
\hline $\begin{array}{c}\text { Percent annual } \\
\text { increase }\end{array}$ & $7.3 \%$ \\
\hline
\end{tabular}

The rates in Table 2 show that the cost for a single unit of electrical energy, measured in kilo-watt hours (kWh), increased each year by an average of 7.3 percent.

The cost of electricity shown in Table 2 is the aggregate price, or a "blended rate", which is calculated by dividing the total amount of money spent to purchase electricity by the amount of electricity consumed during one year. Actual electricity rates vary significantly from one facility to the next based on the type of service (single phase or three phase), the average demand, and the amount of energy used each month.

Table 3. Small Commercial/Industrial Electricity Rates

\begin{tabular}{|c|c|c|}
\hline Year & $\begin{array}{c}\text { Rate CG-5 } \\
\text { Price per } \\
\text { kWh }\end{array}$ & $\begin{array}{c}\text { Rate CG-1 } \\
\text { Price per } \\
\text { kWh }\end{array}$ \\
\hline 2003 & $\$ 0.06767$ & $\$ 0.07790$ \\
\hline 2004 & $\$ 0.07252$ & $\$ 0.08535$ \\
\hline 2005 & $\$ 0.07852$ & $\$ 0.09262$ \\
\hline 2006 & $\$ 0.08473$ & $\$ 0.10101$ \\
\hline 2007 & $\$ 0.09232$ & $\$ 0.10670$ \\
\hline $\begin{array}{c}\text { Percent annual } \\
\text { increase }\end{array}$ & $8.1 \%$ & $8.2 \%$ \\
\hline
\end{tabular}

Two examples of WPS electric rates that apply to small commercial and industrial customers are shown in Table 3. Rate CG-5 shows an average annual increase of 8.1 percent, with rate CG-1 at $8.2 \%$.

\subsubsection{Price of Propane}

The increase in the price of propane has doubled that of electricity between 2003 and 2007. Table 4 shows the rate that was published by the seller of propane. Note that this is the "pre-buy bulk" rate which will apply to most tribal facilities but is likely not representative of the price that smaller consumers such as residents would pay. Also, propane rates fluctuate throughout the year so purchasing habits of building managers will affect the rate they will receive depending on when an order is placed.

Table 4. Advertised Propane Rates

\begin{tabular}{|c|c|}
\hline Year & $\begin{array}{c}\text { Advertised rate } \\
\text { (price per gallon) }\end{array}$ \\
\hline 2003 & $\$ 0.85$ \\
\hline 2004 & $\$ 0.99$ \\
\hline 2005 & $\$ 1.30$ \\
\hline 2006 & $\$ 1.37$ \\
\hline 2007 & $\$ 1.46$ \\
\hline $\begin{array}{c}\text { Percent annual } \\
\text { increase }\end{array}$ & $14.5 \%$ \\
\hline
\end{tabular}




\subsubsection{Wisconsin's Historical Fuel Prices}

To place the rate increases that the Tribe has experienced into context, long-term price trends from the United States and Wisconsin are summarized below.

Electricity rates have increased rapidly in the United States and in Wisconsin over the past few years. As shown in Figure 6, from 2003 to 2006 electricity rates in Wisconsin increased on average $6.4 \%$ per year and in the United States, $5.2 \%$ per year. Analysis of longer-term averages, including the mid-90s when prices actually dropped, shows a more moderate increase. From 1995 to 2006 annual electricity price increases averaged 3.7\% in Wisconsin and 1.8\% in the United States.

Figure 6. U.S. and Wisconsin Long-term Electricity Price Trends, 1980 to 2006

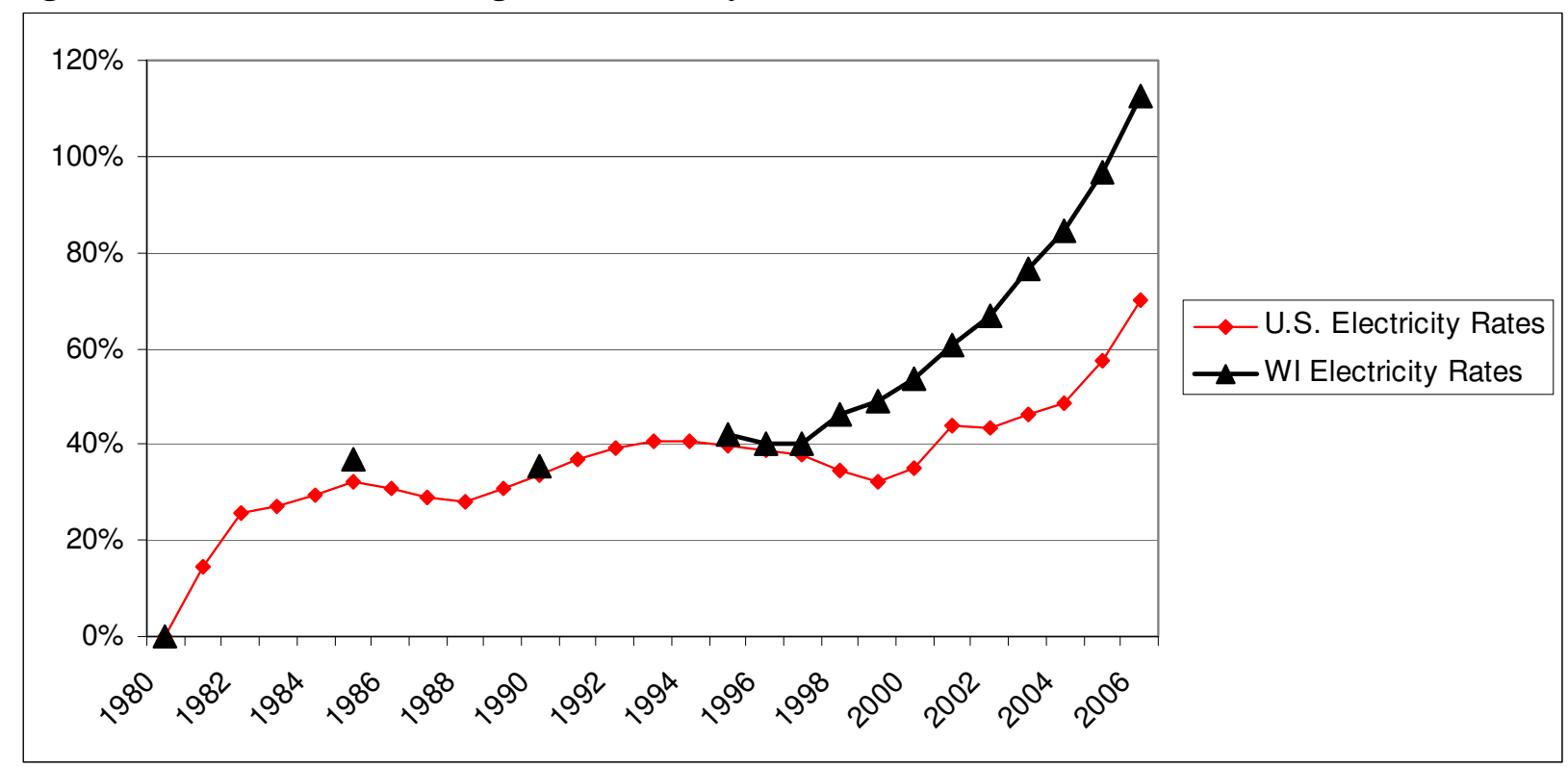

*Sources: EIA - Average Retail Prices of Electricity by Sector 1980 to 2006 2007 Wisconsin Energy Statistics

Figure 7 shows the increase in propane prices from 1980 levels. When looking at short-term price increases (2003 to 2006), we see an average annual increase in Wisconsin of $13.1 \%$ and an increase in the United States of 26.8\%. Taking a longer-term average (1995 through 2006), in Wisconsin we see average price increases of $8.0 \%$ per year and national averages of $9.7 \%$. 
Figure 7. U.S. and Wisconsin Long-term Propane Price Trends, 1980 to 2006

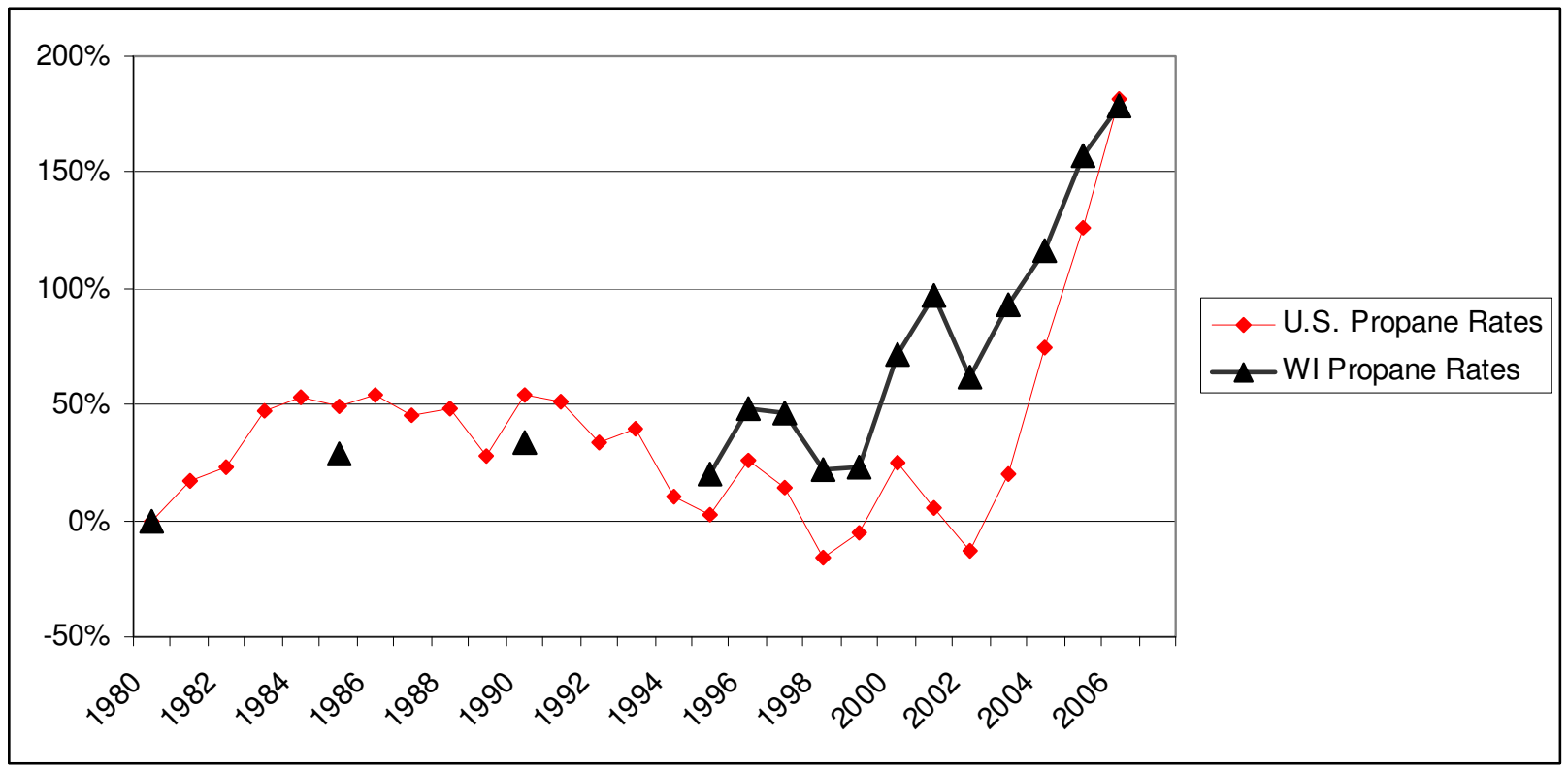

*Sources: EIA - Monthly Refinery Prices of Petroleum Products to End Users 1978 to 2008 2007 Wisconsin Energy Statistics

\subsection{Environmental Impacts}

What effect do the emissions from Tribal electricity and propane consumption have on the environment? Emissions of carbon dioxide, nitrogen oxides $\left(\mathrm{NO}_{\mathrm{x}}\right)$ and sulfur oxides $\left(\mathrm{SO}_{\mathrm{x}}\right)$ contribute to global and local climate change, as well as public and ecosystem health degradation.

The Tribe's utility, WPS, creates the majority of its electricity from coal. Nuclear energy provides almost one fourth of the WPS power mix, while renewable energy supplies $1 \%$ of the Tribe's electricity. 
Figure 8. WPS power supply mix

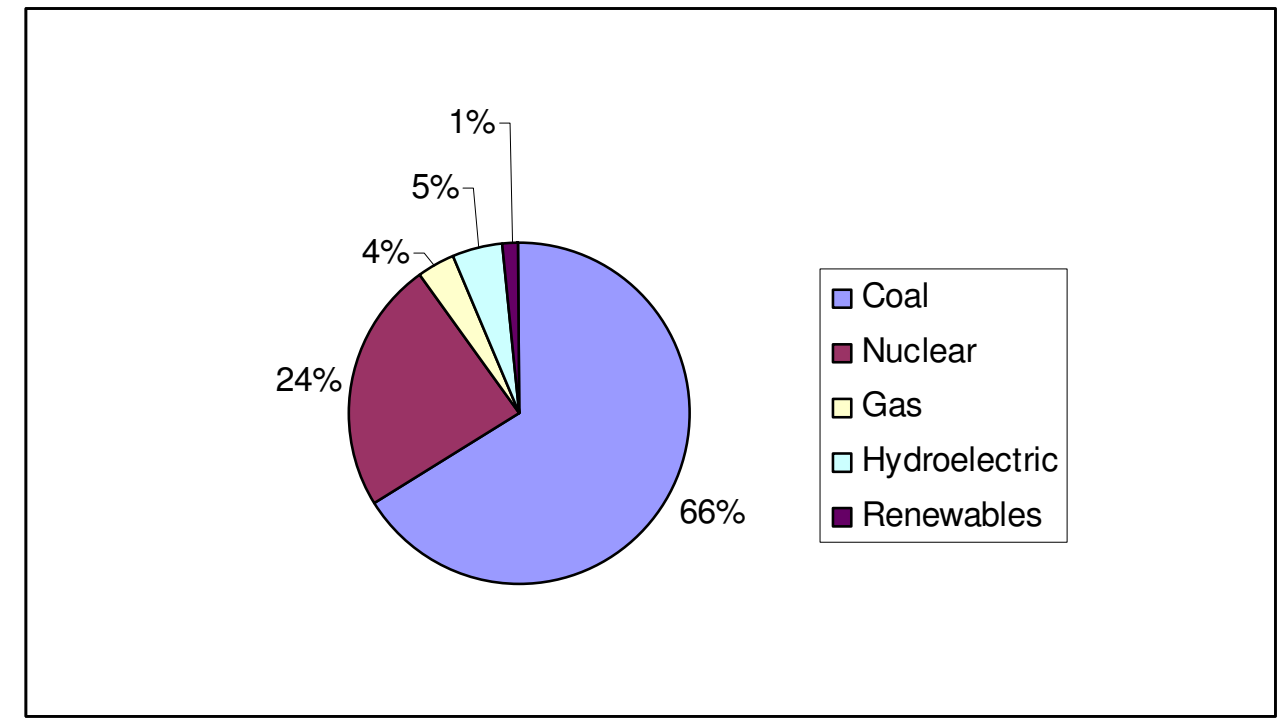

The table below summarizes the environmental impact of the Tribal energy consumption during 2007 based on WPS emission factors and average propane emission factors (See Appendix D

Appendix D).

Table 5. Emissions associated with average Tribal energy consumption per year (metric pound)

\begin{tabular}{|r|l|l|c|c|c|}
\hline $\begin{array}{c}\text { Total } \\
\text { Production }\end{array}$ & & $\begin{array}{c}2007 \\
\text { electricity } \\
(\mathrm{kWh})\end{array}$ & & $\begin{array}{c}2007 \\
\text { propane } \\
\text { (gallons) }\end{array}$ \\
\hline $31,331,860$ & Pounds of CO2 & are released from & $11,870,059$ & and & 407,476 \\
\hline 73,364 & Pounds of NOx & are released from & $11,870,059$ & and & 407,476 \\
\hline 144,831 & Pounds of SOx & are released from & $11,870,059$ & and & 407,476 \\
\hline 1 & Pound of mercury (HG) & are released from & $11,870,059$ & and & 407,476 \\
\hline
\end{tabular}

The electricity and propane used by the government and commercial buildings in 2007 is the equivalent of burning 8,800 tons of coal per year and is enough to power 1200 homes. The Tribal initiatives in energy efficiency and renewable energy will help decrease these emissions and their associated negative environmental and health impacts.

\subsection{Summary of Load by Sector}

To help understand the energy use of major tribal activities and programs, 15 sectors were identified by tribal staff. Energy records from individual facilities were then associated with their corresponding sector. This section allows the Tribe to see the relative amounts of energy that each sector consumes. Percentages are based on the total amount of electricity and propane consumed over the years 2003 through 2007. For a detailed table of energy use by sector, see Appendix A. A list of all facilities and their associated sectors is presented in Appendix B. 
Figure 9. Electricity Consumption by Sector

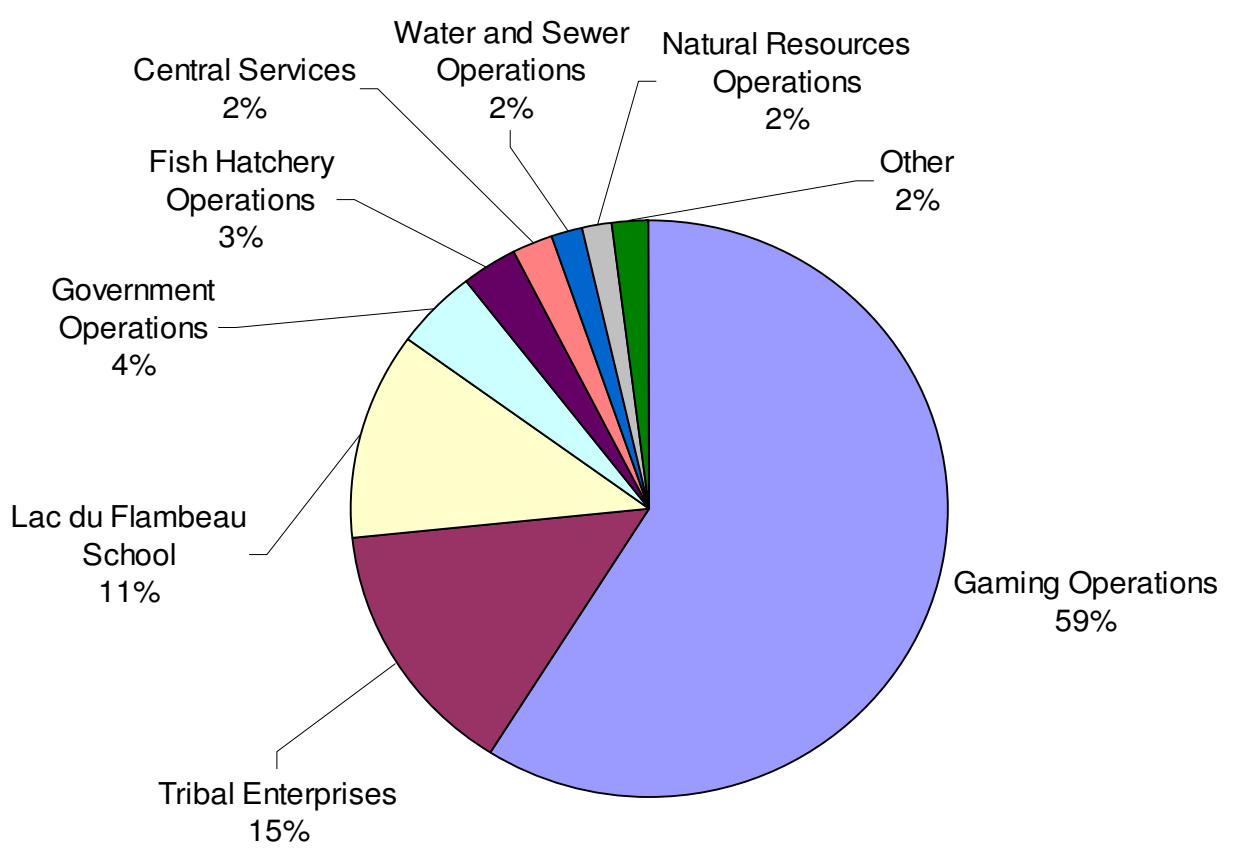

${ }^{*}$ Other Sectors is the sum of the sectors with less than $2 \%$ of the total.

Figure 10. Propane Consumption by Sector

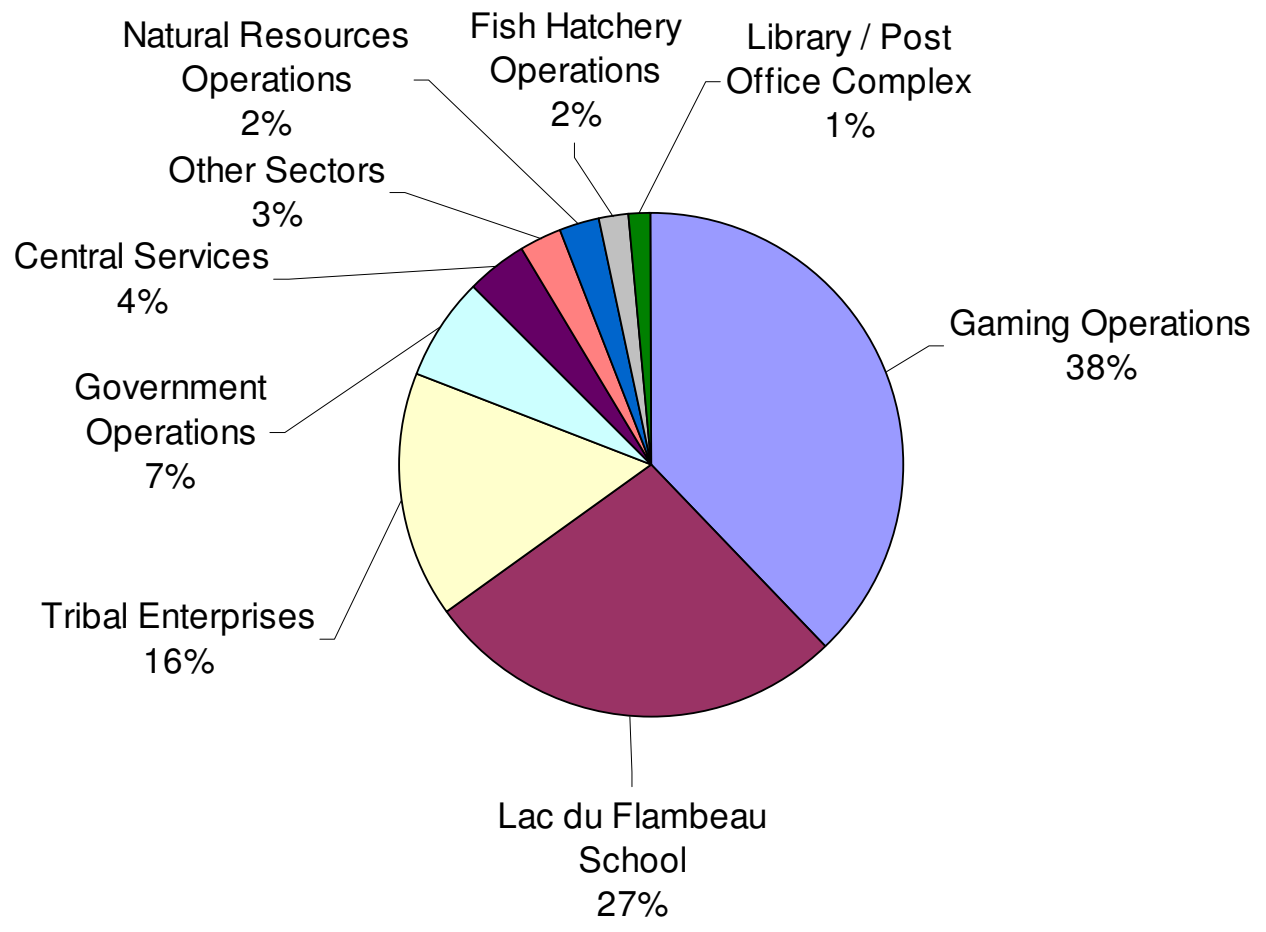

*Other Sectors is the sum of sectors with less than $1 \%$ of the total 


\subsection{Summary of All Structures}

Working with Tribal staff, an inventory of 92 facilities was created. These facilities include all tribal office buildings, gaming facilities, and urban service infrastructure such as water towers and pump houses. A list of all facilities and their addresses is included in Appendix B. The Top 10 electricity users in 2007 are presented in Table 6 and the top 10 propane users are presented in Table 7. The top ten electricity consumers were responsible for 86 percent of the Tribe's total electricity consumption in 2007 . The top ten propane users were responsible for $83 \%$.

Table 6. Top 10 Consumers of Electricity in 2007

\begin{tabular}{|c|c|c|c|c|c|c|c|}
\hline Facility Name & $\begin{array}{c}2003 \\
(\mathrm{kWh}) \\
\text { (dollars) }\end{array}$ & $\begin{array}{c}2004 \\
(\mathrm{kWh}) \\
\text { (dollars) }\end{array}$ & $\begin{array}{c}2005 \\
\text { (kWh) } \\
\text { (dollars) }\end{array}$ & $\begin{array}{c}2006 \\
\text { (kWh) } \\
\text { (dollars) }\end{array}$ & $\begin{array}{c}2007 \\
\text { (kWh) } \\
\text { (dollars) }\end{array}$ & $\begin{array}{c}\text { Total } \\
\text { (kWh) } \\
\text { (dollars) }\end{array}$ & $\begin{array}{c}\text { Percent of } \\
\text { total } 2007 \\
\text { tribal } \\
\text { electricity } \\
\text { consumption }\end{array}$ \\
\hline \multirow{2}{*}{ Casino } & $4,513,864$ & $4,626,159$ & $4,402,505$ & $5,078,879$ & $5,043,793$ & $23,665,200$ & $42.5 \%$ \\
\hline & $\$ 183,928$ & $\$ 209,557$ & $\$ 215,565$ & $\$ 233,538$ & $\$ 264,087$ & $\$ 1,106,675$ & \\
\hline \multirow{2}{*}{ Casino Hotel } & $1,312,320$ & $1,338,840$ & $1,059,360$ & $1,269,480$ & $1,380,360$ & $6,360,360$ & $11.6 \%$ \\
\hline & $\$ 57,214$ & $\$ 64,126$ & $\$ 55,583$ & $\$ 60,790$ & $\$ 76,007$ & $\$ 313,720$ & \\
\hline \multirow{2}{*}{$\begin{array}{l}\text { Lac du Flambeau } \\
\text { School }\end{array}$} & $1,287,800$ & $1,281,600$ & $1,281,600$ & $1,286,200$ & $1,242,200$ & $6,379,400$ & $10.5 \%$ \\
\hline & $\$ 64,035$ & $\$ 71,111$ & $\$ 80,073$ & $\$ 85,786$ & $\$ 91,078$ & $\$ 392,083$ & \\
\hline \multirow{2}{*}{ Store (Ojibwe mall) } & 637,514 & 633,893 & 596,518 & 636,073 & 638,475 & $3,142,473$ & $5.4 \%$ \\
\hline & $\$ 30,692$ & $\$ 34,465$ & $\$ 32,314$ & $\$ 36,739$ & $\$ 39,863$ & $\$ 174,073$ & \\
\hline \multirow{2}{*}{$\begin{array}{l}\text { Community } \\
\text { Center/Clinic }\end{array}$} & 417,720 & 388,320 & 399,600 & 404,400 & 473,000 & $2,083,040$ & $4.0 \%$ \\
\hline & $\$ 22,868$ & $\$ 23,313$ & $\$ 26,708$ & $\$ 28,763$ & $\$ 33,661$ & $\$ 135,313$ & \\
\hline \multirow{2}{*}{$\begin{array}{l}\text { Simpson's Plastics } \\
\text { Plant }\end{array}$} & 442,295 & 471,936 & 417,517 & 428,636 & 415,967 & $2,176,351$ & $3.5 \%$ \\
\hline & $\$ 30,345$ & $\$ 35,126$ & $\$ 33,996$ & $\$ 38,754$ & $\$ 40,176$ & $\$ 178,397$ & \\
\hline \multirow{2}{*}{ Simpson's Main Plant } & 275,040 & 381,360 & 341,280 & 389,600 & 398,960 & $1,786,240$ & $3.4 \%$ \\
\hline & $\$ 20,882$ & $\$ 30,253$ & $\$ 28,233$ & $\$ 33,763$ & $\$ 36,906$ & $\$ 150,037$ & \\
\hline \multirow{2}{*}{ Smoke Shop } & & & & 84,901 & 227,598 & 312,499 & $1.9 \%$ \\
\hline & & & & $\$ 8,340$ & $\$ 21,818$ & $\$ 30,158$ & \\
\hline \multirow{2}{*}{$\begin{array}{l}\text { Pump House (Walleye } \\
\text { ponds) }\end{array}$} & 152,948 & 169,032 & 117,999 & 175,928 & 205,175 & 821,082 & $1.7 \%$ \\
\hline & $\$ 10,819$ & $\$ 12,736$ & $\$ 9,718$ & $\$ 15,087$ & $\$ 18,879$ & $\$ 67,239$ & \\
\hline \multirow{2}{*}{ Bingo Hall } & 197,146 & 180,839 & 194,219 & 199,156 & 197,361 & 968,721 & $1.7 \%$ \\
\hline & $\$ 15,548$ & $\$ 15,500$ & $\$ 17,752$ & $\$ 19,261$ & $\$ 20,675$ & $\$ 88,736$ & \\
\hline
\end{tabular}


Table 7. Top 10 Consumers of Propane in 2007

\begin{tabular}{|c|c|c|c|c|c|c|c|}
\hline Facility Name & $\begin{array}{c}2003 \\
\text { (gallons) } \\
\text { (dollars) }\end{array}$ & $\begin{array}{c}2004 \\
\text { (gallons) } \\
\text { (dollars) }\end{array}$ & $\begin{array}{c}2005 \\
\text { (gallons) } \\
\text { (dollars) }\end{array}$ & $\begin{array}{c}2006 \\
\text { (gallons) } \\
\text { (dollars) }\end{array}$ & $\begin{array}{c}2007 \\
\text { (gallons) } \\
\text { (dollars) }\end{array}$ & $\begin{array}{c}\text { Total } \\
\text { (gallons) } \\
\text { (dollars) }\end{array}$ & $\begin{array}{c}\text { Percent of } \\
\text { total } 2007 \\
\text { tribal } \\
\text { propane } \\
\text { consumption }\end{array}$ \\
\hline \multirow{2}{*}{ Casino } & 55,700 & 130,106 & 75,844 & 161,727 & 163,200 & 586,577 & $40.1 \%$ \\
\hline & $\$ 47,345$ & $\$ 128,805$ & $\$ 98,597$ & $\$ 221,404$ & $\$ 238,272$ & $\$ 734,424$ & \\
\hline \multirow{2}{*}{ Lac du Flambeau School } & 108,000 & 108,000 & 86,520 & 84,300 & 90,000 & 476,820 & $22.1 \%$ \\
\hline & $\$ 75,600$ & $\$ 102,600$ & $\$ 97,764$ & $\$ 122,244$ & $\$ 130,500$ & $\$ 528,708$ & \\
\hline \multirow{2}{*}{ Simpson's Plastics Plant } & 28,303 & 31,746 & 26,404 & 27,416 & 27,159 & 141,027 & $6.7 \%$ \\
\hline & $\$ 24,058$ & $\$ 31,428$ & $\$ 34,325$ & $\$ 37,532$ & $\$ 39,652$ & $\$ 166,994$ & \\
\hline \multirow{2}{*}{ Community Center/Clinic } & 23,192 & 23,190 & 21,704 & 20,940 & 21,236 & 110,262 & $5.2 \%$ \\
\hline & $\$ 19,713$ & $\$ 22,958$ & $\$ 28,215$ & $\$ 28,667$ & $\$ 31,004$ & $\$ 130,558$ & \\
\hline \multirow{2}{*}{ Simpson's Main Plant } & 18,796 & 16,605 & 15,066 & 17,600 & 16,352 & 84,419 & $4.0 \%$ \\
\hline & $\$ 15,977$ & $\$ 16,438$ & $\$ 19,586$ & $\$ 24,095$ & $\$ 23,874$ & $\$ 99,970$ & \\
\hline \multirow{2}{*}{ Bingo Hall } & 2,832 & 6,466 & 3,775 & 9,225 & 11,534 & 33,832 & $2.8 \%$ \\
\hline & $\$ 2,407$ & $\$ 6,401$ & $\$ 4,908$ & $\$ 12,629$ & $\$ 16,840$ & $\$ 43,185$ & \\
\hline \multirow{2}{*}{ Fish Hatchery } & 2,338 & 9,731 & 7,170 & 8,830 & 8,156 & 36,225 & $2.0 \%$ \\
\hline & $\$ 1,987$ & $\$ 9,634$ & $\$ 9,321$ & $\$ 12,089$ & $\$ 11,908$ & $\$ 44,938$ & \\
\hline \multirow{2}{*}{$\begin{array}{l}\text { Casino HR/Education } \\
\text { Building (LOTC }\end{array}$} & 825 & 4,648 & 1,400 & 5,725 & 7,626 & 20,224 & $1.9 \%$ \\
\hline & $\$ 701$ & $\$ 4,602$ & $\$ 1,820$ & $\$ 7,838$ & $\$ 11,133$ & $\$ 26,094$ & \\
\hline \multirow{2}{*}{$\begin{array}{l}\text { Casino Engineering } \\
\text { Building }\end{array}$} & 2,829 & 7,125 & 2,700 & 5,950 & 6,550 & 25,154 & $1.6 \%$ \\
\hline & $\$ 2,405$ & $\$ 7,054$ & $\$ 3,510$ & $\$ 8,146$ & $\$ 9,564$ & $\$ 30,678$ & \\
\hline \multirow{2}{*}{$\begin{array}{l}\text { Roads Garage (Tribal } \\
\text { garage) }\end{array}$} & 2,511 & 6,403 & 6,570 & 5,303 & 6,525 & 27,312 & $1.6 \%$ \\
\hline & $\$ 2,134$ & $\$ 6,339$ & $\$ 8,541$ & $\$ 7,259$ & $\$ 9,527$ & $\$ 33,800$ & \\
\hline
\end{tabular}

*Note that propane data records are not as accurate as electricity usage. Some propane tanks are shared by more than one building but data is only associated with a single building. For example, the Casino shares propane tanks with the Casino Hotel and as a result of this "aggregated accounting", there appears to be no propane used by the Casino Hotel.

\subsection{Projected Tribal Load Assessment}

To project the trends in total electrical and heating costs for the next 10 years, we need to estimate the rate at which consumption and energy rates will change. This type of projection is not an exact science and is dependent upon many external factors. (i.e. carbon taxation, supply constraints, global demand, weather patterns, economic growth, etc.) To recognize these factors, we present three future price projections (low, middle, and high) and three future energy consumption projections (increased demand, stable demand, and lower demand). These projections will then be used to produce worst case, middle-of-the-road, and best case scenarios for the future of Lac du Flambeau's energy consumption and expenditures.

\subsubsection{Fuel Price Projections}

"With the forces driving demand outside the United States as strong as, or stronger than, previously expected but with global supply projections somewhat weaker, oil prices in ... 2008 are higher than projected in ... 2007." This statement from a report titled "Annual Energy 
Outlook 2008" published by the United State's Energy Information Administration shows the difficulty in predicting future prices of a finite global resource.

For the past five to ten years the EIA's Annual Energy Outlook fuel price forecasts have consistently underestimated the actual prices. For this reason we will treat the Annual Energy Outlook's prices as the low projection. The AEO2008 forecasts prices from 2006 to 2017 to increase annually at $2.1 \%$ for electricity and about $1 \%$ for propane.

The middle price projection will be based on the past 12-year trend in Wisconsin (from 1995 to 2006). This trend, as presented previously in this report, showed an average annual increase in electricity prices of $3.7 \%$ and propane prices of $8.0 \%$.

Finally, the high price projection will be based on the actual prices that the Tribe experienced over the past five years (2003 to 2007). This average annual increase was $7.3 \%$ for electricity and $14.5 \%$ for propane. The actual five-year history is used as the high projection since energy rates during this period increased at an unusually rapid rate.

These price projections are summarized in Table 8.

Table 8. Fuel Price Projections - Average Annual Increase through 2017

\begin{tabular}{|l|c|c|c|}
\hline FUEL TYPE & LOW-CASE & MIDDLE-CASE & HIGH-CASE \\
\hline ELECTRICITY & $2.1 \%$ & $3.7 \%$ & $7.3 \%$ \\
\hline PROPANE & $1.0 \%$ & $8.0 \%$ & $14.5 \%$ \\
\hline & $\begin{array}{l}\text { SOURCE: EIA } \\
\text { PROJECTIONS, 2006 TO } \\
\text { 2017 }\end{array}$ & $\begin{array}{l}\text { SOURCE: WISCONSIN'S } \\
\text { HISTORICAL PRICES 1995 } \\
\text { TO 2007 }\end{array}$ & $\begin{array}{l}\text { SOURCE: PRICES PAID BY } \\
\text { LAC DU FLAMBEAU, 2003 } \\
\text { TO 2007 }\end{array}$ \\
\hline
\end{tabular}

${ }^{*}$ EIA projections were provided in real 2006 dollars. To be able to convert the EIA projections to nominal prices, an inflation rate of $2.5 \%$ was applied to generate the average annual price increase based on nominal figures.

\subsubsection{Tribal Energy Use Projections}

Future energy use projections of Lac du Flambeau will be based on three different cases.

\section{Case One}

The first case assumes that electricity and propane consumption will increase annually at the rate that the Tribe experienced between 2003 and 2007, 2.5\% per year for electricity and 10.4\% per year for propane. This "worst case" assumes that energy use will continue to grow as new facilities are built, additional energy consuming appliances are used, and no conservation measures are implemented.

\section{Case Two}

The second case assumes that electricity and propane consumption will remain stable and not increase beyond that of 2007. This projection assumes that there will be very little growth in new facility construction and that basic conservation measures will be implemented, such as efficient lighting, insulation and occupancy sensors. 


\section{Case Three}

The third case is based on an ambitious investment in both conservation improvements and the utilization of renewable energy to offset purchases of fossil fuels. Assuming that these efforts would reduce tribal energy consumption at a rate that would meet carbon reduction goals of the Kyoto protocol, the Tribe would need to reduce emissions from 2008 to 2017 by 30\%. This can be translated to a reduction in electricity and propane use of about $3.0 \%$ per year.

These three consumption projections are summarized in Table 9.

Table 9. Energy Consumption Projections - Average Annual Change through 2017

\begin{tabular}{|l|c|c|c|}
\hline FUEL TYPE & REDUCED DEMAND & STABLE DEMAND & INCREASED DEMAND \\
\hline ELECTRICITY & $-3.0 \%$ & $0 \%$ & $2.5 \%$ \\
\hline PROPANE & $-3.0 \%$ & $0 \%$ & $10.4 \%$ \\
\hline
\end{tabular}

\subsubsection{Future Energy Consumption and Expense Scenarios}

Considering the three different price increase projections and the three different consumption projections presented above, Table 10 shows the range of scenarios that the Tribe could experience in 2017. Projections use 2007 consumption and price figures as the base case for estimating 2017 values.

Table 10. Projected Energy Consumption and Expenses in 2017

\begin{tabular}{|l|l|l|l|l|l|l|}
\hline $\begin{array}{l}\text { Price } \\
\text { Projections }\end{array}$ & \multicolumn{4}{|l|}{ Electricity Consumption and Expense } & \multicolumn{3}{l|}{ Propane Consumption and Expense } \\
\hline & $\begin{array}{l}\text { Reduced } \\
\text { demand } \\
\text { (kWh) } \\
\text { (dollars) }\end{array}$ & $\begin{array}{l}\text { Stable } \\
\text { demand } \\
\text { (kWh) } \\
\text { (dollars) }\end{array}$ & $\begin{array}{l}\text { Increased } \\
\text { demand } \\
\text { (kWh) } \\
\text { (dollars) }\end{array}$ & $\begin{array}{l}\text { Reduced } \\
\text { demand } \\
\text { (gallons) } \\
\text { (dollars) }\end{array}$ & $\begin{array}{l}\text { Stable } \\
\text { demand } \\
\text { (gallons) } \\
\text { (dollars) }\end{array}$ & $\begin{array}{l}\text { Increased } \\
\text { demand } \\
\text { (gallons) } \\
\text { (dollars) }\end{array}$ \\
\hline & & & & & & \\
\hline Low-case & $8,753,268$ & $11,870,059$ & $15,194,679$ & 300,483 & 407,476 & $1,095,955$ \\
\hline & $\$ 749,850$ & $\$ 1,016,851$ & $\$ 1,301,655$ & $\$ 484,603$ & $\$ 657,156$ & $\$ 1,767,500$ \\
\hline Middle-case & $8,753,268$ & $11,870,059$ & $15,194,679$ & 300,483 & 407,476 & $1,095,955$ \\
\hline & $\$ 876,001$ & $\$ 1,187,920$ & $\$ 1,520,638$ & $\$ 947,130$ & $\$ 1,284,377$ & $\$ 3,454,484$ \\
\hline High-case & $8,753,268$ & $11,870,059$ & $15,194,679$ & 300,483 & 407,476 & $1,095,955$ \\
\hline & $\$ 1,232,294$ & $\$ 1,671,079$ & $\$ 2,139,122$ & $\$ 1,699,132$ & $\$ 2,304,145$ & $\$ 6,197,271$ \\
\hline
\end{tabular}

These nine scenarios show that future expenses will increase due to the simple fact that energy prices will continue increasing. However, the rate at which tribal energy expenditures increase varies dramatically with how the Tribe chooses to increase or decrease its energy consumption. Table 11 presents three different scenarios, each assuming that prices increase according to the middle-case projection. This example shows outcomes that are entirely dependent on whether the Tribe continues to consume more energy each year, implements basic conservation measures, or invests significantly in conservation and renewable energy systems. 
These projections show that the Tribe can protect itself against energy rate hikes through aggressive investment to reduce demand. This strategy could reduce annual energy costs by nearly $\$ 5$ million per year by 2017 if energy rates continue their current trend.

Table 11. Projected Tribal Energy Expenses with Mid-range Price Increases

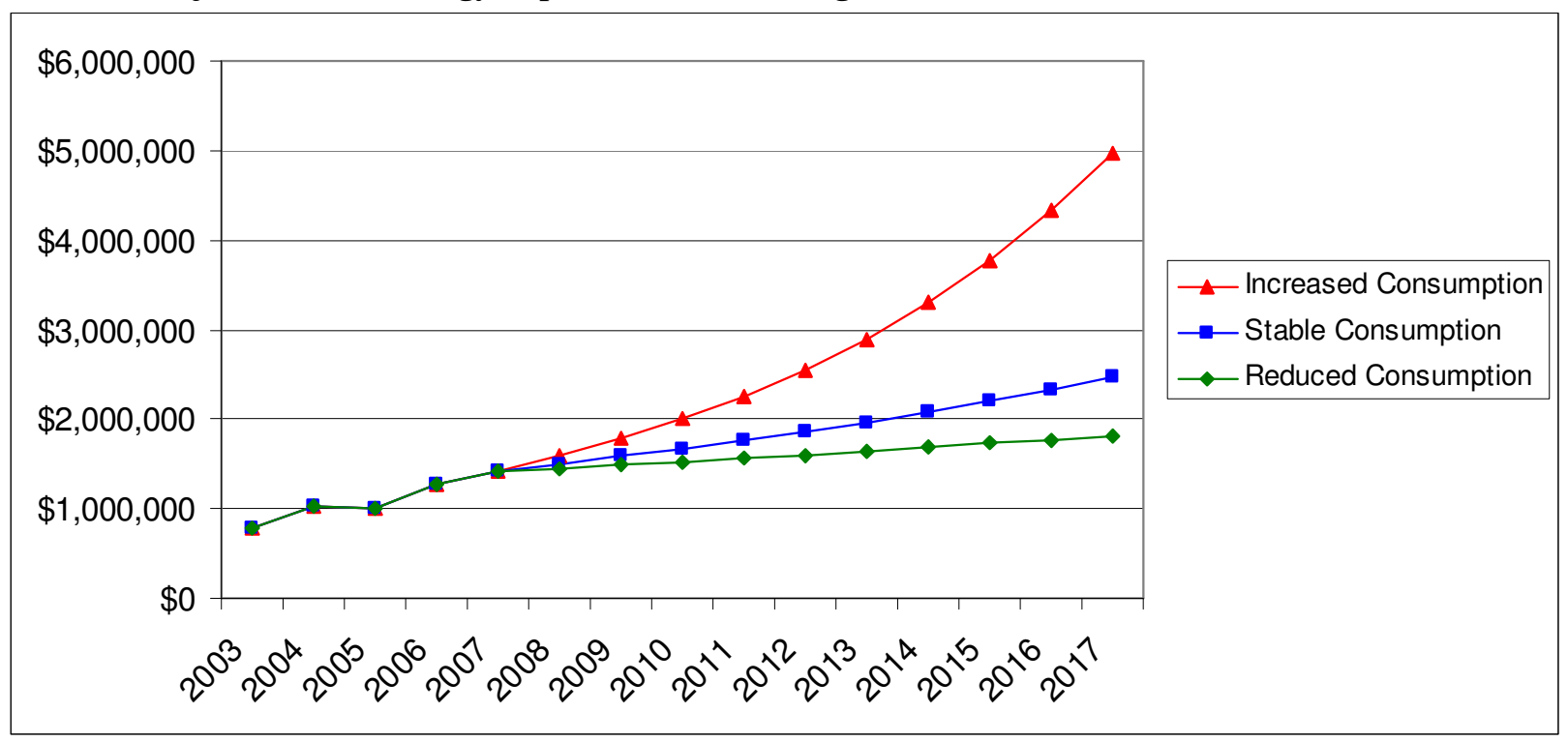




\subsection{Appendices}

Appendix A. Energy Use by Sector

Table 12. Electricity Use by Sector, 2003 to 2007

\begin{tabular}{|l|c|c|c|}
\hline \multicolumn{1}{|c|}{ Sector } & Electricity $(\mathrm{kWh})$ & Expenditures & $\begin{array}{c}\text { Percent Total } \\
\text { Electricity Use }\end{array}$ \\
\hline Gaming Operations & $32,678,282$ & $\$ 1,643,099$ & $58.8 \%$ \\
\hline Tribal Enterprises & $8,166,173$ & $\$ 607,869$ & $14.7 \%$ \\
\hline Lac du Flambeau School & $6,379,400$ & $\$ 392,086$ & $11.5 \%$ \\
\hline Government Operations & $2,478,292$ & $\$ 175,025$ & $4.5 \%$ \\
\hline Fish Hatchery Operations & $1,686,360$ & $\$ 140,554$ & $3.0 \%$ \\
\hline Central Services & $1,296,802$ & $\$ 130,580$ & $2.3 \%$ \\
\hline Water and Sewer Operations & 933,738 & $\$ 103,448$ & $1.7 \%$ \\
\hline Natural Resources Operations & 837,065 & $\$ 79,008$ & $1.5 \%$ \\
\hline Campground Operations & 403,501 & $\$ 41,110$ & $0.7 \%$ \\
\hline Cultural Buildings & 246,933 & $\$ 26,355$ & $0.4 \%$ \\
\hline Library / Post Office Complex & 182,239 & $\$ 19,892$ & $0.3 \%$ \\
\hline Street Lighting - General & 153,463 & $\$ 21,128$ & $0.3 \%$ \\
\hline Miscellaneous & 138,214 & $\$ 15,195$ & $0.2 \%$ \\
\hline $\begin{array}{l}\text { Residential Homes (Tribe } \\
\text { owned) }\end{array}$ & 17,076 & $\$ 1,902$ & $<0.1 \%$ \\
\hline Adaawe Place & 10,697 & $\$ 2,750$ & $<0.1 \%$ \\
\hline Unassociated & 2,564 & $\$ 2,908$ & $<0.1 \%$ \\
\hline TOTAL & $55,610,799$ & $\$ 3,402,909$ & \\
\hline
\end{tabular}

Table 13. Propane Use by Sector, 2003 to 2007

\begin{tabular}{|l|c|c|c|}
\hline \multicolumn{1}{|c|}{ Sector } & $\begin{array}{c}\text { Propane } \\
\text { (gallons) }\end{array}$ & Expenditures & $\begin{array}{c}\text { Percent Total } \\
\text { Propane Use }\end{array}$ \\
\hline Gaming Operations & 665,787 & $\$ 834,380$ & $36.8 \%$ \\
\hline Lac du Flambeau School & 476,820 & $\$ 528,708$ & $26.4 \%$ \\
\hline Tribal Enterprises & 281,618 & $\$ 333,518$ & $15.6 \%$ \\
\hline Government Operations & 116,922 & $\$ 139,029$ & $6.5 \%$ \\
\hline Central Services & 69,369 & $\$ 87,847$ & $3.8 \%$ \\
\hline Natural Resources Operations & 47,864 & $\$ 60,543$ & $2.6 \%$ \\
\hline Fish Hatchery Operations & 36,225 & $\$ 44,938$ & $2.0 \%$ \\
\hline Library / Post Office Complex & 23,698 & $\$ 27,649$ & $1.3 \%$ \\
\hline Water and Sewer Operations & 14,527 & $\$ 17,198$ & $0.8 \%$ \\
\hline Cultural Buildings & 14,447 & $\$ 18,561$ & $0.8 \%$ \\
\hline Miscellaneous & 8,969 & $\$ 11,106$ & $0.5 \%$ \\
\hline Adaawe Place & 5,000 & $\$ 7,128$ & $0.3 \%$ \\
\hline Unassociated & 3,700 & $\$ 5,087$ & $0.2 \%$ \\
\hline Campground Operations & 1,220 & $\$ 1,462$ & $0.1 \%$ \\
\hline Street Lighting - General & 0 & $\$ 0$ & $0.0 \%$ \\
\hline $\begin{array}{l}\text { Residential Homes (Tribe } \\
\text { owned) }\end{array}$ & 0 & $\$ 0$ & $0.0 \%$ \\
\hline TOTAL & $1,760,999$ & $\$ 2,108,755$ & \\
\hline
\end{tabular}


Appendix B. List of Facilities, Grouped by Sector

\begin{tabular}{|c|c|c|}
\hline Sector & Facility & Street Address \\
\hline Adaawe Place & Adaawe Place & \\
\hline Adaawe Place & Adaawe place incubator unit 10 & 591 Peace Pipe Rd \\
\hline Adaawe Place & Adaawe place incubator unit 5 & 581 Peace Pipe Rd \\
\hline Adaawe Place & Adaawe place incubator unit 6 & 583 Peace Pipe Rd \\
\hline Adaawe Place & Adaawe place incubator unit 7 & 585 Peace Pipe Rd \\
\hline Adaawe Place & Adaawe place incubator unit 8 & 587 Peace Pipe Rd \\
\hline Adaawe Place & Adaawe place incubator unit 9 & 589 Peace Pipe Rd \\
\hline Campground Operations & Bath House \#1 & 2549 State Highway 47 \\
\hline Campground Operations & Bath House \#2 & 2549 State Highway 47 \\
\hline Campground Operations & Campground Office & 2549 State Highway 47 \\
\hline Central Services & Domestic Abuse Shelter & 157 Cedar Ave. \\
\hline Central Services & Family Resource Center & 533 Peace Pipe Rd. \\
\hline Central Services & Food Distribution Building & 220 Industrial Park Rd. \\
\hline Central Services & Planning / Bank Building & 602 Peace Pipe Rd. \\
\hline Central Services & Wellness Center & 125 Old Abe Rd \\
\hline Central Services & $\begin{array}{l}\text { Youth Center (Abinoojiiyag } \\
\text { Center) }\end{array}$ & 407 Huron St. \\
\hline Cultural Buildings & Indian Bowl & 536 Simpson Ave. \\
\hline Cultural Buildings & Round House & 14640 Indian Village Rd \\
\hline Fish Hatchery Operations & Fish Hatchery & 2500 Hwy 47 North \\
\hline Fish Hatchery Operations & Net Garage (ponds) & \\
\hline Fish Hatchery Operations & Pump - North Pokegama Ponds & \\
\hline Fish Hatchery Operations & Pump House (Walleye ponds) & Longs Point Ln \\
\hline Gaming Operations & Bingo Hall & 424 Little Pines Rd. \\
\hline Gaming Operations & Casino & 510 Old Abe \\
\hline Gaming Operations & Casino Billboard (Highway 47) & \\
\hline Gaming Operations & Casino Billboard (Highway $47 / \mathrm{H}$ ) & \\
\hline Gaming Operations & Casino Billboard (Highway 70) & \\
\hline Gaming Operations & Casino Engineering Building & 200 Industrial Park Rd. \\
\hline Gaming Operations & Casino Hotel & 510 Old Abe. \\
\hline Gaming Operations & $\begin{array}{l}\text { Casino Human Resources / } \\
\text { Education Building (LOTC }\end{array}$ & 562 Peace Pipe Rd. \\
\hline Gaming Operations & Casino Storage Building & 849 Old Abe Rd \\
\hline Gaming Operations & Light post (employee lot) & 421 Chippewa St \\
\hline Government Operations & Community Center/Clinic & 418/408 Little Pines Rd \\
\hline Government Operations & Judicial building & 623 Peace Pipe Rd. \\
\hline Government Operations & Radio Tower Building & \\
\hline Housing Operations & Housing Garage \#1 & \\
\hline Housing Operations & Housing garage \#2 & \\
\hline Housing Operations & Housing Office & 554 Chicog \\
\hline Housing Operations & Vet Center & 409 Little Pines Rd \\
\hline Lac du Flambeau School & Lac du Flambeau School & 2899 State Hwy 47 South \\
\hline Library / Post Office Complex & Library & 626 Peace Pipe Rd. \\
\hline Library / Post Office Complex & Post Office & 622 Peace Pipe Rd. \\
\hline Library / Post Office Complex & Tribal Office & 624 Peace Pipe $\mathrm{Rd}$. \\
\hline Miscellaneous & Boys Dormitory (Niijii) & 838 White Feather St. \\
\hline Miscellaneous & Fireside & 703 Peace Pipe Rd. \\
\hline
\end{tabular}


Task One: Current Tribal load assessment Seventh Generation Energy Systems

\begin{tabular}{|c|c|c|}
\hline Sector & Facility & Street Address \\
\hline Miscellaneous & Multipurpose Building & 143 Cedar Ave \\
\hline Miscellaneous & Storage building (robert elm) & \\
\hline Miscellaneous & Veterans Memorial & 408 Little Pines Rd. \\
\hline Natural Resources Operations & Conservation Law / Bait Shop & \\
\hline Natural Resources Operations & Deer Registration Station & 826 White Feather St. \\
\hline Natural Resources Operations & Forestry & 2936 Cemetery Rd \\
\hline Natural Resources Operations & Land Management Office & 14284 Hwy 70 West \\
\hline Natural Resources Operations & Natural Resources Office & 2500 Hwy 47 North \\
\hline Natural Resources Operations & Old Water / Sewer Office & \\
\hline Natural Resources Operations & Roads Garage (Tribal garage) & 280 Industrial Park Rd. \\
\hline Natural Resources Operations & Strawberry Farm Shed & 13593 Highway 70 West \\
\hline Natural Resources Operations & Water Resource office & 2500 Hwy 47 North \\
\hline $\begin{array}{l}\text { Residential Homes (Tribe } \\
\text { owned) }\end{array}$ & 1219 Arnold Stock Ln & 1219 Arnold Stock Ln \\
\hline $\begin{array}{l}\text { Residential Homes (Tribe } \\
\text { owned) }\end{array}$ & 2355 Bobidosh Point Ln & 2355 Bobidosh Point Ln \\
\hline Street Lighting - General & Street Lighting - downtown & Highway 47 \& Peace Pipe Rd \\
\hline Street Lighting - General & Street Lighting - Indian Village Rd & Indian Village Rd \\
\hline Tribal Enterprises & Gas Station & 509 Old Abe Rd \\
\hline Tribal Enterprises & Gas Station Storage & 509 Old Abe Rd \\
\hline Tribal Enterprises & Home Rehab Office / WOLF & 705 Peace Pipe Rd. \\
\hline Tribal Enterprises & Museum & 603 Peace Pipe Rd. \\
\hline Tribal Enterprises & Simpson's Main Plant & 520 Simpson Ave. \\
\hline Tribal Enterprises & Simpson's Plastics Plant & 851 White Feather St. \\
\hline Tribal Enterprises & Smoke Shop & 597 Peace Pipe Rd. \\
\hline Tribal Enterprises & Store (Ojibwe mall) & 501 Old Abe Rd \\
\hline Water and Sewer Operations & Effluent Pump & Elk Point Ln \\
\hline Water and Sewer Operations & Lift Station 1 & Cemetery Rd \\
\hline Water and Sewer Operations & Lift Station 10 & 114 Old Abe Rd \\
\hline Water and Sewer Operations & Lift Station 11 & Cedar St \\
\hline Water and Sewer Operations & Lift Station 12 & Wayman Lane \\
\hline Water and Sewer Operations & Lift Station 2 & 14241 Long Point Ln \\
\hline Water and Sewer Operations & Lift Station 3 & 814 Old Abe Rd \\
\hline Water and Sewer Operations & Lift Station 4 & 987 Peace Pipe Rd \\
\hline Water and Sewer Operations & Lift Station 5 & 604 Chicog St \\
\hline Water and Sewer Operations & Lift Station 6 & 838 Elks Point Ln \\
\hline Water and Sewer Operations & Lift Station 7 & 205 Makoons Trail \\
\hline Water and Sewer Operations & Lift Station 8 & 2863 Little Pines \\
\hline Water and Sewer Operations & Lift Station 9 & 241 Industrial Park \\
\hline Water and Sewer Operations & Pump House 1 & 553 Chicog St \\
\hline Water and Sewer Operations & Pump House 2 & 1960 Old Prairie Rd \\
\hline Water and Sewer Operations & Pump House 3 & 2159 Wildcat Lane \\
\hline Water and Sewer Operations & Sand Filter Station & West River Trail \\
\hline Water and Sewer Operations & Water \& Sewer Office & 2828 State Highway 47 \\
\hline Water and Sewer Operations & $\begin{array}{l}\text { Water \& Sewer Storage (old } \\
\text { office) }\end{array}$ & 2650 State Highway 47 \\
\hline Water and Sewer Operations & Water Tower 1 & 628 Old Abe Rd \\
\hline
\end{tabular}


Task One: Current Tribal load assessment Seventh Generation Energy Systems

\begin{tabular}{|l|l|l|}
\hline \multicolumn{1}{|c|}{ Sector } & \multicolumn{1}{|c|}{ Facility } & \multicolumn{1}{c|}{ Street Address } \\
\hline Water and Sewer Operations & Water Tower 2 & 187 Old Abe Rd \\
Water and Sewer Operations & Water Tower 3 & Indian Village Rd \\
\hline Water and Sewer Operations & Water Tower 4 & 3047 Cemetery Rd \\
\hline
\end{tabular}


Appendix C. Energy Consumption for all Facilities (Grouped by Sector, Ordered by Five-year Electricity Consumption)

\begin{tabular}{|c|c|c|c|c|c|c|c|c|c|c|c|c|c|}
\hline & \multirow[b]{2}{*}{ Facility Name } & \multicolumn{4}{|c|}{ Electricity Consumption and Expense } & \multirow[b]{2}{*}{$\begin{array}{c}2007 \\
\text { (kWh) } \\
\text { (dollars) }\end{array}$} & \multirow[b]{2}{*}{$\begin{array}{c}\text { Total } \\
\text { (kWh) } \\
\text { (dollars) }\end{array}$} & \multicolumn{4}{|c|}{ Propane Consumption and Expense } & \multirow[b]{2}{*}{$\begin{array}{c}2007 \\
\text { (gallons) } \\
\text { (dollars) }\end{array}$} & \multirow[b]{2}{*}{$\begin{array}{c}\text { Total } \\
\text { (gallons) } \\
\text { (dollars) }\end{array}$} \\
\hline & & $\begin{array}{c}2003 \\
\text { (kWh) } \\
\text { (dollars) }\end{array}$ & $\begin{array}{c}2004 \\
\text { (kWh) } \\
\text { (dollars) }\end{array}$ & $\begin{array}{c}2005 \\
\text { (kWh) } \\
\text { (dollars) }\end{array}$ & $\begin{array}{c}2006 \\
\text { (kWh) } \\
\text { (dollars) }\end{array}$ & & & $\begin{array}{c}2003 \\
\text { (gallons) } \\
\text { (dollars) }\end{array}$ & $\begin{array}{c}2004 \\
\text { (gallons) } \\
\text { (dollars) }\end{array}$ & $\begin{array}{c}2005 \\
\text { (gallons) } \\
\text { (dollars) }\end{array}$ & $\begin{array}{c}2006 \\
\text { (gallons) } \\
\text { (dollars) }\end{array}$ & & \\
\hline \multicolumn{14}{|c|}{ Adaawe Place } \\
\hline & \multirow{2}{*}{$\begin{array}{c}\text { Adaawe place } \\
\text { incubator unit } 10\end{array}$} & & & & 878 & 2,380 & 3,258 & & & & & & \\
\hline & & & & & $\$ 171$ & $\$ 440$ & $\$ 611$ & & & & & & \\
\hline & \multirow{2}{*}{$\begin{array}{c}\text { Adaawe place } \\
\text { incubator unit } 7\end{array}$} & & & & 255 & 1,558 & 1,813 & & & & & & \\
\hline & & & & & $\$ 115$ & $\$ 352$ & $\$ 467$ & & & & & & \\
\hline & \multirow{2}{*}{$\begin{array}{l}\text { Adaawe place } \\
\text { incubator unit } 8\end{array}$} & & & & 410 & 1,368 & 1,778 & & & & & & \\
\hline & & & & & $\$ 125$ & $\$ 331$ & $\$ 456$ & & & & & & \\
\hline & \multirow{2}{*}{$\begin{array}{c}\text { Adaawe place } \\
\text { incubator unit } 9\end{array}$} & & & & 454 & 1,055 & 1,509 & & & & & & \\
\hline & & & & & $\$ 129$ & $\$ 297$ & $\$ 426$ & & & & & & \\
\hline & \multirow{2}{*}{$\begin{array}{l}\text { Adaawe place } \\
\text { incubator unit } 5\end{array}$} & & & & 392 & 795 & 1,187 & & & & & & \\
\hline & & & & & $\$ 124$ & $\$ 271$ & $\$ 395$ & & & & & & \\
\hline & \multirow{2}{*}{$\begin{array}{l}\text { Adaawe place } \\
\text { incubator unit } 6\end{array}$} & & & & 330 & 822 & 1,152 & & & & & & \\
\hline & & & & & $\$ 118$ & $\$ 274$ & $\$ 392$ & & & & & & \\
\hline & \multirow[b]{2}{*}{ Adaawe Place } & & & & & & & & & & 1,900 & 3,100 & 5,000 \\
\hline & & & & & & & & & & & $\$ 2,601$ & $\$ 4,527$ & $\$ 7,128$ \\
\hline \multicolumn{14}{|c|}{$\begin{array}{l}\text { Campground } \\
\text { Operations }\end{array}$} \\
\hline & \multirow[b]{2}{*}{ Bath House \#1 } & 46,791 & 42,319 & 46,345 & 44,358 & 47,084 & 226,897 & & & & & & \\
\hline & & $\$ 3,829$ & $\$ 3,835$ & $\$ 4,504$ & $\$ 4,584$ & $\$ 5,270$ & $\$ 22,022$ & & & & & & \\
\hline & \multirow[b]{2}{*}{ Bath House \#2 } & 42,081 & 37,302 & 32,646 & 33,629 & 30,946 & 176,604 & & & & & & \\
\hline & & $\$ 3,457$ & $\$ 3,401$ & $\$ 3,229$ & $\$ 3,523$ & $\$ 3,544$ & $\$ 17,154$ & & & & & & \\
\hline & \multirow{2}{*}{$\begin{array}{l}\text { Campground } \\
\text { Office }\end{array}$} & & & & & & & 280 & 200 & 340 & & 400 & 1,220 \\
\hline & & $\$ 318$ & $\$ 359$ & $\$ 384$ & $\$ 428$ & $\$ 453$ & $\$ 1,942$ & $\$ 238$ & $\$ 198$ & $\$ 442$ & & $\$ 584$ & $\$ 1,462$ \\
\hline \multicolumn{14}{|c|}{ Central Services } \\
\hline & \multirow[b]{2}{*}{ Wellness Center } & & & & 114,240 & 191,720 & 305,960 & & & 6,400 & 8,601 & 5,614 & 20,615 \\
\hline & & & & & $\$ 11,003$ & $\$ 17,683$ & $\$ 28,686$ & & & $\$ 8,320$ & $\$ 11,775$ & $\$ 8,196$ & $\$ 28,292$ \\
\hline & Youth Center & 55,881 & 50,726 & 51,600 & 49,614 & 48,638 & 256,459 & 3,233 & 2,750 & 1,930 & 2,775 & 2,501 & 13,189 \\
\hline
\end{tabular}




\begin{tabular}{|c|c|c|c|c|c|c|c|c|c|c|c|c|}
\hline \multirow[b]{2}{*}{ Facility Name } & \multicolumn{4}{|c|}{ Electricity Consumption and Expense } & \multirow[b]{2}{*}{$\begin{array}{c}2007 \\
\text { (kWh) } \\
\text { (dollars) }\end{array}$} & \multirow[b]{2}{*}{$\begin{array}{c}\text { Total } \\
\text { (kWh) } \\
\text { (dollars) }\end{array}$} & \multicolumn{4}{|c|}{ Propane Consumption and Expense } & \multirow[b]{2}{*}{$\begin{array}{c}2007 \\
\text { (gallons) } \\
\text { (dollars) }\end{array}$} & \multirow[b]{2}{*}{$\begin{array}{c}\text { Total } \\
\text { (gallons) } \\
\text { (dollars) }\end{array}$} \\
\hline & $\begin{array}{c}2003 \\
\text { (kWh) } \\
\text { (dollars) }\end{array}$ & $\begin{array}{c}2004 \\
\text { (kWh) } \\
\text { (dollars) }\end{array}$ & $\begin{array}{c}2005 \\
\text { (kWh) } \\
\text { (dollars) }\end{array}$ & $\begin{array}{c}2006 \\
\text { (kWh) } \\
\text { (dollars) }\end{array}$ & & & $\begin{array}{c}2003 \\
\text { (gallons) } \\
\text { (dollars) }\end{array}$ & $\begin{array}{c}2004 \\
\text { (gallons) } \\
\text { (dollars) }\end{array}$ & $\begin{array}{c}2005 \\
\text { (gallons) } \\
\text { (dollars) }\end{array}$ & $\begin{array}{c}2006 \\
\text { (gallons) } \\
\text { (dollars) }\end{array}$ & & \\
\hline $\begin{array}{l}\text { (Abinoojiiyag } \\
\text { Center) }\end{array}$ & $\$ 5,234$ & $\$ 5,313$ & $\$ 5,858$ & $\$ 6,090$ & $\$ 6,336$ & $\$ 28,831$ & $\$ 2,748$ & $\$ 2,723$ & $\$ 2,509$ & $\$ 3,799$ & $\$ 3,652$ & $\$ 15,430$ \\
\hline \multirow{2}{*}{$\begin{array}{l}\text { Domestic Abuse } \\
\text { Shelter }\end{array}$} & 38,673 & 47,346 & 44,128 & 44,026 & 44,320 & 218,493 & 1,705 & 2,320 & 2,405 & 2,197 & 1,901 & 10,529 \\
\hline & $\$ 3,228$ & $\$ 4,339$ & $\$ 4,268$ & $\$ 4,559$ & $\$ 4,855$ & $\$ 21,249$ & $\$ 1,449$ & $\$ 2,297$ & $\$ 3,127$ & $\$ 3,008$ & $\$ 2,776$ & $\$ 12,657$ \\
\hline \multirow{2}{*}{$\begin{array}{l}\text { Family Resource } \\
\text { Center }\end{array}$} & 37,064 & 48,682 & 41,652 & 43,356 & 47,466 & 218,220 & 550 & 1,842 & 1,600 & 3,126 & 2,800 & 9,918 \\
\hline & $\$ 3,013$ & $\$ 4,419$ & $\$ 4,289$ & $\$ 4,766$ & $\$ 5,485$ & $\$ 21,972$ & $\$ 468$ & $\$ 1,824$ & $\$ 2,080$ & $\$ 4,279$ & $\$ 4,088$ & $\$ 12,738$ \\
\hline \multirow{2}{*}{$\begin{array}{l}\text { Food Distribution } \\
\text { Building }\end{array}$} & 31,720 & 37,266 & 34,391 & 35,493 & 31,972 & 170,842 & 325 & 1,698 & 1,431 & 1,160 & 1,535 & 6,149 \\
\hline & $\$ 2,601$ & $\$ 3,325$ & $\$ 3,360$ & $\$ 3,717$ & $\$ 3,550$ & $\$ 16,553$ & $\$ 276$ & $\$ 1,681$ & $\$ 1,860$ & $\$ 1,588$ & $\$ 2,241$ & $\$ 7,647$ \\
\hline \multirow{2}{*}{$\begin{array}{l}\text { Planning / Bank } \\
\text { Building }\end{array}$} & & & & 64,236 & 62,592 & 126,828 & 490 & 2,515 & 2,490 & 1,450 & 2,024 & 8,969 \\
\hline & & & & $\$ 6,542$ & $\$ 6,753$ & $\$ 13,295$ & $\$ 417$ & $\$ 2,490$ & $\$ 3,237$ & $\$ 1,985$ & $\$ 2,955$ & $\$ 11,084$ \\
\hline \multicolumn{13}{|l|}{ Cultural Buildings } \\
\hline \multirow[b]{2}{*}{ Indian Bowl } & 48,387 & 55,116 & 41,084 & 43,846 & 39,480 & 227,913 & 850 & 2,819 & 1,740 & 2,052 & 3,170 & 10,631 \\
\hline & $\$ 4,170$ & $\$ 5,043$ & $\$ 4,083$ & $\$ 4,651$ & $\$ 4,408$ & $\$ 22,355$ & $\$ 723$ & $\$ 2,791$ & $\$ 2,262$ & $\$ 2,809$ & $\$ 4,628$ & $\$ 13,213$ \\
\hline \multirow[b]{2}{*}{ Round House } & 2,554 & 2,950 & 2,955 & 4,264 & 6,297 & 19,020 & & & 615 & 1,370 & 1,831 & 3,816 \\
\hline & $\$ 584$ & $\$ 679$ & $\$ 684$ & $\$ 896$ & $\$ 1,165$ & $\$ 4,008$ & & & $\$ 800$ & $\$ 1,876$ & $\$ 2,673$ & $\$ 5,348$ \\
\hline \multicolumn{13}{|l|}{$\begin{array}{l}\text { Fish Hatchery } \\
\text { Operations }\end{array}$} \\
\hline \multirow[b]{2}{*}{ Fish Hatchery } & 141,695 & 161,492 & 162,401 & 204,615 & 184,225 & 854,428 & 2,338 & 9,731 & 7,170 & 8,830 & 8,156 & 36,225 \\
\hline & $\$ 10,351$ & $\$ 12,522$ & $\$ 13,522$ & $\$ 17,859$ & $\$ 17,416$ & $\$ 71,670$ & $\$ 1,987$ & $\$ 9,634$ & $\$ 9,321$ & $\$ 12,089$ & $\$ 11,908$ & $\$ 44,938$ \\
\hline \multirow{2}{*}{$\begin{array}{l}\text { Pump House } \\
\text { (Walleye ponds) }\end{array}$} & 152,948 & 169,032 & 117,999 & 175,928 & 205,175 & 821,082 & & & & & & \\
\hline & $\$ 10,819$ & $\$ 12,736$ & $\$ 9,718$ & $\$ 15,087$ & $\$ 18,879$ & $\$ 67,239$ & & & & & & \\
\hline \multirow{2}{*}{$\begin{array}{l}\text { Pump - North } \\
\text { Pokegama } \\
\text { Ponds }\end{array}$} & 1,556 & 1,686 & 2,092 & 2,037 & 3,479 & 10,850 & & & & & & \\
\hline & $\$ 232$ & $\$ 263$ & $\$ 314$ & $\$ 329$ & $\$ 513$ & $\$ 1,651$ & & & & & & \\
\hline \multirow{2}{*}{$\begin{array}{l}\text { Net Garage } \\
\text { (ponds) }\end{array}$} & & & & & & & & & & & & \\
\hline & & & & & & & & & & & & \\
\hline \multicolumn{13}{|l|}{ Gaming Operations } \\
\hline \multirow[b]{2}{*}{ Casino } & $4,513,864$ & $4,626,159$ & $4,402,505$ & $5,078,879$ & $5,043,793$ & $23,665,200$ & 55,700 & 130,106 & 75,844 & 161,727 & 163,200 & 586,577 \\
\hline & $\$ 183,928$ & $\$ 209,557$ & $\$ 215,565$ & $\$ 233,538$ & $\$ 264,087$ & $\$ 1,106,675$ & $\$ 47,345$ & $\$ 128,805$ & $\$ 98,597$ & $\$ 221,404$ & $\$ 238,272$ & $\$ 734,424$ \\
\hline \multirow[b]{2}{*}{ Casino Hotel } & $1,312,320$ & $1,338,840$ & $1,059,360$ & $1,269,480$ & $1,380,360$ & $6,360,360$ & & & & & & \\
\hline & $\$ 57,214$ & $\$ 64,126$ & $\$ 55,583$ & $\$ 60,790$ & $\$ 76,007$ & $\$ 313,720$ & & & & & & \\
\hline
\end{tabular}




\begin{tabular}{|c|c|c|c|c|c|c|c|c|c|c|c|c|}
\hline \multirow[b]{2}{*}{ Facility Name } & \multicolumn{4}{|c|}{ Electricity Consumption and Expense } & \multirow[b]{2}{*}{$\begin{array}{c}2007 \\
\text { (kWh) } \\
\text { (dollars) }\end{array}$} & \multirow[b]{2}{*}{$\begin{array}{c}\text { Total } \\
\text { (kWh) } \\
\text { (dollars) }\end{array}$} & \multicolumn{4}{|c|}{ Propane Consumption and Expense } & \multirow[b]{2}{*}{$\begin{array}{c}2007 \\
\text { (gallons) } \\
\text { (dollars) }\end{array}$} & \multirow[b]{2}{*}{$\begin{array}{c}\text { Total } \\
\text { (gallons) } \\
\text { (dollars) }\end{array}$} \\
\hline & $\begin{array}{c}2003 \\
\text { (kWh) } \\
\text { (dollars) }\end{array}$ & $\begin{array}{c}2004 \\
\text { (kWh) } \\
\text { (dollars) }\end{array}$ & $\begin{array}{c}2005 \\
\text { (kWh) } \\
\text { (dollars) }\end{array}$ & $\begin{array}{c}2006 \\
\text { (kWh) } \\
\text { (dollars) }\end{array}$ & & & $\begin{array}{c}2003 \\
\text { (gallons) } \\
\text { (dollars) }\end{array}$ & $\begin{array}{c}2004 \\
\text { (gallons) } \\
\text { (dollars) }\end{array}$ & $\begin{array}{c}2005 \\
\text { (gallons) } \\
\text { (dollars) }\end{array}$ & $\begin{array}{c}2006 \\
\text { (gallons) } \\
\text { (dollars) }\end{array}$ & & \\
\hline \multirow{2}{*}{$\begin{array}{l}\text { Casino Human } \\
\text { Resources / } \\
\text { Education } \\
\text { Building (LOTC }\end{array}$} & 303,680 & 318,240 & 300,720 & 267,600 & 179,520 & $1,369,760$ & 825 & 4,648 & 1,400 & 5,725 & 7,626 & 20,224 \\
\hline & $\$ 22,264$ & $\$ 22,592$ & $\$ 19,808$ & $\$ 19,597$ & $\$ 16,050$ & $\$ 100,311$ & $\$ 701$ & $\$ 4,602$ & $\$ 1,820$ & $\$ 7,838$ & $\$ 11,133$ & $\$ 26,094$ \\
\hline \multirow{4}{*}{$\begin{array}{l}\text { Bingo Hall } \\
\text { Casino } \\
\text { Engineering } \\
\text { Building }\end{array}$} & 197,146 & 180,839 & 194,219 & 199,156 & 197,361 & 968,721 & 2,832 & 6,466 & 3,775 & 9,225 & 11,534 & 33,832 \\
\hline & $\$ 15,548$ & $\$ 15,500$ & $\$ 17,752$ & $\$ 19,261$ & $\$ 20,675$ & $\$ 88,736$ & $\$ 2,407$ & $\$ 6,401$ & $\$ 4,908$ & $\$ 12,629$ & $\$ 16,840$ & $\$ 43,185$ \\
\hline & 63,441 & 62,918 & 44,385 & 53,694 & 45,467 & 269,905 & 2,829 & 7,125 & 2,700 & 5,950 & 6,550 & 25,154 \\
\hline & $\$ 5,075$ & $\$ 5,534$ & $\$ 4,301$ & $\$ 5,554$ & $\$ 5,010$ & $\$ 25,474$ & $\$ 2,405$ & $\$ 7,054$ & $\$ 3,510$ & $\$ 8,146$ & $\$ 9,564$ & $\$ 30,678$ \\
\hline \multirow{2}{*}{$\begin{array}{l}\text { Light post } \\
\text { (employee lot) }\end{array}$} & 6,186 & 6,486 & 4,949 & 2,568 & 3,191 & 23,380 & & & & & & \\
\hline & $\$ 725$ & $\$ 817$ & $\$ 769$ & $\$ 553$ & $\$ 663$ & $\$ 3,527$ & & & & & & \\
\hline \multirow{2}{*}{$\begin{array}{l}\text { Casino Billboard } \\
\text { (Highway } 47 / \mathrm{H})\end{array}$} & 2,619 & 2,207 & 2,000 & 1,820 & 1,851 & 10,497 & & & & & & \\
\hline & $\$ 338$ & $\$ 331$ & $\$ 330$ & $\$ 330$ & $\$ 350$ & $\$ 1,679$ & & & & & & \\
\hline \multirow{2}{*}{$\begin{array}{l}\text { Casino Billboard } \\
\text { (Highway 47) }\end{array}$} & 1,963 & 1,324 & 2,032 & 2,177 & 2,331 & 9,827 & & & & & & \\
\hline & $\$ 288$ & $\$ 254$ & $\$ 323$ & $\$ 369$ & $\$ 403$ & $\$ 1,637$ & & & & & & \\
\hline \multirow{2}{*}{$\begin{array}{l}\text { Casino Storage } \\
\text { Building }\end{array}$} & 141 & 211 & 177 & 9 & 94 & 632 & & & & & & \\
\hline & $\$ 118$ & $\$ 136$ & $\$ 125$ & $\$ 121$ & $\$ 139$ & $\$ 639$ & & & & & & \\
\hline \multirow{2}{*}{$\begin{array}{l}\text { Casino Billboard } \\
\text { (Highway 70) }\end{array}$} & & & & & & & & & & & & \\
\hline & $\$ 132$ & $\$ 138$ & $\$ 138$ & $\$ 150$ & $\$ 155$ & $\$ 713$ & & & & & & \\
\hline \multicolumn{13}{|l|}{$\begin{array}{l}\text { Government } \\
\text { Operations }\end{array}$} \\
\hline \multirow{2}{*}{$\begin{array}{l}\text { Community } \\
\text { Center/Clinic }\end{array}$} & 417,720 & 388,320 & 399,600 & 404,400 & 473,000 & $2,083,040$ & 23,192 & 23,190 & 21,704 & 20,940 & 21,236 & 110,262 \\
\hline & $\$ 22,868$ & $\$ 23,313$ & $\$ 26,708$ & $\$ 28,763$ & $\$ 33,661$ & $\$ 135,313$ & $\$ 19,713$ & $\$ 22,958$ & $\$ 28,215$ & $\$ 28,667$ & $\$ 31,004$ & $\$ 130,558$ \\
\hline \multirow[b]{2}{*}{ Judicial building } & 70,482 & 80,288 & 68,131 & 71,829 & 73,272 & 364,002 & 1,018 & 677 & 1,040 & 1,607 & 2,317 & 6,660 \\
\hline & $\$ 5,909$ & $\$ 7,376$ & $\$ 6,838$ & $\$ 7,686$ & $\$ 8,304$ & $\$ 36,113$ & $\$ 865$ & $\$ 670$ & $\$ 1,352$ & $\$ 2,200$ & $\$ 3,383$ & $\$ 8,471$ \\
\hline \multirow{2}{*}{$\begin{array}{l}\text { Radio Tower } \\
\text { Building }\end{array}$} & 971 & 9,246 & 7,499 & 7,470 & 6,064 & 31,250 & & & & & & \\
\hline & $\$ 122$ & $\$ 937$ & $\$ 848$ & $\$ 906$ & $\$ 800$ & $\$ 3,613$ & & & & & & \\
\hline \multicolumn{13}{|l|}{ Housing Operations } \\
\hline \multirow{2}{*}{$\begin{array}{l}\text { Housing Garage } \\
\# 1\end{array}$} & & & & & & & & & & & & \\
\hline & & & & & & & & & & & & \\
\hline \multirow{2}{*}{$\begin{array}{l}\text { Housing garage } \\
\text { \#2 }\end{array}$} & & & & & & & & & & & & \\
\hline & & & & & & & & & & & & \\
\hline
\end{tabular}




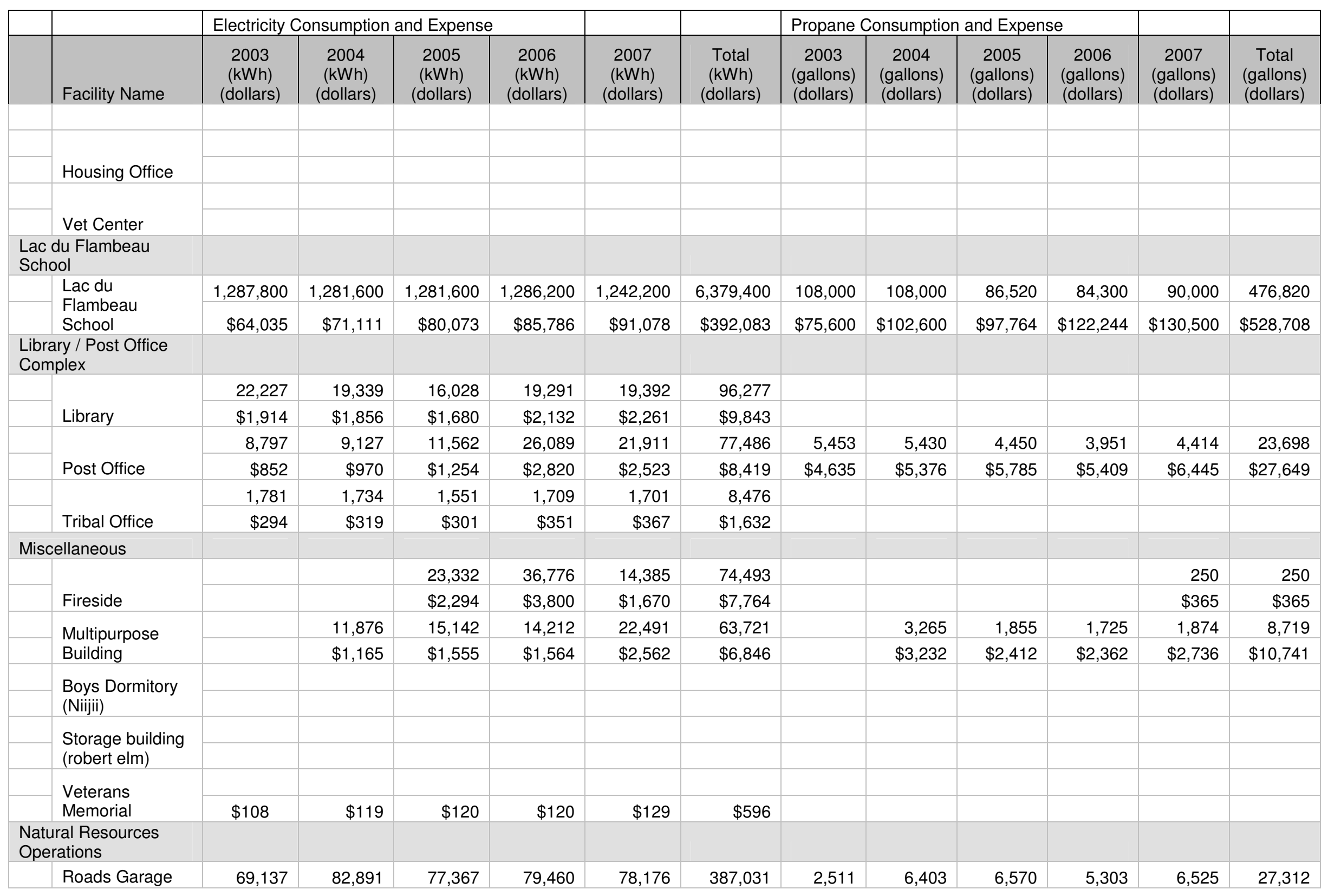




\begin{tabular}{|c|c|c|c|c|c|c|c|c|c|c|c|c|}
\hline \multirow[b]{2}{*}{ Facility Name } & \multicolumn{4}{|c|}{ Electricity Consumption and Expense } & \multirow[b]{2}{*}{$\begin{array}{c}2007 \\
\text { (kWh) } \\
\text { (dollars) }\end{array}$} & \multirow[b]{2}{*}{$\begin{array}{c}\text { Total } \\
\text { (kWh) } \\
\text { (dollars) }\end{array}$} & \multicolumn{4}{|c|}{ Propane Consumption and Expense } & \multirow[b]{2}{*}{$\begin{array}{c}2007 \\
\text { (gallons) } \\
\text { (dollars) }\end{array}$} & \multirow[b]{2}{*}{$\begin{array}{c}\text { Total } \\
\text { (gallons) } \\
\text { (dollars) }\end{array}$} \\
\hline & $\begin{array}{c}2003 \\
\text { (kWh) } \\
\text { (dollars) }\end{array}$ & $\begin{array}{c}2004 \\
\text { (kWh) } \\
\text { (dollars) }\end{array}$ & $\begin{array}{c}2005 \\
\text { (kWh) } \\
\text { (dollars) }\end{array}$ & $\begin{array}{c}2006 \\
\text { (kWh) } \\
\text { (dollars) }\end{array}$ & & & $\begin{array}{c}2003 \\
\text { (gallons) } \\
\text { (dollars) }\end{array}$ & $\begin{array}{c}2004 \\
\text { (gallons) } \\
\text { (dollars) }\end{array}$ & $\begin{array}{c}2005 \\
\text { (gallons) } \\
\text { (dollars) }\end{array}$ & $\begin{array}{c}2006 \\
\text { (gallons) } \\
\text { (dollars) }\end{array}$ & & \\
\hline (Tribal garage) & $\$ 5,516$ & $\$ 7,234$ & $\$ 7,353$ & $\$ 8,102$ & $\$ 8,394$ & $\$ 36,599$ & $\$ 2,134$ & $\$ 6,339$ & $\$ 8,541$ & $\$ 7,259$ & $\$ 9,527$ & $\$ 33,800$ \\
\hline \multirow{2}{*}{$\begin{array}{l}\text { Natural } \\
\text { Resources Office }\end{array}$} & 150,299 & 84,461 & 88,220 & 6,069 & 8,245 & 337,294 & & & & & & \\
\hline & $\$ 11,788$ & $\$ 7,428$ & $\$ 7,377$ & $\$ 1,043$ & $\$ 1,056$ & $\$ 28,692$ & & & & & & \\
\hline \multirow{2}{*}{$\begin{array}{l}\text { Land } \\
\text { Management } \\
\text { Office }\end{array}$} & 14,544 & 13,631 & 13,779 & 14,150 & 13,498 & 69,602 & 1,019 & 3,043 & 1,550 & 2,125 & 926 & 8,663 \\
\hline & $\$ 1,451$ & $\$ 1,522$ & $\$ 1,645$ & $\$ 1,784$ & $\$ 1,839$ & $\$ 8,241$ & $\$ 866$ & $\$ 3,013$ & $\$ 2,015$ & $\$ 2,909$ & $\$ 1,352$ & $\$ 10,155$ \\
\hline \multirow{4}{*}{$\begin{array}{l}\text { Forestry } \\
\text { Deer } \\
\text { Registration } \\
\text { Station }\end{array}$} & 5,948 & 8,223 & 6,243 & 7,436 & 6,838 & 34,688 & 190 & 462 & 475 & 725 & 650 & 2,502 \\
\hline & $\$ 580$ & $\$ 835$ & $\$ 700$ & $\$ 877$ & $\$ 860$ & $\$ 3,852$ & $\$ 162$ & $\$ 457$ & $\$ 618$ & $\$ 993$ & $\$ 949$ & $\$ 3,178$ \\
\hline & 1,463 & 1,187 & 1,086 & 1,457 & 1,715 & 6,908 & 560 & 570 & 494 & 476 & 506 & 2,605 \\
\hline & $\$ 225$ & $\$ 218$ & $\$ 207$ & $\$ 270$ & $\$ 314$ & $\$ 1,234$ & $\$ 476$ & $\$ 564$ & $\$ 642$ & $\$ 651$ & $\$ 738$ & $\$ 3,072$ \\
\hline \multirow{2}{*}{$\begin{array}{l}\text { Strawberry Farm } \\
\text { Shed }\end{array}$} & & & & 657 & 885 & 1,542 & & & & & & \\
\hline & & & & $\$ 147$ & $\$ 251$ & $\$ 398$ & & & & & & \\
\hline \multirow{2}{*}{$\begin{array}{l}\text { Conservation } \\
\text { Law / Bait Shop }\end{array}$} & & & & & & & 200 & 490 & 200 & 375 & 349 & 1,614 \\
\hline & & & & & & & $\$ 170$ & $\$ 485$ & $\$ 260$ & $\$ 513$ & $\$ 510$ & $\$ 1,938$ \\
\hline \multirow{2}{*}{$\begin{array}{l}\text { Old Water / } \\
\text { Sewer Office }\end{array}$} & & & & & & & & & & & & \\
\hline & & & & & & & & & & & & \\
\hline \multirow{2}{*}{$\begin{array}{l}\text { Water Resource } \\
\text { office }\end{array}$} & & & & & & & & & & & & \\
\hline & & & & & & & & & & & & \\
\hline \multicolumn{13}{|l|}{$\begin{array}{l}\text { Residential Homes } \\
\text { (Tribe owned) }\end{array}$} \\
\hline \multirow{2}{*}{$\begin{array}{l}1219 \text { Arnold } \\
\text { Stock Ln }\end{array}$} & & 9,257 & & & & 9,257 & & & & & & \\
\hline & & $\$ 860$ & & & & $\$ 860$ & & & & & & \\
\hline \multirow{2}{*}{$\begin{array}{l}2355 \text { Bobidosh } \\
\text { Point Ln }\end{array}$} & & & & 7,054 & 765 & 7,819 & & & & & & \\
\hline & & & & $\$ 838$ & $\$ 205$ & $\$ 1,043$ & & & & & & \\
\hline \multicolumn{13}{|l|}{$\begin{array}{l}\text { Street Lighting - } \\
\text { General }\end{array}$} \\
\hline \multirow{2}{*}{$\begin{array}{l}\text { Street Lighting - } \\
\text { downtown }\end{array}$} & 7,606 & 35,371 & 39,399 & 36,872 & 34,215 & 153,463 & & & & & & \\
\hline & $\$ 1,029$ & $\$ 2,658$ & $\$ 3,157$ & $\$ 3,212$ & $\$ 3,218$ & $\$ 13,274$ & & & & & & \\
\hline \multirow{2}{*}{$\begin{array}{l}\text { Street Lighting - } \\
\text { Indian Village Rd }\end{array}$} & & & & & & & & & & & & \\
\hline & $\$ 1,308$ & $\$ 1,470$ & $\$ 1,560$ & $\$ 1,703$ & $\$ 1,801$ & $\$ 7,842$ & & & & & & \\
\hline & & & & & & & & & & & & \\
\hline
\end{tabular}




\begin{tabular}{|c|c|c|c|c|c|c|c|c|c|c|c|c|}
\hline \multirow[b]{2}{*}{ Facility Name } & \multicolumn{4}{|c|}{ Electricity Consumption and Expense } & \multirow[b]{2}{*}{$\begin{array}{c}2007 \\
\text { (kWh) } \\
\text { (dollars) }\end{array}$} & \multirow[b]{2}{*}{$\begin{array}{c}\text { Total } \\
\text { (kWh) } \\
\text { (dollars) }\end{array}$} & \multicolumn{4}{|c|}{ Propane Consumption and Expense } & \multirow[b]{2}{*}{$\begin{array}{c}2007 \\
\text { (gallons) } \\
\text { (dollars) }\end{array}$} & \multirow[b]{2}{*}{$\begin{array}{c}\text { Total } \\
\text { (gallons) } \\
\text { (dollars) }\end{array}$} \\
\hline & $\begin{array}{c}2003 \\
\text { (kWh) } \\
\text { (dollars) }\end{array}$ & $\begin{array}{c}2004 \\
\text { (kWh) } \\
\text { (dollars) }\end{array}$ & $\begin{array}{c}2005 \\
\text { (kWh) } \\
\text { (dollars) }\end{array}$ & $\begin{array}{c}2006 \\
\text { (kWh) } \\
\text { (dollars) }\end{array}$ & & & $\begin{array}{c}2003 \\
\text { (gallons) } \\
\text { (dollars) }\end{array}$ & $\begin{array}{c}2004 \\
\text { (gallons) } \\
\text { (dollars) }\end{array}$ & $\begin{array}{c}2005 \\
\text { (gallons) } \\
\text { (dollars) }\end{array}$ & $\begin{array}{c}2006 \\
\text { (gallons) } \\
\text { (dollars) }\end{array}$ & & \\
\hline \multicolumn{13}{|l|}{ Tribal Enterprises } \\
\hline \multirow{2}{*}{$\begin{array}{l}\text { Store (Ojibwe } \\
\text { mall) }\end{array}$} & 637,514 & 633,893 & 596,518 & 636,073 & 638,475 & $3,142,473$ & 6,523 & 7,052 & 6,295 & 4,635 & 4,775 & 29,280 \\
\hline & $\$ 30,692$ & $\$ 34,465$ & $\$ 32,314$ & $\$ 36,739$ & $\$ 39,863$ & $\$ 174,073$ & $\$ 5,545$ & $\$ 6,981$ & $\$ 8,184$ & $\$ 6,346$ & $\$ 6,972$ & $\$ 34,027$ \\
\hline \multirow{2}{*}{$\begin{array}{l}\text { Simpson's } \\
\text { Plastics Plant }\end{array}$} & 442,295 & 471,936 & 417,517 & 428,636 & 415,967 & $2,176,351$ & 28,303 & 31,746 & 26,404 & 27,416 & 27,159 & 141,027 \\
\hline & $\$ 30,345$ & $\$ 35,126$ & $\$ 33,996$ & $\$ 38,754$ & $\$ 40,176$ & $\$ 178,397$ & $\$ 24,058$ & $\$ 31,428$ & $\$ 34,325$ & $\$ 37,532$ & $\$ 39,652$ & $\$ 166,994$ \\
\hline \multirow{2}{*}{$\begin{array}{l}\text { Simpson's Main } \\
\text { Plant }\end{array}$} & 275,040 & 381,360 & 341,280 & 389,600 & 398,960 & $1,786,240$ & 18,796 & 16,605 & 15,066 & 17,600 & 16,352 & 84,419 \\
\hline & $\$ 20,882$ & $\$ 30,253$ & $\$ 28,233$ & $\$ 33,763$ & $\$ 36,906$ & $\$ 150,037$ & $\$ 15,977$ & $\$ 16,438$ & $\$ 19,586$ & $\$ 24,095$ & $\$ 23,874$ & $\$ 99,970$ \\
\hline \multirow[b]{2}{*}{ Gas Station } & 69,350 & 70,574 & 62,977 & 71,132 & 93,183 & 367,216 & 320 & 663 & 360 & 700 & 525 & 2,568 \\
\hline & $\$ 5,684$ & $\$ 6,380$ & $\$ 6,185$ & $\$ 7,409$ & $\$ 10,138$ & $\$ 35,796$ & $\$ 272$ & $\$ 656$ & $\$ 468$ & $\$ 958$ & $\$ 767$ & $\$ 3,121$ \\
\hline \multirow[b]{2}{*}{ Smoke Shop } & & & & 84,901 & 227,598 & 312,499 & & & & & & \\
\hline & & & & $\$ 8,340$ & $\$ 21,818$ & $\$ 30,158$ & & & & & & \\
\hline \multirow[b]{2}{*}{ Museum } & 58,384 & 56,294 & 55,646 & 62,656 & 70,909 & 303,889 & 1,300 & 4,357 & 4,355 & 3,967 & 3,638 & 17,617 \\
\hline & $\$ 5,127$ & $\$ 5,370$ & $\$ 5,653$ & $\$ 6,757$ & $\$ 8,035$ & $\$ 30,942$ & $\$ 1,105$ & $\$ 4,313$ & $\$ 5,662$ & $\$ 5,430$ & $\$ 5,311$ & $\$ 21,822$ \\
\hline \multirow{2}{*}{$\begin{array}{l}\text { Gas Station } \\
\text { Storage }\end{array}$} & 8,387 & 7,877 & 11,314 & 12,335 & 10,435 & 50,348 & & & & & & \\
\hline & $\$ 775$ & $\$ 806$ & $\$ 1,185$ & $\$ 1,375$ & $\$ 1,249$ & $\$ 5,390$ & & & & & & \\
\hline \multirow{2}{*}{$\begin{array}{l}\text { Home Rehab } \\
\text { Office / WOLF } \\
\text { (REHAB/HIP } \\
\text { PROGRAM) }\end{array}$} & 7,365 & 5,758 & 4,634 & 4,733 & 4,667 & 27,157 & 1,890 & 1,621 & 1,291 & 955 & 950 & 6,707 \\
\hline & $\$ 689$ & $\$ 621$ & $\$ 550$ & $\$ 602$ & $\$ 627$ & $\$ 3,089$ & $\$ 1,607$ & $\$ 1,605$ & $\$ 1,678$ & $\$ 1,307$ & $\$ 1,387$ & $\$ 7,584$ \\
\hline \multicolumn{13}{|l|}{$\begin{array}{l}\text { Water and Sewer } \\
\text { Operations }\end{array}$} \\
\hline \multirow[b]{2}{*}{ Pump House 1} & 60,715 & 62,687 & 50,307 & 59,198 & 58,987 & 291,894 & & & & & & \\
\hline & $\$ 4,949$ & $\$ 5,682$ & $\$ 4,990$ & $\$ 6,234$ & $\$ 6,578$ & $\$ 28,433$ & & & & & & \\
\hline \multirow[b]{2}{*}{ Pump House 2} & 38,075 & 36,030 & 36,857 & 40,123 & 39,868 & 190,953 & & & & & & \\
\hline & $\$ 3,120$ & $\$ 3,271$ & $\$ 3,613$ & $\$ 4,194$ & $\$ 4,412$ & $\$ 18,610$ & & & & & & \\
\hline \multirow[b]{2}{*}{ Lift Station 3} & 47,291 & 45,268 & 31,698 & 30,055 & 31,213 & 185,525 & & & & & & \\
\hline & $\$ 4,188$ & $\$ 4,449$ & $\$ 3,405$ & $\$ 3,407$ & $\$ 3,706$ & $\$ 19,155$ & & & & & & \\
\hline \multirow{2}{*}{$\begin{array}{l}\text { Water \& Sewer } \\
\text { Office }\end{array}$} & 9,650 & 9,146 & 7,890 & 8,764 & 8,626 & 44,076 & 3,060 & 2,796 & 3,556 & 2,879 & 2,237 & 14,527 \\
\hline & $\$ 871$ & $\$ 918$ & $\$ 857$ & $\$ 1,012$ & $\$ 1,048$ & $\$ 4,706$ & $\$ 2,601$ & $\$ 2,768$ & $\$ 4,623$ & $\$ 3,941$ & $\$ 3,265$ & $\$ 17,198$ \\
\hline Lift Station 10 & 8,436 & 7,191 & 5,812 & 10,225 & 11,031 & 42,695 & & & & & & \\
\hline
\end{tabular}




\begin{tabular}{|c|c|c|c|c|c|c|c|c|c|c|c|c|}
\hline \multirow[b]{2}{*}{ Facility Name } & \multicolumn{4}{|c|}{ Electricity Consumption and Expense } & \multirow[b]{2}{*}{$\begin{array}{c}2007 \\
\text { (kWh) } \\
\text { (dollars) }\end{array}$} & \multirow[b]{2}{*}{$\begin{array}{c}\text { Total } \\
\text { (kWh) } \\
\text { (dollars) }\end{array}$} & \multicolumn{4}{|c|}{ Propane Consumption and Expense } & \multirow[b]{2}{*}{$\begin{array}{c}2007 \\
\text { (gallons) } \\
\text { (dollars) }\end{array}$} & \multirow[b]{2}{*}{$\begin{array}{c}\text { Total } \\
\text { (gallons) } \\
\text { (dollars) }\end{array}$} \\
\hline & $\begin{array}{c}2003 \\
\text { (kWh) } \\
\text { (dollars) }\end{array}$ & $\begin{array}{c}2004 \\
\text { (kWh) } \\
\text { (dollars) }\end{array}$ & $\begin{array}{c}2005 \\
\text { (kWh) } \\
\text { (dollars) }\end{array}$ & $\begin{array}{c}2006 \\
\text { (kWh) } \\
\text { (dollars) }\end{array}$ & & & $\begin{array}{c}2003 \\
\text { (gallons) } \\
\text { (dollars) }\end{array}$ & $\begin{array}{c}2004 \\
\text { (gallons) } \\
\text { (dollars) }\end{array}$ & $\begin{array}{c}2005 \\
\text { (gallons) } \\
\text { (dollars) }\end{array}$ & $\begin{array}{c}2006 \\
\text { (gallons) } \\
\text { (dollars) }\end{array}$ & & \\
\hline & $\$ 816$ & $\$ 791$ & $\$ 719$ & $\$ 1,218$ & $\$ 1,363$ & $\$ 4,907$ & & & & & & \\
\hline \multirow{2}{*}{$\begin{array}{l}\text { Sand Filter } \\
\text { Station }\end{array}$} & 7,537 & 7,281 & 7,050 & 8,681 & 9,273 & 39,822 & & & & & & \\
\hline & $\$ 729$ & $\$ 777$ & $\$ 800$ & $\$ 1,028$ & $\$ 1,146$ & $\$ 4,480$ & & & & & & \\
\hline \multirow[b]{2}{*}{ Lift Station 1} & 4,877 & 4,784 & 4,889 & 6,007 & 5,224 & 25,781 & & & & & & \\
\hline & $\$ 494$ & $\$ 533$ & $\$ 570$ & $\$ 734$ & $\$ 690$ & $\$ 3,021$ & & & & & & \\
\hline \multirow[b]{2}{*}{ Pump House 3} & 4,932 & 4,643 & 4,327 & 5,025 & 4,967 & 23,894 & & & & & & \\
\hline & $\$ 525$ & $\$ 546$ & $\$ 543$ & $\$ 656$ & $\$ 687$ & $\$ 2,957$ & & & & & & \\
\hline \multirow[b]{2}{*}{ Lift Station 7} & 2,460 & 4,004 & 3,875 & 5,914 & 6,122 & 22,375 & & & & & & \\
\hline & $\$ 346$ & $\$ 517$ & $\$ 535$ & $\$ 778$ & $\$ 837$ & $\$ 3,013$ & & & & & & \\
\hline \multirow[b]{2}{*}{ Water Tower 4} & 5,965 & 4,539 & 4,163 & & & 14,667 & & & & & & \\
\hline & $\$ 573$ & $\$ 514$ & $\$ 504$ & & & $\$ 1,591$ & & & & & & \\
\hline \multirow[b]{2}{*}{ Lift Station 2} & 2,807 & 2,786 & 2,545 & 2,900 & 2,979 & 14,017 & & & & & & \\
\hline & $\$ 329$ & $\$ 359$ & $\$ 347$ & $\$ 417$ & $\$ 447$ & $\$ 1,899$ & & & & & & \\
\hline \multirow[b]{2}{*}{ Water Tower 2} & 141 & 1,353 & 1,542 & 2,254 & 2,107 & 7,397 & & & & & & \\
\hline & $\$ 119$ & $\$ 234$ & $\$ 263$ & $\$ 349$ & $\$ 350$ & $\$ 1,315$ & & & & & & \\
\hline \multirow{4}{*}{$\begin{array}{l}\text { Lift Station } 6 \\
\text { Water \& Sewer } \\
\text { Storage (old } \\
\text { office) }\end{array}$} & 1,677 & 1,323 & 1,045 & 1,188 & 1,142 & 6,375 & & & & & & \\
\hline & $\$ 285$ & $\$ 282$ & $\$ 253$ & $\$ 298$ & $\$ 308$ & $\$ 1,426$ & & & & & & \\
\hline & 1,680 & 880 & 1,040 & 1,280 & 1,120 & 6,000 & & & & & & \\
\hline & $\$ 409$ & $\$ 379$ & $\$ 379$ & $\$ 461$ & $\$ 472$ & $\$ 2,100$ & & & & & & \\
\hline \multirow[b]{2}{*}{ Lift Station 4} & 1,141 & 1,241 & 1,098 & 1,189 & 786 & 5,455 & & & & & & \\
\hline & $\$ 244$ & $\$ 276$ & $\$ 258$ & $\$ 299$ & $\$ 269$ & $\$ 1,346$ & & & & & & \\
\hline \multirow[b]{2}{*}{ Lift Station 8} & 1,468 & 1,113 & 979 & 779 & 703 & 5,042 & & & & & & \\
\hline & $\$ 224$ & $\$ 209$ & $\$ 207$ & $\$ 203$ & $\$ 203$ & $\$ 1,046$ & & & & & & \\
\hline \multirow[b]{2}{*}{ Lift Station 12} & 751 & 594 & 607 & 975 & 1,002 & 3,929 & & & & & & \\
\hline & $\$ 191$ & $\$ 191$ & $\$ 184$ & $\$ 247$ & $\$ 259$ & $\$ 1,072$ & & & & & & \\
\hline \multirow[b]{2}{*}{ Lift Station 9} & 308 & 322 & 610 & 783 & 426 & 2,449 & & & & & & \\
\hline & $\$ 177$ & $\$ 192$ & $\$ 223$ & $\$ 260$ & $\$ 231$ & $\$ 1,083$ & & & & & & \\
\hline \multirow[b]{2}{*}{ Effluent Pump } & 198 & 109 & 141 & 214 & 101 & 763 & & & & & & \\
\hline & $\$ 125$ & $\$ 122$ & $\$ 119$ & $\$ 146$ & $\$ 141$ & $\$ 653$ & & & & & & \\
\hline
\end{tabular}




\begin{tabular}{|c|c|c|c|c|c|c|c|c|c|c|c|c|}
\hline \multirow[b]{2}{*}{ Facility Name } & \multicolumn{4}{|c|}{ Electricity Consumption and Expense } & \multirow[b]{2}{*}{$\begin{array}{c}2007 \\
\text { (kWh) } \\
\text { (dollars) }\end{array}$} & \multirow[b]{2}{*}{$\begin{array}{c}\text { Total } \\
\text { (kWh) } \\
\text { (dollars) }\end{array}$} & \multicolumn{4}{|c|}{ Propane Consumption and Expense } & \multirow[b]{2}{*}{$\begin{array}{c}2007 \\
\text { (gallons) } \\
\text { (dollars) }\end{array}$} & \multirow[b]{2}{*}{$\begin{array}{c}\text { Total } \\
\text { (gallons) } \\
\text { (dollars) }\end{array}$} \\
\hline & $\begin{array}{c}2003 \\
\text { (kWh) } \\
\text { (dollars) }\end{array}$ & $\begin{array}{c}2004 \\
\text { (kWh) } \\
\text { (dollars) }\end{array}$ & $\begin{array}{c}2005 \\
\text { (kWh) } \\
\text { (dollars) }\end{array}$ & $\begin{array}{c}2006 \\
\text { (kWh) } \\
\text { (dollars) }\end{array}$ & & & $\begin{array}{c}2003 \\
\text { (gallons) } \\
\text { (dollars) }\end{array}$ & $\begin{array}{c}2004 \\
\text { (gallons) } \\
\text { (dollars) }\end{array}$ & $\begin{array}{c}2005 \\
\text { (gallons) } \\
\text { (dollars) }\end{array}$ & $\begin{array}{c}2006 \\
\text { (gallons) } \\
\text { (dollars) }\end{array}$ & & \\
\hline \multirow[b]{2}{*}{ Lift Station 11} & 216 & 125 & 94 & 99 & 95 & 629 & & & & & & \\
\hline & $\$ 126$ & $\$ 125$ & $\$ 123$ & $\$ 131$ & $\$ 140$ & $\$ 645$ & & & & & & \\
\hline Lift Station 5 & & & & & & & & & & & & \\
\hline Water Tower 1 & & & & & & & & & & & & \\
\hline Water Tower 3 & & & & & & & & & & & & \\
\hline
\end{tabular}

\section{Appendix D. Assumed emission factors for electricity and propane.}

The assumed emission factors for electricity and propane presented below were gathered from WPS, Focus on Energy and the World Resources Institute.

\section{Table 14. Summary of Emission Factors}

\begin{tabular}{|l|r|r|}
\hline \multicolumn{1}{|c|}{ Metric } & Electric Conversion Factor & Propane Conversion Factor \\
\hline Pounds of CO2 & 2.2 & 12.805 \\
\hline Pounds of Nox & 0.0057 & 0.014 \\
\hline Pounds of Sox & 0.0122 & 0.00004 \\
\hline $\begin{array}{l}\text { Pounds of mercury } \\
\text { (HG) }\end{array}$ & $4.98 \mathrm{E}-08$ & 1000 \\
\hline Number of Homes & 9,960 & 0.00589 \\
\hline Tons of Coal & 0.0005 & \\
\hline
\end{tabular}




\section{Task Two: Electricity Rates and Energy Intensity Analysis}

\section{Table of Contents}

TASK TWO: ELECTRICITY RATES AND ENERGY INTENSITY ANALYSIS................................................1

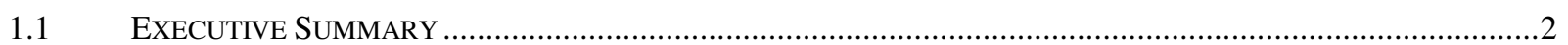

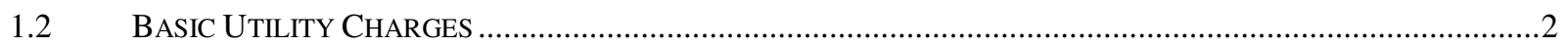

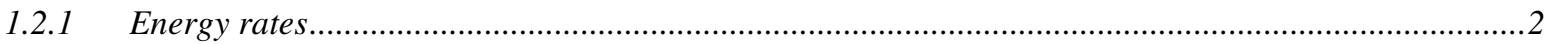

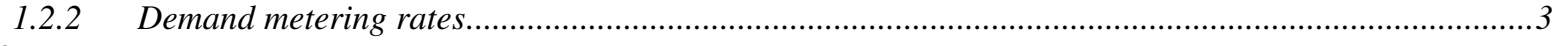

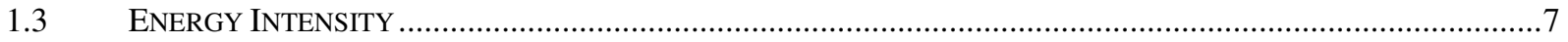

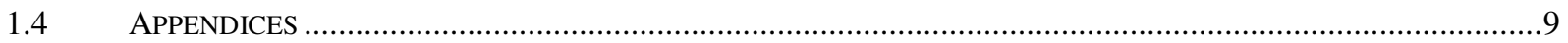

\section{List of Appendices}

APPENDIX A. LIST OF TRIBAL FACILITIES RANKED BY ENERGY USE INTENSITY. 9 


\subsection{Executive Summary}

The section below explains how WPS charges the Tribe for the electricity consumed at their facilities and discusses the associated WPS rate schedules. The Tribe pays $\$ 0.06$ to $\$ 0.11$ per kilowatt hour $(\mathrm{kWh})$, depending on how much energy the facility consumes. Rates that are charged per $\mathrm{kWh}$ are referred to as 'energy charges'.

The Tribe also pays a power charge, or demand charge, of $\$ 10.67$ per kilowatt for the 6 largest Tribal end users: Casino, Hotel, Community Center/Clinic, Store, School, and the Plastics Plant. The demand charge allows utilities to charge facilities that require a large amount of power, based on the building's highest power need for any given 15 minute period for the entire month. This has important implications for decreasing utility payments through facility management and incorporation of renewable energy systems.

Energy use intensity (EUI) for almost 40 of the Tribal buildings is also presented below. Understanding a building's performance begins by looking at its Energy Use Intensity (EUI). Annual EUI is calculated by dividing the amount of energy that a building uses during one year by the square footage of the building. The EUI can help identify facilities that are using a disproportionately high amount of energy for their size. The top 6 EUI buildings are summarized below in Table 1 .

Table 1. Summary of Tribal facilities with greatest Energy Use Intensity

\begin{tabular}{|c|c|c|}
\hline Facility Name & $\begin{array}{l}\text { Energy Use } \\
\text { Intensity } \\
\left(\mathrm{kBtu} / \mathrm{ft}^{2} \mathrm{t}\right)\end{array}$ & Facility Size $\left(\mathrm{ft}^{2}\right)$ \\
\hline Gas Station & 476 & 768 \\
\hline Casino & 426 & 75,340 \\
\hline Fish Hatchery & 293 & 4,680 \\
\hline Simpson's Plastics Plant & 264 & 14,780 \\
\hline Bath House \#1 & 243 & 660 \\
\hline Store (Ojibwe mall) & 231 & 11,305 \\
\hline
\end{tabular}

The "Energy Cost Intensity" is presented as well, which is a method of analyzing the cost of energy (based on utility rates and consumption) verses the square footage of the building. The two Tribal buildings with the greatest energy cost intensity are the Gas Station and the Casino. The Gas Station has an Energy Cost Intensity of $\$ 14.20$ per square foot, almost twice as much as the second ranked building (Casino, \$6.70/sq ft).

\subsection{Basic Utility Charges}

\subsubsection{Energy rates}

Throughout this report, we will refer to the WPS 'rate schedule', or specific charges for the buildings. Buildings are assigned rate schedules based on how much energy they use throughout the month and year and the size of the building load. 
The main WPS rates associated with Tribal buildings are summarized below.

Cg 20: This rate is for buildings that are demand-metered, as described below. The larger Tribal facilities (Casino, Community Center, School, etc) that have a demand greater than $100 \mathrm{~kW}$, at any time throughout the month, are on this rate schedule. These facilities are charged based on "on-peak" and "off-peak" demand (kWh) usage, which also differ during the winter and summer. These facilities are also charged for the maximum 'demand' from the last year.

[Peak energy charge: $\mathbf{\$ 0 . 0 6 0 4 / \mathbf { k W h } ]}$

[Peak Demand Charge: \$10.67]

Cg 5: This rate includes the mid-sized Tribal buildings, what have a demand less than $100 \mathrm{~kW}$ but energy use greater than 12,500 kWh for three months in a row (Simpson's, Smoke Shop, Bingo Hall).

[Peak energy charge: \$0.0949/kWh]

Cg 1: The Cg1 rate includes all of the Tribal buildings that do not have an energy use greater than $12,500 \mathrm{kWh}$ for three months in a row (gas station, judicial building, museum).

[Peak energy charge: \$0.10911/kWh]

Gy 3: The Gy 3 rate applies to all of the outdoor overhead lighting services.

DLC: Direct Load Control, or DLC, is a rate schedule that arises through a one-year contract with WPS. Under DLC, WPS installs load control devices in the facility on the larger appliances that run during peak-demand times, i.e. air conditioners. The Tribe will receive credit by allowing WPS the option to control the load of those appliances. This schedule is utilized in the casino, hotel and community center.

These rates are subject to review and approval by the Public Service Commission (PSCW). As a WPS customer, the Tribe may intervene in any WPS rate case to support or oppose the utility's request to change rates.

\subsubsection{Demand metering rates}

An important concept to understand is "demand metering" and "peak demand." Facilities can be charged not only for the amount of energy they use (total kilowatt hour consumption per month) but also for the greatest amount of power they need in any given 15 minute period throughout the month (i.e. a building's greatest demand occurs when all of the equipment is turned on simultaneously).

Peak demand charges can be reduced through behavior change, conservation, energy efficiency and renewable energy. For example, building managers can ensure that equipment with large energy needs are not used at the same time, or are used during off-peak time periods. Energy efficient equipment can be installed to reduce the demand of large equipment, such as pumps and motors. 
The consideration of demand charges also becomes important when looking at renewable energy, because renewable energy systems only effectively reduce expensive demand charges if the wind is blowing or the sun is shining during that 15 minute period of the month when the facility is pulling its largest amount of power. The economic benefits of a renewable energy project are increased if the energy production will coincide with periods of higher rate charges or high demand.

\subsubsection{Demand metered Tribal facilities}

Six Tribal facilities were on demand rate schedules in 2007. Table 2 shows these facilities along with their average demand during the five years 2003 through 2007 and the peak demand in 2007. As mentioned previously, a facility's demand is averaged and recorded by WPS every 15 minutes. The maximum peak demand is the highest 15-minute average. In Wisconsin's climate it is common for electricity demand to peak during the summer due to the use of air conditioning. This is true of most Tribal facilities. The one exception is the Casino Hotel which uses electricity for heating and, as a result, this facility peaks in the winter.

Table 2. Demand metering facilities

\begin{tabular}{|l|c|c|l|}
\hline \multicolumn{1}{|c|}{ Facility Name } & Average $(\mathrm{kW})$ & $\begin{array}{c}2007 \\
\text { Maximum }(\mathrm{kW})\end{array}$ & Peak Seasons \\
\hline Casino & 694 & 974 & Summer \\
\hline Casino Hotel & 239 & 358 & Winter \\
\hline Lac du Flambeau School & 308 & 374 & Summer \& Fall \\
\hline Simpson's Plastics Plant & 138 & 151 & Various \\
\hline Community Center/Clinic & 101 & 139 & Summer \& Fall \\
\hline Store (Ojibwe mall) & 99 & 109 & Summer \\
\hline
\end{tabular}

Note: The Casino Human Resources facility was on a demand rate schedule from August 2004 through August 2007

but is no longer demand metered due to its peak demand remaining below $100 \mathrm{~kW}$ for 12 months. 
Figure 1 shows how the Casino's monthly peak demand has changed over the last five years. This facility has clear peaks during summer months and over the years the annual peak has risen from around $800 \mathrm{~kW}$ to nearly $1,000 \mathrm{~kW}$.

Figure 1. Monthly Casino Demand, 2003 to 2007.

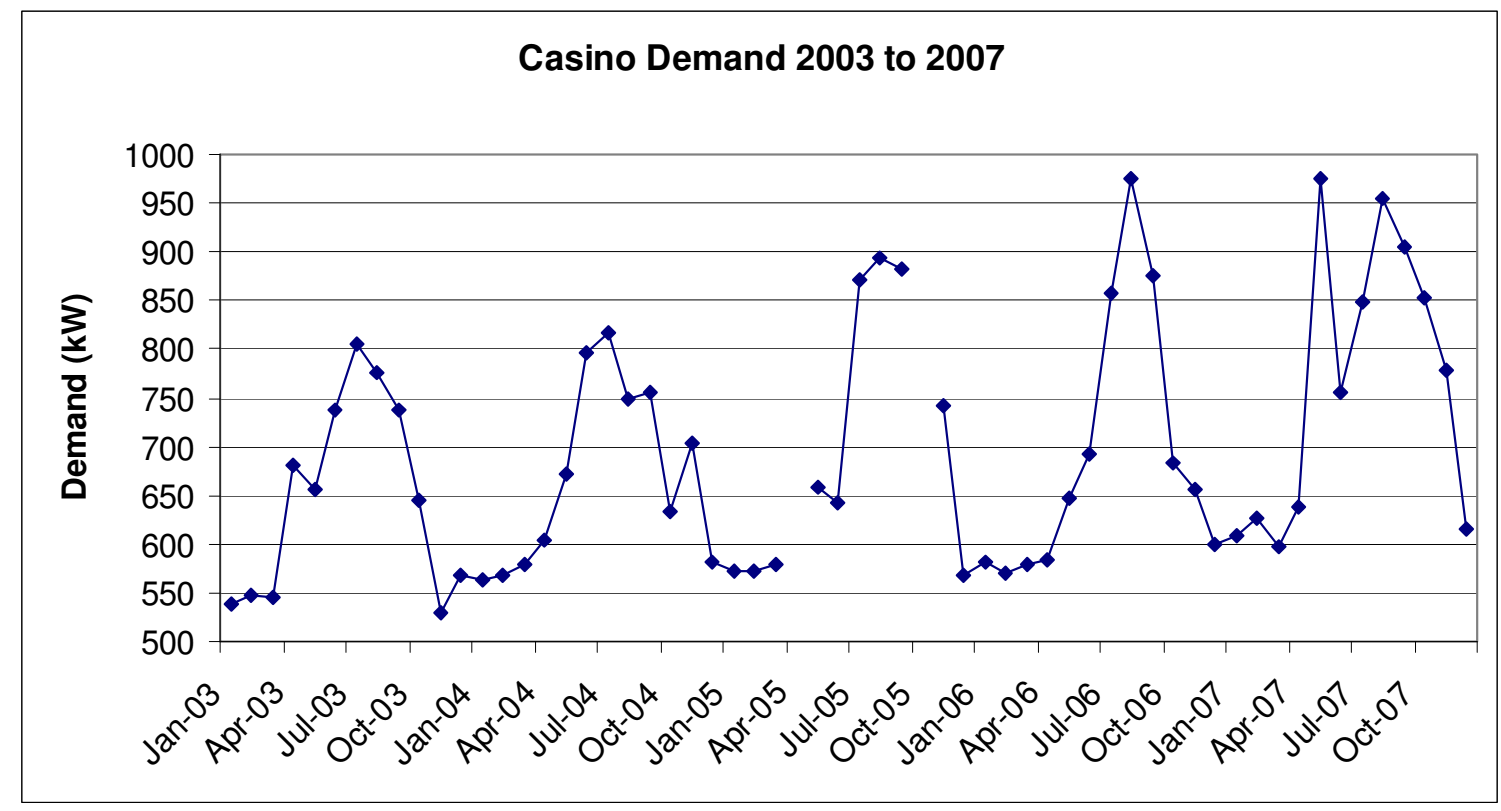

In order to manage demand and reduce peak loads at a facility, a detailed analysis must be done. This analysis requires 15-minute demand averages, rather than the monthly peak data points displayed above in

The actual 15-minute data is available from WPS should the Tribe wish to better understand and work on reducing their peak demand.

As a demonstration of 15-minute demand changes, SGES obtained records from WPS for the Casino Hotel during the month of February 2008. Figure 2 presents the varying demand during each day of the month. The days are grouped by day of the week and for this month there is no clear trend that sets weekdays apart from weekends. However, we do see some hour-to-hour predictability. Looking at the days with the highest demand we see the peak beginning in the late morning and ending in the early afternoon. During the three days February $10^{\text {th }}, 15^{\text {th }}$ and $20^{\text {th }}$, each with demand peaking at or above $300 \mathrm{~kW}$, we see peaks occurring between 10 a.m. and 2 p.m. The fact that greatest energy demand coincides with the hours that the sun is the most intense means that a solar PV system connected to this facility can be expected to help lower peak demand. 


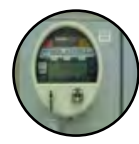

Figure 2. Daily Peak Casino Hotel Demand

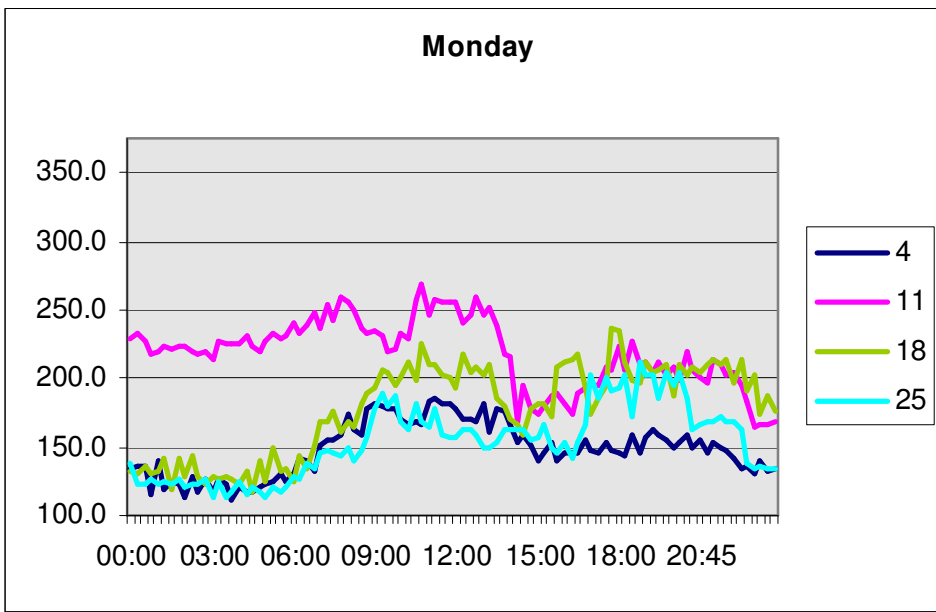

Tuesday

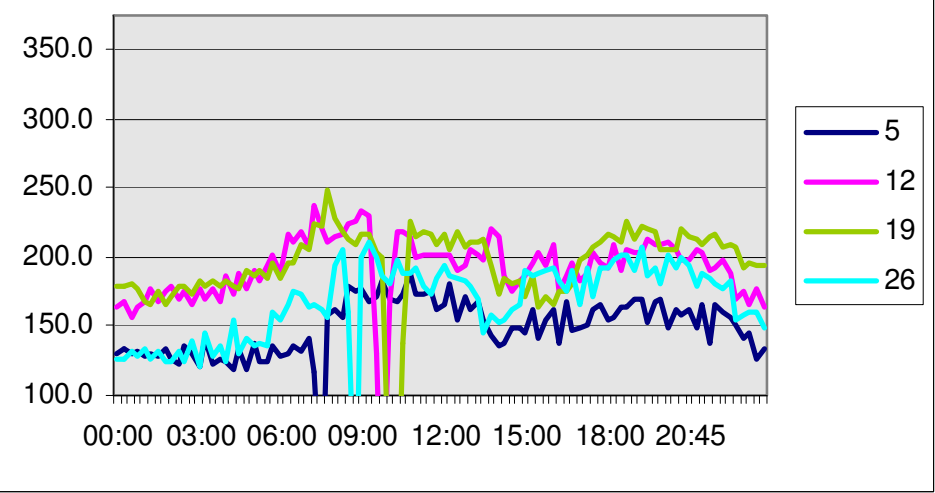

Wednesday

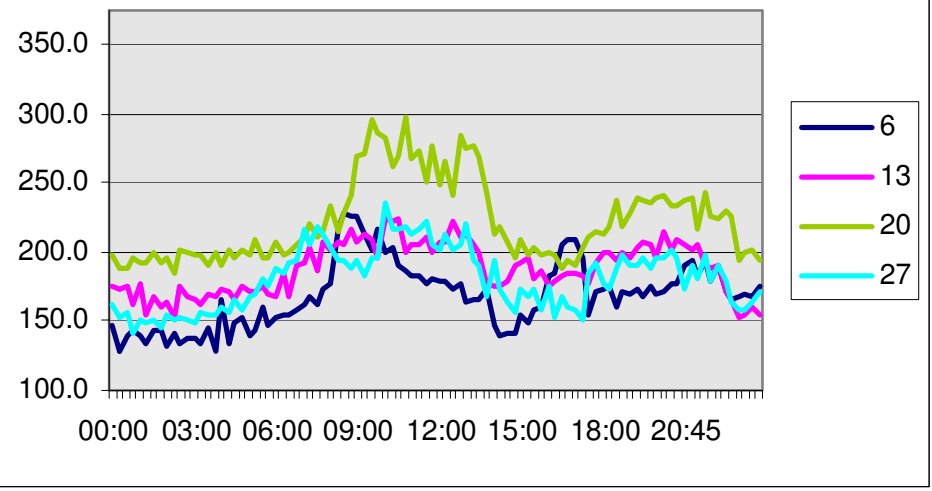

Thursday

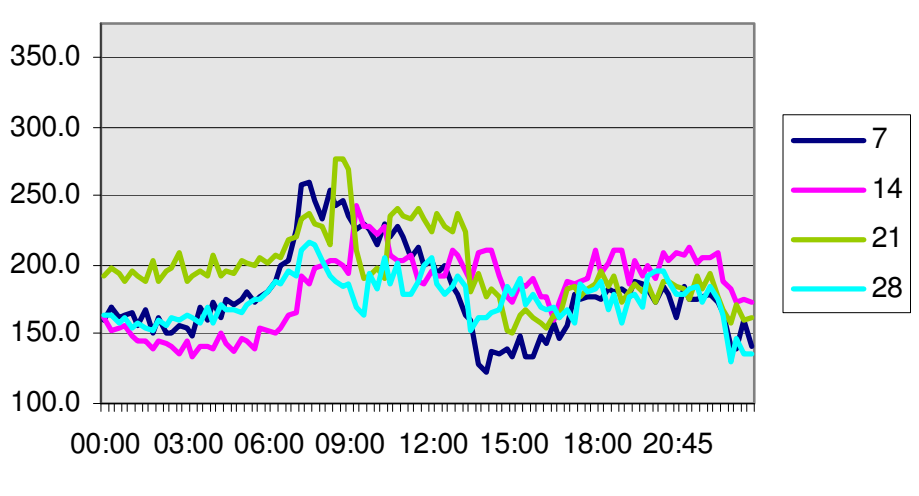

Friday

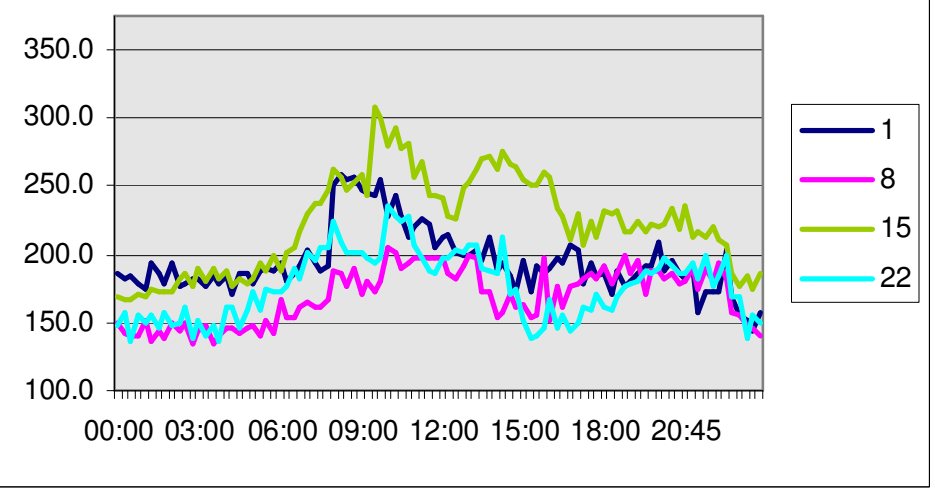

Saturday

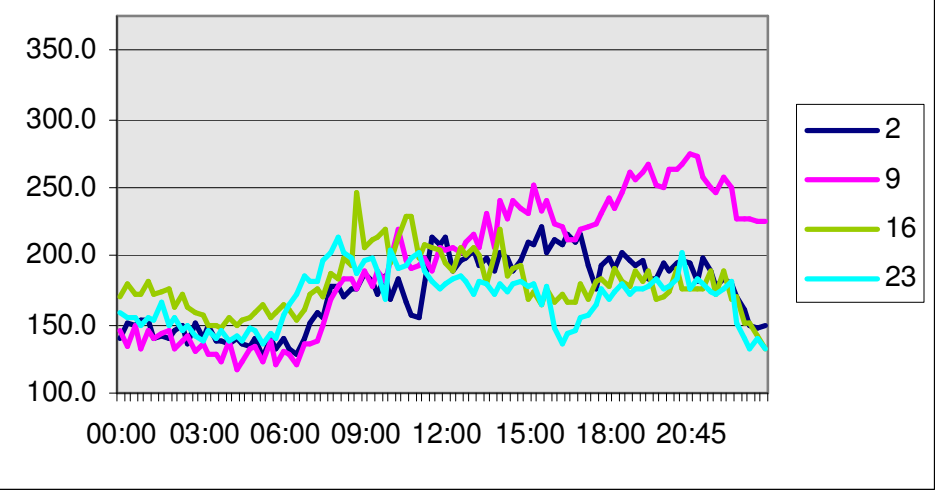

Sunday

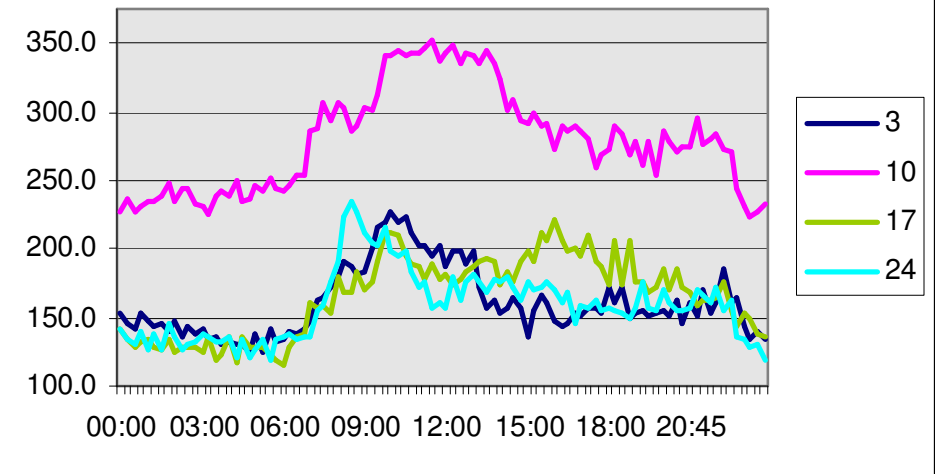




\subsection{Energy Intensity}

In the first section, total energy consumption data was presented for each facility. This raw data is useful to understand how a particular facility uses energy: how much energy; what types of energy; and how energy use varies from one year to the next. The raw data also shows how much energy one building uses compared to another. The raw data does not, however, indicate how efficiently a facility uses energy, or in other words, how well a building performs.

Understanding a building's performance begins by looking at its Energy Use Intensity (EUI). Annual EUI is calculated by dividing the amount of energy that a building uses during one year by the square footage of the building. The EUI can help identify facilities that are using a disproportionately high amount of energy for their size. Table 2 shows the 20 facilities at Lac du Flambeau that have the highest annual EUI. (A complete list of Tribal facilities ranked by EUI is presented in Appendix A)

Table 3. 2007 Annual Energy Use Intensity - Top 20 Facilities

\begin{tabular}{|c|c|c|c|c|c|c|}
\hline Facility Name & $\begin{array}{c}\text { Facility } \\
\text { Size } \\
\left(\mathrm{ft}^{2}\right)\end{array}$ & $\begin{array}{c}\text { Energy } \\
\text { Use } \\
\text { Intensity } \\
\left(\mathrm{kBtu} / \mathrm{ft}^{2}\right)\end{array}$ & $\begin{array}{l}\text { Electricity } \\
\text { Use } \\
\text { Intensity } \\
\left(\mathrm{kBtu} / \mathrm{ft}^{2}\right)\end{array}$ & $\begin{array}{l}\text { Propane } \\
\text { Use } \\
\text { Intensity } \\
\left(\mathrm{kBtu} / \mathrm{ft}^{2}\right)\end{array}$ & $\begin{array}{c}\text { Energy } \\
\text { Cost } \\
\text { Intensity } \\
(\text { dollar/ft })\end{array}$ & $\begin{array}{c}\text { Facility } \\
\text { Share of } \\
\text { Tribal } \\
\text { Energy } \\
\text { Use }\end{array}$ \\
\hline Gas Station & 768 & 476 & 414 & 62 & $\$ 14.20$ & $0.5 \%$ \\
\hline Casino & 75,340 & 426 & 228 & 198 & $\$ 6.67$ & $41.4 \%$ \\
\hline Fish Hatchery & 4,680 & 293 & 134 & 159 & $\$ 6.27$ & $1.8 \%$ \\
\hline Simpson's Plastics Plant & 14,780 & 264 & 96 & 168 & $\$ 5.40$ & $5.0 \%$ \\
\hline Bath House \#1 & 660 & 243 & 243 & 0 & $\$ 7.98$ & $0.2 \%$ \\
\hline Store (Ojibwe mall) & 11,305 & 231 & 193 & 39 & $\$ 4.14$ & $3.4 \%$ \\
\hline Deer Registration Station & 300 & 173 & 20 & 154 & $\$ 3.50$ & $0.1 \%$ \\
\hline Round House & 1,200 & 157 & 18 & 139 & $\$ 3.20$ & $0.2 \%$ \\
\hline $\begin{array}{l}\text { Casino Engineering } \\
\text { Building }\end{array}$ & 5,151 & 146 & 30 & 116 & $\$ 2.83$ & $1.0 \%$ \\
\hline Bath House \#2 & 784 & 135 & 135 & 0 & $\$ 4.52$ & $0.1 \%$ \\
\hline Bingo Hall & 13,741 & 126 & 49 & 77 & $\$ 2.73$ & $2.2 \%$ \\
\hline Lac du Flambeau School & 100,000 & 125 & 42 & 82 & $\$ 2.22$ & $16.0 \%$ \\
\hline Simpson's Main Plant & 27,280 & 105 & 50 & 55 & $\$ 2.23$ & $3.7 \%$ \\
\hline Community Center/Clinic & 35,000 & 102 & 46 & 55 & $\$ 1.85$ & $4.6 \%$ \\
\hline Smoke Shop & 8,000 & 97 & 97 & 0 & $\$ 2.73$ & $1.0 \%$ \\
\hline Multipurpose Building & 2,560 & 97 & 30 & 67 & $\$ 2.07$ & $0.3 \%$ \\
\hline Judicial building & 5,000 & 92 & 50 & 42 & $\$ 2.34$ & $0.6 \%$ \\
\hline $\begin{array}{l}\text { Casino Human Resources } \\
\text { Education Building (LOTC) }\end{array}$ & 14,853 & 88 & 41 & 47 & $\$ 1.83$ & $1.7 \%$ \\
\hline $\begin{array}{l}\text { Roads Garage } \\
\text { (Tribal garage) }\end{array}$ & 9,800 & 88 & 27 & 61 & $\$ 1.83$ & $1.1 \%$ \\
\hline Indian Bowl & 5.250 & 81 & 26 & 55 & $\$ 1.72$ & $0.5 \%$ \\
\hline
\end{tabular}


Energy Use Intensity gives a "first impression" of a building's performance but it does not tell the complete story. Building occupancy rates and the kinds of activities that take place within a building can significantly affect the EUI. For example, the Food Distribution Building has a relatively low EUI of $66 \mathrm{kBtu} / \mathrm{ft}^{2}$ and ranks $24^{\text {th }}$ among Tribal facilities. On first glance, this low EUI might be seen to indicate that this building performs well. However, the Food Distribution Building is not used very often and does not require significant heating. With these considerations in mind, an EUI of $66 \mathrm{kBtu} / \mathrm{ft}^{2}$ for a building with infrequent use may actually show a poorly performing building.

More detailed building performance analysis is beyond the scope of this report but can be done by taking the EUI and comparing this to other energy use characteristics of each building. Additional analysis might also compare Tribal facilities to regional averages. EUI averages for certain types of facilities in the Midwest are presented in Table 2.

Table 4. Average Energy Use Intensity for Midwest facilities (EIA 2003)

\begin{tabular}{|l|c|}
\hline \multicolumn{1}{|c|}{ Facility Type } & $\begin{array}{c}\text { Energy Use Intensity } \\
\left(\mathrm{kBtu}^{2} \mathrm{per} \mathrm{ft}^{2}\right)\end{array}$ \\
\hline Education & 86 \\
\hline Food Sales & 219 \\
\hline Food Service & 219 \\
\hline Health Care & 206 \\
\hline Inpatient & 272 \\
\hline Outpatient & 124 \\
\hline Lodging & 109 \\
\hline Retail (Other Than Mall) & 103 \\
\hline Office & 109 \\
\hline Public Assembly & 102 \\
\hline Religious Worship & 53 \\
\hline Service & 85 \\
\hline Warehouse and Storage & 75 \\
\hline
\end{tabular}

*Source: EIA - 2003 Commercial Buildings Energy Consumption Survey - Table C5

We suggest investigating buildings that are not relatively large energy consumers, but have large a large EUI, such as the Bathhouse's, the Deer Registration Station, and the Roundhouse.

Modern buildings that achieve LEED energy efficiency standards can cut their Energy Use Intensity levels in half. The next section discusses a number of low-cost energy efficiency recommendations that will help existing Tribal facilities improve their energy performance. 


\subsection{Appendices}

Appendix A. List of Tribal facilities ranked by Energy Use Intensity

\begin{tabular}{|c|c|c|c|c|c|c|}
\hline Facility Name & $\begin{array}{l}\text { Energy Use } \\
\text { Intenstity } \\
(\mathrm{kBtu} / \mathrm{sqft})\end{array}$ & $\begin{array}{l}\text { Facility } \\
\text { Size } \\
(\mathrm{ft} 2) \\
\end{array}$ & $\begin{array}{l}\text { Electricity } \\
\text { Use Intensity } \\
\text { (kBtu/sqft) }\end{array}$ & $\begin{array}{l}\text { Propane Use } \\
\text { Intensity } \\
(\mathrm{kBtu} / \mathrm{sqft})\end{array}$ & $\begin{array}{l}\text { Energy Cost } \\
\text { Intensity } \\
\text { (dollar/sqft2) }\end{array}$ & $\begin{array}{c}\text { Facility Share of } \\
\text { Tribal Energy } \\
\text { Use } \\
\end{array}$ \\
\hline Gas Station & 476 & 768 & 414 & 62 & $\$ 14.20$ & $0.5 \%$ \\
\hline Casino & 426 & 75,340 & 228 & 198 & $\$ 6.67$ & $41.4 \%$ \\
\hline Fish Hatchery & 293 & 4,680 & 134 & 159 & $\$ 6.27$ & $1.8 \%$ \\
\hline Simpson's Plastics Plant & 264 & 14,780 & 96 & 168 & $\$ 5.40$ & $5.0 \%$ \\
\hline Bath House \#1 & 243 & 660 & 243 & 0 & $\$ 7.98$ & $0.2 \%$ \\
\hline Store (Ojibwe mall) & 231 & 11,305 & 193 & 39 & $\$ 4.14$ & $3.4 \%$ \\
\hline Deer Registration Station & 173 & 300 & 20 & 154 & $\$ 3.50$ & $0.1 \%$ \\
\hline Round House & 157 & 1,200 & 18 & 139 & $\$ 3.20$ & $0.2 \%$ \\
\hline $\begin{array}{l}\text { Casino Engineering } \\
\text { Building }\end{array}$ & 146 & 5,151 & 30 & 116 & $\$ 2.83$ & $1.0 \%$ \\
\hline Bath House \#2 & 135 & 784 & 135 & 0 & $\$ 4.52$ & $0.1 \%$ \\
\hline Bingo Hall & 126 & 13,741 & 49 & 77 & $\$ 2.73$ & $2.2 \%$ \\
\hline Lac du Flambeau School & 125 & 100,000 & 42 & 82 & $\$ 2.22$ & $16.0 \%$ \\
\hline Simpson's Main Plant & 105 & 27,280 & 50 & 55 & $\$ 2.23$ & $3.7 \%$ \\
\hline Community Center/Clinic & 102 & 35,000 & 46 & 55 & $\$ 1.85$ & $4.6 \%$ \\
\hline Smoke Shop & 97 & 8,000 & 97 & 0 & $\$ 2.73$ & $1.0 \%$ \\
\hline Multipurpose Building & 97 & 2,560 & 30 & 67 & $\$ 2.07$ & $0.3 \%$ \\
\hline Judicial building & 92 & 5,000 & 50 & 42 & $\$ 2.34$ & $0.6 \%$ \\
\hline $\begin{array}{l}\text { Casino HR / Education } \\
\text { Building (LOTC }\end{array}$ & 88 & 14,853 & 41 & 47 & $\$ 1.83$ & $1.7 \%$ \\
\hline $\begin{array}{l}\text { Roads Garage (Tribal } \\
\text { garage) }\end{array}$ & 88 & 9,800 & 27 & 61 & $\$ 1.83$ & $1.1 \%$ \\
\hline Indian Bowl & 81 & 5,250 & 26 & 55 & $\$ 1.72$ & $0.5 \%$ \\
\hline $\begin{array}{l}\text { Home Rehab Office / } \\
\text { WOLF (REHAB/HIP } \\
\text { PROGRAM) }\end{array}$ & 79 & 1,296 & 12 & 67 & $\$ 1.55$ & $0.1 \%$ \\
\hline Planning / Bank Building & 71 & 5,620 & 38 & 33 & $\$ 1.73$ & $0.5 \%$ \\
\hline Family Resource Center & 70 & 5,988 & 27 & 43 & $\$ 1.60$ & $0.5 \%$ \\
\hline $\begin{array}{l}\text { Food Distribution } \\
\text { Building }\end{array}$ & 66 & 3,800 & 29 & 37 & $\$ 1.52$ & $0.3 \%$ \\
\hline Land Management Office & 64 & 2,030 & 23 & 42 & $\$ 1.57$ & $0.2 \%$ \\
\hline Museum & 64 & 9,000 & 27 & 37 & $\$ 1.48$ & $0.7 \%$ \\
\hline Casino Hotel & 63 & 74,400 & 63 & 0 & $\$ 1.02$ & $6.1 \%$ \\
\hline Post Office & 58 & 8,176 & 9 & 49 & $\$ 1.10$ & $0.6 \%$ \\
\hline Wellness Center & 58 & 20,000 & 33 & 26 & $\$ 1.29$ & $1.5 \%$ \\
\hline $\begin{array}{l}\text { Youth Center } \\
\text { (Abinoojiiyag Center) }\end{array}$ & 52 & 7,568 & 22 & 30 & $\$ 1.32$ & $0.5 \%$ \\
\hline Domestic Abuse Shelter & 48 & 6,800 & 22 & 26 & $\$ 1.12$ & $0.4 \%$ \\
\hline Water \& Sewer Office & 47 & 5,000 & 6 & 41 & $\$ 0.86$ & $0.3 \%$ \\
\hline Fireside & 36 & 2,000 & 25 & 11 & $\$ 1.02$ & $0.1 \%$ \\
\hline $\begin{array}{l}\text { Conservation Law / Bait } \\
\text { Shop }\end{array}$ & 33 & 968 & 0 & 33 & $\$ 0.53$ & $0.0 \%$ \\
\hline Adaawe Place & 28 & 10,000 & 0 & 28 & $\$ 0.45$ & $0.4 \%$ \\
\hline
\end{tabular}


Task Two: Electricity charge and consumption analysis Seventh Generation Energy Systems

\begin{tabular}{|c|c|c|c|c|c|c|}
\hline Forestry & 28 & 3,000 & 8 & 20 & $\$ 0.60$ & $0.1 \%$ \\
\hline Campground Office & 25 & 1,440 & 0 & 25 & $\$ 0.72$ & $0.0 \%$ \\
\hline Natural Resources Office & 11 & 2,500 & 11 & 0 & $\$ 0.42$ & $0.0 \%$ \\
\hline Strawberry Farm Shed & 2 & 1,350 & 2 & 0 & $\$ 0.18$ & $0.0 \%$ \\
\hline Old Water / Sewer Office & 0 & 3,416 & 0 & 0 & $\$ 0.00$ & $0.0 \%$ \\
\hline Vet Center & 0 & 2,300 & 0 & 0 & $\$ 0.00$ & $0.0 \%$ \\
\hline Net Garage (ponds) & 0 & 1,440 & 0 & 0 & $\$ 0.00$ & $0.0 \%$ \\
\hline Water Resource office & 0 & 1,000 & 0 & 0 & $\$ 0.00$ & $0.0 \%$ \\
\hline Boys Dormitory (Niijii) & 0 & 4,920 & 0 & 0 & $\$ 0.00$ & $0.0 \%$ \\
\hline 1219 Arnold Stock Ln & $*$ & & & & & \\
\hline 2355 Bobidosh Point Ln & $*$ & & & & & \\
\hline $\begin{array}{l}\text { Adaawe place incubator } \\
\text { unit } 10\end{array}$ & $*$ & & & & & \\
\hline $\begin{array}{l}\text { Adaawe place incubator } \\
\text { unit } 5\end{array}$ & $*$ & & & & & \\
\hline $\begin{array}{l}\text { Adaawe place incubator } \\
\text { unit } 6\end{array}$ & * & & & & & \\
\hline $\begin{array}{l}\text { Adaawe place incubator } \\
\text { unit } 7\end{array}$ & $*$ & & & & & \\
\hline $\begin{array}{l}\text { Adaawe place incubator } \\
\text { unit } 8\end{array}$ & $*$ & & & & & \\
\hline $\begin{array}{l}\text { Adaawe place incubator } \\
\text { unit } 9\end{array}$ & $*$ & & & & & \\
\hline Gas Station Storage & $*$ & & & & & \\
\hline Housing Garage \#1 & $*$ & & & & & \\
\hline Housing garage \#2 & $*$ & & & & & \\
\hline Housing Office & $*$ & & & & & \\
\hline Library & $*$ & 0 & & & & \\
\hline $\begin{array}{l}\text { Pump - North Pokegama } \\
\text { Ponds }\end{array}$ & $*$ & & & & & \\
\hline Radio Tower Building & $*$ & & & & & \\
\hline $\begin{array}{l}\text { Storage building (robert } \\
\text { elm) }\end{array}$ & $*$ & & & & & \\
\hline $\begin{array}{l}\begin{array}{l}\text { Street Lighting - } \\
\text { downtown }\end{array} \\
\end{array}$ & $*$ & & & & & \\
\hline Tribal Office & $*$ & & & & & \\
\hline Veterans Memorial & $*$ & & & & & \\
\hline $\begin{array}{l}\text { Water \& Sewer Storage } \\
\text { (old office) }\end{array}$ & $*$ & & & & & \\
\hline
\end{tabular}




\section{Task Three: Tribal Energy Audits by Focus on Energy}

\section{Table of Contents}

TASK THREE: TRIBAL ENERGY AUDITS BY FOCUS ON ENERGY ....................................................1

1.1 ENERgy EFFICIENCY Audits RESUlts: An INTRODUCTION FrOM SEVENTH GENERATION ENERGY

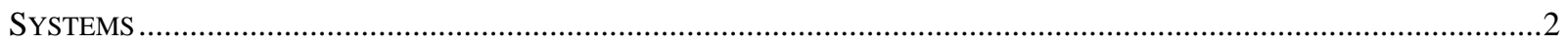

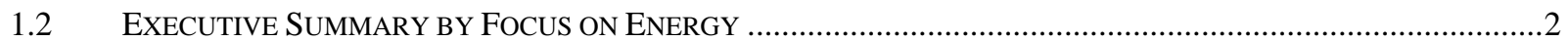

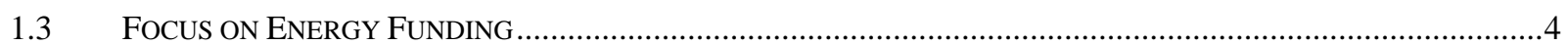

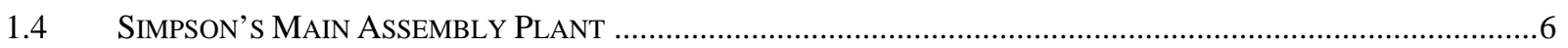

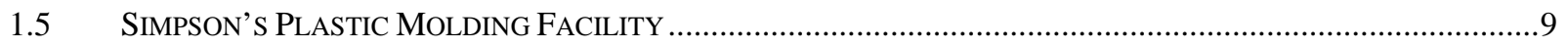

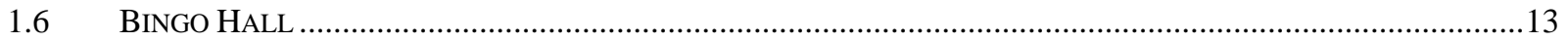

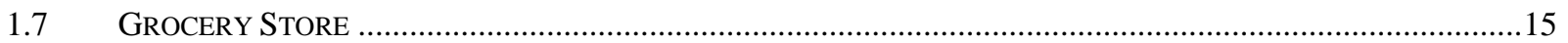

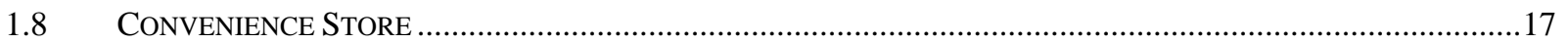

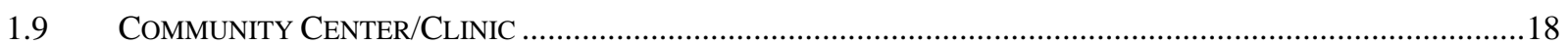

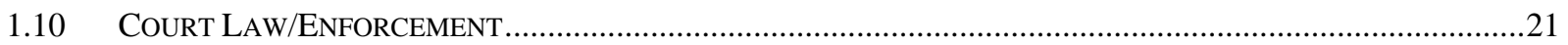

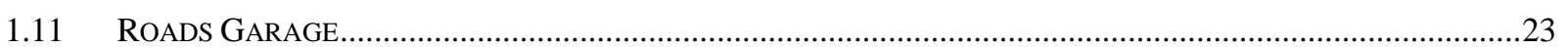

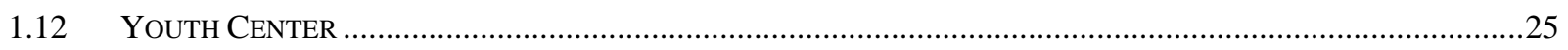

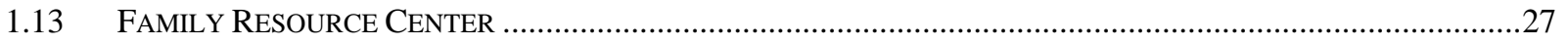

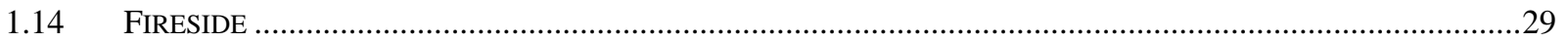

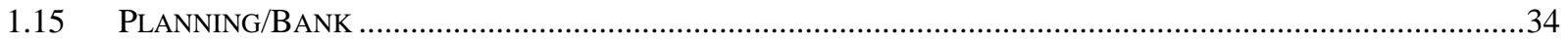

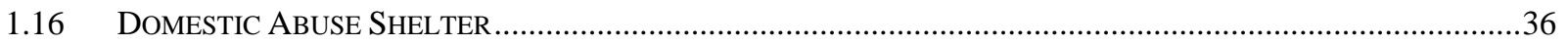

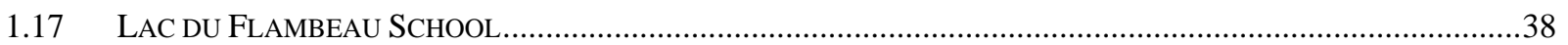

\section{List of Figures}

TABLE 1. COMPARISON OF THE ENERGY CONSUMPTION OF LIGHTING FIXTURES …….............................................

TABLE 2. ENERGY AND COST SAVINGS FOR GROCERY STORE LIGHTING UPGRADE ................................................15

TABLE 3. ENERGY AND COST SAVINGS FOR ROADS GARAGE UPGRADE ……......................................................23

TABLE 4. ENERgY AND COST SAVINGS FOR DOWNTOWN LigHTING UPGRADE ..........................................................24 


\section{Energy Efficiency Audits Results: An Introduction from Seventh Generation Energy Systems}

The overall goal of the Tribe's Renewable Energy and Conservation Planning is to create a Tribal Strategic Energy Plan that encompasses energy conservation and utilization of renewable energy. Energy efficiency is the first and most important step towards energy independence.

This section, prepared by Focus on Energy, summarizes the energy audits and site specific recommendations that should be shared with the appropriate building managers. Implemented technologies and the associated energy and cost savings should be monitored.

Only the top 16 energy user buildings were audited, which comprise over $90 \%$ of the Tribe's total energy use. Energy audits for the rest of the Tribal buildings can be conducted at any time for free through the Focus on Energy program.

The Focus on Energy audits are high-level and report generally on lighting, building shell, heating and cooling.

\section{Executive Summary by Focus on Energy}

In March and September of 2008, Bobbi Rongstad of Focus on Energy completed walk-thru audits to investigate energy-saving opportunities for buildings owned by the Lac du Flambeau Tribe. Her recommendations, based on those observations and review of energy used by the facilities, are detailed in individual reports per building. As an overview, please consider these recommendations ${ }^{1}$. Some facilities are quite up to date with their energy-related systems and others would require considerable upgrades.

\section{Consideration 1. Assign an Energy/Facilities Manager}

Assign an energy and facilities manager to oversee all Tribal properties. A person in this capacity would:

- $\quad$ stay abreast of new technologies, available training and incentives

- educate custodial staff on how best to manage the buildings

- procure materials at a better price

- assure continuity of energy-related policies and products

- manage HVAC tuning, cleaning, repairs and service calls

- negotiate a better price for service contracts with HVAC, controls, and lighting vendors

- serve as one standard point of contact with utility personnel and trades people

\footnotetext{
${ }^{1}$ Focus on Energy is funded by ratepayers of public utilities. Because the Tribe uses LP gas rather than WPS natural gas, Ms. Rongstad spent more time looking at ways to reduce electric usage.
} 
- Work with the Tribe to implement the Tribal ‘Strategic Energy Action Plan’ to address and prioritize upgrades

\section{Consideration 2. Energy Efficiency Procedures and Codes}

Develop procedures that direct all staff to make energy-efficient decisions. For example:

- Energy Star is a federal labeling program for appliances, office machines, heating/cooling systems and lighting. Make this a standard when purchasing new items.

- Turning computers off at the end of the day saves energy. Make it policy for everyone to do so.

- Install controls (or in many cases, just learn to use the controls you have in place) to turn heating down and cooling up during non-working hours.

- Make high-performance T8 lighting (newest and most efficient fluorescent) the standard when replacing any strip-lighting components.

- Install sensors to turn off lights in spaces when no one is present.

- Prohibit the use of personal space heaters which use a great deal of energy and often cause the area heating or cooling system not to operate properly (perpetuating more discomfort with more people).

- Convert to compact fluorescent bulbs in lamps, track lighting and recessed cans instead of standard light bulbs (CFLs use only 25-30\% of the energy and last 10 times longer).

\section{Consideration 3. Address Priority Energy Efficiency Options}

A few buildings should be addressed as soon as possible. These are briefly highlighted below:

Simpson's Plastics facility is using a tremendous amount of heating fuel. The building is not insulated. It is not well sealed — cracks and openings are evident in many places. The boiler system is large enough to heat a building two or three times that size.

Both Simpson facilities have outdated lighting. Upgrading to more appropriate High-Performance T8 lighting would cut the amount of energy used for lighting in half while increasing light levels by $20 \%$.

A large part of the electric energy used at Simpson's plastics facility is for compressed air, and multiple systems have been added through the years. This should be reviewed by a professional compressed air firm and could certainly be consolidated and repaired to reduce energy.

The Bingo Hall lighting appears to be old T12 technology. In addition, the lights are operating far more hours than the space is open for Bingo. Motion detectors and a T8 upgrade are recommended. 
Grocery store lighting is old T12 technology. Installing new, brighter, energy-savings HP T8s would make the store look like it's been updated. Many retail facilities report increased sales after upgrading their lighting.

Canopy lights at the Convenience store are left on during the day. Install a daylight sensor to turn them off, so the employees don't have to.

The Community Center/Health Clinic and the Court/Law Enforcement buildings appear to be using an improper combination of T12 electronic ballasts and T8 lamps. Energy savings are negated with this combination. Upgrade the ballasts to low-ballast factor, energy saving ballasts, and as you replace lamps, select high-lumen long-life T8s.

Convert the metal halide fixtures at the Roads Garage to high-bay fluorescent fixtures that use only half the energy and can be turned off when no one is present. The existing lighting has a 10-minute warm-up period, so it operates from early a.m. until late afternoon, even though the space is often empty.

Convert the old metal halide lighting over the Dental Clinic in the Community Center to more appropriate fluorescent fixtures. The metal halides generate a lot of heat-fighting against the auxiliary air conditioning units that were installed to cool the space. Fluorescent high-bay fixtures would use half the energy of the existing fixtures.

Replace bulbs in the Downtown 'Torches' with compact fluorescent to cut lighting energy use by 60$70 \%$.

Install motion sensors in Casino restrooms to turn off lights when no one is present.

Include in the Tribal "Strategic Energy Action Plan” a Long-Range Plan to address upgrading any heating system greater than 20 years old.

\subsection{Focus on Energy Funding}

Focus on Energy is a state-wide energy efficiency program funded by rate-payers of Wisconsin public utilities. Focus offers energy information and services to customers throughout the state. Focus's goal is to encourage energy efficiency and use of renewable energy to enhance the environment and ensure a future supply of energy in Wisconsin. 
Focus offers incentives to help buy down the cost of many efficiency improvements. Most of the lighting measures mentioned above would qualify. Focus has two methods of financial incentives.

1. Prescriptive incentives are established for 1-for-1 replacements of fixture for fixture. For example, the Roads Garage lighting mentioned above: current incentives through 12/15/08 would provide $\$ 90$ per fixture towards replacement of the 24 fixtures in the garage. If the Tribe incorporated motion sensors, they would receive an additional \$30 per fixture. The same incentive applies to the lights above the dental office.

2. 'Custom' calculated incentives are for projects that don't involve a 1-for-1, but rather are based on energy savings. For example, if the Tribe replaced the light fixtures at the Simpson facility with more efficient lamps and ballasts and as a result could eliminate 10 fixtures, Focus calculates the energy the Tribe will save per year and offer an incentive based on the savings. These projects must be applied for and approved prior to implementation.

Focus has two special promotions right now that would be beneficial to the Tribe.

1. The T12 'bounty' will pay an additional \$2 per lamp to help the Tribe upgrade old T12s to more efficient, longer life T8s that provide much better light. This would apply at the Grocery Store, Community Center, Bingo Hall, Court, and Simpsons (and maybe more).

\section{Example: $\quad$ 4-lamp T12 upgrade to high-performance T8 4-lamp}

Incentive: \$10 PLUS \$2 per lamp=\$18 per fixture

That upgrade at the Grocery Store would save \$1900 per year in energy and result in a \$2052 incentive. This 'bounty' incentive expires 11/15/08. The Tribe must call in for a confirmation number. See details at: www.focusonenergy.com/Incentives/Business/t12bounty.aspx

2. The High-Bay lighting incentive applies to the Roads Garage and Dental Office. It will provide an additional $\$ 30$ per fixture (the usual incentive is $\$ 60$ and the Tribe would receive $\$ 90$ ) for projects completed by $12 / 15 / 08$. See details here: www.focusonenergy.com/Incentives/Business/highbay_bonus.aspx

Investigate all the Focus on Energy incentives and information at www.focusonenergy.com/ and the Financial Incentives tab. Bobbi is available to help with the paperwork process. She is happy to help the Tribe put together specifications when the Tribe requests bids on a project and/or to help the Tribe evaluate proposals. Please keep Bobbi involved so that she can help assure that the Tribe qualifies for available incentives. Bobbi Rongstad, Energy Advisor - brongstad@gmail.com - 715/893-2305 


\subsection{Simpson's Main Assembly Plant}

\section{Lighting}

Employees at the Simpson assembly plant need a lot of light to see tiny parts. A quarter to 1/3 of the ceiling panels are replaced with 4-lamp fluorescent fixtures. It appears that as a workstation needed improved light, the solution was to pop in another fixture overhead. A better solution might be a better quality light with less glare and fewer shadows.

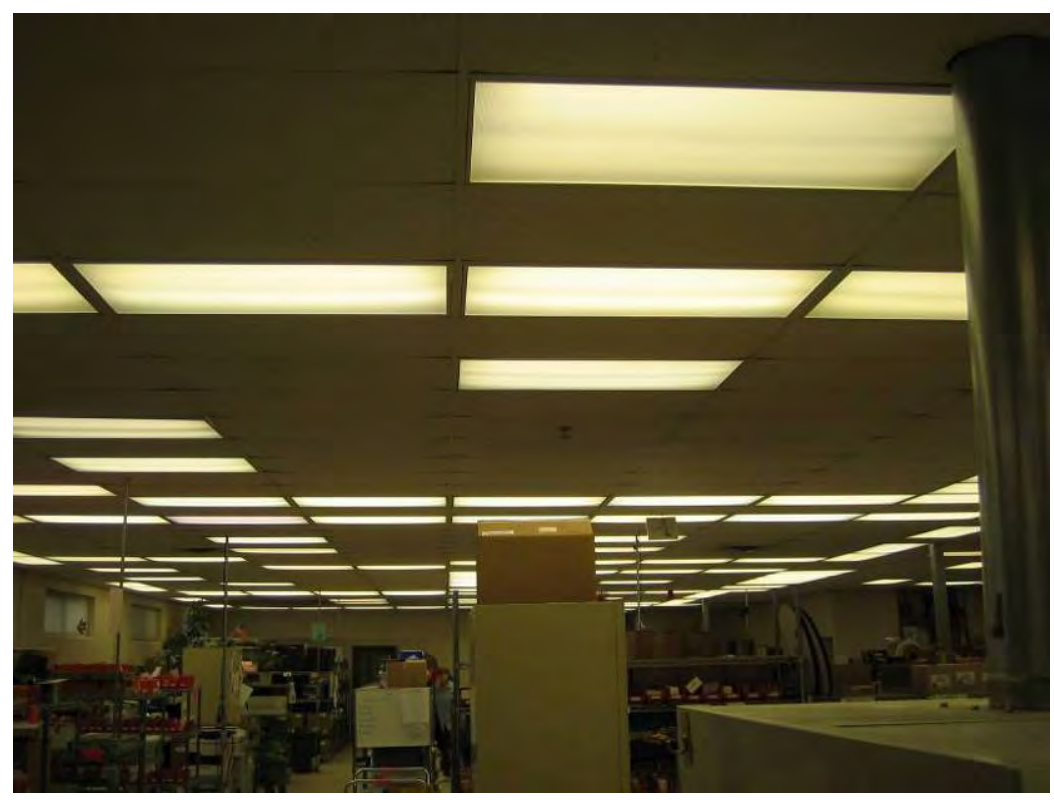

The lighting wattage adds up to a large portion of the plant's electric charges. Some fixtures have been updated to use T8 ballasts (more efficient) as they burn out, so it was not possible to calculate the actual wattage. All can be updated for improved light quality and significant energy savings.

Table 1. Comparison of the Energy consumption of lighting fixtures

$\begin{array}{ll}\text { Lighting Type } & \text { Energy use } \\ \text { 4-lamp T12 fixture } & 144 \text { watts } \\ \text { 4-lamp T8 fixture } & 120 \text { watts } \\ \text { High-performance T8 } & 96 \text { watts }\end{array}$

High-performance T8 not only use less energy, but they also produce about 20\% more light! T12 magnetic ballasts are obsolete and will no longer be manufactured after this year. Learn more about High Performance T8 here: http://www.focusonenergy.com/Business/Lighting/

For each fixture updated from T12 4-lamp to high-performance T8 4-lamp, the Tribe will save \$12.50 per year. But having a complete lighting upgrade with appropriate fixtures to direct the light where you need it could allow you to eliminate a number of fixtures, resulting in far better lighting quality and huge energy savings. 
In Section 3 your existing lighting consists of nine 8' 2-lamp (guessing 60 watt, but may be 72 watt) and three 4' 2-lamp T12s. Converting these fixtures to high-performance lamps and ballasts will save you about $\$ 65$ per year and provide 20\% more light. But improved fixtures which distribute light where you need it, could reduce the need for a few of the fixtures and reduce energy use further.

The color of light, measured in temperature Kelvin, is also significant. Existing light appears to be mix of color temperatures. This is hard on our eyes as they must constantly readjust. We've learned that visual acuity improves under the more natural (daylight) colors of light. The recessed troffers covered in plastic lenses do not do a very good job of getting the light to where you need it. Newer light fixtures are designed to better distribute the light using reflective surfaces that direct light to the work surface while reducing shadows and glare. An experienced lighting designer could lay out energy efficient lighting in this facility that would cut the wattage in half while increasing usable light considerably.

Color rendering index (CRI) is a measurement of how much color shift objects undergo when lighted by an artificial light source as compared to natural light. If detection of colors is important, select lamps with high CRI. High performance T8 lamps have a high CRI, along with higher lumen output (brighter) and much longer life (reduced maintenance).

The most important consideration with lighting is to turn it off when it is not needed. This can easily be accomplished by adding occupancy sensing devices. Several of the areas we walked through the day of my visit had no one present, yet all the lights were burning. Storage areas, meeting rooms, restrooms or offices not occupied full time should be equipped with sensors.

Also note the fixtures that are 'burned out' in the photo. If

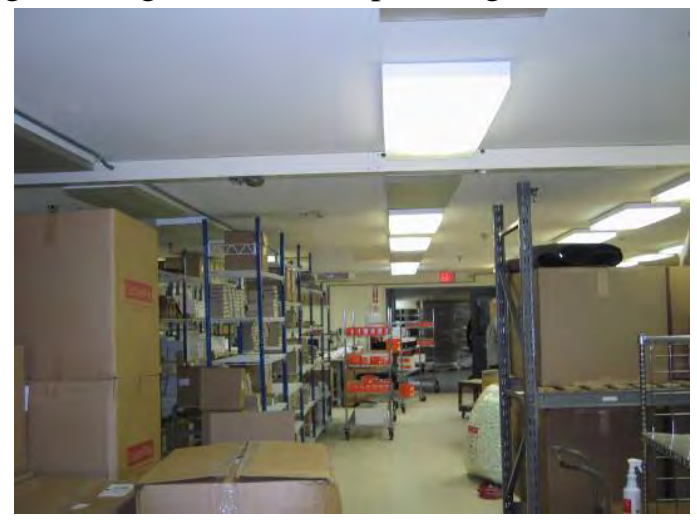
lamps burn out and are not replaced, be aware that the ballast continues to draw energy while trying to drive the lamps. If you find that you don't need all the fixtures, disconnect

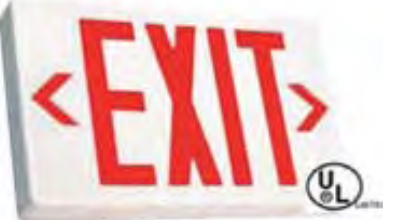
them completely. Leaving a burned out lamp in a fixture also puts undo stress on the remaining lamps and shortens their life.

Some EXIT lights are converted to LED, and some still use other types of lamps. You will save \$20 per year for each one you upgrade to LED, and the LED lights last 20 times longer than other bulbs, so maintenance is considerably reduced. Upgrade kits cost \$12-\$15 each. However, one of my customers found whole new fixtures at http://www.exitlightco.com/ for not much more money. They are nice quality fixtures.

I can recommend several good lighting vendors who can help you find the most efficient solutions. This building needs a lighting redesign, not just replacement of bulbs and ballasts.

\section{Building shell}

Sections 3 and 4 have problems indicative of poor insulation (ice dams, leaks). Adding insulation will reduce heat loss through the roofs and may remedy the problem. Potential savings in energy can be calculated by comparing the thickness and type of existing insulation to the same with the proposed, if you find a way to add more. (Example, if those areas have no insulation and you add 6" of fiberglass, you 
would save 550 gallons of propane per year). If you can provide an actual proposal including the make-up of the existing roof structure, I can do a more precise calculation.

\section{Heating/cooling}

Insulate the boiler piping. This will help deliver the hot water to the areas that are calling for heat rather than overheating the boiler room. Adding at least 1" of insulation to all exposed boiler piping can save you as much as $\$ 900$ per year in LP gas at today’s prices.

The building is heated and cooled in multiple zones with separate thermostats. Programmable controls would allow you to automatically turn down the heat at the end of a shift and warm the space up appropriately prior to workers' arrival. You need 'commercial' stats that allow for each day's program separately. Since you are closed for 3 days per week, you can expect to save $10 \%$, or $\$ 3900$ per year in LP costs. Turning up the AC (or off) when not occupied will save an additional $\$ 500$ per year. If your roof-top cooling units have the capability of an 'economizer' mode, consider pulling in cool outside air in the early morning to pre-cool the building. We discussed a large outside air damper that is triggered by pressure to 'dump' fresh air into the space. Talk with your HVAC contractor about a program/timer system that could utilize 'free' outdoor air when appropriate to cool the building. They may also help find a solution for the comfort issues that exist when the outside air enters through the ceiling during the workday. Check the schedule on the ventilation system to assure all outside air dampers are closed when the building is not occupied. Any fresh air introduced to the space must be heated or cooled, so while you want adequate air changes for comfort and health, you only need to introduce outside air when the full staff is present. 


\subsection{Simpson's Plastic Molding Facility}

This building apparently has 2 electric meters. Only one meter has a measured demand which peaks annually at just over $150 \mathrm{~kW}$. Energy usage remains fairly steady with increases for air conditioning in the summer. But because of rate increases, your costs have increased from an average of 7.9 cents in January 2007 to 9.5 cents in February of this year. We can’t control the cost, but we can try to control usage. Many opportunities exist in this facility.

\section{Building Shell}

The Simpsons molding facility is a very old building which does not appear to be insulated. The building consumed as many gallons of LP in a year as did the assembly plant, and the assembly plant has double the square footage. In addition, the molding plant operates heat-generating machinery that should help keep the space warm. Consider adding a layer of 2" (at least) foam insulation when re-roofing the building. The shingles are in poor shape.

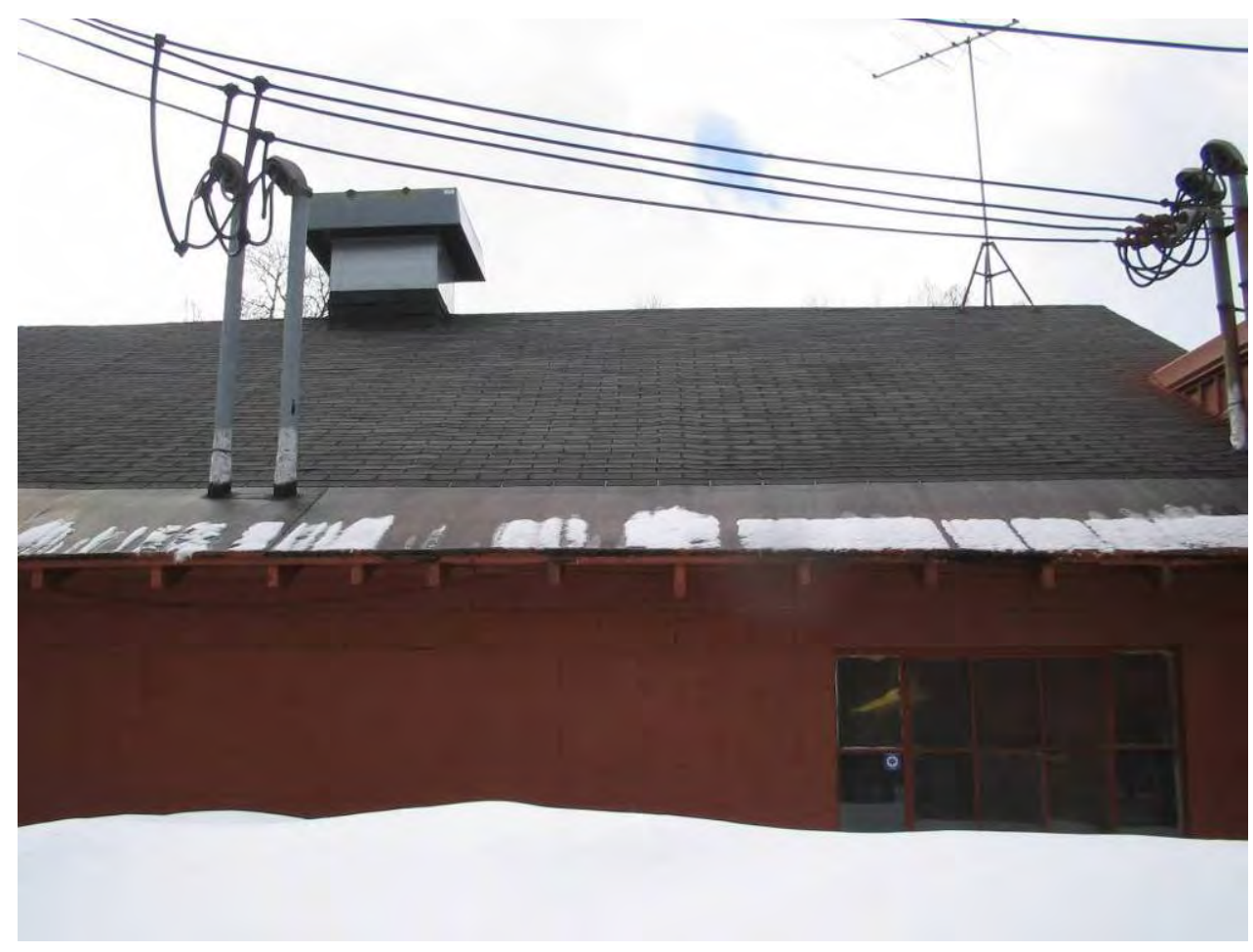




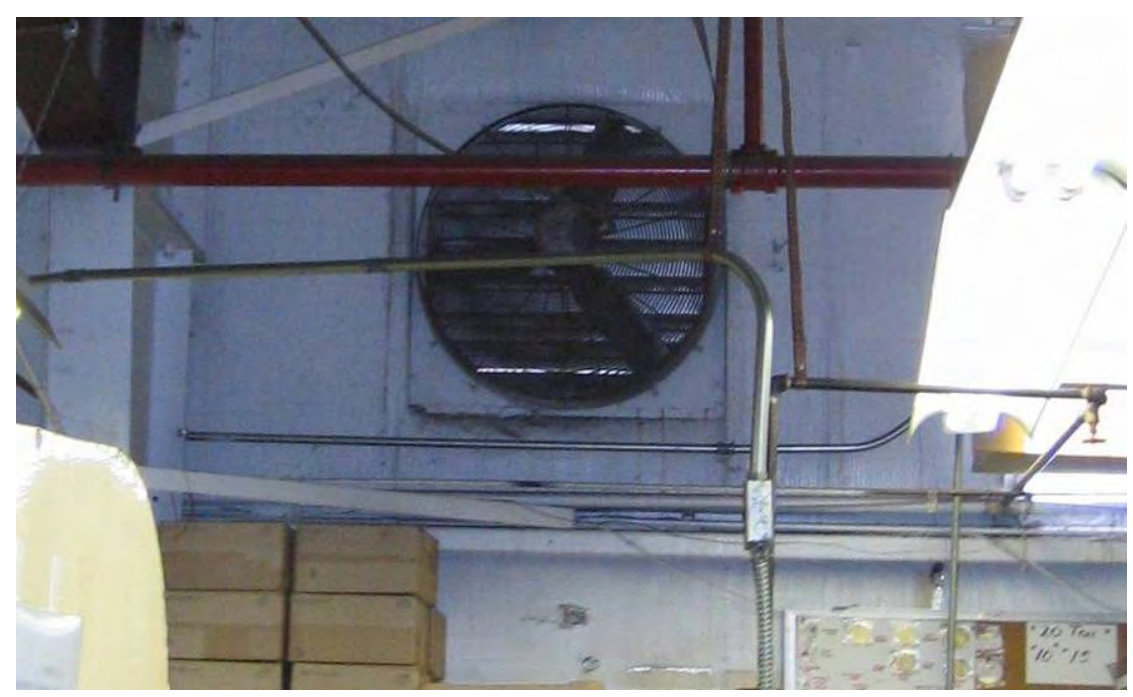

Additional heat is lost through the multitude of exhaust fans and numerous small holes and other openings. The windows appear to be single pane glass-another source of heat loss. If exhaust fans are not needed during the heating season, seal them up for winter. Use expanding foam to seal other cracks and holes.

\section{Heating systems}

Heating systems are numerous, and add up to enough capacity to heat a much larger building. Are all thermostats turned back at night? Setting the heat back 8-10 degrees at night and on the weekend, you will save significant fuel. Expect to save at least 1-2\% per degree of set-back.

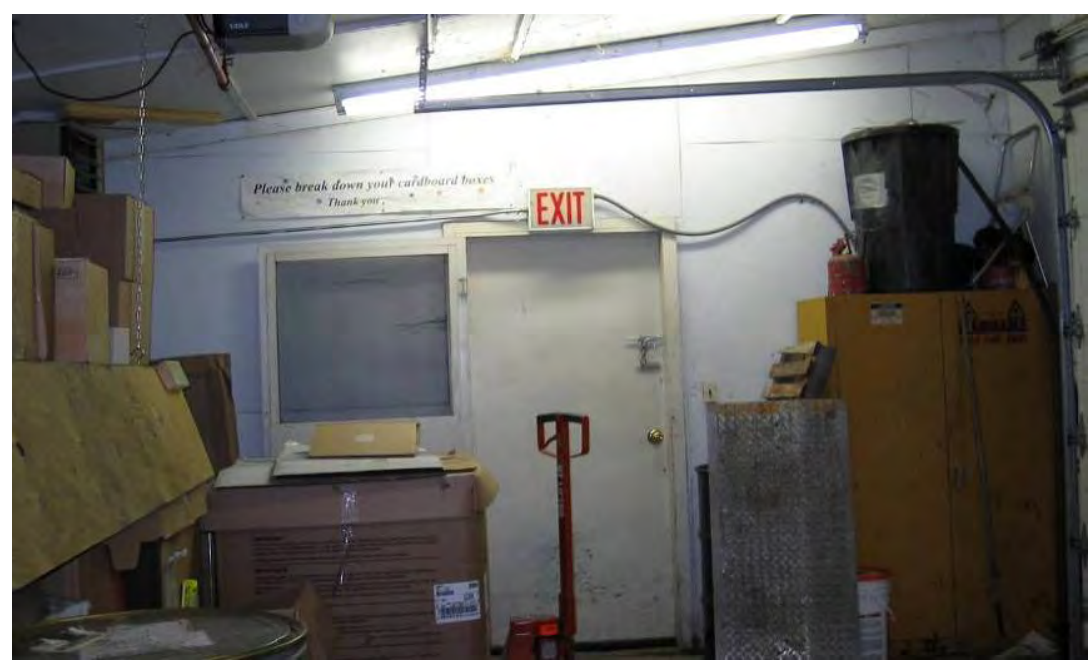

\section{Lighting}


The facility is lit with T12 magnetic ballast fluorescent fixtures. The magnetic ballasts are obsolete and will not be manufactured after this year. Upgrading to T8 high-performance lamps and ballasts would cut the electrical usage by $30 \%$ while increasing light levels by $20 \%$. Improving the quality of light may reduce the need for some fixtures. High performance T8 lighting provides a superior quality of light that is easier on the eyes. Consider adding occupancy sensors in office space, break rooms, storage areas, etc. The day I visited, some areas were fully lit and no one was present. Add task lighting over work spaces that can be switched locally as needed.

\section{Compressed air}

Compressed air is considered the ' $4^{\text {th }}$ utility' after electric, gas, and water. I suggest you commission a compressed air audit. The facility uses air in various processes throughout the building from at least 5 compressors. Often, by adding some storage capacity and/or streamlining a process, you can eliminate all but 1 compressor. Shutting off each and every compressor at the end of the work day must be a bit time consuming. If they are not being turned off, you are wasting a great deal of energy as those compressors kick in to maintain pressure-especially if your air delivery system has leaks, which I'm sure it does.

Since the compressed air load varies throughout the workday, using a variable frequency drive compressed air system could ramp up the system based on the need, saving additional energy.

In the U.S., compressed air systems account for $\$ 1.5$ billion per year in energy costs, and $0.5 \%$ of emissions. Optimization of compressed air systems can provide energy efficiency improvements of 20\% to 50\%. The Focus on Energy Compressed Air Program offers financial incentives to businesses improving the efficiency of their compressed air systems ${ }^{2}$.

\section{Water}

Water is pumped through the building to cool machinery and is discharged at the back of the facility near the lake. We discussed how we might 're-use' this water. In order to make any type of calculation, you will need to know the temperature of the water and the gallons per minute of discharge. A simple cooking thermometer submerged in the flow will give you the temperature. A stopwatch and a 5-gallon bucket will measure the rate of flow in gallons per minute. Based on the observation that 'you can hold your hand under it,' I would surmise that you won't find a great deal of use for the water. You do not use any hot water in your process, and domestic hot water use is limited to the restroom. As I understand the function of the machinery in the facility, cooling is more of an issue than heating (with the exception of trying to keep the un-insulated building heated). I was unable to learn the rated horsepower of the pump. We know only that it runs uninterrupted, and that it has for years-perhaps decades. I question the need

\footnotetext{
${ }^{2}$ See the Focus on Energy fact sheet: www.focusonenergy.com/files/Document_Management_System/Business_Programs/B_GI_MKFS_BPCompressed Air.pdf
} 
for its operation when the facility is not occupied, but personnel felt tuning it off presented too much of a risk (in case it would not start again.) 


\subsection{Bingo Hall}

The Bingo Hall is used Tuesday - Sunday from about 3 p.m. - 10 p.m. Two people were working there earlier in the day when I visited. Unfortunately, all of the lighting in the facility was on at that time. In the main bingo hall, there are $504 \mathrm{~L}$ fluorescent light fixtures. Operating that many fixtures in a basically empty building is quite a waste of energy. People report seeing the lights burning in the bingo hall at 4 a.m. If the lights operate 14 hours/day instead of only the 7 hours during Bingo, you are spending at least an extra $\$ 1200$ per year to light an empty building.

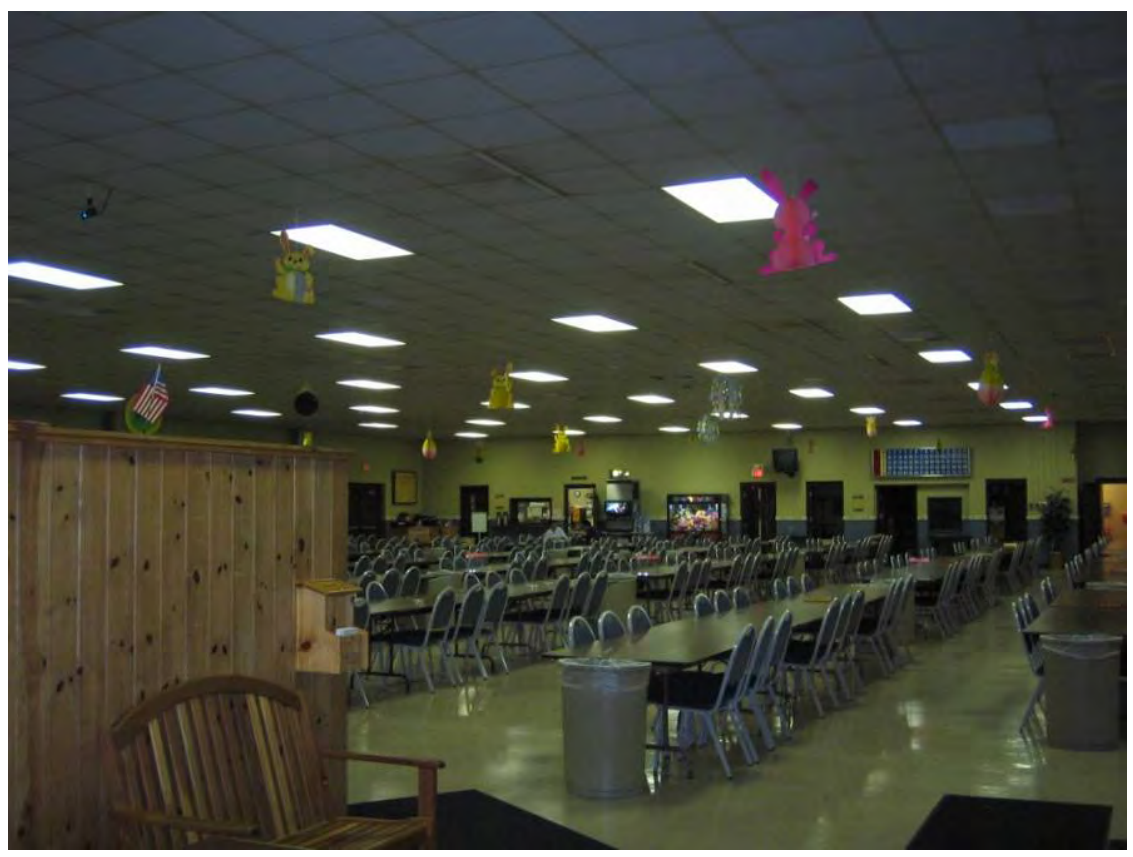

The spare bulbs we found in the storage room were T12s - an almost obsolete technology. You will save another $\$ 800$ per year by upgrading to High Performance T8 lamps and ballasts. You'll gain about 15\% more light, as well.

Consider installing motion sensors on just a couple of fixtures so lights come on if someone enters the space. Then a single worker won't turn on all 50 lights while they set up for the evening.

\section{Heating}

The heating systems are located on both ends of the building and appear quite old and inefficient. Until you are prepared to upgrade to more efficient systems, be sure you are vigilant with tune-ups and cleaning, replacing filters and belts regularly. This building should be operated with a programmed, setback thermostat that turns up the heat only during the hours that Bingo is offered. You can save $15 \%$ $20 \%$ on the fuel costs here by turning down the heat 8-10 degrees during the other hours. Instruct earlyarriving staff to come dressed for slightly cooler temps and save a lot of energy. Average LP gas usage over the last 3 years was 10,700 gallons. At this year's price of LP, a 20\% reduction would have saved $\$ 3,200$. 
Large air handling units are sized to accommodate full capacity of the building. If the building can be set for occupied vs. unoccupied mode, you can heat the space up more effectively in unoccupied mode (dampers closed) without bringing in all the fresh air that is required when the building is full of people. Check with your controls contractor or the heating/ventilating technician.

Vestibule doors are installed in buildings to slow down the migration of conditioned air into outdoor space and the introduction of cold outdoor air into a conditioned space. Propping open a vestibule door defeats the purpose of having it. Outdoor air

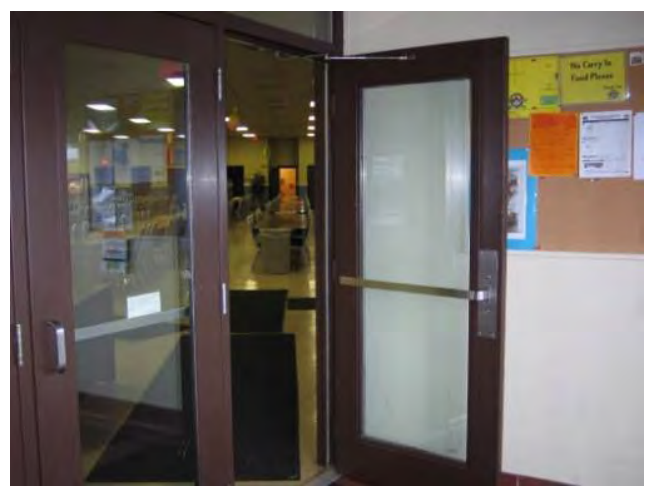
can funnel to thermostats and upset the comfort zone of the building. We found the door propped open the day of my visit. Instruct staff to keep these doors closed at all times.

\section{Kitchen Facilities}

The facility includes a 'short-order' kitchen. Again, as with the lighting, this kitchen can operate most efficiently when appliances are turned on only soon enough to be prepared for the first potential orders. Keeping a grill or fryer heated longer than necessary is a waste of energy. Appliances should be turned off as soon as possible at the end of an event.

Clean under, behind and around any refrigeration equipment frequently to prevent build-up of dust and lint that can decrease compressor efficiency. Make sure door seals are clean, tight, not damaged, and checked often.

If replacing any kitchen equipment, look for Energy Star rated appliances which will use energy most efficiently. You will find information on Energy Star kitchen equipment, lighting incentives and more at: www.focusonenergy.com and www.energystar.gov. 


\subsection{Grocery Store}

Grocery Stores have a large energy consumption compared to the physical footprint of the building. Focus on Energy has developed a virtual tour for Grocery managers to help them identify energy-saving opportunities ${ }^{3}$.

\section{Lighting}

The Grocery store is lit almost entirely with T12 fluorescent strip fixtures. T12 technology is becoming obsolete. After January 2009, manufacturers will no longer produce T12 magnetic ballasts. This conversion should be a priority. In addition to the energy savings, new lighting will brighten up the store, better lighting the aisles. Many retailers report increased sales following a lighting retrofit. The calculation below includes only the main area of the store. Additional opportunities for upgrade can be found in the back rooms and cooler cases. Focus currently offers incentives to encourage customers to upgrade from T12 to

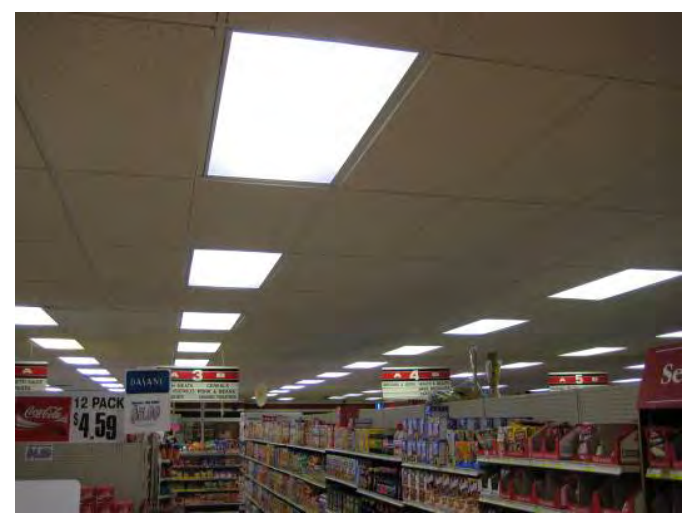
High Performance T8. You need only replace lamps and ballasts. Your existing fixtures will hold the more efficient components. The additional T12 'bounty' of $\$ 2$ per lamp is good only through 11/15/08. The regular incentive is $\$ 10$ for a 4-lamp fixture. The 'bounty' brings it to $\$ 18$ per fixture. The bounty requires calling in to receive a confirmation number.

Table 2. Energy and Cost Savings for Grocery Store Lighting Upgrade

$\begin{array}{rr}\text { Lighting Project Summary } & \\ \text { kW } & 5.5 \\ \text { kWh/Yr Use } & 28,343 \\ \text { Annual Energy Cost } & \$ 1,899 \\ & \\ \text { Project cost Estimate } & \$ 5,700 \\ \text { Incentive } & \$ 2,052^{*} \\ \text { Simple Payback } & 1.9 \\ \text { * this includes the T12 'bounty' which expires } & 11 / 15 / 08\end{array}$

\section{Refrigeration}

The store contains a lot of open cases. Consider adding night curtains to contain the refrigerated air. To calculate savings, measure the length of open cases. You will save 150 kilowatt hours annually per lineal foot of open cases. Multiply that by \$.09 per kilowatt hour. (Lineal feet of open case x 150 annual kWh x $\$$.09.) Focus on Energy can provide a custom calculated incentive to help buy down the cost of the

\footnotetext{
${ }^{3}$ Visit: http://www.focusonenergy.com/Business/Commercial-Business/Grocery/grocery_store.aspx.
} 
curtains. If you decide to pursue this, provide me with a proposal before you commit to the project, and I'll run the numbers.

Hussman takes care of regular tune and cleans on refrigeration equipment. Be sure to continue this.

\section{Heating/Cooling}

Uneven heating/cooling is mentioned on the input form as an area of concern. In a grocery store, this is extremely difficult to manage. You have open refrigerated cases pouring chilled air into some spaces. You have a deli full of heating devices in the corner. You have some self-contained refrigerated cases with their internal compressors heating space around them. And behind the whole back wall is a rack of compressors that generate a great deal of heat. You have a high-efficiency heating system, which probably does not operate too often. Balancing the heat loads of a grocery store is challenging.

\section{Domestic Hot Water}

Some hot water is produced from waste heat from the refrigeration compressors with additional electric unit/s. Wrap all accessible piping to prevent stand-by losses.

\section{Kitchen Equipment}

Activities in the deli consume a lot of energy. As you consider updated or replacement equipment, be aware that the Energy Star rating now applies to Commercial Kitchen equipment. Focus on Energy provides incentives to assist customers in 'buying down' the additional costs associated with more efficient equipment. You can find all the incentives listed here: www.focusonenergy.com/Incentives/Business/FoodService.aspx.

Exhaust air in the deli is a necessary evil. Make sure it is turned off when the deli closes for the day. All the air exhausted must be made up with incoming air that will have to be heated or cooled. Use it when the equipment is operating, but don't leave it on.

\section{Building shell}

Add a sweep at the bottom of the door in the back room. Inspect all doors annually and adjust as needed to close up any spaces that allow air to move through. 


\subsection{Convenience Store}

Convenience stores use quite a bit of energy compared to the physical footprint of the building.

\section{Lighting}

On the day of my visit (and other times as I drove by) I've noticed the canopy lights burning during bright, daytime hours. Even when I mentioned it to the cashier, I noted she did not turn them off. Since this is a pay-at-the-pump facility, the lights obviously stay on all night. Install a daylight sensor to turn them off during the day. This is a relatively inexpensive control that can take the place of forgetful employees (who don't pay the electric bill). Hours of darkness in our area add up to 3200 as opposed to 8760 if left on

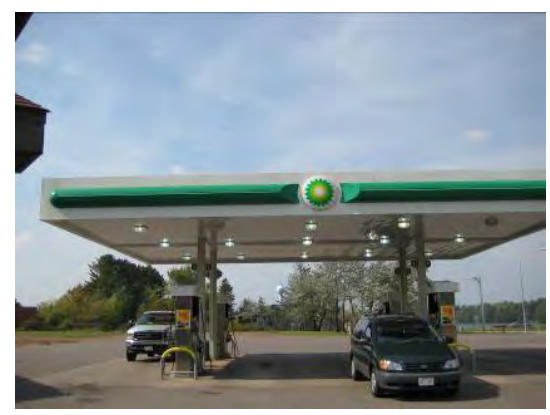
all the time. If these are 400 watt lights, you can save over $\$ 2900$ per year.

Overhead lighting inside the store is T12 technology. Upgrade to high-performance T8 lamps and ballasts to save \$82 per year. T8 HP lighting will provide a brighter, more pleasant light.

\section{Heating/Cooling}

A very good energy-saving practice is to turn down the heating or cooling during unoccupied hours. Install a programmable set-back thermostat to do this for you. Install a lock-box over it and do not allow employees to remove it
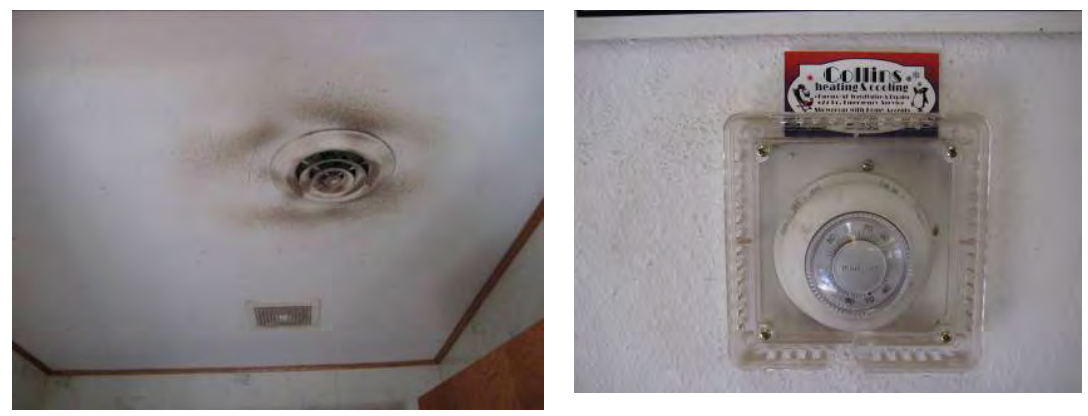
(as they have with the one in the photo).

The HVAC system is apparently dirty. Make sure to change filters monthly. Keep the area around the heating system clean and free of debris that can be sucked into the blower. Consider having ducts cleaned to improve air flow. Clean diffusers on a regular basis. When ducts are clean, air flows more easily and this reduces the cost of delivering conditioned air.

\section{Domestic Hot Water}

The only hot water needed here is for hand washing. 110 degree water should be adequate. Insulate any exposed piping. 


\subsection{Community Center/Clinic}

\section{Lighting}

Although this building incorporates T8 lamps, I suspect from conversation with the facility manager that the lamps were combined with T12 electronic ballasts. T8 lamps should provide brighter light at a lower cost, but you really don't accomplish either by combining the wrong lamp and ballast. They are not interchangeable.

Learn more about High Performance T8 here: http://www.focusonenergy.com/Business/Lighting/.

Focus provides incentives to help buy down the cost of upgrading to this most efficient type of fluorescent lighting. You can install the proper components in existing fixtures.

For each fixture updated from T12 4-lamp to high-performance T8 4-lamp, you will save \$12.50 per year.

Above the dental clinic, the lights are Metal Halide. This has never been good technology for lighting an office, and in fact, most gymnasiums, garages and warehouses are moving to better types of lighting. Replace the metal halide fixtures with high-bay fluorescent fixtures that are designed to distribute light much better using a reflective material behind the lamps. You will have far better visual acuity and color rendering, and the wattage is half what the existing fixtures consume. You would save \$750 per year. Focus is offering an amazing incentive of $\$ 90$ per fixture when customers upgrade to T8 High-bay lighting. Expiration: 12/15/08 (incentive then reverts to $\$ 60$ per fixture).

The most important consideration with lighting is to turn it off when it is not needed. This can easily be accomplished by adding occupancy sensing devices. Several of the areas we walked through the day of my visit had no one present, yet all the lights were burning. Storage areas, meeting rooms, restrooms or offices not occupied full time should be equipped with sensors to turn lights off automatically. Focus offers incentives for installing sensors: \$30 per ceiling mount or \$15 per wall mount.

Several EXIT lights use 40 watt incandescent bulbs at an energy cost of $\$ 56$ per year. New LED EXIT lights would cost about $\$ 2$ per year to operate. Upgrade kits cost \$12-\$15 each. Or purchase new, quality fixtures at http://www.exitlightco.com/ for around \$20.

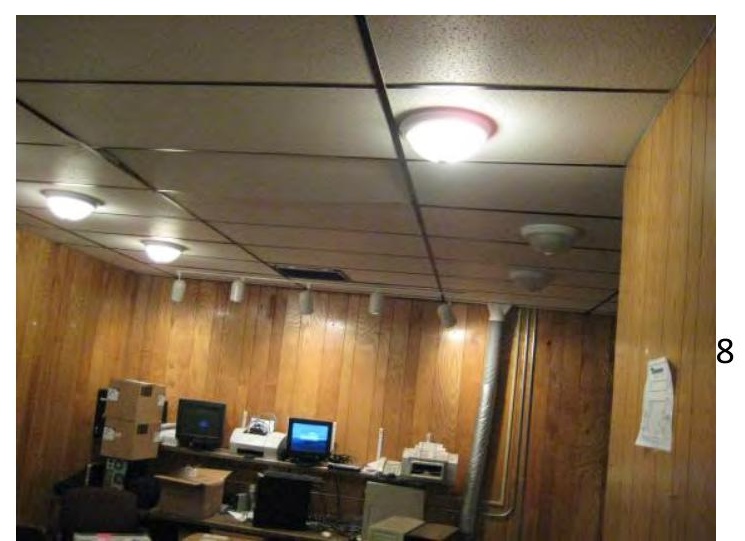


Incandescent light bulbs are fast becoming obsolete. Compact fluorescent bulbs now come in a multitude of shapes and sizes, including reflector flood bulbs. Incandescent technology produces a lot more heat than light, so eliminating them also reduces summer cooling costs. The room in the photo is not occupied, so the best solution would be to turn lights off. Operating this many incandescent bulbs in the space costs about \$256 per year. Using CFLs would cut that to under \$60 per year and reduce cooling costs.

\section{Building shell}

Examine door and window perimeters each year. Look for gaps or cracks where heat is escaping. You can repair a lot of holes with a tube of good quality caulk. Replace worn thresholds, weather-stripping or door sweeps. Some doors can be adjusted to improve their fit. Make sure any window latches are secured prior to heating season.

\section{Heating/cooling}

The heating system is maintained by Johnson Controls. Talk with them about a program/timer system that could utilize 'free' outdoor air when appropriate to cool the building. Check the schedule on the ventilation system to assure all outside air dampers are closed when

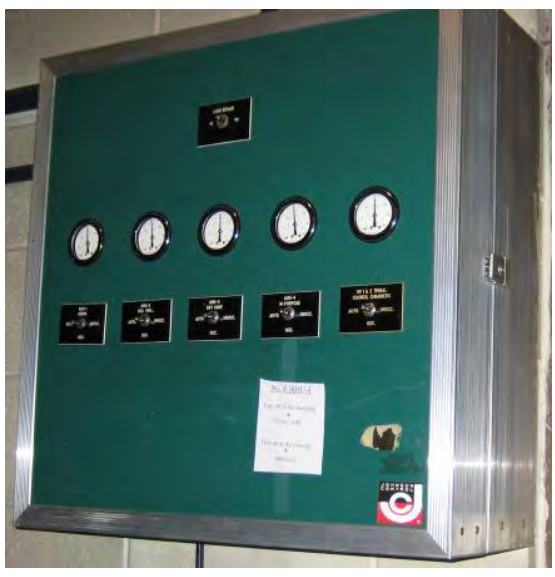
the building is not occupied. Any fresh air introduced to the space must be heated or cooled, so while you want adequate air changes for comfort and health, you only need to introduce outside air when people occupy the space. We see a control panel in place that includes switches for occupied and unoccupied conditions, but it is apparently not used for that purpose. Work with JCI to better understand the system capabilities.

It appears that the building is kept at human comfort temperatures whether people are present or not. This wastes a great deal of energy. Dropping the heating temp, or raising cooling set-points during unoccupied hours can save a lot of energy. If you were to turn the temperature back 8 degrees at night and on weekends for one year, you can save almost 2,000 gallons of gas. At last year's propane price, that would be $\$ 3000$. At this winter's elevated cost, you would realize over $\$ 4,000$ in savings. Make sure your program settings allow adequate time for the building to heat up in the morning. And be sure to inform all staff members of the reasons for the change. You will have fewer complaints and better cooperation.

Your boilers are over 30 years old. Even though the burners are newer, you should have the systems cleaned and tuned up for optimum efficiency.

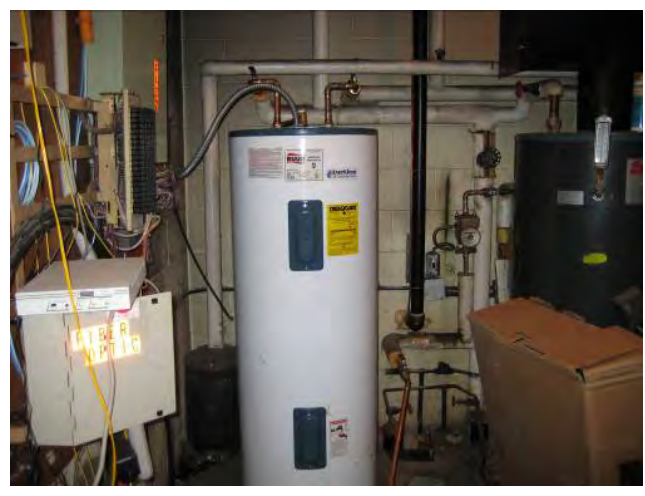


In the summer, turn the AC system off or at least set it way higher during unoccupied hours. It appears that the AC systems have been added independent of the heating system. This can cause control issues. If the 2 are not integrated, you could be heating and cooling the same space at the same time.

\section{Domestic Hot Water}

Water heating is electric. Pipes appear to be wrapped. When replacing water heaters, look for the insulation value of the jacket. You lose heat from a water heater as it stands unused at night and on weekends. 


\subsection{Court Law/Enforcement}

\section{Lighting}

Although this building incorporates T8 lamps, I suspect from conversation with the facility manager that the lamps were combined with T12 electronic ballasts. T8 lamps should provide brighter light at a lower cost, but you really don't accomplish either by combining the wrong lamp and ballast. They are not interchangeable.

As you replace lamps and/or ballasts, select the most efficient options, called High-Performance, from this list: www.cee1.org The Consortium for Energy Efficiency maintains a list of the highest lumen, longest life lamps and the most energy-efficient ballasts. Consider making these components a requirement when ordering for any tribal entities.

Learn more about High Performance T8 here: http://www.focusonenergy.com/Business/Lighting/. Focus provides incentives to help buy down the cost of upgrading to this most efficient type of fluorescent lighting. You can install the proper components-both lamps and ballasts--in existing fixtures.

The 8' fixtures in the back room can be converted with kits that use 1 high-performance ballast and 4 high-performance T8 lamps.

When removing lamps from fixtures, be sure to remove or disconnect the ballast. It will continue to draw power even without the lamp in place.

The most important consideration with lighting is to turn it off when it is not needed. This can easily be accomplished by adding occupancy sensing devices. Offices, conference rooms, break rooms and rest rooms can all benefit from the installation of occupancy sensors to turn off lights when no one is present. Savings depend on the level of occupancy and the wattage of existing fixtures. The folks in this facility seem to be doing a good job of leaving lights off where they are not needed.

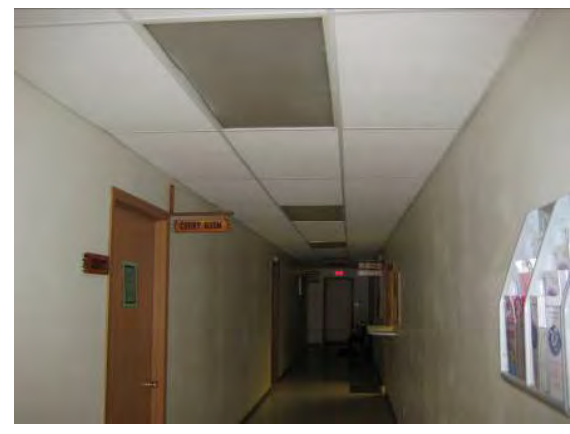

Incandescent light bulbs are fast becoming obsolete. Compact fluorescent bulbs now come in a multitude of shapes and sizes, including reflector flood bulbs. Incandescent technology produces a lot more heat than light, so eliminating them also reduces summer cooling costs. Replace any incandescent bulb in lamps or ceiling fixtures with the appropriate CFL. Check the package for recommended replacements. Focus offers a $\$ 2$ per bulb incentive.

\section{Building shell}

Examine door and window perimeters each year. Look for gaps or cracks where heat is escaping. You can repair a lot of holes with a tube of good quality caulk. Replace worn thresholds, weatherstripping or door sweeps. Some doors can be adjusted to 
improve their fit. Make sure any window latches are secured prior to heating season.

\section{Heating/cooling}

The forced air heating system was probably installed when the building was remodeled in 1995, making them 13 years old. You might expect to get 20 years from them if you take very good care. Make sure to have them cleaned periodically to prolong the life. Change filters monthly.

This facility could benefit by installing programmable set-back thermostats, rather than relying on personnel to remember to turn it down.

This heat recovery ventilation system is a great way to save energy. This device pulls air from the building and uses it to pre-warm incoming air that is fed to the furnace. It 'recovers' about $65 \%$ of the heat rather than blowing it out a vent. The facility caretaker cleans the honeycomb insert as directed by the manufacturer.

\section{Vending Machine}

You don't need lights on the vending machine to let people know it is there. Unplug the ballast inside the door panel to eliminate the light. You'll save \$35 - 50 per year depending on the wattage of the bulb. Another option is to install a device called a Vending Miser. It works with a motion sensor and not only turns off the light, but kicks the

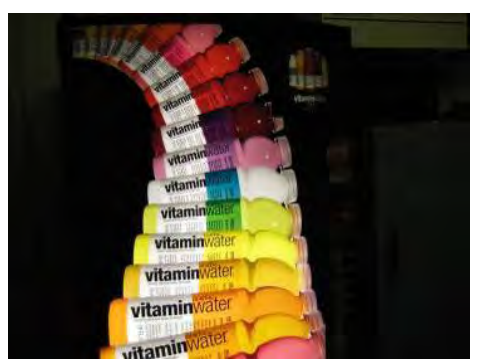
compressor into a lower mode when no one is around to buy the product. Focus offers an incentive of $\$ 60$ per unit. Check them out at : http://www.usatech.com/energy_management/energy_vm.php. 


\subsection{Roads Garage}

\section{Lighting}

Garage lights are Metal Halide.. Replace the metal halide fixtures with high-bay fluorescent fixtures that are designed to distribute light much better using a reflective material behind the lamps. You will have far better visual acuity and color rendering, and the wattage is half what the existing fixtures consume. You would save $\$ 750$ per year. Focus is offering an amazing incentive of $\$ 90$ per fixture when customers upgrade to T8 High-bay lighting. Expiration: 12/15/08 (incentive then probably reverts to $\$ 60$ per

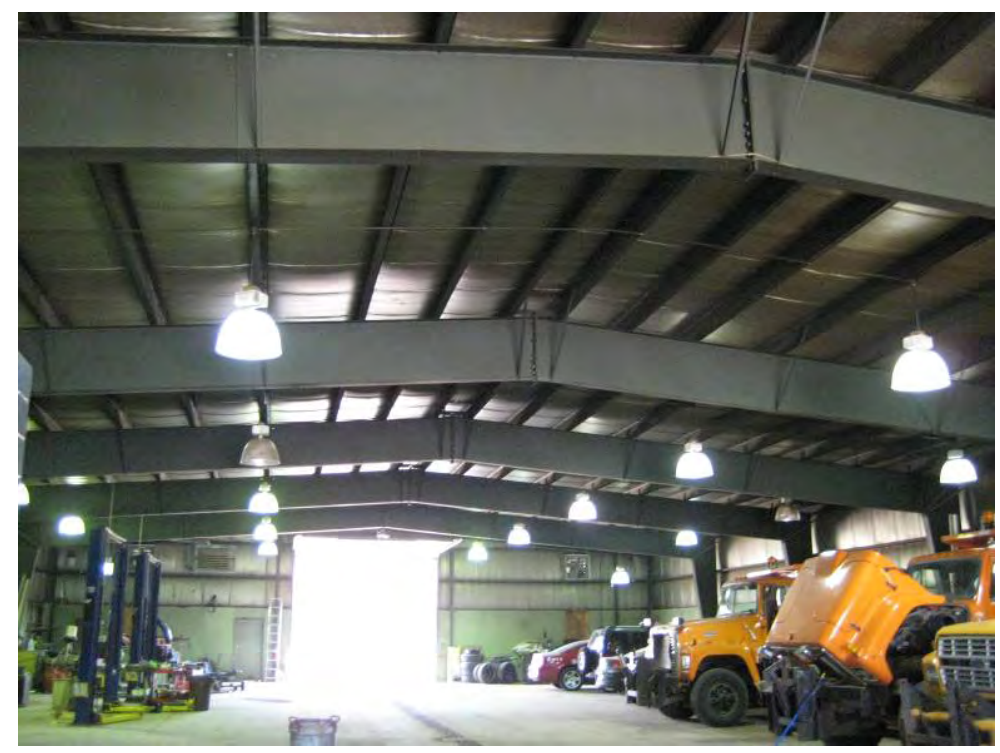
fixture).

The most important consideration with lighting is to turn it off when it is not needed. This can easily be accomplished by adding occupancy sensing devices. The garage is probably empty for a good part of each day when workers are out on the roads. Fluorescent lights do not require a warm-up time, so they can be easily turned off when no one is present, and back on instantly. Occupancy sensors can be wired on each fixture or by row or section to best suit the needs in the space. An additional \$30 per fixture incentive applies when adding sensors.

Table 3. Energy and Cost Savings for Roads Garage Upgrade

\section{Project Summary}

$\begin{array}{rr}\text { kW } & 6 \\ \text { kWh/Yr Use } & 15,869 \\ \text { Annual Energy Cost } & \$ 1,586 \\ & \\ \text { Project cost Estimate } & \$ 5,640 \\ \text { Incentive } & \$, 880^{*} \\ \text { Simple Payback } & 1.7 \\ \text { includes occupancy sensors } & \end{array}$

\section{Downtown lighting}

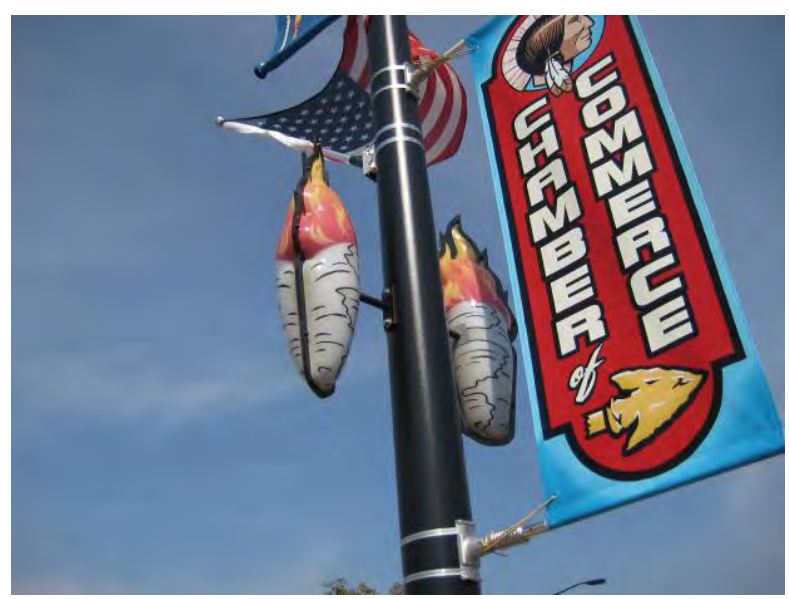


The torches on street lights in the downtown area currently use 60 watt incandescent bulbs. Converting to 15 watt compact fluorescent bulbs would save about $\$ 850$ per year. In addition, it would save a great deal of maintenance time because the CFLs last 8 to 10 times longer than the bulbs you use now. In the coldest winter, the CFLs will take a few minutes to warm up the space before reaching their full brightness. Look for bulbs that are rated for colder start temps.

Table 4. Energy and Cost Savings for Downtown Lighting Upgrade

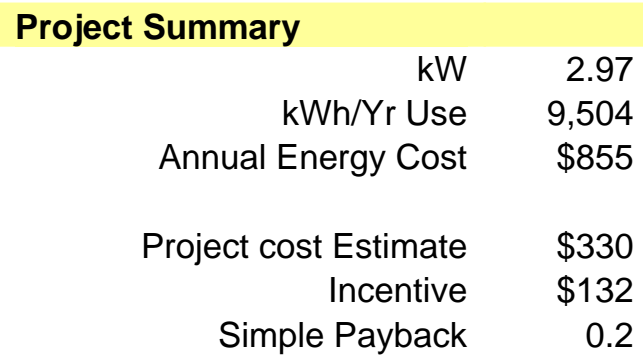

\section{Building shell}

Examine overhead doors and service doors annually for proper gaskets or sweeps on the bottom. If overhead doors allow a gap when closed, have a door company adjust them so they seal properly.

\section{Heating}

Vehicles probably need temps about 50 degrees to start easily in the coldest months. Have workers dress appropriately for this temperature and don't attempt to heat this huge space to 'shirt-sleeve' conditions in winter. 


\subsection{Youth Center}

\section{Lighting}

Strip lighting appears to all be T8. As you need to replace lamps and ballasts, select more energy-efficient options. Learn more about High Performance T8 here: www.focusonenergy.com/Business/Lighting/. Focus provides incentives to help buy down the cost of upgrading to this most efficient type of fluorescent lighting when you update both the lamps and ballast in a fixture. Since the facility doesn't operate long hours, it isn’t a top priority item. But be aware that better lamps and ballasts exist.

Incandescent light bulbs are fast becoming obsolete. Compact fluorescent bulbs now come in a multitude of shapes and sizes, including reflector flood bulbs. Incandescent technology produces a lot more heat than light, so eliminating them also reduces summer cooling costs. The TV room is lit with reflector floods. Consider converting to CFL reflector floods. Don't use CFLs with a dimmer unless you've purchased dimmable CFLs.

Lights in the gym are fluorescent covered with protective grids. Leave lights off unless space is occupied.

Check the fixture outside the front door. It was illuminated in the middle of the day, which indicates the sensor may be bad, or perhaps it is dirty.

\section{Building shell}

Examine door and window perimeters each year. Look for gaps or cracks where heat is escaping. Replace worn thresholds, weatherstripping or door sweeps. Some doors can be adjusted to improve their fit. Make sure any window latches are secured prior to heating season.

Keep an eye on the damper vent from the weight room. We found it stuck open, allowing cold air into the room. It may just take a bit of lubrication on the hinge to keep it closed properly.

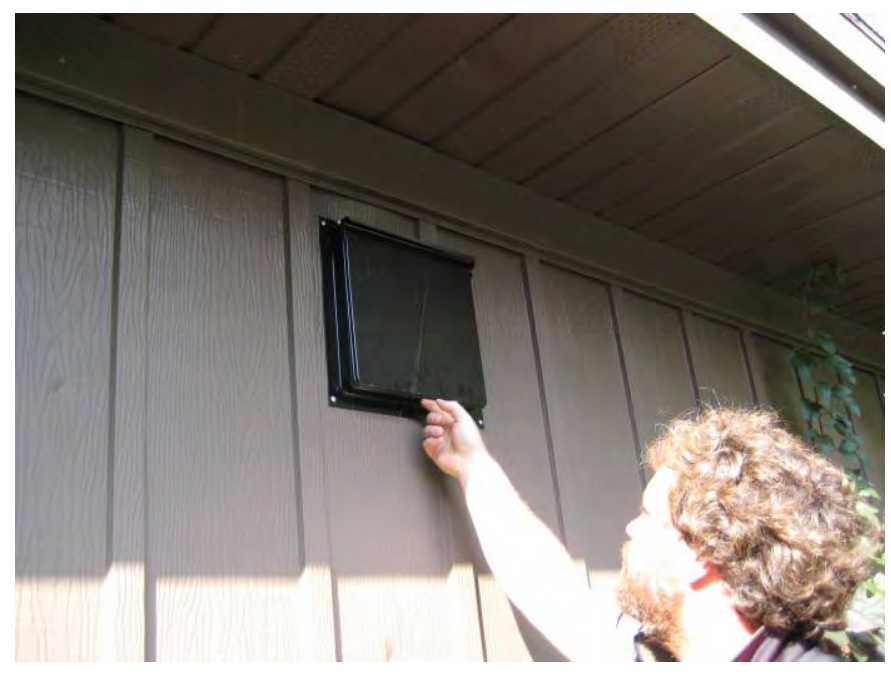

\section{Heating/cooling}

Furnaces are high-efficiency models. Make sure to replace filters on a regular basis (monthly during the heating season) to maintain optimum efficiency and prolong the life of the blower.

The day we visited the building, it was quite cool in the weight room. I understand the need to keep temps and humidity down, but consider setting the temperature up during unoccupied hours. You are wasting a 
lot of energy by cooling the space when no one is present. Install a programmable thermostat to automatically adjust the temperature just prior to kids arrival and readjust at closing time.

Use night set-back stats to turn the heat back in the rest of the building.

\section{Domestic Hot Water}

Water heating is electric. Pipes appear to be wrapped. When replacing water heaters, look for the insulation value of the jacket. You lose heat from a water heater as it stands unused at night and on weekends. 


\subsection{Family Resource Center}

\section{Lighting}

Lighting in this facility appeared to be T8. As you replace lamps and/or ballasts, select the most efficient options, called High-Performance, from this list: www.cee1.org The Consortium for Energy Efficiency maintains a list of the highest lumen, longest life lamps and the most energy-efficient ballasts. Consider making these components a requirement when ordering for any tribal entities.

Learn more about High Performance T8 here: http://www.focusonenergy.com/Business/Lighting/. Focus provides incentives to help buy down the cost of upgrading to this most efficient type of fluorescent lighting. You can install the proper components in existing fixtures.

The most important consideration with lighting is to turn it off when it is not needed. This can easily be accomplished by adding occupancy sensing devices. Offices, conference rooms, break rooms and rest rooms can all benefit from the installation of occupancy sensors to turn off lights when no one is present. Savings depend on the level of occupancy and the wattage of existing fixtures.

Incandescent light bulbs are fast becoming obsolete. Compact

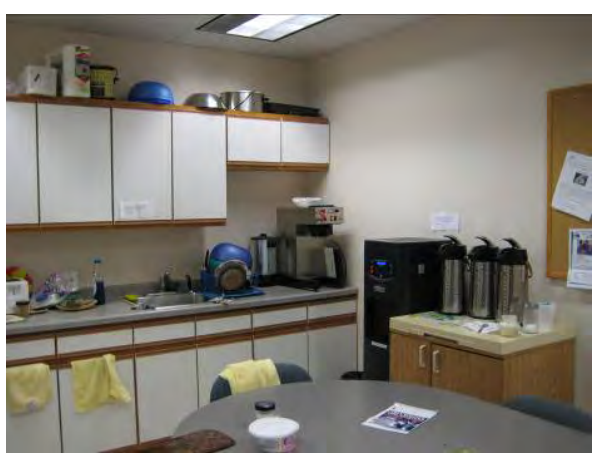
fluorescent bulbs now come in a multitude of shapes and sizes, including reflector flood bulbs. Incandescent technology produces a lot more heat than light, so eliminating them also reduces summer cooling costs. Replace any incandescent bulb in lamps or ceiling fixtures with the appropriate CFL. Check the package for recommended replacements. Focus offers a \$2 per bulb incentive.

\section{Building shell}

Examine door and window perimeters each year. Look for gaps or cracks where heat is escaping. You can repair a lot of holes with a tube of good quality caulk. Replace worn thresholds, weatherstripping or door sweeps. Some doors can be adjusted to improve their fit. Make sure any window latches are secured prior to heating season.

\section{Heating/cooling}

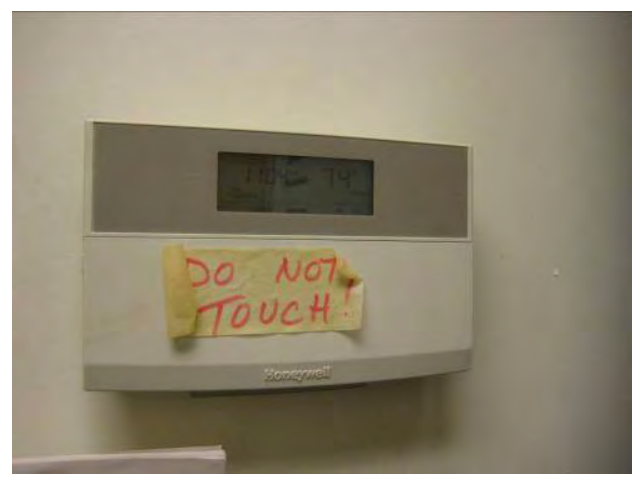


Your heating and cooling is provided by 3 forced air furnaces controlled in separate zones. There are programmable night-setback thermostats for each. Someone in the building needs to learn how to program and check the stats. You should monitor and modify the program when daylight savings starts and stops. Turning back the heating or turning up the cooling can save significant amounts of energy. In a newer, well insulated building like this one, you should easily be able to change the temperature setting by 8-10 degrees when not occupied. Experiment cautiously with settings and be sure you have the 'return' time set so that the first arrivals in the morning don't complain of the cold. Be sure to inform all staff members of the reasons for the change. You will have fewer complaints and better cooperation.

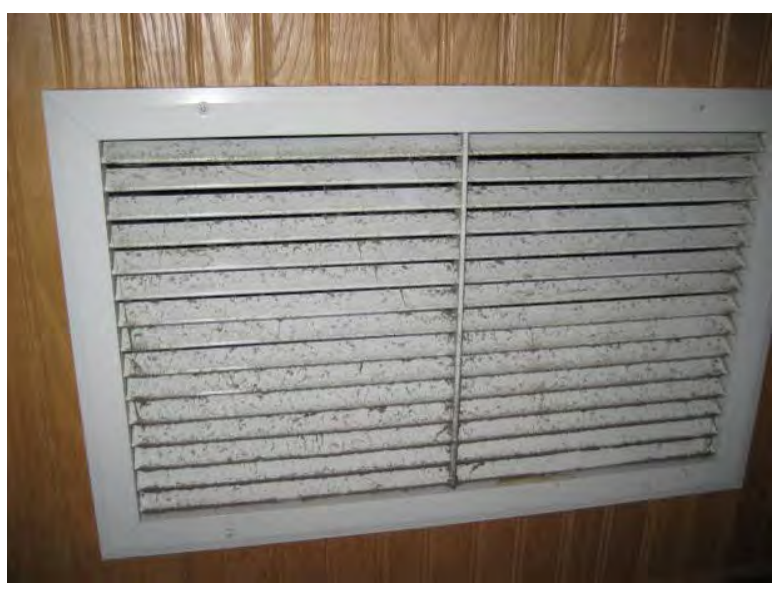

Changing furnace filters is like changing the oil in your car. It's a small price to pay for prolonging the life of the equipment. Most systems benefit from monthly filter changes. Keep furnace rooms clean and free of debris to prevent dirt and dust from being pulled into the system. Keeping the building clean will prevent debris from being sucked into the system. Clean this and any other cold air returns.

\section{Domestic Hot Water}

Water heating is electric. Install foam insulation on pipes to reduce standby losses. In this building, hot water is probably only used for hand washing. Turn the water heater/s down to their lowest setting. When replacing water heaters, look for the insulation value of the jacket. You lose heat from a water heater as it stands unused at night and on weekends.

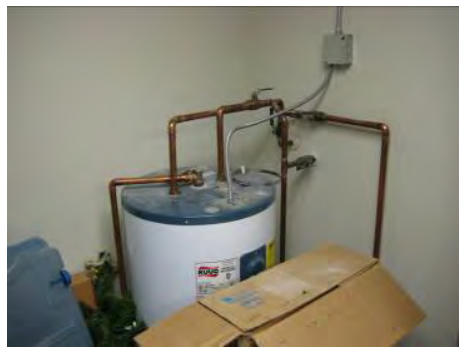

\section{Vending Machine}

You don't need lights on the vending machine to let people know it is there. Unplug the ballast inside the door panel to eliminate the light. You'll save \$35 - 50 per year depending on the wattage of the bulb. Another option is to install a device called a Vending Miser. It works with a motion sensor and not only turns off the light, but kicks the compressor into a lower mode when no one is around to buy the product. Focus offers an incentive of $\$ 60$ per unit. Check them out at : http://www.usatech.com/energy_management/energy_vm.php. 


\subsection{Fireside}

Since the Fireside has been closed for a long time, we don't have a lot of energy history data to analyze, so I won't get into old, insignificant data. The 1935 building doesn't appear to have built with the intention of heating it in the winter. The first step in making this a sustainable building is to tighten the shell so you can afford to heat it.

\section{Insulation}

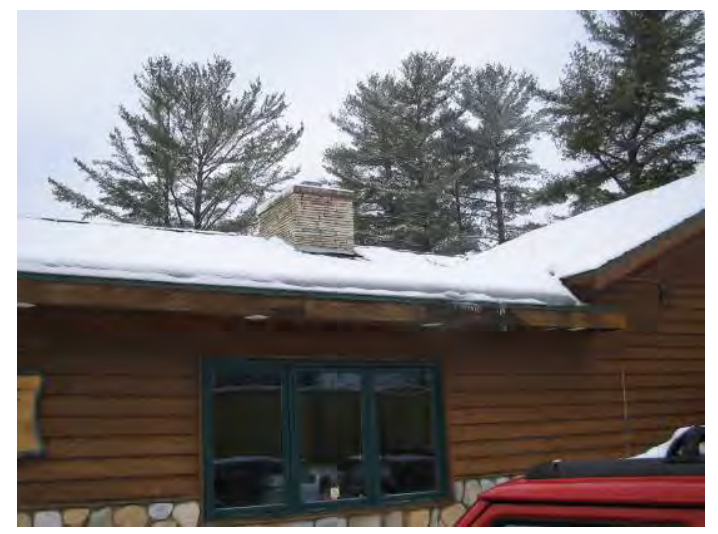

Lack of insulation in the roof of the Fireside building creates the ice dams along the roof edge. This will eventually destroy shingles and rot away the soffit. You can already see the dark staining of the wood under the worst part of the ice dam. The solution is to insulate.

The most air-tight way to insulate is to apply sprayfoam. This seals the cracks and does not allow air migration through the roof. If you insulate with foam, you will need to provide a fire barrier; sheetrock qualifies. Talk with your insulating contractor for the

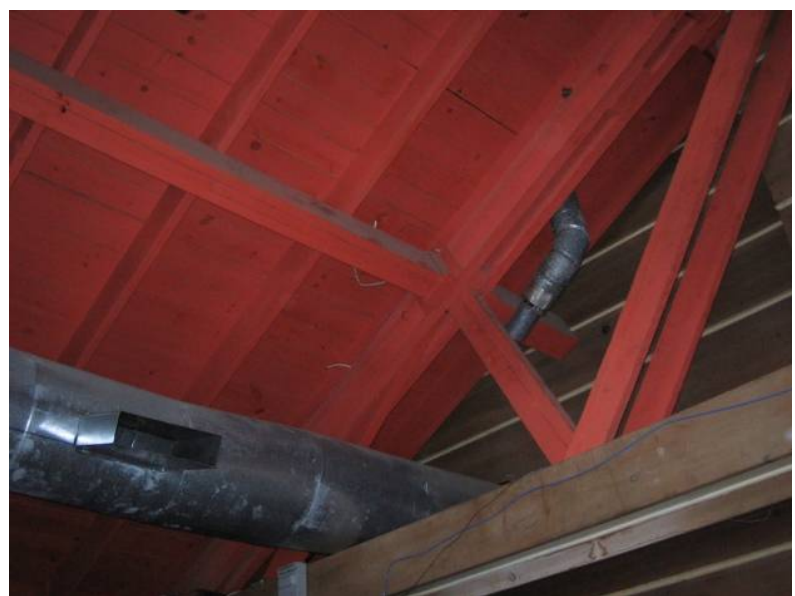
best way to accomplish this. Adding insulation to this area, which you estimate at $1000 \mathrm{ft} 2$ would result in energy savings of $\$ 900$ if you can add R20.

The bathroom ceiling is water damaged from frozen, broken pipes. Unfortunately, the bathroom water piping was installed outside the insulated shell of the building, basically in the attic. Insulation must be installed under the rafters in this area in order to bring this unheated space into the heated envelope. Another cause of water damage on bathroom ceilings is condensation that forms on the exhaust fan duct where warm, moist air leaving the space contact the

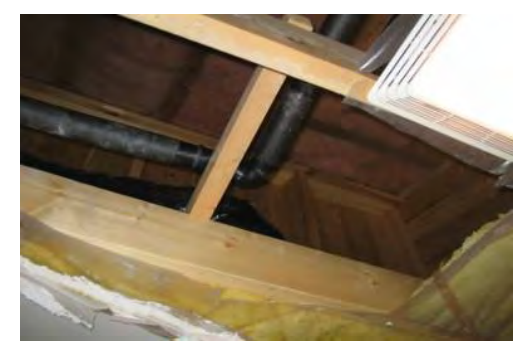
cold, attic air. Again by insulating the underside of the rafters, you will bring the ducts into the heated space and eliminate the potential for water damage.

\section{Domestic Hot Water}

Rest room hot water is provided with a small, appropriately sized electric heater. While the hot water piping is exposed, add foam insulation. This keeps water in the pipes warm between uses and prevents a lot of water from running down the drain while customers wait for it to 'warm up.'

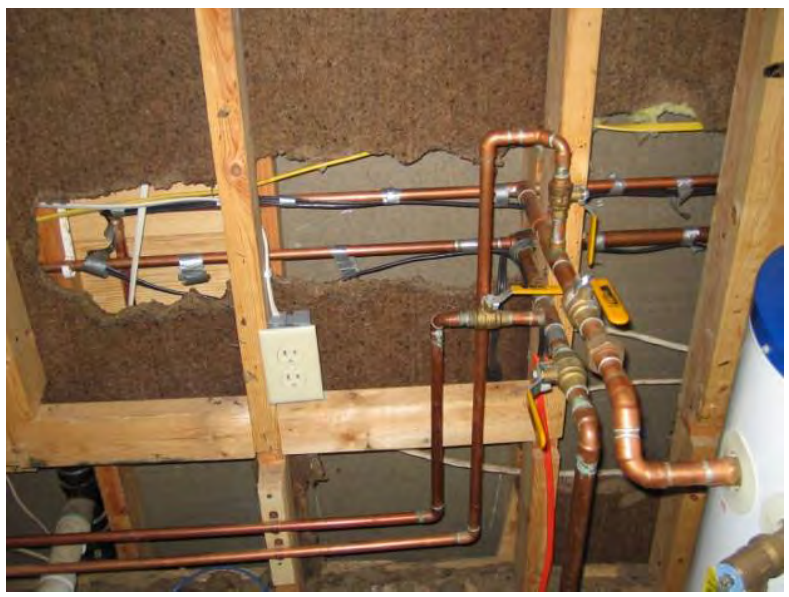


Do the same in the basement from the pipes from the 80 gallon water heater that have not been insulated.

The water heater serving the kitchen is an electric model, approximately 10 years old. Electricity is not the best choice for heating large amounts of water because the elements cannot get as hot or recover as quickly as gas. Consider installing a high-efficiency gas water heater. Based on your estimate of 100 meals per day, you would save \$150 per year.

As you purchase equipment for the kitchen, look for the Energy Star logo. http://www.energystar.gov/index.cfm?c=commercial_food_service.commercial_food_service

Focus on Energy offers incentives to help buy down the added cost of these most efficient models. You will qualify for electric appliances only. You mentioned you will need a dishwasher. Energy Star rated commercial dishwashers are on the market and you will find them listed here: http://www.energystar.gov/index.cfm?c=comm dishwashers.pr_comm_dishwashers

Dishwashers are not yet on the Focus on Energy 'prescriptive' list, so I'll have to custom calculate an incentive. This must be completed and approved PRIOR to you purchasing the unit.

\section{Lighting}

First, convert your EXIT lights to LEDs. You can accomplish this with EXIT light retrofit kits, or by simply replacing the signs. This is a very economical place to look:

http://www.exitlightco.com/ You'll save about \$20 per year per sign.

Fixtures mounted under the beams contain old T12 lamps and magnetic ballasts. Convert to High Performance T8 lamps and ballasts. You can find a list of all the qualifying components at www.cee1.org.

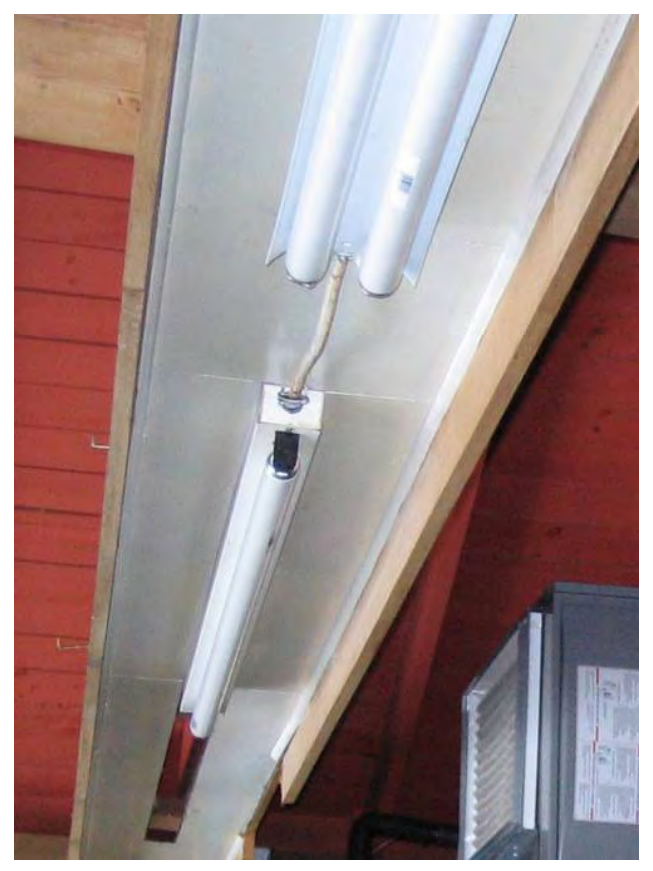

Convert your track lights to use compact fluorescent floods. If you purchase lighted signs, specify LED, which is the best way to efficiently back light a sign.

Install a compact fluorescent light in the cooler and in basement fixtures. You mentioned having purchased some CFLs recently. Focus on Energy has incentives for energy efficient lighting. You will find the forms for lighting and all the other incentives at: http://www.focusonenergy.com/Incentives/Business/ 
When you look for specialty bulbs like dimming CFLs, candle-shaped bulbs for chandeliers, etc. you may have better luck with on-line stores than local department or hardware stores. I've found a lot of options at these, but I'm sure there are many, many more.

www.1000bulbs.com, www.buylighting.com, www.bulbs.com or you may just want to do a search for compact fluorescent bulbs. You will find an option for almost any light fixture.

\section{Heating system}

The propane forced air furnace is installed in a rather unusual way (sideways) and the ducting is rather crude. But with a vaulted ceiling and no basement under that part of the building, I suppose they did what they could. Work with your heating contractor as you remodel so you don't further compromise this system. We talked about upgrading to a more efficient system. This furnace is $80-85 \%$ and you could get up to a $90-95 \%$ system. But at this point, your money is better spent insulating the building. You also asked about using wood or wood pellets and a fireplace insert. Wood will certainly take some of the load off the gas furnace and add ambiance to the building. But you will need to consider where you will store the wood or pellets, how to get them in and ashes out of the building. Chimneys create a large heat loss for a building as warm is naturally drawn up and out. If you do not use the fireplace, make sure the damper is closed and consider sealing it off. If you opt to use it, get a good, efficient and well-sealed insert.

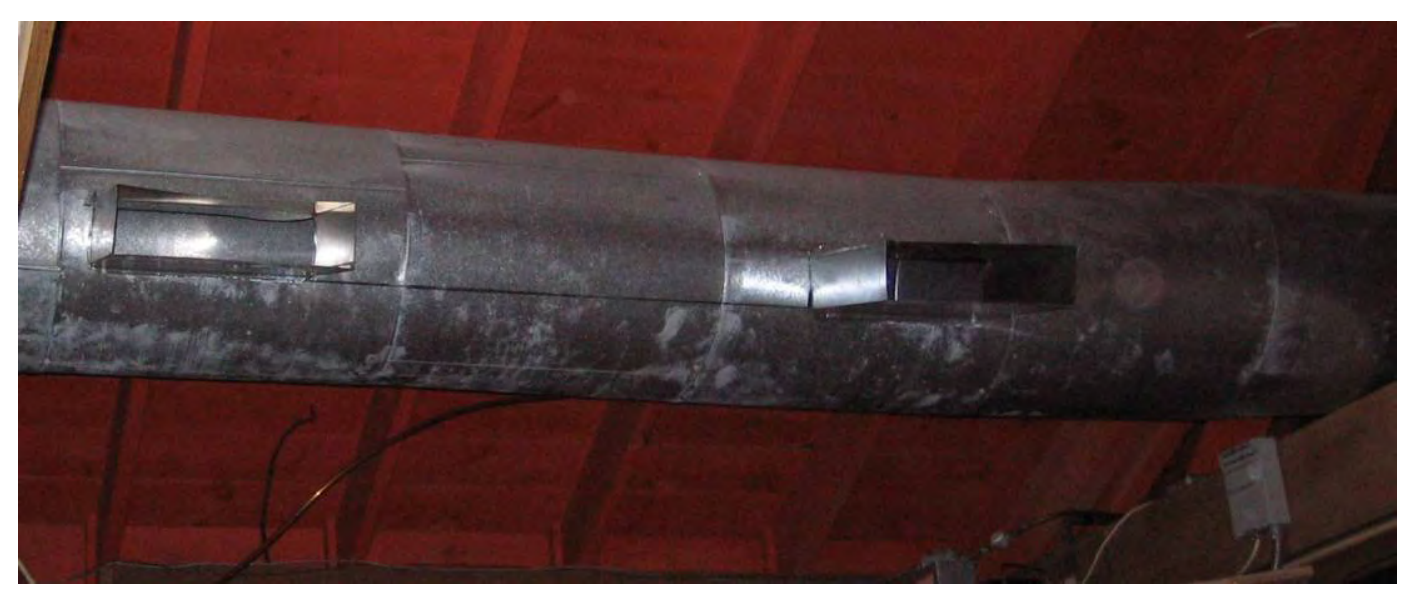




\section{Ventilation}

We talked a about the ventilation hood in the kitchen and the make-up air system. Commercial kitchens require that you exhaust a lot of air so that you are not allowing smoke, grease and odors into the dining area. To make up for that exhaust, it appears you have a make-up air system. This should eliminate creating a negative pressure that pulls air from the dining area into the kitchen. But make sure that it works correctly before you consider using the fireplace or could create some back-drafting. You also would not want to create a situation that pulled air up from the basement since it doesn't smell very good down there!

A good way to use the bathroom vents is to tie both lights and ventilation to a motion sensor. Then adjust the sensor so it stays on for 5 minutes or so. That way both lights and exhaust are there when you need them, but they are not left on to waste energy the rest of the time. Focus on Energy offers incentives for motion sensors, too. A switch-mount style earns a \$15 incentive.

Incentives change as new technologies arise and others become common practice. Please check with Focus on Energy for updates.

I hope you were able to turn off the gas valve behind your cooking equipment and eliminate the strong gas odor we noticed the day I visited. As I explained, you need to be very careful with LP gas as it is heavier than air and it can 'pool' on the floor where it becomes a treacherous hazard to a lit match or spark. Once you are ready to fire up the equipment, consider having a plumber check out the piping and help get your pilots lit.

We talked about so many things when I visited the Fireside; I hope I have adequately covered them here. 


\subsection{Planning/Bank}

\section{Lighting}

This building appears to have T8 lamp and ballast systems. As you replace lamps and/or ballasts, select the most efficient options, called High-Performance, from this list: www.cee1.org The Consortium for Energy Efficiency maintains a list of the highest lumen, longest life lamps and the most energy-efficient ballasts.

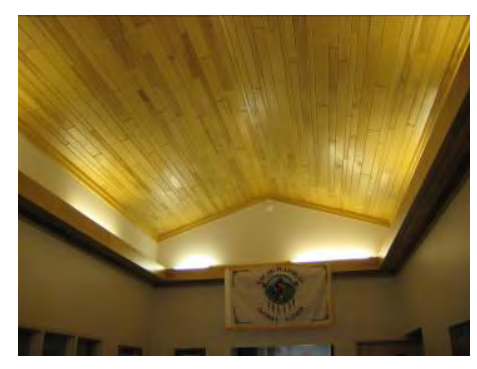

Learn more about High Performance T8 here: http://www.focusonenergy.com/Business/Lighting/. Focus provides incentives to help buy down the cost of upgrading to this most efficient type of fluorescent lighting. You can install the proper components—both lamps and ballasts--in existing fixtures.

The most important consideration with lighting is to turn it off when it is not needed. This can easily be accomplished by adding occupancy sensing devices. Offices, conference rooms, break rooms and rest rooms can all benefit from the installation of occupancy sensors to turn off lights when no one is present. Savings depend on the level of occupancy and the wattage of existing fixtures. I did not have access to the lights that illuminate the ceiling. It is very attractive, but make sure the system uses the most efficient lamps and ballast combination and that it is turned off when the building is closed.

Offices have 3-lamp, inboard-outboard light fixtures. This allows occupants to choose the level of light that works for them. In many cases, people appreciate a lower level of light while working on computers. Incandescent light bulbs are fast becoming obsolete. Compact fluorescent bulbs now come in a multitude of shapes and sizes, including reflector flood bulbs. Incandescent technology produces a lot more heat than light, so eliminating them also reduces summer cooling costs. Replace any incandescent bulb in lamps or ceiling fixtures with the appropriate CFL. Check the package for recommended replacements. Focus offers a $\$ 2$ per bulb incentive.

\section{Building shell}

This is a newer facility and it appears very well maintained. But regardless, examine door and window perimeters each year. Look for gaps or cracks where heat is escaping. You can repair a lot of holes with a tube of good quality caulk. Replace worn thresholds, weather-stripping or door sweeps. Some doors can be adjusted to improve their fit. Make sure any window latches are secured prior to heating season. 


\section{Heating/cooling}

The building has 3 high-efficiency forced air furnaces. Change filters monthly.

This facility could benefit by installing programmable set-back thermostats, rather than relying on personnel to remember to turn it down. Lock boxes are recommended to prevent staff from readjusting (especially when they don't understand the program). And don't allow staff to pry off the covers-it defeats the purpose!
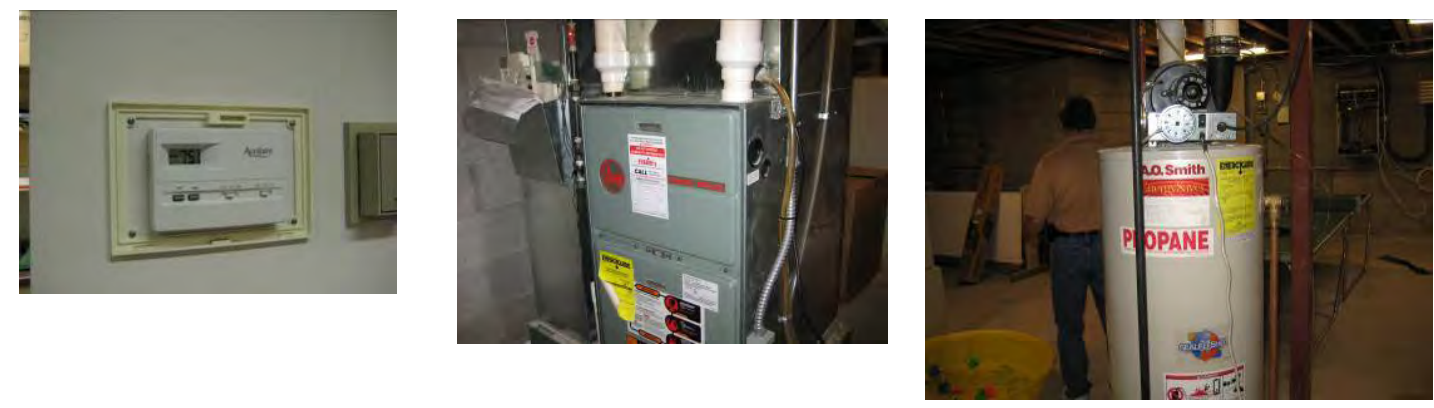

\section{Domestic Hot Water}

The water heater is a new model, induced draft gas unit. Insulate any exposed piping. Turn the unit down to its lowest setting. 


\subsection{Domestic Abuse Shelter}

\section{Lighting}

The most important consideration with lighting is to turn it off when it is not needed. This can easily be accomplished by adding occupancy sensing devices. Storage areas, meeting rooms, restrooms or offices not occupied full time should be equipped with sensors to turn lights off automatically. Focus offers incentives for installing sensors: \$30 per ceiling mount or \$15 per wall mount.

Incandescent light bulbs are fast becoming obsolete. Compact fluorescent bulbs now come in a multitude of shapes and sizes, including reflector flood bulbs. Incandescent technology produces a lot more heat than light, so eliminating them also reduces summer cooling costs. Install compact fluorescent bulbs for lamps and ceiling fixtures throughout the building. Remember the Focus on Energy incentive of \$2 per lamp.

\section{Building shell}

The building is new and appears well-constructed. Remember to take a walk around the outside each year before heating season and inspect caulk around windows, look for worn or damaged door stripping, thresholds or sweeps. Repair or replace. These sources of infiltration can cause occupant discomfort and may lead to heating systems running beyond what is necessary to satisfy a thermostat.

\section{Heating/cooling}

The facility has a set-back thermostat installed. Staff need to understand how to operate it. Turning the heat down at night will result in significant energy savings. The directions are on the back side of the door. You might also look for the manual that came with the unit. This model has an override built in so that if someone comes in during the night and you need the heat turned up, it is easy to accomplish.

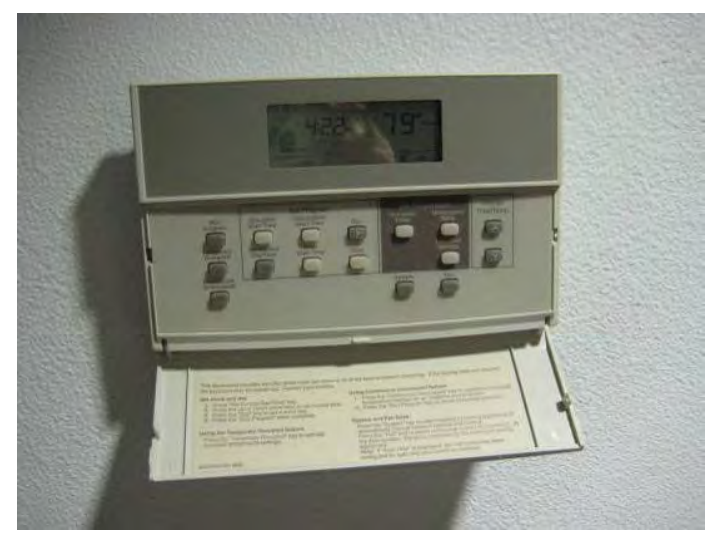

\section{Appliances}

When shopping for replacement appliances, look for the Energy Star logo. The federal government has designed this program to help customers select the most energy-efficient products without having to do a lot of research. 


\section{Domestic Hot Water}

You mentioned a problem with getting hot water to the tap quickly. Because your building is very large, the water has to travel through many feet of pipe. Add insulation to the pipes to help maintain the heat as long as possible. Purchase strips of foam with a slit down the side at any hardware store. It is easy to install. Wrap ALL the hot water pipes and the first couple feet of cold water pipe as it goes into the tank. You may also consider adding a circulation pump (but be sure you insulate first!!) that continuously moves water through the pipes to assure it's there when you need it. This will increase your energy costs because the pump uses electricity and the pipes (even insulated ones) lose a certain amount of the heat as the water flows through. I would try the pipe insulation first and see if it helps. If you do add the circulating pump, have a timer installed on it to turn the circulation off at night and manually turn off when you don't have clients.

Focus on Energy can provide assistance with calculating specific energy-savings measures, review proposals from vendor and offers incentives to help buy-down the costs of some. Incentives change from year to year. You will find the most up-to-date incentive forms at www.focusonenergy.com. 


\subsection{Lac du Flambeau School}

Since this site assessment, the school has completed the gym lighting project and they are currently looking at a proposal to install motion sensors.

There are certainly some opportunities to decrease the school's energy costs.

\section{Lighting}

Reduce the lamp wattage in hallway fluorescent fixtures by replacing the 32 watt lamps with 25 or 28 watt lamps. I took footcandle readings that showed levels of around 30, when the Illumination Engineering Society of North America (IESNA) standard says you only need 15. The new 'low watt' T8 lamps are actually so close in brightness that the human eye usually can't tell the difference. Focus on Energy offers \$.50 per lamp to help with the cost.

In your arched hallways, the metal halide lamps could possibly be replaced with large watt compact fluorescent bulbs by disconnecting ballasts. The large CFLs need some air space, though, to prevent overheating. Check the top of the fixtures for venting. A $65 \mathrm{~W}$ lamp would provide more light than you have now. Focus rebates $\$ 5$ per lamp. The same technology could apply in your lunch room.

Install occupancy sensors in teacher workrooms, restrooms, supply rooms, lunchroom, library, labs, etc. We found many rooms totally unoccupied, yet all the lights were on. The proper application of sensors can reduce energy usage by $40 \%$ or more in some spaces. Focus on Energy can loan you a device to temporarily install in these spaces. It monitors when people are present and when they are not, so we could get very accurate calculations of your savings. But based on what we observed, you would certainly save considerable energy. In a typical 15-fixture classroom, eliminating 200 hours of on-time (about 10\%) will save you \$240 per room, per year! Focus rebates \$15 for wall sensors and \$30 for ceiling mount units.

Your classrooms are lit with 3-lamp, dual switched fixtures that allow teachers a choice of light levels. What I observed was that in almost all cases, the very highest level of light was used. We saw $>70$ footcandles in the room we monitored. The IESNA standard for classrooms is 30-50 f.c. Consider adding an occupancy sensor to the 2 lamp switch so the 50 f.c. level comes on automatically, leaving the $3^{\text {rd }}$ and final level to be switched only when the teacher finds it necessary. Make sure you allow for the lights to be manually switched off for watching movies, etc.

The gym lights are 400W metal halide. This technology was the best choice ten years ago. But recently, the highly reflective fixtures for fluorescent lights, and multi-level switching, have made high-bay fluorescent a better choice. Metal halide lights can't be turned off unless you have 10 minutes or more to wait for them to return to their full light level. Fluorescent lights can be turned off and on as needed with 
immediate results. Metal halide begins to lose its brightness almost immediately. By the time they actually burn out, they may only be giving off about $35-40 \%$ of their original light—but the energy cost is the same! Replacing your MH with high-bay fluorescent would allow you to use occupancy sensors. We found the large gym empty the day I visited. Multi-level switching allows you to use only the number of lights needed for a specific activity. I show savings of over $\$ 1800$ per year for switching to fluorescent and another $\$ 600$ for being able to turn lights off when the gyms are not occupied.

Convert your EXIT lights to LEDs They use less than 3 watts and last for 20 years. www.exitlightco.com/

\begin{tabular}{|l|r|r|}
\hline \multicolumn{1}{|c|}{ Lighting Upgrade Savings* } & \\
\hline \multicolumn{1}{|c|}{ Item } & $\mathbf{k W h} / \mathbf{y r}$ & \multicolumn{1}{c|}{ \$/yr Elect } \\
\hline LED Exits & 735 & $\$ 69$ \\
\hline Compact Fluorescent for 175W MH & 13,200 & $\$ 1,241$ \\
\hline Reduced Lighting Operating Hours & 7,872 & $\$ 740$ \\
\hline Install Occupancy Sensors & 76,950 & $\$ 7,233$ \\
\hline Disconnect Vending Machine Lights & 613 & $\$ 58$ \\
\hline Metal Halide to T8 or T5 Fluorescent (gyms) & 13,284 & $\$ 1,249$ \\
\hline TOTALS & 111,919 & $\$ 10,520$ \\
& & \\
\hline
\end{tabular}

*If you wish, I can show you the individual calculations for each measure. Some fixture counts are estimated.

\section{Heating and Cooling}

Talk with your HVAC technician about how best to reduce the energy used in your heating and cooling system. Discuss the value of adding variable speed drives to your air handlers. Focus offers $\$ 50$ per h.p. for VFDs on HVAC systems. Check the scheduling of outside air dampers. Make sure they are closed during all unoccupied hours. Revisit schedules periodically to assure that they still match the building usage.

Gymnasium air handlers are designed to bring in the recommended fresh air for maximum capacity. You don't need fresh air for 750 people when you only have a gym class of 20 little kids (or no one at all). Adding controls with proper sensors can drastically reduce the cost of air handling in a gym without affecting comfort of the occupants. You are having to heat or cool every cubic foot of air that enters the building. Focus can offer 'custom' grants to help pay for these projects.

Without knowing the specifics of your HVAC system, I can only offer that schools can usually save about $15 \%$ by improving controls and adding VFDs. That could result in $\$ 18,000$ per year in savings based on 
last year's propane usage. Focus can help by paying for $1 / 2$ (up to $\$ 7500$ ) of an engineering study, if that’s what you decide you need.

People do not like change. The best way to gain acceptance if you want to save energy is to get the entire community involved. If teachers, students and parents understand the reasons for and the savings behind energy-saving measures, you will see less resistance and get better results.

Focus on Energy helps sponsor a program offered through UW-Stevens Point called K-12 Energy Education Program (KEEP). Teachers get continuing education credits for day-long training sessions that show them how to incorporate energy awareness into their curriculum. You can learn more about it here: www.uwsp.edu/cnr/wcee/keep/. If there is enough interest in your district, or region, they bring the program to you. Think what a difference we could make if your entire staff would take the course while you worked on making the building more efficient! 
Task Four: Wind and Solar Technologies

Seventh Generation Energy Systems

\section{Task Four: Wind and Solar Technologies}

\section{Table of Contents}

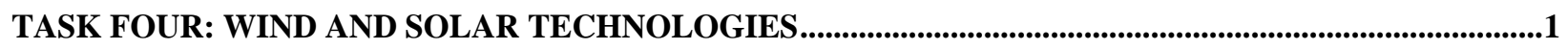

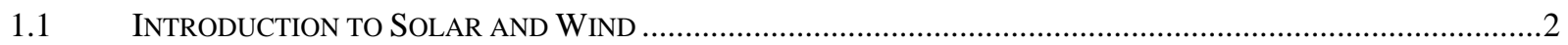

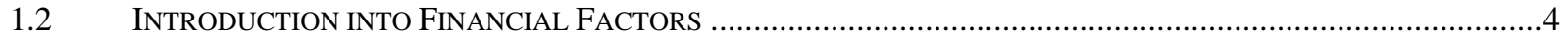

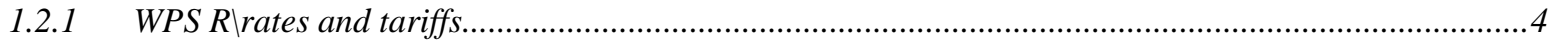

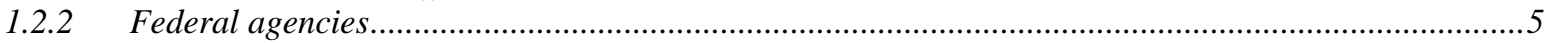

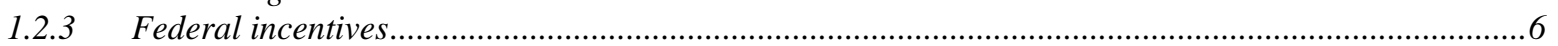

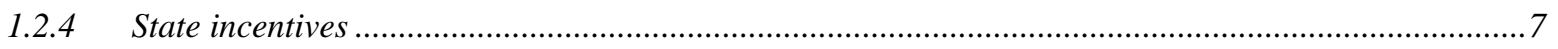

1.2.5 Carbon credits/renewable energy credits .........................................................................................

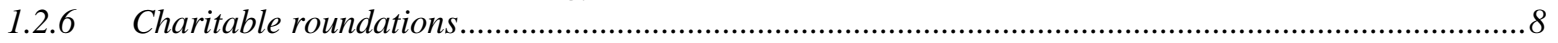

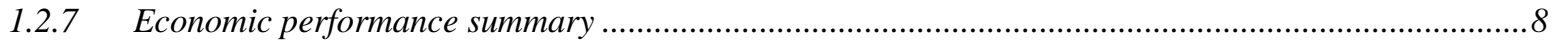

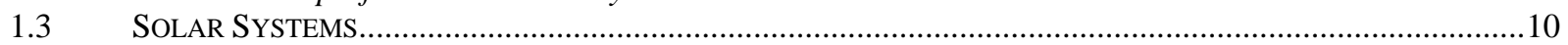

1.3.1 Summary of the Tribe's solar resource ............................................................................................

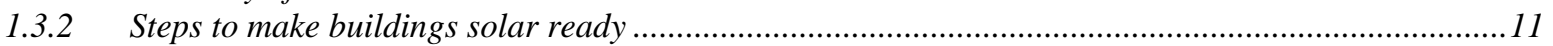

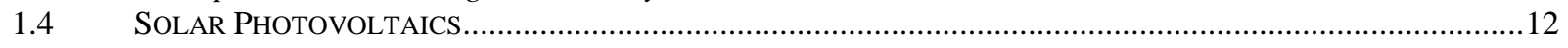

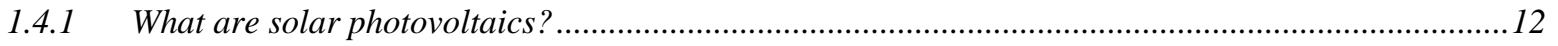

1.4.2 What is the Tribe's solar resource?...............................................................................................12

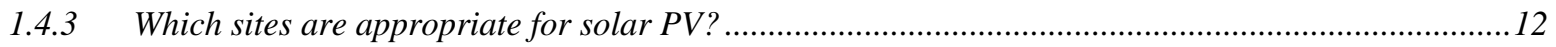

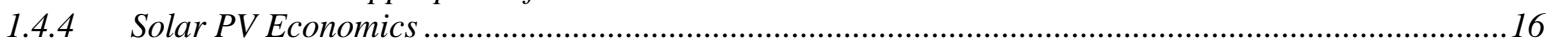

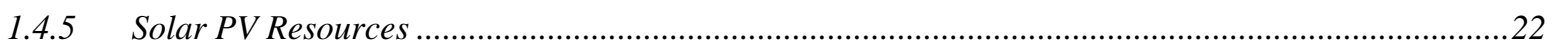

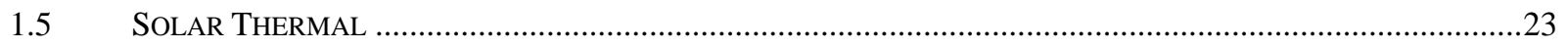

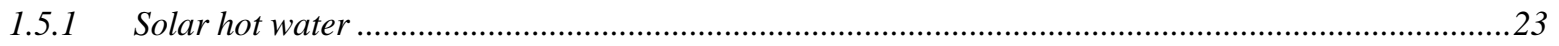

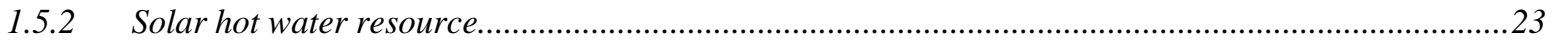

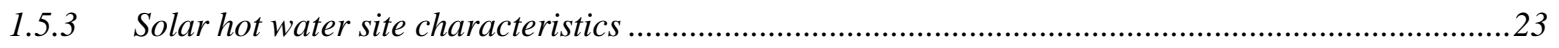

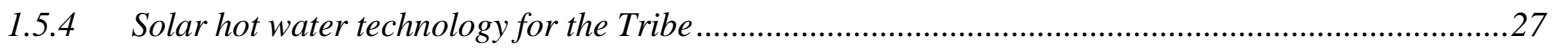

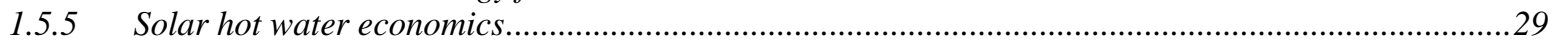

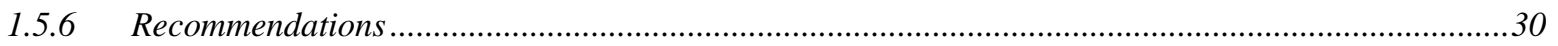

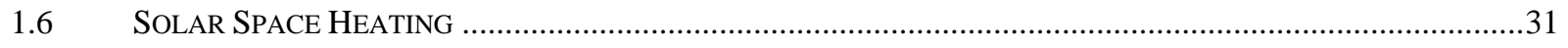

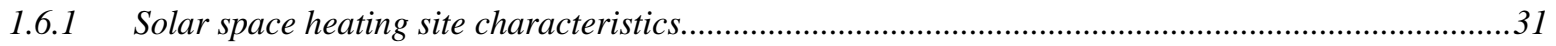

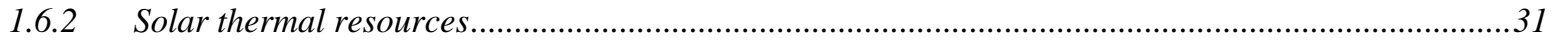

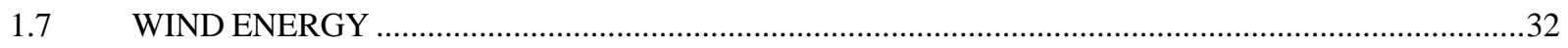

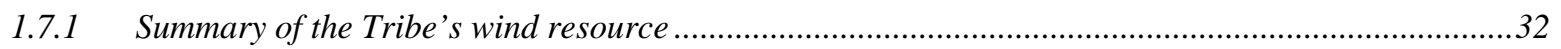

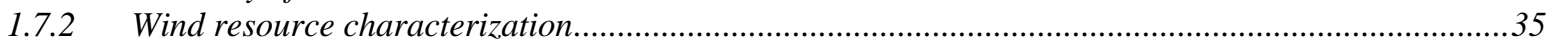

1.7.3 Detailed Lac du Flambeau wind analysis.........................................................................................35

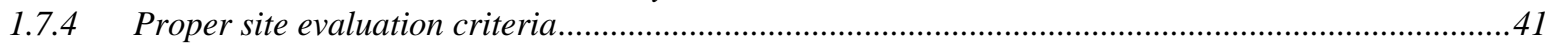

1.7.5 Possible wind turbine locations ..............................................................................................

1.7.6 Estimated turbine energy production and costs.................................................................................4

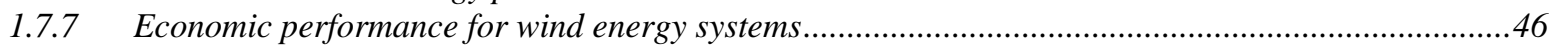

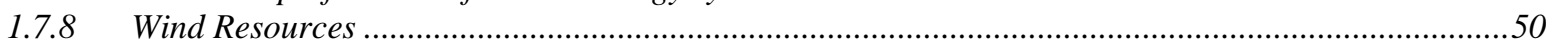

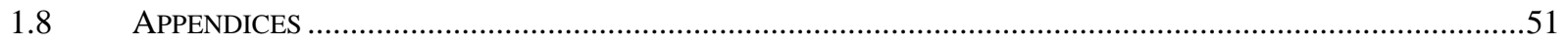

1.8.1 2008 Farm Bill Renewable Energy Provisions............................................................................51

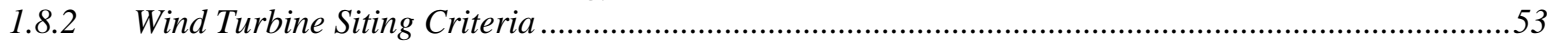

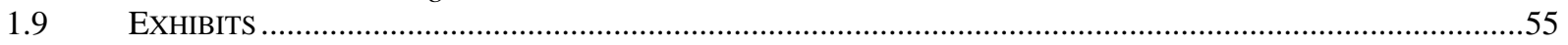

1.9.1 Non-residential Wind Site Assessment for Lac du Flambeau; Seventh Generation..................................55

1.9.2 Non-residential Solar Thermal Report for Lake of the Torches Hotel; Jamie Paterson ......................55

1.9.3 Non-residential Solar Thermal Report for Lac du Flambeau School; Jamie Paterson.........................55 


\subsection{Introduction to Solar and Wind}

The Lac du Flambeau Tribe can become 25\% renewable by 2025 by aggressively incorporating solar electric, solar thermal and wind energy into their current facilities and planned construction, in conjunction with greater energy efficiency and the utilization of geothermal and biomass energy systems.

To help meet their electricity needs, the Tribe can install large solar electric systems on 15 buildings throughout the reservation. There are an additional 12 sites for small pole-mounted systems that would serve to educate the community, advocate for renewable energy, and off-set very small loads (such as road signs). A total potential PV capacity is $997 \mathrm{~kW}$.

The Tribe also can also offset a portion its hot water and space heating needs by installing solar thermal systems. A total of 13 possible locations for solar hot water applications have been identified on the reservation, with a total potential capacity of 4,896 square feet of panels.

The Tribe has access to a slower wind resource, therefore commercial wind projects are not viable, but small scale wind projects could be employed to directly off-set electricity usage for facilities located near the north and northeastern shores of the larger lakes. We have indentified 8 possible locations for wind systems with a total potential capacity of $310 \mathrm{~kW}$.

A matrix is presented below of the Tribe facilities with opportunities for wind and solar. Together these systems could produce approximately $20 \%$ of the Tribe energy needs. 
Task Four: Wind and Solar Technologies Seventh Generation Energy Systems

Table 1. Tribe Facilities Suitable for Wind (W), Solar Electric (PV), Solar Hot Water (SHW)

\begin{tabular}{|c|c|c|c|}
\hline Facility & $\mathrm{PV}(\mathrm{kW})$ & SHW (sq feet) & Wind $(\mathrm{kW})$ \\
\hline Bingo Hall & 90 & 160 & \\
\hline Casino & $35-300$ & 448 & $35-50$ \\
\hline Casino Billboard (Highway 47) & 2 & & \\
\hline Casino Billboard (Highway 47/H) & 2 & & \\
\hline Casino Engineering Building & 2 & & \\
\hline Casino Hotel & & 1216 & 35 \\
\hline Casino HR / Education Building (LOTC) & 2 & 192 & \\
\hline Community Center/Clinic & 175 & 224 & \\
\hline Elks Point Elder Housing & 32 & 352 & 35 \\
\hline Family Resource Center & 2 & & \\
\hline Food Distribution Building & 2 & & \\
\hline Gas Station & 10 & & \\
\hline Indian Bowl & 2 & & \\
\hline Judicial building & 29 & & \\
\hline Lac du Flambeau School & 200 & 896 & \\
\hline Museum & 4 & 32 & \\
\hline Natural Resources (PLANNED) & 20 & & 15 \\
\hline Planning / Bank Building & 2 & & \\
\hline Post Office & 2 & & \\
\hline Roads Garage (Tribe garage) & 2 & 64 & \\
\hline Simpson's Main Plant & 61 & 64 & \\
\hline Simpson's Plastics Plant & 10 & 224 & \\
\hline Smoke Shop & 2 & & \\
\hline Store (Ojibwe mall) & 2 & 416 & \\
\hline Water Resource office & 12 & & \\
\hline Wellness Center & 2 & & \\
\hline Youth Center (Abinoojiiyag Center) & 14 & 192 & \\
\hline Great Lakes Inter-Tribe Council Building & & & $10-20$ \\
\hline Tribe Housing, Cloud Street & 10 & 32 & $1-10$ \\
\hline Tribe Housing, Wayman Lane & 2 & 32 & $1-10$ \\
\hline $\begin{array}{l}\text { Tribe Housing; Apartments, Bearskin } \\
\text { Circle }\end{array}$ & 2 & 352 & 35 \\
\hline Highway 47 and Cemetery Road & & & $1-100$ \\
\hline Total potential capacity & 997 & 4,896 & 310 \\
\hline
\end{tabular}

A more detailed analysis of the appropriate system size and cost for these facilities is presented below and in the Building Summaries at the end of this report. In the section we:

- $\quad$ outline the Tribe access to the wind and solar resource,

- describe how to evaluate the wind and solar systems for current and future Tribe buildings,

- $\quad$ summarize the technological performance of each technology; and,

- explain the economic performance of each technology with a Life Cycle Analysis. 


\subsection{Introduction into Financial Factors}

Tribal governments and municipalities want to understand the economic performance of renewable energy systems, before they invest. Typically, externalities of energy consumption are not included in the economic analysis, such as air, water, environmental and health degradation. These externalities are very real and should also be weighed and considered alongside any economic analysis. Investing in Tribely-owned energy improves environmental and community health. Renewable energy also increases Tribe self-determination, provides protection against utility rate increases and creates jobs for Tribe members. The value of renewable energy systems is much bigger than the economic analyses show and these unaccounted for externalities should be communicated during discussions on the price of renewable energy.

The economic performance of renewable energy systems is based on the quality and quantity of the renewable resource. The economic performance is also based on the cost of the system, required maintenance, and current market prices of basic materials. The costs of wind and solar systems have been rising due to increased demand and cost of commodities, but it is difficult to predict what cost trends will result from the current market recession.

Another variable in the economic analysis is the price of fossil fuels and the efficiency of the system that is being replaced by renewable energy. While the cost of fossil fuels has fluctuated in the past 6 months, we can expect the cost of energy to rise, as summarized in Task 1.

In the section below we outline the utility rate structures (tariffs) relating to renewable energy and incentives that affect the financing of renewable energy systems, including:

- Net-metering

- Advanced Renewables Tariff

- Federal incentives

- State incentives

- Renewable energy credits

Within the Wind and Solar sections, we will then briefly summarize the appropriate economic factors for each technology.

\subsubsection{WPS rates and tariffs}

Understanding the economic performance of a renewable energy system is closely linked to understanding the rates and tariffs of WPS and the propane providers. Each facility is charged certain electrical rates based on the amount of energy the building requires. Renewable energy systems that can offset the most expensive utility costs will have a quicker return on investment (for further discussion on specific rates, see Task 2). 


\subsubsection{Net-metering}

"Net-metering" is an important economic consideration for renewable energy systems. Netmetering refers to how WPS will value any 'excess' electricity that the Tribe produces with wind and solar technologies, or any electricity that is not consumed on site and it put back on to the utility grid. If the aggregate renewable energy system installed on one meter is $20 \mathrm{~kW}$ or less, the customer will receive retail credit for excess energy generation. For customers with an aggregate rating over $20 \mathrm{~kW}$, the customer will receive between essentially 'whole-sale' rates for excess generation, currently 9 cents for on-peak generation and 3 cents for off-peak generation, under a parallel generation tariff.1

For example, a $20 \mathrm{~kW}$ wind turbine connected to a Tribe facility that generates more electricity than is needed at the site, the excess is fed back onto the utility grid, and WPS will pay the Tribe retail credit for each $\mathrm{kWh}$. When the turbine is not producing excess power, it simply runs the electrical meter backwards. In effect, as utility prices increase, the simple payback of the renewable energy decreases.

\subsubsection{Advanced renewables tariff}

Several utilities in Wisconsin are offering advanced renewable tariffs, or solar buy-back rates, which means that all of the electricity generated by the solar system is sold directly back to the utility and is not used to offset the facility's energy consumption. WPS will begin offering this type of rate in January of 2009, as part of their 'Advanced Renewables Tariff.' Details for the WPS Advanced Renewables Tariff have not been finalized, but typically solar buy-back contracts last for 10 years, after which point the solar electricity will be used to offset the facility's energy needs. The solar buy-back rate is an attractive option because the utility will typically pay about 25 cents per kWh for systems $20 \mathrm{~kW}$ or smaller. The Tribe should consult with WPS about this tariff before installing any PV systems to ensure the system's eligibility.

\subsubsection{Federal agencies}

Funding opportunities for renewable energy arise in various federal agencies, and we recommend signing on to their "Notice of Funding Available" list serves. These federal agencies include:

- Department of Energy:

- Bureau of Indian Affairs:

- Administration for Native Americans

- National Science Foundation, Energy for Sustainability

- National Center for Appropriate Technologies (Smart Communities)

- US Department of Labor (WIRED grants)

The Lac du Flambeau Tribe was already successful in receiving a grant through the Tribe Energy Program for the evaluation of renewable energy sources and the DOE funds could be utilized again to help with the implementation stage.

\footnotetext{
${ }^{1}$ For more information about WPS and net-metering, see the Rate Schedules for Net Energy Billing and Parallel Generation Rules: http://www.wisconsinpublicservice.com/news/wirates.aspx
} 


\subsubsection{USDA Farm Bill renewable energy provisions}

The 2008 Farm Bill funds 12 programs for renewable energy grants and loans, from biomass to wind to comprehensive rural community self-sufficiency. Five sections in particular are of relevance to the Lac du Flambeau Tribe:

- Section 9006: Biodiesel Fuel Education Program

- Section 9007: Rural Energy for America Program

- Section 9009: Rural Energy Self-Sufficiency Program

- Section 9012: Forest Biomass for Energy

- Section 9013: Community Wood Energy Program

Section 9007 is explained in more detail below and a description of all of the opportunities is in the appendices. $\mathrm{S}$

\section{Section 9007: Rural Energy for America Program (REAP)}

REAP provides grants and loan guarantees for energy efficiency improvements and renewable energy systems. These incentives are available to agricultural producers and rural small businesses to purchase renewable energy systems, to make energy efficiency improvements, and to conduct relevant feasibility studies. The Tribe businesses may qualify for a USDA REAP grant which could provide $25 \%$ of the installed cost (up to $\$ 500,000$ ). The USDA will also guarantee fixed rate loans of up to $\$ 10$ million; loan amounts cannot exceed $75 \%$ of the eligible project cost 2 .

Even more appropriate for the Tribe may be the REAP grants to provide assistance to agricultural producers and rural small businesses "to become more energy efficient" and "to use renewable energy technologies and resources." These grants are available to Tribe governments and may be used for conducting and promoting energy audits; and for providing recommendations and information related to energy efficiency and renewable energy.

\subsubsection{Federal incentives}

There are several federal tax incentives which may be available to Tribe Enterprises, the tax paying entity. The Tribe could also investigate partnering with other tax paying entities in order to take advantage of these incentives, but we believe a partnership of this type is yet to be demonstrated in Wisconsin.

The federal tax incentives include:

- $\quad 30 \%$ Federal Investment Tax Credit

- Equipment depreciation (Modified Accelerated Cost Recovery System)

- Commercial production tax credits

- Renewable Energy Production Incentive

\footnotetext{
${ }^{2}$ Complete details of the USDA bill: http://agriculture.house.gov/inside/2007FarmBill.html
} 
- $\quad$ Clean Renewable Energy Bonds (CREBs)

- Qualified Energy Conservation Bonds (QECBs)

There are several models that the Tribe could explore if their goal is to install larger renewable energy systems and take advantage of all of the federal tax credits. Examples could include:

Forming a Tribe Utility. The Tribe could form a Tribe Utility that would 'own' the renewable energy systems across the Reservation and sell the power to the Tribe. More research would be required to understand the intricate legalities of this situation.

Joint Limited Liability Company (LLC) “Flip” Structures. The Tribe would unite with a corporate partner who has a large enough tax appetite to take advantage of the tax credits. The Tribe could contribute anywhere from $1-25 \%$ of the investment into the project via equity or financing, while the corporate partner contributes the remaining portion. After the expiration of the tax credits, the ownership of the entire renewable energy system would 'flip' completely to the Tribe.

Another option is to partner with investing companies. Several companies have dedicated their investments solely to renewable energy projects, including Investors Circle and Momentum Advantage Partners3. Mentioning these companies is not an endorsement, but rather examples for further research.

Tribe governments can also purchase Clean Renewable Energy Bonds to finance energy producing facilities and Qualified Energy Conservation Bonds to finance local government conservation and greenhouse gas reduction programs.4

State incentives

Wisconsin's Focus on Energy program offers incentives for a variety of energy efficiency technologies and renewable energy systems, including wind, solar electric, solar hot water, biomass, and biogas digestion, if the systems off-set electricity or natural gas. Propane systems are not eligible for Focus on Energy funding.

Typically the grants for each technology are available in three levels:

- Cash Back Rewards for small systems: up to 25-35\% or $\$ 35,000$

- Implementation Grants for large systems: up to $35 \%$ or $\$ 50,000$

- Opportunity Grants for new technology or education: up to 35\% or $\$ 100,000$

The State’s Office of Energy Independence has grants currently available for community energy base-lining and assessment, and the OEI plans to offer 'capital costs' grants in the future5.

The Wisconsin Housing and Economic Development Authority may also be an option for the Tribe to secure financing if necessary.

\footnotetext{
${ }^{3}$ Investor's Circle: www.investorscircle.net; Momentum Advantage Partners: www.momentum-advantage.com

${ }^{4}$ Environmental Law and Policy Center: elpc.org/category/clean-energy/clean-renewable-energy-bonds

${ }^{5}$ Wisconsin Office of Energy Independence: power.wisconsin.gov/section.asp?linkid=1238\&locid=131
} 


\subsubsection{Carbon credits/renewable energy credits}

Green tags, also known as renewable energy credits (RECs) or tradable renewable energy certificates (TRCs) are the traded stock of a market set-up to capitalize on the "green-ness" of renewable energy projects. One green tag is assigned to each renewably-driven megawatt-hour (or every $1000 \mathrm{kWh}$ ) a system puts into the grid. The green tags from most renewable energy systems can be bought by a utility as part of a power purchase agreement. The Tribe could sell the green tags to companies that have required RECs goals through state mandates, such as utilities. The Tribe could also sell the green tags to an open market or a private company that sells RECs as part of the voluntary carbon market, such as Native Energy, although price volatility in the green tag market makes predicting the value difficult (with a current range of \$5 to $\$ 90$ per $\mathrm{MWh})$.

Typically, companies such as Native Energy, enter into a 5, 10 or 20 year contract with the client. Native Energy will estimate, based on the project characteristics, how many RECs they expect the system to produce during the contract duration, and will provide an upfront payment for all of the RECs. The benefits to this partnership include capital funds for the project. However, Native Energy may increase the retail value of the RECs quite substantially after they purchase them from the Tribe. Also, if the value of RECs increase during the length of the contract, the Tribe will not be able obtain that higher value, until the contract expires. As well, private company may not pay as much money as those entities that are required to meet certain renewable energy standards.

Renewable energy can also be quantified in terms of carbon emissions that have been offset, i.e. fossil fuels have not been burned because the energy has been supplied by the wind. These carbon offsets can be sold on the carbon market; however environmental attributes, such as renewable energy credits (RECs) must be surrendered to and retired in order to prevent double counting. This market is also quite volatile. For example, the value was of a metric ton of carbon was valued at \$7.00 May 2008 in on the Chicago Climate Exchange, and has since dropped to $\$ 1.50$ in October 2008.

\subsubsection{Charitable roundations}

As the world becomes increasingly focused on energy, foundations have also re-adjusted their focus. There are several foundations in Wisconsin and the United States that could be courted for large scale, community wide sustainability initiatives.

\subsubsection{Economic performance summary}

When looking at all of these economic factors, it is challenging to accurately estimate the economic performance of these systems, even though we can remain confident in their positive impact on the environment, energy and budget security, and development of jobs. However, to provide a more comprehensive economic picture, we will provide two financial scenarios for each technology: a Baseline Scenario and an Optimistic Scenario. The scenarios include factors that affect the cost of the renewable energy system and the cost of energy from the utility.

Within the Baseline Scenario we will assume the following economic factors: 
Factors that affect the cost of the renewable energy system:

- Focus on Energy Funding (25 - 35\% of installed cost)

- Lower value of Renewable Energy Credits

- Loan interest rate of $3 \%$ for 15 years

Factors that affect the cost of energy:

- Energy cost increase at $3.7 \%$ annually

The Optimistic Scenario will show a more positive economic performance by assuming:

Factors that affect the cost of the renewable energy system:

- Focus on Energy Funding (25 - 35\% of installed cost)

- Higher value of Renewable Energy Credits

- Loan interest rate of $1.5 \%$ for 15 years

- Access to Federal Tax Incentives

Factors that affect the cost of energy:

- Energy cost increase at 7\% annually

We present the outcomes of these scenarios in terms of Life Cycle Analysis to demonstrate how much the renewable energy system will cost the Tribe over the system life (30 years) verses how much it will cost the Tribe to pay utility rates for 30 years. Typically, life cycle analysis can be broken down into three components: the pertinent costs of ownership, the period of time over which these costs are incurred, and the discount rate that is applied to future costs to equate them with present day costs.

The first component in a life cycle cost equation is cost, including both initial expenses (equipment) and future expenses (maintenance). The second component is the time period for these systems, which was assumed to be 30 years, although solar electric and solar thermal may last 40 years, and wind systems may only last 25 years. The life cycle costing in this financial analysis has not been discounted, similar to the utility costs in Task One, because the nondiscounted financial numbers may be easier for lay readers to understand. It was also uncertain which discount rate is typically used for Tribe budgeting.

Again, this financial analysis does not capture the importance of externalities such as improved ecosystem services, improved health of the community, and energy budgeting security.

If the Tribe wants to proceed with the projects listed below, we recommend refining the factors to the specifics of the Tribe (i.e. available funding, loan interest rate). Also, we have not included a discount rate in our analysis, therefore, we also encourage the Tribe to explore other methods of economic analysis. 


\subsection{Solar Systems}

Wisconsin has an extremely viable solar resource for solar energy systems. Thousands of solar energy systems have been installed in Wisconsin over the last 30 years and escalating energy prices and federal tax policies makes them more affordable than ever.

There are two kinds of solar panels. Solar electric panels (also known as photovoltaic or PV panels) generate electricity, and solar thermal panels produce hot water, which can be used to heat water or space. Options for the Tribe to incorporate these technologies are summarized below.

Solar energy is well-suited for urban and suburban settings, like Lac du Flambeau. Many Tribe buildings have the need and characteristics necessary for solar systems. After a number of years, the energy savings provided by the solar system investment will completely pay for the system and after that all the energy produced is free. Solar systems typically have a 25 year warranty, and systems tend to last $30-40$ years.

\subsubsection{Summary of the Tribe's solar resource}

Access to the solar resource is measured as solar radiation in $\mathrm{kWh}$ per square meter per day, which can then be converted into expected electricity or thermal energy produced per solar panel. According to the National Renewable Energy Laboratory, the solar radiation at Lac du Flambeau is $4.44 \mathrm{kWh} / \mathrm{m}^{2}$ per day with an expected 3.5 to 4 peak sun hours per day.

Solar radiation of $4.44 \mathrm{kWh} / \mathrm{m}^{2} /$ day equates to an estimated energy production of $100 \mathrm{kWh}$ per month for every $1 \mathrm{~kW}$ of installed capacity assuming no shading.

Access to the solar resource for solar thermal systems can be further quantified as storage capacity, or heating capacity per square foot of solar collector. Solar radiation of 4.44 $\mathrm{kWh} / \mathrm{m}^{2} /$ day is equivalent to $1,407.9 \mathrm{BTU} / \mathrm{ft}^{2} /$ day, enough to heat 25 gallons of water by 60 degrees per day. ${ }^{6}$

Taking into account the available roof space on and ground space near Tribe buildings, an estimated $15 \%$ of the Tribe energy use could be offset by solar electric. An estimated $2 \%$ of the Tribe's hot water and space heating requirements could be offset by solar thermal systems.

Typically, before solar systems are installed, on the roofs of buildings, a roof inspection should take place before committing to installation. The inspection will verify that the age and construction of the roof is adequate to support the renewable energy equipment.

\footnotetext{
${ }^{6}$ BTU=British Thermal Unit and is the amount of energy required to heat 1 gram of water 1 degree centigrade. Each kilowatt hour of electricity is equal to 3413 BTU's of energy.
} 


\subsubsection{Steps to make buildings solar ready}

Small building design changes that are easily and inexpensively implemented during construction can reduce the cost to install solar electric and solar thermal systems at a later date. These include:

- Southern building orientation.

- No shading or minimal shading on roof. Group mechanical penthouses, vents and other equipment as far to the north side of the building as possible to avoid shading from these sources

- Install an appropriate number of electrical and plumbing chase-ways runs from the roof to the utility room. Label clearly and permanently.

- Provide space in the utility room for inverters and the solar balance of system.

- Ensure easy roof access to an electrical grounding electrode.

The Tribe should consult with engineers before installing any solar system on any roof space, to ensure the roof is designed to handle the snow and wind loading due to a solar system. 


\subsection{Solar Photovoltaics}

\subsubsection{What are solar photovoltaics?}

Solar photovoltaic (PV) systems convert energy from the sun directly into electricity. PV panels are composed of photovoltaic cells, usually thin wafers or strips of semiconductor material that generate a small current when sunlight strikes them. Small photovoltaic cells are found in calculators; the largest arrays have capacities in excess of $5 \mathrm{MW}$ and take up an area the size of a football field.

A complete solar PV system consists of the following components:

- Solar modules grouped into an array

- Inverters to convert the direct current electricity produced by the array into high quality alternating current

- Switches, fuses and circuit breakers to control the system and provide for worker and electrical safety

- Grounding and lighting protection

- Performance monitoring meters and/or data loggers

\subsubsection{What is the Tribe's solar resource?}

The most helpful method of quantifying the solar resource is to determine the solar radiation of the geographic area, or the kWh per square meter per day.

PVWatts is a solar resource estimation tool, developed by the National Renewable Energy Laboratory (NREL) to estimate the energy output of solar systems taking into account such factors as: the daily solar radiation, mounting type, direction of the solar system towards south, and shading ${ }^{7}$. PVWatts estimates a solar radiation of $4.4 \mathrm{kWh} / \mathrm{m}^{2} /$ day.

\subsubsection{Which sites are appropriate for solar PV?}

The Tribe receives sufficient solar radiation to incorporate solar PV technology. The question then becomes: what are the other required site characteristics for solar PV?

Other site characteristics include:

- South-facing or flat roof space, or open ground space with minimal shading.

- Significant amount of space (each one kW requires 100 square feet of space)

- Access to the sun all year round during peak solar times of 9AM to 3PM.

- No future shading issues caused by future roof penetrations, tree growth, etc.

- A roof that can be repaired in conjunction with the solar installation

- The return on investment is improved if:

\footnotetext{
${ }^{7}$ http://rredc.nrel.gov/solar/codes_algs/PVWATTS/
} 
o the solar system off-sets high energy and demand charges

o the utility offers a solar buy back rate

As discussed above, WPS offers net-metering up to $20 \mathrm{~kW}$, however if a system larger than 20 $\mathrm{kW}$ is installed the system should be sized so that it will not produce more than the facility needs. Ideally the solar systems would be installed on buildings in which the solar panel will have the greatest reduction on the energy charge.

The table below summarizes the Tribe buildings with good solar PV opportunities ranked generally by the quickest return on investment.

The buildings in Group 1 can hold medium sized systems (10-35 kW) and are on the Cg1 tariff, which means that these systems will displace the most expensive electricity.

Group 2 represents locations for small systems (2-4 kW) which are more expensive to install per $\mathrm{kW}$, or systems that are installed on buildings with the Cg5 tariff.

Group 3 represents demand-metering buildings that have substantial roof space to accommodate large systems $(>100 \mathrm{~kW})$. The utility costs at these buildings are greatly impacted by the demand charges. Solar PV systems will reduce energy charges and will most certainly reduce demand, but we have not seen any quantitative studies in Wisconsin where a solar system has consistently and reliably reduced demand charges. Therefore, the amount of money invested in these systems verses the amount of money saved (investment intensity) is not as great as Group 1 and Group 2. ${ }^{8}$

The indicative system sizes below are based on the available roof space, assuming $1 \mathrm{~kW}$ requires 100 square feet.

\footnotetext{
${ }^{8}$ We have yet to see any studies in Wisconsin in regards to solar PV systems reliably reducing the demand charge. If the Tribe installs a PV system on a Cg 1 building, with peaking demand between 9am-3pm, we would suggest monitoring the impact of the system on demand and reporting the findings to Focus on Energy.
} 
Table 2. Tribe buildings with the opportunity to retro-fit with roof-mounted solar PV

\begin{tabular}{|c|c|c|c|c|c|}
\hline \multirow{2}{*}{ Group } & \multirow{2}{*}{ Building } & \multirow{2}{*}{$\begin{array}{l}\text { Available } \\
\text { roof area } \\
\left(\text { total } \mathrm{ft}^{2}\right)\end{array}$} & \multirow{2}{*}{$\begin{array}{l}\text { Indicative } \\
\text { system } \\
\text { size }(\mathrm{kW})\end{array}$} & \multicolumn{2}{|c|}{$\begin{array}{c}\text { Current electrical } \\
\text { rate } \\
\end{array}$} \\
\hline & & & & \$/kWh & $\$ / \mathrm{kW}$ \\
\hline 1 & Youth Center & 1,406 & 14 & $\$ 0.109$ & - \\
\hline 1 & Judicial building & 2,880 & 29 & $\$ 0.109$ & - \\
\hline 1 & $\begin{array}{l}\text { Planned Natural } \\
\text { Resources* }\end{array}$ & 1,200 & 12 & $\$ 0.109$ & - \\
\hline 1 & Casino & 37,950 & 35 & $\$ 0.109$ & - \\
\hline 1 & Elks Point Elder Housing & 3,200 & 32 & $\$ 0.109$ & - \\
\hline 1 & Gas Station & 1,008 & 10 & $\$ 0.109$ & - \\
\hline \multirow{2}{*}{1} & \multirow{2}{*}{ Simpsons Plastics Plant } & \multirow{2}{*}{1,000} & 10 & $\$ 0.109$ & - \\
\hline & & & - & $\$ 0.064$ & $\$ 10.67$ \\
\hline 1 & Water Resource office & 1,200 & 12 & $\$ 0.109$ & - \\
\hline 2 & Museum & 390 & 4 & $\$ 0.109$ & - \\
\hline \multirow{2}{*}{2} & \multirow{2}{*}{ Smoke Shop } & \multirow{2}{*}{200} & 2 & $\$ 0.109$ & - \\
\hline & & & - & $\$ 0.095$ & - \\
\hline 2 & Simpson's Main Plant & 6,075 & 61 & $\$ 0.095$ & - \\
\hline 2 & Bingo Hall & 9,028 & 90 & $\$ 0.095$ & - \\
\hline 3 & Casino & 37,950 & 300 & $\$ 0.064$ & $\$ 10.67$ \\
\hline 3 & Community Center / Clinic & 22,000 & 220 & $\$ 0.064$ & $\$ 10.67$ \\
\hline 3 & Lac du Flambeau School* & 29,660 & 297 & $\$ 0.064$ & $\$ 10.67$ \\
\hline
\end{tabular}

* Pole-mounted systems at these locations would make offer educational and advocacy opportunities.

The appropriate size of a PV system is limited not only by the roof size as shown above, but also by the energy needs of the building and/or the available budget. All of the PV systems listed above would produce less than the associated facility consumes. The economic performance of these systems is discussed below. Also, PV systems can be installed incrementally therefore the answer of appropriate PV size is flexible. However it is cheaper to install the entire PV system in a single installation.

The Tribe also has the opportunity to install PV systems on the ground, a pole or an arbor if the facility's roof is not amenable to solar and there is ground space available, or if the Tribe believes the site would make an appropriate spot to demonstrate their commitment to clean energy. The ground, pole and arbor PV opportunities are summarized below.

Group 1 would have the quickest return on investment, because the billboard accounts pay the highest cost per kWh. Group 2 represents buildings on the Cg 1 tariff, and Group 3 represents buildings on the Cg 5 tariff. 
Table 3. Tribe buildings with the opportunity to retro-fit with ground or pole-mounted solar PV

\begin{tabular}{|c|c|c|c|c|c|}
\hline \multirow[t]{2}{*}{ Group } & \multirow{2}{*}{ Building } & \multirow{2}{*}{$\begin{array}{l}\text { Ground } \\
\left(\text { total } \mathrm{ft}^{2}\right)\end{array}$} & \multirow{2}{*}{$\begin{array}{c}\text { Pole/Arbor } \\
\left(\text { total } \mathrm{ft}^{2}\right)\end{array}$} & \multirow{2}{*}{$\begin{array}{c}\text { Possible } \\
\text { system size } \\
(\mathrm{kW})\end{array}$} & $\begin{array}{c}\text { Electrical } \\
\text { rate }\end{array}$ \\
\hline & & & & & $\$ / \mathrm{kWh}$ \\
\hline 1 & Casino Billboard & - & 200 & 2 & $\$ 0.15$ \\
\hline 1 & Casino Billboard & - & 150 & 1.5 & $\$ 0.15$ \\
\hline 2 & Roads Garage (Tribe garage) & 3250 & - & 32.5 & $\$ 0.109$ \\
\hline 2 & Planning / Bank Building & - & 400 & 4 & $\$ 0.109$ \\
\hline 2 & Family Resource Center & - & 200 & 2 & $\$ 0.109$ \\
\hline 2 & Casino Engineering Building & - & 200 & 2 & $\$ 0.109$ \\
\hline 2 & Indian Bowl & - & 200 & 2 & $\$ 0.109$ \\
\hline 2 & Food Distribution Building & - & 200 & 2 & $\$ 0.109$ \\
\hline 2 & $\begin{array}{l}\text { Post Office (Tribe Office, } \\
\text { Library) }\end{array}$ & - & 1000 & 10 & $\$ 0.109$ \\
\hline 2 & Planned Natural Resources & - & 200 & 2 & $\$ 0.109$ \\
\hline 3 & Store (Ojibwe mall) & - & 200 & 2 & $\$ 0.095$ \\
\hline 3 & Wellness Center & - & 200 & 2 & $\$ 0.095$ \\
\hline 3 & $\begin{array}{l}\text { Casino HR / Education } \\
\text { Building }\end{array}$ & - & 200 & 2 & $\$ 0.095$ \\
\hline 4 & LdF School & - & 200 & 2 & $\$ 0.064$ \\
\hline
\end{tabular}

Pole-mounted systems are $\$ 2,000$ - $\$ 4,000$ more expensive to install per $\mathrm{kW}$ than roof-mounted systems, but pole-mounted systems are an extremely visual opportunity for the Tribe to demonstrate their commitment to clean, renewable energy.

Installing a pole-mounted system at the LdF School offers a great opportunity to educate the public about solar, however, the rate schedule is a Cg 20 - the cheapest rate the Tribe pays. This results in a long payback period for the PV system. However, a PV system at the school may also be eligible for the most grant funding because of the high value ascribed to educating youth and the prominence of the school in the community.

The table below demonstrates how to size PV systems for the Tribe buildings with a large electrical consumption, based on their demand and available roof space.

Table 4. PV system sizing for Tribe facilities

\begin{tabular}{|l|l|l|l|l|l|r|}
\hline \multicolumn{1}{|c|}{ Facility } & $\begin{array}{c}\text { Average } \\
\text { Demand }\end{array}$ & $\begin{array}{c}\text { Peak Period } \\
\text { (Season/month) }\end{array}$ & $\begin{array}{c}\text { Max PV Size } \\
\text { based on roof }\end{array}$ & $\begin{array}{c}\text { \% Average } \\
\text { Demand }\end{array}$ & $\begin{array}{c}\text { PV } \\
\text { AEO } \\
\text { (MWh) }\end{array}$ & $\begin{array}{c}\text { \% Facility } \\
\text { Energy }\end{array}$ \\
\hline Casino & $691 \mathrm{~kW}$ & S/Aug & $350 \mathrm{~kW}$ & $55 \%$ & 456 & $9 \%$ \\
\hline School & $307 \mathrm{~kW}$ & S/ July \& Oct & $297 \mathrm{~kW}$ & $96 \%$ & 356 & $29 \%$ \\
\hline $\begin{array}{l}\text { Community } \\
\text { Center/Clinic }\end{array}$ & $100 \mathrm{~kW}$ & S/ Jul-Sep & $200 \mathrm{~kW}$ & $>100 \%$ & 264 & $56 \%$ \\
\hline
\end{tabular}

Based on the information above, the School and the Community Center would be a good fit for solar electric, if the Tribe wanted to install a large system, because the roof size is able to accommodate a system large enough to meet on average $100 \%$ of the building's demand. 
Several Focus on Energy experts believe that a solar system will reduce a building's demand by the equivalent of $30 \%$ of the system size. For example, a $297 \mathrm{~kW}$ system would reduce the school's demand by an estimated $90 \mathrm{~kW}$, which represents up to $\$ 900$ every month. We have yet to see conclusive evidence of this therefore we do not include demand reduction in our economic analysis.

\subsubsection{Solar PV Economics}

As mentioned above, the economics of a solar system depend on the utility electric rate and available financial incentives, including:

- Focus on Energy

- Renewable Energy Credits

- Federal tax credits and depreciation rates

- Low interest loans

- USDA grants (See Appendix on 2008 Farm Bill Renewable Energy Provisions)

- Other grants

The economics are also dependent upon the type of system installed. Solar PV systems can be installed as fixed angle, single axis tracking or dual axis tracking systems.

Fixed angle systems hold the solar panels at a set tilt angle and azimuth ${ }^{9}$, have no moving parts and therefore require very little maintenance. The solar collector tilt angle for optimum annual performance is approximately equal to the global latitude of the collector location or about 46 degrees for Lac du Flambeau. However, this angle can be changed by $+/-15 \%$ to account for snow loads, wind loads, or aesthetics without significant impact on total annual energy production. Fixed axis systems are typically $\$ 8000$ per installed kW.

More complicated and slightly more expensive roof mounting racks systems allow the tilt angle to be adjusted to better match the sun's altitude. This adjustment is typically made twice a year with a tilt of approximately 30 degrees in the summer months and a reset in October to about 60 degrees tilt for the winter months. Solar electric production increases by 4 or $5 \%$. Single axis systems are typically $\$ 9000$ per installed $\mathrm{kW}$.

Pole mounted systems with single or dual axis trackers constantly keep the system facing the sun throughout the day (single axis) and throughout the year (dual axis). Dual axis systems will produce 30\% more energy per year as compared to fixed angle systems. However, tracking systems have higher maintenance costs throughout the life of the system because of the moving parts and motors. Also, pole mounted, dual axis systems cost between $\$ 11,000$ and $\$ 12,000$ per installed $\mathrm{kW}$.

Table 5 summarizes the differences between solar system mounts, costs and output.

Table 5. Summary of Solar PV mounts, cost and output. Solar PV Mounting Type Cost per kW to Install Annual Output

${ }^{9}$ Azimuth quantifies how closely an object faces south. For example, a solar panel with an azimuth of 180 degrees is facing directly south. A solar panel with an azimuth of 150 is facing east while an azimuth of 210 is facing west. 
Task Four: Wind and Solar Technologies

Seventh Generation Energy Systems

\begin{tabular}{|l|l|l|}
\hline & & \multicolumn{1}{c|}{ per kW } \\
\hline Fixed Mount & $\$ 9000$ & $1200 \mathrm{kWh}$ \\
\hline Adjustable Tilt & $\$ 10,000$ & $1272 \mathrm{kWh}$ \\
\hline Pole Mount Single and Dual Axis & $\$ 11,000-\$ 12,000$ & $1600 \mathrm{kWh}$ \\
\hline
\end{tabular}

For the analysis below, we assume that the Tribe installs fixed axis systems unless otherwise noted.

The price of a fixed mount system can be brought down by utilizing the economies of scale when purchasing solar systems, as summarized by Table 6 .

Table 6. Solar system economies of scale for fixed tilt systems.

\begin{tabular}{|l|l|}
\hline \multicolumn{1}{|c|}{ System Size } & \multicolumn{1}{c|}{ Cost per $\mathrm{kW}$} \\
\hline $1-3 \mathrm{~kW}$ & $\$ 10,000-\$ 11,000$ \\
\hline $4-10 \mathrm{~kW}$ & $\$ 9,000-\$ 10,000$ \\
\hline $11-20 \mathrm{~kW}$ & $\$ 8,000-\$ 9,000$ \\
\hline$>20 \mathrm{~kW}$ & $\$ 8,000$ \\
\hline
\end{tabular}

For our analysis below, we will assume the low end cost per installed kW.

As discussed previously, large commercial and industrial buildings are often charged for the power demand, as well as their energy use. The peak amount of power draw during any 15 minute interval through out the month will provide the utility with the building's peak demand, or $\mathrm{kW}$. WPS then charges the Tribe $\$ 10.67$ per $\mathrm{kW}$. Some studies show that solar can reduce the demand charges of buildings by $20-30 \%$, if the building typically peaks during 9am to 3pm, however we have not seen evidence that the solar system can reliably reduce demand charges, even though it will most certainly reduce demand.

Many of the Tribe buildings would be appropriate for solar PV, but the Tribe may prioritize sites that have the quickest return on investment. These sites typically have roof-mounted systems on the Cg 1 tariff, i.e. are charged 11 cents per kWh, and take advantage of the WPS Advanced Renewables Tariff.

Below we compare the economic performance of $10 \mathrm{~kW}$ and $50 \mathrm{~kW}$ solar PV system in the Baseline and Optimistic scenarios:

- a $10 \mathrm{~kW}$ system with a Cg 1 tariff (10 cents per kWh) and the Advanced Renewables Tariff

- a $10 \mathrm{~kW}$ system on a demand metered building (6.4 cents per kWh; $\$ 10$ per kW) assuming no reduction in demand charges and the Advanced Renewables Tariff

- $50 \mathrm{~kW}$ system on a Cg 5 tariff (9 cents per $\mathrm{kW}$ ) and the Advanced Renewables Tariff

- $50 \mathrm{~kW}$ system on a demand metered building (a 6.4 cents per kWh; $\$ 10$ per kW) assuming no reduction in demand charges and the Advanced Renewables Tariff 
The solar PV Baseline and Optimistic Economic Scenarios include the assumptions outlined in Table 7.

Table 7. Financial variables for solar PV systems

\section{Baseline Scenario}

\begin{tabular}{ll}
\hline \multicolumn{2}{c}{ Variables affecting Cost of Solar System: } \\
Focus on Energy & $25-35 \%$ of installed cost \\
15-year Loan Interest Rate & $3 \%$ \\
Advanced Renewable Tariff & $\$ 0.25$ per kWh for 10 years (up to 20 kW) \\
\hline \multicolumn{2}{c}{ Variable affecting Cost of WPS Electricity: } \\
\hline Annual Energy Rate Increase & $3.7 \%$ \\
\hline
\end{tabular}

\section{Optimistic Scenario}

\begin{tabular}{ll}
\hline \multicolumn{2}{c}{ Variables affecting Cost of Solar System: } \\
Focus on Energy & $25-35 \%$ of installed cost \\
15-year Loan Interest Rate & $1.5 \%$ \\
Advanced Renewable Tariff & $\$ 0.25$ per kWh for 10 years (up to 20 kW) \\
MACRS (Depreciation Rate) & $\sim 20 \%$ of installed cost \\
Federal Investment Tax Credit & $30 \%$ \\
\hline \multicolumn{2}{c}{ Variable affecting Cost of WPS Electricity: } \\
Annual Energy Rate Increase & $7 \%$
\end{tabular}

Using the variables above, we demonstrate the difference in 30-year Life Cycle Analysis for systems of varying sizes and differing rate schedules.

\subsubsection{Comparison of a $10 \mathrm{~kW}$ system}

The first comparison is for a $10 \mathrm{~kW}$ system on a Cg 1 schedule, or 10.9 cents per $\mathrm{kWh}$, which is representative of a system for the Water Resources Office, and a $10 \mathrm{~kW}$ system on a Cg 20 schedule, or 6.14 cents per kWh (with a \$10 demand charge), which is representative of the Community Center. Both systems are on the Advanced Renewables Tariff. The rate schedule of the building greatly impacts the economic performance. 
Task Four: Wind and Solar Technologies

Seventh Generation Energy Systems

Table 8. Comparison of Baseline Economic scenario for $10 \mathrm{~kW}$

\begin{tabular}{|l|l|l|}
\hline \multicolumn{1}{|c|}{ Variable } & \multicolumn{1}{|c|}{$\begin{array}{c}\text { Water Resources } \\
\text { Office }\end{array}$} & \multicolumn{1}{|c|}{ Community Center } \\
\hline Annual Energy Output of 10kW & $11,640 \mathrm{kWh}$ & $11,640 \mathrm{kWh}$ \\
\hline Rate Schedule & $\begin{array}{l}\text { Cg 1 }(\$ 0.109 / \mathrm{kWh}), \\
\text { and Advanced Re }\end{array}$ & $\begin{array}{l}\text { Cg 20 (\$0.064/kWh) } \\
\text { and Advanced Re }\end{array}$ \\
\hline Amount of CO2 reduced annually & 14 tons & 14 tons \\
\hline Total PV Cost to install (after Focus) & $\$ 66,720$ & $\$ 66,720$ \\
\hline $\begin{array}{l}\text { Total PV Cost for 30 Years, including loan } \\
\text { interest and maintenance. } 10\end{array}$ & $\$ 72,756$ & $\$ 66,574$ \\
\hline Total WPS Electricity Cost after 30 Years & $\$ 67,695$ & $\$ 39,835$ \\
\hline $\begin{array}{l}\text { Amount of Additional Grants/Capital funds } \\
\text { to break even with Baseline WPS after 30 } \\
\text { years }\end{array}$ & $\$ 4,000$ & $\$ 21,000$ \\
\hline
\end{tabular}

*Without the Advanced Renewables Tariff, the cost of the PV system over 30 years would be $\$ 83,400$ for both systems. Because the Community Center is on a cheaper tariff, the Advanced Renewables Tariff effectively pays the Tribe more for the energy the solar energy, and therefore decreases the cost of the PV system over 30 years from $\$ 83,400$ to $\$ 66,500$.

The table above demonstrates how buildings with a higher utility rate will cost the Tribe more in utility charges over 30 years (\$67,700 as apposed to $\$ 39,800)$. This price difference means that a solar system on buildings with higher rates will save the Tribe more money over 30 years. If a small system $(<20 \mathrm{~kW})$ is going to be installed, we recommend installing it on a buildings with the higher $\mathrm{Cg} 1$ or $\mathrm{Cg} 5$ electric rates.

In the Optimistic Scenario, the electric rates increase at 7\% per year and the Tribe is able to secure more incentives. The economics look more favorable.

Table 9. Optimistic Scenario of $10 \mathrm{~kW}$ PV panel

\begin{tabular}{|l|r|r|}
\hline \multicolumn{1}{|c|}{ Variable } & $\begin{array}{c}\text { Water Resources } \\
\text { Office }\end{array}$ & \multicolumn{1}{c|}{ Community Center } \\
\hline Annual Energy Output of PV system & $11,640 \mathrm{kWh}$ & $11,640 \mathrm{kWh}$ \\
\hline Total PV cost after 30 years & $\$ 20,709$ & $\$ 14,526$ \\
\hline Total WPS cost after 30 years & $\$ 126,516$ & $\$ 74,447$ \\
\hline
\end{tabular}

If the Tribe Enterprises can take advantage of the Federal Tax Credits, the solar system costs are greatly reduced.

According to the Optimistic scenario, the Tribe will save between $\$ 60,000$ and $\$ 120,000$ by installing a $10 \mathrm{~kW}$ solar system on the Water Resources Office.

Below we summarize the 30-year Life Cycle Analysis for the Water Resources Office, in a Baseline and Optimistic Scenario, with the assumptions for each scenario listed below.

\footnotetext{
${ }^{10}$ The total PV system costs for these two systems differ because the revenue from the Advanced Renewable Energy Tariff is accounted for by decreasing the 30 year cost of the system. The Community Center is charged 6c per kWh but earns 25c per kWh, with a net gain of 19c per kWh. The Water Resources office is charged 11c per kWh but earns 25c per kWh, with a net gain of 14c per kWh. Therefore, the Community Center will earn \$52,624 from the utility’s buy back tariff. The Water Resources office will earn \$14,077 from WPS’s Advanced Renewable Tariff.
} 
Figure 1. 30-Year Life Cycle Analysis for the Water Resources Office (11,640 kWh per year)
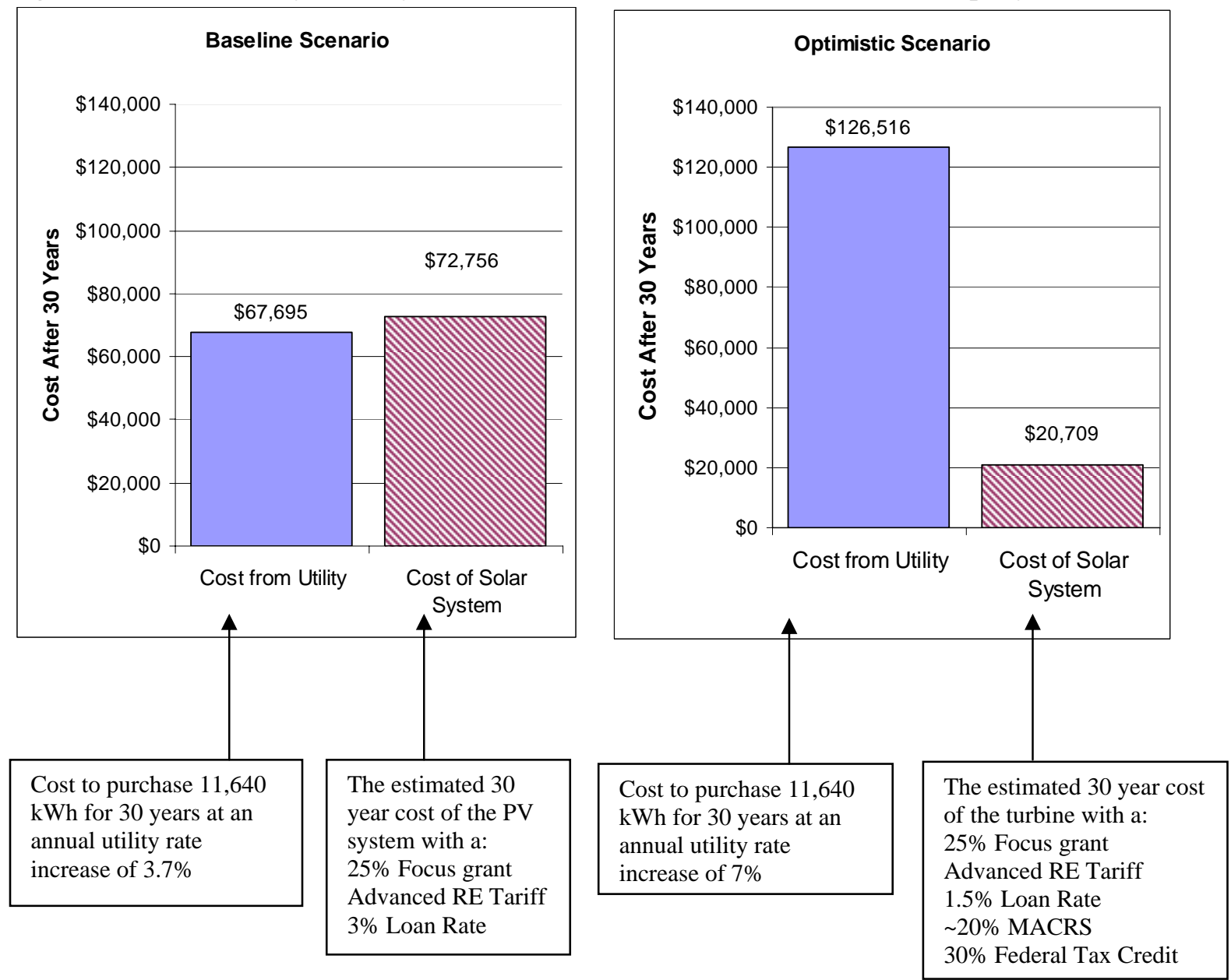

The Life Cycle Analysis figure above demonstrates how solar PV will be a good investment for the Tribe, regardless of the incentives the Tribe receives, if electricity prices increase at $7 \%$ per year, as both systems cost much less than the estimated \$126,000 costs from WPS.

\subsubsection{Comparison of a $50 \mathrm{~kW}$ system}

We also demonstrate the performance of a larger PV system, $50 \mathrm{~kW}$, on a Cg 5 building verses a Cg 20 building.

We choose the Casino Hotel and the Bingo Hall as examples, showing the difference in economic performance of a $50 \mathrm{~kW}$ system. 
Table 10. Comparison of Baseline Scenario for Bingo Hall and Casino Hotel with a 50 kW system

\begin{tabular}{|l|l|l|}
\hline \multicolumn{1}{|c|}{ Variable } & \multicolumn{1}{|c|}{$\begin{array}{c}\text { Bingo Hall } \\
(\text { Cg 5) } \\
50 \mathrm{~kW}\end{array}$} & \multicolumn{1}{|c|}{$\begin{array}{c}\text { Casino Hotel* } \\
\text { (Cg20) } \\
50 \mathrm{~kW}\end{array}$} \\
\hline Annual Energy Output of PV system & $58,200 \mathrm{kWh}$ & $58,200 \mathrm{kWh}$ \\
\hline Amount of CO2 reduced annually & 69.8 tons & 69.8 tons \\
\hline Total PV Cost after Focus & $\$ 350,000$ & $\$ 350,000$ \\
\hline $\begin{array}{l}\text { Total PV Cost for 30 Years (includes loan interest and } \\
\text { maintenance) }\end{array}$ & $\$ 413,198$ & $\$ 402,101$ \\
\hline Total WPS Cost after 30 Years & $\$ 295,002$ & $\$ 198,738$ \\
\hline $\begin{array}{l}\text { Amount of additional grants/capital funds to break } \\
\text { even with WPS after 30 years }\end{array}$ & $\$ 94,000$ & $\$ 162,000$ \\
\hline
\end{tabular}

*This system would need to be installed on the Hall of Nations roof in order to access a good solar window.

The comparison above summarizes that installing a $50 \mathrm{~kW}$ system on a Cg 5 building would be a better investment that installing the system on a Cg 20 building. On the other hand if the system is promoted at it's location after it is installed, a PV system on the casino may have higher PR value due to the number of visitors as compared to the Bingo Hall. As well, the Casino Hotel, as discussed in Task 2, has peak demand periods that fall between $10 \mathrm{am}-2 \mathrm{pm}$. If the solar system would reduce average demand by $30 \%$, then the economics would be more favorable for the Casino Hotel, but still not as favorable as a $50 \mathrm{~kW}$ system on the Cg 5 building.

Table 11. Comparison of Baseline Scenario, assuming $30 \%$ demand charge reduction.

\begin{tabular}{|l|l|l|}
\hline \multicolumn{1}{|c|}{ Variable } & \multicolumn{1}{|c|}{$\begin{array}{c}\text { Bingo Hall } \\
50 \mathrm{~kW}\end{array}$} & $\begin{array}{c}\text { Casino Hotel* } \\
50 \mathrm{~kW}\end{array}$ \\
\hline $\begin{array}{l}\text { Total PV Cost for 30 Years (includes loan interest and } \\
\text { maintenance) }\end{array}$ & $\$ 413,198$ & $\$ 439,697 \quad$ (11) \\
\hline Total WPS Cost after 30 Years & $\$ 295,002$ & $\$ 302,160$ \\
\hline $\begin{array}{l}\text { Amount of Grants/Capital funds to break even with } \\
\text { WPS after 30 years }\end{array}$ & $\$ 94,000$ & $\$ 110,000$ \\
\hline
\end{tabular}

The Casino Hotel still requires approximately $\$ 16,000$ more in grants to breakeven, than the Bingo Hall, even after a 30\% reduction in demand is accounted for.

We cannot guarantee that a reduction in demand charges will take place, therefore we have not accounted for demand reduction charges in this report, but further research should be conducted in order to provide a more reliable assessment of potential demand savings. But again, a PV system on the casino may have higher PR value due to the number of visitors as compared to the Bingo Hall.

In this comparison, the Bingo Hall is a more favorable investment therefore we present the Baseline Scenario verses the Optimistic Scenario for the Bingo Hall below.

\footnotetext{
11 The price of the Casino Hotel has increased from the $\$ 402,000$ presented in the scenario above, because it is no longer on the Advanced Renewables Tariff. Instead the Casino Hotel will have the solar system connected to its meter, in order to take advantage of the demand reductions.
} 
Table 12. A 30-Year Life Cycle Analysis for a $50 \mathrm{~kW}$ system at the Bingo Hall (58,200 kWh per year)
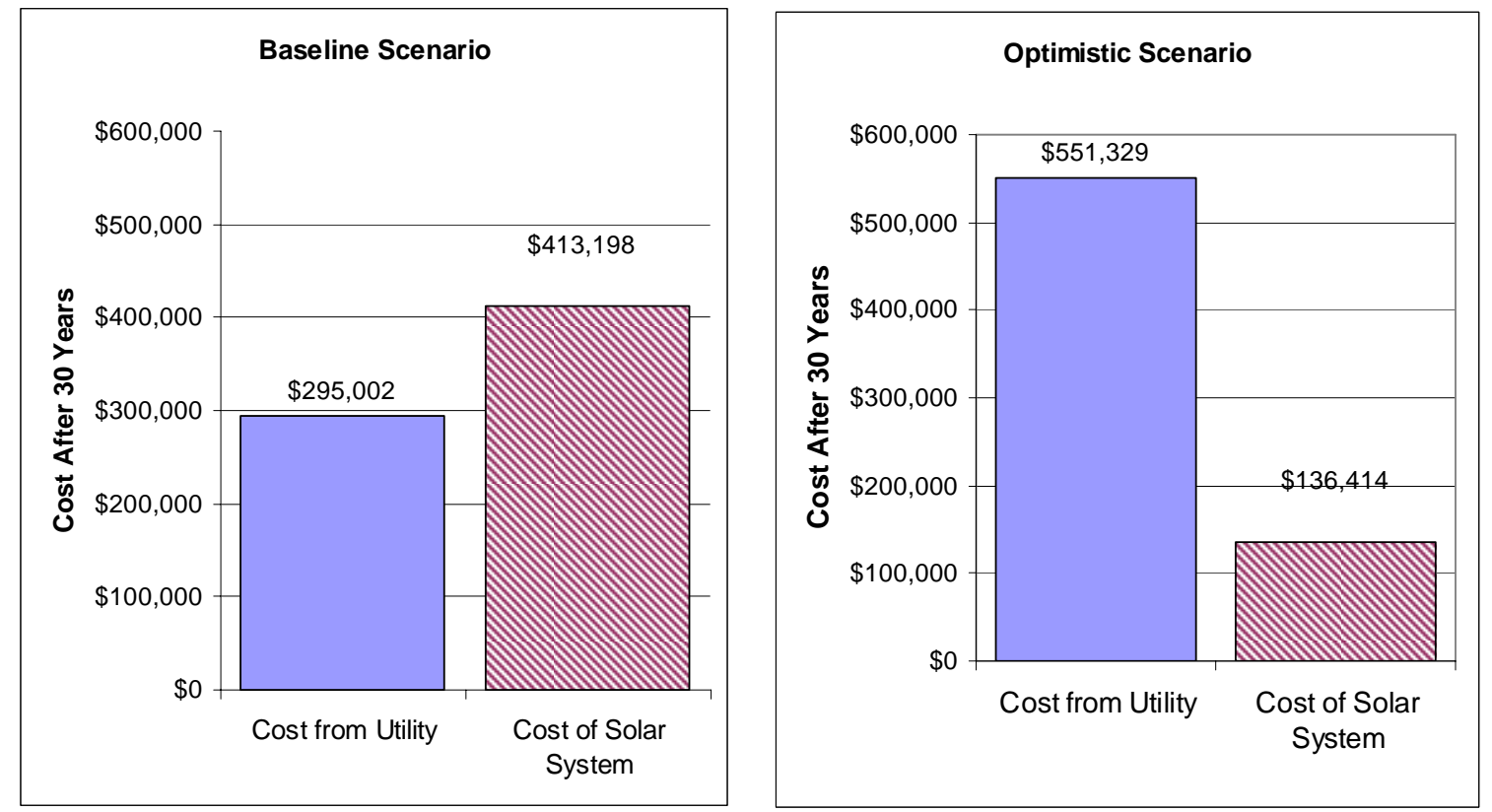

If the Tribe were able to take advantage of the incentives modeled in the Optimistic Scenario, to reduce the cost of the solar system (including the federal tax incentives and depreciation rates), the solar system would be save the Tribe between $\$ 150,000$ and $\$ 400,000$ over the 30 year life of the solar system.

Please see the Building Summaries at the end of this report to see summaries of the economic performance of solar systems on other Tribe buildings.

\subsubsection{Solar PV Resources}

Focus on Energy Solar Electric Case Studies: www.focusonenergy.com/Information-Center/

Solar Energy Industries Association: www.seia.org/

American Solar Energy Society: www.ases.org/ 


\subsection{Solar Thermal}

The sun can be effectively harnessed to heat water for a variety of uses including laundries and space heating, as well as standard domestic uses. Solar thermal panels are low-maintenance and durable. Systems used in Wisconsin are designed for cold weather to prevent pipes from freezing, and equipment is now certified for reliable performance. Even with reduced effectiveness during cloudy winter months, solar thermal systems can significantly reduce energy costs by preheating the water, as well as extending the life of back-up water heating systems.

There are many appropriate applications for solar water heating on public facilities. They are most economical where large volumes of hot water are needed, i.e. vehicle garages, community and senior centers, and health centers.

It is also possible to pre-heat the air for space heating with a solar thermal system. These systems are effective and economical in Wisconsin because they are simple and relatively inexpensive. Air collectors can be wall mounted, roof mounted or ground mounted. They draw inside or outside air into the solar collector and then disperse it into the building for space heating or makeup air. Typical applications include warehouses, shops and vehicle maintenance facilities, and kitchens or medical facilities where makeup air is needed in large quantities.

\subsubsection{Solar hot water}

Most solar hot water systems are designed to furnish 40 to $70 \%$ of the annual demand for hot water, the remainder being met by conventional heating sources, which either raise the temperature of the water further or provide hot water when the solar water heating system cannot meet demand.

\subsubsection{Solar hot water resource}

As mentioned above, the solar radiation is $4.4 \mathrm{kWh}$ per square meter per day, or 1,407 $\mathrm{BTU} / \mathrm{ft}^{2} /$ day. This solar radiation is used to calculate the available solar energy. The need of a buildings' hot water usage is quantified (as daily BTU requirements) and then the solar system is designed to provide the desired amount of BTU's per day.

\subsubsection{Solar hot water site characteristics}

The optimal site characteristics for solar hot water include locations with:

- A roof azimuth between 160 and 200 degrees (within 20 degrees of facing due south)

- Exposure to the sun for as much of the day as possible, year-round, especially during the peak sun hours of 9 a.m. to 3 p.m.

- Relatively consistent hot water requirements throughout the week and the year

Solar thermal systems are not as nearly sensitive to shading as solar PV systems. Therefore if both systems are to be installed on a roof, prioritize the PV system for the area with the least amount of shading. 
Table 13 summarizes a group of buildings are appropriate for solar-hot water systems, based on these criteria. We note the size of a hot water system that is expected to provide between 40$70 \%$ of the buildings hot water energy use. Before any system is installed on the building, the exact amount of daily water use should be determined. A system that is installed to provide $100 \%$ of the building's hot water use will overheat in the summer unless the system is partially shaded (with tarps for example) or unless a summer bypass loop is installed to safely divert excess heat into the ground.

We present the buildings in 3 groups, representative of the priority for solar hot water systems. The priority is based on the amount of hot water usage and the solar access.

The buildings in Group One use an estimated 240 to 1650 gallons per day and/or have very good solar access.

Group Two contains buildings that use smaller amounts of water 300 - 540 gallons per day and may not have as consistent hot water needs as Group One.

Group Three has considerably smaller water needs, less than an estimated 120 gallons per day.

To estimate the size of the solar hot water system, the required BTUs to heat the daily water use for each facility must be determined, based on daily water volume and the required temperature rise. We assume an average 8 x 4 foot solar hot water panel will produce 19,200 BTUs per day, in the Wisconsin climate. 
Task Four: Wind and Solar Technologies

Seventh Generation Energy Systems

Table 13. Tribe buildings with the opportunity to retro-fit with solar hot water

\begin{tabular}{|c|c|c|c|c|c|c|c|}
\hline \multirow{2}{*}{ Group } & \multirow{2}{*}{ Building } & \multirow{2}{*}{$\begin{array}{c}\text { No. } \\
\text { of } \\
\text { Tanks }\end{array}$} & \multirow{2}{*}{$\begin{array}{l}\text { Tank Size } \\
\text { (gal) }\end{array}$} & \multirow{2}{*}{ Use } & \multirow{2}{*}{$\begin{array}{c}\text { Propane } \\
\text { Water } \\
\text { Heaters } \\
\text { (\$/gal) }\end{array}$} & \multicolumn{2}{|c|}{$\begin{array}{c}\text { Electric Hot } \\
\text { Water Heaters }\end{array}$} \\
\hline & & & & & & \$/kWh & $\$ / \mathrm{kW}$ \\
\hline 1 & Bingo Hall & 2 & 40 & Bathrooms/Snack Bar & - & $\$ 0.095$ & - \\
\hline 1 & Hall of Nations & 2 & $100 *$ & Cooking/Cleaning & $\$ 2.00$ & - & - \\
\hline 1 & $\begin{array}{l}\text { Lac du Flambeau } \\
\text { School }\end{array}$ & 2 & $1000 / 100^{* * *}$ & $\begin{array}{l}\text { Bathrooms/Cleaning/ } \\
\text { Cooking/Showers }\end{array}$ & $\$ 2.00$ & - & - \\
\hline 1 & Hotel Laundry & 2 & $100 / 60$ & Laundry & - & $\$ 0.064$ & $\$ 10.67$ \\
\hline 1 & $\begin{array}{l}\text { Elks Point Elder } \\
\text { Housing* }\end{array}$ & ? & ? & $\begin{array}{l}\text { Laundry, showering, } \\
\text { etc }\end{array}$ & $\$ 2.00$ & - & - \\
\hline 2 & $\begin{array}{l}\text { Community } \\
\text { Center / Clinic }\end{array}$ & 3 & 40 & Bathrooms & - & $\$ 0.064$ & $\$ 10.67$ \\
\hline 2 & $\begin{array}{l}\text { Simpson's Main } \\
\text { Plant }\end{array}$ & 3 & 40 & Bathrooms & - & $\$ 0.095$ & - \\
\hline 2 & Youth Center & 2 & 50 & Bathrooms & - & $\$ 0.109$ & - \\
\hline 2 & Ojibwe Mall** & 3 & $100 / 40 / 40$ & Bathroom, cleaning & - & $\$ 0.064$ & $\$ 10.67$ \\
\hline 2 & Casino HR and Ed & 3 & $20 / 40 / 40$ & Bathroom & - & $\$ 0.095$ & - \\
\hline 3 & $\begin{array}{l}\text { Simpsons Plastics } \\
\text { Plant }\end{array}$ & 1 & $1 \times 40$ & Bathrooms & - & $\$ 0.064$ & $\$ 10.67$ \\
\hline 3 & Roads Garage & 1 & $1 \times 40$ & Bathroom & $\$ 2.00$ & - & - \\
\hline 3 & Museum & 1 & 40 & Bathroom & $\$ 2.00$ & - & - \\
\hline
\end{tabular}

*Assumptions of the Elks Point Elder Housing

The Wellness Center would also be a good candidate for solar hot water based on the expected amount of hot water use, however the access to the solar resource should be verified with a solar Pathfinder.

Generally we would prioritize these buildings based on the greatest amount of hot water use and adequate room for solar hot water storage. In most cases collectors can be positioned to face due south with a variety of different mounting hardware. It is also common to mount collectors on the ground if there is no roof mount option.

Based on these two criteria, the prioritized buildings for solar hot water would be the buildings highlighted in Group 1.

As mentioned above, the size of the solar hot water system depends mainly on the daily amount of hot water use, as well as the current hot water heating system in place and the available storage area. To provide the Tribe with approximate size ranges of solar systems, we have estimated the daily hot water use and required temperature of the hot water of the buildings below, based on what the hot water is used for and the occupancy of the buildings.

A simple calculation is used to estimate the approximate energy required from the solar panels, before a detailed site assessment is conducted. The energy (BTUs) required equals: 
Task Four: Wind and Solar Technologies

Seventh Generation Energy Systems

\section{$\mathrm{V} \times \mathrm{T} \times 8.33$}

Where:

$\mathrm{V} \quad=$ gallons of hot water used on a daily basis (gallons)

$\mathrm{T}=$ required temperature rise of the water $\left({ }^{\circ} \mathrm{F}\right)$

8.33 = BTU conversion factor; Constant value representing the density of water multiplied by its specific heat

We then multiplied the estimated daily water requirements by 0.55 to determine how much energy is required to meet $40-70 \%$ of the buildings daily needs. Then, estimating that a single, 8 by 4 foot flat plat collector can provide 19,200 BTU per day, we divide the total energy building requirements by 19,200 BTUs per day to estimate the number of collectors needed. The calculations are summarized in Error! Reference source not found.

Table 14. Estimated Solar Hot Water Sizing for Tribe Facilities

\begin{tabular}{|c|c|c|c|c|c|c|}
\hline Group & Facility & $\begin{array}{c}\text { Estimated } \\
\text { Temperature } \\
\text { Rise } \\
\text { (degrees) } \\
\end{array}$ & $\begin{array}{l}\text { Estimated } \\
\text { daily hot } \\
\text { water } \\
\text { (gal) } \\
\end{array}$ & $\begin{array}{l}\text { Total } \\
\text { daily } \\
\text { BTU } \\
\text { used }\end{array}$ & $\begin{array}{l}\text { No. of } \\
\text { 8’ x 4' } \\
\text { panels* }\end{array}$ & $\begin{array}{c}\text { Space } \\
\text { needed for } \\
\text { system } \\
\text { size (sq ft) }\end{array}$ \\
\hline 1 & Bingo Hall & 80 & 240 & 159,936 & 5 & 160 \\
\hline 1 & Hall of Nations & 100 & 600 & 499,800 & 14 & 448 \\
\hline 1 & Lac du Flambeau School & 90 & 1300 & 974,610 & 28 & 896 \\
\hline 1 & Hotel Laundry & 100 & 1600 & $1,332,800$ & 38 & 1216 \\
\hline 1 & Elks Point Elder Housing & 80 & 240 & 399,840 & 11 & 352 \\
\hline 2 & Community Center / Clinic & 80 & 360 & 239,904 & 7 & 224 \\
\hline 2 & Simpson's Main Plant & 80 & 360 & 239,904 & 7 & 224 \\
\hline 2 & $\begin{array}{l}\text { Youth Center (Abinoojiiyag } \\
\text { Center) }\end{array}$ & 80 & 300 & 199,920 & 6 & 192 \\
\hline 2 & Store (Ojibwe Mall) & 100 & 540 & 449,820 & 13 & 416 \\
\hline 2 & $\begin{array}{l}\text { Casino Human Resources and } \\
\text { Education }\end{array}$ & 80 & 300 & 199,920 & 6 & 192 \\
\hline 3 & Simpsons Plastics Plant & 80 & 120 & 79,968 & 2 & 64 \\
\hline 3 & Roads Garage (Tribe garage) & 80 & 120 & 79,968 & 2 & 64 \\
\hline 3 & Museum & 80 & 50 & 33,320 & 1 & 32 \\
\hline
\end{tabular}

*Estimated to meet $40 \%-70 \%$ of hot water.

There should be ample space for all of the systems indicated above on the roof of the facilities.

The Bingo Hall does not have the highest amount of hot water needs, but it is on the highest WPS rate schedule, which helps the economic analysis, and because the hot water system is electric a system here will be eligible for Focus on Energy funding.

The Hotel and Hall of Nations are a key priority for solar hot water because they are the largest and most consistent hot water users of the Tribe. 


\subsubsection{Solar hot water technology for the Tribe}

While each solar hot water system is unique, they all share certain components, including:

- Solar collectors and a mounting system to securely hold the collectors at the proper angle

- Insulated copper piping to transfer the heat from the solar collectors to the building

- Heat Transfer fluid (non-toxic anti-freeze) and heat exchanger

- An additional hot water storage tank

- Valves, pumps and controls to operate and maintain the system

The figure below is a diagram of a typical solar hot water system.

Figure 2. Diagram of solar hot water system (Focus on Energy and Bob Ramlow, 2008)

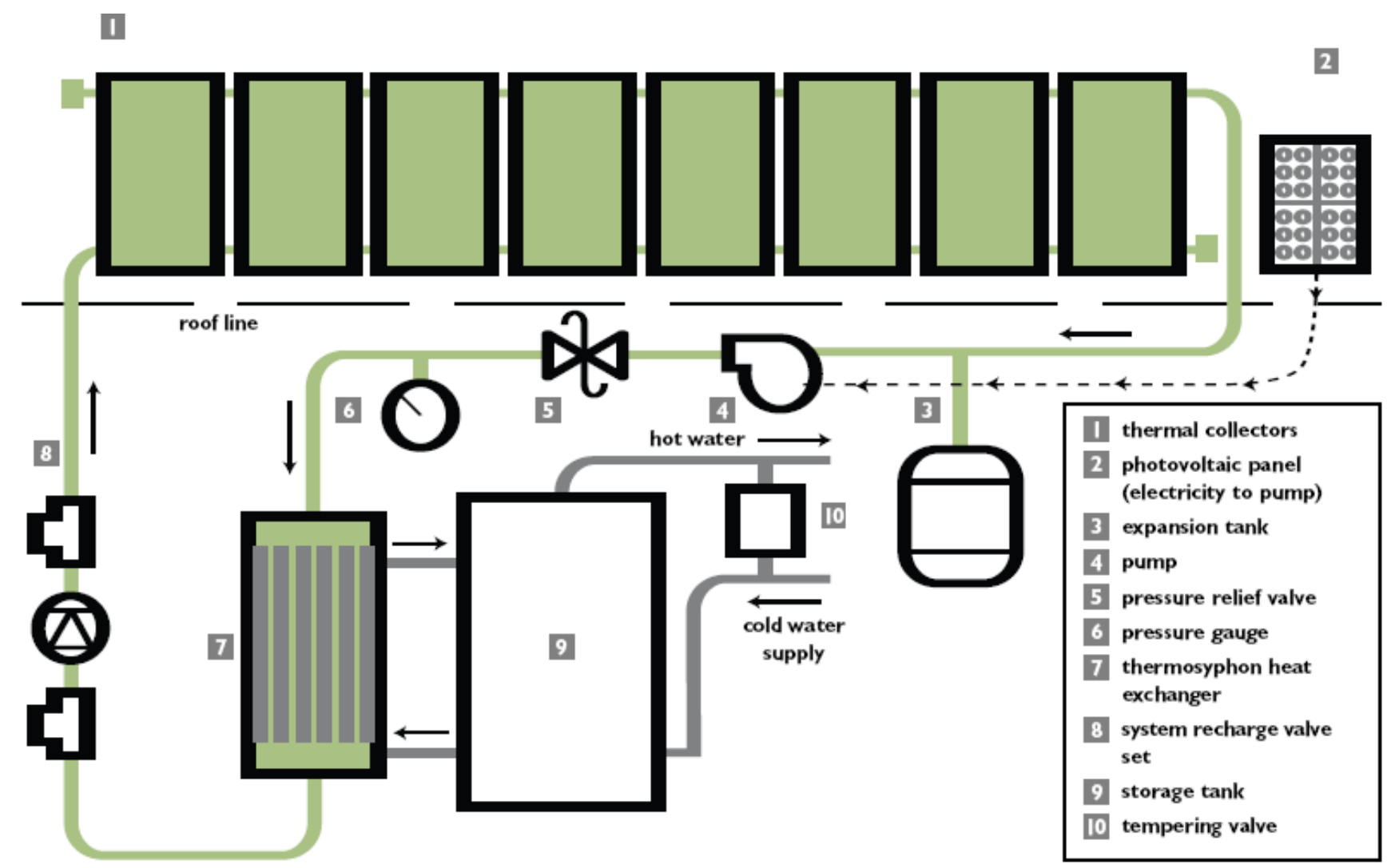

\section{Types of solar collectors}

There are two types of solar collectors that are used in Wisconsin today: flat plate collectors and evacuated tube collectors. Flat plate collectors are by far the most popular kind of collector used in our climate and they are the type of collector used in our modeling.

Evacuated tube collectors are a newer technology in solar thermal collectors and they are used in commercial solar thermal systems, or where higher temperatures fluids are required. 


\section{Types of solar systems}

There are two main types of systems that are used in solar thermal systems; closed-loop pressurized anti-freeze systems and drain-back systems.

\section{Closed-loop pressurized antifreeze systems}

- An antifreeze solution fills the collectors and piping at all times.

- When solar energy is available, a circulating pump circulates this heat transfer fluid throughout the system.

- The solar fluid gets heated in the collectors and moves that heat into the building.

- The heat is then transferred from the solar fluid to the facility water supply.

- The heated water can be used directly or can be stored for use at a later time.

o This heated water can be used for domestic hot water, process hot water, or space heating.

- When there is no solar energy to be harvested, the pump does not operate and the solar fluid stops circulating.

- Closed-loop antifreeze systems are the most popular type of system installed in our climate.

The advantages of closed-loop pressurized antifreeze systems include:

- Proven system type for cold climates.

- The most versatility in system configurations.

- Cost competitive.

- Ease of installation.

The disadvantage of closed-loop pressurized antifreeze systems include:

- Systems can overheat (resulting in degradation of the solar fluid) if left with no load and/or no circulation over extended periods of time.

\section{Drain-back systems}

Drain-back systems are very similar to closed-loop pressurized antifreeze systems except that the solar fluid does not stay in the piping and the collectors at all times.

- The solar fluid is stored in a special drain-back tank, which is located below the collectors and inside heated space.

- When solar energy is available for harvesting a high-head pump turns on and pumps the solar fluid from the drain-back tank into the piping and solar collectors.

The main advantages of drain-back systems include:

- When the solar storage tank is fully heated the system simply turns off and the solar fluid drains back to the drain-back tank.

- Eliminates any potential overheating problems.

- This type of system works well with the seasonal use facilities 
The main disadvantages are that:

- The collectors must be located above the drain-back tank, which eliminates the option of mounting the collectors in any place except above the drain-back tank.

- There are also piping limitations in drain-back systems, as the piping must be run in such a way that there is a continuous downward slope to all the piping to facilitate complete draining of all the collectors and piping when the system is not operating.

\subsubsection{Solar hot water economics}

The section below outlines the basic economics of the solar hot water systems. The economics of a solar hot water system is based on the cost of the fuel to heat the water, the grants available, such as Focus on Energy or USDA, the opportunity to sell RECs, and the opportunity to take advantage of the tax credits.

Table 15. Financial variables for solar thermal systems

Baseline Scenario

\begin{tabular}{|c|c|}
\hline \multicolumn{2}{|c|}{ Variables affecting Cost of Solar System: } \\
\hline Focus on Energy & $25-35 \%$ of installed cost \\
\hline 15-year Loan Interest Rate & $3 \%$ \\
\hline $\begin{array}{l}\text { Lower value of Renewable } \\
\text { Energy Credits }\end{array}$ & Solar: $5 \%$ of installed cost \\
\hline \multicolumn{2}{|c|}{ Variable affecting Cost of WPS Electricity: } \\
\hline Annual Energy Rate Increase & $3.7 \%$ \\
\hline
\end{tabular}

\section{Optimistic Scenario}

Variables affecting Cost of Solar System:

Focus on Energy 25-35\% of installed cost

15-year Loan Interest Rate $\quad 1.5 \%$

MACRS (Depreciation Rate) $\quad$ 20\% of installed cost

Federal Investment Tax Credit $\quad 30 \%$

Higher value of Renewable Solar: $10 \%$ of installed cost

Energy Credits

\section{Variable affecting Cost of WPS Electricity:}

Annual Energy Rate Increase $\quad 7 \%$

We present three economic indicators: the 30 year utility costs, the 30 year solar hot water costs (including maintenance and loan interest), and the 30 year potential savings if the solar system is installed. Each solar hot water system is expected to have a positive return on investment, even in the Baseline Scenarios. Below we present the summary for the Baseline Scenarios. 
Table 16. Economic performance of solar hot water systems

\begin{tabular}{|l|l|c|c|c|r|r|}
\hline Group & \multicolumn{1}{|c|}{ Building } & $\begin{array}{c}\text { Fuel } \\
\text { Type }\end{array}$ & $\begin{array}{c}\text { System } \\
\text { Size (sq. } \\
\text { feet) }\end{array}$ & $\begin{array}{c}30 \text { year } \\
\text { Utility } \\
\text { Costs }\end{array}$ & $\begin{array}{c}\text { 30 Year } \\
\text { Solar Hot } \\
\text { Water } \\
\text { Costs }\end{array}$ & $\begin{array}{c}\text { Total } \\
\text { Potential } \\
\text { 30- year } \\
\text { Savings }\end{array}$ \\
\hline 1 & Lac du Flambeau School & $\mathrm{P}$ & 896 & $\$ 716,112$ & $\$ 138,021$ & $\$ 578,091$ \\
\hline 1 & Casino & $\mathrm{P}$ & 448 & $\$ 358,056$ & $\$ 69,010$ & $\$ 289,046$ \\
\hline 1 & Elks Point Elder Housing & $\mathrm{P}$ & 352 & $\$ 281,330$ & $\$ 54,222$ & $\$ 227,108$ \\
\hline 1 & Casino Hotel & $\mathrm{P}$ & 1216 & $\$ 313,676$ & $\$ 136,138$ & $\$ 177,538$ \\
\hline 1 & Bingo Hall & $\mathrm{E}$ & 160 & $\$ 61,265$ & $\$ 16,877$ & $\$ 44,388$ \\
\hline 2 & Youth Center & $\mathrm{E}$ & 192 & $\$ 84,352$ & $\$ 20,252$ & $\$ 64,100$ \\
\hline 2 & Store (Ojibwe mall) & $\mathrm{E}$ & 416 & $\$ 107,310$ & $\$ 43,880$ & $\$ 63,430$ \\
\hline 2 & Casino HR / Ed (LOTC) & $\mathrm{E}$ & 192 & $\$ 73,518$ & $\$ 20,252$ & $\$ 53,266$ \\
\hline 2 & Community Center/Clinic & $\mathrm{E}$ & 224 & $\$ 57,782$ & $\$ 23,628$ & $\$ 34,154$ \\
\hline 2 & Simpson's Main Plant & $\mathrm{E}$ & 64 & $\$ 16,509$ & $\$ 6,481$ & $\$ 10,028$ \\
\hline 3 & Simpson's Plastics Plant & $\mathrm{E}$ & 224 & $\$ 85,771$ & $\$ 23,628$ & $\$ 62,143$ \\
\hline 3 & Roads Garage & $\mathrm{P}$ & 64 & $\$ 51,151$ & $\$ 9,859$ & $\$ 41,292$ \\
\hline 3 & Museum & $\mathrm{P}$ & 32 & $\$ 25,575$ & $\$ 4,929$ & $\$ 20,646$ \\
\hline
\end{tabular}

Facilities with propane hot water heating systems will have a faster return on investment, even though they are not eligible for Focus on Energy funding. Three of the buildings in Group One have propane water heating systems: Hall of Nations, School, and Hotel Laundry. Please see the attached Focus on Energy Certified Solar Hot Water site assessments, conducted by Jamie Paterson at Paterson Solar.

\subsubsection{Recommendations}

Solar hot water typically has the quickest payback of all renewable energy systems.

We recommend that the Tribe prioritize solar hot water systems for the building that: 1) use the greatest amount of hot water, 2) have a south facing roof with a good solar window, and 3) have old, inefficient hot water systems. If the cost of propane remains at or exceeds $\$ 2.00$ a gallon, propane hot water systems are expected to have a greater return on investment than electric hot water heating.

We also recommend comprehensively documenting the following solar thermal characteristics of each candidate site:

- hot water equipment of all the Tribe buildings

- the daily amount of hot water used

- the required water temperature rise for each facility (i.e. from 50 to 130 degrees?)

- the specific uses for each building 


\subsection{Solar Space Heating}

Solar space heating systems use solar energy to heat air for building ventilation or industrial processes such as drying. These systems raise the temperature of the outside air by $41^{\circ} \mathrm{F}$ to $59^{\circ} \mathrm{F}$ on average, and typically supply a portion of the required heat load (from $1-50 \%$ ), with the remainder being furnished by conventional heaters.

In Northern Wisconsin, successful solar space heating system design can be a challenge. Heat is needed most when the solar resource is at its minimum - November through January. As a result, solar heating systems must be over-sized as compared to an "optimally" sized system to meet a building's annual heating load. In effect, the capital must be invested in a portion of the system that is unnecessary for part of the year. For this reason, solar heating systems are typically considered when there is a relatively constant thermal load such as industrial processing.

\subsubsection{Solar space heating site characteristics}

The optimal site characteristics for solar thermal include locations with:

- A roof azimuth between 160 and 200 degrees (within 20 degrees of south)

- Sufficient roof or ground space to hold the solar system

- Exposure to the sun, especially during the peak sun hours of 9 a.m. to 3 p.m.

- A large heating requirement for a relatively large space

- Radiant floor heating tubes in slab or "JibCrete" on a wood sub-floor

- Occasionally solar space heating can work with forced air systems

If the buildings use radiant heat in part or all of the square footage it is a good candidate for solar space heating. However, heating systems that use radiant floor under wood sub floors, base board heaters, and radiators are not good applications due to the high operating temperatures at which boiler(s) operate.

Based on the heating information gathered, we did not find any existing Tribe buildings with radiant floor heating. We would recommend a more extensive review of the Tribe buildings to verify the heating system of each. Commercial solar space heating systems can range from $\$ 20,000$ - \$30,000.

\subsubsection{Solar thermal resources}

Focus on Energy Solar Thermal Case Studies: www.focusonenergy.com/Information-Center/ US Department of Energy, Solar Technology Programs: www1.eere.energy.gov/solar/solar_heating.html Rural Renewable Energy Alliance: www.rreal.org/ 


\subsection{WIND ENERGY}

\subsubsection{Summary of the Tribe's wind resource}

With more than 94,000 megawatts now in service worldwide, wind power is an economical and reliable option to produce clean energy at sites with viable wind speeds. All over the Midwest, wind turbines are appearing not only on farms, but at factories and in schoolyards as well. In this section, we will present the options for wind power development on the Lac du Flambeau Reservation.

According to the Wisconsin Wind Map ${ }^{12}$, the Tribe has access to 'slower' wind speeds, however there are several potential locations that are relevant for small-scale wind projects (100 kW and under). Specifically, viable locations would be the north and northeast shores of the larger lakes and within 1000 feet of a Tribe electrical meter. These areas are expected to receive wind speeds between $10-12 \mathrm{mph}$, which is suitable and common for successful small wind system operation in Wisconsin.

The estimated wind speeds on the reservation are not fast enough to support commercial wind projects in which the power is put directly onto the transmission grid.

Below, Figure 3 shows the wind resource on the Lac du Flambeau Reservation at a height of 30 meters, according to the 2007 Wisconsin wind map. Thirty meters is typically the minimum tower height for small turbines in Wisconsin. At 30 meters or 99 feet, the majority of wind speeds are $10.1 \mathrm{mph}$, but a few areas highlighted by light yellow are between $10.1-11.2 \mathrm{mph}$. At 40 meters (131.2 feet), the majority of the Tribe's wind speeds are slower than $11.2 \mathrm{mph}$, but a few areas are between 11.2 - $12.3 \mathrm{mph}$.

If the Tribe were to install 5 wind turbines with a power capacity of $35 \mathrm{~kW}$ each, the Tribe could expect to produce around 360,000 kWh per year, representing at $3 \%$ of the Tribe electricity needs.

The large energy users (casino and hotel) and the multi-family dwellings will be able to physically accommodate turbines between $35-100 \mathrm{~kW}$, while a turbine range of $1-20 \mathrm{~kW}$ is more appropriate for the smaller facilities and single family dwellings.

\footnotetext{
${ }^{12}$ Focus on Energy, Wisconsin State Wind Map: www.focusonenergy.com.
} 
Task Four: Wind and Solar Technologies Seventh Generation Energy Systems

Figure 3. Wind speed for Lac du Flambeau Reservation at 30 meters (99 feet)

The $10.1-11.2$ mph wind speeds on the Reservation are expected on the north east borders of the lakes and in the wetland areas to the north.

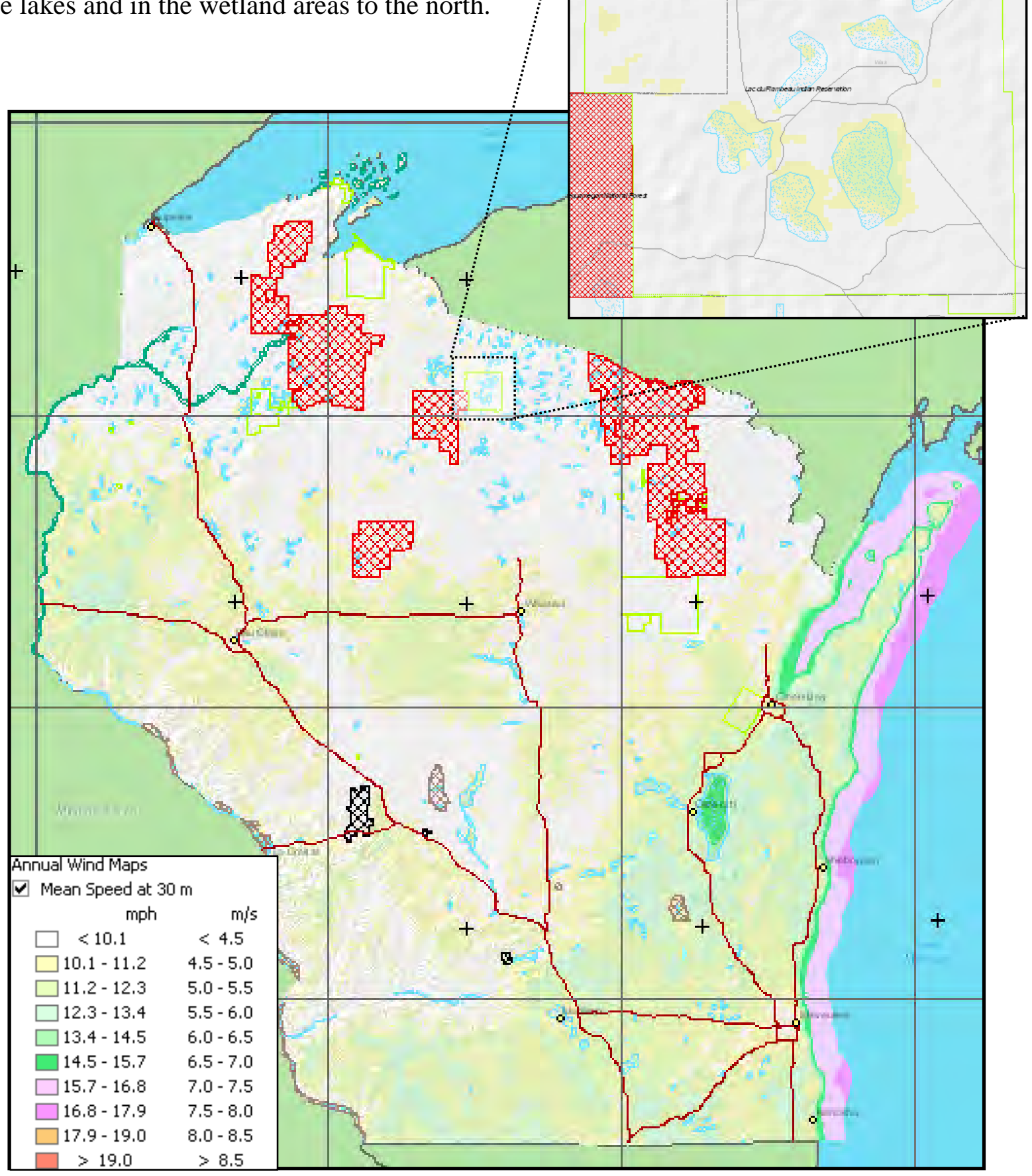

The Wisconsin state wind map above, created by AWS Truewind in 2007, provides wind speed estimates at varying heights. The table below summarizes the expected wind speeds on the reservation.

Table 17. Wind speeds on the Lac du Flambeau reservation 


\begin{tabular}{|c|c|c|}
\hline Height Meters (Feet) & $\begin{array}{l}\text { MAX WIND speed on } \\
\text { reservation (mph) }\end{array}$ & $\begin{array}{l}\text { AVERAGE wind speed expected } \\
\text { across the majority of the reservation } \\
(\mathrm{mph})\end{array}$ \\
\hline $30 \mathrm{~m} \quad(98 \mathrm{ft})$ & $10.1-11.2$ & $>10.1$ \\
\hline $40 \mathrm{~m}(131 \mathrm{ft})$ & $11.2-12.3$ & $10.1-11.2$ \\
\hline $60 \mathrm{~m}(197 \mathrm{ft})$ & $12.3-13.4$ & $>12.3$ \\
\hline $70 \mathrm{~m}(230 \mathrm{ft})$ & $13.4-14.5$ & $12.3-13.4$ \\
\hline $100 \mathrm{~m} \quad(328 \mathrm{ft})$ & $14.5-15.7$ & $12.3-13.4$ \\
\hline
\end{tabular}

The maximum wind speed is seen on the north and northeastern portions of the larger lakes. Again, the wind speeds would not support utility-scale projects but they would support small turbine projects at 40 meters or 131 feet.

Because of the heavily wooded topography of the reservation, the Tribe should site turbines with unobstructed access to the predominant southwest wind direction. Another key siting criteria for the Tribe is to ensure that any turbines is erected so that the bottom tip of the blades are 30 feet higher than any obstacle within a 500 foot distance, to avoid turbulence caused by the tall trees.

Figure 4. Wind Turbine Siting: Blades must be 30 feet taller than obstacles within 500 feet

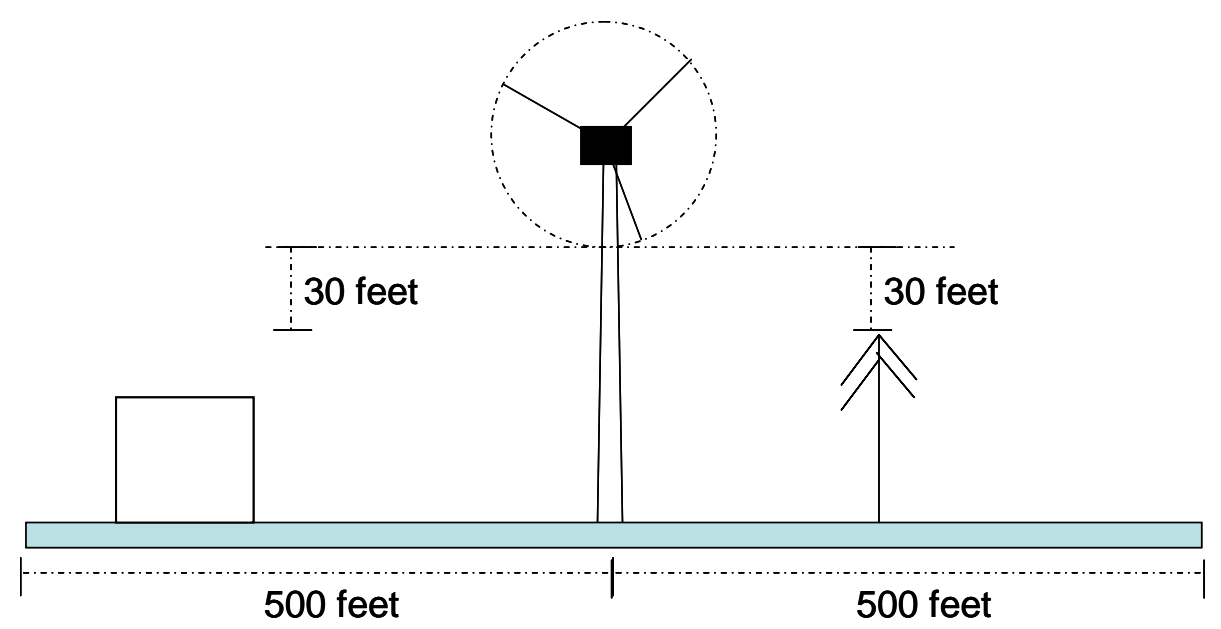

Wind turbines have the best economic performance in locations with a medium to fast wind speed, high electricity prices and for entities that are eligible for federal grants and tax breaks. While the Tribe has access to slower wind speeds and may not be able to take advantage of the tax credits, there are grants available that will lower the installed capital cost of the turbine. 


\subsubsection{Wind resource characterization}

The most important technical factor for a wind turbine is the quality and quantity of the local wind resource. The wind characterization is the basis for all wind turbine energy production estimates.

The wind resource is characterized by several key variables, including:

- $\quad$ average wind speed

- predominant wind direction

- wind shear (change in wind speed with change in elevation)

- wind speed frequency distribution

- turbulence intensity of the site

\subsubsection{Detailed Lac du Flambeau wind analysis}

The section below describes the important components of the wind characterization and the expected characteristics of the Lac du Flambeau wind.

This analysis is based on the 2007 Wisconsin Wind Map and as such it is an estimate of the reservation wind resource. Wind maps are computer programs and as such are inherently inaccurate to varying degrees. The data and conclusions presented here are based on the best available information. If the Tribe wants a better or more certain understanding of the wind resource, it should consider a tall tower monitoring study. See the NREL Anemometer Loan Program for more information. ${ }^{13}$

\subsubsection{Wind speed}

The power available in the wind for a wind turbine is proportional to the cube of the average wind speed. Simply put, small changes in average annual wind speed result in large changes in annual energy production and project performance.

The average annual wind speed in miles per hour (mph) or meters per second $(\mathrm{m} / \mathrm{s})$ is the primary means by which a potential site is described. Typically, the average speed is expressed at specified elevation above ground level.

The wind speed is further classified according to the Battelle wind power classes as shown in the table below.

\footnotetext{
${ }^{13}$ NREL's Native American Anemometer Loan Program: www.windpoweringamerica.gov/na_anemometer_loan.asp
} 
Figure 5. Battelle Wind Power Classes

\begin{tabular}{|c|l|l|}
\hline $\begin{array}{c}\text { Wind Power } \\
\text { Class }\end{array}$ & \multicolumn{1}{|c|}{$\begin{array}{c}\text { Resource } \\
\text { Potential }\end{array}$} & Wind Speed at 50 m (mph) \\
\hline 1 & Poor & $0.0-12.5$ \\
\hline 2 & Marginal & $12.5-14.3$ \\
\hline 3 & Fair & $14.3-15.7$ \\
\hline 4 & Good & $15.7-16.8$ \\
\hline 5 & Excellent & $16.8-17.9$ \\
\hline 6 & Outstanding & $17.9-19.7$ \\
\hline 7 & Superb & $>19.7$ \\
\hline
\end{tabular}

Small wind projects and large wind projects become viable in different Wind Power Classes.

Figure 6. Viable Wind Speeds for a Range of Wind Turbine Projects

\begin{tabular}{|l|c|c|l|}
\hline \multicolumn{1}{|c|}{ Turbine Size } & $\begin{array}{c}\text { Typical Tower } \\
\text { Height }\end{array}$ & $\begin{array}{c}\text { Wind Power } \\
\text { Class }\end{array}$ & $\begin{array}{c}\text { Required Wind Speed at } \\
\text { Tower Height for Project } \\
\text { Viability }\end{array}$ \\
\hline Small Wind $(1-100 \mathrm{~kW})$ & $100-140$ feet & 1 & $10 \mathrm{mph}$ \\
\hline $\begin{array}{l}\text { Medium Wind }(100- \\
900 \mathrm{~kW})\end{array}$ & $100-250$ feet & 2 & $12.5 \mathrm{mph}$ \\
\hline Large Wind $(>1 \mathrm{MW})$ & $400-650$ feet & 3 & $14.3 \mathrm{mph}$ \\
\hline
\end{tabular}

The average annual wind speed can also be described according to its seasonal and daily variations. In general, Wisconsin winds are strongest during the spring, fall and winter months and lowest in the summer months.

During the feasibility study portion of a wind energy development project, publicly available wind resource data are used to estimate the wind resource at a particular site. These data include:

- $\quad$ State or federal wind resource maps

- Local airport data

- Federal navigation buoy data

- State or federal air quality monitoring sites

The wind resource data from these sources often can be analyzed to provide a reasonable firstorder wind resource estimate, sufficient for a feasibility determination but insufficient to make an investment decision about large wind energy systems.

The only way to accurately understand the site-specific wind resource is through a tall tower wind measurement study. A temporary tilt-up tower 50-60 meters tall is erected on site and outfitted with wind speed measurement devices at multiple elevations. The wind speeds are measured and recorded and then analyzed and compared to publicly available long-term data records. In general, a 3-year study is required to achieve a 95\% confidence level, and account for normal annual variations. In practice, commercial wind investment decisions are made in as little as 6-months to a year if there are correlation data available.

A wind speed tall tower monitoring study can cost ranges from $\$ 30,000$ - \$40,000 and therefore is usually not justified for small turbine projects unless the project requires an exact 
determination of turbine performance and return on investment. Tall tower monitoring is essential for projects using large turbines.

The Department of Energy’s National Renewable Energy Laboratory has a Tall Tower Anemometer Loan Program, if the Tribe is interested in monitoring wind speeds for no-cost. ${ }^{14}$

\subsubsection{Lac du Flambeau wind speeds}

The maximum wind speeds are found on the northeast shores of the large lakes and in the northern wetlands.

The figure below shows wind speeds at 40 meters, or 131 feet.

Figure 7. Wind speeds at 40 meters, or 130 feet (AWS TrueWind 2007)

At 40 meters or feet, the maximum wind are between 11.2 mph on the north side of the lakes because of the to the predominant coming from the southwest.

The figure below

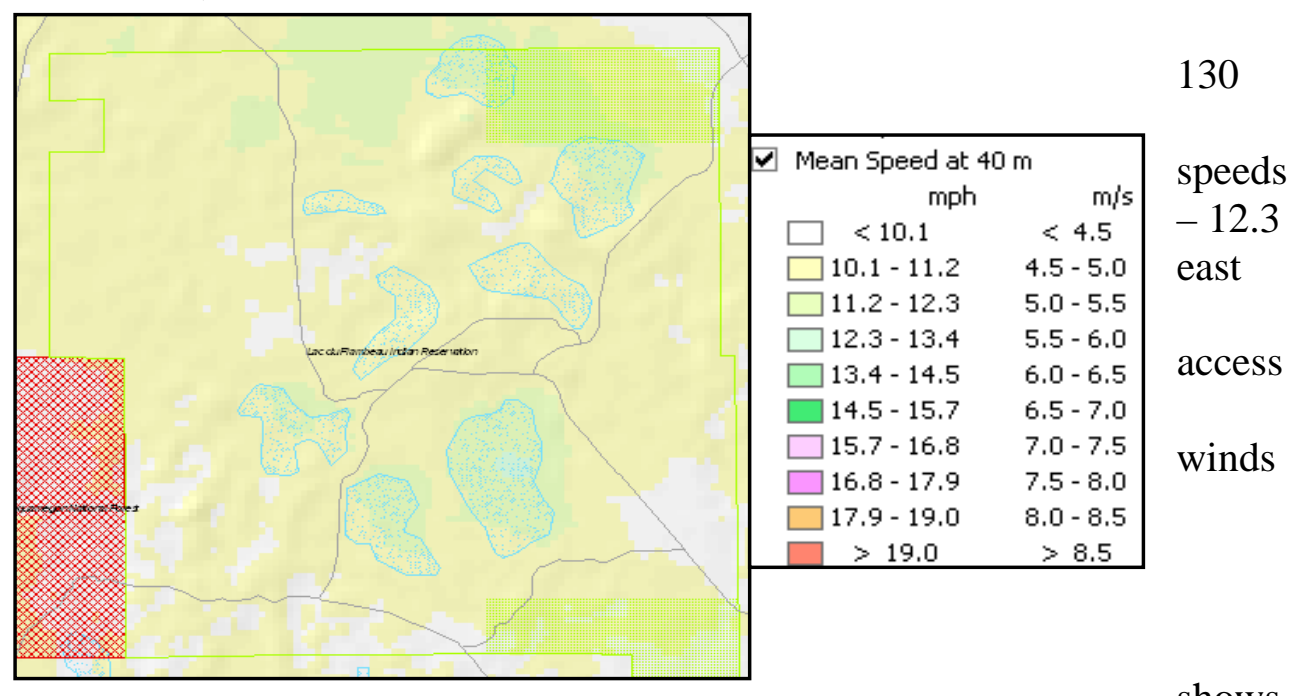
wind speeds at 60 meters, or 197 feet.

shows

\footnotetext{
${ }^{14}$ NREL’s Tall Tower Anemometer Loan Program: www.windpoweringamerica.gov/na_anemometer_loan.asp
} 
Figure 8. Wind speeds at 60 meters, or 197 feet (AWS Truewind 2007)

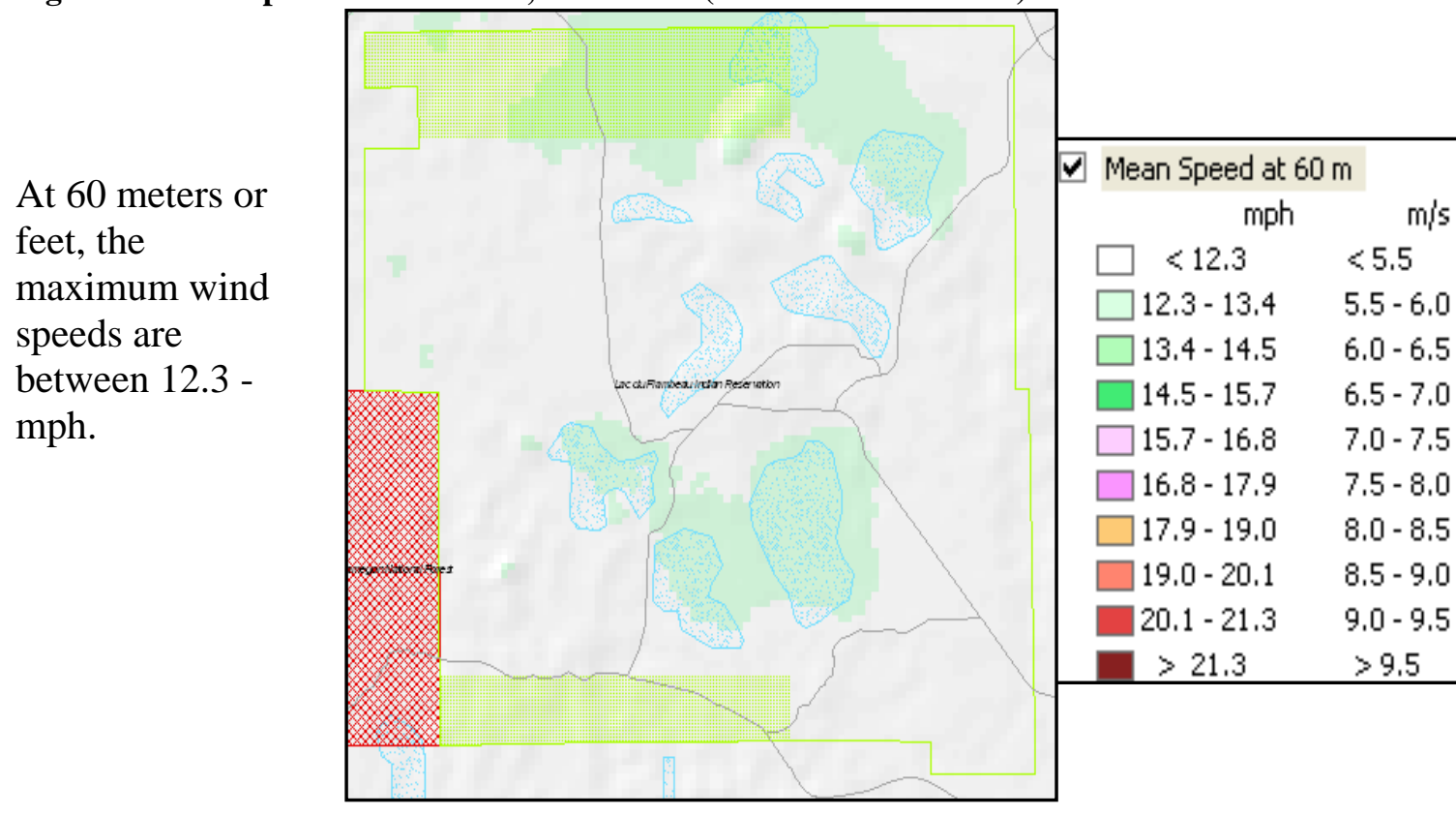

Large scale wind turbines are placed at heights of 197 feet, but these are marginal wind speeds and are not viable to support large scale wind.

\subsubsection{Predominant wind direction}

Direction is an important factor to consider when siting wind turbines so as to understand how obstacles, if any, in the prevailing wind direction will affect the performance of the wind turbine.

The predominant wind direction is presented in 'wind rose' diagrams, which shows how often the wind blows from each direction and how fast the wind blows in each direction. The predominant wind directions for the Lac du Flambeau reservation are the south, southwest, and west. 
Figure 9. Wind rose for Lac du Flambeau

Wind Rose Chart

Longitude -89.89, Latitude $\mathbf{4 5 . 9 8 6}$

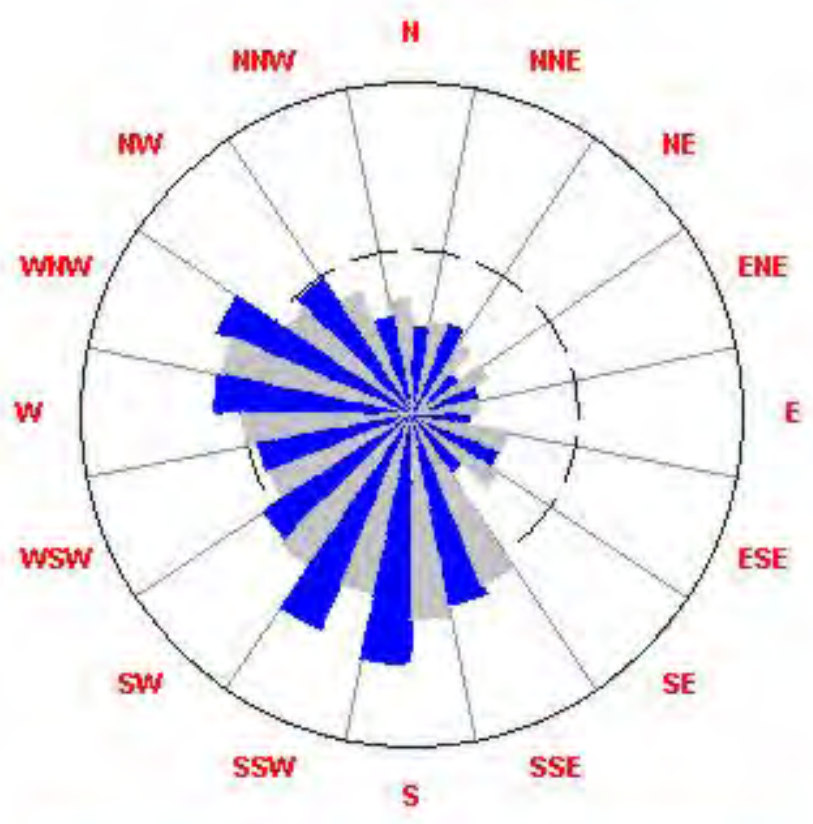

Percent of Total Wind Energy (Blue) and Tirne (Gray):

Circle Center $=\mathbf{0 . 0} \%$

Inner Circle $=7.5 \%$

Outer Circle $=15.0 \%$

The dark blue bars above represent the percent of total wind energy coming from each direction, while the light gray bars represent the percent of total time the wind is coming from the direction. In other words the blue bar represents the strength of the wind and the gray bar represents the frequency.

\subsubsection{Wind shear}

Wind speed increases with rising elevation above ground level. At ground level, friction caused by the interaction of the wind with vegetation, trees, buildings and the naturally occurring contours and topography all slows the wind down. At higher elevations above the ground, the wind moves unimpeded and its speed increases. All other factors being equal, a wind turbine should always be installed on the tallest available tower. The relationship between changes in wind speed and elevation, or wind shear, is well established. The speed at any elevation can be predicted if a reference wind speed, reference elevation and wind shear coefficient are known. Based on the wind speeds estimated at specific heights, the wind shear is estimated mathematically using the following formula:

$\mathrm{V}=(\mathrm{H} / \mathrm{Ho}) \alpha \mathrm{Vo}$ 
where:

$\mathrm{Vo}=$ the reference wind speed;

$\mathrm{V}=$ wind speed at the elevation of interest;

Ho = the reference height; $\mathrm{H}=$ the elevation of interest;

$\alpha=$ alpha: the wind shear coefficient

The appropriate wind shear value is determined by the ground clutter, topography and vegetation at the site. The table below shows the normal range of alpha values as a function of the site's surface characteristics.

Figure 10. Wind shear $(\alpha)$ and surface characteristics. ${ }^{15}$

\begin{tabular}{|l|l|}
\hline Surface Description & Wind Shear $\alpha$ \\
\hline Smooth, hard ground, lake or ocean & 0.10 \\
\hline Short grass on untilled ground & 0.14 \\
\hline Level country with foot-high grass, occasional tree & 0.16 \\
\hline Tall row crops, hedges, a few trees & 0.20 \\
\hline Many trees and occasional buildings & $0.22-0.24$ \\
\hline Wooded country - small towns and suburbs & 0.30 \\
\hline Urban areas with tall buildings & 0.40 \\
\hline
\end{tabular}

A site with a high wind shear value, (i.e. 0.40) means that the wind speeds increase much faster with increasing height due to the complex ground cover.

Most sites at Lac du Flambeau would be subject to wind shears of 0.30 or greater because of the heavily wooded geography.

\subsubsection{Wind speed frequency distribution}

The annual average wind speed does not tell the whole accurate story about the energy available in the wind. To estimate a turbine's energy production more accurately, the frequency of wind speeds must be estimated. The frequency distribution profile shows how many hours per year the wind is expected to blow at any given wind speed. Again, recall that the power available in the wind is proportional to the cube of the wind speed. Two potential turbine sites may have the same average wind speed. But if the wind blows steadily at one site while the other site experiences a lot of calm periods broken up by the occasional gale, a turbine at the first site will produce much more energy than a turbine at the other site.

A Weibull statistical distribution is used to model the wind speed frequency. Historically, measured data has shown that a Weibull distribution is representative of wind speed variations at a given site. Weibull distribution modeling requires three factors - the average wind speed at a site, the wind speed for which one wishes to know the frequency, and a shape factor, "k.” Absent

${ }^{15}$ Source: Analysis of Wind Shear Models and Trends in Different Terrains. M.L. Ray, A.L. Rogers, and J.G. McGowan. University of Massachusetts, Department of Mechanical \& Industrial Engineering Renewable Energy Research Laboratory 
site specific information, a Weibull $\mathrm{K}$ factor of 2 is used. When $\mathrm{k}=2$, the distribution is assumed to be normal.

Absent on-site monitoring data, we have assumed a Weibull $\mathrm{K}$ factor of 2 for Lac du Flambeau.

\subsubsection{Turbulence intensity (TI)}

In practical terms, TI indicates how 'gusty' a wind site is ${ }^{16}$. Gusty or turbulent sites, defined as $\mathrm{TI} \geq 15 \%$, adversely affect energy production and will result in higher maintenance costs over the project life due to increased mechanical fatigue. Avoiding turbulence requires tall towers and good siting.

The turbulence intensity of a particular site is best determined by on-site monitoring, however, without real data, we would estimate the turbulence intensity of turbines at the Lac du Flambeau reservation at $15 \%$, as long as the turbine blades are installed at a height 30 ' higher than any obstacle to the wind within a 500' distance.

\subsubsection{Proper site evaluation criteria}

The performance and ultimate success of any wind energy project is critically dependent on the characteristics of the site. While a region may be blessed with an abundant wind resource, the viability of a particular site may be adversely affected by topography, ground cover, access to power lines, buildings, etc.

For "inside the fence" installations, or wind projects connecting to a facility or Tribely-owned meter, the goal is to site the turbine at the best location on that parcel subject to existing physical and political constraints. At times, it may be necessary to reach the prudent but difficult conclusion that a particular site is not amenable to wind energy development for any number of reasons. If there are no fatal flaws, we then proceed to select a position on the spot that offers the optimal balance of the following factors:

- $\quad$ Best exposure to prevailing winds

- Shortest electrical run to the point of interconnection

- Compliance with all applicable zoning and permitting requirements

Development of commercial wind farms takes a decidedly different approach. Typically a wind farm developer searches for the best tracts of land available that meet a predefined set of criteria. The wind developer has the luxury of searching for the best wind sites to host a project rather than trying to fit a project onto a predefined parcel of land. The primary criteria are nonetheless similar. When a wind developer is searching for land, the following criteria are applied:

- High expected wind resource

- Close proximity to adequately sized power lines

- Favorable regulatory environment for zoning and wind permitting

\footnotetext{
${ }^{16}$ Turbulence intensity (TI) is statistically defined as the standard deviation of wind speed divided by the mean wind speed.
} 
Within this broad framework for site selection, there are a number of detailed factors that merit consideration, including:

- Topography. Ideally smooth topography with few obstructions.

- Proximity to airports. Turbines located with-in a four mile radius of an airport will be under FAA jurisdiction.

- Traditional land use and land ownership. Projects need community development, avoid sites with important cultural value.

- Environmental impact. The environmental impacts of a wind project are minimal.

- Aesthetics. Opponents of wind turbines may pick up on this issue, but according to Wisconsin State Statute 66.0401 renewable energy systems can not be denied for aesthetic reasons.

- Sound. Some sound is produced by a spinning turbine, but if an individual is standing at a distance equal to the height of the turbine, the sound should be equal to other ambient noise.

- $\quad$ Safety. Public health and safety is protected through meeting code and set back requirements.

- Electrical interconnection. The Public Service Commission has Chapter 119, Rules for Interconnection that outline the proper procedure.

- Ordinances and permitting. At this point in time the Tribe does not have a specific wind ordinance, but a turbine may be permitted through a Tribe Resolution??

These are discussed in more detail in the appendices.

\subsubsection{Possible wind turbine locations}

Based on the above criteria and the predominant wind direction, below we list possible locations for wind turbines on the Lac du Flambeau Reservation, including examples of:

- Large energy users (casino and hotel)

- Smaller Tribe facilities (Great Lakes Inter-Tribe Council Building)

- Multi-family housing (Bearskin Circle Apartments and Elder housing)

- Single-family residence (Wayman Lane and Cloud Street)

- Possible Development (Planned DNR facility and Hwy 47/Cemetary Road)

The closest airport to Lac du Flambeau is the Lakeland/Noble F Lee Memorial Field, approximately 7.5 miles to the southeast therefore all of the sites below should not require FAA approval. 
Figure 11. Aerial of Possible Wind Turbine Locations

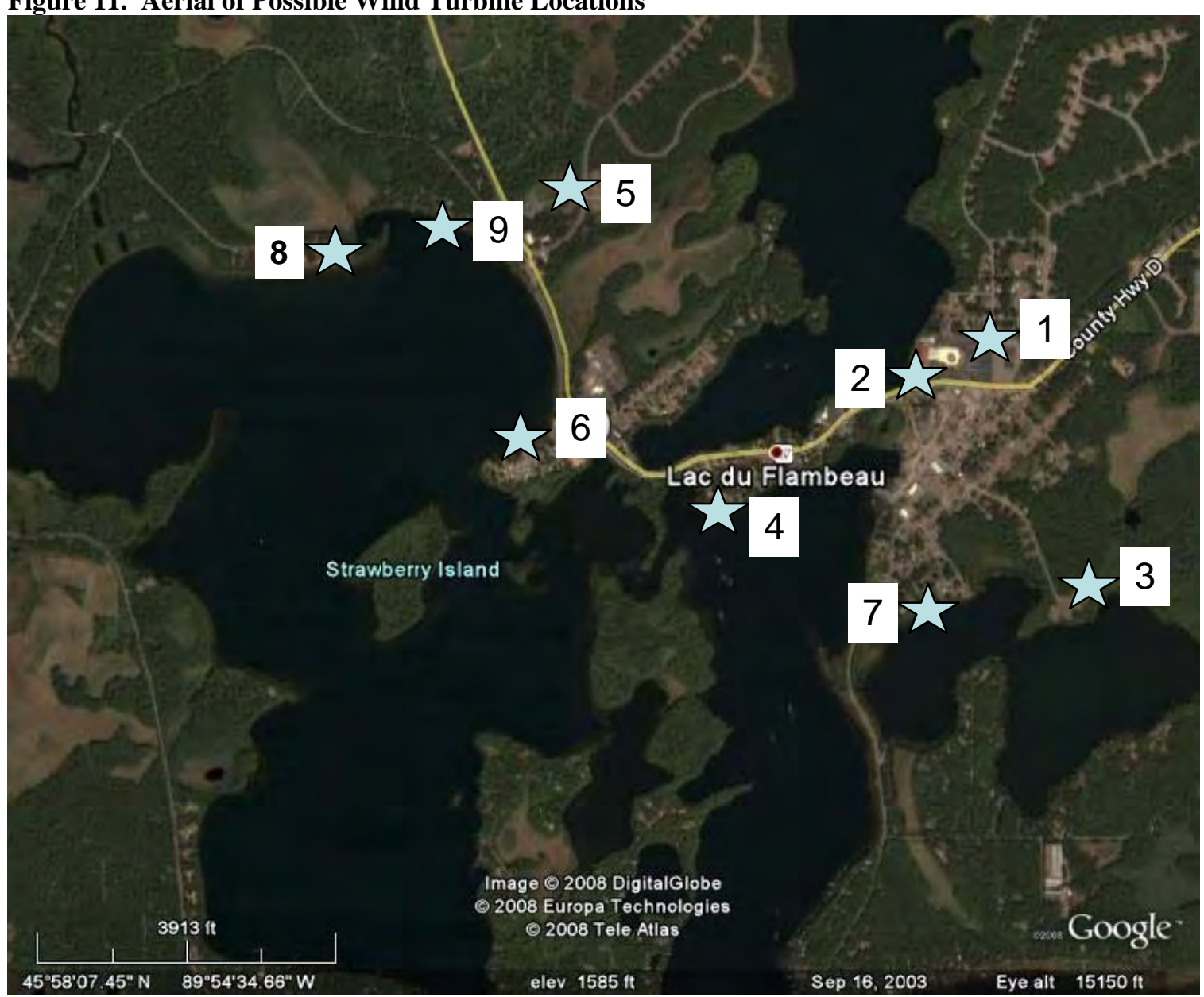

The locations shown above are summarized in Table 18, ranked by appropriate size of wind turbine. Several of the locations listed below include Tribe Housing Authority buildings. We do not know the actual energy consumption of the Tribe Housing locations, but we estimated energy needs based on number of housing units.

Table 18. Summary of Possible Wind Turbine Locations

\begin{tabular}{|l|r|r|r|r|}
\hline \multicolumn{1}{|c|}{ Location } & $\begin{array}{c}\text { Appropriate } \\
\text { Turbine Range } \\
\text { Size (kW) }\end{array}$ & $\begin{array}{c}\text { 2007 } \\
\text { Electricity } \\
\text { consumption }\end{array}$ & $\begin{array}{c}\text { Estimate } \\
60 \mathrm{~m} \text { wind } \\
\text { speed (mph) }\end{array}$ & $\begin{array}{c}\text { Amount of } \\
\text { energy off-set }\end{array}$ \\
\hline 1) Casino & $35-100 \mathrm{~kW}$ & $5,043,793$ & 12.1 & $1-3 \%$ \\
\hline 2) Hotel & $35-100 \mathrm{~kW}$ & $1,380,360$ & 12.1 & $4-7 \%$ \\
\hline 3) Tribe Housing; Elder Housing & $35 \mathrm{~kW}$ & $240,000 *$ & 12.6 & $20-40 \%$ \\
\hline $\begin{array}{l}\text { 4) Tribe Housing; Apartments, } \\
\text { Bearskin Circle }\end{array}$ & $35 \mathrm{~kW}$ & $120,000 *$ & 12.3 & $40-70 \%$ \\
\hline $\begin{array}{l}\text { 5) Great Lakes Inter-Tribe } \\
\text { Council Building* }\end{array}$ & $10-20 \mathrm{~kW}$ & $40,000 *$ & 11.9 & $10-40 \%$ \\
\hline 6) Planned DNR Facilities & $5-20 \mathrm{~kW}$ & $50,000 *$ & 12.4 & $10-150 \%$ \\
\hline 7) Tribe House, Cloud Street & $1-10 \mathrm{~kW}$ & $10,000 *$ & 12.5 & $40-140 \%$ \\
\hline
\end{tabular}




\begin{tabular}{|l|r|r|r|r|}
\hline 8) Tribe House, Wayman Lane & $1-10 \mathrm{~kW}$ & $8,000 *$ & 12.5 & $45-150 \%$ \\
\hline 9) Hwy 47 and Cemetery Road & $1-100 \mathrm{~kW}^{* *}$ & $\mathrm{n} / \mathrm{a}$ & 12.4 & $\mathrm{n} / \mathrm{a}$ \\
\hline
\end{tabular}

*Estimated electricity use

** Depending upon facility constructed here.

The large energy users and the multi-family dwellings will be able to accommodate turbines between 35 - $100 \mathrm{~kW}$ (Sites 1-4 above), while a turbine range of $1-20 \mathrm{~kW}$ is more appropriate for the smaller facilities and single family dwellings (Sites 5 - 8 above). The Hwy 47 and Cemetery Road location will be sized based on the facilities that are developed there (Site 9).

In the Lac du Flambeau wind regime, the appropriate size of a wind turbine is roughly determined by two factors:

- The electrical service at the site - its ampacity and whether it is site single-phase or threephase.

- The wind turbine should be scaled to meet the annual electrical needs of the building. If the wind turbine is greater than $20 \mathrm{~kW}$ power capacity, and the turbine generates excess electricity, then the Tribe will only be paid wholesale rates.

\subsubsection{Estimated turbine energy production and costs}

The below summarizes the cost of a variety of small turbines, and the expected annual energy output for these turbines in $10 \mathrm{mph}$ wind speeds and $12 \mathrm{mph}$ wind speeds. 
Table 19. Typical Prices and Typical Outputs for Installed Systems (Focus on Energy, 2008)

\begin{tabular}{|c|c|c|c|c|c|c|}
\hline Model & $\begin{array}{l}\text { Swept } \\
\text { Area }\end{array}$ & $\begin{array}{l}\text { 'Rated } \\
\text { output' }\end{array}$ & $\begin{array}{l}\text { Typlcal } \\
\text { Tower }\end{array}$ & $\begin{array}{l}\text { Tumkey } \\
\text { Installed } \\
\text { Cost }\end{array}$ & $\begin{array}{l}\text { kWh/year } \\
\text { @ } 10 \mathrm{mph}\end{array}$ & $\begin{array}{l}\text { kWh/year } \\
\text { @ } 12 \mathrm{mph}\end{array}$ \\
\hline Whisper 200 & 64 & $1 \mathrm{~kW}$ & $84^{\prime} \mathrm{T}$ & $\$ 21,000$ & 1,500 & 2,280 \\
\hline Proven 2.5 & 97 & $2.5 \mathrm{~kW}$ & 105' T & $\$ 33,000$ & 3,516 & 5,004 \\
\hline ARE 110 & 110 & $2.5 \mathrm{~kW}$ & 105' T & $\$ 26,000$ & 3,144 & 5,040 \\
\hline Skystream & 115 & $1.8 \mathrm{~kW}$ & $84^{\prime} \mathrm{T}$ & $\$ 19,000$ & 2,880 & 4,560 \\
\hline Whisper 500 & 175 & $3 \mathrm{~kW}$ & 105' T & $\$ 31,000$ & 3,960 & 6,456 \\
\hline Endurance & 254 & $5 \mathrm{~kW}$ & 126' T & $\$ 45,000$ & 4,587 & 8,068 \\
\hline Proven 6.0 & 254 & $5 \mathrm{~kW}$ & $120^{\prime} \mathrm{G}$ & $\$ 62,000$ & 8,004 & 12,996 \\
\hline BWC XL-S & 415 & $10 \mathrm{~kW}$ & $120^{\prime} \mathrm{G}$ & $\$ 60,000$ & 6,240 & 10,800 \\
\hline ARE 442 & 442 & $10 \mathrm{~kW}$ & $120^{\prime} \mathrm{G}$ & $\$ 71,000$ & 14,052 & 21,972 \\
\hline Jacobs $31-20$ & 754 & $20 \mathrm{~kW}$ & $120^{\prime} \mathrm{F}$ & $\$ 77,000$ & 19,728 & 32,292 \\
\hline Entegrity EW 15 & 1,902 & $50 \mathrm{~kW}$ & $120^{\prime} \mathrm{F}$ & $\$ 190,000$ & 50,000 & 88,000 \\
\hline V-15 35-16 & 1,964 & $35 \mathrm{~kW}$ & $110^{\prime} \mathrm{F}$ & $\$ 150,000$ & 43,000 & 64,000 \\
\hline V-17 90-36 & 2,462 & $90 \mathrm{~kW}$ & $132^{\prime} \mathrm{F}$ & $\$ 190,000$ & 62,520 & 101,640 \\
\hline PGE 20/32-16́ & 3,120 & $35 \mathrm{~kW}$ & $120^{\prime} \mathrm{G}$ & $\$ 260,000$ & 56,234 & 79,893 \\
\hline PGE 20/32-36́ & 3,120 & $50 \mathrm{~kW}$ & $120^{\prime} \mathrm{G}$ & $\$ 260,000$ & 70,811 & 105,918 \\
\hline
\end{tabular}

As turbine size increases, the cost per installed $\mathrm{kW}$ decreases, which means the return on investment is typically faster for larger turbines.

To provide context for the turbines listed above, the Tribe homes on the northern lake shores would need a $5 \mathrm{~kW}$ machine to offset their energy usage, based on the energy need of an average home (6,000 kWh annually) and the wind speeds expected at 140 feet along the north and northeast shores of the lakes,.

The 'typical towers' referenced above refer to the tower type typically installed with these types of turbines:

- $\mathrm{G}=$ Guyed Lattice

- $\mathrm{F}=$ Free Standing

- $\mathrm{T}=$ Tilt-up

The tower type will affect the turn-key installed cost of any wind project and therefore the Tribe should explore all tower types when moving ahead with a wind turbine project. 
Wind turbines typically have 2 year warranties.

\subsubsection{Economic performance for wind energy systems}

Wind turbines will offset the use of electricity produced from coal, and the associated externalities of decreased coal emissions are challenging to incorporate into economic scenarios, but must be remembered.

The graph below presents a prioritized list for possible wind development sites based on their estimated wind speed and utility rates, two of the main factors in the economic performance of a wind system. The locations have been divided into four groups.

Group 1 represents locations that have access to the faster wind speeds off the lake, are appropriate for larger systems, and will most likely have the highest utility rates. These factors together will create a faster return on investment.

Group 2 represents locations that have access to the faster wind speeds and will have the highest utility rates. However, these locations are single Tribe homes therefore the wind system will need to remain smaller than $20 \mathrm{~kW}$.

Group 3 represents locations that are more complicated due to their proximity further inland, or have location next to high volumes of people and visitors. Theses sites also have slower wind speeds.

Group 4 represents locations along the northern sides of the lakes that have not yet been developed. We recommend waiting to install systems in these locations until a building or electrical load is needed there.

Table 20. Ranked list of turbine developments

\begin{tabular}{|c|l|c|l|}
\hline Group & \multicolumn{1}{|c|}{ Location } & $\begin{array}{c}\text { Estimate 60 m } \\
\text { wind speed (mph) }\end{array}$ & \multicolumn{1}{|c|}{ Rate } \\
\hline 1 & Planned Natural Resource Facilities* & 12.4 & Cg 1 \\
\hline 1 & Tribe Housing; Elder Housing* & 12.6 & unknown \\
\hline 1 & Tribe Housing; Apartments, Bearskin Circle* & 12.3 & unknown \\
\hline 2 & Tribe House, Cloud Street* & 12.5 & unknown \\
\hline 2 & Tribe House, Wayman Lane* & 12.5 & unknown \\
\hline 3 & Casino & 12.1 & Cg 1 \\
\hline 3 & Hotel & 12.1 & Cg 20 \\
\hline 3 & Great Lakes Inter-Tribe Council Building* & 11.9 & unknown \\
\hline 4 & Hwy 47 and Cemetery Road & 12.4 & unknown \\
\hline
\end{tabular}

The economic performance of a wind system is also contingent on several other factors, therefore in our financial analysis of wind systems, we include:

- The electrical rate at the facility 
- The expected amount of wind energy produced: impacted by wind speed and turbulence of the site, and its access to predominant wind direction

- The cost per installed kW capacity of the wind turbine

- Available grants and incentives

The Tribe has several incentives available to pay for their wind system, including:

- Net-metering with WPS or energy displacement

- Focus on Energy Incentives ${ }^{17}$ :

- Green Tags or Carbon Credits

- Tax Credits (in certain ownership structures)

- USDA Farm Bill “REAP” grant

In order to demonstrate the impacts of these variables on the economic performance of a wind system, we will compare the economic performance of the following systems in both a Baseline Scenario and an Optimistic Scenario:

- a $10 \mathrm{~kW}$ system with an electricity rate of $\$ 0.10$ / $\mathrm{kWh}$ in a $12.6 \mathrm{mph}$ wind regime with open access to the predominant wind direction (representative of the Elks Point Tribe Elder Housing location)

- a $10 \mathrm{~kW}$ system with an electricity rate of $\$ 0.10$ / $\mathrm{kWh}$ in a $11.9 \mathrm{mph}$ wind regime with a turbulent wind site (representative of the Great Lakes Inter-Tribe Council location)

- a $10 \mathrm{~kW}$ system with a $\$ 0.06$ / $\mathrm{kWh}$ charge and a $\$ 10$ per $\mathrm{kW}$ in a $12.1 \mathrm{mph}$ wind regime (representative of the Casino and Hotel location)

Again, for the Economic Scenarios, we include the following assumptions outlined below.

${ }^{17}$ For more detailed information on these grants, please visit:www.focusonenergy.com/Incentives/ 
Table 21. Financial variables for wind energy systems

Baseline Scenario

\begin{tabular}{ll}
\hline \multicolumn{3}{c}{ Variables affecting Cost of Solar System: } \\
Focus on Energy & $25-35 \%$ of installed cost \\
15-year Loan Interest Rate & $3 \%$ \\
Lower value of REC's & Wind: 7\% of installed cost \\
\hline \multicolumn{2}{c}{ Variable affecting Cost of WPS Electricity: } \\
\hline Annual Energy Rate Increase & $3.7 \%$ \\
\hline
\end{tabular}

\section{Optimistic Scenario}

\begin{tabular}{ll}
\hline \multicolumn{3}{c}{ Variables affecting Cost of Solar System: } \\
Focus on Energy & $25-35 \%$ of installed cost \\
15-year Loan Interest Rate & $1.5 \%$ \\
MACRS (Depreciation Rate) & $\sim 20 \%$ of installed cost \\
Federal Investment Tax Credit & $30 \%$ \\
\hline Higher value of REC's & Wind: 15\% of installed cost \\
\hline \multicolumn{2}{c}{ Variable affecting Cost of WPS Electricity: } \\
Annual Energy Rate Increase & $7 \%$
\end{tabular}

The table below demonstrates the difference in energy production and return in investment when a turbine in placed in a slower wind speed area or has a low electricity rate.

Table 22. Baseline financial comparison for a $10 \mathrm{~kW}$ turbine at three different sites

\begin{tabular}{|l|l|l|l|}
\hline Variable & GLITC & Elks Point & Casino \\
\hline Wind speed at 60 meters & $11.9 \mathrm{mph}$ & $12.6 \mathrm{mph}$ & $12.1 \mathrm{mph}$ \\
\hline Turbulence Intensity & $20 \%$ & $15 \%$ & $20 \%$ \\
\hline Wind Shear & 0.40 & 0.25 & 0.30 \\
\hline WPS charge per kWh & $\$ 0.11$ & $\$ 0.11$ & $\$ 0.06$ \\
\hline Annual Energy Output of 10kW & $\mathbf{1 1 , 4 0 0} \mathbf{~ k W h}$ & $\mathbf{1 6 , 8 0 0} \mathbf{~ k W h}$ & $\mathbf{1 3 , 8 9 0 ~} \mathbf{k W h}$ \\
\hline Amount of CO2 reduced annually & 13.7 tons & 20.2 tons & 16.6 tons \\
\hline Baseline Turbine Cost after Focus & $\mathbf{\$ 6 1 , 3 6 7}$ & $\mathbf{\$ 5 5 , 1 8 2}$ & $\$ 58,545$ \\
\hline $\begin{array}{l}\text { Baseline Turbine Cost for 30 Years (includes } \\
\text { loan interest and maintenance) }\end{array}$ & $\mathbf{\$ 1 0 1 , 1 0 8}$ & $\mathbf{\$ 9 3 , 3 3 6}$ & $\mathbf{\$ 9 7 , 5 6 2}$ \\
\hline Baseline WPS Electricity Cost after 30 Years & $\mathbf{\$ 6 6 , 3 6 6}$ & $\mathbf{\$ 9 7 , 8 0 3}$ & $\mathbf{\$ 4 0 , 0 0 0}$ \\
\hline $\begin{array}{l}\text { Amount of Grants/Capital funds to break } \\
\text { even with Baseline WPS after 30 years }\end{array}$ & $\mathbf{\$ 2 7 , 7 0 0}$ & $\mathbf{\$ 0}$ & $\mathbf{\$ 3 9 , 0 0 0}$ \\
\hline
\end{tabular}

The summary above reiterates two of the most important factors when judging the economic performance of a wind turbine: 1 ) the access to smooth, faster wind speeds and 2) the electrical rate of the facility. Elks Point, for example, is expected to experience lower turbulence levels, have access to higher wind speeds, and a have a lower wind shear, which means the turbine can operate at a greater capacity. A turbine at Elks Point is expected to produce about 5,000 kWh more per year than the same turbine at GLITC. This extra energy production means that after 30 years, the cost to install and maintain a turbine at Elks Point will have cost the Tribe less than purchasing electricity through WPS. A turbine at GLITC will require \$33,200 in grants (in a Baseline Scenario) to break even with WPS costs after 30 years. 
The Casino would require $\$ 39,000$ in grants to break even with WPS after 30 years. The Casino is predicted to be a better wind site than GLITC, but the low energy charge for the Casino means that there is a slower return on investment. However, as mentioned with the solar projects, a turbine at the casino would receive high visibility and provide a greater educational and marketing opportunity.

In an Optimistic Scenario, the economic performance of every turbine is improved greatly.

Table 23. Optimistic financial comparison for three wind sites

\begin{tabular}{|l|r|r|r|}
\hline Variable & GLITC & Elks Point & \multicolumn{1}{l|}{ Casino } \\
\hline Annual Energy Output of Turbine & $11,400 \mathrm{kWh}$ & $16,800 \mathrm{kWh}$ & $13,889 \mathrm{kWh}$ \\
\hline Total turbine cost after 30 years* & $\$ 13,299$ & $\$ 8,362$ & $\$ 11,009$ \\
\hline $\begin{array}{l}\text { Total WPS cost after 30 years to } \\
\text { purchase the AEO equivalent }\end{array}$ & $\$ 117,495$ & $\$ 173,151$ & $\$ 84,252$ \\
\hline
\end{tabular}

*The 30 year cost for each location is different because the Focus on Energy Grant is based on expected Annual Energy Output. The Elks Point is predicted to be the best wind location, therefore the Focus grant for this location is the largest.

In the Optimistic Scenario, installing a $10 \mathrm{~kW}$ turbine will save the Tribe between $\$ 73,000$ and $\$ 164,000$ over 30 years.

Below we summarize the 30-year Life Cycle Analysis for the Elks Point location, in a Baseline and Optimistic Scenario, with the assumptions for each scenario listed below. 
Table 24. 30-Year Life Cycle Analysis for Elks Point in a Baseline and Optimistic Scenario (16,800 kWh per year)

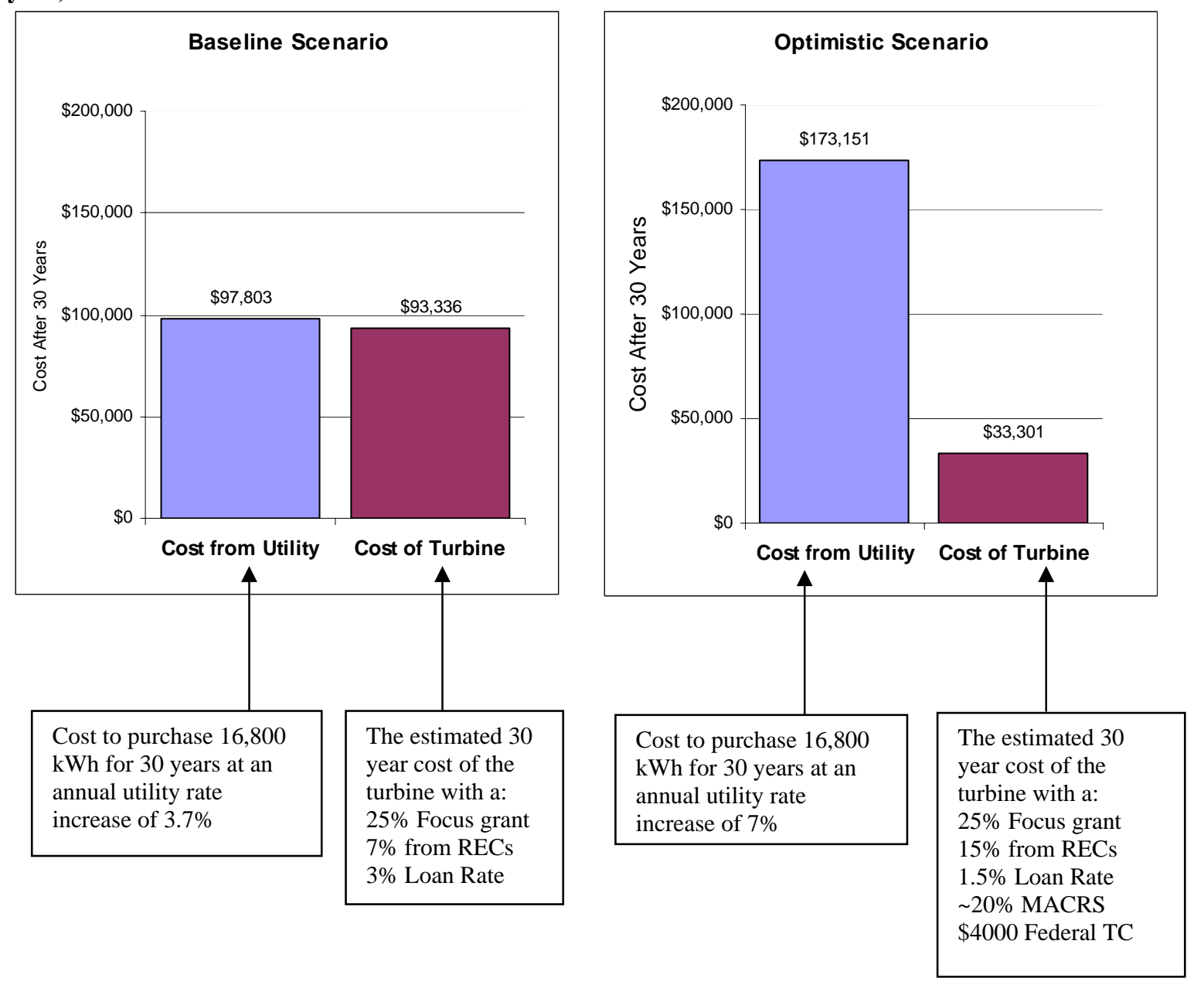

The cost benefits of wind energy are highly dependent upon the wind speed and utility's rates. The graph above demonstrates the sensitivity of the economic payback on the utility rate increase and the amount of incentives available to the Tribe.

Please see the Building summary for the economic performance of other sites.

\subsubsection{Wind Resources}

Midwest Renewable Energy Association: www.the-mrea.org

Focus on Energy: www.focusoneneryg.com

American Wind Energy Association: www.awea.org

Websites of Small Wind Manufacturers on AWEA: http://www.awea.org/smallwind/smsyslst.html

Renew Wisconsin Small Wind Toolbox: Www.renewwisconsin.org 
Task Four: Wind and Solar Technologies

Seventh Generation Energy Systems

\subsection{Appendices}

\subsubsection{Farm Bill Renewable Energy Provisions}

The following is a brief summary of the authorities found under Title IX of the 2008 Farm Bill. The sections referenced are ones contained in the 2002 Farm Bill that are amended by the Section 9001 of the 2008 Farm Bill.

\section{Section 9002: Biobased Market Program}

Provides provisions for a federal procurement program and a voluntary labeling program for biobased products. The bill provides \$1 million in mandatory Fiscal Year (FY) 2008 funding and \$2 million per year from FY 2009 through 2012. Additionally, the bill authorizes additional funds in the amount of \$2 million per year, from FY 2009 to 2012.

\section{Section 9003: Biorefinery Assistance Program}

Provides loan guarantees for the development, construction and retrofitting of commercial-scale biorefineries, and grants to help pay for the development and construction costs of demonstration-scale biorefineries. Provides \$75 million in FY 2009 and \$245 million in FY 2010 for commercial-scale biorefinery loan guarantees. It also authorizes funding of \$150 million per year starting in FY 2009 and continuing through FY 2012 for both demonstration- and commercial scale biorefineries.

\section{Section 9004: Repowering Assistance}

Provides for payments to biorefineries (that were in existence at the time the 2008 Farm Bill was passed) to replace fossil fuels used to produce heat or power to operate the biorefineries with renewable biomass. The bill provides \$35 million for FY 2009 that will remain available until the funds are exhausted. The bill also authorizes additional funding of \$15 million per year, from FY 2009 through 2012.

\section{Section 9005: Bioenergy Program for Advanced Biofuels}

Provides for payments to be made to eligible agricultural producers to support and ensure an expanding production of advanced biofuels. The bill provides \$55 million in FYs 2009 and 2010, \$85 million in FY 2011, and \$105 million in FY 2012. Additionally, the bill authorizes additional funds in the amount of \$25 million per year, from FY 2009 to 2012.

\section{Section 9006: Biodiesel Fuel Education Program}

Provides competitive grants to eligible entities to educate government and private entities that operate vehicle fleets and the public about the benefits of biodiesel fuel use. The bill provides \$1 million in funds per year, from FY 2008 to 2012 .

\section{Section 9007: Rural Energy for America Program}

Expands and renames the program formerly called the Renewable Energy Systems and Energy Efficiency Improvements Program. Under the expansion, hydroelectric source technologies will be added as eligible; energy audits will be included as eligible costs, and; loan limits will be increased. The bill provides $\$ 55$ million for FY 2009, \$60 million for FY 2010, and \$70 million for FYs 2011 and 2012. It also authorizes additional funds of \$25 million per year, from FY 2009 through 2012.

\section{Section 9008: Biomass Research and Development Initiative}

Provides competitive grants, contracts and financial assistance to eligible entities to carry out research on and development and demonstration of biofuels and biobased products, and the methods, practices and technologies for their production. The bill provides \$20 million in funds in FY 2009; \$28 million in FY 2010; \$30 million in FY 2011 and \$40 million in FY 2012. In addition, there is a funding authorization of \$35 million per year, from FY 2009 through 2012.

\section{Section 9009: Rural Energy Self-Sufficiency Initiative}

Provides grants for the purpose of enabling eligible rural communities to substantially increase their energy selfsufficiency. The bill authorizes funds of \$5 million per year, beginning in FY 2009 and continuing through FY 2012. 


\section{Task Four: Wind and Solar Technologies \\ Seventh Generation Energy Systems}

\section{Section 9010: Feedstock Flexibility Program for Bioenergy Producers}

Subsidizes the use of sugar for ethanol production through federal purchases of surplus sugar for sale to ethanol producers. Funds will be provided in sufficient amounts to carry out this program.

\section{Section 9011: Biomass Crop Assistance Program}

Provides support to establish and produce crops for conversion to bioenergy in project areas, and to help with collection, harvest, storage and transportation of eligible material for use in a biomass conversion facility. The program will be implemented by the Farm Service Agency with support from other federal and local agencies.

\section{Section 9012: Forest Biomass for Energy}

The bill authorizes the Forest Service to conduct a comprehensive research and development program to use forest biomass for energy. The Forest Service, other federal agencies, state and local governments, Indian Tribes, landgrant colleges and universities, and private entities are eligible to compete for program funds. Priority research projects include:

- The use of low-value forest biomass for energy from forest health and hazardous fuels reduction treatment.

- The integrated production of energy from forest biomass into biorefineries or other existing manufacturing.

- The development of new transportation fuels from forest biomass.

- The improved growth and yield of trees for renewable energy production.

\section{Section 9013: Community Wood Energy Program}

Provides grants to state and local governments to develop community wood energy plans and to acquire or upgrade wood energy systems. The bill authorizes funds in the amount of \$5 million per year from FY 2009 through FY 2012. 
Task Four: Wind and Solar Technologies
Seventh Generation Energy Systems

\subsubsection{Wind Turbine Siting Criteria}

Rarely is there one 'perfect' spot to site a wind turbine. Instead the preferred site represents a balanced series of trade-offs between competing criteria. In general, optimal turbine placement is a decision that maximizes turbine performance and minimizes economics and social concerns.

\section{Topography}

Topography effects how quickly wind can move across the land and if the wind flows in a straight stream or if it is turbulent. Wind shear is the change in wind speed with height above the ground, as the wind encounters fewer obstructions. Not only can choosing locations with a smooth, obstruction-free access to wind improve the chances of a higher wind speed, but it decreases the amount of turbulence in the wind. Turbines close to lakes, such as offshore wind turbines or a turbine on the north side of Flambeau Lake or Fence Lake, are good locations due to the expected lower wind shear and turbulence.

Swirling, turbulent wind not only can not be effectively harvested, it causes premature failure of a wind turbine. As a rule of thumb, the effect of an outcropping of rocks or a house and other such obstacles extends to a height and to a distance downwind of 10-20 times the obstacle height.

\section{Traditional land use and land ownership}

In order for a wind energy project to be successful, it should have the broad support of members of the community. When evaluating potential sites, be sure to clearly identify historical and cultural land use, as well as land ownership and access routes to the site. Projects should avoid sites with significant historical value or that are used for recreation or hunting.

\section{Environmental impact}

The environmental impact of wind turbines is minimal especially when compared to nuclear and fossil fuel energy resources. However, no form of electric generation is impact-free. There will be minor short term and long term environmental impacts associated with any wind energy project. Short term impacts are due primarily to construction activities. Long term impacts stem from the ongoing operation and maintenance of the wind turbine. The effects are typically limited to: aesthetics, sound, avian impact, and safety.

Even if the Tribe law does not require an environmental assessment or environmental impact statement, the Tribe may want to work with their Tribe environmental department to assess the potential impact of a wind turbine.

Avian impact has been more thoroughly researched than any other aspect of wind energy operations. The data is clear - on average, a commercial scale wind turbine can be expected to cause two bird deaths per year. This is an insignificant mortality source as compared to all sources of bird deaths. Moreover, there is no known avian threat caused by small-scale wind turbines. Due diligence during the development process should attempt to avoid known migratory routes of birds and bats, and habitats of threatened endangered species.

\section{Aesthetics}

Aesthetics have been repeatedly raised as a major concern by opponents when new wind turbines are being proposed and developed. If the Tribe proceeds with a wind project, the Tribe should, at a minimum, discuss this issue with people in the community and within view of the project, and listen to their concerns.

\section{Sound}

Wind turbines make sound as the blades turn through the air and small turbines are noisier than large turbines. Our experience with both small and very large wind turbines is that the noise of blowing wind is louder than the noise made by the turbines. However, it is important to recognize that there is some sound produced and that the monitoring station and turbines should be sited far enough away from homes to avoid any potential conflict 18 .

\section{Safety}

${ }^{18}$ Daniel J. Alberts: “Primer for Addressing Wind Turbine Noise”, Nov. 20, 2005, p. 9. 


\section{Task Four: Wind and Solar Technologies Seventh Generation Energy Systems}

Public health and safety is protected through common sense measures usually applied at the local level to ensure a safe and reliable wind energy installation. Safety is assured through two primary means:

- $\quad$ Code compliance

- $\quad$ Set back requirements

Wind turbines should be designed and installed in accordance with all applicable state, utility, national and international codes. Compliance should be assured for the foundation, tower, and electrical systems.

Wind turbines should be installed in accordance with standard set back requirements. This will minimize the chance of an incident involving anyone other than project personnel or the system owner.

\section{Electrical Interconnection}

There are specific technical and engineering requirements that govern the electrical interconnection between a wind turbine and the grid. For small and mid-size machines, the turbine should be located as close to the point of interconnection as possible to keep costs under control. In general, its best to keep wire runs under 1000 feet. Critical components of the interconnection include:

- $\quad$ Electrical safety: over/under voltage, frequency and over current protection

- Lightening protection

- $\quad$ Proper system grounding

- $\quad$ Adequate controls and shut down capability

These factors are integrated elements of most commercially available wind turbines and any qualified wind turbine installer will ensure a safe and fully code compliant system installation.

In Wisconsin, the interconnection process is standardized and governed by PSCW 119 "Rules for Interconnecting Distributed Generation Facilities”. The scope and cost of the interconnection process depends on the size of the generator. Applications for home-sized systems $20 \mathrm{~kW}$ or less are easy to fill out and are free. See the Wisconsin Public Service Commission for more information: http://psc.wi.gov/.

\section{Ordinances and Permitting}

By far, the best vehicle to address public health and safety concerns is through the promulgation of a local, county, state or Tribe wind zoning ordinance. A copy of the Wisconsin model zoning ordinance is available in the RENEW Wisconsin Small Wind Toolbox (www.renewwisconsin.org). The Tribe may want to consider amending and adopting a variation of the zoning ordinance.

A permit may be required by the local or Tribe government prior to the installation of a wind energy system. The permit may cover the electrical subsystem and/or foundation as well as the entire system under a building permit. Permitting agencies will want to verify the system or its components are designed and will be built according to industry standards. Permit fees vary and the process can be as simple as filling out a form or as complicated as multiple public hearings. Find out what information your jurisdiction requires early in the process. 


\subsection{Exhibits}

The following exhibits are considered supporting documentation for this report but are separate files presented with this report.

1.9.1 Non-residential Wind Site Assessment for Lac du Flambeau; Seventh Generation

1.9.2 Non-residential Solar Thermal Report for Lake of the Torches Hotel; Jamie Paterson

1.9.3 Non-residential Solar Thermal Report for Lac du Flambeau School; Jamie Paterson 
Task Four: Wind and Solar Technologies Seventh Generation Energy Systems

1.9 .4 


\section{Focus on Energy \\ Wind Turbine Site Assessment}

Submitted to:

Lac du Flambeau c/o Bryan Hoover

Lac du Flambeau Tribal Natural Resources Department PO Box 67

Lac du Flambeau, WI 54538

715.588.7214

hooverb2003@yahoo.com

Focus Coupon: \#356

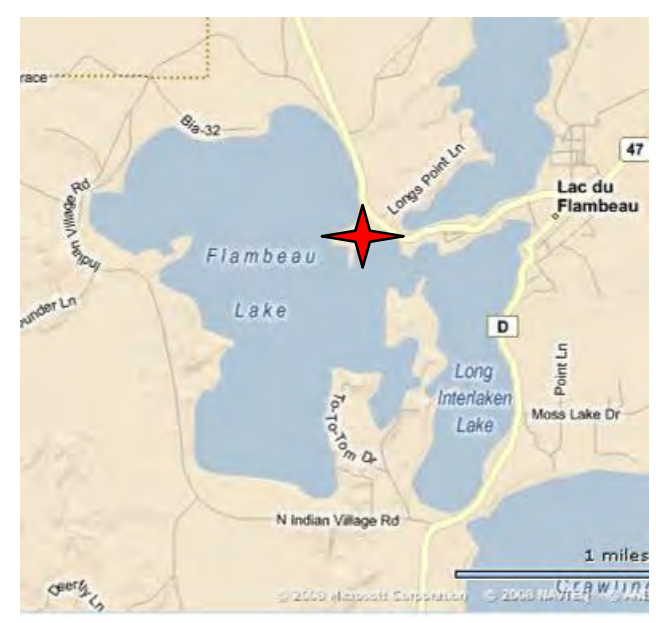

\section{SEVENTH \\ GENERAT I ON \\ or \\ E N E R G Y \\ SYSTEMS}

Submitted by:

Seventh Generation Energy Systems, Inc.

100 South Baldwin Street, Suite 304

Madison, WI 53703

www.seventhGenergy.org

info@seventhGenergy.org

Phone: 877-222-9201

Fax: 866-762-7496

November 3, 2008

\section{Project Overview}

The Lac du Flambeau Tribe is interested in installing renewable energy systems as part of their new Department of Natural Resources office space. The office space is intended to be a model and education center for green building for the Tribe and surrounding region. 
Acres: 20 acres (the approximate area of the peninsula)

Elevation: 1590 feet

Soil Type: mix of sand, silt, gravel, and clay

Nearest Airport: Lakeland/Noble F Lee airport, 9 miles to the SE

Latitude: $45^{\circ} 58^{\prime} 12.98 " \mathrm{~N}$

Longitude: $89^{\circ} 54^{\prime} 37.16^{\prime \prime} \mathrm{W}$

Minimum tower height: 91 ' for an ARE 110

Wind speed at minimum tower height: $10.4 \mathrm{mph}$ at 91 '

Annual load: planned facility estimated to be $\sim 25,000 \mathrm{kWh}$

Municipality: Lac du Flambeau Indian Reservation

County: Vilas County

Electricity: WPS (Focus)

Gas: $n / a$ (facility is served with LP, not natural gas)

\section{EXECUTIVE SUMMARY}

The site reviewed for this Lac du Flambeau wind site assessment is a decent location for a wind system, located at the tip of a peninsula in one of the Reservation's lakes. The Wisconsin Wind Map predicts a wind speed of $12.5 \mathrm{mph}$ at 60 meters at this site on the peninsula. The majority of the Reservation land is populated with tall pine trees, between 50 and 65 feet tall, which are not conducive to effective production from wind turbines because of the slower wind speeds at regular tower heights for small turbines (typically under 140 feet). The need for significantly taller towers to reach viable wind speeds would typically make wind projects in this area not cost-effective. However, the locations that are on the north side of the Lac du Flambeau lakes have access to the predominant southern wind direction and will have access to faster wind speeds than most locations on the reservation. Because it is not economically feasible to monitor the wind speeds for small turbines (turbines $<100 \mathrm{~kW}$ ), the wind estimates as predicted by the Wisconsin Wind Map for this site were used in the analysis of this report.

The Tribe should be able to provide a portion or all of their electricity needs for the planned natural resources office with a turbine. An investment in a turbine would provide energy independence against increasing electrical prices, and it would support clean energy.

Several turbines are presented in this site assessment to provide a wide scope on system size, efficiency and cost. The following table is a summary of the five turbines in this report and their expected annual energy output in an $\mathbf{1 1 . 1} \mathrm{mph}$ wind speed, at 120' tower height, and system cost after incentives.

Table 1. Wind turbine output and cost summary for Site One.

\begin{tabular}{|l|c|c|c|c|c|}
\hline Manufacturer & ARE 110 & Endurance & ARE 442 & $\begin{array}{c}\text { Proven } \\
\text { WT 15 }\end{array}$ & PGE 20/35 \\
\hline $\begin{array}{l}\text { Annual Energy } \\
\text { Output (kWh) }\end{array}$ & 3,109 & 4,785 & 13,419 & 17,390 & 66,859 \\
\hline $\begin{array}{l}\text { System Cost After } \\
\text { Focus }\end{array}$ & $\$ 30,041$ & $\$ 42,773$ & $\$ 59,154$ & $\$ 91,775$ & $\$ 200,000$ \\
\hline $\begin{array}{l}\text { System Cost After } \\
\begin{array}{l}\text { Focus, MACRS and } \\
\text { Business Tax Credit }\end{array}\end{array}$ & $\$ 15,141$ & $\$ 21,723$ & $\$ 30,354$ & $\$ 50,575$ & $\$ 103,000$ \\
\hline
\end{tabular}

The energy outputs and costs in this report are just estimates. Current costs should be verified with installers and energy outputs will be verified through turbine performance monitoring at the site. 


\section{Table of Contents:}

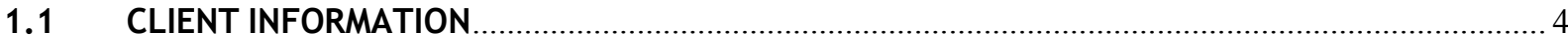

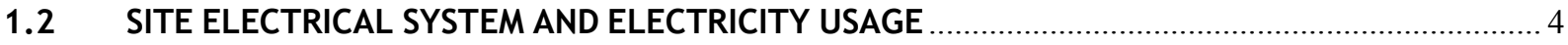

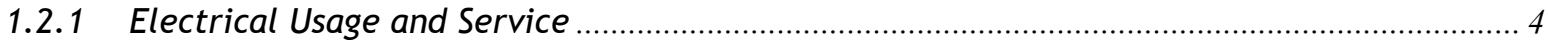

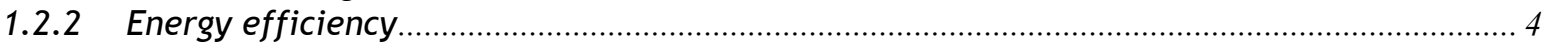

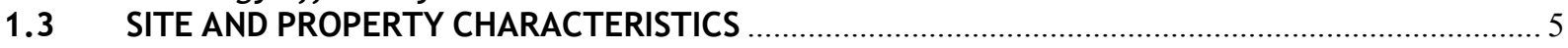

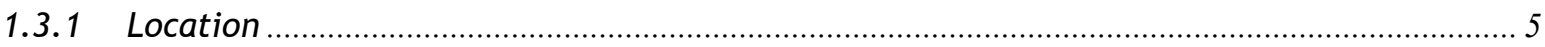

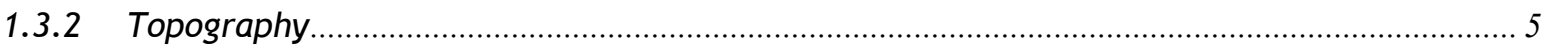

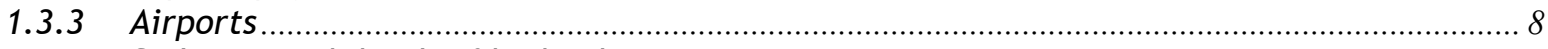

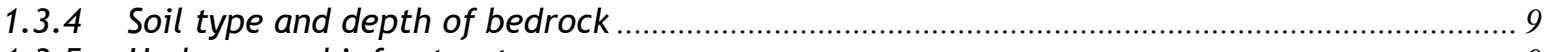

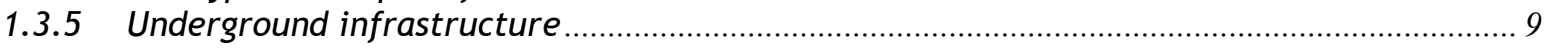

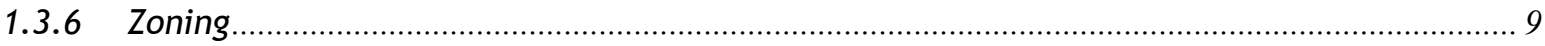

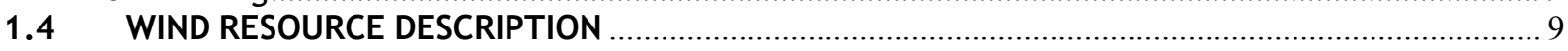

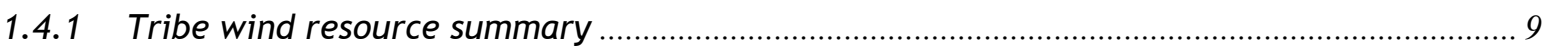

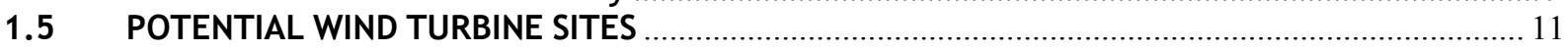

1.5.1 Site One - 1000' south-west of proposed Natural Resources office ................................... 12

1.5.2 Anecdotal analysis of a second site (more info required) - 600' south east of proposed

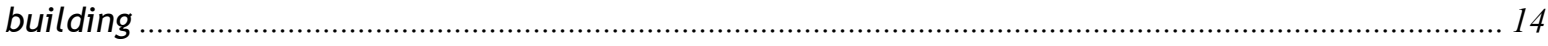

1.6 TURBINE POSSIBILITIES

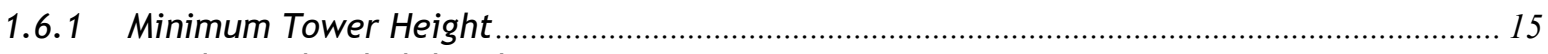

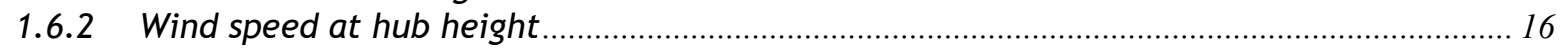

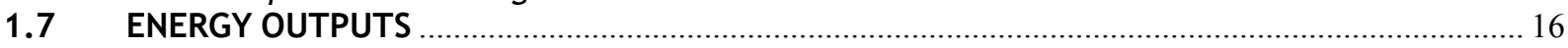

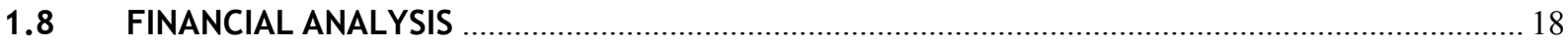

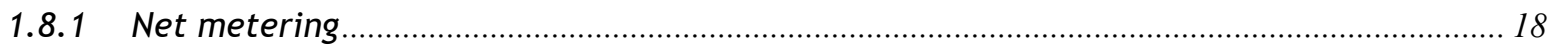

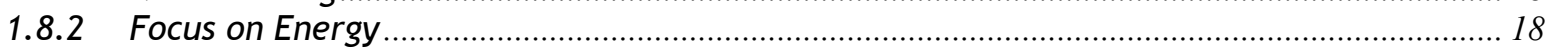

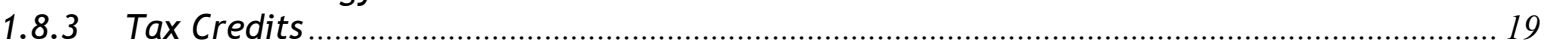

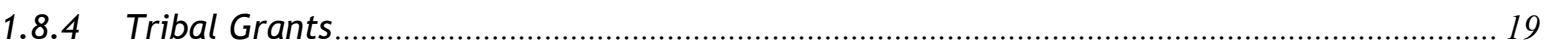

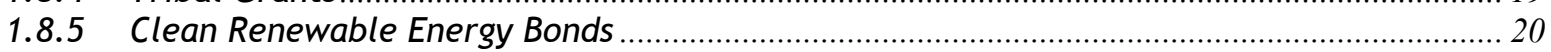

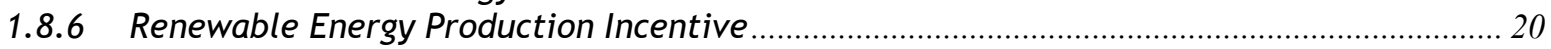

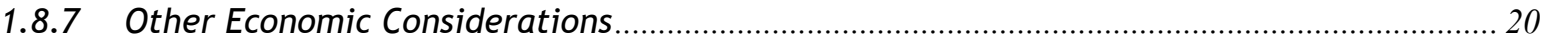

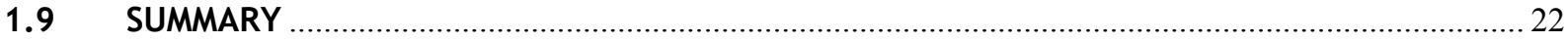

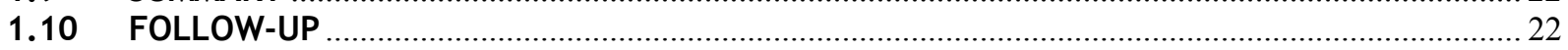

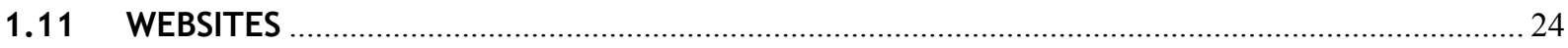

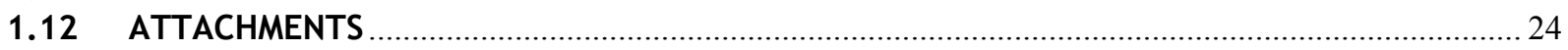

\section{Table of Appendices:}

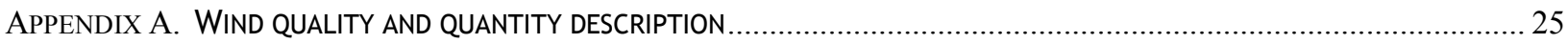

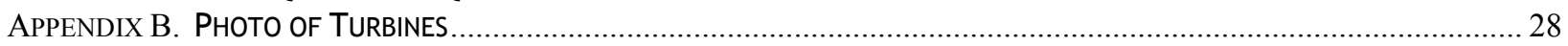

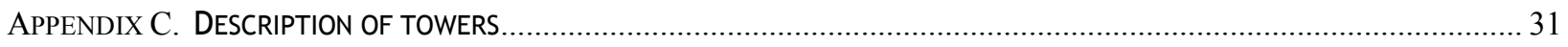




\subsection{CLIENT INFORMATION}

The Tribe is investigating renewable energy systems for economic, environmental, and self reliance reasons.

The Tribe's wind system would be a new development project for their site. Currently the site is a campground, and this land use may continue, but the Tribe would like to demonstrate their commitment to renewable energy as well as demonstrate the applications of renewable energy at their new Department of Natural Resources office space. The earliest turbine installation would be fall 2009. The Tribe would like to secure a maintenance contract for technical turbine services, but is interested in training Tribal members to conduct basic maintenance.

\subsection{SITE ELECTRICAL SYSTEM AND ELECTRICITY USAGE}

The site has access to three phase on Hwy 47, passing the peninsula where the new building is to be located. Currently, there is no electrical infrastructure at the location of the new building.

\subsubsection{Electrical Usage and Service}

The energy load of the new building is estimated to be 25,000 kWh per year (a total of the consumptions of current DNR offices). However, the building is expected to be a model of efficiency, therefore the energy consumption may be less.

The Tribe has also expressed interest in connecting the turbine to the new campground office space or the bath houses, whose combined annual energy consumption is around 80,000 kWh per year, however this is yet to be determined.

The site is expected to be on the Commercial General Service (Cg1) at 10.9 cents per $\mathrm{kWh}^{1}$.

\subsubsection{Energy efficiency}

When undertaking a renewable energy project, it is important, and economical, to make the buildings as energy efficient as possible. Typically every dollar spent on energy efficiency results in a savings of about $\$ 3$ - 5 when sizing a wind turbine to meet your load.

Tribe is planning on incorporating many energy efficiency measures at their new building, specifically through working with Focus on Energy. The "New Construction" program offers information, consultant support and incentives. More information can be found at: www.focusonenergy.com/Business/New-Business-Construction

\footnotetext{
${ }^{1}$ WPS Rates: www.wisconsinpublicservice.com/business/wielecrate.aspx
} 


\subsection{SITE AND PROPERTY CHARACTERISTICS}

\subsubsection{Location}

The Reservation is located in northern Wisconsin, about 15 miles northeast of Minocqua/Woodruff. The turbine location is on a peninsula in Flambeau Lake that is on Tribal Trust land. Aside from the peninsula, the Reservation is heavily forested with pine trees reaching an average height of 60'.

\subsubsection{Topography}

The Tribe's site (1590' elevation) lies on the south side of the peninsula, which enters the lake from the north-east side. The topography is extremely flat, almost no rise in elevation across the Reservation.

Figure 1. Distant Topographical Map (DeLorme Topo)

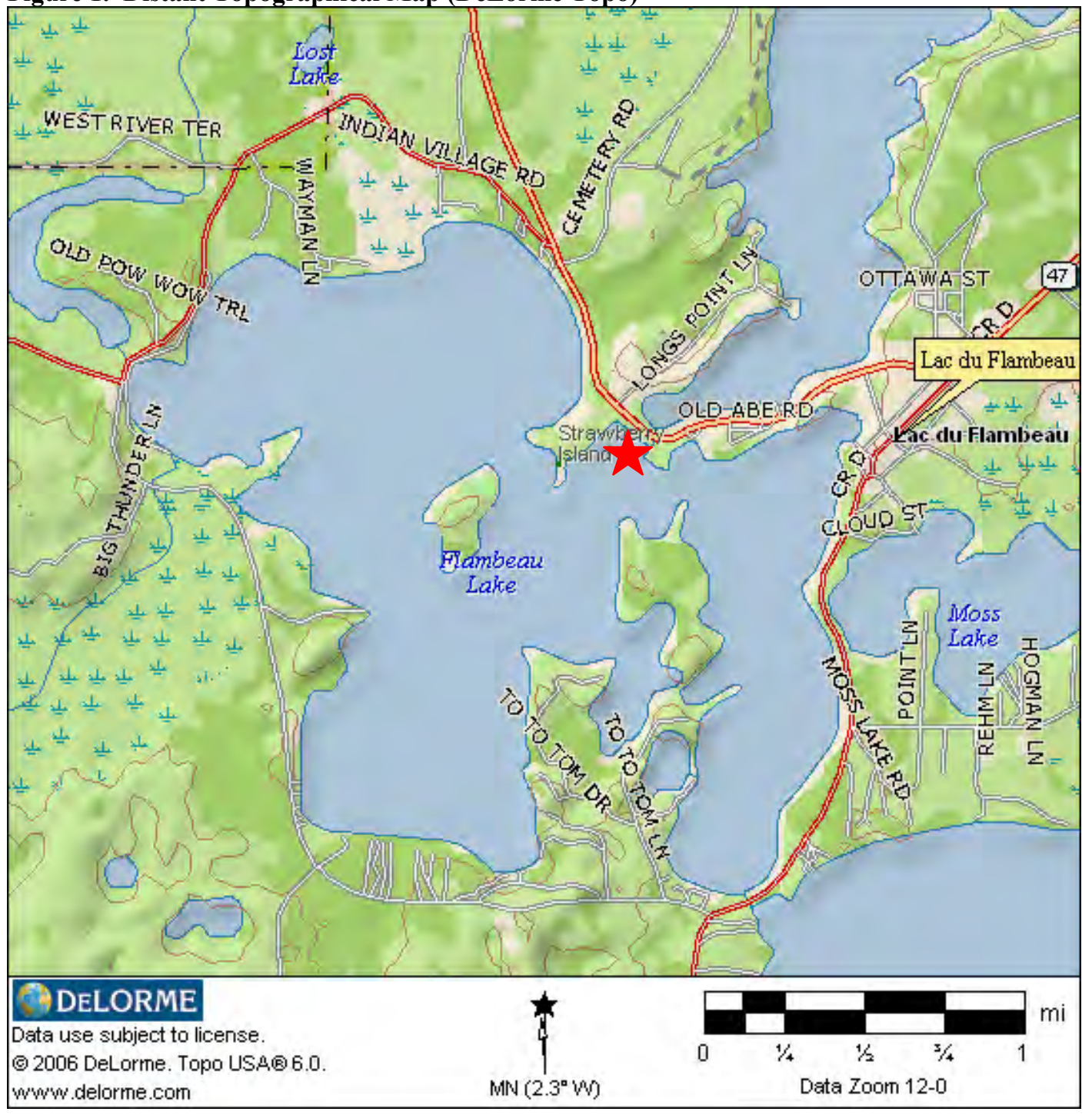


Note the extremely flat landscape surrounding the lake system in the topo map above.

\section{Figure 2. Distant aerial photo (Google Earth)}

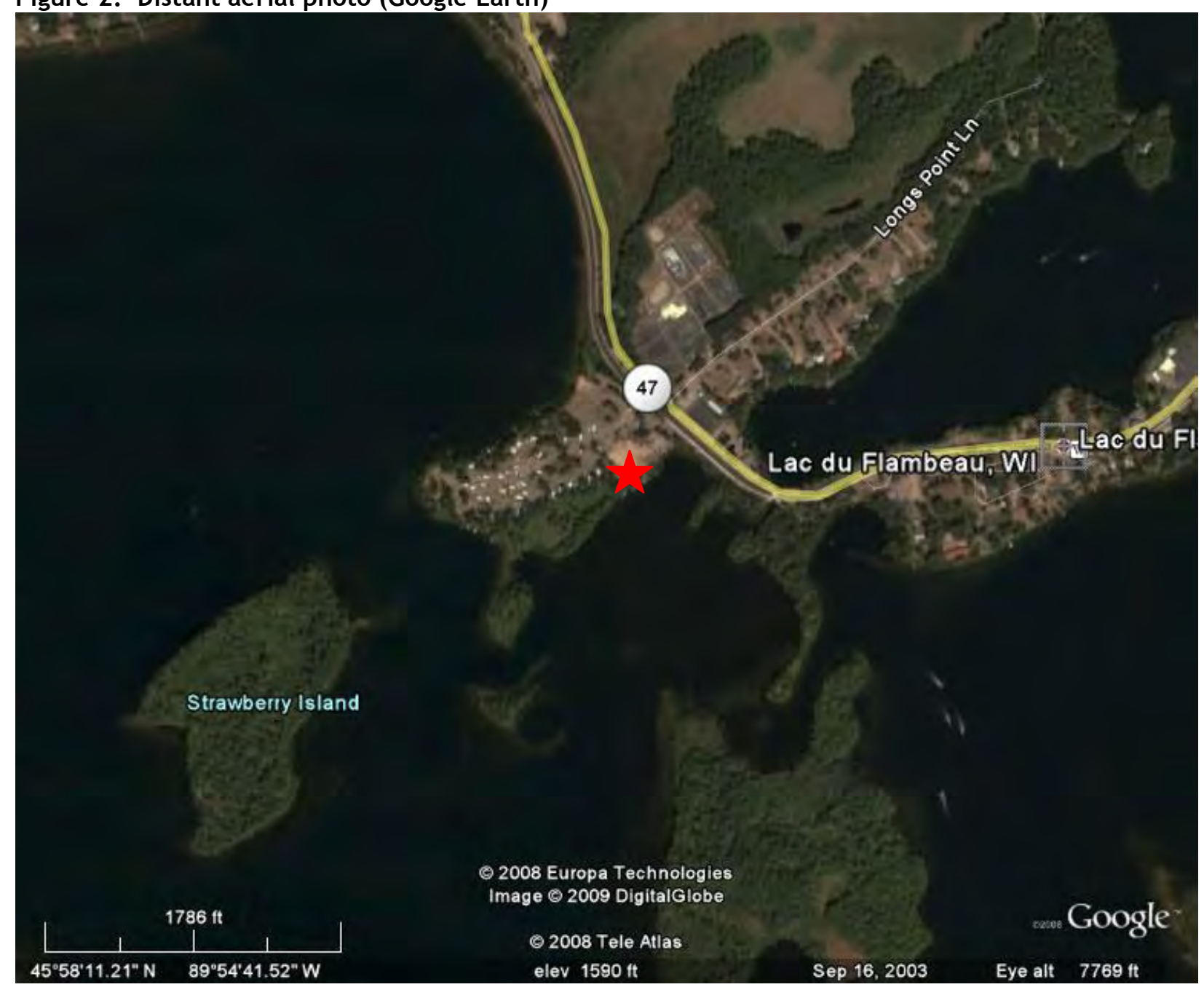

One possible turbine location is identified in the report, which is show in the aerial below. 
Figure 3. Close up Aerial Photo of Tribe Site and the Turbine Locations

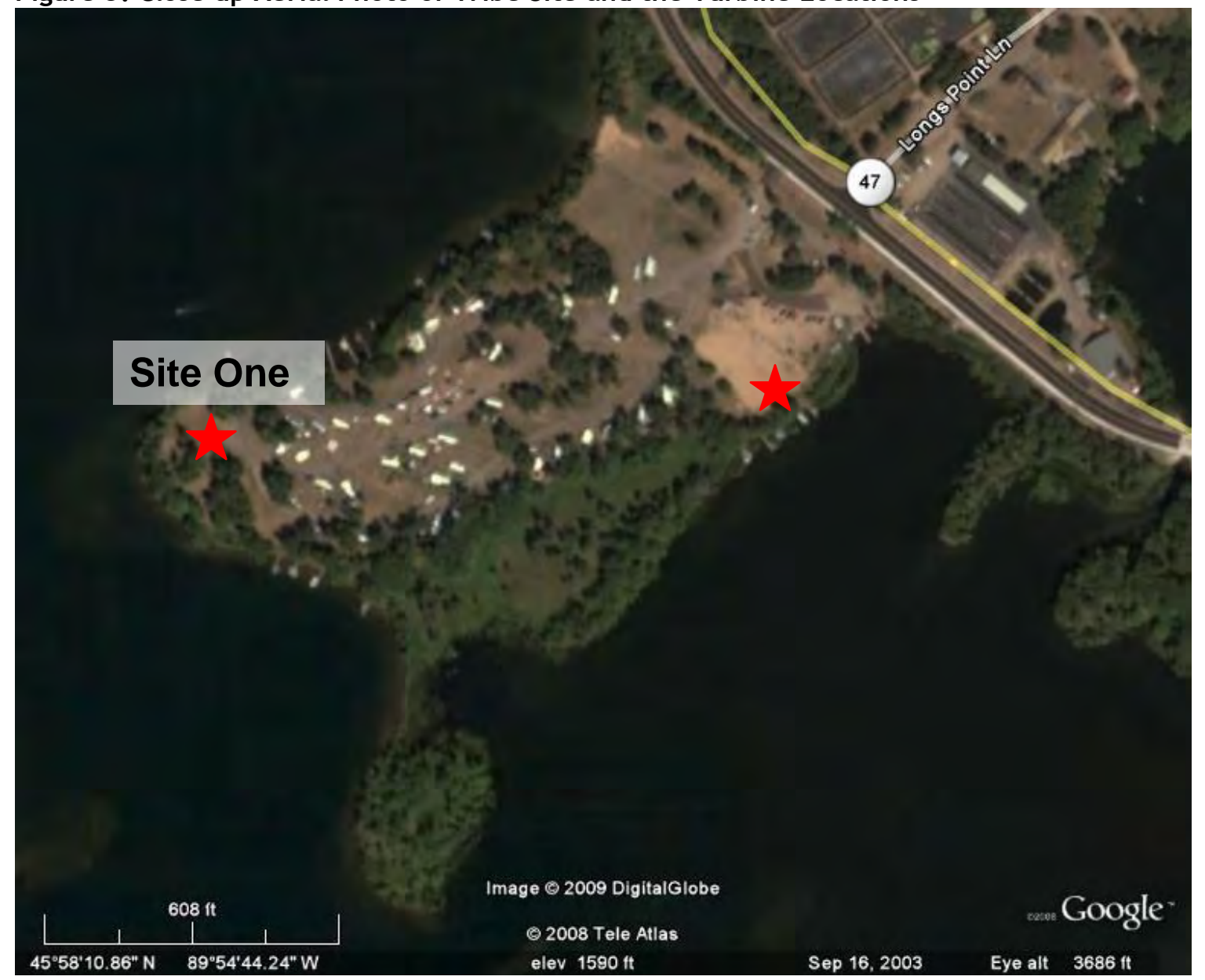

Site One is roughly 1590 feet in elevation. The other star represents a site that has been discussed as a possibility after the site assessment occurred, however the amount of building development to take place at that location is yet to be determined.

The close-up topographical map below shows the relatively flat landscape of the peninsula. 
Figure 4. Close-up Topographical Map of Tribe Site

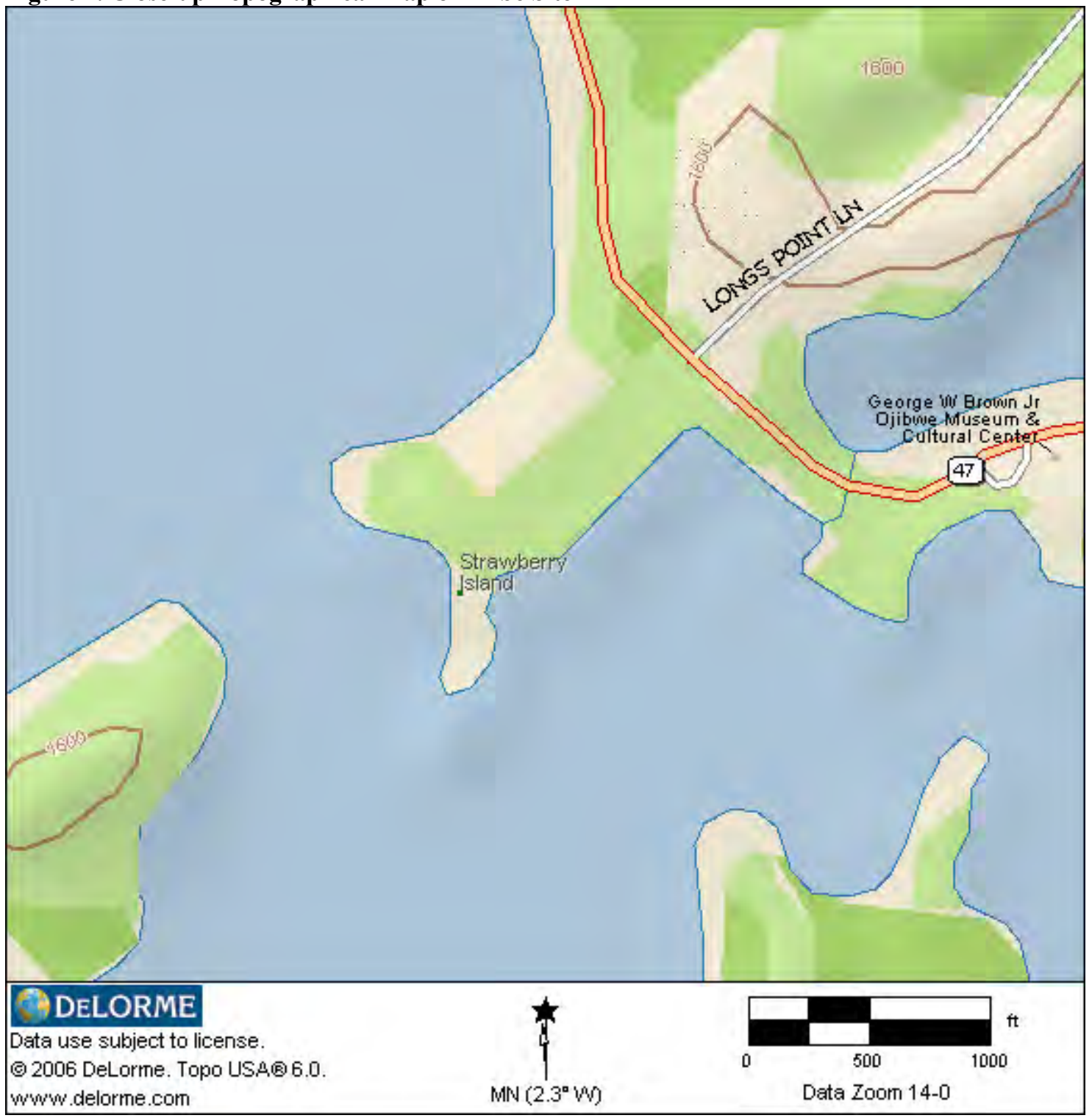

\subsubsection{Airports}

The Federal Aviation Administration (FAA) regulates the construction of towers within a 20,000 foot radius of all airports. The closest airport to the client is the Lakeland/Noble $\mathrm{F}$ Lee airport, approximately 9 miles south east. The turbine location lies outside of their 4 mile radius of FAA regulated air-space. To be certain that a wind turbine would be allowed at their location, the installer can submit a non-committal FAA "application to construct" on the client's behalf. A review of their application will notify the Tribe if a turbine at the specific recommended height in this report would be determined a hazard to aviation. If it is determined to be a hazard, the FAA will provide us with an acceptable height limit. 


\subsubsection{Soil type and depth of bedrock}

The soil type is a mix of sand, silt, gravel and clay. The depth to static water on the Reservation is typically greater than 10 feet and the depth to granite is typically greater than 100 feet ((based on well bore samples from the Reservation). The soil type for at the specific location of the turbine foundation should be verified prior to foundation erection to understand the difficult or ease of constructing a turbine foundation.

\subsubsection{Underground infrastructure}

Any underground infrastructure should be determined before trenching the wire run from the wind system to the main electrical panel.

\subsubsection{Zoning}

The wind energy system may require approval from the Tribal Zoning department.

\subsection{WIND RESOURCE DESCRIPTION}

The quality and quantity of the local wind resource is the most important technical project development factor and is the basis for all wind turbine energy production estimates. Wind quality and quantity is important because the power available in the wind is proportional to the cube of the average wind speed. Simply put, small changes in average annual wind speed result in large changes in annual energy production and project performance.

The characteristics of a moving air mass are affected by the topography (elevation and contour), ground cover (vegetation and trees) and land use (human-made structures) of the site and the surrounding region. As such, the tower height is site specific.

The wind resource is characterized by several key variables, including:

- $\quad$ wind speed

- predominant wind direction

- wind shear (change in wind speed with change in elevation)

- distribution of wind speeds at site (Weibull factor)

- turbulence intensity of site

These are discussed in detail in the Appendices.

\subsubsection{Tribe wind resource summary}

Wind turbine performance is based on the speed and the consistency of the wind intercepted by the turbine; a continuous high-speed wind is the best condition. Knowing the average annual wind speed at a specific site enables site assessors to determine how various turbines will perform at the Tribe's site. AWS Truewind, a company specializing in wind monitoring and analysis, created a Wisconsin wind map in 2007 . The wind map indicates average annual wind speeds at an elevation of $30 \mathrm{~m}, 40 \mathrm{~m}, 60 \mathrm{~m}, 70 \mathrm{~m}$ and $100 \mathrm{~m}$. The wind speed estimate for the peninsula at $60 \mathrm{~m}$ is shown below. 
Figure 5. Estimated wind speed at $60 \mathrm{~m}$ at Site One

\begin{tabular}{|l|c|}
\hline Height & Site One $(\mathrm{mph})$ \\
\hline 60 meters (197') & 12.5 \\
\hline
\end{tabular}

A close-up of the AWS Truewind map is shown below, showing the mean wind speed at 131 feet.

Figure 6. Wind Speed at 60 meters at Tribe's site (designated by red circle)

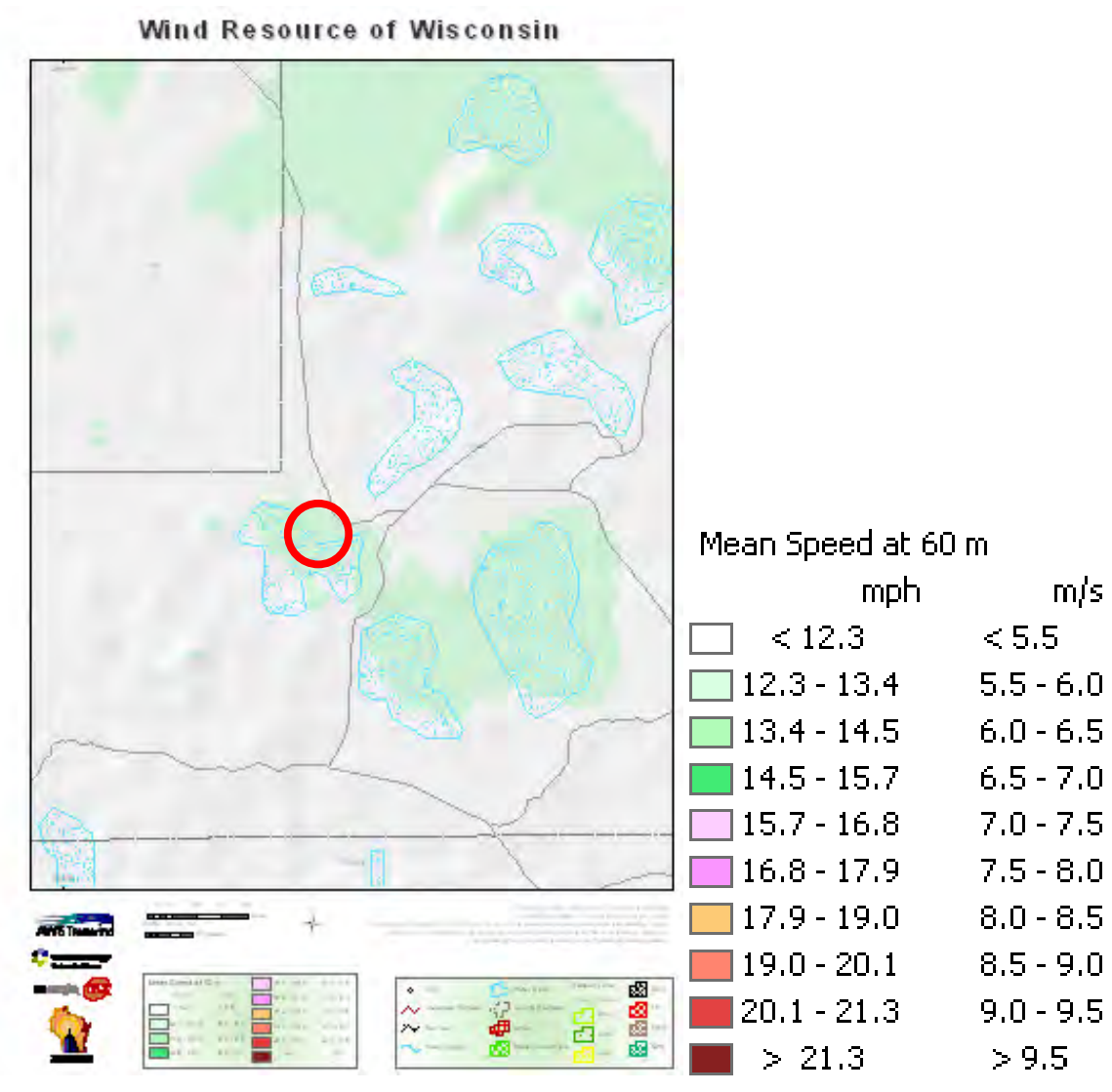

The Wisconsin map also provides information on the prevailing wind directions. A diagram called a wind rose is displayed below and shows the prevailing winds near the Tribe's site come from the south predominantly and also the west-north-west. 
Figure 7. Wind Rose for Tribe site, 1.5 miles west (AWS Truewind 2007)

Wind Rose Chart

Longitude -89.89 , Latitude 45.986

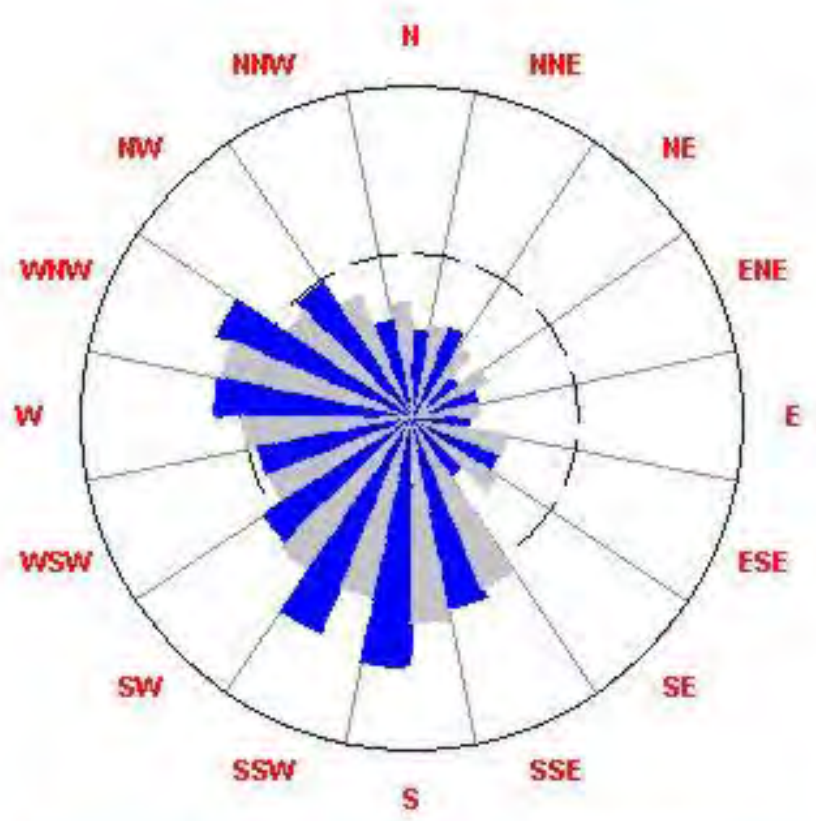

Percent of Total Wind Energy (Blue) and Time (Gray):

Circle Center $=\mathbf{0 . 0} \%$

Inner Circle $=7.5 \%$

Outer Circle $=15.0 \%$

The blue bars of the wind rose represent the percent of total energy and the gray bars illustrate the percent of total time in each of the sixteen direction sectors.

For the best turbine performance it is best to assume that there are winds coming from all directions, but if there are tall obstructions at the site, the wind rose helps to determine where to position the wind system so as to be upwind of these.

According to the site assessor's experience and accepted wind shear models, a wind shear of 0.24 was chosen for Site One, representing an area with "tall row crops, hedges and a few trees", because of its relatively open access to predominant wind directions.

For lack of real-world data and based on our assessment of the site, a Weibull factor of 2 is used to describe the distribution of wind speeds. A turbulence intensity of $20 \%$ describes the turbulence of the wind speed at the Sites because of the occasional ground clutter.

\subsection{POTENTIAL WIND TURBINE SITES}


The turbine should be located to intercept the most wind, based on the prevailing wind directions and the locations of the highest obstructions. The more wind the more electricity. Obstructions, such as buildings, large topographical features, rough terrain, and tall trees disrupt the flow of the wind and create turbulence.

Turbulence reduces the amount of energy that can be extracted, and creates a harsher environment for the wind turbine, especially the rotor blades, and their may shorten the life of the system. The best sites for wind systems are on wide open land and on the tops of ridges. If wide open land is not available, it is best to site the turbine where the obstructions do not block the wind from the prevailing wind directions, and/or significantly above the tallest obstruction so the tower height must be sufficiently tall to place the rotor above the turbulence. Tower heights are addressed later in the report. At this location the wind rose indicates the strongest winds are from the northwest and south.

The other considerations when siting a wind turbine include the length of the wire run to the meter (when connecting a residential wind system to the grid it must tie into an existing meter), the convenience of location to the property owner (to make sure that the wind system does not interfere with the day to day activities), the accessibility to the system by a crane (which is needed for raising the tower and connecting the turbine), and the local zoning regulations for setback distance requirements from roads and property lines.

One site for a wind turbine is analyzed below in regards to its potential to host a wind turbine.

\subsubsection{Site One - 1000' south-west of proposed Natural Resources office}

\section{Advantages}

- Site One is the most exposed to prevailing wind directions, as it has open access to the northwest and the south winds, and has a slightly faster wind speed than the second site.

- The tallest obstructions within 500 feet of the site are the deciduous trees, with an estimated maximum height of 55'.

- The Wisconsin Small Wind Model Zoning Ordinance recommends a distance of 1 times the turbine's total extended height from inhabited neighbor dwellings, roads, and above ground electricity lines. This location meets the model zoning recommendations, except for the campground roads.

- This site has easy crane access.

- This location is also farthest from the main amount of activity on the peninsula.

Disadvantages

- The wire run at this site is approximately 1,000 feet. The maximum length of wire run that is recommended for small wind turbines, because of cost-effectiveness, is approximately 1,000 feet.

- The campground site at this location may need to be retired. 


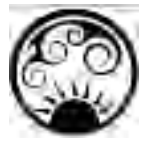

Figure 8. Panoramic photos of Site One

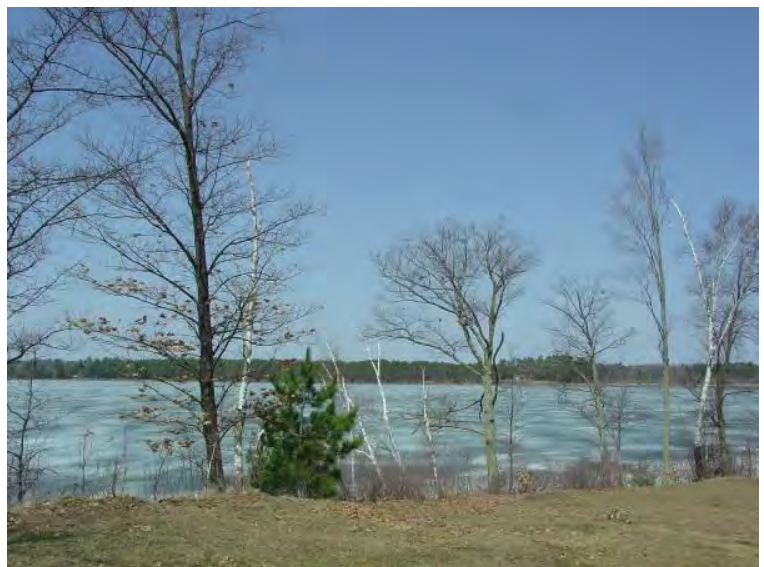

North: 40' tall tree, open access for 500 feet

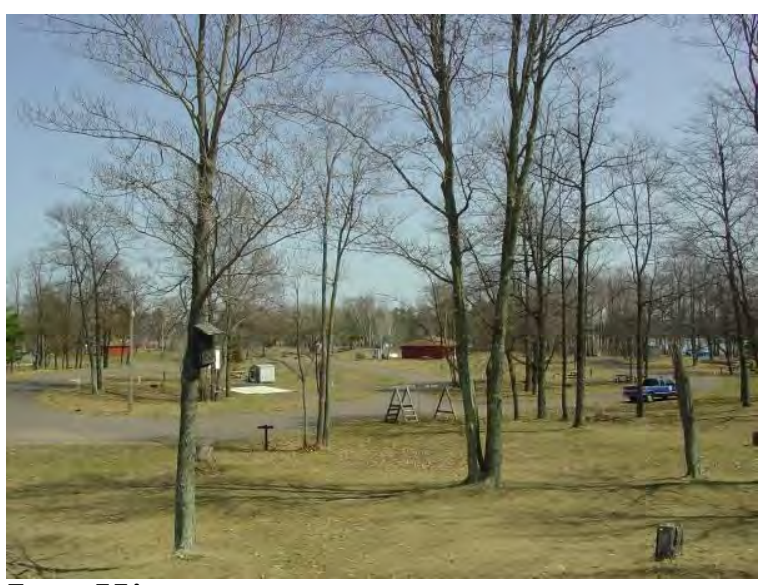

East: $55^{\prime}$ trees

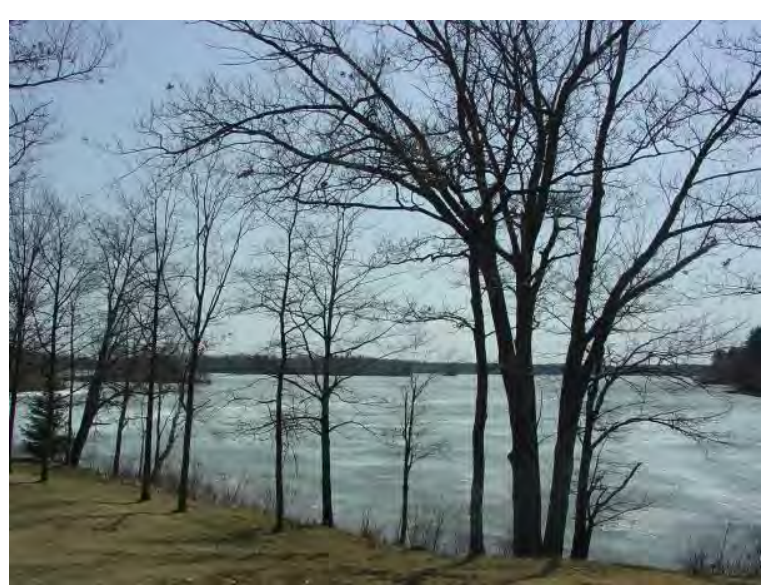

South: $35^{\prime}$ trees

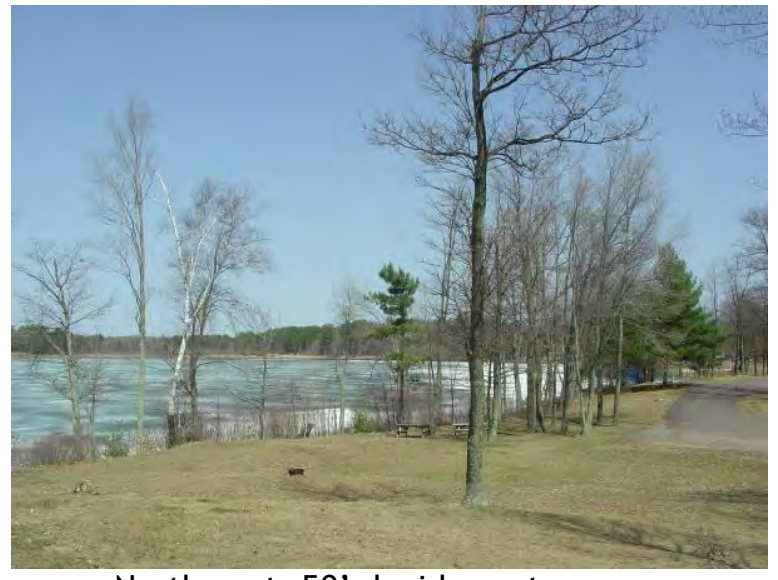

North-east: 50’ deciduous trees

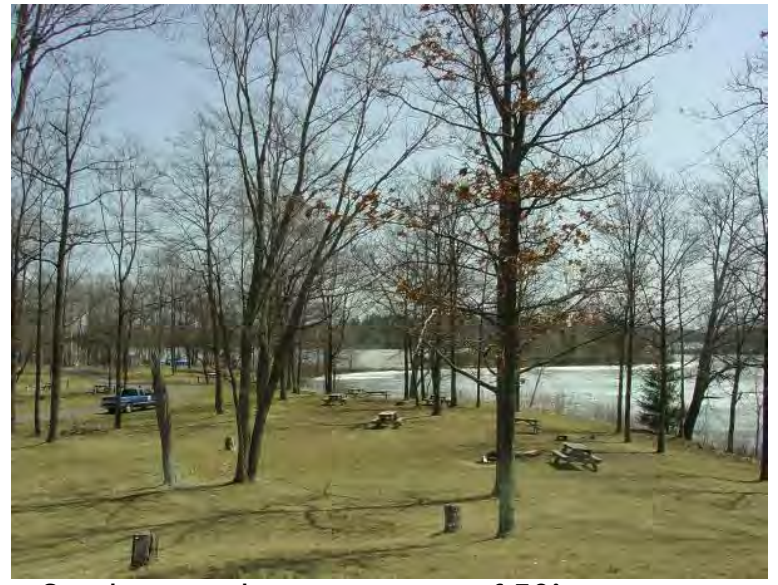

South-east: denser amount of 50' trees

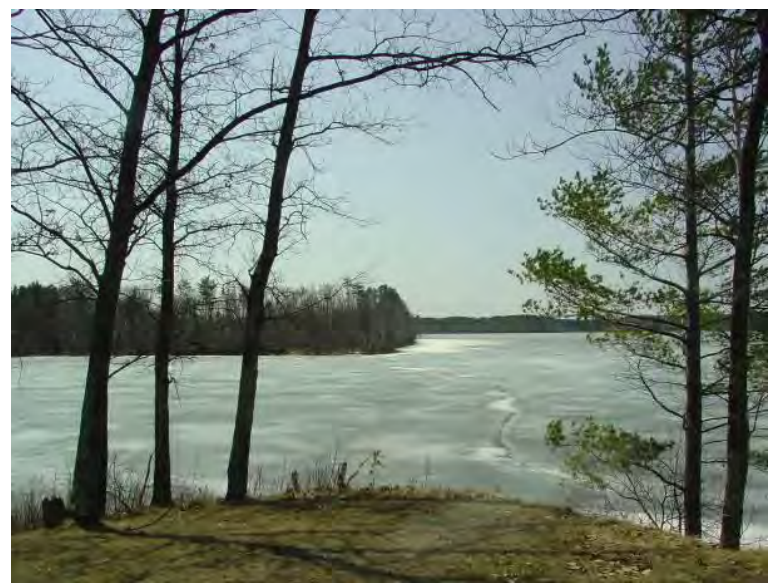

South-west: 35 ' trees, 850 ' to the island 


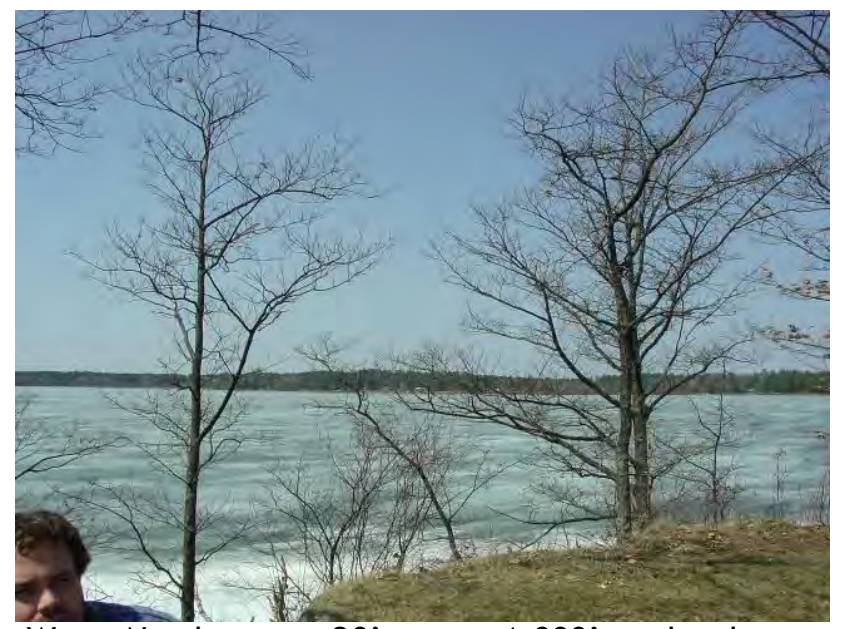

West- North-west: 20 'trees, $>1,000$ ' to the shore

1.5.2 Site Two: Anecdotal analysis, more info required - 600' south east of proposed building

Advantages

- This site has easy crane access.

- This site has a wire run that is shorter than the recommended maximum cost-effective length $(1,000$ '), at an estimated length of 600 feet.

- The Wisconsin Small Wind Model Zoning Ordinance recommends a distance of 1 times the turbine's total extended height from inhabited neighbor dwellings, roads, and above ground electricity lines. This location meets the model zoning recommendations, except for the campground roads.

Disadvantages

- This site is closer to the current location of the boat shop and the general activity of the peninsula, but this area may experience a large amount of re-development in the next two years.

\subsection{TURBINE POSSIBILITIES}

The larger the turbine, the greater the energy output per installed cost.

Listed in the table below are a range of appropriately sized, turbines for Tribe at this site. There are other turbines with similar rated outputs, and Tribe can discuss these options with their installer. The installer can provide Tribe with the time lines for availability. 
Figure 9. Turbine type and size

\begin{tabular}{|l|c|c|l|l|}
\hline \multicolumn{1}{|c|}{ Turbine } & $\begin{array}{c}\text { Rated } \\
\text { Output }\end{array}$ & $\begin{array}{c}\text { Rotor } \\
\text { Diameter (ft) }\end{array}$ & $\begin{array}{c}\text { Machine } \\
\text { Type }\end{array}$ & \multicolumn{1}{|c|}{ Webpage } \\
\hline ARE 110 & $2.5 \mathrm{~kW}$ & 12 & Inverter & www.abundantre.com \\
\hline Endurance & $5 \mathrm{~kW}$ & 20 & Induction & www.endurancewindpower.com \\
\hline ARE 442 & $10 \mathrm{~kW}$ & 24 & Inverter & www.abundantre.com \\
\hline Proven WT 15 & $15 \mathrm{~kW}$ & 30 & Inverter & www.provenenergy.co.uk \\
\hline PGE 20/35 & $35 \mathrm{~kW}$ & 64 & Induction & www.energiepge.com \\
\hline
\end{tabular}

For more specific information on these turbines, please see the Appendices.

\subsubsection{Minimum Tower Height}

There are several factors to take into account when determining a minimum tower height for a wind system. The goal is to position the entire rotor (the area swept out by the blades) in an area of consistent wind. If the wind speed and/or wind direction is not consistent on the blades as they spin from the lowest position to the highest, then the energy in the wind is not being used effectively and it also imposes more wear and tear on the wind turbine. Wind shear, the inconsistency in wind speed/direction, is caused by the natural friction of the wind with the ground (ground drag), and by turbulence which is created when the wind encounters local obstructions such as trees, buildings, etc. As the height above the ground increases, the wind speed increases exponentially.

Therefore, adding height to the tower reduces turbulence on the blades and will allow the turbine to operate more efficiently and with less maintenance. The larger the turbine, the longer the blade length, and the more critical it is to have the rotor even further away from the ground into the more consistent wind speeds.

There are two general rules of thumb to calculate the minimum required height of a tower:

1a. Minimum Tower Height $=60^{\prime}+$ blade length (if blade length $<15^{\prime}$ )

1b. Minimum Tower Height $=80^{\prime}+$ blade length (if blade length is $>14$ ')

2. Minimum Tower Height $=$ highest obstacle within $500^{\prime}+30^{\prime}+$ blade length

At Site One, the closest obstructions within a 500 foot radius are the trees to the east, with a combined estimated height of $\mathbf{5 5}$ feet, although the obstructions do not lie in the predominant wind direction.

Based on these rules of thumb, the minimum tower heights are listed below.

Figure 10.Turbine type, required tower height and available tower height

\begin{tabular}{|l|c|c|c|l|}
\hline \multicolumn{1}{|c|}{ Turbine } & $\begin{array}{c}\text { Rated } \\
\text { Output }\end{array}$ & $\begin{array}{c}\text { Blade } \\
\text { Length } \\
(\mathrm{ft})\end{array}$ & $\begin{array}{c}\text { Minimum } \\
\text { Tower Height } \\
(\mathrm{ft})\end{array}$ & \multicolumn{1}{c|}{$\begin{array}{c}\text { Available } \\
\text { Tower Height }\end{array}$} \\
\hline ARE 110 & $2.5 \mathrm{~kW}$ & 6 & 91 & $85^{\prime}, 106^{\prime}$ Tilt-up \\
\hline Endurance & $5 \mathrm{~kW}$ & 10 & 95 & $105^{\prime}, 126^{\prime}$ Tilt-up \\
\hline ARE 442 & $10 \mathrm{~kW}$ & 12 & 97 & $100^{\prime}, 120^{\prime}, 140^{\prime}$ Guyed \\
\hline Proven WT 15 & $15 \mathrm{~kW}$ & 15 & 100 & $100^{\prime}, 120^{\prime}, 140^{\prime}$ Freestanding \\
\hline PGE 20/35 & $35 \mathrm{~kW}$ & 32 & 117 & $120^{\prime}, 140^{\prime}$ Lattice \\
\hline
\end{tabular}


While manufacturers typically provide towers fitted for their turbines, it is possible to source towers from other tower manufacturers, if a taller tower height is needed. Most small turbine manufacturers provide only tilt-up towers, but the installer should be able to source an alternative tower type for Tribe's desired turbine.

Towers usually come in 20' sections, therefore a 100' tower is sufficient for all of the turbines except for the PGE 20/25, which requires a 120' tower. The taller the tower, the higher the wind speed, resulting in a higher energy output for any given turbine, and less turbulence, so taller towers should always be considered, and for this site assessment, a height of 120' will be used.

\subsubsection{Wind speed at hub height}

According to the Wisconsin state wind map, Site One can expect a wind speed of $12.5 \mathrm{mph}$ at 60 meters. Wind speed increases with rising elevation above ground level. At ground level, friction caused by the interaction of the wind with vegetation, trees, buildings and the naturally occurring contours and topography all slows the wind down. At higher elevations above the ground, the wind moves unimpeded and its speed increases. All other factors being equal, a wind turbine should always be installed on the tallest available tower. The relationship between changes in wind speed and elevation, or wind shear, is well established. The wind shear coefficient is a variable used to adjust wind speed at varying heights, based on the type of ground clutter at a site.

Using the wind shear equation to estimate wind speed at possible tower heights and the 0.24 wind shear for Site One, the estimated average annual wind speeds are:

- $11.5 \mathrm{mph}$ at 140 feet

- $11.1 \mathrm{mph}$ at 120 feet

- $10.6 \mathrm{mph}$ at 100 feet

These will be the wind speeds used to calculate the average annual energy output of the potential wind turbine choices at Site One.

\subsection{ENERGY OUTPUTS}

The estimated energy outputs in the table below were calculated using the " $7^{\text {th }}$ Wind Turbine Performance Model v. 10.72", an Excel spread sheet developed by Seventh Generation Energy Systems and used by the Wisconsin State Public Benefits renewable energy program. Taken into account are factors such as: the elevation of the site, the air density, the wind speed from the wind map, the probability of the distribution of wind speeds, the turbine rotor area, the tower height, and the manufacturers' power curve for the turbine. It is conservative to de-rate inverter based systems $5 \%$ for inverter losses, which typically includes the smaller machines $(<35 \mathrm{~kW})$. This need not be done for the induction machines, which are typically the larger machines $(>35 \mathrm{~kW})$.

An estimated annual energy demand of $25,000 \mathrm{kWh}$ is used in the analysis below. The energy outputs below assume a tower height of $\mathbf{1 2 0}$ feet and a wind speed of $\mathbf{1 1 . 1} \mathrm{mph}$ hour at hub height. The inverter based systems have been decreased by $5 \%$ for inverter losses.

The inputs for Tribe's site are high-lighted in purple, and outputs of the turbines are presented below for two tower heights, a 120 foot tower and a 140 foot tower, at Site One. 
Figure 11. Turbine energy output and percent of facility production

\begin{tabular}{|c|c|c|c|c|c|c|}
\hline SITE INPUTS & \multicolumn{6}{|c|}{ Lac du Flambeau Peninsula Site One } \\
\hline Annual Energy Use $(\mathrm{kWh} / \mathrm{yr})=$ & 25,000 & & \multicolumn{2}{|c|}{ Wind Shear Exp. = } & 0.24 & $\begin{array}{l}\text { per site } \\
\text { assessment }\end{array}$ \\
\hline Site Wind Speed from Map $(\mathrm{mph})=$ & 12.5 & from wind map & \multicolumn{2}{|r|}{ Weibull $\mathrm{K}=$} & 2.00 & $\begin{array}{l}\text { assume } \mathrm{k}= \\
2\end{array}$ \\
\hline Map Wind Speed Height $(\mathrm{m})=$ & 60 & from wind map & \multicolumn{2}{|c|}{ Turbulence Intensity = } & $20 \%$ & $\begin{array}{l}\text { per site } \\
\text { assessment }\end{array}$ \\
\hline Recommended Tower Height $(\mathrm{ft})=$ & 120 & $\begin{array}{l}\text { per site } \\
\text { assessment }\end{array}$ & & & & \\
\hline Site Altitude $(\mathrm{ft})=$ & 1590 & from topo map & & & & \\
\hline \multicolumn{7}{|l|}{ SPECIFICATIONS } \\
\hline Manufacturer & ARE & EWP & $\mathrm{ARE}$ & Proven & \multicolumn{2}{|c|}{ Energie PGE } \\
\hline Model & 110 & Endurance & 442 & WT 15 & \multicolumn{2}{|c|}{ PGE 20/35 } \\
\hline Nameplate Capacity (kW) & 2.5 & 5.0 & 10.0 & 15.0 & \multicolumn{2}{|c|}{35.0} \\
\hline Turbine capacity at $11 \mathrm{~m} / \mathrm{s}(\mathrm{kW})$ & 2.5 & 4.3 & 10.3 & 14.8 & \multicolumn{2}{|r|}{32.4} \\
\hline Output Voltage (V) & $48 / 240$ & 240 & $48 / 240$ & 240 & \multicolumn{2}{|r|}{240} \\
\hline Phase & 1 & 1 & 1 & 1 & \multicolumn{2}{|r|}{1} \\
\hline Rotor Diameter (ft) & 11.8 & 18.0 & 23.6 & 29.5 & \multicolumn{2}{|r|}{63.0} \\
\hline Rotor Diameter $(\mathrm{m})$ & 3.6 & 5.5 & 7.2 & 9.0 & \multicolumn{2}{|r|}{19.2} \\
\hline Tower Height (ft) & 130 & 130 & 130 & 130 & \multicolumn{2}{|r|}{130} \\
\hline Tower Height $(\mathrm{m})$ & 40 & 40 & 40 & 40 & \multicolumn{2}{|r|}{40} \\
\hline Total Structure Height AGL (ft) & 136 & 139 & 142 & 145 & \multicolumn{2}{|r|}{161} \\
\hline Total Structure Height AGL (m) & 41 & 42 & 43 & 44 & \multicolumn{2}{|r|}{49} \\
\hline \multicolumn{7}{|l|}{ PERFORMANCE (120' tower) } \\
\hline Wind Speed at Hub Height (mph) & 11.1 & 11.1 & 11.1 & 11.1 & \multicolumn{2}{|c|}{11.1} \\
\hline Annual Energy Output (kWh) & 3,109 & 4,785 & 13,419 & 17,390 & \multicolumn{2}{|c|}{66,859} \\
\hline Monthly Energy Output (kWh) & 259 & 399 & 1,118 & 1,449 & \multicolumn{2}{|c|}{5,572} \\
\hline Wind Percent of Facility Energy Use & $12.4 \%$ & $19.1 \%$ & $53.7 \%$ & $69.6 \%$ & \multicolumn{2}{|c|}{$267.4 \%$} \\
\hline Excess Energy Production (kWh/yr) & 0 & 0 & 0 & 0 & \multicolumn{2}{|c|}{41,859} \\
\hline $\begin{array}{l}\text { Turbine Capacity Factor at Rated } \\
\text { Output }\end{array}$ & $14 \%$ & $11 \%$ & $15 \%$ & $13 \%$ & \multicolumn{2}{|r|}{$22 \%$} \\
\hline $\begin{array}{l}\text { Turbine Capacity Factor at } 11 \mathrm{~m} / \mathrm{s} \\
\text { Output }\end{array}$ & $14 \%$ & $13 \%$ & $15 \%$ & $13 \%$ & \multicolumn{2}{|r|}{$24 \%$} \\
\hline \multicolumn{7}{|l|}{ PERFORMANCE (140' tower) } \\
\hline Wind Speed at Hub Height (mph) & $\begin{array}{l}\text { 140' n/a for } \\
\text { ARE } 110\end{array}$ & $\begin{array}{l}140 \text { ' n/a for } \\
\text { Endurance }\end{array}$ & 11.5 & 11.5 & \multicolumn{2}{|r|}{11.5} \\
\hline Annual Energy Output (kWh) & & & 14,653 & 19,246 & \multicolumn{2}{|c|}{71,582} \\
\hline Monthly Energy Output (kWh) & & & 1,221 & 1,604 & & 5,965 \\
\hline Wind Percent of Facility Energy Use & & & $58.6 \%$ & $77.0 \%$ & & $86.3 \%$ \\
\hline Excess Energy Production (kWh/yr) & & & 0 & 0 & & 46,582 \\
\hline $\begin{array}{l}\text { Turbine Capacity Factor at Rated } \\
\text { Output }\end{array}$ & & & $17 \%$ & $15 \%$ & & $23 \%$ \\
\hline $\begin{array}{l}\text { Turbine Capacity Factor at } 11 \mathrm{~m} / \mathrm{s} \\
\text { Output }\end{array}$ & & & $16 \%$ & $15 \%$ & & $25 \%$ \\
\hline
\end{tabular}


The values presented here for Site One are rough estimates. The turbines chosen are all single phase and will produce between 3,100 and $71,000 \mathrm{kWh}$ per year.

If the turbines are placed on 140' towers, they are expected to produce between 300 and 3,500 $\mathrm{kWh}$ more than the same turbine on a 120' tower, because of the access to faster wind speeds.

\subsection{FINANCIAL ANALYSIS}

Tribe has several financial considerations and incentives for their wind project, including:

- Net-metering with WPS

- Focus on Energy Cash Back Reward for systems $20 \mathrm{~kW}$ and under; or,

- Focus's Implementation Grant for systems > $20 \mathrm{~kW}$ (25\% of system cost)

- Federal tax and energy production incentives

- Tribal grants and bonds

These incentives are described below.

\subsubsection{Net metering}

Renewable energy systems, including wind systems, can take advantage of what is called "net metering". Net metering refers to the situation when the wind turbine is generating more electricity than is needed at the site, and the excess is fed back onto the power grid. The electrical meter simply runs backward, so the utility is essentially "paying" a certain rate for the power. True net metering implies that the customer receives retail rate for excess generation.

Net-metering is available for customer in WPS territory. If the aggregate renewable energy system is $20 \mathrm{~kW}$ or less, the customer will receive retail credit for excess energy generation, or 10.9 cents per $\mathrm{kWh}^{2}$.

Another option for receiving value for 'green energy' from the utility is through Renewable Energy Buyback rates. At this point in time, WPS only offers buy-back rates for solar electric energy ( $25 \mathrm{c}$ per $\mathrm{kWh}$ ). The Tribe should check with WPS at the time of installation to determine if WPS offers a Renewable Buyback rate for wind.

\subsubsection{Focus on Energy}

Focus on Energy offers Cash Back Rewards and Implementation grants based on how well the wind turbine performs at each specific site. The "Reward Factor" is based on the expected annual energy production of the turbine at a good site, the cost of the wind system, and the turbine's rated capacity at $11 \mathrm{~m} / \mathrm{s}$. The cash back amount is based on the estimated turbine output at this site multiplied by this reward factor. The Focus incentive program is therefore designed to reward higher performance turbines and turbines that are better suited to a site's specific wind regime.

The chart below shows the estimated Focus Cash Back Reward for the turbines mentioned above at Site One.

\footnotetext{
${ }^{2}$ Tribe's December 2008 bill charged approximately 10.26 cents per $\mathrm{kWh}$, although the Rate Schedule is 10.6 cents.
} 
Figure 12. Expected Cash Back Reward (Focus Reward Calculator, v. 1.6).

\begin{tabular}{|c|c|c|c|c|c|c|c|}
\hline Turbine & Tower & $\begin{array}{l}\text { Turbine Capacity } \\
(11 \mathrm{~m} / \mathrm{s})\end{array}$ & $\begin{array}{c}\text { Typical Installed } \\
\text { Cost }\end{array}$ & Reward Factor & kWh/year & $\begin{array}{l}\text { Reward } \\
\text { Amount }\end{array}$ & $\begin{array}{l}\text { Typical Cost } \\
\text { Less Award }\end{array}$ \\
\hline ARE 110 & $120^{\prime}$ & 2.5 & $\$ 40,00$ & $\$ 3$. & 3,109 & $\$ 9,959$ & $\$ 30,041$ \\
\hline Endurance & $120^{\prime}$ & 4.3 & $\$ 55,00$ & $\$ 2$. & 4,785 & $\$ 12,227$ & $\$ 42,773$ \\
\hline ARE 442 & $120^{\prime}$ & 10.3 & $\$ 80,00$ & $\$ 1$. & 13,419 & $\$ 20,846$ & $\$ 59,154$ \\
\hline Proven WT 15 & $120^{\prime}$ & 14.8 & $\$ 120,0$ & $\$ 1$. & 17,390 & $\$ 28,225$ & $\$ 91,775$ \\
\hline PGE 20/35 & $120^{\prime}$ & 32.4 & $\$ 300,0$ & 85 & 66,859 & $\$ 100,000$ & $\$ 200,000$ \\
\hline
\end{tabular}

In order to receive the Focus on Energy grants, the following requirements must be met:

Wind Speed Logger and Anemometer: A cup anemometer must be mounted on the tower one rotor diameter below the top of the tower. The anemometer must be installed on at least a four foot boom in the approximate direction of the annual prevailing winds. The anemometer must be connected to a wind speed data logger of the owner's choice.

(A second anemometer can be installed to help determine wind shear at the site. If a second anemometer is installed, it should be placed approximately 15 feet below the upper anemometer. Thirty feet would work but only if the site is very open with no upwind obstacles towards the prevailing wind direction.)

System Performance Meter: A kilowatt-hour meter and meter base must be installed between the inverter and the AC circuit breaker for the system. The inverter kWh meter does not satisfy this requirement.

\subsubsection{Tax Credits}

If the turbine is installed as a Tribal Enterprise, or through an entity that may have a tax appetite, the Tribe may be able to take advantage of the federal Modified Accelerated Cost-Recovery System (MACRS). MACRS allows businesses to recover investments in certain property through depreciation deductions. For solar, wind and geothermal property placed in service after 1986, the current MACRS property class is five years. The 5-year depreciation typically will equal about $18 \%$ of the system cost.

A Business Energy Tax Credit is also available, if the Tribal Enterprise, or taxed entity, were to own the system. For small wind, the available credit is equal to $30 \%$ of expenditures, with a maximum credit of $\$ 4,000$. Eligible small wind property includes wind turbines up to $100 \mathrm{~kW}$ in capacity. This credit applies to eligible property placed into service after October 3, 2008.

To understand the full benefits available, the Tribe should consult with their accountant.

\subsubsection{Tribal Grants}

The U.S. Department of Energy's (DOE) Tribal Energy Program promotes tribal energy sufficiency, economic growth and employment on tribal lands through the development of renewable energy and energy efficiency technologies. The program provides financial assistance, technical assistance, education and training to tribes for the evaluation 
and development of renewable energy resources. Currently there are not grant solicitations through the DOE, but the Tribe should continue to check the Department's webpage or the grant coordinator ${ }^{3}$.

\subsubsection{Clean Renewable Energy Bonds}

Clean Renewable Energy Bonds (CREBs) provide an option for public sector entities, including Tribal Governments, to finance renewable energy projects, typically at a zero-interest rate. CREBs may be issued by electric cooperatives, government entities (states, cities, counties, territories, Indian tribal governments, or any political subdivision thereof), and certain lenders. The advantage of CREBs is that they are issued -- theoretically -- with a $0 \%$ interest rate. The borrower pays back only the principal of the bond, and the bondholder receives federal tax credits in lieu of the traditional bond interest. For more information visit: www.irs.gov/irb/2007-14_IRB/ar17.html

\subsubsection{Renewable Energy Production Incentive}

The federal Renewable Energy Production Incentive (REPI) provides incentive payments for electricity produced and sold by new qualifying renewable energy facilities. Qualifying systems are eligible for annual incentive payments of $1.5 \notin$ per kilowatt-hour (in 1993 dollars and indexed for inflation) for the first 10-year period of their operation, subject to the availability of annual appropriations in each federal fiscal year of operation. Eligible production facilities include Tribal governments, and the production payment applies only to the electricity sold to another entity. For more information, please contact Christine Carter at christine.carter@go.doe.gov.

\subsubsection{Other Economic Considerations}

The total installed cost of a wind energy system includes the materials and labor for installing the entire system including: pouring the foundation for the tower and/or the guy wire anchors, tower assembly, crane rental for raising the tower and attaching the turbine, trenching, installing the balance of system (BOS - inverter, disconnect, etc) and all the wiring for the electronics. Costs may be lowered by purchasing a used tower (some wind system dealers may have access to these), and by doing the tower assembly and/or the trenching in-house. This will need to be determined with the installer.

- Tower: The tower options available for turbines are free-standing monopole towers, guyed lattice towers, and tilt-up towers. The tower cost is dependent upon tower type and height. Please see the appendix and the attached article on tower types.

- Maintenance: In addition to the installation costs, the owner of a wind system should expect to put aside $1 \%$ (for turbines $<20 \mathrm{~kW}$ ) and $0.5 \%$ (for turbines $>20 \mathrm{~kW}$ ) of the installed cost for ongoing maintenance ( $2 \%$ for a Jacobs $20 \mathrm{~kW}$ ). This amount may not be used every year, but down the road there may be some replacement parts needed, e.g. new blades or a gearbox.

- Insurance: When the wind system is rated at under $20 \mathrm{~kW}$, the system is usually covered under the normal site owners' policy as an "uninhabited structure" like a detached garage. When the wind system is rated between $20 \mathrm{kw}$ and $200 \mathrm{~kW}$, the insurance required is typically $\$ 1$ million dollars. This is usually the level of insurance that is held on a business. No special policy for a wind turbine is required, only standard business insurance with liability coverage. The client should verify this with their insurance agent.

- Green tags: Green tags, also known as renewable energy credits (RECs) or tradable renewable energy certificates (TRCs) are the traded stock of a market set-up to capitalize on the "green-ness" of renewable energy projects. One green tag is assigned to each wind-driven megawatt-hour (or every $1000 \mathrm{kWh}$ ) a wind

\footnotetext{
${ }^{3}$ Tribal Energy Program Grant: www.eere.energy.gov/tribalenergy
} 
machine puts into the grid. The green tags from any wind electricity the customer produces can be bought by a utility as part of a power purchase agreement. The customer could also sell the green tags to an open market, although price volatility in the green tag market makes predicting the value difficult (with a current range of $\$ 5$ to $\$ 90$ per $\mathrm{MW}$ ).

- Carbon offsets: Wind energy can also be quantified in terms of carbon emissions that have been offset, i.e. fossil fuels have not been burned because the energy has been supplied by the wind. These carbon offsets can be sold on the carbon market; however environmental attributes, such as renewable energy credits (RECs) must be surrendered to and retired in order to prevent double counting. This market is also quite volatile. For example, the value was of a metric ton of carbon was valued at $\$ 7.00$ May in on the Chicago Climate Exchange, and has since dropped to $\$ 4.00$ in July.

The table below provides the costs of the wind systems. This financial analysis is very simplified and does not assume any energy rate increases for the next 20 years, which will inevitably happen. The financial analysis uses a retail rate at an unchanging 10.9 cents/ $\mathrm{kWh}$. This financial model is just a preliminary analysis. Its real purpose is to show how the turbines compare to one another for overall value.

For the purposes of the first economic analysis, only the Focus on Energy grant has been assumed. The second analysis assumes the Tribal Enterprises can take advantage of the tax credits.

The Tribe should investigate the other grants and incentives listed above.

The table below provides an example of the economic considerations for following turbines and tower types at Site One, on a 120' tower, assuming only the Focus incentive has been acquired.

Figure 13. Simple economic analysis for Site One: Focus only

\begin{tabular}{|l|c|c|c|c|c|}
\hline Turbine Name & ARE110 & Endurance & ARE442 & $\begin{array}{c}\text { Proven } \\
\text { WT15000 }\end{array}$ & $\begin{array}{c}\text { PGE 20|35- } \\
\text { ph }\end{array}$ \\
\hline Annual Energy Output $(\mathrm{kWh})$ & 3,109 & 4,785 & 13,419 & 17,390 & 66,859 \\
\hline SYSTEM COSTS & & & & & \\
\hline Installed Capital Cost $(\$)$ & $\$ 40,000$ & $\$ 55,000$ & $\$ 80,000$ & $\$ 120,000$ & $\$ 300,000$ \\
\hline Installed Cost $(\$ / \mathrm{kW})$ & $\$ 16,000$ & $\$ 11,000$ & $\$ 8,000$ & $\$ 8,000$ & $\$ 8,571$ \\
\hline O\&M - \$ per turbine per year & $\$ 200$ & $\$ 275$ & $\$ 400$ & $\$ 600$ & $\$ 3,000$ \\
\hline & & & & & \\
\hline INCENTIVES & & & & & \\
\hline System Cost After FOE Rebate & $\$ 30,041$ & $\$ 42,773$ & $\$ 59,154$ & $\$ 91,775$ & $\$ 200,000$ \\
\hline Total Incentives & $\$ 9,959$ & $\$ 12,227$ & $\$ 20,846$ & $\$ 28,225$ & $\$ 100,000$ \\
\hline & & & & & \\
\hline FINANCIAL SUMMARY & & & & & \\
\hline Net System Cost After Incentives & $\$ 30,041$ & $\$ 42,773$ & $\$ 59,154$ & $\$ 91,775$ & $\$ 200,000$ \\
\hline Energy Bill Savings per Year & $\$ 361$ & $\$ 522$ & $\$ 1,560$ & $\$ 588$ & $\$ 2,725$ \\
\hline
\end{tabular}

While the PGE offers the greatest savings on an annual basis, this machine also requires the largest upfront costs.

The table below provides an example of the economic considerations for following turbines and tower types at Site One, on a 120' tower, assuming the Focus incentive and the tax credits have been acquired.

Figure 14. Simple economic analysis for Site One; Focus and tax credits 


\begin{tabular}{|l|c|c|c|c|c|}
\hline Turbine Name & ARE110 & Endurance & ARE442 & $\begin{array}{c}\text { Proven } \\
\text { WT15000 }\end{array}$ & $\begin{array}{c}\text { PGE 20|35- } \\
1 \mathrm{ph}\end{array}$ \\
\hline Annual Energy Output $(\mathrm{kWh})$ & 3,109 & 4,785 & 13,419 & 17,390 & 66,859 \\
\hline INCENTIVES & & & & & \\
\hline System Cost After FOE Rebate & $\$ 30,041$ & $\$ 42,773$ & $\$ 59,154$ & $\$ 91,775$ & $\$ 200,000$ \\
\hline MACRS & $\$ 12,400$ & $\$ 17,050$ & $\$ 24,800$ & $\$ 37,200$ & $\$ 93,000$ \\
\hline Business Tax Credit & $\$ 2,500$ & $\$ 4,000$ & $\$ 4,000$ & $\$ 4,000$ & $\$ 4,000$ \\
\hline Total Incentives & $\$ 24,859$ & $\$ 33,277$ & $\$ 49,646$ & $\$ 69,425$ & $\$ 197,000$ \\
\hline & & & & & \\
\hline FINANCIAL SUMMARY & & & & & \\
\hline Net System Cost After Incentives & $\$ 15,141$ & $\$ 21,723$ & $\$ 30,354$ & $\$ 50,575$ & $\$ 103,000$ \\
\hline Energy Bill Savings per Year & $\$ 361$ & $\$ 522$ & $\$ 1,560$ & $\$ 588$ & $\$ 2,725$ \\
\hline
\end{tabular}

If the Tribe is able to take advantage of the tax credits and tax depreciation benefits, the expenses of the turbine drop significantly; from $\$ 30,000$ to $\$ 15,000$ for the ARE 110 and from $\$ 200,000$ to $\$ 100,000$ for the PGE 20/25.

Please note that the calculations above assume energy will remain at 10.9 cents per $\mathrm{kWh}$. As the price of electricity inevitably increases, the return on investment will increase as well. The calculations also do not include any interest rate for loans that may be required.

Turbine life is expected to be $20-25$ years if properly maintained. Purchasing a wind system is like pre-paying for electricity for the length of the payback period. After the payback period, the electricity generated for the remaining life of the turbine would be free, except for maintenance costs.

\subsection{SUMMARY}

The site reviewed for this Lac du Flambeau wind site assessment is a decent location for a wind system, located at the tip of a peninsula in one of the Reservation's lakes. The Wisconsin Wind Map predicts a wind speed of $12.5 \mathrm{mph}$ at 60 meters at this site on the peninsula. The majority of the Reservation land is populated with tall pine trees, between 50 and 65 feet tall, which are not conducive to effective production from wind turbines because of the slower wind speeds at regular tower heights for small turbines (typically under 140 feet). The need for significantly taller towers to reach viable wind speeds would typically make wind projects in this area not cost-effective. However, the locations that are on the north side of the Lac du Flambeau lakes have access to the predominant southern wind direction and will have access to faster wind speeds than most locations on the reservation. Because it is not economically feasible to monitor the wind speeds for small turbines (turbines $<100 \mathrm{~kW}$ ), the wind estimates as predicted by the Wisconsin Wind Map for this site were used in the analysis of this report.

The Tribe should be able to provide a portion or all of their electricity needs for the planned natural resources office with a turbine. An investment in a turbine would provide energy independence against increasing electrical prices, and it would support clean energy.

\subsection{FOLLOW-UP}


A. Talk to your accountant to see if you qualify for the tax depreciation credits. Conduct a more detailed economic analysis which also considers inflation, interest rates on loans, increase in electricity prices, etc.

B. Review the Small Wind Toolbox, a resource of RENEW Wisconsin that contains information on zoning, maintenance, etc: www.renewwisconsin.org/wind/windtoolbox.html

C. Contact several of the qualified full-service wind installers to choose a turbine and other system components, determine delivery timelines, get the latest prices for installation and maintenance, as well as discussing what permits may be needed. The full-service installer will also help you determine the best point of interconnection. Please see attached list.

D. Visit locations where your turbines of interest are up and running. Talk to the owners to gain further insight on these systems. Wind installers should be able to provide locations of past clients.

E. Check with the Tribal and/or county building and zoning offices to understand the local ordinances regulating the installation of wind turbines and towers (including set backs from the road and property lines), and begin the permitting process. You will need to apply for the required permits within 30 days of receiving the Focus on energy grant, and receive the permit within 90 days. If no permit is required, you must submit a letter stating so which includes the name and contact information of the zoning official who supplied this information. If any of these conditions are not met, the Focus on Energy program will terminate you grant, and you will be notified in writing that your reward has been cancelled until you decide to reapply.

F. Once the turbine has been decided upon, work with your installer to submit a Notice of Construction Form with the FAA. Contact for FAA is: Gary Dikkers, 608.267.5018.

G. Apply for the Focus on Energy grant.

H. Begin to inform the property neighbors of the desire to install the system, to educate them on wind systems in general, and to meet with the local zoning authorities. This will help to avoid problems and get the support of your neighbors, and pave the way for continued contact with local authorities to identify and address any building permit or zoning issues such as required set backs.

I. Decide if the economics work out to your satisfaction based on all the costs and available incentives, and the energy savings/income from the estimated energy output of the wind systems provided in this report for this site. Remember that electrical rates will probably continue to rise.

J. Check with your utility to discuss the grid inter-tie procedures and requirements, insurance issues, and to verify buy-back rates. Your installer should provide support, and if you have any questions, please contact Mick Sagrillo, the Focus on Energy contact for wind: msagrillo@wizunwired.net. Phone: (920) 433 - 1869. The WPS contact is: Chip Bercher (920) 433-5518)

K. Contact your insurance agent about insuring the wind system, as an appurtenant structure. If your insurance company is unfamiliar with wind systems and unwilling to insure them, your installer should provide further guidance.

L. Insure that all zoning, utility agreements, financial incentive and any other required approvals are in hand prior to making any commitment to purchase. 


\subsection{WEBSITES}

- Focus on Energy: www.focusonenergy.com

- Midwest Renewable Energy Association: www.the-mrea.org

- American Wind Energy Association: www.awea.com

- $\quad$ Site Power Magazine/Website: www.sitepower.com

\subsection{ATTACHMENTS}

- "Wind Generator Tower Basics" Ian Woofenden. www.sitepower.com

- List of MREA Certified Installers

- "How to Buy a Wind Energy System" by Mick Sagrillo and lan Woofenden www.sitepower.com

- Wisconsin State Statute 66.0401: Regulation relating to wind and solar systems. 


\section{Appendices}

Appendix A. Wind quality and quantity description

\section{Average annual wind speed}

The average annual wind speed is the primary means by which a potential site is described. Typically, the average speed is expressed in meters per second or miles per hour at a specified elevation above ground level. The wind speed is further classified according to the Battelle wind power classes as shown in the table below.

Figure 15. Battelle Wind Power Classes

\begin{tabular}{|c|l|c|c|c|}
\hline $\begin{array}{l}\text { Wind } \\
\text { Power } \\
\text { Class }\end{array}$ & Resource Potential & $\begin{array}{l}\text { Wind Speed at } \\
\mathbf{5 0} \mathbf{m}(\mathbf{m p h})\end{array}$ & $\begin{array}{l}\text { Wind speed at } \\
\mathbf{5 0 m}(\mathbf{m} / \mathbf{s})\end{array}$ & $\begin{array}{l}\text { Wind Power } \\
\text { Density at } \\
\mathbf{5 0 m}\left(\mathbf{W} / \mathbf{m}^{2}\right)\end{array}$ \\
\hline $\mathbf{1}$ & Poor & $0.0-12.5$ & $<5.6$ & $0-200$ \\
\hline $\mathbf{2}$ & Marginal & $12.5-14.3$ & $5.6-6.4$ & $200-300$ \\
\hline $\mathbf{3}$ & Fair & $14.3-15.7$ & $6.4-7.0$ & $300-400$ \\
\hline $\mathbf{4}$ & Good & $15.7-16.8$ & $7.0-7.5$ & $400-500$ \\
\hline $\mathbf{5}$ & Excellent & $16.8-17.9$ & $7.5-8.0$ & $500-600$ \\
\hline $\mathbf{6}$ & Outstanding & $17.9-19.7$ & $8.0-8.8$ & $600-800$ \\
\hline $\mathbf{7}$ & Superb & $>19.7$ & $>8.8$ & $>800$ \\
\hline
\end{tabular}

The average annual wind speed can also be described according to its seasonal and daily (diurnal) variations. In general, the winds are strongest during the spring, fall and winter months and lowest in the summer months. Ttheir is an important consideration when trying to match a wind turbines' output to the electrical demands of the site.

The most favorable situation exists when the demand for power correlates well with the strongest winds.

During the feasibility study portion of a wind energy development project, publicly available wind resource data are used to estimate the wind resource at a particular site. These data include:

- State or federal wind resource maps

- Local airport data

- Federal navigation buoy data

- State or federal air quality monitoring sites

The wind resource data from these sources often can be analyzed to provide a reasonable first-order wind resource estimate, sufficient for a feasibility determination but insufficient to make an investment decision about large wind energy systems.

The only way to accurately understand the site-specific wind resource is through a tall tower wind measurement study. A temporary tilt-up tower 50-60 meters tall is erected on site and outfitted with wind speed measurement devices at multiple elevations. The wind speeds are measured and recorded and then analyzed and compared to publicly available long-term data records. In general, a 3-year study is required to achieve a $95 \%$ confidence level, and account for normal annual variations. In practice, commercial wind investment decisions are made in as little as 6-months to a year if there are correlation data available.

A wind speed tall tower monitoring study can cost between $\$ 25,000-\$ 40,000$ and therefore is usually not justified for small turbine projects unless the project requires an exact determination of turbine performance and return on investment. Tall tower monitoring is essential for projects using large turbines. 


\section{$\underline{\text { Wind shear }}$}

Wind speed increases with rising elevation above ground level. At ground level, friction caused by the interaction of the wind with vegetation, trees, buildings and the naturally occurring contours and topography all slows the wind down. At higher elevations above the ground, the wind moves unimpeded and its speed increases. All other factors being equal, a wind turbine should always be installed on the tallest available tower. The relationship between changes in wind speed and elevation, or wind shear, is well established.

Based on the wind speeds estimated at specific heights, the wind shear is estimated mathematically using the following formula:

$\mathrm{V}=(\mathrm{H} / \mathrm{HO})^{a} \mathrm{VO}$ where:

Where:

$V o=$ the reference wind speed

$V=$ wind speed at the elevation of interest

$H o=$ the reference height

$H=$ the elevation of interest

$a=$ alpha: the wind shear coefficient

One of the purposes of the site visit is to determine the appropriate value of alpha which is determined by the ground clutter, topography and vegetation at the site. The table below shows the normal range of alpha values as a function of the site's surface characteristics.

Therefore, the speed at any elevation can be predicted in a reference wind speed, reference elevation and wind shear coefficient are known.

Figure 16. Wind shear (a) and surface characteristics.

\begin{tabular}{|l|l|}
\hline Surface Description & Wind Shear a \\
\hline Smooth, hard ground, lake or ocean & 0.10 \\
\hline Short grass on untilled ground & 0.14 \\
\hline Level country with foot-high grass, occasional tree & 0.16 \\
\hline Tall row crops, hedges, a few trees & 0.20 \\
\hline Many trees and occasional buildings & $0.22-0.24$ \\
\hline Wooded country - small towns and suburbs & 0.30 \\
\hline Urban areas with tall buildings & 0.40 \\
\hline
\end{tabular}

Source: Analysis of Wind Shear Models and Trends in Different Terrains. M.L. Ray, A.L. Rogers, and J.G. McGowan. University of Massachusetts, Department of Mechanical \& Industrial Engineering Renewable Energy Research Laboratory

\section{Wind direction}

The wind direction is often changing in response to the movement of wind turbines so as to minimize interference and turbulence between machines. It is also important for a single turbine project to understand how obstacles, if any, in the prevailing wind direction will affect the performance of the wind turbine.

\section{Wind speed frequency distribution}

A Weibull statistical distribution is used to model the wind speed frequency. Theirtorically, measured data has shown that a Weibull distribution is representative of wind speed variations at a given site. Weibull distribution 
modeling requires three factors - the average wind speed at a site, the wind speed for which one wishes to know the frequency, and a shape factor, "k." Absent site specific information, a Weibull $\mathrm{K}$ factor of 2 is used. When $\mathrm{k}=2$, the distribution is assumed to be normal.

\section{Turbulence intensity}

Turbulence intensity is statistically defined as the standard deviation of wind speed divided by the mean wind speed. In practical terms, TI indicates how 'gusty' a wind site is. Gusty or turbulent sites, defined as $\mathrm{TI} \geq 15 \%$, adversely affect energy production and will result in higher maintenance costs over the project life due to increased mechanical fatigue. 
Appendix B. Photo of Turbines
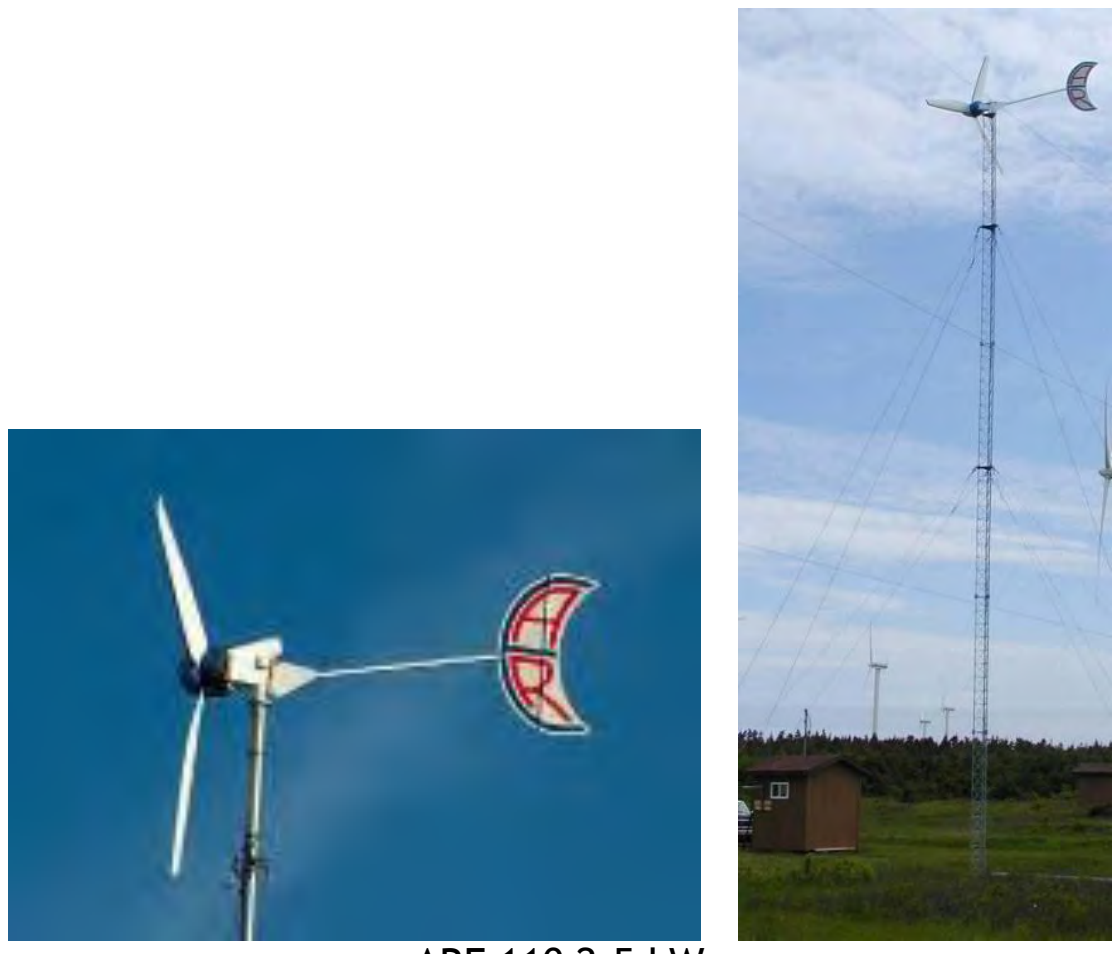

http://www.abundantre.com/Wind_FAQs.htm
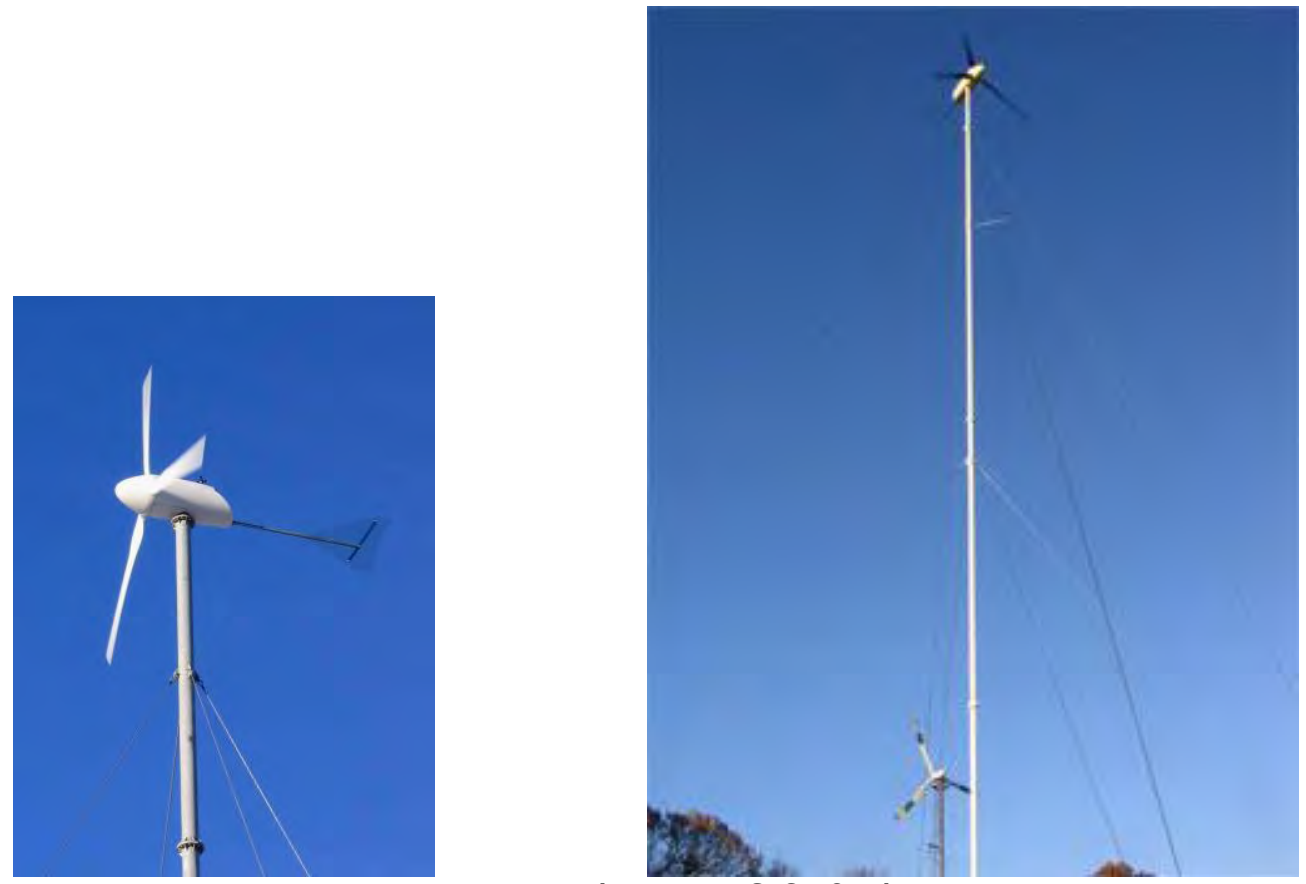

Endurance S-250 5kW

http://www.endurancewindpower.com 

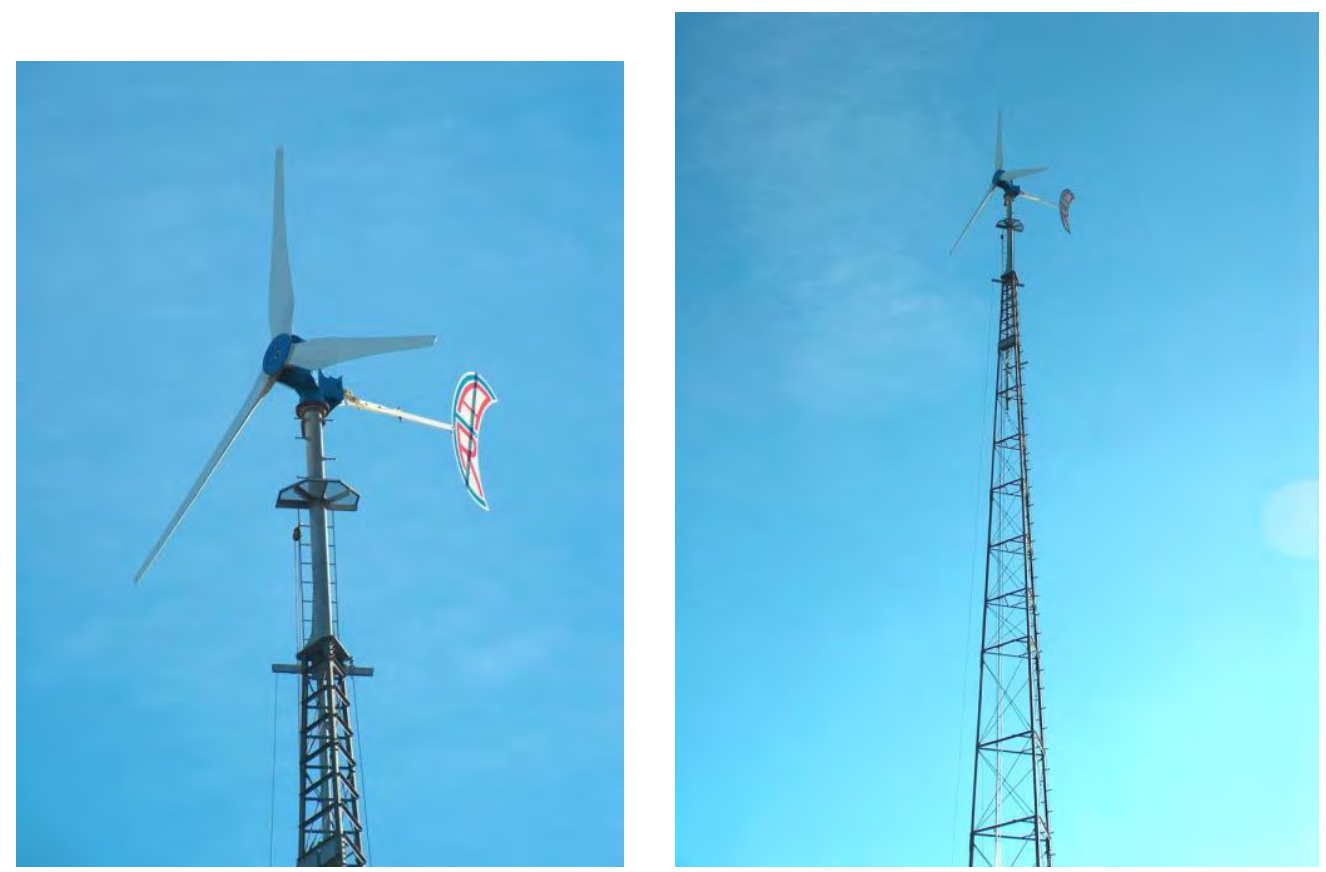

Abundant Renewable 442 10kW www.abundantre.com/ARE442 Gen Photos2.htm

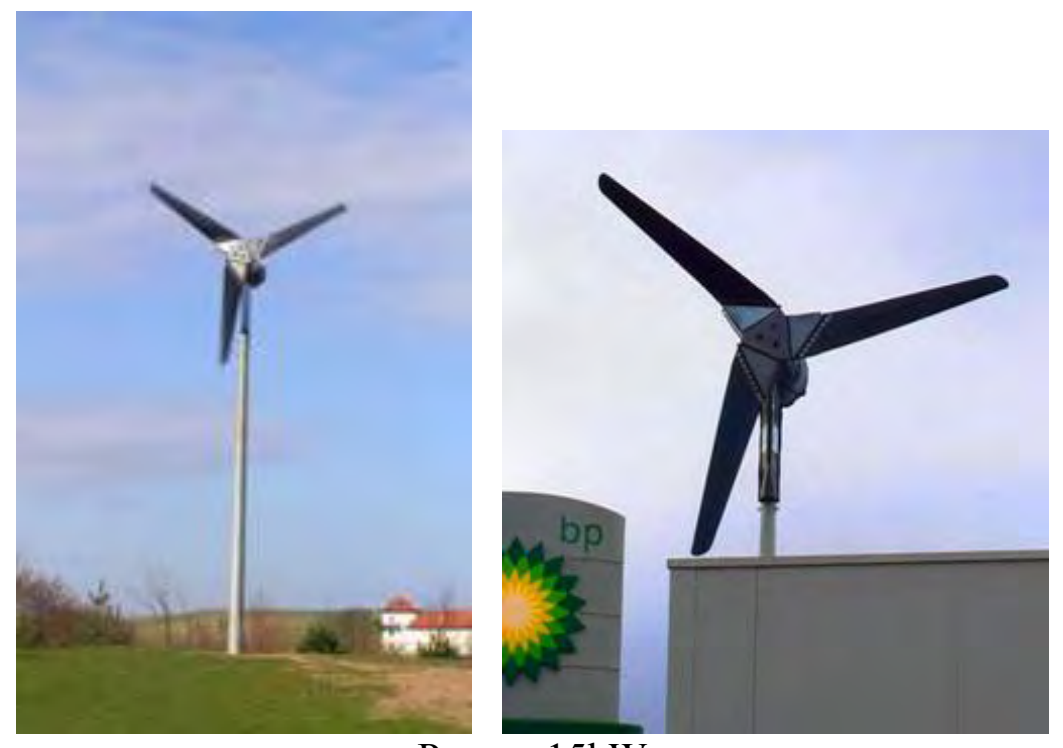

Proven 15kW 

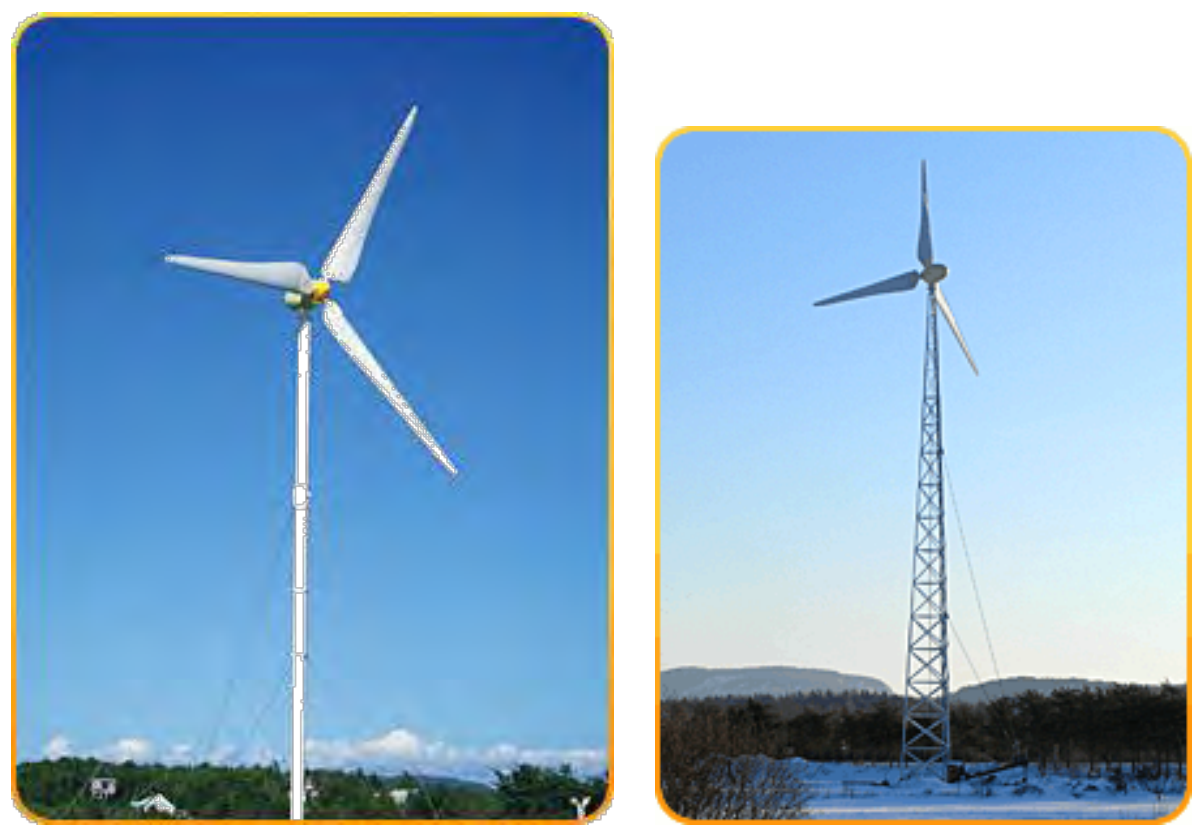

PGE 20-35 and PGE 20-50 (have same rotor diameter) http://www.energiepge.com/page produit.php?produit=pge2050 


\section{Appendix C. Description of towers}

Free-standing towers:

- Have no guy wires.

- Small footprint (about $12^{\prime}-15^{\prime}$ ' square), which is good for tight spaces.

- More expensive because it contains the most steel and weighs more than the other types.

- Most visible on the landscape because of all the steel.

- Requires climbing the tower for maintenance.

- Will provide the strength necessary to handle not only the weight of the turbine, but also the torque as the winds push on the rotor.

- Requires heavy foundations

Guyed Lattice towers:

- Have three sets of guy wires.

- Least expensive type of tower.

- Guy wires holding up the tower have a radius of around $75 \%$ of the tower height.

- Requires climbing the tower for maintenance.

Tilt-up towers:

- Have four sets of guy wires.

- Only slightly more expensive than guyed lattice towers.

- Maintenance can be performed without climbing the tower.

- Guy wires have a radius of 25' - 50' from the base depending on tower height.

- Requires relatively flat terrain for the length of the tower in at least one direction from the base of the tower, in order to lower the tower to the ground. 


\title{
NON-RESIDENTIAL SOLAR THERMAL REPORT
}

\author{
By Jamie Paterson \\ 87975 County Hwy J \\ Bayfield, WI 54814 \\ 715-779-5440 \\ info@patersonsolarpros.com
}

Business Name: Lake of the Torches Hotel

Address of Site: 510 Old Abe Road Lac Du Flambeau WI 54538

County of site: Vilas

Mailing Address: 510 Old Abe Road Lac Du Flambeau WI 54538

Contact Name: Facilities Manager

Contact Telephone: 1-800-258-6724

Contact Email:

Electric Utility: Wisconsin Public Service

Gas Utility: Varies (LP)

Focus Territory: No.

Client Interest (technology): Solar Thermal

Client motivation: The tribe would like to reduce there carbon footprint as well as operation cost

Type of Facility: Hotel, Pool, Casino

\section{Executive summary}

This Hotel is attached to the Casio building, but because of the different water heating systems and there proximity to each other this report focus on the hot water needs of the hotel. The primary hot water needs for the hotel are the swimming pool, restaurants, and guest showers. It should also be noted that pool heating with solar thermal is not eligible for the federal tax credit. 
The water heating load was identified as:

- Pool Heating

- There are three pools:

- Adult- 25,400 gallons at 85 (F)

- Children's- 1257 gallons at $87(\mathrm{~F})$

- Hot Tub- 3254 gallons at 103 (F)

- Solar heating is will be most beneficial for the children's pool and the adult pool as they operate at lower temperatures

- Solar collector array size as recommended by RETScreen $=320$ sq.ft. of flat plate collector or equivalent evacuated tube collector

- Estimated solar water heating system cost range based on recent Wisconsin averages $=\$ 42,400(\$ 115-150 /$ sq.ft. $)$

- $\quad$ Estimated energy saved per year $=756.7$ therms

- Estimated solar contribution of total load $=23 \%$ (if a cover is used on each of the pools for $8 \mathrm{hrs} /$ day. If no cover is used this will be reduced to $16 \%$

- Estimated Focus Cash-Back Reward $=\$ N A$

- Estimated Federal Tax Credit = \$NA

- Pretax ROI = 17.4\% (from RETScreen)

- Years to positive cash flow $=8.5$ (from solar economics spreadsheet)

- Estimated greenhouse gas emission reduction per year $=7.79$ tons (from RETScreen)

- See Specifics on PG 14-15 and Appendices

- Eagle Nest Dining Room and Snack Bar

- Peak months are June, July, August

- Eagle Nest and Snack Bar serve and estimated 1600 guests per day in peak months, with the rest of the year at around 900 guest per year.

- Solar collector array size as recommended to meet the needs of off peak months $=400$ sq.ft. of flat plate collector or equivalent evacuated tube collector

- Estimated solar water heating system cost range based on recent Wisconsin averages $=\$ 53,000(\$ 115-150 /$ sq.ft. $)$

- Estimated energy produced per year $=690$ therms

- Estimated solar contribution of total load $=42 \%$

- Estimated Focus Cash-Back Reward = NA

- Estimated Federal Tax Credit $=\$ 2000$ (if eligible)

- Pretax ROI = 15.1\% (from RETScreen)

- Years to positive cash flow $=10.2$ (from solar economics spread sheet)

- Recommend storage hot water storage 400-550 gallons

- Estimated greenhouse gas emission reduction per year $=7$ tons (from RETScreen)

- See Specifics on PG 15 and Appendices

- Lake of the Torches Guest Room Loads 
- Peak months are June-October

- The average is about 73 guest per day at the hotel

- Solar collector array size as recommended to meet the needs of off average daily occupancy $=1080$ sq.ft. of flat plate collector or equivalent evacuated tube collector

- Estimated solar water heating system cost range based on recent Wisconsin averages $=\$ 143,100(\$ 115-150 /$ sq.ft. $)$

- Estimated energy produced per year $=1842.4$ therms

- Estimated solar contribution of total load $=70 \%$

- Estimated Focus Cash-Back Reward = NA

- Estimated Federal Tax Credit $=\$ 2000$ (if eligible)

- Pretax ROI $=14.8 \%$ (from RETScreen)

- Years to positive cash flow $=10.5$ (from solar economics spread sheet)

- Recommend storage hot water storage 1200-1500 gallons

- Estimated greenhouse gas emission reduction per year $=17$ tons (from RETScreen)

- See Specifics on PG 15-16 and Appendices

Specifics about the solar thermal system at your facility mentioned above are detailed at the end of this report.

Solar collector mounting location:

Collector location is assumed to be on the roof of the building. The installing contractor will determine exact collector placement. Care must be taken whenever penetrating the existing roof membrane and the roofer of record should be consulted whenever any roof penetrations are made. A structural engineer should be consulted to determine the appropriate method of attaching the solar collector array to the building.

Table of Contents

1. Introduction

2. Solar Thermal Systems.

2.1 Businesses using solar thermal

2.2 Solar Thermal System Components

3. Types of Solar Collectors

3.1 Flat Plate Collectors

3.2 Evacuated Tube Collectors.

4. Types of Systems

4.1 Closed-loop Pressurized Antifreeze Systems....

4.2 Drainback Systems. 
5. Solar Collector Sites

6. Incentives

6.1 Focus on Energy Incentives

6.2 State of Wisconsin Incentives

6.3 Federal Tax Credit

6.4 Application Forms

7. Economics of Solar

7.1 Energy Prices

Graph of Energy Costs

8. Environmental.

9. Retscreen

10 Next Steps.

11 Your Facility.

1. Introduction:

Controlling operating costs is a high priority for all businesses and institutions in this age of escalating energy costs. Many businesses and institutions are also concerned about the environmental consequences of using fossil fuels and are looking for alternatives.

Energy Conservation:

0 The first area to address when attempting to control these costs is energy conservation.

- Recent studies show that we can reduce our energy demand by up to $50 \%$ by using the best technologies available today.

- The use of low-flow showerheads and low-flow sink aerators can have a large impact on hot water usage in hotels and motels.

- Insulating all hot water pipes can also have a positive impact on energy savings.

Good Investment:

- Investing in energy conservation has a very high return on investment.

- Of all the renewable energy options available today, solar thermal systems often have the fastest return on investment.

- The Focus program may offer assistance with your efforts to conserve energy.

Please call our main office (1-800-762-7077) and ask how the Focus program can help your particular type of business or institution can save energy through energy conservation.

\section{2.}

Solar Thermal Systems:

Solar thermal systems can include solar water heating systems and solar space heating systems. 
- Solar thermal systems rarely are designed to provide $100 \%$ of the heating needs because in our climate we have significant cloudy periods during some seasons.

- Most places in the world have cloudy periods during late fall and early winter, and sometimes also during part of the springtime.

- Despite the cloudy periods, it is still very worthwhile investing in solar thermal systems.

- All these systems can provide at least $50 \%$ of the annual heating load, and in some cases even more.

- Systems are sized to meet the particular heating load of your business or institution.

2.1 Examples of businesses and institutions in Wisconsin that are using solar thermal energy systems include:

○ restaurants, hotels, motels, B\&B's, health clubs, health care facilities, commercial laundries, laundromats, car washes, schools, government buildings, office buildings, multi-family housing, storage facilities, manufacturing facilities, shops of all kinds, storefronts and others.

- Several Focus fact sheets about solar thermal energy systems are attached to this report.

2.2 Solar Thermal System Components:

While each solar thermal system is unique, they all share certain components.

- Solar thermal collectors.

- Insulated piping to transfer the heat from the solar collectors to the building.

- Heat transfer fluid (non-toxic antifreeze).

- In most case a heat storage medium (usually water).

This report uses Statewide and National averages to calculate your heating load and gives typical sizing options.

The report also uses statewide installation cost averages for calculating typical energy savings and payback analyses.

\section{Types of solar collectors:}

There are two types of solar collectors that are used in Wisconsin today.

\section{- $3.1 \quad$ Flat plate collectors:}

- Flat plate collectors are by far the most popular kind of collector used in our climate.

- These collectors have a long and positive track record in our climate and are the type of collector I have used in my modeling.

- There are pictures and information about flat plate collectors in the fact sheets that are attached to this report.

- $3.2 \quad$ Evacuated tube collectors:

- A newer technology in solar thermal collectors.

- These collectors are popular in certain parts of the world and are used in commercial solar thermal systems.

4.

Types of Systems: 
There are two main types of systems that are used in solar thermal systems; closed-loop pressurized antifreeze systems and drainback systems.

\subsection{Closed-loop Pressurized Antifreeze Systems:}

○ An antifreeze solution (usually non-toxic propylene glycol and water mixture) fills the collectors and piping at all times.

- When there is solar energy available to collect a circulating pump turns on and circulates this fluid (called the heat transfer fluid or solar fluid) throughout the system.

○ The solar fluid gets heated in the collectors and moves that heat into the building.

$\circ$ The heat is then transferred from the solar fluid to water.

o The heated water can be used directly or can be stored for use at a later time.

- This heated water can be used for domestic hot water, process hot water, or space heating.

- When there is no solar energy to be harvested, the pump does not operate and the solar fluid stops circulating.

o Closed-loop antifreeze systems are the most popular type of system installed in our climate.

The advantages of closed-loop pressurized antifreeze systems include;

o Proven system type for cold climates.

$\circ$ The most versatility in system configurations.

○ Cost competitive.

- Ease of installation.

The disadvantage of closed-loop pressurized antifreeze systems include:

$\circ$ Systems can overheat (resulting in degradation of the solar fluid) if left with no load and/or no circulation over extended periods of time.

\subsection{Drainback systems:}

Drainback systems are very similar to closed-loop pressurized antifreeze systems except that the solar fluid does not stay in the piping and the collectors at all times.

- The solar fluid is stored in a special drainback tank, which is located below the collectors and inside heated space.

- When solar energy is available for harvesting a high-head pump turns on and pumps the solar fluid from the drainback tank into the piping and solar collectors.

The main advantages of drainback systems include:

- When the solar storage tank is fully heated the system simply turns off and the solar fluid drains back to the drainback tank.

- Eliminates any potential overheating problems.

The main disadvantage is that the collectors include:

- The collectors must be located above the drainback tank, which eliminates the option of mounting the collectors in any place except above the drainback tank.

- There are also piping limitations in drainback systems, as the piping must be run in such a way that there is a continuous downward slope to all the piping to facilitate complete draining of all the collectors and piping when the system is not operating.

\section{Solar collector sites:}


- All solar collectors must face in a southerly direction and must have access to the sun all year round from at a minimum of $10 \mathrm{AM}$ to $2 \mathrm{PM}$ every day. 9AM to 3PM is best.

- Most shading problems happen during the winter when the sun is low in the sky.

- Shade and snow cover on the solar collectors reduce the system's production

- As solar thermal systems can last 50 years or more, system siting should consider shading by future roof penetrations, tree grow, building activity, etc.

- Most businesses have good places to install solar collectors because the buildings they occupy tend to be tall, have large roof areas and have parking lots around them reducing potential shading.

6.

\section{Incentives:}

6.1 Focus on Energy incentives:

- The Focus on Energy Program offers incentives for the installation of solar water heating systems.

- We also give incentives for combination water heating and space heating systems where the space heating system is part of the water heating system (a common design).

- Swimming pool heating systems are covered under the Focus program.

- We do not currently give incentives for space heating only systems.

- The Focus program offers a feasibility grant where Focus will pay up to $50 \%$ of the cost of that study.

- Often on large projects, a vendor may need to charge a fee to do this analysis and design work, and the feasibility study serves that purpose.

- This feasibility study grant is in addition to the grants Focus offers for the installation of systems.

- You can find the application for the feasibility study on our web site (http://www.focusonenergy.com/page.jsp?pageId=905).

The Focus incentive is based on the annual estimated energy produced by the solar energy system and is calculated in therms $(1$ therm $=100,000 \mathrm{Btu})$.

- Small and medium sized systems (up to 5,000 therms per year) are served by the CashBack Reward form (a copy is attached to this report).

- For systems that produce less than 1,000 therms per year the incentive is $\$ 10.00$ per therm

- For systems that produce between 1,000 and 5,000 therms per year the incentive is $\$ 8.00$ per therm

- Large systems (over 5,000 therms per year) are served by the implementation grant reward form.

- For systems that produce over 5,000 therms per year the incentive is $\$ 6.00$ per therm

- Both forms are available for download from our web site.

- Maximum Focus incentive is $\$ 50,000$ per system or $25 \%$ of total system cost. 


\section{$\underline{\text { State Taxes }}$}

Wisconsin's depreciation is based on the Federal depreciation formula for solar water heating systems. So the Federal five-year accelerated depreciation applies to Wisconsin business income taxes as well.

\section{Property Tax Exemption}

Solar water heating systems are exempt from Wisconsin property taxes.

- The federal government also offers federal tax credits and accelerated depreciation for all qualifying solar thermal systems.

- The federal tax credit equals $30 \%$ of the system cost plus the investment qualifies for accelerated depreciation.

- For a business that pays taxes, the total combined federal tax credit and depreciation value equals around $50 \%$ of the system cost for most businesses.

- Federal tax credit does not cover solar swimming pool heating systems.

- Please consult your tax advisor for details on how these tax credits can work for your business.

Application Forms:

- If you are interested in receiving a Focus incentive, please note that you must submit your application and receive approval before you spend any money on the project.

- Please read all the conditions specified in the application.

- The installing contractor should assist you in gaining all the required information you will need to completely fill in the application.

- If you have any additional questions about submitting these forms, please feel free to contact me.

\section{Economics of solar:}

Solar thermal energy systems have several economic advantages:

- They offset money you would pay for fossil fuels. The energy provided by the solar thermal system will offset a fossil fuel energy bill, thus reducing that bill.

- They also fix the energy costs provided by the solar energy system.

- When you install a solar thermal energy system, that system provides energy to your facility with little or no operating cost. The sun's energy is free. All you have to pay for is the solar harvesting equipment.

- In most cases there will be very little impact on your monthly cash flow when you first install the solar energy system. The monthly savings on your fossil fuel bill will pay the monthly bill on your solar energy system.

- In a short amount of time the energy savings on your fossil fuel bill will be greater than your payment on the solar energy system, resulting in a positive cash flow. 
- The accumulated savings on your fossil fuel bill will completely pay off the solar energy system, and after that point is reached all the energy from the solar energy system is free.

7.1

Energy prices:

- Many business and facility owners have mentioned to me that it is very difficult to operate a business and make future plans when you have no idea what your energy bills will be like in the future.

- Energy prices escalated at a predictable rate for a long time, and this energy escalation rate averaged around $7 \%$ per year from 1970 to 2000 .

- Since 2000 energy prices have escalated at around $14 \%$ per year.

- All other fuels such as coal, fuel oil, electricity and propane have seen similar price escalation.

- By investing in a solar thermal system, a business fixes the cost of the energy provided by that system, which isolates that energy price from the natural gas price fluctuations seen recently

If you borrow the money to pay for the system your payments will remain constant.

- Your monthly loan payments will typically be slightly larger than the annual energy savings for a few years, resulting in a slightly negative or neutral cash flow impact.

- Soon afterward the monthly fuel savings will equal your loan payment, resulting in a neutral cash flow impact.

- Very shortly after that your monthly energy savings will be greater than your loan payment, resulting in a positive cash flow.

- Not long after that your energy savings will have completely paid for the loan and all the energy will be free after that.

- If you finance the solar energy system internally, you will see that the return on investment averages between $15 \%$ and $25 \%$.

8.

\section{Environmental:}

There are a number of reasons that businesses are concerned about the environmental impacts of their operation.

- The environmental impacts include Carbon emissions from heating.

- Using renewable energy can reduce those negative impacts.

- The use of renewable energy systems can help reduce the carbon footprint of a business.

- The RETScreen program calculates the net greenhouse gas emission reduction that results from the modeled system.

- The figure given is tons of $\mathrm{C} 02$ per year. To put the number into perspective, each ton of $\mathrm{C} 02$ reduction is equivalent to 1,778 miles driven at an efficiency of 22 miles per gallon.

Many businesses are also interested in the benefits of "being a green business" from a marketing perspective.

- Polls show that consumers would rather do business with a company that incorporates renewable energy into their business. 


\section{RETScreen:}

I have included a RETScreen analysis for your business as an attachment to this report.

- RETScreen is a state of the art computer-modeling program that is used for modeling solar energy systems.

- The program uses certified collector performance data, weather data from NASA, National averages for water consumption, and the heating load we identify, to recommend and analyze a specific solar thermal system for your business.

- For system pricing I use average installed prices for similar sized systems that have been installed in Wisconsin over the last several years.

- Note that the cost factors I use are averages. Every installation is unique and some installations are above or below this average.

- Also note that the cost of raw materials fluctuates and are on an upward trend, which can also affect the cost of a system.

- The data that I have entered into these programs is detailed at the beginning of this report.

- Please check that information for accuracy.

I have included 1 page from RETScreen for your inspection.

- The financial analysis pages calculate a payback, cash flow, and ROI analysis for the modeled system.

\section{Next steps: Note, if you have any questions about the information presented above, please feel free to give me a call.}

a) Evaluate the options presented in this report, and make a decision on system size, location and mounting methods.

b) For roof mounted systems confirm with the building designer and/or qualified structural engineer as to the building roof structure's ability to support the additional weight and wind loading of a solar thermal system. Also, review the impact on roofing warrantee of siting panels over roofing.

c) Determine the project's economics with your financial and tax advisors.

d) Contact installers to get price quotes (we recommend that you get several quotes from different vendors, see Focus on Energy's full service solar thermal installers attached to this report).

e) Refine system size, siting, etc. decision based on installer quotes and consultation with financial and tax advisors. Re-bid system quotes as needed. 
f) Contact your insurance agent and advise them of the intent to install the renewable energy system, and ask for written confirmation of the liability coverage currently provided (as needed to meet utility requirements). Confirm that current insurance provides the needed coverage, and resolve any issues with the agent.

g) Define any permitting requirements for the installation of the system.

h) With your financial advisors, make the decision to go forward with the project

i) Apply and receive approval for Focus on Energy incentives and other incentives as appropriate, before you spend any money on the system.

j) Sign the installation contract with your selected installation firm.

- Insure that all zoning, financial incentive and any other required approvals are in hand prior to making any commitment to purchase.

k) When the system is installed you submit a notice of installation to Focus and your incentive will be mailed to you.

1) If, at any time during this process you have any questions, please feel free to give me a call or email.

\section{1: Specifics about your facility}

- The Hotel Pool is located on the west of the hotel complex.

- There is the option of mounting the collectors directly above the pool. There is about 1500 sq feet of south facing roof space available at this location. Care would have to be taken in placing the collectors on the roof, as there is potential shading from the hotel roof. There may also be some visual impacts noted from the guest rooms. There is the option of ground mounting the collectors near the pool facility.

- The pool boiler room, located below the pool area, doesn't have much room for addition storage.

- The pool boiler uses a munchkin boiler for all pool water heating.

- The roof system is shingled with asphalt shingles and is about 12 years old. I did not inspect the condition of the shingles, as there was snow on the roof.

- The roof doesn't have any access from underneath. It is strongly recommended that a structural engineer look over roof system to determine the load capacity of the structure.

$\circ$ The roof pitch is roughly $4 / 12-6 / 12$

- Eagles Nest Restaurant and Snack Bar

- The Restaurant and snack bar are located in the main part of the casino building and share the same water haters.

- The water heater is a 100 Gallon Bosch "Energy Saver" Propane heater.

$\circ$ There is room for additional storage in the room where the water heater is kept.

- The door opening is about 43 inches.

- Collectors can be mounted above the water heater at this location. 
- The main loads for the kitchen is dish washing. After talking with the staff it is estimated that the Hobart dishwasher runs for about 455 cycles per day (336.7 gallons@180 (f)). It is also estimated that the dishwashing sinks are filled about eight times a day (32 gallons), with about 10 gallons of additional water used for cleaning

○ It is recommended that between 400 and 550 gallons of additional storage be used with the recommended 400 square feet of solar thermal collector.

- The roof structure above the hot water heater is a flat roofing material that is about 12 years old.

- It appears that there is adequate room above this hot water heater to install the recommended number of collectors.

\section{- Hotel Guest Rooms}

○ There are three 100 Gallon AO Smith Propane heaters that provide the hot water for the hotel rooms.

o There is room for additional storage in the room next where the water heater are kept.

○ This room is limited to about 7 foot ceiling and about 400 Square feet of space.

o The door opening is about 43 inches.

- It may be challenging to identify where the solar thermal pipe runs can enter this room.

- The load calculation were made with information provided by the Hotel staff (see occupancy page in appendixes)

- The average daily occupancy for the hotel is about 73 guest per year with the peak months in the summer and fall.

○ It is estimated that each guest uses about 15 gallons of hot water for showers and washing per day.

○ It is recommended that between 1200-1500 gallons of additional storage be used with the recommended 1080 square feet of solar thermal collector.

- According to the staff the hotel laundry services use cold water for washing linens. So the laundry service was not factored into this report.

\section{Appendices:}

- Retscreen \& spreadsheets

- Photo's of building

- Full Service Installer List

\section{Resources:}

- Focus on Energy Web Site: www.focusonenergy.com

\section{Disclaimers:}

- $\quad$ All numerical values in this report are estimates. 
- $\quad$ Proper legal counsel, along with IRS guidance, is required to definitively determine the tax ramification of installing a solar thermal system.

- To get an accurate installed cost of the system get at least three bids from qualified solar thermal installers.

- $\quad$ The information provided here should NOT be considered legal advice.

Material in this report does not imply a recommendation or endorsement of any product or service, by the Focus on Energy Program or any subcontractor of Focus on Energy. The Focus on Energy Program, or any subcontractor of Focus on Energy, is not responsible for inaccurate or incomplete data in this report.

Attachment 1. Solar Thermal System Terminology Definitions

Absorber - The part of a solar collector that absorbs the sun's energy and changes that energy into heat.

Active solar energy system - Any solar energy system that uses a collector to absorb solar energy.

Ambient - The temperature of the surrounding air.

Aquastat - A thermostat that measures the temperature of a liquid.

Azimuth - The distance in degrees from north. (South would have an azimuth of 180).

Batch heater - Another name for ICS collector.

Battery - A storage device for energy.

British Thermal Unit (Btu) - The amount of energy it takes to raise the temperature of one pound of water one degree $\mathrm{F}$.

Centrifugal pump - A pump that moves a fluid by spinning it with enough force to throw the fluid outward.

Check valve - A valve that allows a fluid to travel in only one direction within a circuit. Circulator - A pump designed to move a fluid within a circuit. 
Closed-loop solar heating system - A type of system where the solar fluid stays in the solar loop and does not mix with the domestic water.

Collector - A device that collects solar energy.

Collector loop - Another name for solar loop.

Collector tilt - The angle between the solar collector plane and the horizontal plane.

Conduction - Heat flow within a material that is caused by the difference of temperature within that material.

Convection - The movement of parts of a fluid because of variations in the fluid's density caused by temperature differences.

Counter-flow heat exchanger - A heat exchanger where the two fluids pass each other in opposite directions.

Coupler - A pipe fitting that joins two pieces of pipe together.

Degree-day - The difference between $65^{\circ} \mathrm{F}$ and the ambient temperature, when the ambient temperature is below $65^{\circ} \mathrm{F}$.

Differential temperature controller - An electrical device that measures the difference in temperature between two locations and switches a pump on or off in relation to the difference in the temperatures at the two locations.

Diffuse radiation - Solar radiation that is scattered by the atmosphere and everything that is suspended in the atmosphere, particularly water vapor.

Direct radiation - Solar radiation that has not been scattered.

Drainback - A solar water heating method where the solar fluid is pumped to the collectors and fills the solar loop piping when solar energy is available for harvest but drains back to a holding tank when not collecting energy. 
Draindown system - A solar water heating system that drains when not in use.

Emittance - The property of a material to radiate energy.

Expansion tank - A tank used in solar energy systems to compensate for the expansion of liquids in a closed-loop circuit.

Evacuated tube collector - A collector that uses absorber plates that are enclosed in a glass tube that has a vacuum inside of it.

Flat-plate collector - A rectangular solar thermal collector, typically four inches deep, four feet wide and eight feet or ten feet tall.

Flow meter - A device that measures the flow of a liquid within a pipe. It is often a clear pipe with a scale on the side.

Flow rate - A measure of the rate of a certain volume of fluid flowing through a circuit. Fossil Fuel - A carbon-rich and energy-dense fuel that was created from concentrated organic matter that lived or grew on the earth millions of years ago.

Head - The total pressure or resistance to the flow of a liquid within a circuit exerted by gravity and friction.

Header - A manifold

Heat exchanger - A device that facilitates the transfer of heat from one fluid to another.

Heat transfer fluid - A fluid that is used to transfer heat from one location to another. This fluid could be a liquid or a gas.

Hydronic - Hydronic heating systems use a liquid to transfer heat. Forced air systems use air. Indirect system - A solar water heating system where the domestic water is not heated in the collectors but is heated using a heat transfer fluid and a heat exchanger.

Liquid collector - A collector that uses a liquid as the heat transfer fluid. 
Manifold - A pipe with several outlets.

Open-loop system - A kind of solar water heating system where some part of the system is vented, or the solar loop contains potable water.

Orientation - The direction the solar collectors face in relation to South.

Passive systems - Solar heating systems that do not use a collector to absorb the sun's energy.

A term used to describe a solar heating system where the house itself is the solar collector.

Photovoltaic panel - A type of solar collector that absorbs solar energy and converts it to electrical energy. Also called PV.

Potable water - Drinkable water.

Propylene glycol - A non-toxic antifreeze used in solar heating systems. It is mixed with water and used as a heat transfer fluid.

Pump - A device that moves a fluid through a circuit.

Radiation - The flow of energy through a space.

Renewable energy - Energy that is replenished by nature on a regular basis.

Risers - The pipes that connect the top and bottom manifolds in an absorber plate.

Sensor - A device that identifies the temperature at a certain location.

Solar collector - A device that collects the energy of the sun that is radiated to the earth's surface.

Solar energy - Energy produced by the sun that is radiated to the earth's surface.

Solar fluid - The heat transfer fluid used in a solar heating system.

Solar loop - The circuit of piping that travels from the collectors to the heat exchanger/storage and back to the collectors. 
Specific heat - The amount of heat, in Btu, needed to raise the temperature of one pound of a substance by one degree F.

Stagnation - When the solar fluid in a closed-loop solar heating system is not circulating.

Static head - The pressure created by a column of water in a pipe.

Therm - 100,000 Btu.

Thermosiphon - The movement of a fluid caused by convection.

Wrench - A solar installer 


\section{Appendices 1 :Lake of the Torches Hotel}

Pool Financial Summary 1
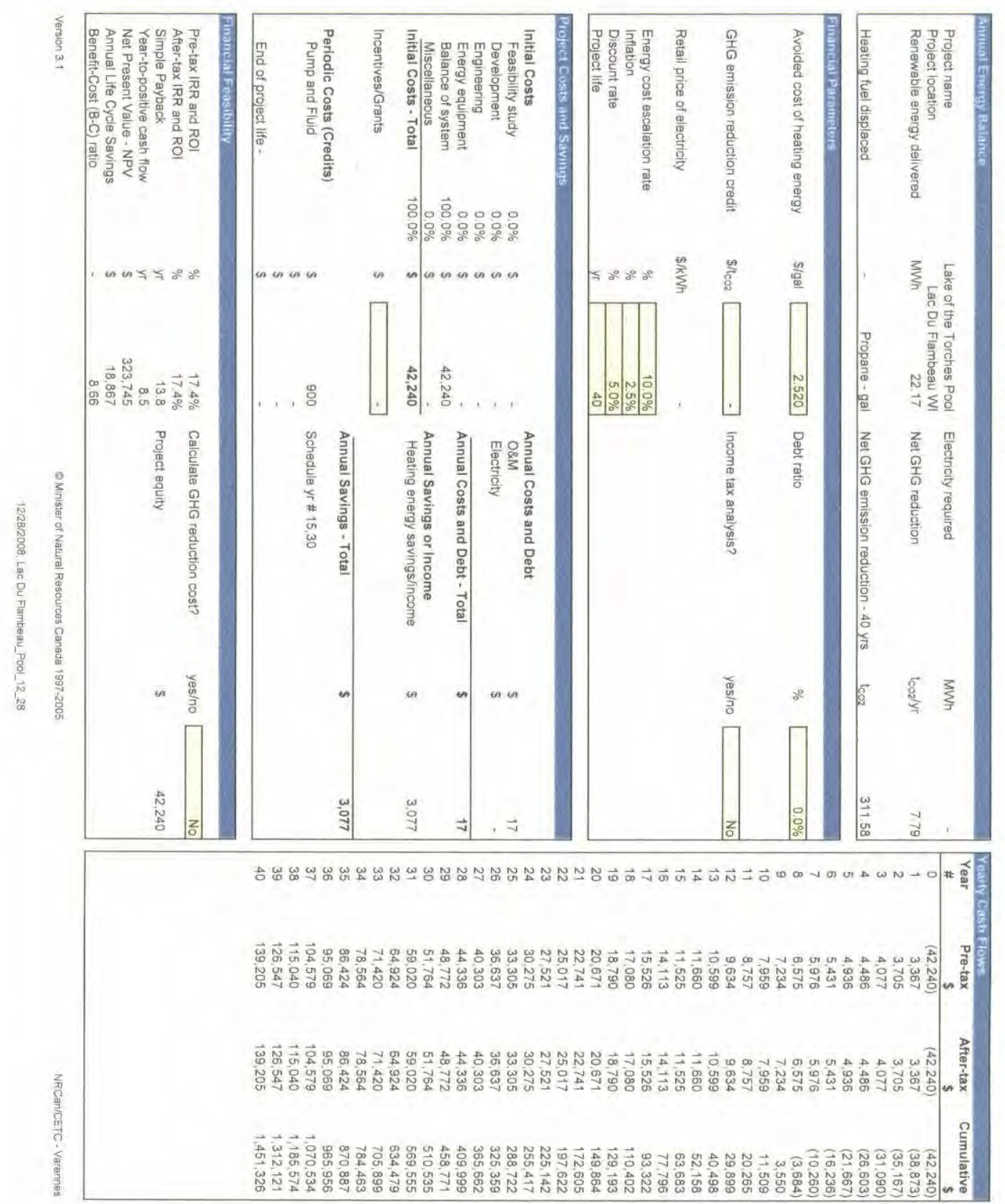
Appendices 2:Lake of the Torches Hotel Pool Financial Summary 2

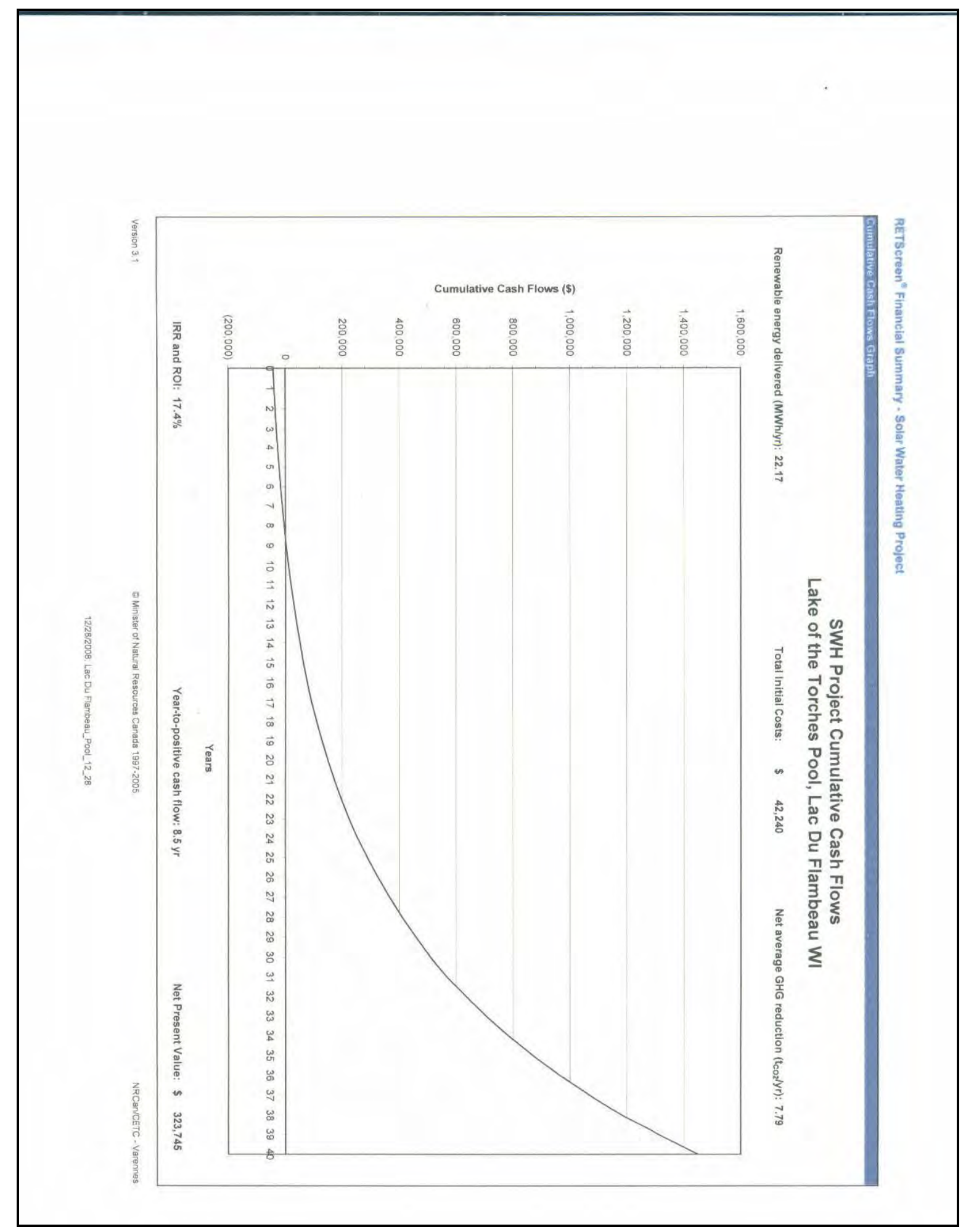


Appendices 3: Eagles Nest and

Snack Bar Financial Summary

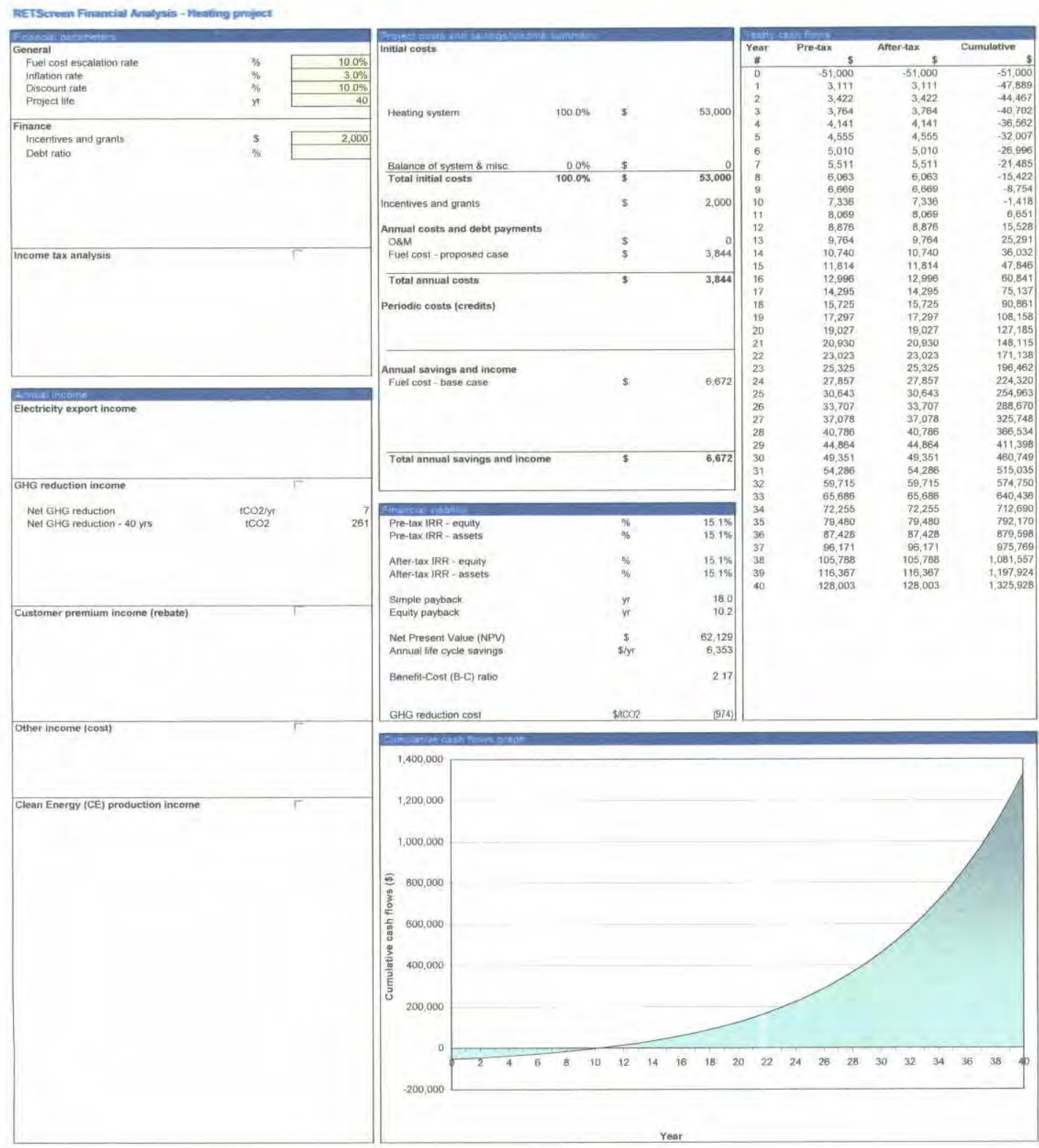


Appendices 4: Hotel Guest Rooms

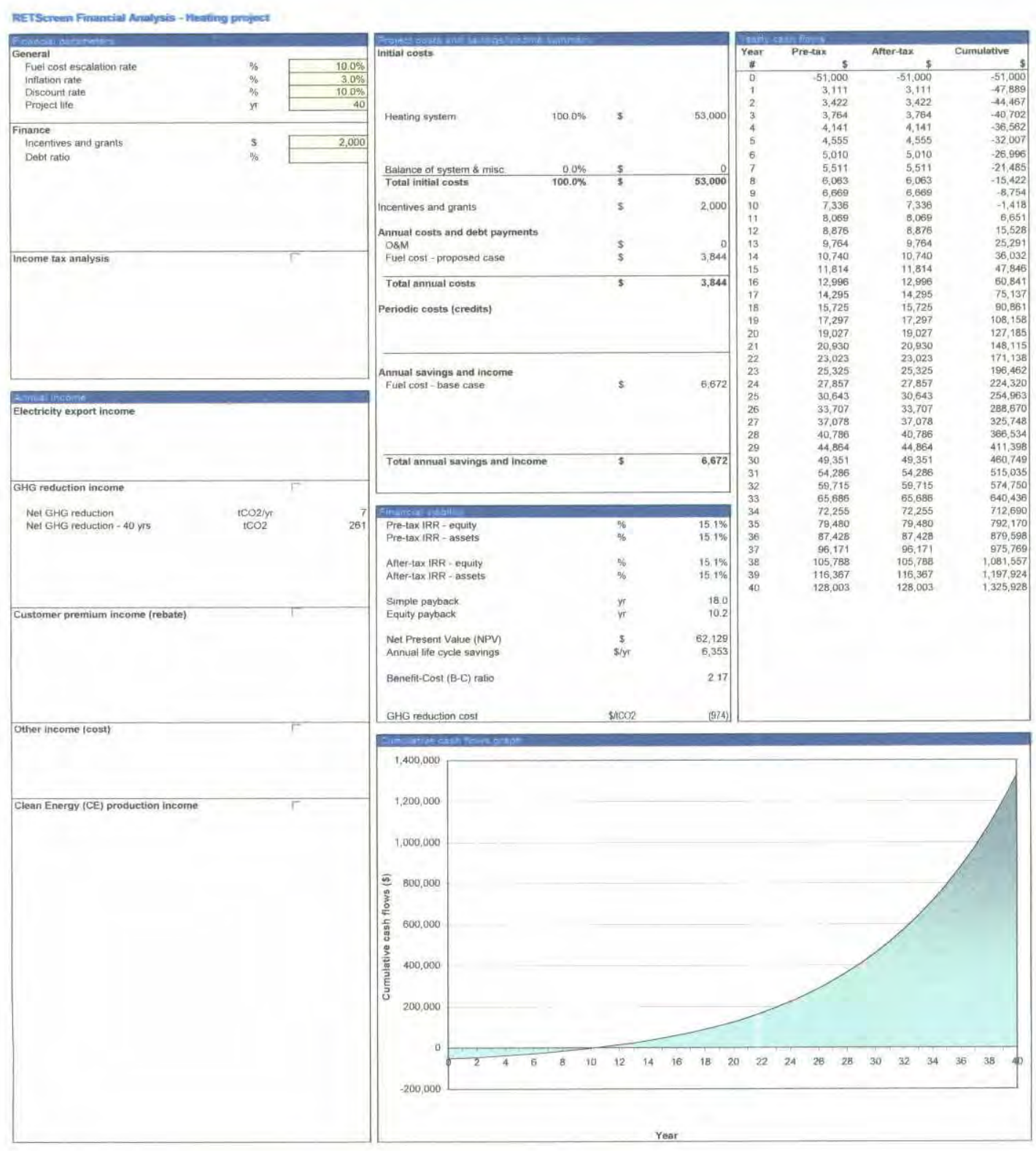



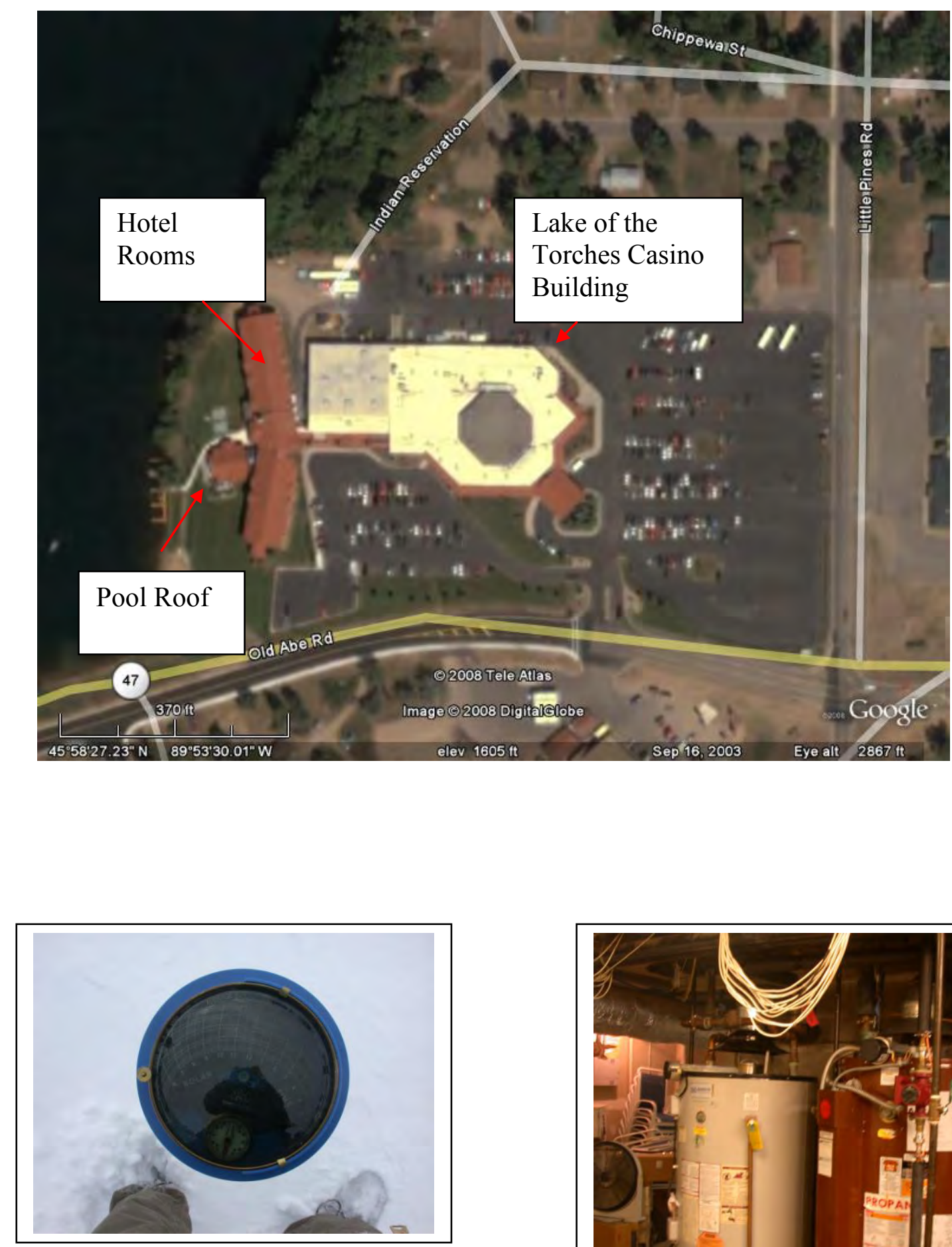

Pathfinder Reading Taken on Casino Roof Top

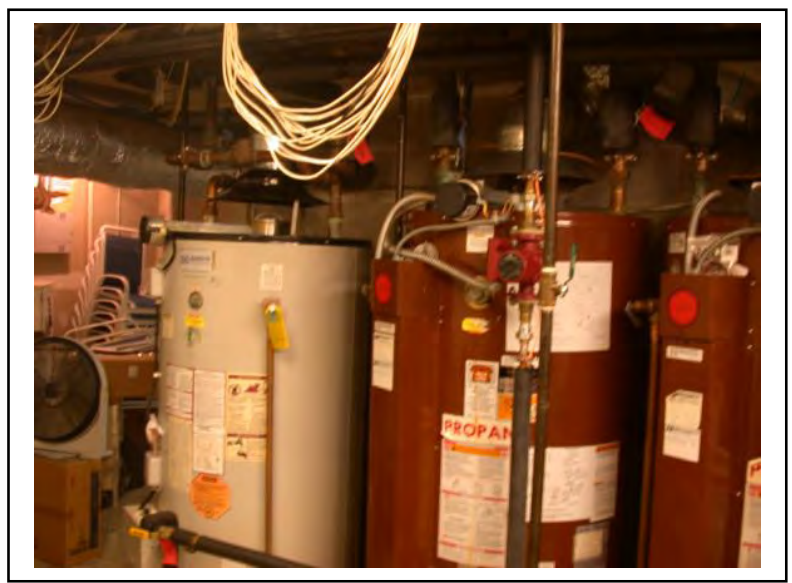

3 AO Smith Water Heaters that Supply Hotel Guest Rooms 


\title{
NON-RESIDENTIAL SOLAR THERMAL REPORT
}

\author{
By Jamie Paterson \\ 87975 County Hwy J \\ Bayfield, WI 54814 \\ 715-779-5440 \\ info@patersonsolarpros.com
}

Business Name: Lac Du Flambeau Head Start \& Lac Du Flambeau School

Address of Site: 2899 HWY 47 S Lac Du Flambeau WI 54538

County of site: Vilas

Mailing Address: 2899 HWY 47 S Lac Du Flambeau WI 54538

Contact Name: Facilities Manager

Contact Telephone: 715-588-7214

Contact Email:

Electric Utility: Wisconsin Public Service

Gas Utility: Varies (LP)

Focus Territory: NO -Does not have natural gas or electric water heaters

Client Interest (technology): Solar Thermal

Client motivation: The tribe would like to reduce there carbon footprint as well as operation cost

Type of Facility: The head start program is located in the Lac Du Flambeau School Building

\section{Executive summary}

The water heating load was identified as:

- Domestic water heating Head Start

- About 250 Students Per Day

- Occupancy rate: $100 \%$ for 5 Days per Week

- Solar collector array size as recommended by RETScreen $=160$ sq.ft. of flat plate collector or equivalent evacuated tube collector 
- Estimated solar water heating system cost range based on recent Wisconsin averages $=\$ 21,200$ ( $\$ 115-150 /$ sq.ft. $)$

- Estimated energy saved per year $=242.8$ therms

- Estimated solar contribution of total load $=82 \%$

- Estimated Focus Cash-Back Reward = \$NA

- Estimated Federal Tax Credit $=\$ 2000$ (if eligible)

- Pretax ROI $=14 \%$ (from RETScreen)

- Years to positive cash flow $=10.7$ (from solar economics spreadsheet)

- Estimated greenhouse gas emission reduction per year $=2$ tons (from RETScreen)

- Domestic water heating at School

- About 480 Students Per Day

- Occupancy rate: $100 \%$ for 5 Days per Week

- Solar collector array size as recommended by RETScreen $=320$ sq.ft. of flat plate collector or equivalent evacuated tube collector

- Estimated solar water heating system cost range based on recent Wisconsin averages $=\$ 42,400(\$ 115-150 /$ sq.ft. $)$

- Estimated energy produced per year $=471$ therms

- Estimated solar contribution of total load $=78 \%$

- Estimated Focus Cash-Back Reward = NA

- Estimated Federal Tax Credit $=\$ 2000$ (if eligible)

- $\quad$ Pretax ROI $=11.7 \%$ (from RETScreen)

- Years to positive cash flow $=13.7$ (from solar economics spreadsheet)

- Estimated greenhouse gas emission reduction per year $=3$ tons (from RETScreen)

Specifics about the solar thermal system at your facility mentioned above are detailed at the end of this report.

\section{Solar collector mounting location:}

Collector location is assumed to be on the roof of the building. The installing contractor will determine exact collector placement. Care must be taken whenever penetrating the existing roof membrane and the roofer of record should be consulted whenever any roof penetrations are made. A structural engineer should be consulted to determine the appropriate method of attaching the solar collector array to the building.

Table of Contents

1. Introduction

2. Solar Thermal Systems

2.1 Businesses using solar thermal

2.2 Solar Thermal System Components

3. Types of Solar Collectors 
3.1 Flat Plate Collectors.

3.2 Evacuated Tube Collectors

4. Types of Systems

4.1 Closed-loop Pressurized Antifreeze Systems....

4.2 Drainback Systems.

5. Solar Collector Sites.

6. Incentives. .

6.1 Focus on Energy Incentives.

6.2 State of Wisconsin Incentives....

6.3 Federal Tax Credit....

6.4 Application Forms

7. Economics of Solar

7.1 Energy Prices

Graph of Energy Costs

8. Environmental.

9. Retscreen.

10 Next Steps. .

11 Your Facility.

\section{Introduction:}

Controlling operating costs is a high priority for all businesses and institutions in this age of escalating energy costs. Many businesses and institutions are also concerned about the environmental consequences of using fossil fuels and are looking for alternatives.

Energy Conservation:

$\circ$ The first area to address when attempting to control these costs is energy conservation.

- Recent studies show that we can reduce our energy demand by up to $50 \%$ by using the best technologies available today.

- The use of low-flow showerheads and low-flow sink aerators can have a large impact on hot water usage in hotels and motels.

- Insulating all hot water pipes can also have a positive impact on energy savings.

Good Investment:

- Investing in energy conservation has a very high return on investment.

- Of all the renewable energy options available today, solar thermal systems often have the fastest return on investment.

○ The Focus program may offer assistance with your efforts to conserve energy. 
Please call our main office (1-800-762-7077) and ask how the Focus program can help your particular type of business or institution can save energy through energy conservation.

2. Solar Thermal Systems:

Solar thermal systems can include solar water heating systems and solar space heating systems.

$\circ$ Solar thermal systems rarely are designed to provide $100 \%$ of the heating needs because in our climate we have significant cloudy periods during some seasons.

- Most places in the world have cloudy periods during late fall and early winter, and sometimes also during part of the springtime.

- Despite the cloudy periods, it is still very worthwhile investing in solar thermal systems.

- All these systems can provide at least $50 \%$ of the annual heating load, and in some cases even more.

- Systems are sized to meet the particular heating load of your business or institution.

2.1 Examples of businesses and institutions in Wisconsin that are using solar thermal energy systems include:

○ restaurants, hotels, motels, B\&B's, health clubs, health care facilities, commercial laundries, laundromats, car washes, schools, government buildings, office buildings, multi-family housing, storage facilities, manufacturing facilities, shops of all kinds, storefronts and others.

- Several Focus fact sheets about solar thermal energy systems are attached to this report.

2.2 Solar Thermal System Components:

While each solar thermal system is unique, they all share certain components.

○ Solar thermal collectors.

- Insulated piping to transfer the heat from the solar collectors to the building.

- Heat transfer fluid (non-toxic antifreeze).

- In most case a heat storage medium (usually water).

This report uses Statewide and National averages to calculate your heating load and gives typical sizing options.

The report also uses statewide installation cost averages for calculating typical energy savings and payback analyses.

\section{Types of solar collectors:}

There are two types of solar collectors that are used in Wisconsin today.

- $3.1 \quad$ Flat plate collectors:

- Flat plate collectors are by far the most popular kind of collector used in our climate.

- These collectors have a long and positive track record in our climate and are the type of collector I have used in my modeling.

- There are pictures and information about flat plate collectors in the fact sheets that are attached to this report.

- 3.2 Evacuated tube collectors: 
- A newer technology in solar thermal collectors.

- These collectors are popular in certain parts of the world and are used in commercial solar thermal systems.

\section{4.}

Types of Systems:

There are two main types of systems that are used in solar thermal systems; closed-loop pressurized antifreeze systems and drainback systems.

\subsection{Closed-loop Pressurized Antifreeze Systems:}

- An antifreeze solution (usually non-toxic propylene glycol and water mixture) fills the collectors and piping at all times.

- When there is solar energy available to collect a circulating pump turns on and circulates this fluid (called the heat transfer fluid or solar fluid) throughout the system.

- The solar fluid gets heated in the collectors and moves that heat into the building.

- The heat is then transferred from the solar fluid to water.

- The heated water can be used directly or can be stored for use at a later time.

- This heated water can be used for domestic hot water, process hot water, or space heating.

- When there is no solar energy to be harvested, the pump does not operate and the solar fluid stops circulating.

- Closed-loop antifreeze systems are the most popular type of system installed in our climate.

The advantages of closed-loop pressurized antifreeze systems include;

- Proven system type for cold climates.

- The most versatility in system configurations.

- Cost competitive.

- Ease of installation.

The disadvantage of closed-loop pressurized antifreeze systems include:

- Systems can overheat (resulting in degradation of the solar fluid) if left with no load and/or no circulation over extended periods of time.

\subsection{Drainback systems:}

Drainback systems are very similar to closed-loop pressurized antifreeze systems except that the solar fluid does not stay in the piping and the collectors at all times.

- The solar fluid is stored in a special drainback tank, which is located below the collectors and inside heated space.

- When solar energy is available for harvesting a high-head pump turns on and pumps the solar fluid from the drainback tank into the piping and solar collectors.

The main advantages of drainback systems include:

- When the solar storage tank is fully heated the system simply turns off and the solar fluid drains back to the drainback tank.

- Eliminates any potential overheating problems.

The main disadvantage is that the collectors include:

- The collectors must be located above the drainback tank, which eliminates the option of mounting the collectors in any place except above the drainback tank. 
- There are also piping limitations in drainback systems, as the piping must be run in such a way that there is a continuous downward slope to all the piping to facilitate complete draining of all the collectors and piping when the system is not operating.

5.

\section{Solar collector sites:}

- All solar collectors must face in a southerly direction and must have access to the sun all year round from at a minimum of 10AM to 2PM every day. 9AM to 3PM is best.

- Most shading problems happen during the winter when the sun is low in the sky.

- Shade and snow cover on the solar collectors reduce the system's production

- As solar thermal systems can last 50 years or more, system siting should consider shading by future roof penetrations, tree grow, building activity, etc.

- Most businesses have good places to install solar collectors because the buildings they occupy tend to be tall, have large roof areas and have parking lots around them reducing potential shading.

6.

\section{Incentives:}

6.1 Focus on Energy incentives:

- The Focus on Energy Program offers incentives for the installation of solar water heating systems.

- We also give incentives for combination water heating and space heating systems where the space heating system is part of the water heating system (a common design).

- Swimming pool heating systems are covered under the Focus program.

- We do not currently give incentives for space heating only systems.

- The Focus program offers a feasibility grant where Focus will pay up to $50 \%$ of the cost of that study.

- Often on large projects, a vendor may need to charge a fee to do this analysis and design work, and the feasibility study serves that purpose.

- This feasibility study grant is in addition to the grants Focus offers for the installation of systems.

- You can find the application for the feasibility study on our web site (http://www.focusonenergy.com/page.jsp?pageId=905).

The Focus incentive is based on the annual estimated energy produced by the solar energy system and is calculated in therms $(1$ therm $=100,000 \mathrm{Btu})$.

- Small and medium sized systems (up to 5,000 therms per year) are served by the CashBack Reward form (a copy is attached to this report).

○ For systems that produce less than 1,000 therms per year the incentive is $\$ 10.00$ per therm

- For systems that produce between 1,000 and 5,000 therms per year the incentive is $\$ 8.00$ per therm

- Large systems (over 5,000 therms per year) are served by the implementation grant reward form.

○ For systems that produce over 5,000 therms per year the incentive is $\$ 6.00$ per therm

- Both forms are available for download from our web site. 
- Maximum Focus incentive is $\$ 50,000$ per system or $25 \%$ of total system cost.

$\underline{\text { State Taxes }}$

Wisconsin's depreciation is based on the Federal depreciation formula for solar water heating systems. So the Federal five-year accelerated depreciation applies to Wisconsin business income taxes as well.

\section{Property Tax Exemption}

Solar water heating systems are exempt from Wisconsin property taxes.

6.3

Federal Tax Credit:

- The federal government also offers federal tax credits and accelerated depreciation for all qualifying solar thermal systems.

- The federal tax credit equals $30 \%$ of the system cost plus the investment qualifies for accelerated depreciation.

- For a business that pays taxes, the total combined federal tax credit and depreciation value equals around $50 \%$ of the system cost for most businesses.

- Federal tax credit does not cover solar swimming pool heating systems.

- Please consult your tax advisor for details on how these tax credits can work for your business.

6.4 Application Forms:

- If you are interested in receiving a Focus incentive, please note that you must submit your application and receive approval before you spend any money on the project.

- Please read all the conditions specified in the application.

- The installing contractor should assist you in gaining all the required information you will need to completely fill in the application.

- If you have any additional questions about submitting these forms, please feel free to contact me.

\section{Economics of solar:}

Solar thermal energy systems have several economic advantages:

- They offset money you would pay for fossil fuels. The energy provided by the solar thermal system will offset a fossil fuel energy bill, thus reducing that bill.

- They also fix the energy costs provided by the solar energy system.

- When you install a solar thermal energy system, that system provides energy to your facility with little or no operating cost. The sun's energy is free. All you have to pay for is the solar harvesting equipment. 
- In most cases there will be very little impact on your monthly cash flow when you first install the solar energy system. The monthly savings on your fossil fuel bill will pay the monthly bill on your solar energy system.

- In a short amount of time the energy savings on your fossil fuel bill will be greater than your payment on the solar energy system, resulting in a positive cash flow.

- The accumulated savings on your fossil fuel bill will completely pay off the solar energy system, and after that point is reached all the energy from the solar energy system is free.

7.1

Energy prices:

- Many business and facility owners have mentioned to me that it is very difficult to operate a business and make future plans when you have no idea what your energy bills will be like in the future.

- Energy prices escalated at a predictable rate for a long time, and this energy escalation rate averaged around 7\% per year from 1970 to 2000 .

- Since 2000 energy prices have escalated at around $14 \%$ per year.

- All other fuels such as coal, fuel oil, electricity and propane have seen similar price escalation.

- By investing in a solar thermal system, a business fixes the cost of the energy provided by that system, which isolates that energy price from the natural gas price fluctuations seen recently

If you borrow the money to pay for the system your payments will remain constant.

- Your monthly loan payments will typically be slightly larger than the annual energy savings for a few years, resulting in a slightly negative or neutral cash flow impact.

- Soon afterward the monthly fuel savings will equal your loan payment, resulting in a neutral cash flow impact.

- Very shortly after that your monthly energy savings will be greater than your loan payment, resulting in a positive cash flow.

- Not long after that your energy savings will have completely paid for the loan and all the energy will be free after that.

- If you finance the solar energy system internally, you will see that the return on investment averages between $15 \%$ and $25 \%$.

8.

\section{Environmental:}

There are a number of reasons that businesses are concerned about the environmental impacts of their operation.

- The environmental impacts include Carbon emissions from heating.

- Using renewable energy can reduce those negative impacts.

- The use of renewable energy systems can help reduce the carbon footprint of a business.

- The RETScreen program calculates the net greenhouse gas emission reduction that results from the modeled system.

- The figure given is tons of $\mathrm{C} 02$ per year. To put the number into perspective, each ton of $\mathrm{C} 02$ reduction is equivalent to 1,778 miles driven at an efficiency of 22 miles per gallon. 
Many businesses are also interested in the benefits of "being a green business" from a marketing perspective.

- Polls show that consumers would rather do business with a company that incorporates renewable energy into their business.

\section{RETScreen:}

I have included a RETScreen analysis for your business as an attachment to this report.

- RETScreen is a state of the art computer-modeling program that is used for modeling solar energy systems.

- The program uses certified collector performance data, weather data from NASA, National averages for water consumption, and the heating load we identify, to recommend and analyze a specific solar thermal system for your business.

- For system pricing I use average installed prices for similar sized systems that have been installed in Wisconsin over the last several years.

- Note that the cost factors I use are averages. Every installation is unique and some installations are above or below this average.

- Also note that the cost of raw materials fluctuates and are on an upward trend, which can also affect the cost of a system.

- The data that I have entered into these programs is detailed at the beginning of this report.

- Please check that information for accuracy.

I have included 1 page from RETScreen for your inspection.

- The financial analysis pages calculate a payback, cash flow, and ROI analysis for the modeled system.

\section{Next steps: Note, if you have any questions about the information presented above, please feel free to give me a call.}

a) Evaluate the options presented in this report, and make a decision on system size, location and mounting methods.

b) For roof mounted systems confirm with the building designer and/or qualified structural engineer as to the building roof structure's ability to support the additional weight and wind loading of a solar thermal system. Also, review the impact on roofing warrantee of siting panels over roofing.

c) Determine the project's economics with your financial and tax advisors.

d) Contact installers to get price quotes (we recommend that you get several quotes from different vendors, see Focus on Energy's full service solar thermal installers attached to this report). 
e) Refine system size, siting, etc. decision based on installer quotes and consultation with financial and tax advisors. Re-bid system quotes as needed.

f) Contact your insurance agent and advise them of the intent to install the renewable energy system, and ask for written confirmation of the liability coverage currently provided (as needed to meet utility requirements). Confirm that current insurance provides the needed coverage, and resolve any issues with the agent.

g) Define any permitting requirements for the installation of the system.

h) With your financial advisors, make the decision to go forward with the project

i) Apply and receive approval for Focus on Energy incentives and other incentives as appropriate, before you spend any money on the system.

j) Sign the installation contract with your selected installation firm.

- Insure that all zoning, financial incentive and any other required approvals are in hand prior to making any commitment to purchase.

k) When the system is installed you submit a notice of installation to Focus and your incentive will be mailed to you.

1) If, at any time during this process you have any questions, please feel free to give me a call or email.

\section{1: Specifics about your facility}

- Lac Du Flambeau Head Start is located on the West side of the School building.

○ There is the option of mounting the collectors directly above the room where the existing propane water heater is installed. This will minimize the pipe runs to the balance of the system.

- This room is about $12 \mathrm{ftX} 30 \mathrm{ft}$ with a 43 in door.

$\circ$ The water existing heater supplies the kitchen, bathrooms, and the laundry for this side of the building.

- The roof system is a metal roof with a rubber rolled roofing covering.

- The roof system was installed about 12 years ago when the building was constructed.

- Lac Du Flambeau School.

o There is the option of mounting the collectors directly above the room where the existing propane water heater is installed. This will minimize the pipe runs to the balance of the system.

o This room is about $12 \mathrm{ftX} 30 \mathrm{ft}$ with a 43 in door.

$\circ$ The water existing heater supplies the kitchen, bathrooms, and the laundry and shower for this side of the building.

- The roof system is a metal roof with a rubber rolled roofing covering.

○ The utility/boiler room contains a 1000 storage tank gallon tank. Additional storage can be placed in the room next to the boiler room. 
- The roof system was installed about 12 years ago when the building was constructed

\section{Appendices:}

- Retscreen \& spreadsheets

- Photo's of building

- Full Service Installer List

\section{Resources:}

- Focus on Energy Web Site: www.focusonenergy.com

\section{Disclaimers:}

- $\quad$ All numerical values in this report are estimates.

- $\quad$ Proper legal counsel, along with IRS guidance, is required to definitively determine the tax ramification of installing a solar thermal system.

- $\quad$ To get an accurate installed cost of the system get at least three bids from qualified solar thermal installers.

- $\quad$ The information provided here should NOT be considered legal advice.

Material in this report does not imply a recommendation or endorsement of any product or service, by the Focus on Energy Program or any subcontractor of Focus on Energy. The Focus on Energy Program, or any subcontractor of Focus on Energy, is not responsible for inaccurate or incomplete data in this report.

\section{Attachment 1. Solar Thermal System Terminology Definitions}

Absorber - The part of a solar collector that absorbs the sun's energy and changes that energy into heat.

Active solar energy system - Any solar energy system that uses a collector to absorb solar energy.

Ambient - The temperature of the surrounding air.

Aquastat - A thermostat that measures the temperature of a liquid.

Azimuth - The distance in degrees from north. (South would have an azimuth of 180).

Batch heater - Another name for ICS collector. 
Battery - A storage device for energy.

British Thermal Unit (Btu) - The amount of energy it takes to raise the temperature of one pound of water one degree $\mathrm{F}$.

Centrifugal pump - A pump that moves a fluid by spinning it with enough force to throw the fluid outward.

Check valve - A valve that allows a fluid to travel in only one direction within a circuit.

Circulator - A pump designed to move a fluid within a circuit.

Closed-loop solar heating system - A type of system where the solar fluid stays in the solar loop and does not mix with the domestic water.

Collector - A device that collects solar energy.

Collector loop - Another name for solar loop.

Collector tilt - The angle between the solar collector plane and the horizontal plane.

Conduction - Heat flow within a material that is caused by the difference of temperature within that material.

Convection - The movement of parts of a fluid because of variations in the fluid's density caused by temperature differences.

Counter-flow heat exchanger - A heat exchanger where the two fluids pass each other in opposite directions.

Coupler - A pipe fitting that joins two pieces of pipe together.

Degree-day - The difference between $65^{\circ} \mathrm{F}$ and the ambient temperature, when the ambient temperature is below $65^{\circ} \mathrm{F}$. 
Differential temperature controller - An electrical device that measures the difference in temperature between two locations and switches a pump on or off in relation to the difference in the temperatures at the two locations.

Diffuse radiation - Solar radiation that is scattered by the atmosphere and everything that is suspended in the atmosphere, particularly water vapor.

Direct radiation - Solar radiation that has not been scattered.

Drainback - A solar water heating method where the solar fluid is pumped to the collectors and fills the solar loop piping when solar energy is available for harvest but drains back to a holding tank when not collecting energy.

Draindown system - A solar water heating system that drains when not in use.

Emittance - The property of a material to radiate energy.

Expansion tank - A tank used in solar energy systems to compensate for the expansion of liquids in a closed-loop circuit.

Evacuated tube collector - A collector that uses absorber plates that are enclosed in a glass tube that has a vacuum inside of it.

Flat-plate collector - A rectangular solar thermal collector, typically four inches deep, four feet wide and eight feet or ten feet tall.

Flow meter - A device that measures the flow of a liquid within a pipe. It is often a clear pipe with a scale on the side.

Flow rate - A measure of the rate of a certain volume of fluid flowing through a circuit. Fossil Fuel - A carbon-rich and energy-dense fuel that was created from concentrated organic matter that lived or grew on the earth millions of years ago. 
Head - The total pressure or resistance to the flow of a liquid within a circuit exerted by gravity and friction.

Header - A manifold.

Heat exchanger - A device that facilitates the transfer of heat from one fluid to another.

Heat transfer fluid - A fluid that is used to transfer heat from one location to another. This fluid could be a liquid or a gas.

Hydronic - Hydronic heating systems use a liquid to transfer heat. Forced air systems use air. Indirect system - A solar water heating system where the domestic water is not heated in the collectors but is heated using a heat transfer fluid and a heat exchanger.

Liquid collector - A collector that uses a liquid as the heat transfer fluid.

Manifold - A pipe with several outlets.

Open-loop system - A kind of solar water heating system where some part of the system is vented, or the solar loop contains potable water.

Orientation - The direction the solar collectors face in relation to South.

Passive systems - Solar heating systems that do not use a collector to absorb the sun's energy. A term used to describe a solar heating system where the house itself is the solar collector. Photovoltaic panel - A type of solar collector that absorbs solar energy and converts it to electrical energy. Also called PV.

Potable water - Drinkable water.

Propylene glycol - A non-toxic antifreeze used in solar heating systems. It is mixed with water and used as a heat transfer fluid.

Pump - A device that moves a fluid through a circuit.

Radiation - The flow of energy through a space. 
Renewable energy - Energy that is replenished by nature on a regular basis.

Risers - The pipes that connect the top and bottom manifolds in an absorber plate.

Sensor - A device that identifies the temperature at a certain location.

Solar collector - A device that collects the energy of the sun that is radiated to the earth's surface.

Solar energy - Energy produced by the sun that is radiated to the earth's surface.

Solar fluid - The heat transfer fluid used in a solar heating system.

Solar loop - The circuit of piping that travels from the collectors to the heat exchanger/storage and back to the collectors.

Specific heat - The amount of heat, in Btu, needed to raise the temperature of one pound of a substance by one degree $\mathrm{F}$.

Stagnation - When the solar fluid in a closed-loop solar heating system is not circulating.

Static head - The pressure created by a column of water in a pipe.

Therm - 100,000 Btu.

Thermosiphon - The movement of a fluid caused by convection.

Wrench - A solar installer 
Annendices 1: "Retscreen" School

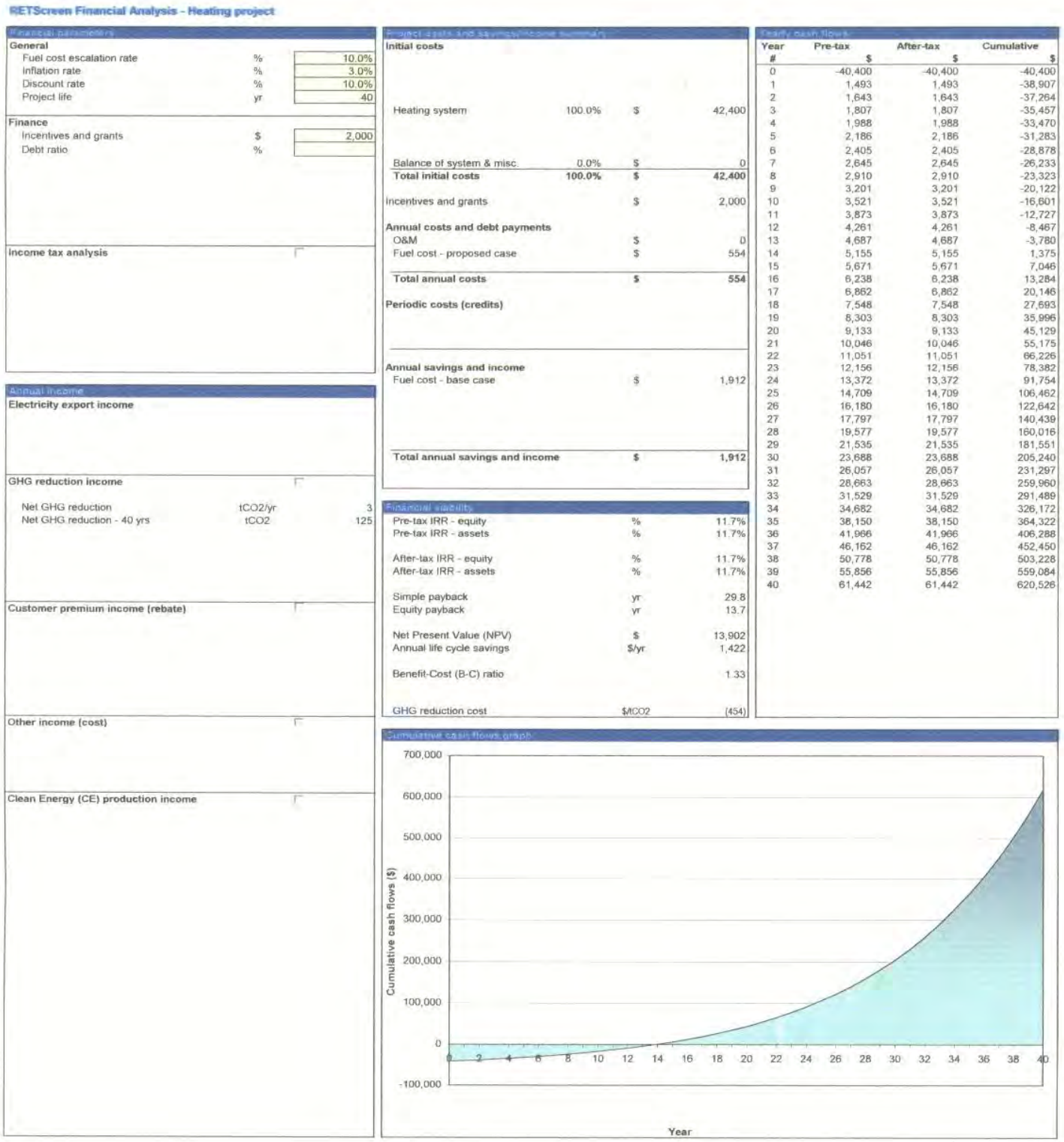




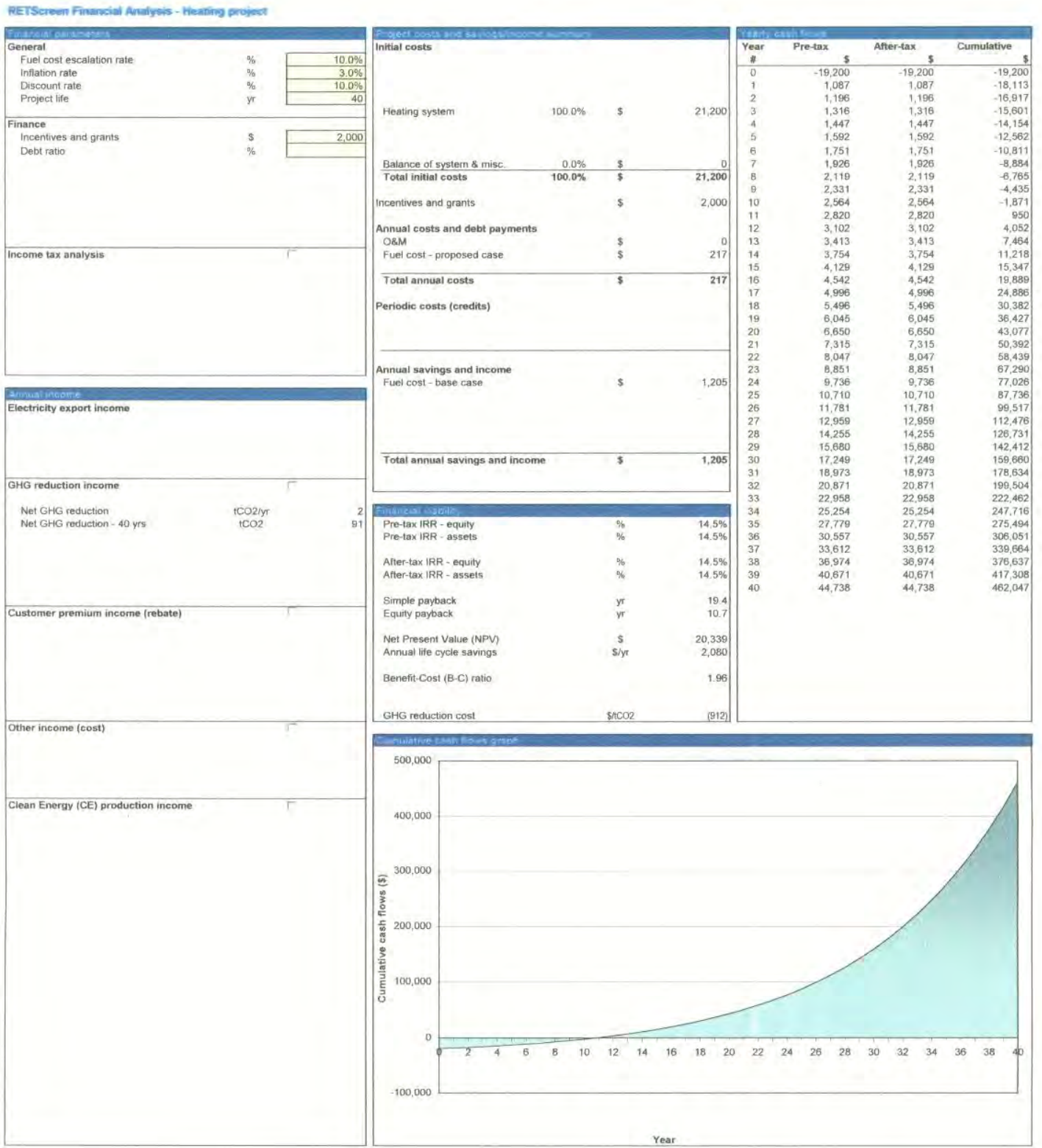




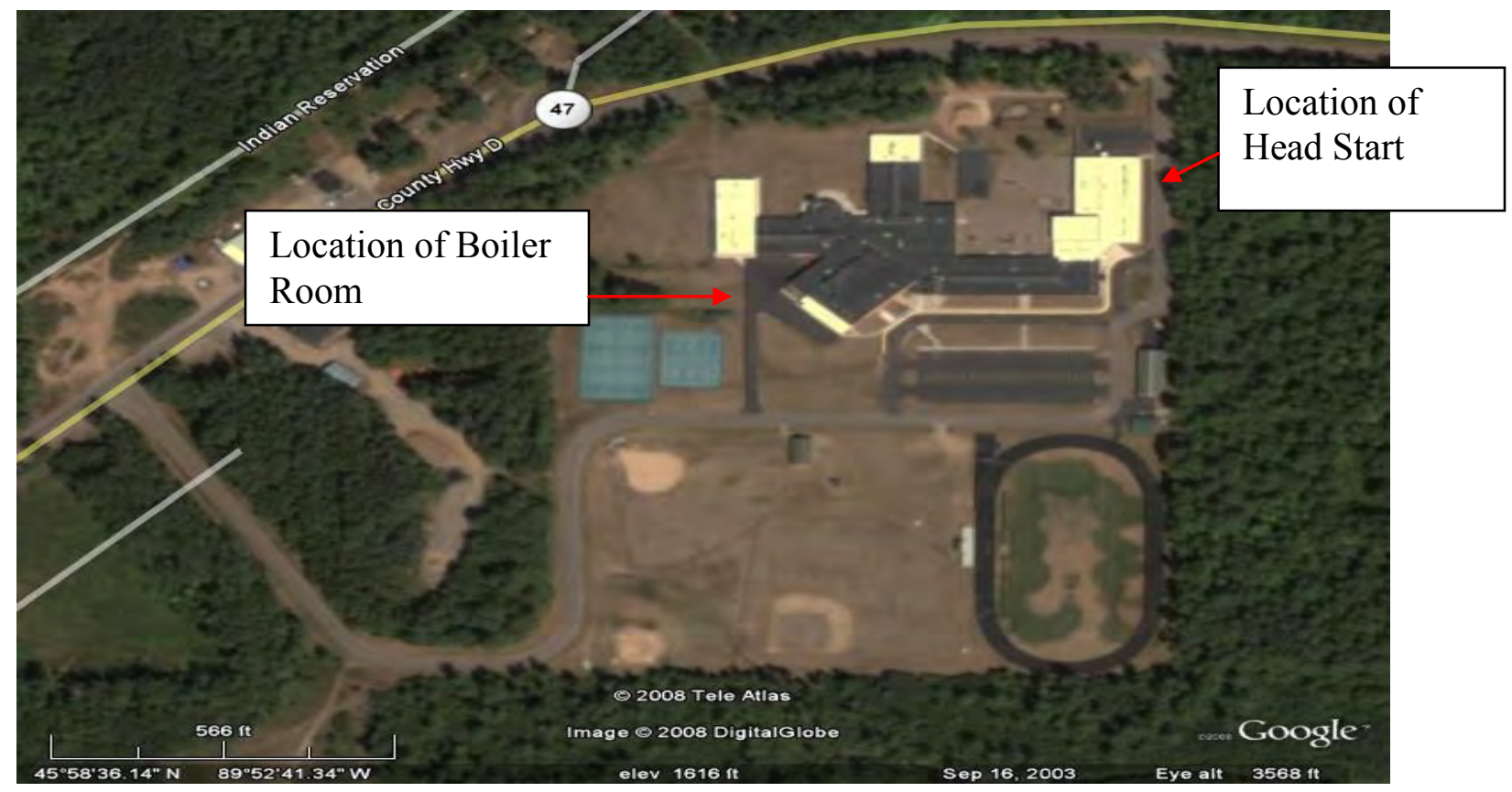

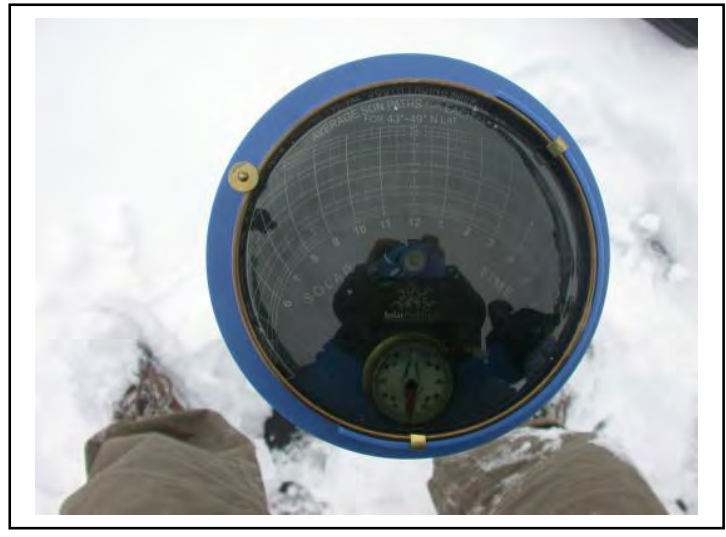

Pathfinder reading from above Boiler Room

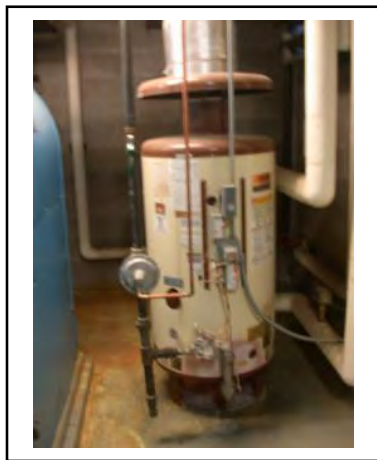

Propane Hot water in School Boiler Room
The roof of the building is large enough to accomadate the space needs for the recommended solar thermal system. Because of the current hot water heating system I believe having two separate systems on each part of the building should be considered.

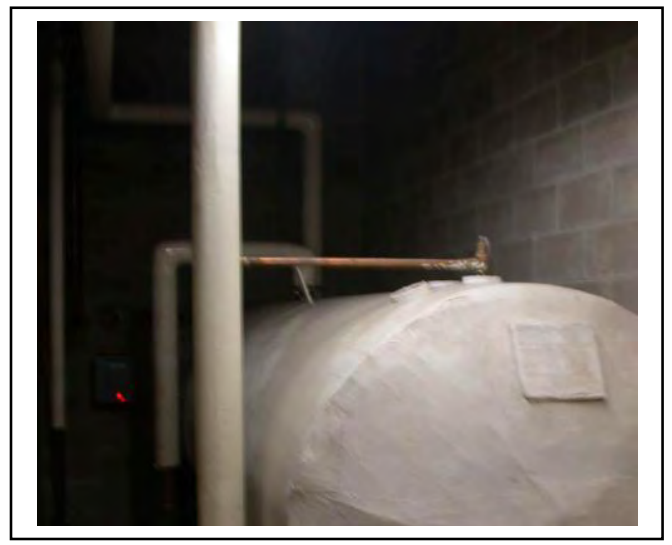

Existing 1000 Gallon Storage

tank. Water is kept at 140

(F)Degrees. Mixing Valve at taps

reduce water to $110(\mathrm{~F})$ 


\section{Sustainable \\ C- Engineering \\ '1) Group LLC \\ Geothermal Feasibility Study}

\section{Lac Du Flambeau Reservation}

\section{Lac Du Flambeau, WI}
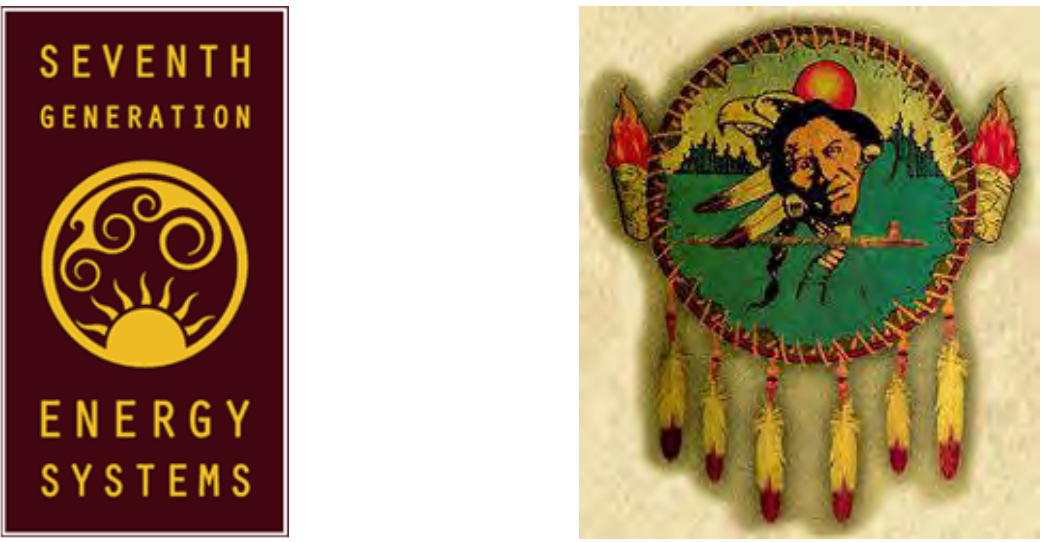

January $28^{\text {th }} 2009$

Prepared by:

Sustainable Engineering Group, LLC

431 Charmany Drive, Suite 102

Madison WI 53719

Phone: 608.231.9664

Email: jevans@sustaineng.com

Web: http://www.sustaineng.com/ 


\section{Table of Contents}

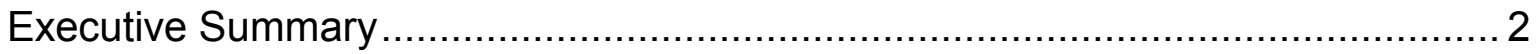

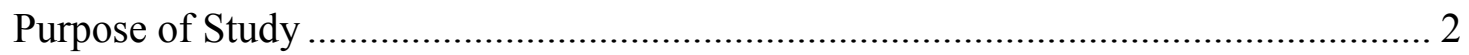

Summary of Results and Recommendations......................................................... 2

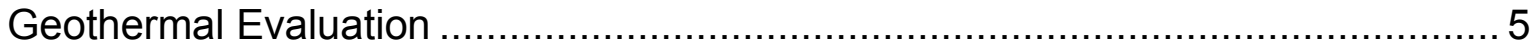

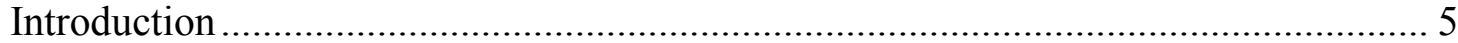

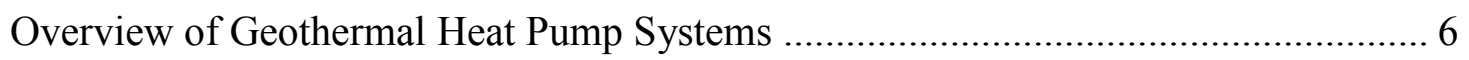

Potential for Vertical Bore Systems .......................................................................... 7

Potential for Lake Systems .............................................................................. 9

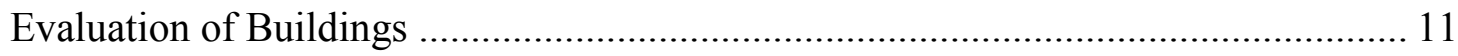

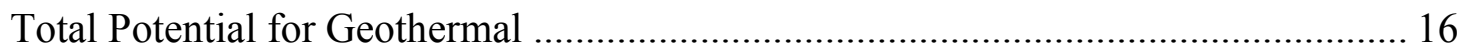

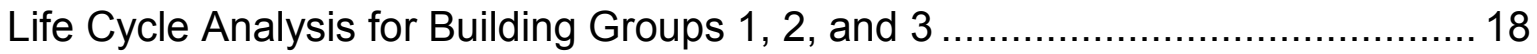

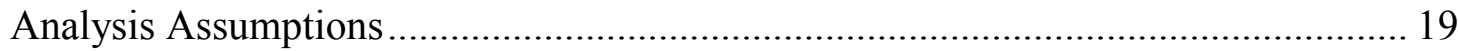

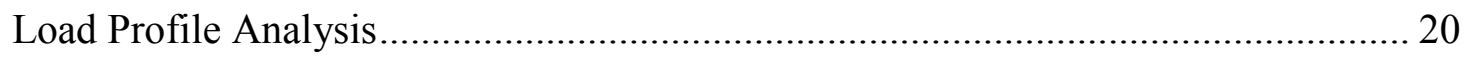

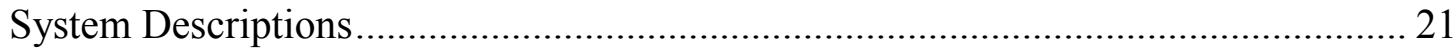

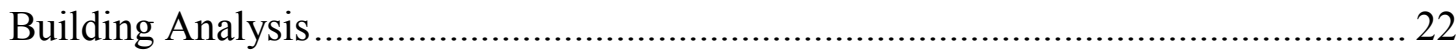

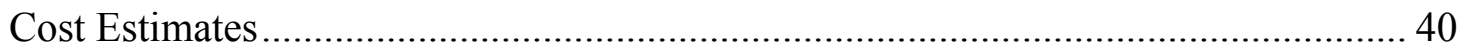

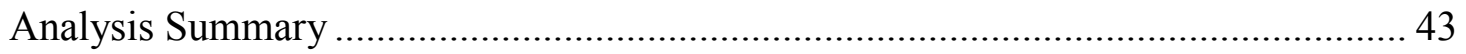

Appendix 


\section{Executive Summary}

\section{Purpose of Study}

Sustainable Engineering Group (SEG) was requested to study the economic feasibility of installing geothermal heat pump systems in buildings on the Lac Du Flambeau Indian Reservation in Lac Du Flambeau, Wisconsin. As part of the study, existing buildings on the reservation were evaluated and prioritized for retrofit with geothermal systems. The following categories were used to evaluate and prioritize the buildings:

- Energy Efficiency

- Environmental Stewardship

- Life Cycle Analysis

- Maintenance and Reliability

\section{Summary of Results and Recommendations}

Based on our review of the Lac Du Flambeau Reservation, it appears that there are several buildings that are suitable for geothermal systems, using either a vertical bore field or a lake heat exchanger type configuration. These buildings in order of suitability are:

- Indian Bowl

- Judicial building

- Museum

- Planned Natural Resources Building

- Community Center / Clinic

- Youth Center (Abinoojiiyag Center)

- Bingo Hall

- Simpson's Main Plant

- Adaawe Place

- Post Office, Library, Tribal Office

- Planning / Bank Building

- Casino Human Resources / Education Building

- Smoke Shop

- Hotel

- Lac Du Flambeau School

- Casino / Hall of Nations 


\section{1 , Sustainable \\ - Engineering

Table 1: Life Cycle Analysis Summary

Selected Building

Indian Bowl

$5,000 \mathrm{ft}^{2}$

Annual Electricity Saved (kW-h) 5950

Annual Propane Saved (gallons) 5474

Annual Utility Cost Savings (\$) \$5727

25 Year Cost Savings (\$)

$\$ 146,960$
Youth Center, Bingo

Hall, Community

Center

$50,300 \mathrm{ft}^{2}$

133,980

35,968

$\$ 92,488$

$\$ 2,426,425$

25 Year Cost Savings $(\$)$

$\begin{array}{ll} & \text { Post Office Complex } \\ & 8,000 \mathrm{ft}^{2} \\ \text { Annual Electricity Saved (kW-h) } & \mathrm{n} / \mathrm{a} \\ \text { Annual Propane Saved (gallons) } & 4,096 \\ \text { Annual Utility Cost Savings (\$) } & \$ 6,819 \\ 25 \text { Year Cost Savings (\$) } & \$ 160,017\end{array}$

\section{Group}

Building Group 1

$25,962 \mathrm{ft}^{2}$

18,366

8,669

$\$ 19,174$

Building Group 2

$77,100 \mathrm{ft}^{2}$

112,594

51,987

$\$ 115,233$

$--$

Building Group 3

$27,800 \mathrm{ft}^{2}$

49,162

13,361

$\$ 31,638$ 

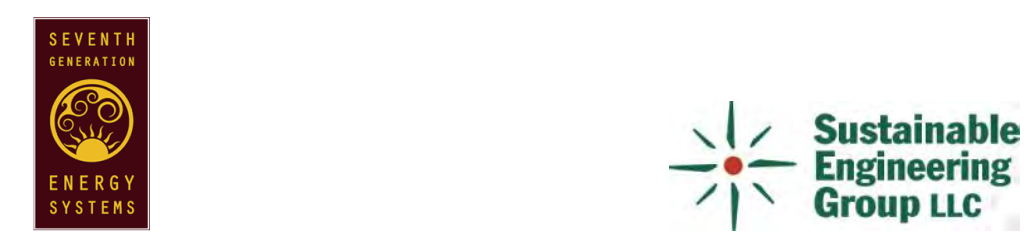

This study shows that the reservation has the potential to offset $864,000 \mathrm{~kW}$-hr of electric use and 176,000 gallons of propane use if geothermal systems are installed in the 16 buildings identified in the report. These buildings are classified into several categories based on retrofit and cost savings potential. In general, paybacks range from 4 to 8 years for the buildings.

These favorable paybacks are mainly due to the following advantages of the geothermal systems:

- Lower electric costs

- Eliminated propane costs for building heating

- Low maintenance costs due to simplicity of system

- Longer service life of heat pump equipment and geothermal bore field / lake heat exchanger

Also, when considering environmental stewardship the geothermal systems are more favorable. Compared to the conventional systems, the geothermal systems could reduce carbon emissions by $\sim 40 \%$ for the Reservation.

Based on this study, geothermal systems are suitable options at the Lac du Flambeau Reservation for existing buildings slated for retrofit, and new construction. 


\section{Sustainable \\ Engineering

\section{Geothermal Evaluation}

\section{Introduction}

Sustainable Engineering Group (SEG) was requested to study the economic feasibility of installing geothermal heat pump systems in buildings on the Lac Du Flambeau Indian Reservation in Lac Du Flambeau, Wisconsin. The following table outlines the steps in this analysis:

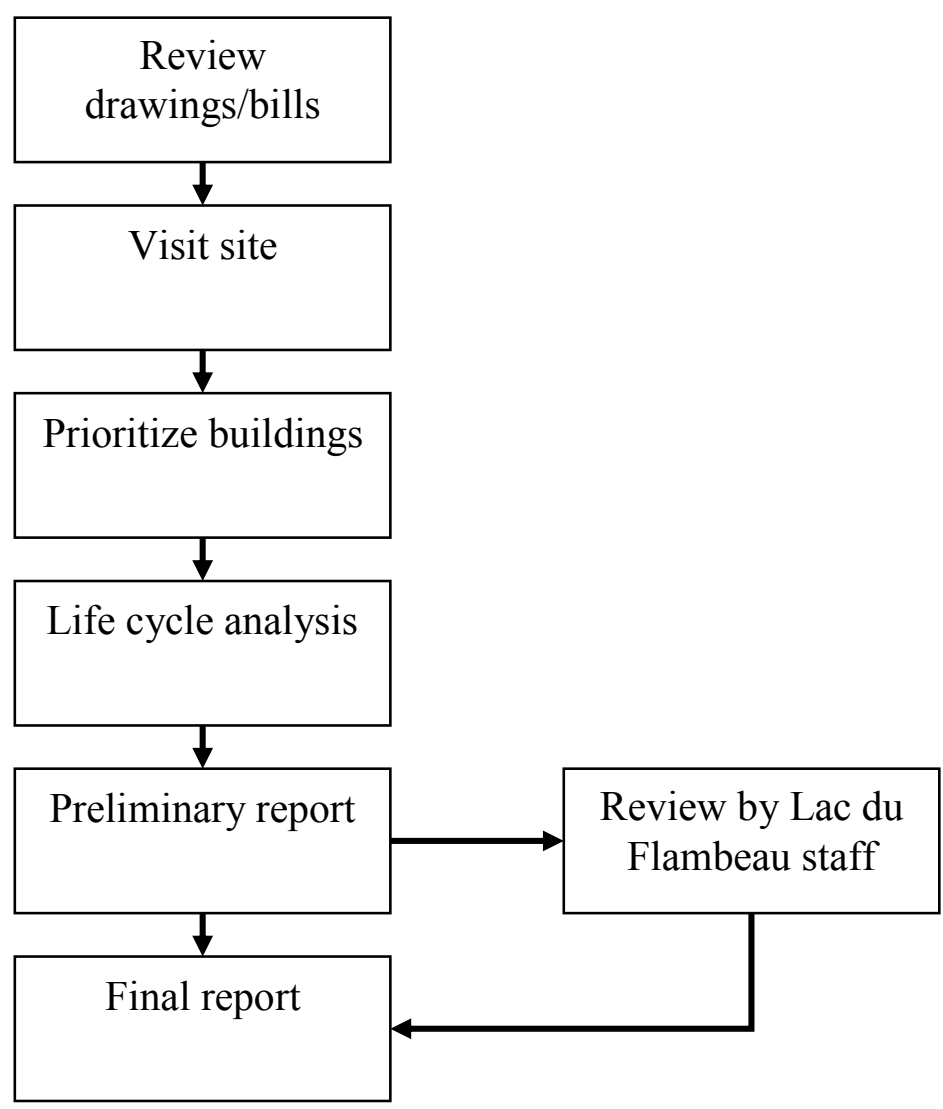

Table 2: Feasibility Study Steps 


\section{Sustainable

\section{Overview of Geothermal Heat Pump Systems}

A geothermal heat pump system consists of a reversible vapor compression cycle that is linked to a closed ground/submerged heat exchanger buried in the soil or sunk in a body of water. The most widely used heat pump unit is a water-to-air type, which circulates a water-antifreeze solution through a liquid-to-refrigerant coil and a buried/submerged piping network.

There are two categories of geothermal heat pump systems appropriate for the Lac Du Flambeau Reservation:

- Vertical Bore - Commercial buildings typically use vertical bore systems for several reasons. The land area required is less for vertical bore systems compared to other horizontal type systems. In addition horizontal type systems rely mainly on rules of thumb for design and are more susceptible to issues if surface conditions change. Vertical bore systems also minimize the disturbance to existing landscaping. For a vertical bore system, holes (approximately five inches in diameter) are drilled about 15 to 20 feet apart and 200-300 feet deep. Into these holes go two pipes that are connected at the bottom with a U-bend to form a loop. The vertical loops are connected into lateral pipe circuits, placed in trenches, and connected to heat pump(s) in the building.

- Lake or Pond - If the site has an adequate water body, this may be the lowest cost option. Supply and return pipes are run underground from the building to the water and coiled into circles at least twelve feet under the surface to prevent freezing. The coils should only be placed in a water source that meets minimum volume, depth, and quality criteria. An alternative to the coils are submerged stainless steel heat exchangers.

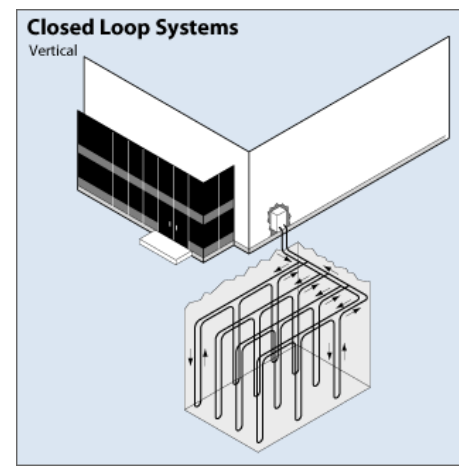

Figure 1: Vertical Bore Schematic ${ }^{1}$

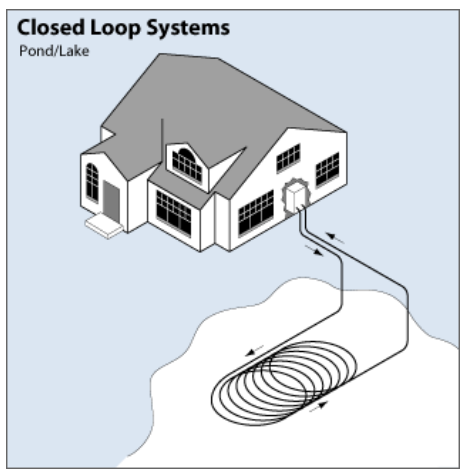

Figure 2: Pond/Lake Schematic ${ }^{1}$

\footnotetext{
${ }^{1} \mathrm{http}$ //apps1.eere.energy.gov/consumer/your_home/space_heating_cooling/index.cfm/mytopic=12650
} 


\section{Sustainable

\section{Potential for Vertical Bore Systems}

The DNR water well database was surveyed to assess the potential of the geological formations in the Lac Du Flambeau area. Table 3 includes the location parameters required to query the database. In general most water wells in the area are 50 to 150 feet in depth. Several deeper wells, on the order of 300 feet were found and are used as the basis for this analysis. The target depth for geothermal wells is 300 feet. Table 4 summarizes the findings.

The Lac Du Flambeau area has a high static water table therefore the sand, clay, and gravel layers (unconsolidated formation) will have high moisture content. Beneath the unconsolidated formation is granite bedrock about 100 to 140 feet below the surface. Two wells (SL676 and KR015) were used to develop an estimate of the formations' geothermal potential. Tables 5 and 6 summarize the results. The appendix includes copies of the well record logs for reference. Estimated preliminary design values based on data from these two wells are:

- Ground Temperature $-50^{\circ} \mathrm{F}$

- $\quad$ Thermal Conductivity $-1.45 \mathrm{Btu} / \mathrm{h}-\mathrm{ft}-{ }^{\circ} \mathrm{F}$

- Thermal Diffusivity - $0.96 \mathrm{ft}^{2} /$ day

Note: A formation and conductivity test should be performed at potential building sites prior to proceeding with design of a geothermal system.

Table 3: Location parameters for DNR database

$\begin{array}{ll}\text { County } & \text { Vilas } \\ \text { Township } & \text { T40N } \\ \text { Range } & \text { R5E } \\ \text { Section } & 17\end{array}$




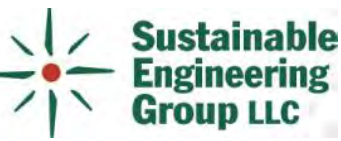

Table 4: Deep water wells used to evaluate geothermal potential

\begin{tabular}{|c|c|c|c|c|c|}
\hline ID & $\begin{array}{l}\text { Distance from } \\
\text { Casino (mile) }\end{array}$ & $\begin{array}{c}\text { Well } \\
\text { Depth (ft) }\end{array}$ & $\begin{array}{l}\text { Static Water } \\
\text { Level (ft) }\end{array}$ & $\begin{array}{c}\text { Depth to } \\
\text { Granite (ft) }\end{array}$ & $\begin{array}{c}\text { Formation above } \\
\text { Bedrock }\end{array}$ \\
\hline SD821 & $\sim 1$ & 140 & 17 & 140 & $\begin{array}{r}\text { Sand, Silt, Clay } \\
\text { Sand, Silt, Clay, }\end{array}$ \\
\hline TL225 & $\sim 1$ & 139 & 13 & 139 & Gravel \\
\hline SL676 & $1-2$ & 305 & 19 & 125 & Sand, Gravel, Clay \\
\hline KR015 & $1-2$ & 300 & 20 & 146 & Sand, Gravel, Silt \\
\hline MS184 & $2-3$ & 445 & 8 & 85 & $\begin{array}{l}\text { Sand, Clay, Silt } \\
\text { Sand, Clay, Silt, }\end{array}$ \\
\hline MR388 & $2-3$ & 300 & 43 & 125 & Gravel \\
\hline SD961 & $2-3$ & 260 & 13 & 147 & Sand, Clay \\
\hline NS584 & $3-4$ & 238 & 60 & 136 & $\begin{array}{l}\text { Sand, Clay, Gravel } \\
\text { Sand, Clay, Silt, }\end{array}$ \\
\hline QL337 & $4-5$ & 305 & 25 & 149 & Gravel \\
\hline TK180 & $4-5$ & 305 & 13 & 102 & Sand, Clay, Silt \\
\hline SD812 & $4-5$ & 300 & 16 & 100 & Sand, Clay, Silt \\
\hline LE681 & $5-6$ & 325 & 17 & 97 & Sand, Clay, Gravel \\
\hline
\end{tabular}

Table 5: SL676 water well conductivity estimates

\begin{tabular}{|c|c|c|c|c|c|}
\hline \multirow[b]{2}{*}{ Depth } & \multirow[b]{2}{*}{ Formation } & \multicolumn{2}{|c|}{ SL676 Well (80\% range average) } & \multicolumn{2}{|c|}{ SL676 Well (100\% range average) } \\
\hline & & $\begin{array}{c}\text { Ther. Con. } \\
\text { (Btu/h-ft-F) }\end{array}$ & $\begin{array}{l}\text { Therm. Diff. } \\
\left(\mathrm{ft}^{\wedge} \text { 2/day) }\right.\end{array}$ & $\begin{array}{l}\text { Ther. Con. } \\
\text { (Btu/h-ft-F) }\end{array}$ & $\begin{array}{l}\text { Therm. Diff. } \\
\left(\mathrm{ft}^{\wedge} \mathbf{2} / \mathrm{day}\right)\end{array}$ \\
\hline 0 & & & & & \\
\hline 15 & Caving Sand & 1.55 & 0.93 & 1.55 & 0.93 \\
\hline 25 & Sand \& Gravel & 0.90 & 0.7 & 0.90 & 0.7 \\
\hline 125 & Clay & 0.70 & 0.5 & 0.70 & 0.5 \\
\hline 305 & Bedrock, Granite & 1.75 & 1.2 & 1.95 & 1.2 \\
\hline & Total & 1.37 & 0.94 & 1.49 & 0.94 \\
\hline
\end{tabular}

Table 6: KR015 water well conductivity estimates

\begin{tabular}{|c|c|c|c|c|c|}
\hline \multirow[b]{2}{*}{ Depth } & \multirow[b]{2}{*}{ Formation } & \multicolumn{2}{|c|}{ SL676 Well (80\% range average) } & \multicolumn{2}{|c|}{ SL676 Well (100\% range average) } \\
\hline & & $\begin{array}{l}\text { Ther. Con. } \\
\text { (Btu/h-ft-F) }\end{array}$ & $\begin{array}{c}\text { Therm. Diff. } \\
\left(\mathrm{ft}^{\wedge} 2 / \text { day }\right)\end{array}$ & $\begin{array}{l}\text { Ther. Con. } \\
\text { (Btu/h-ft-F) }\end{array}$ & $\begin{array}{c}\text { Therm. Diff. } \\
\left(\mathrm{ft}^{\wedge} \mathbf{2} / \text { day) }\right.\end{array}$ \\
\hline 0 & & & & & \\
\hline 146 & Sand, Gravel, Silt & 1.00 & 0.75 & 1.00 & 0.75 \\
\hline 300 & Bedrock, Granite & 1.75 & 1.2 & 1.95 & 1.2 \\
\hline & Total & 1.39 & 0.98 & 1.49 & 0.98 \\
\hline
\end{tabular}




\section{Potential for Lake Systems}

The Lac Du Flambeau reservation is situated between several large lakes as can be seen in Figure 3. Several buildings are located adjacent to lakes which make them ideal to be considered for geothermal. Permitting for these systems should be handled by the tribe's natural resources department.

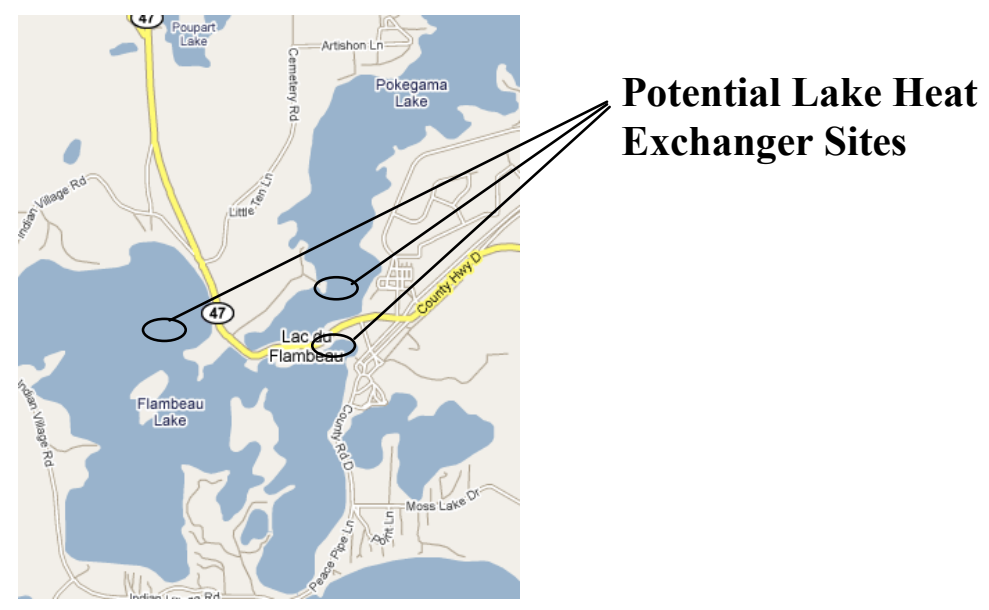

Figure 3: Overview of Lac Du Flambeau site ${ }^{2}$

Figures 4, 5, and 6 show the potential locations for lake heat exchangers. The lake heat exchanger should be submerged in deep enough water so the bottom can be anchored about 1 foot from the lake bed and the top is below the lakes thermo cline or in about 12 to 15 feet of water.

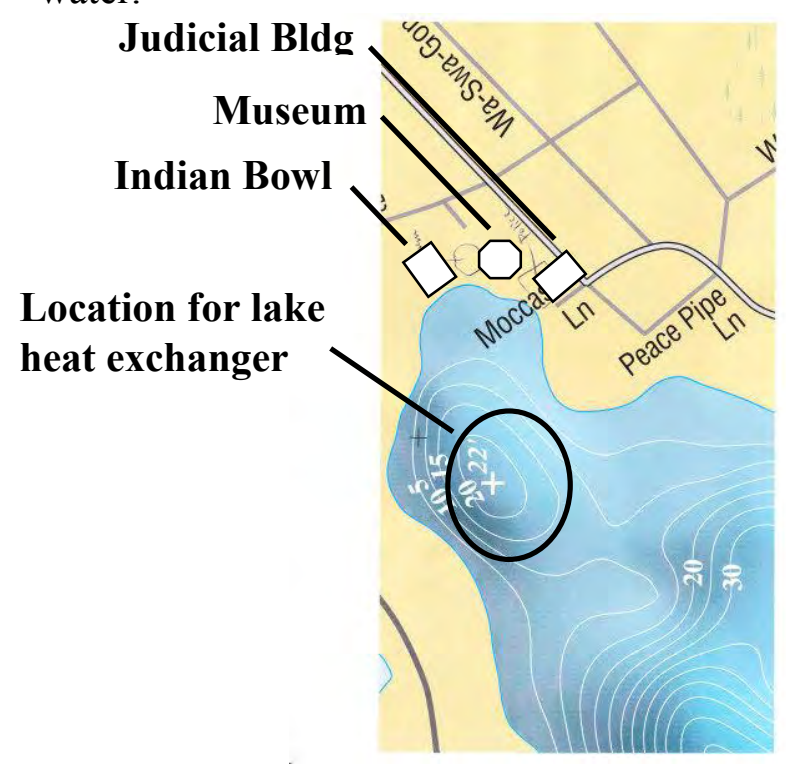

Figure 4: Flambeau Lake profile at Indian Bowl, Museum, and Judicial Building sites

\footnotetext{
${ }^{2} \mathrm{http}: / /$ maps.google.com
} 


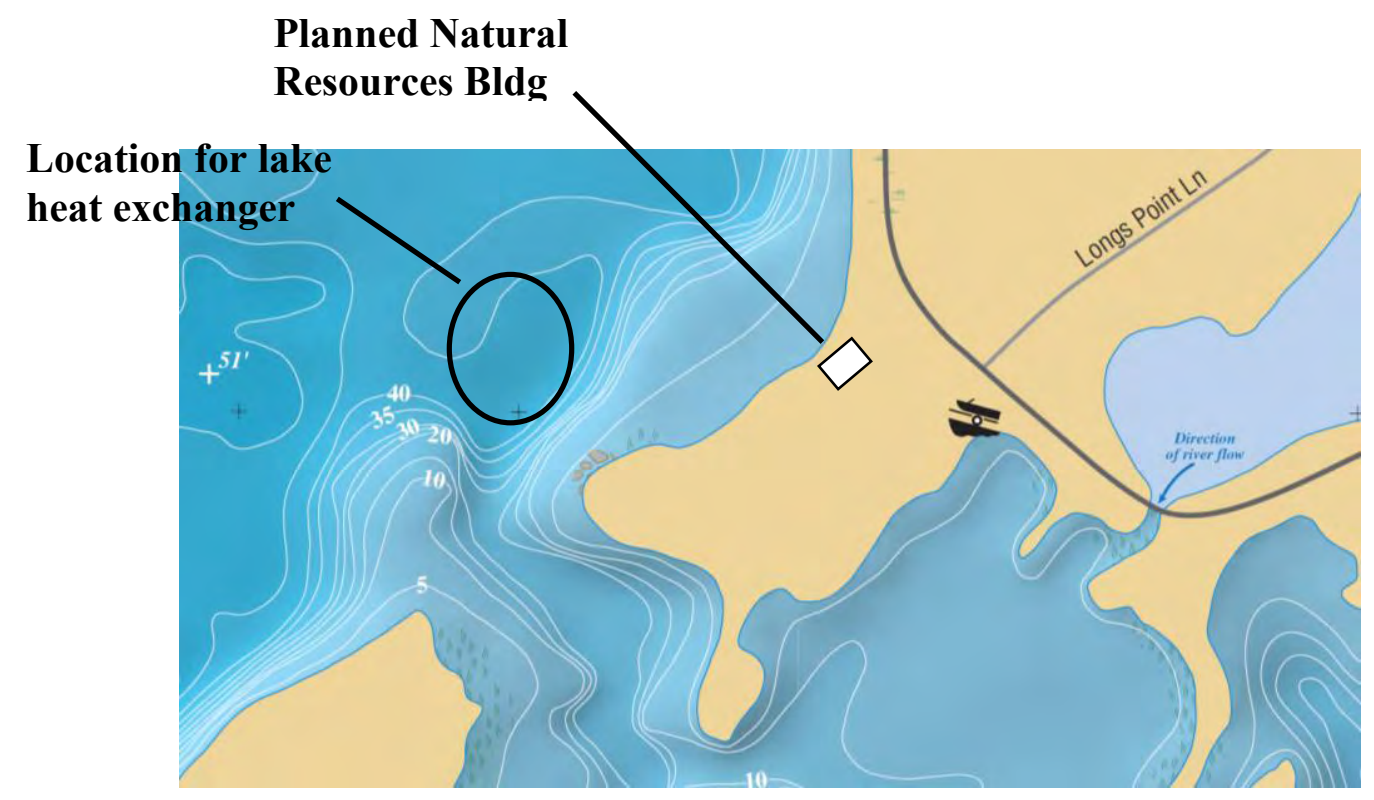

Figure 5: Flambeau Lake profile at Planned Natural Resources building site

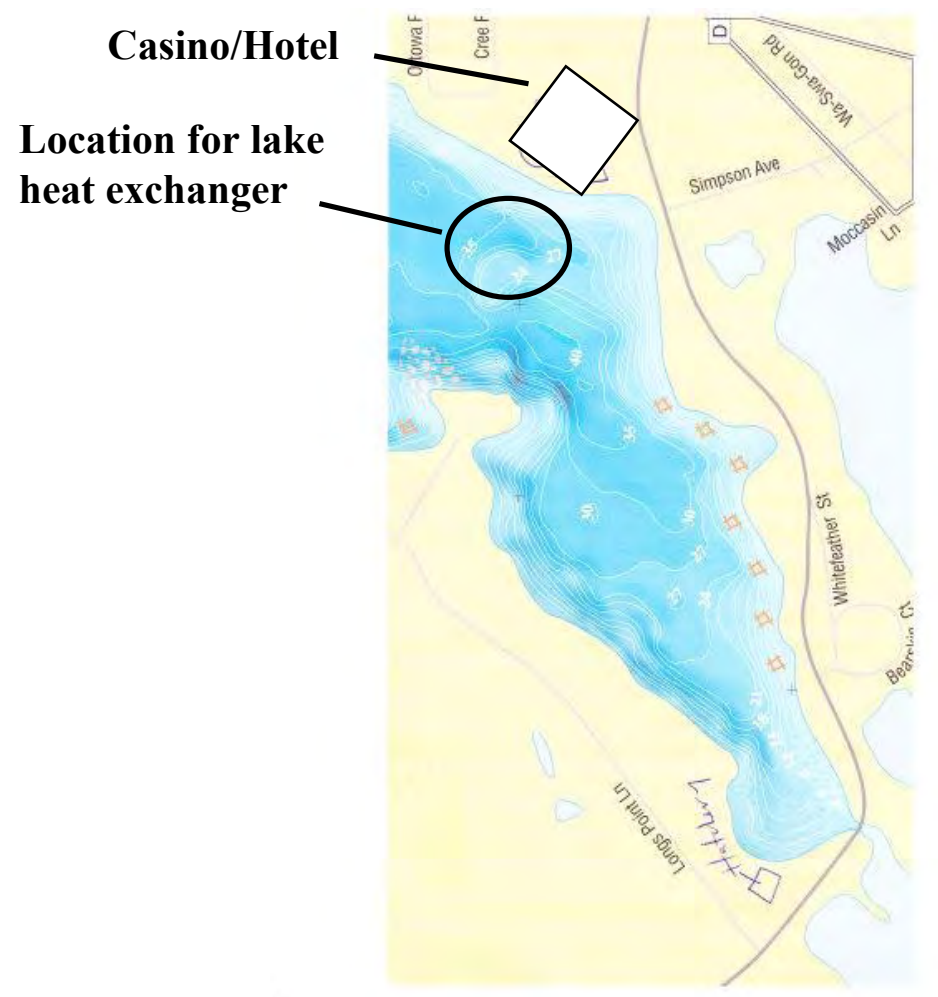

Figure 6: Flambeau Lake profile at Casino/Hotel site 


\section{Sustainable \\ Engineering \\ Group LLC}

\section{Evaluation of Buildings}

\section{Introduction}

The following criteria were used to evaluate the buildings for appropriateness for a geothermal retrofit:

- Size of Building - Buildings less than 5,000 $\mathrm{ft}^{2}$ were given a lower priority due to economies of scale.

- Year of Construction - Buildings recently constructed were given a lower priority. Likewise, buildings due for renovation, planned for construction and buildings with older HVAC equipment due for retrofit were given a high priority

- Heated/Cooled - Buildings that were not cooled were given a lower priority.

- Occupancy - Buildings with sporadic or low occupancy rates were given a lower priority.

- Site Appropriateness - Buildings located near one of the lakes or with open land (parking lots, grassy areas, etc) were given a higher priority. 


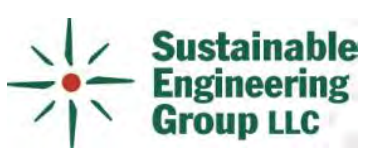

\section{$\underline{\text { Site Walkthrough }}$}

A survey of Reservation buildings was provided by Reservation staff and used to develop an initial list of 16 target buildings. These 16 buildings represent the different types and sizes of buildings found on the Reservation. On October 15, 2008 Sustainable Engineering met with Lac Du Flambeau staff and performed a site walkthrough. 16 buildings were prioritized based on the findings from the walkthrough and are noted in Table 7.

The buildings were prioritized into three groups based on size and type of geothermal system appropriate for the site.

- Group 1 - Medium sized buildings with lake geothermal systems. Geothermal lake systems will be the most cost effective and easiest to retrofit. The Indian Bowl, The Judicial Building, Museum, and The Planned Natural Resources Building are good candidates for geothermal lake systems.

- Group 2 - Medium and Large sized buildings located proximate to each other that can share a vertical bore geothermal system. A shared borefield can take advantage of diversity from each of the buildings and be constructed at a reduced size and cost. In combination, The Youth Center, Bingo Hall, and Community Center are good candidates for a shared geothermal vertical bore system. The Simpson Assembly Plant in combination with Adaawae Place is also a good candidate for a shared geothermal vertical bore system.

- Group 3 - Medium and Large sized buildings with individual vertical bore geothermal systems. The Post Office Complex, Planning/Banking Building, The Casino Human Resources Building and the Smoke Shop would be good candidates for a geothermal vertical bore system

- Group 4 - Medium and Large sized buildings with lower potential for geothermal systems. These buildings are not good candidates for a geothermal system at this time. This group includes the Casino Hotel, Lac du Flambeau School, and the Casino/Hall of Nations. 


\section{Selected Buildings from Building Groups}

The energy usage of the Group 1, 2, 3 (and 4) buildings was also evaluated. Using existing electrical and propane data energy models of a selected building from each building group (excluding group 4) were developed and calibrated. Probable construction costs for retrofitting a conventional HVAC system and a geothermal heat pump system along with estimates of energy use from the energy models were used to generate a life cycle analysis for each selected building. The buildings modeled are:

- $\quad$ Selected Group 1 Building - Indian Bowl

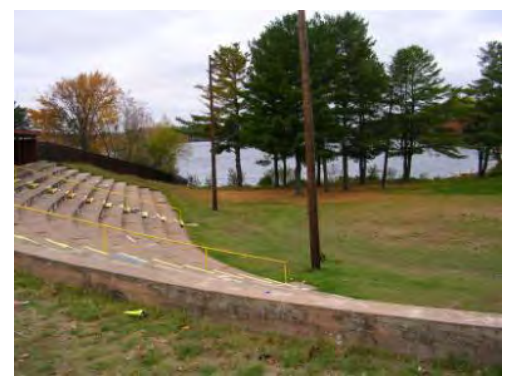

Figure 7: Exterior view of Indian Bowl

- Selected Group 2 Buildings - Youth Center, Bingo Hall, Community Center
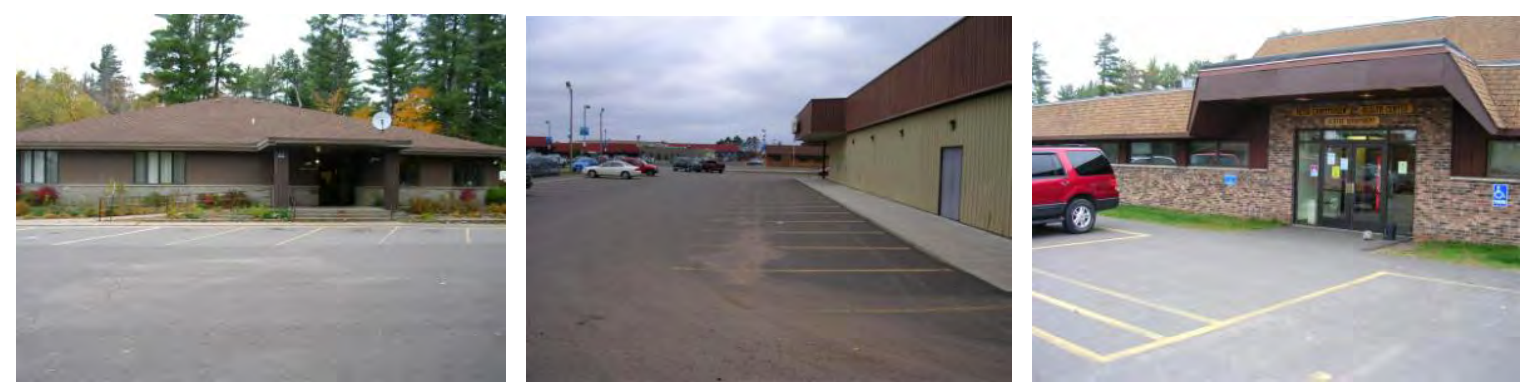

Figure 8: Exterior view of buildings

- $\quad$ Selected Group 3 Buildings - Post Office Complex

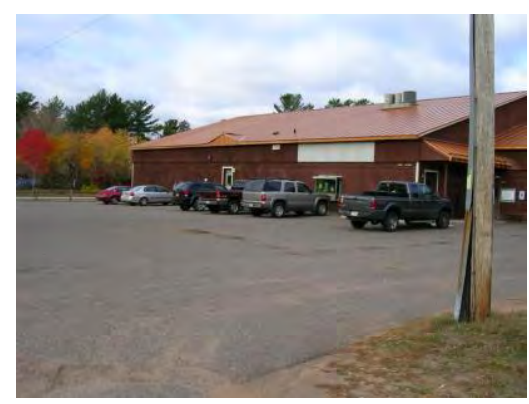

Figure 9: Exterior view of Post Office Building 


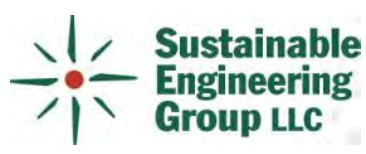

\section{Group 4 Buildings}

\section{Casino Hotel}

The Casino Hotel was deemed not a good candidate at this time for a geothermal upgrade. An upgrade of the hotel would involve a relatively large investment and disruption to tourism. When the building HVAC equipment does reach its service life it would be feasible to upgrade the PTAC units in each residential room and office furnace units to geothermal heat pumps. There is appropriate room in the parking lot proximate to the building for a vertical well field. The hotel is also situated on the lake and a lake geothermal system could be considered.

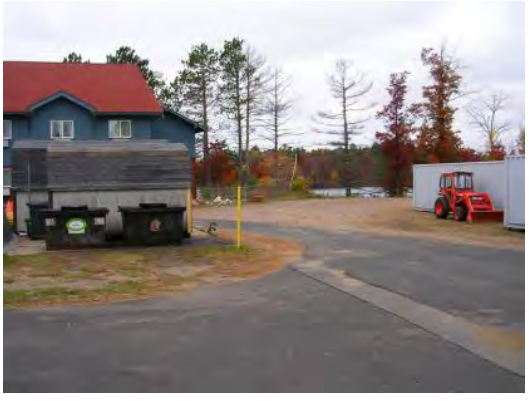

\section{Lac du Flambeau School}

The Lac Du Flambeau School was deemed not a good candidate at this time for a geothermal upgrade. An upgrade of the school systems would involve a relatively large investment and potential disruption to the ball fields around the school. Instead, there are multiple non-geothermal energy saving measures that could be incorporated into the building to reduce electrical and propane consumption. When the building HVAC equipment does reach its service life it may be feasible to upgrade the boilers, chillers, and terminal units to geothermal heat pumps. There is appropriate room in the parking lot or ball fields proximate to the building for a vertical well field.

\section{Casino/ Hall of Nations}

The Casino/Hall of Nations was also deemed not a good candidate at this time for a geothermal upgrade. The current HVAC system, rooftop units with DX coils (DX RTU), economizes (free cooling from outside air) the majority of the year. An upgrade of the casino would involve a relatively large investment and disruption to tourism. When the building HVAC equipment does reach its service life it would be feasible to upgrade the rooftop units to geothermal heat pumps. There is appropriate room in the parking lot proximate to the building for a vertical well field. The casino is also situated on the lake and a lake geothermal system could be considered.

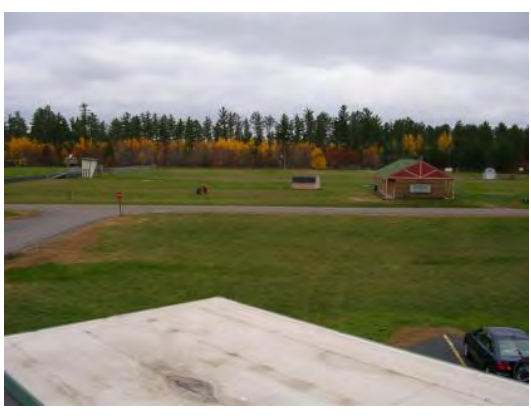

The freezers and self contained refrigeration at the casino/hotel kitchen could utilize a geothermal lake system to reject condenser heat to. Further analysis of the equipment would be required. 


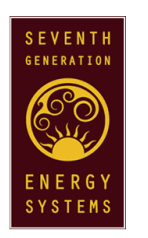

Sustainable

Engineering

Group LLC

Table 7: Prioritized List of Lac Du Flambeau Buildings

\begin{tabular}{|c|c|c|c|c|c|c|c|c|c|c|c|c|c|}
\hline GRP & BUILDING & $\begin{array}{l}\text { SQUARE } \\
\text { FOOTAGE }\end{array}$ & $\begin{array}{l}\text { YEAR } \\
\text { BUILT }\end{array}$ & HEATED & COOLED & USAGE & $\begin{array}{l}\text { OCCUPANCY } \\
\text { SCHEDULE }\end{array}$ & $\begin{array}{l}\text { PHYSICAL } \\
\text { ADDRESS }\end{array}$ & $\begin{array}{l}\text { TYPE OF } \\
\text { GEO }\end{array}$ & $\begin{array}{l}\text { ELECTRIC } \\
\text { USE (kWh) }\end{array}$ & $\begin{array}{l}\text { PROPANE } \\
\text { USE (gal) }\end{array}$ & $\begin{array}{l}\text { ENERGY } \\
\text { (kBtu/yr) }\end{array}$ & $\begin{array}{c}\text { ENERGY } \\
(\mathrm{kBtu} / \mathrm{sq}-\mathrm{ft} / \mathrm{yr})\end{array}$ \\
\hline 1 & Indian Bowl & 5,250 & $\begin{array}{l}\text { slated for } \\
\text { remodel }\end{array}$ & Furnace & DX & $\begin{array}{l}\text { Tribal } \\
\text { Enterprises }\end{array}$ & office & $\begin{array}{l}535 \text { Simpson } \\
\text { Ave. }\end{array}$ & $\begin{array}{l}\text { Lake or } \\
\text { Vertical }\end{array}$ & 39,480 & 3,170 & 424,761 & 81 \\
\hline 1 & Judicial building & 5,000 & $\begin{array}{l}\text { slated for } \\
\text { remodel }\end{array}$ & Furnace & DX & $\begin{array}{l}\text { Government } \\
\text { Operations }\end{array}$ & office & $\begin{array}{l}623 \text { Peace } \\
\text { Pipe Rd. }\end{array}$ & $\begin{array}{l}\text { Lake or } \\
\text { Vertical }\end{array}$ & 73,272 & 2,317 & 462,010 & 92 \\
\hline 1 & Museum & 9,000 & 1989 & Furnace & DX & $\begin{array}{l}\text { Tribal } \\
\text { Enterprises }\end{array}$ & office & $\begin{array}{l}603 \text { Peace } \\
\text { Pipe Rd. }\end{array}$ & $\begin{array}{l}\text { Lake or } \\
\text { Vertical }\end{array}$ & 70,909 & 3,638 & 574,819 & 64 \\
\hline 1 & $\begin{array}{l}\text { Planned Natural Resources } \\
\text { Building }\end{array}$ & $\sim 6,700$ & $\mathrm{n} / \mathrm{a}$ & $\mathrm{n} / \mathrm{a}$ & $\mathrm{n} / \mathrm{a}$ & $\begin{array}{l}\text { Tribal } \\
\text { Enterprises }\end{array}$ & $\begin{array}{l}\text { office \& } \\
\text { visitors center }\end{array}$ & $\mathrm{n} / \mathrm{a}$ & $\begin{array}{l}\text { Lake or } \\
\text { Vertical }\end{array}$ & $\mathrm{n} / \mathrm{a}$ & $\mathrm{n} / \mathrm{a}$ & $\mathrm{n} / \mathrm{a}$ & $\mathrm{n} / \mathrm{a}$ \\
\hline $2 \mathrm{~A}$ & $\begin{array}{l}\text { Community Center / } \\
\text { Clinic }\end{array}$ & 35,000 & 1,973 & Furnace & DX & $\begin{array}{l}\text { Government } \\
\text { Operations }\end{array}$ & M-F 7am-5pm & $\begin{array}{l}408 / 418 \\
\text { Little Pines } \\
\text { Rd }\end{array}$ & $\begin{array}{l}\text { Vertical } \\
\text { (shared } \\
\text { field) }\end{array}$ & 473,000 & 21,236 & $3,556,970$ & 102 \\
\hline $2 \mathrm{~A}$ & $\begin{array}{l}\text { Youth Center } \\
\text { (Abinoojiiyag Center) }\end{array}$ & 7,500 & 1990 's & Furnace & DX & $\begin{array}{l}\text { Central } \\
\text { Services }\end{array}$ & $\begin{array}{l}\text { M-Sat 8am- } \\
8 \mathrm{pm}\end{array}$ & $\begin{array}{l}407 \text { Huron } \\
\text { St. }\end{array}$ & $\begin{array}{l}\text { Vertical } \\
\text { (shared } \\
\text { field) }\end{array}$ & 48,638 & 2,501 & 394,794 & 53 \\
\hline $2 \mathrm{~A}$ & Bingo Hall & 9,000 & 1960 's & Furnace & DX & $\begin{array}{l}\text { Gaming } \\
\text { Operations }\end{array}$ & $\begin{array}{l}\text { W,Th,Sat 6pm- } \\
11 \mathrm{pm} / \text { Fri } \\
10 \mathrm{am}-11 \mathrm{pm} / \\
\text { Sun } 12 \mathrm{pm}-6 \mathrm{pm} \\
\end{array}$ & $\begin{array}{l}424 \text { Little } \\
\text { Pines Rd. }\end{array}$ & $\begin{array}{l}\text { Vertical } \\
\text { (shared } \\
\text { field) }\end{array}$ & 197,361 & 11,534 & $1,728,757$ & 192 \\
\hline $2 \mathrm{~B}$ & Simpson's Main Plant & 15,600 & $\begin{array}{c}\text { various } \\
\text { additions }\end{array}$ & Boiler & DX & $\begin{array}{l}\text { Tribal } \\
\text { Enterprises }\end{array}$ & M-Th 7am-5pm & $\begin{array}{l}520 \text { Simpson } \\
\text { Ave. }\end{array}$ & $\begin{array}{l}\text { Lake or } \\
\text { Vertical }\end{array}$ & 398,960 & 16,352 & $2,857,460$ & 183 \\
\hline $2 \mathrm{~B}$ & Adaawe Place & 10,000 & 2000 's & Furnace & DX & $\begin{array}{l}\text { Tribal } \\
\text { Enterprises }\end{array}$ & $\begin{array}{l}\text { varies based on } \\
\text { tenant }\end{array}$ & $\begin{array}{l}573-591 \\
\text { Peace Pipe. }\end{array}$ & Vertical & 7,978 & 3,100 & 310,871 & 31 \\
\hline 3 & $\begin{array}{l}\text { Post Office, Library, } \\
\text { Tribal Office }\end{array}$ & 8,200 & 1975 & Furnace & DX & $\begin{array}{l}\text { Tribal } \\
\text { Enterprises }\end{array}$ & $\begin{array}{l}\text { M-F 7am-5pm } \\
\text { Sat 8am-12pm }\end{array}$ & $\begin{array}{l}622 \text { Peace } \\
\text { Pipe Rd. }\end{array}$ & Vertical & 21,911 & 4,414 & 478,641 & 58 \\
\hline 3 & Planning / Bank Building & 5,600 & 2002 & Furnace & DX & $\begin{array}{l}\text { Central } \\
\text { Services }\end{array}$ & $\begin{array}{l}\text { M-F 7am-5pm } \\
\text { (Bank Sat 7:30- } \\
\text { 12) }\end{array}$ & $\begin{array}{l}602 \text { Peace } \\
\text { Pipe Rd. }\end{array}$ & Vertical & 62,592 & 2,024 & 398,760 & 71 \\
\hline 3 & $\begin{array}{l}\text { Casino Human Resources / } \\
\text { Education Building }\end{array}$ & 6,000 & 1960 's & RTU & DX RTU & $\begin{array}{l}\text { Gaming } \\
\text { Operations }\end{array}$ & $\begin{array}{l}\text { M-F 7am-4pm } \\
\text { (classes untill } \\
7 \mathrm{pm} \text { ) }\end{array}$ & $\begin{array}{l}562 \text { Peace } \\
\text { Pipe Rd. }\end{array}$ & Vertical & 179,520 & 7,626 & $1,310,301$ & 218 \\
\hline 3 & Smoke Shop & 8,000 & 2005 & Furnace & DX & $\begin{array}{l}\text { Tribal } \\
\text { Enterprises }\end{array}$ & $\begin{array}{l}\text { 7days/week } \\
\text { 10am -12am }\end{array}$ & $\begin{array}{l}\text { 597 Peace } \\
\text { Pipe Rd. }\end{array}$ & Vertical & 227,598 & 0 & 776,564 & 97 \\
\hline 4 & Hotel & 70,000 & 1995 & PTAC & DX & $\begin{array}{l}\text { Gaming } \\
\text { Operations }\end{array}$ & 24 hours & 510 Old Abe & $\begin{array}{l}\text { Lake or } \\
\text { Vertical }\end{array}$ & $1,380,360$ & 0 & $4,709,788$ & 67 \\
\hline 4 & Lac Du Flambeau School & 100,000 & 1993 & Boiler & DX & School & M-F 7am-5pm & & Vertical & $1,242,200$ & 90,000 & $12,473,386$ & 125 \\
\hline 4 & Casino / Hall of Nations & 56,000 & 1995 & RTU & DX RTU & $\begin{array}{l}\text { Gaming } \\
\text { Operations }\end{array}$ & 24 hours & 510 Old Abe & $\begin{array}{l}\text { Lake or } \\
\text { Vertical }\end{array}$ & $5,043,793$ & 163,200 & $32,142,222$ & 574 \\
\hline
\end{tabular}

$\mathrm{DX}=$ refrigerant coil in furnace with remote condensing unit

DX RTU = refrigerant coil in rooftop unit with condensing unit 


\section{Sustainable \\ Engineering \\ Group LLC}

\section{Total Potential for Geothermal}

Table 8 summarizes the assumptions for each building and building group used to develop this estimate. The School is classified as group 3 and the Hotel is classified as group 1 for purposes of this analysis.

Table 8: Assumptions for total reservation potential

\begin{tabular}{l|l|l|c}
\hline & Energy Savings & Additional Cost & Energy Cost Savings \\
\hline Group 1 and Hotel & $60 \%$ & $\$ 6 / \mathrm{ft}^{2}$ & $95 \%$ propane, 10\% electricity \\
Group 2 & $70 \%$ & $\$ 7 / \mathrm{ft}^{2}$ & $95 \%$ propane, 10\% electricity \\
Group 3 and School & $70 \%$ & $\$ 7 / \mathrm{ft}^{2}$ & $95 \%$ propane, 10\% electricity \\
Casino/ Hall of Nations & $10 \%$ & $\$ 7 / \mathrm{ft}^{2}$ & $10 \%$ propane, 10\% electricity \\
\hline
\end{tabular}




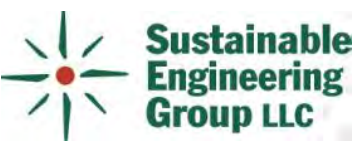

Table 9 includes:

- $\quad$ square footage assigned to each building group - corresponds to square footage in Table 6 .

- $\quad$ energy use for each building group - corresponds to energy use in Table 6.

- estimates for energy savings - consistent with results of life cycle analysis for selected building from each group.

- additional costs for geothermal retrofits - consistent with assumptions in life cycle analysis for each building group.

- and annual energy cost savings - note that the potential savings is de-rated at the Casino due to a low number of hours where equipment is in mechanical cooling mode.

Table 9: Potential for geothermal on Reservation

\begin{tabular}{|c|c|c|c|c|c|}
\hline & $\begin{array}{l}\text { SQUARE } \\
\text { FOOTAGE }\end{array}$ & $\begin{array}{c}\text { ENERGY } \\
\text { (kBtu/yr) }\end{array}$ & $\begin{array}{l}\text { ENERGY } \\
\text { SAVINGS } \\
(\mathbf{k B t u} / \mathbf{y r})\end{array}$ & $\begin{array}{l}\text { ADDITIONAL } \\
\text { COST TO } \\
\text { RETROFIT } \\
\end{array}$ & $\begin{array}{l}\text { ANNUAL } \\
\text { COST } \\
\text { SAVINGS }\end{array}$ \\
\hline Group 1 & 25,950 & $1,461,589$ & 876,953 & $\$ 155,772$ & $\$ 19,174$ \\
\hline Group 2 & 77,100 & $8,848,852$ & $6,194,196$ & $\$ 539,700$ & $\$ 115,233$ \\
\hline Group 3 & 27,800 & $2,964,267$ & $2,074,987$ & $\$ 194,600$ & $\$ 31,638$ \\
\hline $\begin{array}{l}\text { Casino / } \\
\text { Hall of }\end{array}$ & & & & & \\
\hline Nations & 56,000 & $32,142,222$ & $3,214,222$ & $\$ 392,000$ & $\$ 84,201$ \\
\hline $\begin{array}{l}\text { Lac Du } \\
\text { Flambeau }\end{array}$ & & & & & \\
\hline School & 100,000 & $12,473,386$ & $8,731,370$ & $\$ 700,000$ & $\$ 183,422$ \\
\hline Hotel & 70,000 & $4,709,788$ & $2,825,873$ & $\$ 420,000$ & $\$ 55,214$ \\
\hline Total & 356,862 & $62,600,104$ & $23,917,602$ & $\$ 2,402,072$ & $\$ 488,882$ \\
\hline
\end{tabular}

These numbers equate to the following utility savings:

- Potential Electrical Savings - 864,000 kW-hr

- Potential Propane Savings - 176,000 gallons

While Focus on Energy doesn't offer incentives for propane savings, an incentive estimate for the electrical savings is $\$ 0.04 / \mathrm{kW}$-hr, or approximately $\$ 35,000$. 


\section{Sustainable

\section{Life Cycle Analysis for Building Groups 1, 2, and 3}

The selected building from each building group was analyzed to show the difference in operation and maintenance costs over a 25 year period for a geothermal system compared to a conventional HVAC system. The payback is based on the difference in first cost between the two systems.

The analysis was performed on a selected building from each building group that best represented the characteristics of the group. The buildings modeled included:

- Building Group 1 - Indian Bowl

- Building Group 2 - Bingo Hall / Youth Center / Community Center

- $\quad$ Building Group 3 - Post Office Complex

The analysis was based on the most cost effective engineering solutions that responded to the following study goals:

- Energy Efficiency

- Maintenance and Reliability

- Life Cycle Cost Analysis

- Environmental Stewardship

The energy models were developed based upon SEG's professional judgment in accordance with the standards of the profession. However, these energy savings figures do not constitute a guarantee of actual energy costs or savings. In addition, a series of assumptions were made in order to complete this study. These assumptions are listed within the report. Any variations from the assumed values will impact the analysis results. 


\section{Sustainable

\section{Analysis Assumptions}

With the development of the analysis, several assumptions were made regarding the calculation of operating costs, payback, etc. The following is a list of these assumptions:

\section{Buildings}

- Buildings are slated for renovation, addition, or HVAC retrofit within 1 to 5 years.

- The selected building from each group is representative of other buildings in group.

- Construction will bring building up to current WI Code

- Buildings will utilize lake or vertical well field for geothermal resource

\section{Life Cycle Analysis}

- $\quad 3 \%$ Inflation Rate

- $\quad 7 \%$ Discount Rate

- No loan interest rate

- $\quad 5 \%$ Inflation Rate for Electricity

- $\quad 5 \%$ Inflation Rate for Propane

- Present Value analysis performed for a 25-year period

- Utility incentive programs are not included in analysis

- Bin weather data and peak load estimates were used to develop the load profiles

- WPS Uniform electric rate of $\$ 0.1067 / \mathrm{kWh}$ and Propane rate of $\$ 2 /$ therm

- Conventional CAV system maintenance at $\$ 0.30 /$ sq- $\mathrm{ft}$ per year

- Conventional CAV system unit life at 18 years

- Conventional CAV system replacement costs equal to half installed costs at 18 years

- Geothermal Heat Pump system maintenance at $\$ 0.20 /$ sq- $\mathrm{ft}$ per year

- Geothermal Heat Pump unit life at 19 years

- Geothermal Heat Pump replacement costs equal to half installed costs after deducting the cost of the borefield or lake heat exchanger at 19 years 


\section{Sustainable

\section{Load Profile Analysis}

The methods of calculation were in accordance with ASHRAE (American Society of Heating, Refrigeration and Air-Conditioning Engineers) guidelines using weather data for Wausau, Wisconsin. The peak heating and cooling loads are summarized below.

Table 10. Peak heating/cooling loads for Selected Buildings

\begin{tabular}{c|c|r|r|r}
\hline & Selected Building & Area & $\begin{array}{c}\text { Peak Heating } \\
\text { Load }\end{array}$ & $\begin{array}{c}\text { Peak Cooling } \\
\text { Load }\end{array}$ \\
\hline Group 1 & Indian Bowl & $5,000 \mathrm{ft}^{2}$ & $200 \mathrm{MBH}$ & 10 tons \\
Group 2 & $\begin{array}{c}\text { Bingo Hall / Youth Center / } \\
\text { Community Center } \\
\text { Group 3 }\end{array}$ & $50,300 \mathrm{ft}^{2}$ & $2012 \mathrm{MBH}$ & 100 tons \\
\hline
\end{tabular}

1 ton of cooling load $=12,000 \mathrm{btu} / \mathrm{hr}=12 \mathrm{kBtu} / \mathrm{hr}$

$1 \mathrm{MBH}$ of heating load $=1000 \mathrm{btu} / \mathrm{hr}=1 \mathrm{kBtu} / \mathrm{hr}$ 


\section{Sustainable

\section{System Descriptions}

The heating and cooling system options analyzed are as follows:

- Conventional Constant Air Volume (CAV) System. The conventional CAV system includes the following major components:

- $\quad$ Propane furnaces

- One high efficiency furnace per zone

- DX cooling with air cooled condensing units.

- $\quad$ Remotely located air cooled condenser - one per furnace

- Utility power and propane to serve the furnaces and domestic hot water

- $\quad$ Lake Geothermal Heat Pump System. The major components of the lake system include:

- $\quad$ Coils of DR-11 High Density Polyethylene (HDPE) pipe placed in lake.

- $\quad$ DR-11 HDPE supply and return piping from lake to buildings

- $\quad$ Heat pump refrigeration units - combination of water-to-water and water-to-air.

- $\quad$ Variable speed drive circulating pumps

- Utility power and propane to serve the furnaces and domestic hot water

- Vertical Bore Geothermal Heat Pump System. The major components of the vertical bore system include:

- $\quad 300^{\prime}$ deep vertical wells with geothermal grout and DR-11 High Density Polyethylene (HDPE) pipe

- $\quad$ Header pit and header piping

- $\quad$ DR-11 HDPE supply and return piping from header pit to buildings

- $\quad$ Heat pump refrigeration units - combination of water-to-water and water-to-air.

- Variable speed drive circulating pumps

- Utility power and propane to serve the furnaces and domestic hot water 


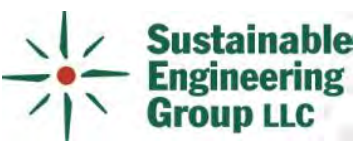

\section{Building Analysis}

\section{$\underline{\text { Selected Building from Group } 1}$}

\subsection{Energy Analysis}

The Indian Bowl building is slated for remodel and the energy model used here is based on a two story $5,000 \mathrm{ft}^{2}$ office building.

The geothermal system is expected to reduce total building energy use, as shown in Table 11 by $\sim 60 \%$. The total building energy includes energy for heating and cooling as well as energy for lights, computers, domestic hot water, etc. Actual energy consumption rates may vary from these estimates depending on several variables such as occupancy patterns, uses of spaces, electric and gas utility rate fluctuations and operational issues.

Table 11: Annual energy use for each system

\begin{tabular}{|l|r|r|}
\hline & Conventional CAV & \multicolumn{1}{|c|}{ Geothermal } \\
\hline \hline Annual Gas Consumption (therms) & 2,619 & 72 \\
\hline Annual Electric Consumption $(\mathrm{kW}-\mathrm{h})$ & 60,260 & 54,310 \\
\hline Peak Demand August $(\mathrm{kW})$ & 30.5 & 25.1 \\
\hline Building Energy Use $(\mathrm{kBtu} / \mathrm{sq}-\mathrm{ft} / \mathrm{yr})$ & 94 & 39 \\
\hline Energy Saved by Geothermal $(\%)$ & \multicolumn{2}{|c|}{$59 \%$} \\
\hline Building Energy Cost $(\$ / \mathrm{sq}-\mathrm{ft} / \mathrm{yr})$ & $\$ 2.37$ & $\$ 1.23$ \\
\hline
\end{tabular}

The geothermal system is expected to reduce the building's annual carbon dioxide emissions by $\sim 27 \%$, as shown in Table 12 .

Table 12: Total annual building carbon dioxide emissions.

\begin{tabular}{|l|r|r|}
\hline & Conventional CAV & Geothermal \\
\hline \hline Emissions from Electricity (lbs CO2) & 112,006 & 100,947 \\
\hline Emissions from Gas (lbs CO2) & 30,642 & 848 \\
\hline Total (lbs CO2) & 142,648 & 101,795 \\
\hline CO2 Saved by Geothermal (lbs CO2) & & 40,853 \\
\hline
\end{tabular}




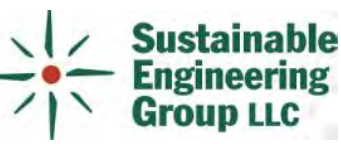

The geothermal system is expected to provide first year cost savings of about $\$ 6,200$ and payback of about 5 years as shown in Table 13. While the geothermal system has a higher first cost, the total cost of ownership over 25 years is expected to be reduced by more than $\$ 147,000$ (net present value).

Projected initial costs for both the conventional CAV systems and the geothermal heat pump systems are based on an analysis of recently completed projects of similar size. Discussions with local mechanical contractors on the estimated construction timeline and projected bidding climate were factored into these cost estimates to determine likely construction costs in 2008/09.

Table 13: Cost comparison of a conventional CAV furnace system to a geothermal system.

\begin{tabular}{|c|c|c|}
\hline & Conventional CAV & Geothermal \\
\hline First Cost & $\$ 80,000$ & $\$ 110,000$ \\
\hline Additional First Cost & Base & $\$ 30,000$ \\
\hline First Year Gas Cost & $\$ 5,238$ & $\$ 145$ \\
\hline First Year Electric Consumption Cost & $\$ 6,429$ & $\$ 5,795$ \\
\hline First Year Service Charges & $\$ 204$ & $\$ 204$ \\
\hline First Year Electric Demand Cost & $\$ 0$ & $\$ 0$ \\
\hline Total First Year Energy Cost & $\$ 11,871$ & $\$ 6,144$ \\
\hline First Year Maintenance Cost & $\$ 1,500$ & $\$ 1,000$ \\
\hline Total First Year Building Cost & $\$ 13,371$ & $\$ 7,144$ \\
\hline First Year Savings & Base & $\$ 6,227$ \\
\hline Simple Payback (Years) & Base & 4.8 \\
\hline Life Cycle Cost Payback (Years) & Base & 4.7 \\
\hline Cost Savings (25-Year basis) & Base & $\$ 146,960$ \\
\hline
\end{tabular}


The following figure shows the 25 year (net present value) cost of the two systems, showing a higher first cost but smaller Operation and Maintenance (O\&M) cost of a geothermal system over a conventional CAV system.

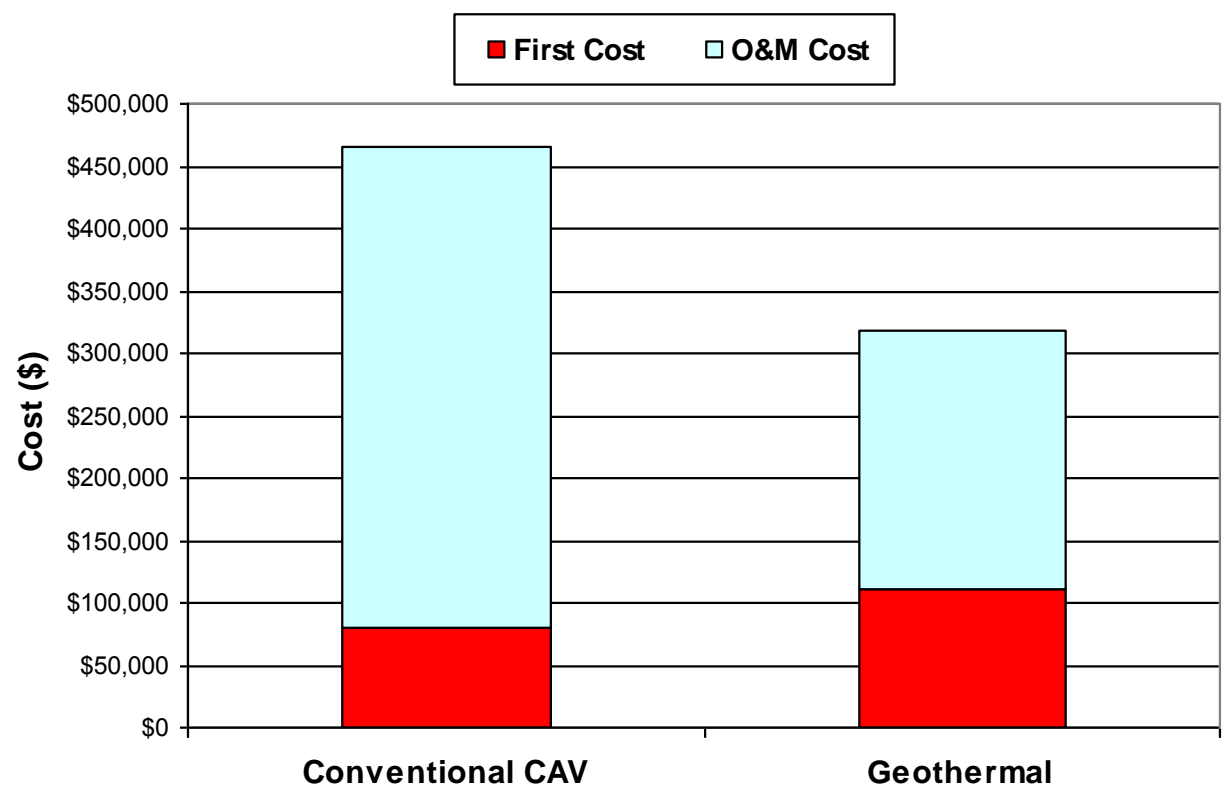

Figure 10. 25 year total cost in current dollars 
The following figure shows the cumulative life cycle cost of the two systems over the first 25 years. The life cycle payback of the geothermal heat pump system is shown at around 5 years from initial construction (the jump in each line corresponds to expected replacement costs in the future).

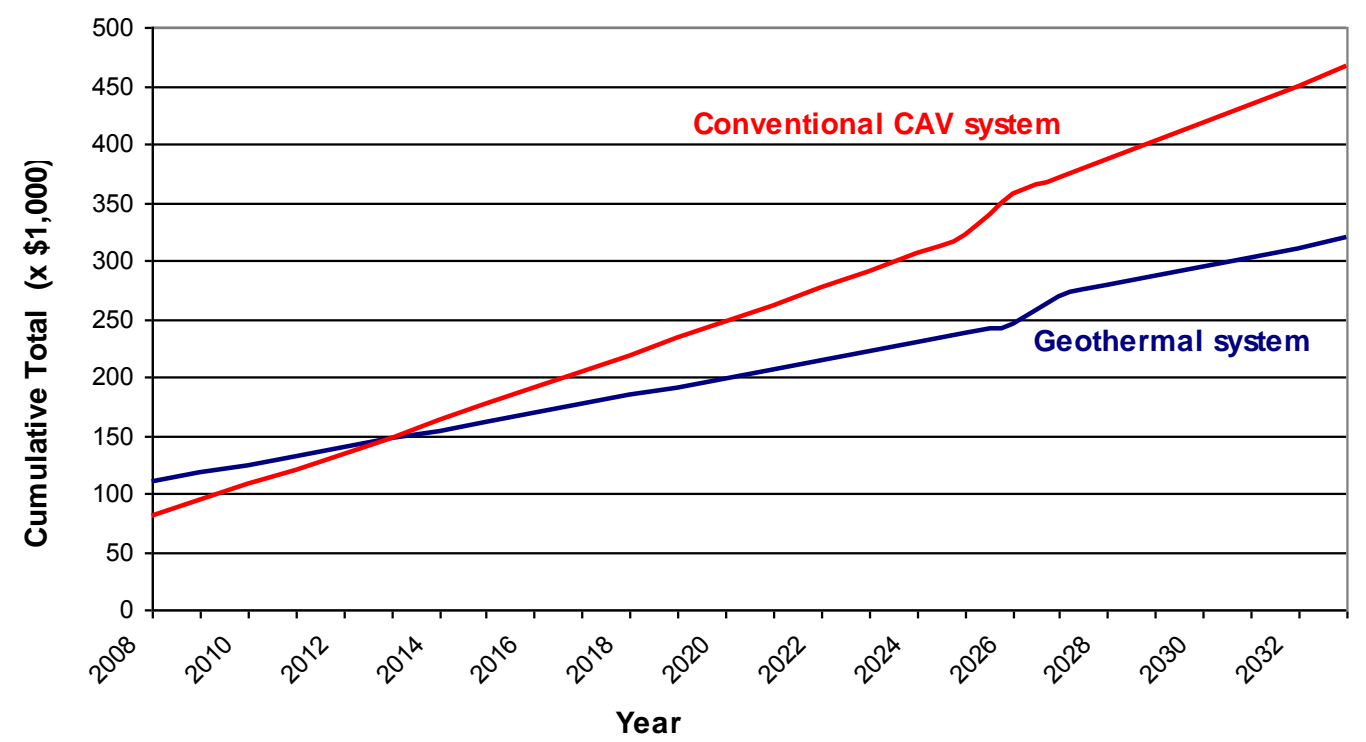

Figure 11. 25 year cumulative life cycle cost 
The following figure shows the monthly electric and gas costs for the two systems for an entire year. It can be seen that the monthly utility bills for the geothermal heat pump system are consistently lower when compared to the conventional CAV system.

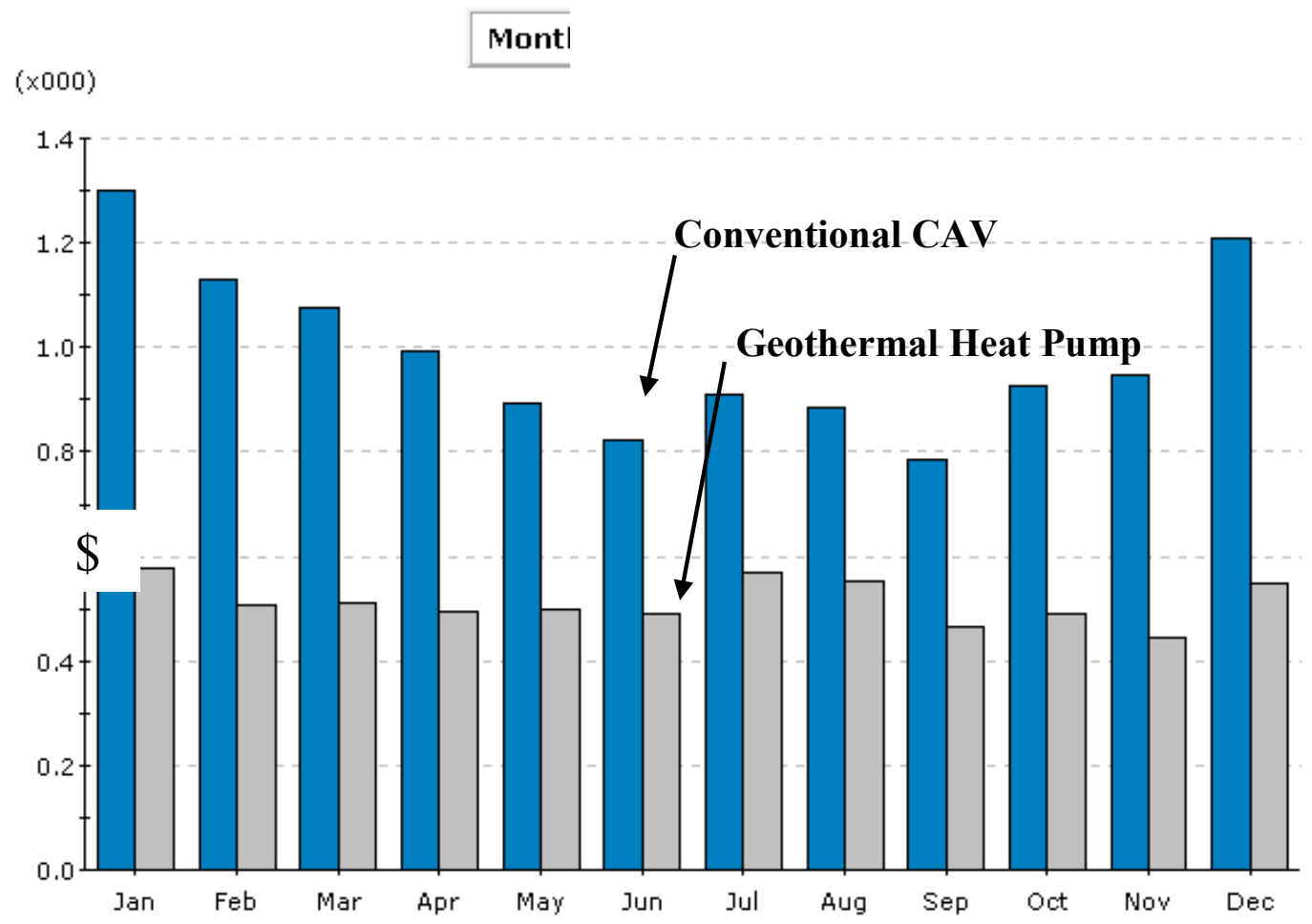

Figure 12. Monthly utility bills for each system 


\subsection{Preliminary Bore Field Location}

The figures below show a preliminary location for a geothermal lake system. The heat exchanger resides in about 20 feet of water in the bay on Long Lake by the Museum and Indian Bowl about 100 feet from the shoreline. This location allows the geothermal installer to keep the heat exchanger below the lakes thermo cline, ice in the winter, and below surface traffic on the lake other times of the year. The supply and return pipes from the lake would have easy access to the mechanical rooms in either the Indian Bowl, Museum, or Judicial Building.

Placement of the lake heat exchanger will need to be coordinated with the tribe's natural resources department and supply/return pipes will need to be coordinated with any underground utilities, including sewer and water.

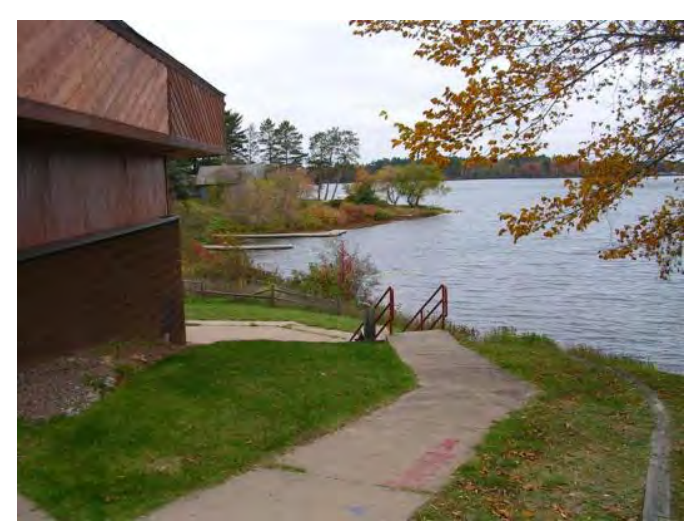

Figure 13: View of Bay on Long Lake by Museum and Indian Bowl

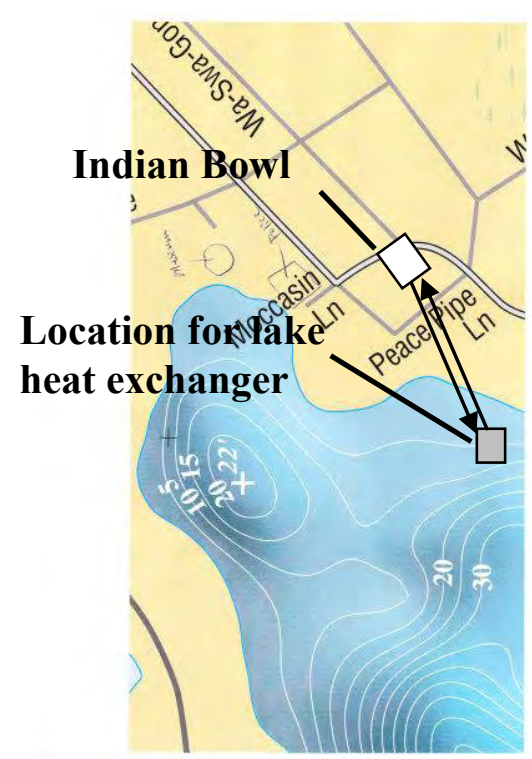

Figure 14: Schematic view of preliminary lake heat exchanger location in relation to buildings and shore. 


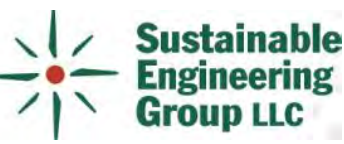

\section{$\underline{\text { Selected Buildings from Group } 2}$}

\subsection{Energy Analysis}

The Youth Center $\left(6,300 \mathrm{ft}^{2}\right)$, Bingo Hall $\left(9,000 \mathrm{ft}^{2}\right)$, and Community Center $\left(35,000 \mathrm{ft}^{2}\right)$ were modeled together to take advantage of diversity and a shared borefield.

The geothermal system is expected to reduce total building energy use, as shown in Table 14 by $\sim 70 \%$. The total building energy includes energy for heating and cooling as well as energy for lights, computers, domestic hot water, etc. Actual energy consumption rates may vary from these estimates depending on several variables such as occupancy patterns, uses of spaces, electric and gas utility rate fluctuations and operational issues.

Table 14: Annual energy use for each system

\begin{tabular}{|l|r|r|}
\hline & Conventional CAV & Geothermal \\
\hline \hline Annual Gas Consumption (therms) & 40,161 & 1,065 \\
\hline Annual Electric Consumption $(\mathrm{kW}-\mathrm{h})$ & 662,360 & 528,380 \\
\hline Peak Demand August $(\mathrm{kW})$ & 312.6 & 216.3 \\
\hline Building Energy Use $(\mathrm{kBtu} / \mathrm{sq}-\mathrm{ft} / \mathrm{yr})$ & 125 & 38 \\
\hline Energy Saved by Geothermal $(\%)$ & & $70 \%$ \\
\hline Building Energy Cost $(\$ / \mathrm{sq}-\mathrm{ft} / \mathrm{yr})$ & $\$ 3.01$ & $\$ 1.17$ \\
\hline
\end{tabular}

The geothermal system is expected to reduce the building's annual carbon dioxide emissions by $\sim 42 \%$, as shown in Table 15 .

Table 15: Total annual building carbon dioxide emissions.

\begin{tabular}{|l|r|r|}
\hline & Conventional CAV & Geothermal \\
\hline \hline Emissions from Electricity (lbs CO2) & $1,231,142$ & 982,110 \\
\hline Emissions from Gas (lbs CO2) & 469,873 & 12,458 \\
\hline Total (lbs CO2) & $1,701,015$ & 994,568 \\
\hline CO2 Saved by Geothermal (lbs CO2) & \multicolumn{2}{|l}{706,446} \\
\hline
\end{tabular}




\section{Sustainable}

The geothermal system is expected to provide first year cost savings of about $\$ 97,500$ and payback of about 4 years as shown in Table 16. While the geothermal system has a higher first cost, the total cost of ownership over 25 years is expected to be reduced by more than $\$ 2,426,000$ (net present value).

Table 16: Cost comparison of a conventional CAV furnace system to a geothermal system.

\begin{tabular}{|c|c|c|}
\hline & Conventional CAV & Geothermal \\
\hline First Cost & $\$ 800,000$ & $\$ 1,156,900$ \\
\hline Additional First Cost & Base & $\$ 356,900$ \\
\hline First Year Gas Cost & $\$ 80,682$ & $\$ 2,490$ \\
\hline First Year Electric Consumption Cost & $\$ 70,674$ & $\$ 56,378$ \\
\hline First Year Service Charges & $\$ 204$ & $\$ 204$ \\
\hline First Year Electric Demand Cost & $\$ 0$ & $\$ 0$ \\
\hline Total First Year Energy Cost & $\$ 151,560$ & $\$ 59,072$ \\
\hline First Year Maintenance Cost & $\$ 15,090$ & $\$ 10,060$ \\
\hline Total First Year Building Cost & $\$ 166,650$ & $\$ 69,132$ \\
\hline First Year Savings & Base & $\$ 97,518$ \\
\hline Simple Payback (Years) & Base & 3.7 \\
\hline Life Cycle Cost Payback (Years) & Base & 3.6 \\
\hline Cost Savings (25-Year basis) & Base & $\$ 2,426,425$ \\
\hline
\end{tabular}


The following figure shows the 25 year (net present value) cost of the two systems, showing a higher first cost but smaller Operation and Maintenance (O\&M) cost of a geothermal system over a conventional CAV system.

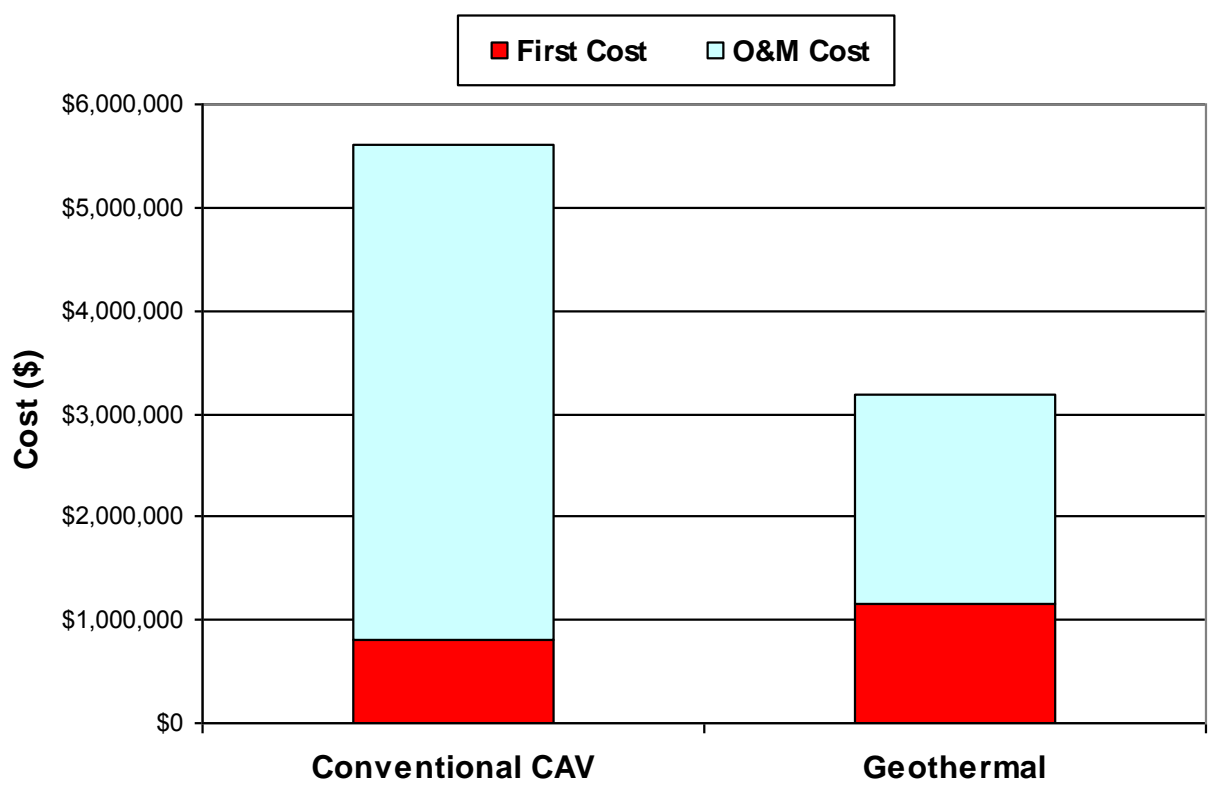

Figure 15. 25 year total cost in current dollars 
The following figure shows the cumulative life cycle cost of the two systems over the first 25 years. The life cycle payback of the geothermal heat pump system is shown at around 4 years from initial construction (the jump in each line corresponds to expected replacement costs in the future).

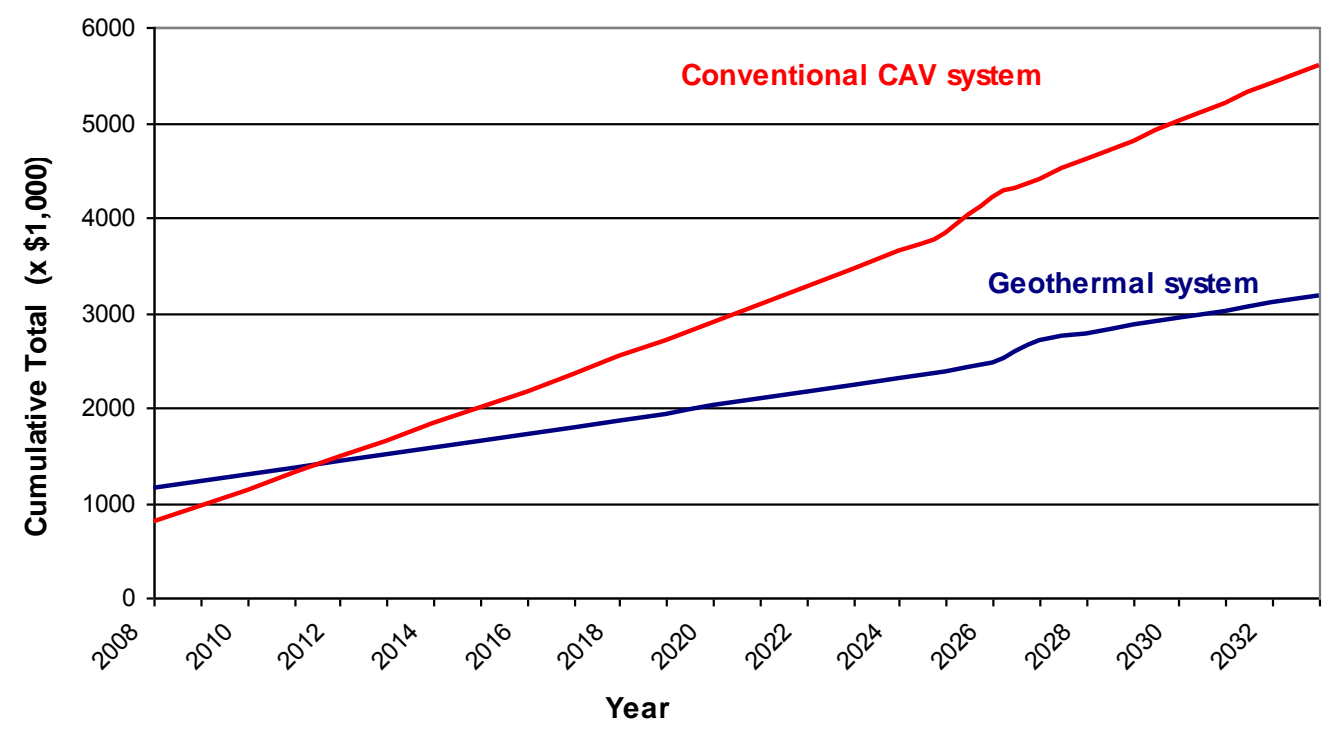

Figure 16. 25 year cumulative life cycle cost 


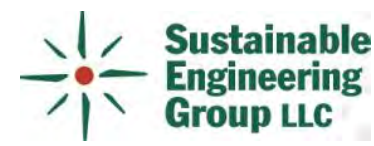

The following figure shows the monthly electric and gas costs for the two systems for an entire year. It can be seen that the monthly utility bills for the geothermal heat pump system are consistently lower when compared to the conventional CAV system.

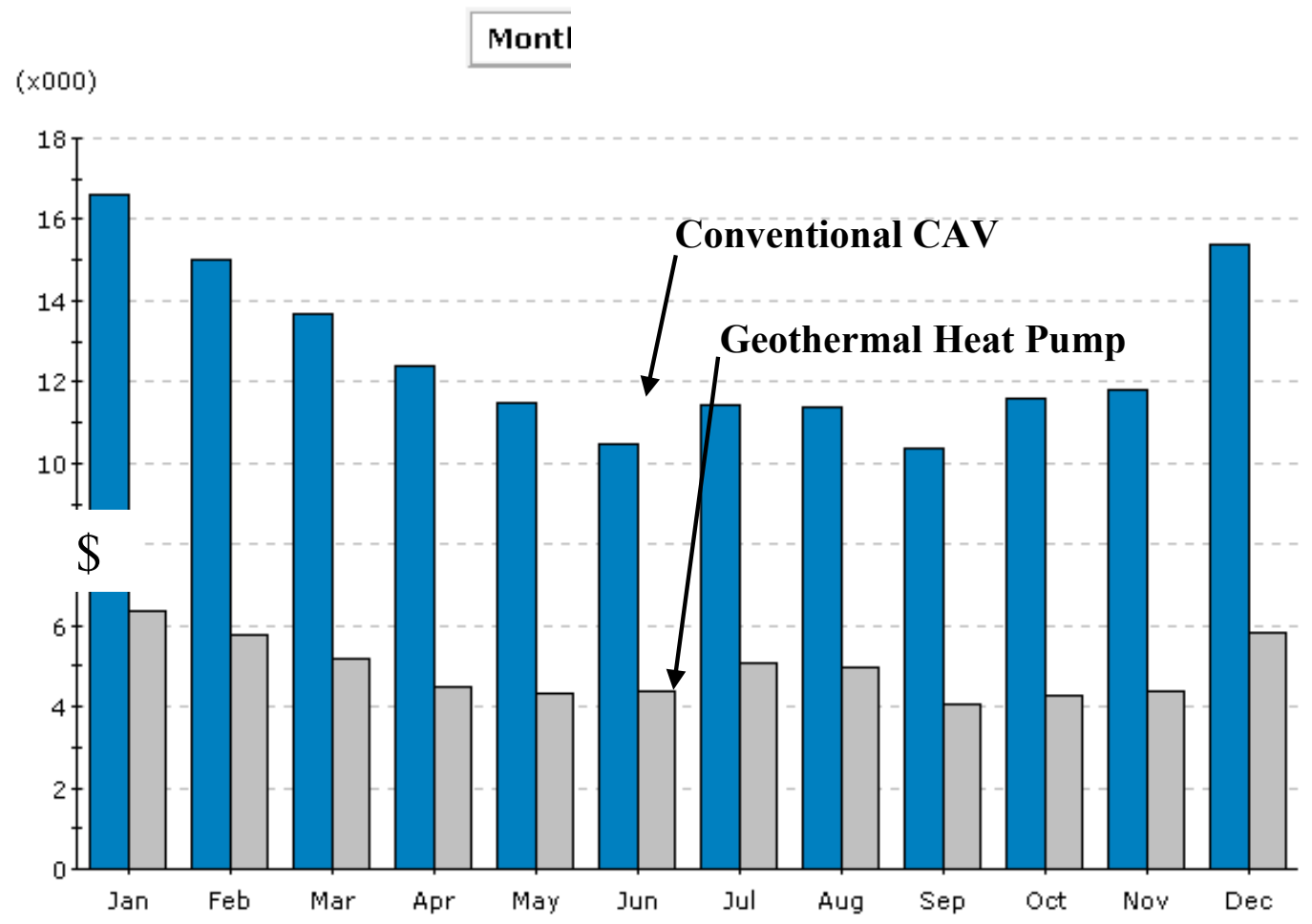

Figure 17. Monthly utility bills for each system 


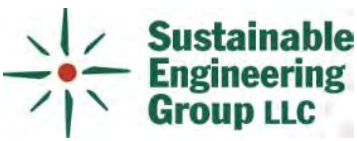

\subsection{Preliminary Bore Field Location}

The photographs below show a preliminary location for a geothermal bore system. The borefield resides in the parking and alley area between the three buildings. This location is centrally located between the buildings allows the geothermal well driller to remain relatively clear of activities in each of the buildings. This position also allows for easy access to the mechanical rooms in each of the buildings. Placement of bore holes will need to be coordinated with any underground utilities, including sewer and water.

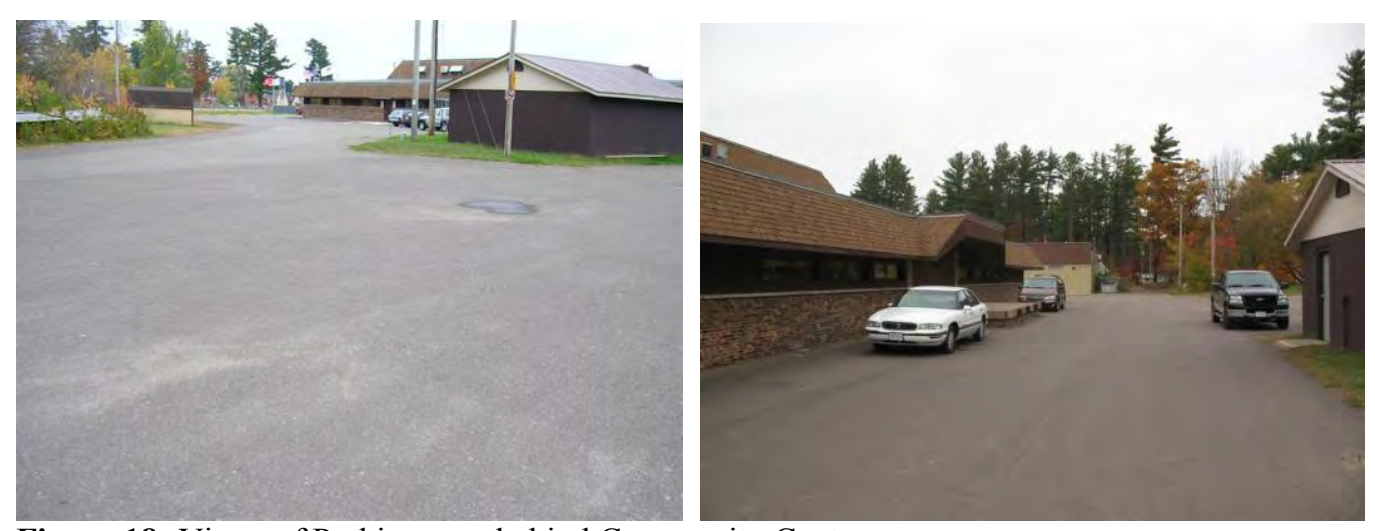

Figure 18: Views of Parking area behind Community Center

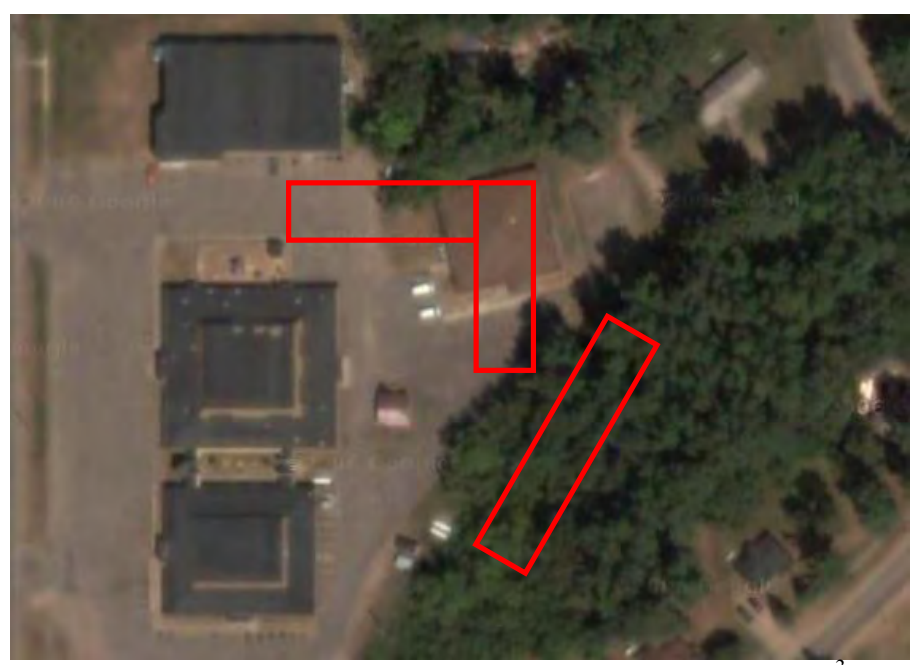

Figure 19: Schematic view of preliminary bore field location in relation to buildings ${ }^{3}$.

\footnotetext{
${ }^{3} \mathrm{http}: / /$ maps.google.com
} 


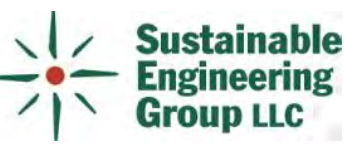

\section{Selected Building from Group 3}

\subsection{Energy Analysis}

The Post Office Building is modeled as a one story $8,000 \mathrm{ft}^{2}$ office building.

The geothermal system is expected to reduce total building energy use, as shown in Table 17 by $\sim 70 \%$. The total building energy includes energy for heating and cooling as well as energy for lights, computers, domestic hot water, etc. Actual energy consumption rates may vary from these estimates depending on several variables such as occupancy patterns, uses of spaces, electric and gas utility rate fluctuations and operational issues.

Table 17: Annual energy use for each system

\begin{tabular}{|l|c|c|}
\hline & Conventional CAV & Geothermal \\
\hline \hline Annual Gas Consumption (therms) & 4,567 & 115 \\
\hline Annual Electric Consumption $(\mathrm{kW}-\mathrm{h})$ & 25,640 & 45,170 \\
\hline Peak Demand August $(\mathrm{kW})$ & 20.6 & 21.1 \\
\hline Building Energy Use $(\mathrm{kBtu} / \mathrm{sq}-\mathrm{ft} / \mathrm{yr})$ & 68 & 21 \\
\hline Energy Saved by Geothermal $(\%)$ & \multicolumn{2}{|c|}{$70 \%$} \\
\hline Building Energy Cost $(\$ / \mathrm{sq}-\mathrm{ft} / \mathrm{yr})$ & $\$ 1.51$ & $\$ 0.66$ \\
\hline
\end{tabular}

The geothermal system is expected to reduce the building's annual carbon dioxide emissions by $\sim 16 \%$, as shown in Table 18 .

Table 18: Total annual building carbon dioxide emissions.

\begin{tabular}{|l|c|c|}
\hline & Conventional CAV & Geothermal \\
\hline Emissions from Electricity (lbs CO2) & 47,658 & 83,958 \\
\hline Emissions from Gas (lbs CO2) & 53,430 & 1,347 \\
\hline Total (lbs CO2) & 101,088 & 85,305 \\
\hline CO2 Saved by Geothermal (lbs CO2) & \multicolumn{2}{|l}{15,783} \\
\hline
\end{tabular}




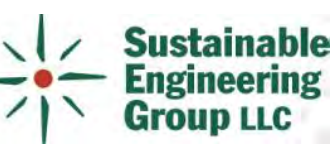

The geothermal system is expected to provide first year cost savings of about $\$ 7,600$ and payback of about 7 years as shown in Table 19. While the geothermal system has a higher first cost, the total cost of ownership over 25 years is expected to be reduced by more than $\$ 160,000$ (net present value).

Table 19: Cost comparison of a conventional CAV furnace system to a geothermal system.

\begin{tabular}{|c|c|c|}
\hline & Conventional CAV & Geothermal \\
\hline First Cost & $\$ 128,000$ & $\$ 184,000$ \\
\hline Additional First Cost & Base & $\$ 56,000$ \\
\hline First Year Gas Cost & $\$ 9,134$ & $\$ 230$ \\
\hline First Year Electric Consumption Cost & $\$ 2,735$ & $\$ 4,820$ \\
\hline First Year Service Charges & $\$ 204$ & $\$ 204$ \\
\hline First Year Electric Demand Cost & $\$ 0$ & $\$ 0$ \\
\hline Total First Year Energy Cost & $\$ 12,073$ & $\$ 5,254$ \\
\hline First Year Maintenance Cost & $\$ 2,400$ & $\$ 1,600$ \\
\hline Total First Year Building Cost & $\$ 14,473$ & $\$ 6,854$ \\
\hline First Year Savings & Base & $\$ 7,619$ \\
\hline Simple Payback (Years) & Base & 7.4 \\
\hline Life Cycle Cost Payback (Years) & Base & 7.2 \\
\hline Cost Savings (25-Year basis) & Base & $\$ 160,017$ \\
\hline
\end{tabular}


The following figure shows the 25 year (net present value) cost of the two systems, showing a higher first cost but smaller Operation and Maintenance (O\&M) cost of a geothermal system over a conventional CAV system.

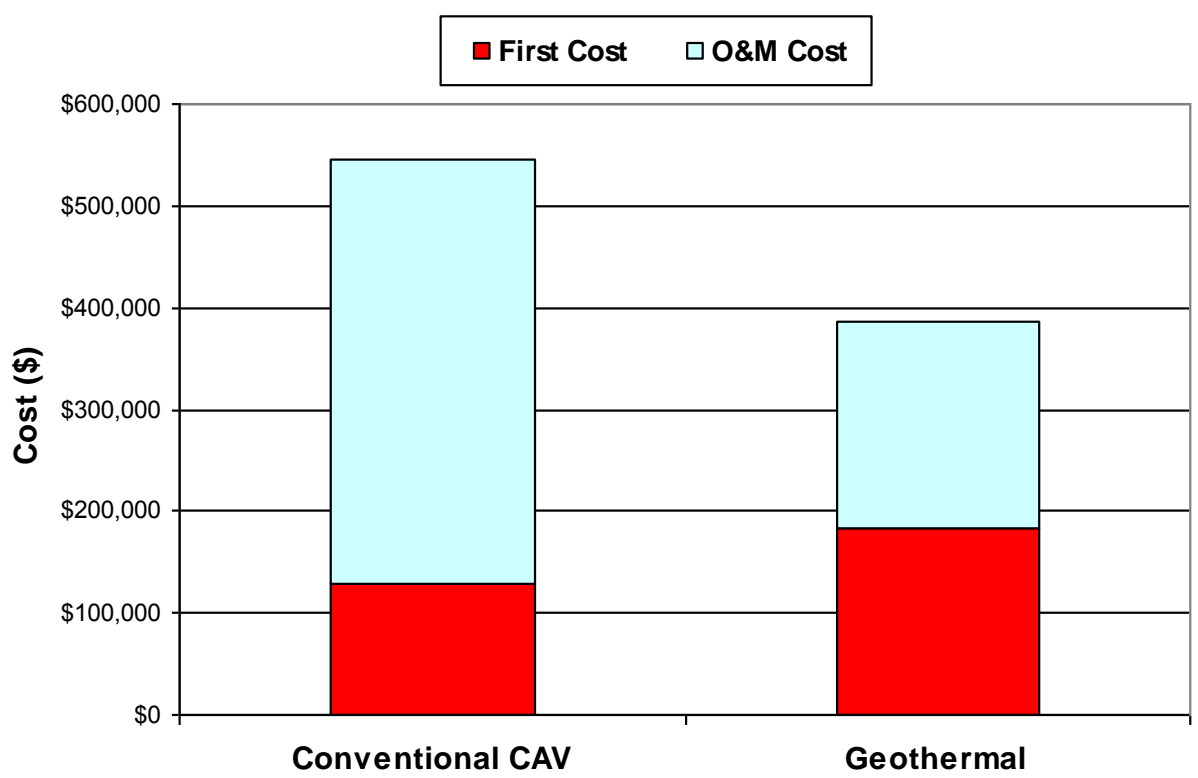

Figure 20: 25 year total cost in current dollars 
The following figure shows the cumulative life cycle cost of the two systems over the first 25 years. The life cycle payback of the geothermal heat pump system is shown at around 7 years from initial construction (the jump in each line corresponds to expected replacement costs in the future).

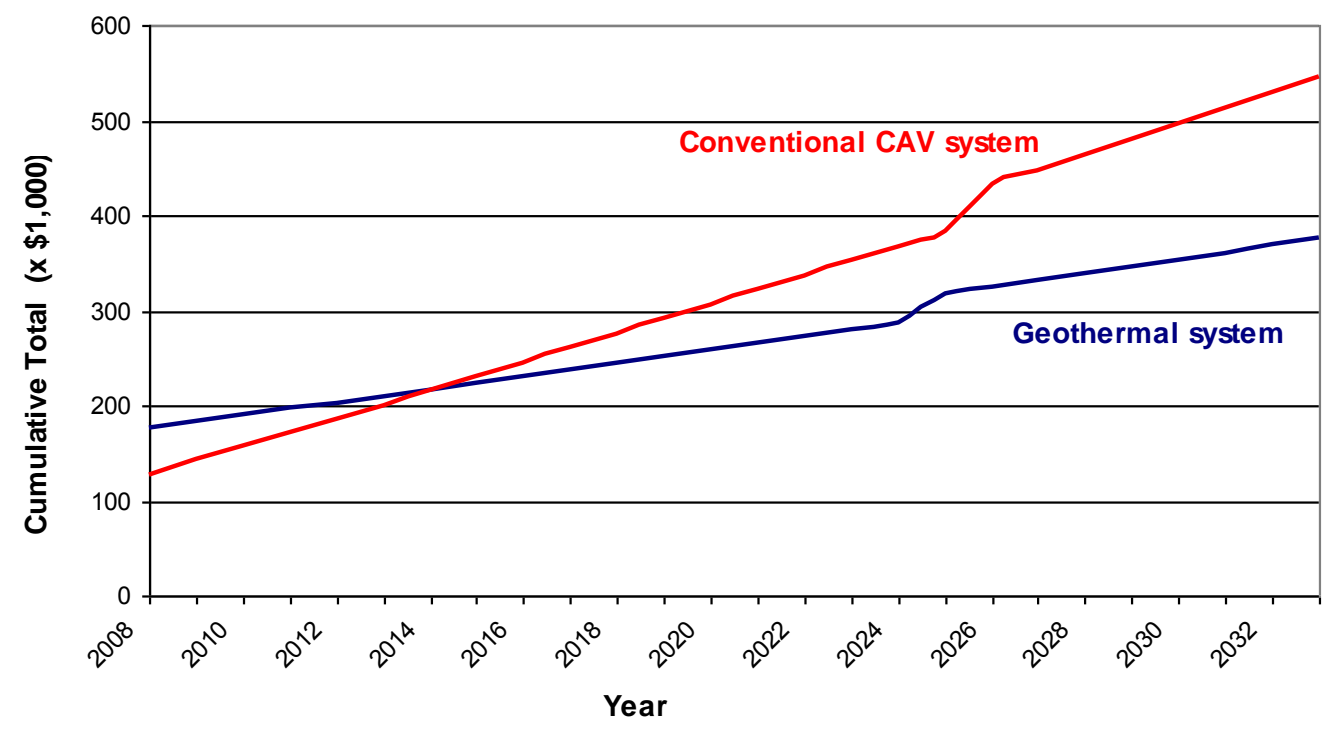

Figure 21: 25 year cumulative life cycle cost 

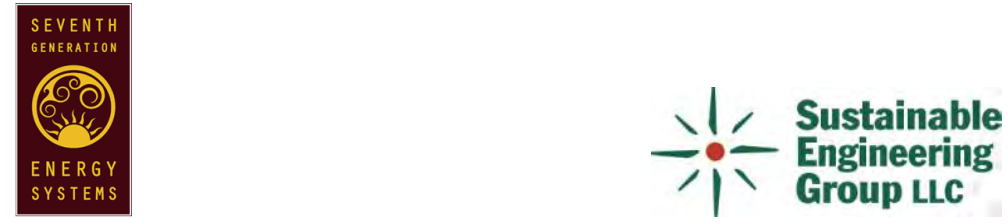

The following figure shows the monthly electric and gas costs for the two systems for an entire year. It can be seen that the monthly utility bills for the geothermal heat pump system are consistently lower when compared to the conventional CAV system.

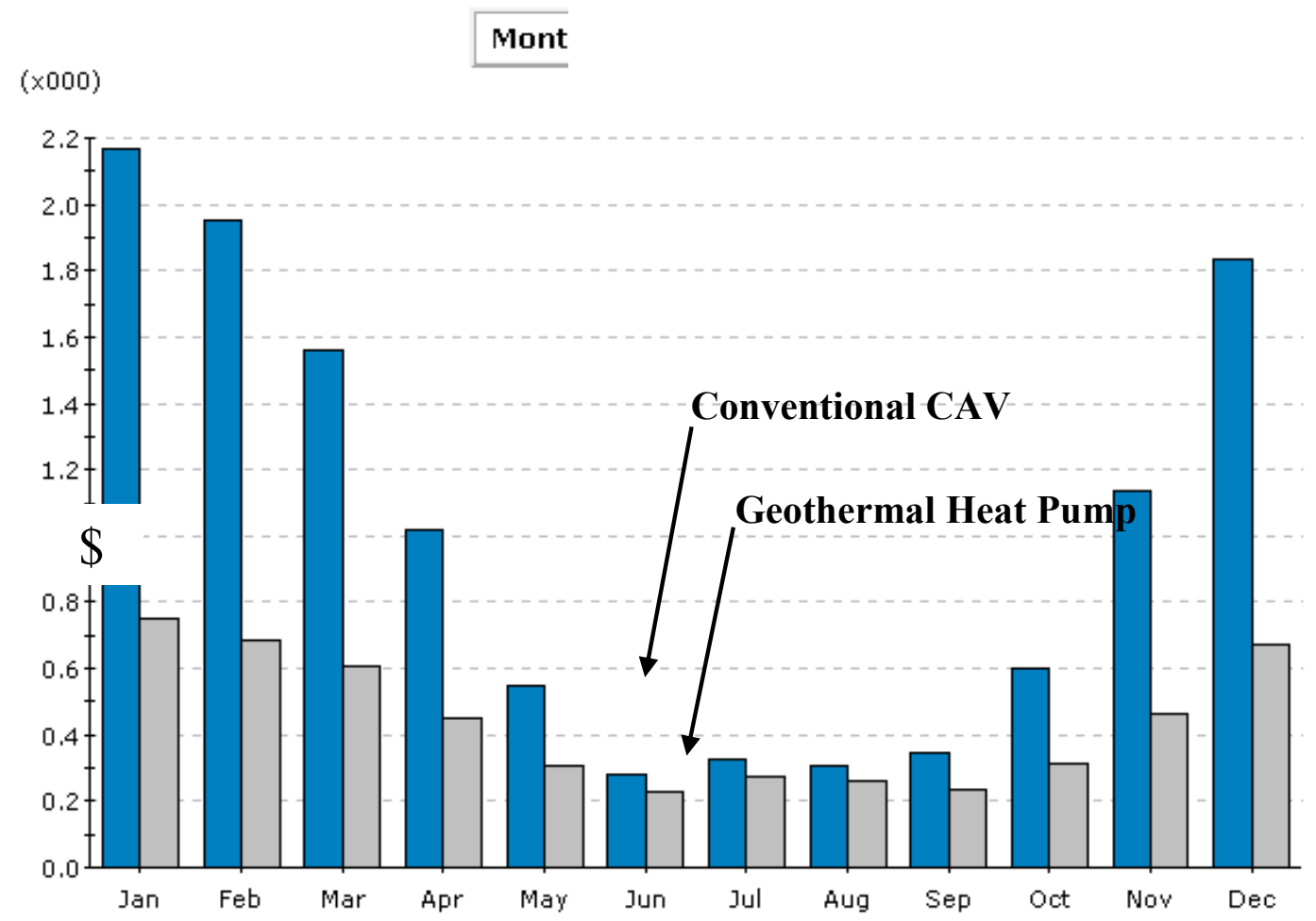

Figure 22: Monthly utility bills for each system 


\subsection{Preliminary Bore Field Location}

The figures below show a preliminary location for a geothermal bore system. The borefield resides in the parking area behind the building. This location allows the geothermal well driller to remain relatively clear of activities in the building. This position also allows for easy access to the mechanical rooms in the building. Placement of bore holes will need to be coordinated with any underground utilities, including sewer and water.

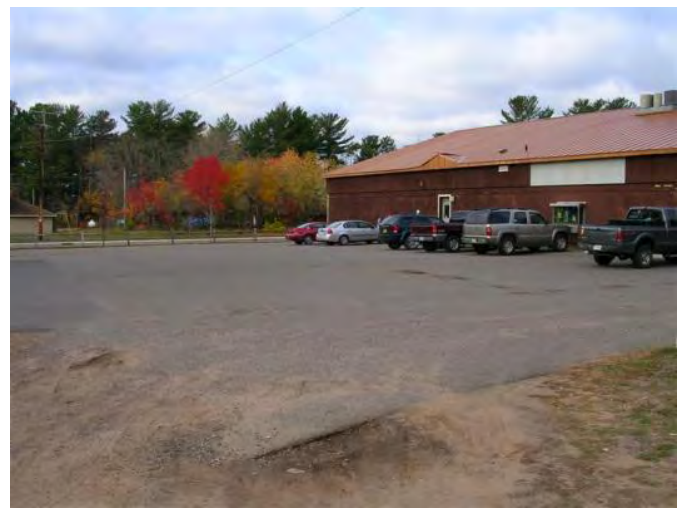

Figure 23: Views of parking area behind the Post Office Building

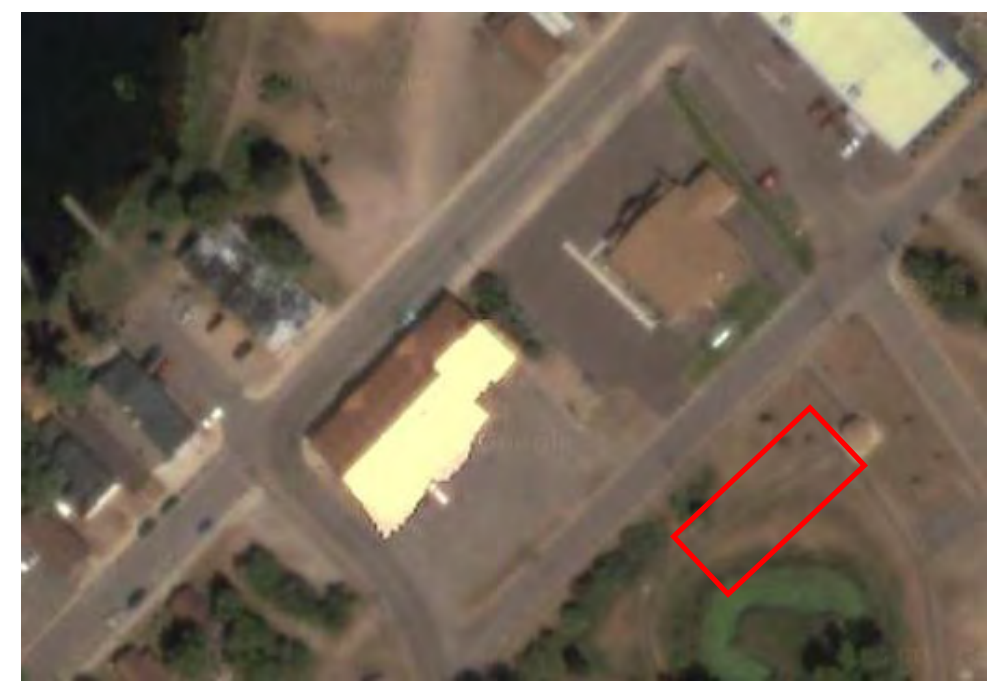

Figure 24: Schematic view of preliminary bore field location in relation to building ${ }^{4}$.

\footnotetext{
${ }^{4}$ http://maps.google.com
} 


\section{Cost Estimates}

Projected initial costs for both the conventional CAV systems and the geothermal heat pump systems are based on an analysis of recently completed projects of similar size. Discussions with local mechanical contractors on the estimated construction timeline and projected bidding climate were factored into these cost estimates to determine likely construction costs in 2008/09.

It should be noted that the exact costs for both systems may vary depending on market conditions at time of bidding. Also, the number and depth of the geothermal bores or size of lake heat exchanger has been based on a preliminary analysis. A thermal conductivity test and refinement of the building heating and cooling loads are required during the design process to determine the exact quantity of bores or size of lake heat exchangers.

Table 20. Cost Summary for Group 1 Buildings (Selected Building: Indian Bowl)

$$
\text { \$/sq-ft Total \$ }
$$

\section{Conventional CAV Furnace}

Including

- Furnaces with DX cooling

stwork and pipe-work distribution

- Testing and Balancing

\section{Geothermal Heat Pumps}

Including

$\$ 22 /$ sq-ft

$\$ 110,000$

re Heat Exchanger - estimated at 10 tons

$(\$ 25,000$, included in cost)

othermal Heat Pumps (typically one per zone)

culating pumps for geothermal fluid

- Ductwork and pipe-work (geothermal loop)

- Testing and Balancing 

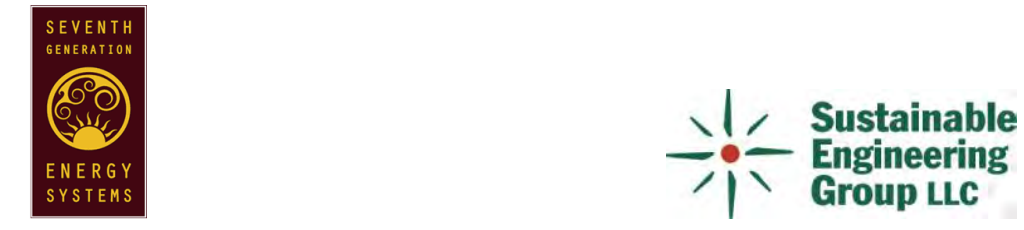

Table 21: Cost Summary for Group 2 Buildings (Youth Center, Bingo Hall, Community Center)

\$/sq-ft Total \$

\section{Conventional CAV Furnace}

Including

$\$ 16 /$ sq-ft $\$ 804,800$

- Furnaces with DX cooling

stwork and pipe-work distribution

- Testing and Balancing

\section{Geothermal Heat Pumps}

Including

$\$ 23 / \mathrm{sq}-\mathrm{ft} \quad \$ 1,156,900$

rtical bore-field - estimated at 55 bores at 300' deep each

(\$486,000, included in cost)

othermal Heat Pumps (typically one per zone)

culating pumps for geothermal fluid

- Ductwork and pipe-work (geothermal loop)

- Testing and Balancing

Table 22: Cost Summary for Group 3 Buildings (Selected Building: Post Office Building)

$\$ / \mathrm{sq}-\mathrm{ft}$

Total $\$$

\section{Conventional CAV Furnace}

Including

$\$ 16 /$ sq-ft $\$ 128,000$

- Furnaces with DX cooling

stwork and pipe-work distribution

- Testing and Balancing

\section{Geothermal Heat Pumps}


Including

$\$ 23 / \mathrm{sq}-\mathrm{ft} \quad \$ 184,000$

rtical bore-field - estimated at 12 bores at 300' deep each

$(\$ 87,120$, included in cost)

othermal Heat Pumps (typically one per zone)

culating pumps for geothermal fluid

- Ductwork and pipe-work (geothermal loop)

- Testing and Balancing 


\section{Sustainable

\section{Analysis Summary}

A selected building from each building group was modeled. The results of the energy modeling were then extrapolated across all 16 buildings evaluated in this study. The table below summarizes the results.

Table 23: Analysis Summary

\begin{tabular}{|c|c|c|}
\hline & Selected Building & Group \\
\hline & Indian Bowl & Building Group 1 \\
\hline & $5,000 \mathrm{ft}^{2}$ & $25,962 \mathrm{ft}^{2}$ \\
\hline Electricity Saved (kW-h) & 5950 & 18,366 \\
\hline Propane Saved (gallons) & 5474 & 8,669 \\
\hline Utility Cost Savings (\$) & $\$ 5727$ & $\$ 19,174$ \\
\hline \multirow[t]{3}{*}{ Carbon Saved (tons) } & 20 & 104 \\
\hline & $\begin{array}{l}\text { Youth Center, Bingo Hall, } \\
\text { Community Center }\end{array}$ & Building Group 2 \\
\hline & $50,300 \mathrm{ft}^{2}$ & $77,100 \mathrm{ft}^{2}$ \\
\hline Electricity Saved (kW-h) & 133,980 & 112,594 \\
\hline Propane Saved (gallons) & 35,968 & 51,987 \\
\hline Utility Cost Savings (\$) & $\$ 92,488$ & $\$ 115,233$ \\
\hline \multirow[t]{3}{*}{ Carbon Saved (tons) } & 353 & 541 \\
\hline & Post Office Complex & Building Group 3 \\
\hline & $8,000 \mathrm{ft}^{2}$ & $27,800 \mathrm{ft}^{2}$ \\
\hline Electricity Saved (kW-h) & $\mathrm{n} / \mathrm{a}$ & 49,162 \\
\hline Propane Saved (gallons) & 4,096 & 13,361 \\
\hline Utility Cost Savings (\$) & $\$ 6,819$ & $\$ 31,638$ \\
\hline Carbon Saved (tons) & 9 & 32 \\
\hline
\end{tabular}




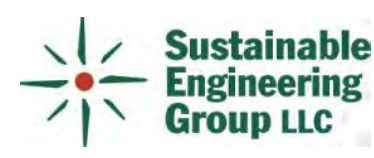

\section{Appendix}

\section{Findings from Well Logs and Driller Survey}

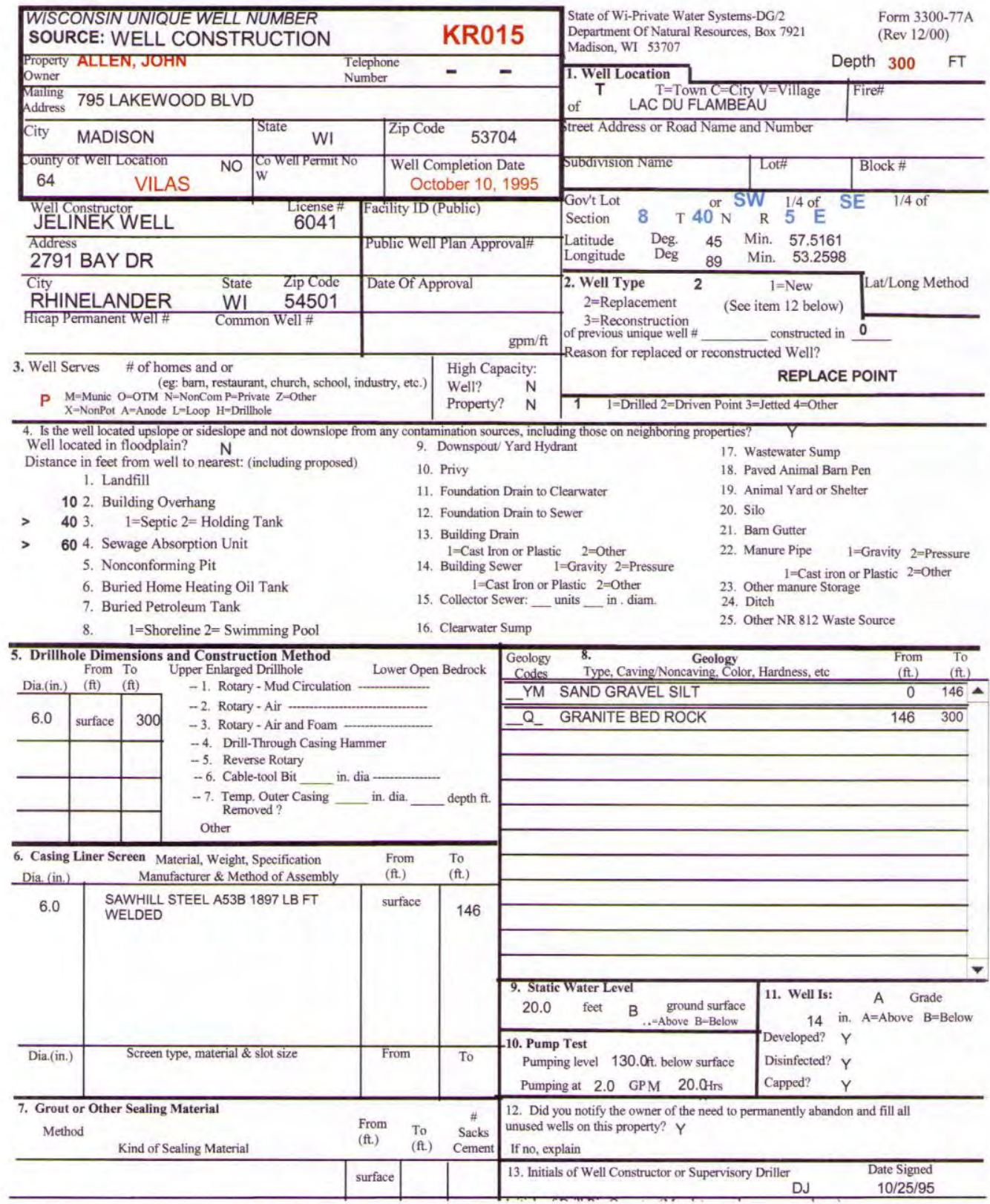




\section{1 - Eustainable}

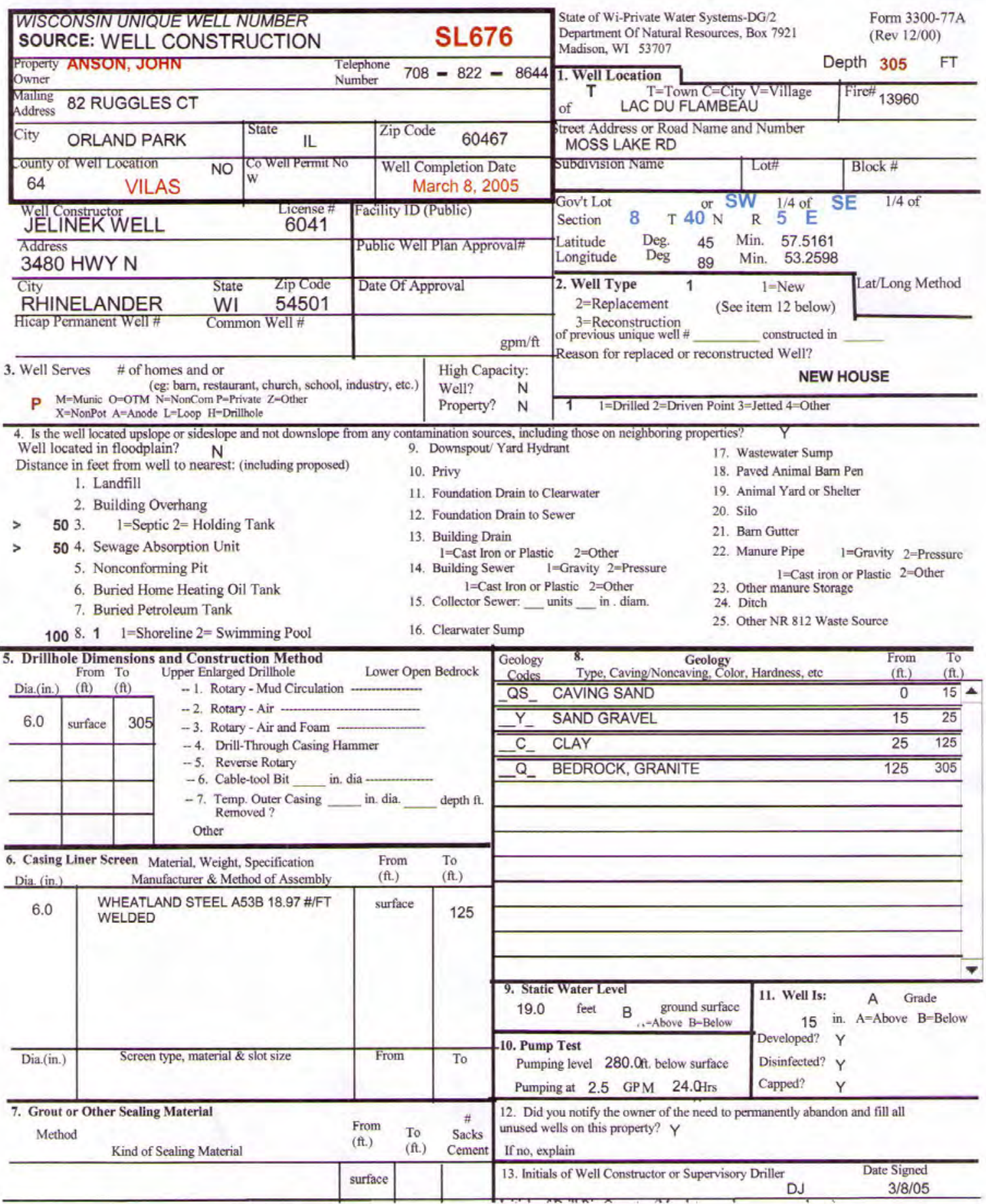




\section{ASHRAE Owning and Operating Costs for HVAC Equipment}

Table 3 Estimates of Service Lives of Various System Components ${ }^{\mathrm{a}}$

\begin{tabular}{|c|c|c|c|c|c|c|}
\hline Equipment Item & $\begin{array}{c}\text { Median } \\
\text { Years }\end{array}$ & Equipment Item & $\begin{array}{c}\text { Median } \\
\text { Years }\end{array}$ & Equipment Item & & $\begin{array}{c}\text { Median } \\
\text { Years }\end{array}$ \\
\hline Air conditioners & & Air terminals & & Air-cooled condensers & & 20 \\
\hline Window unit & 10 & Diffusers, grilles, and registers & 27 & Evaporative condensers & & 20 \\
\hline Residential single or split package & 15 & Induction and fan-coil units & 20 & Insulation & & \\
\hline Commercial through-the-wall & 15 & VAV and double-duct boxes & 20 & Molded & & 20 \\
\hline Water-cooled package & $15 \leftarrow$ & Air washers & 17 & Blanket & & 24 \\
\hline Heat pumps & & Ductwork & 30 & Pumps & & \\
\hline Residential air-to-air & $15^{b}$ & Dampers & 20 & Base-mounted & & 20 \\
\hline Commercial air-to-air & 15 & Fans & & Pipe-mounted & & 10 \\
\hline Commercial water-to-air & $19 \longleftarrow$ & $>$ Centrifugal & 25 & Sump and well & & 10 \\
\hline Roof-top air conditioners & & Axial & 20 & Condensate & & 15 \\
\hline Single-zone & 15 & Propeller & 15 & Reciprocating engines & & 20 \\
\hline Multizone & $15 \leftarrow$ & Ventilating roof-mounted & 20 & Steam turbines & & 30 \\
\hline Boilers, hot water (steam) & & Coils & & Electric motors & & 18 \\
\hline Steel water-tube & $24(30)$ & DX, water, or steam & 20 & Motor starters & & 17 \\
\hline Steel fire-tube & $25(25)$ & Electric & 15 & Electric transformers & & 30 \\
\hline Cast iron & $35(30)$ & Heat exchangers & & Controls & & \\
\hline Electric & 15 & Shell-and-tube & 24 & Pneumatic & & 20 \\
\hline Bumers & 21 & Reciprocating compressors & 20 & Electric & . & 16 \\
\hline Furnaces & & Package chillers & & Electronic & & 15 \\
\hline Gas- or oil-fired & 18 & Reciprocating & 20 & Valve actuators & & \\
\hline Unit heaters & & Centrifugal & 23 & Hydraulic & & 15 \\
\hline Gas or electric & 13 & Absorption & 23 & Pneumatic & & 20 \\
\hline Hot water or steam & 20 & Cooling towers & & Self-contained & & 10 \\
\hline Radiant heaters & & Galvanized metal & 20 & & & \\
\hline - Electric & 10 & Wood & 20 & & & \\
\hline Hot water or steam & 25 & Ceramic & 34 & & & \\
\hline
\end{tabular}

$\begin{array}{lll}\text { Hot water or steam } & \text { Ceramic } & 34 \\ \text { Source: Data obtained from a survey of the United States by ASHRAE Technical Committee TC 1.8 (Akalin 1978). }\end{array}$

'Data updated by TC 1.8 in 1986.

\section{Electrical Energy}

Fundamental changes in the purchase of electrical energy are occurring in the United States, which is opening access to and eventually deregulating the electric energy industry. Individual electric utility rates and regulations may vary widely during this period of deregulation. Consequently, electrical energy providers and brokers or marketers need to be contacted to determine the most competitive supplier Contract conditions need to be reviewed carefully to be sure that the service will suit the purchaser's requirements.

The total cost of electrical energy is usually a combination of several components: energy consumption charges, fuel adjustnent charges, special allowances or other adjustments, anjustment charges.

Energy Consumption Charges. Most utility rates have step rate schedules for consumption, and the cost of the last unit of energy consumed may be substantially different from that of the first. The last unit may be cheaper than the first because the fixed costs to the utility may already have been recovered from earlier consumption costs. Alternatively, the last unit of energy may be sold at a higher rate to encourage conservation.

To reflect time-varying operating costs, some utilities chárge different rates for consumption according to the time of use and season; typically, costs rise toward the peak period of use. This may tify the cost of shifting the load to off-peak periods.

Fuel Adjustment Charge. Due to substantial variations in fuel prices, electric utilities may apply a fuel adjustment charge to recover costs. This adjustment may not be reflected in the rate schedule. The fuel adjustment is usually a charge per unit of energy and may be positive or negative depending on how much of th actual fuel cost is recovered in the energy consumption rate.
Power plants with multiple generating units that use different fuels typically have the greatest effect on this charge (especially during peak periods, when more expensive units must be brough on-line). Although this fuel adjustment charge can vary monthly, the utility should be able to estimate an average annual or seasona fuel adjustment for calculations.

Allowances or Adjustments. Special allowances may be available for customers who can receive power at higher voltages or fo those who own transformers or similar equipment. Special rates may be available for specific interruptible loads such as domestic water heaters.

Certain facility electrical systems may produce a low power factor, which means that the utility must supply more current on an intermittent basis, thus increasing their costs. These costs may be passed on as an adjustment to the utility bill if the power factor is below a level established by the utility. The power factor is the ratio of active (real) kilowatt power to apparent (reactive) kVA the ratio Whe (real) kilowatt power to apparent (reactive) kVA power.

When calculating power bills, utilities should be asked to provide detailed cost estimates for various consumption levels. The final calculation should include any applicable special rates, allowances, taxes, and fuel adjustment charges.

Demand Charges. Electric rates may also have demand charges based on the customer's peak kilowatt demand. While consumption charges typically cover the utility's operating costs, demand charges typically cover the owning costs.

Demand charges may be formulated in a variety of ways:

1. Straight charge-cost per kilowatt per month, charged for the peak demand of the month.

2. Excess charge- cost per kilowatt above a base demand (e.g., $50 \mathrm{~kW}$ ), which may be established each month. 


\section{WPS Electric Rate}

Electric: Wisconsin Public Service Corporation- 3 Phase, Rural, $<12,500$ kW-hr/month http://www.wisconsinpublicservice.com/business/wielecrate.aspx

Customer Charge

\$17/month

On Peak kW-hr

$\$ 0.1067 / \mathrm{kW}-\mathrm{hr}$ 


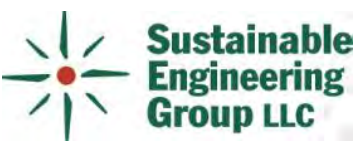

\section{Propane Rate}

The following data was used to determine the average price per gallon of liquid propane gas.

Source(4/22/2008):

http://tonto.eia.doe.gov/dnav/pet/pet_pri_wfr_a_EPLLPA_PWR_cpgal_m.htm

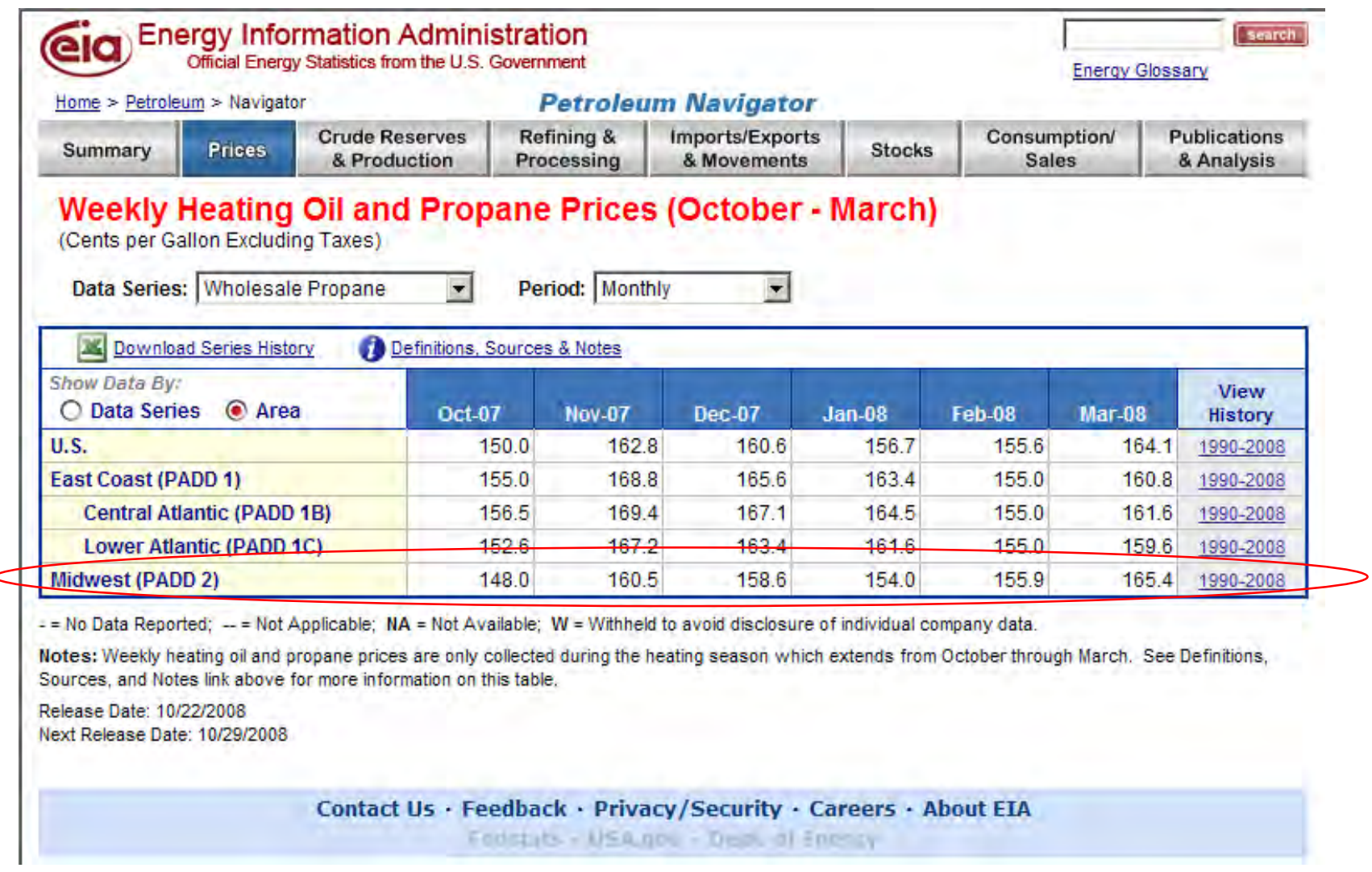

Wholesale Price from March 2008: \$1.65/gallon $=\$ 1.79 /$ therm.

A rate of $\$ 2.00 /$ therm was used for this analysi 
Draft

\section{Biomass Opportunity Assessment for The Lac du Flambeau Tribe}

By: Kaurich Energy Services, LLC

February 2, 2009 


\section{Table of Contents}

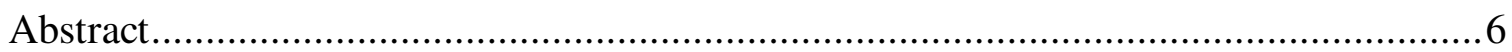

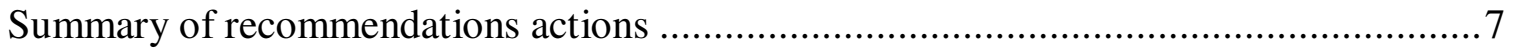

1. Lac du Flambeau biomass resource assessment...................................................

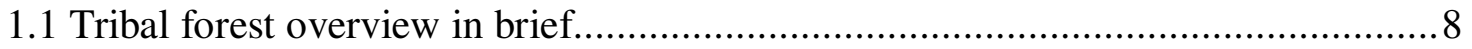

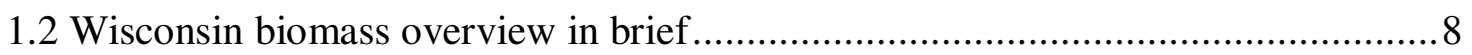

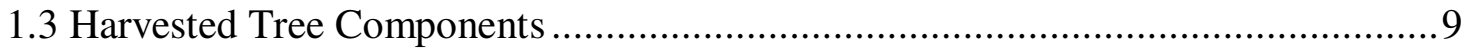

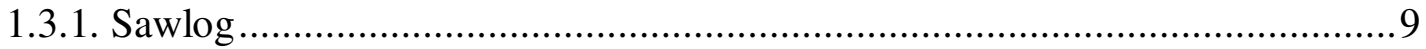

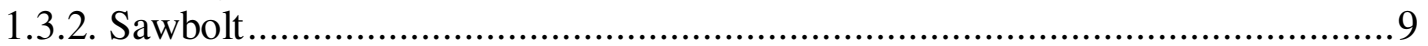

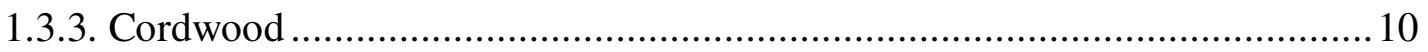

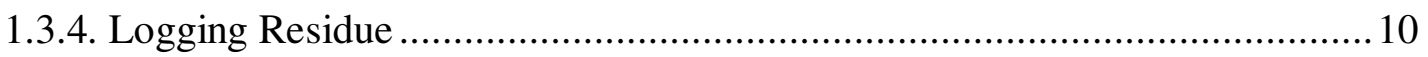

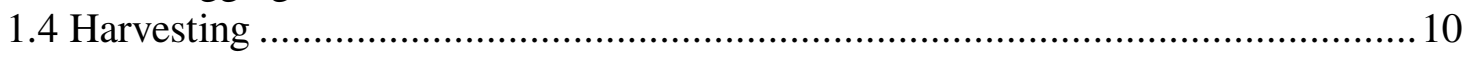

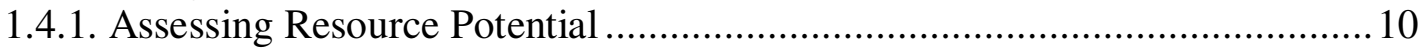

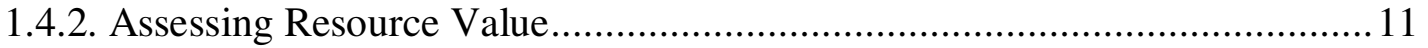

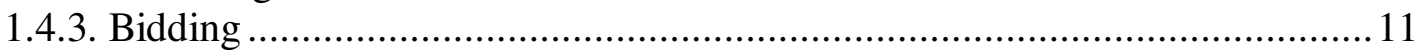

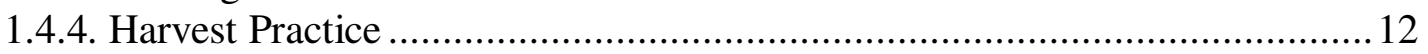

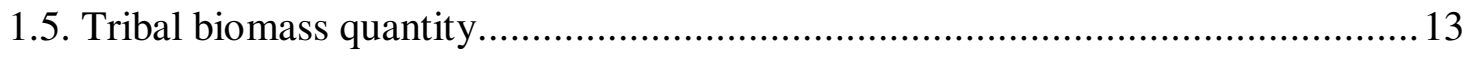

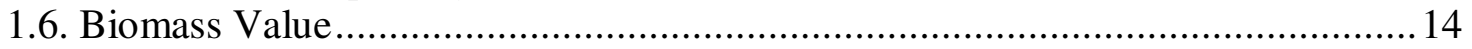

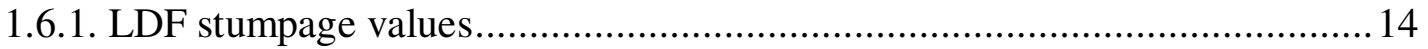

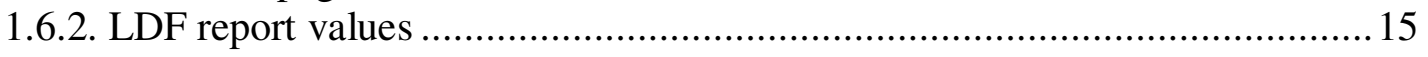

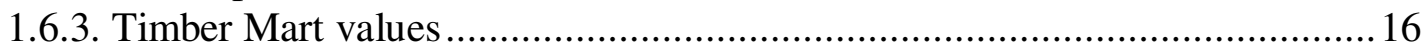

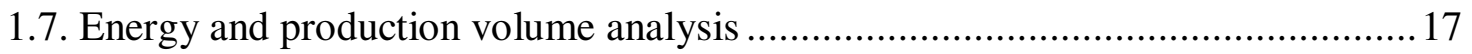

1.7.1. Energy value of current timber harvests ..................................................... 19

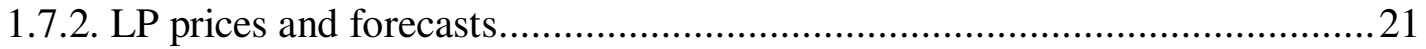

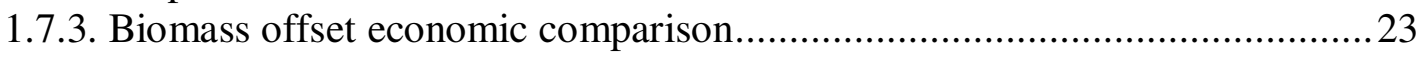

1.7.4. Historic cordwood prices.......................................................................... 24

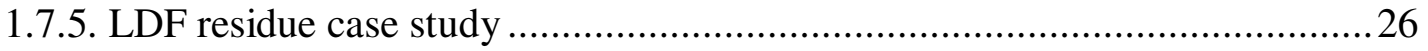

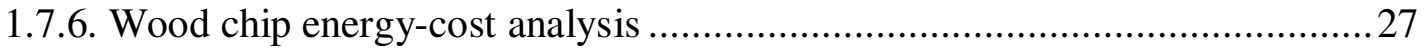

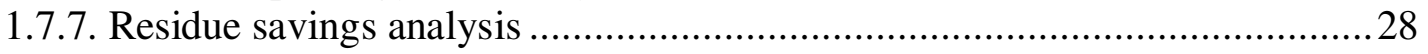

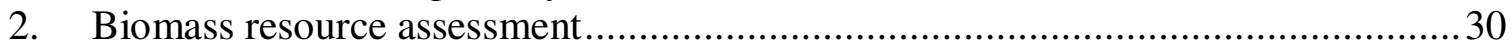

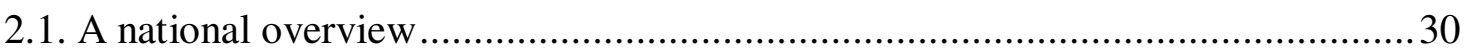

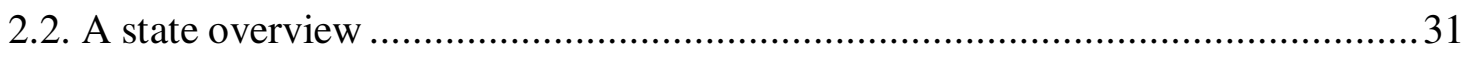

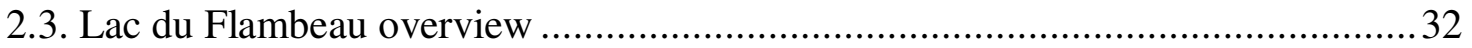

2.3.1. Lac du Flambeau timber assessment by radii................................................32

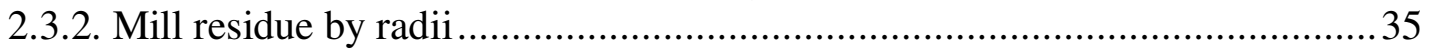

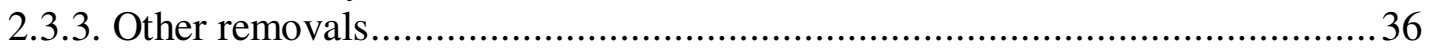

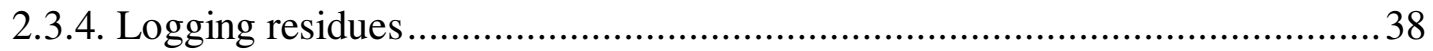

2.3.5. Cordwood resource availability ................................................................. 41

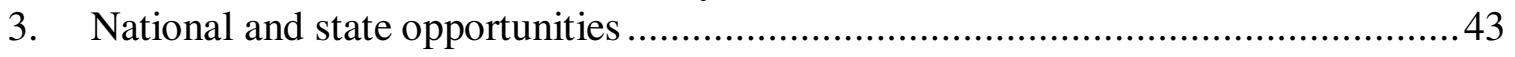

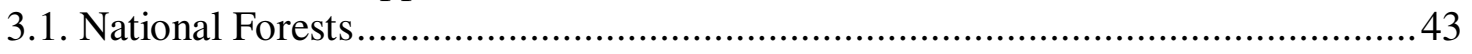

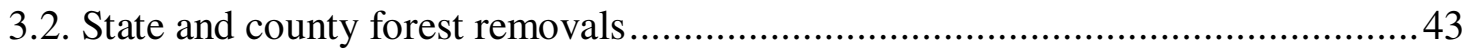

3.3. Major landowner policies for Wisconsin residue ..............................................45

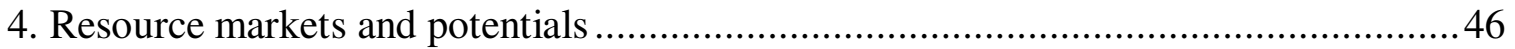

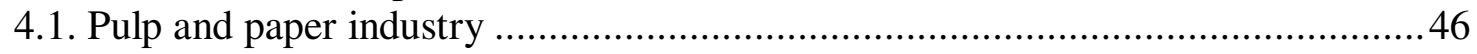

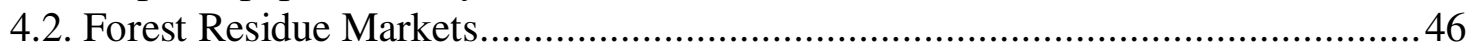




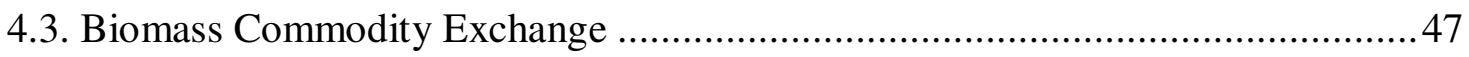

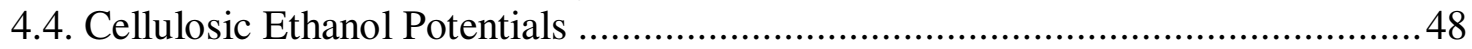

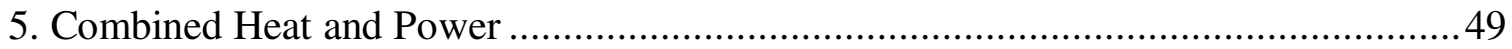

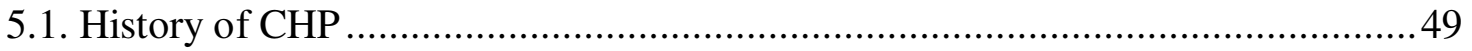

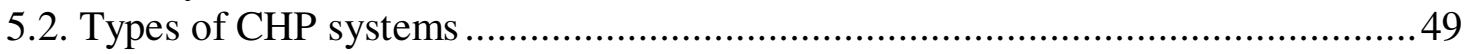

5.3. Key Factors of Combined Heat and Power.........................................................50

5.4. Individualized analysis of CHP (LDF casino and hotel) ...................................51

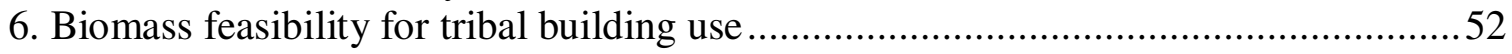

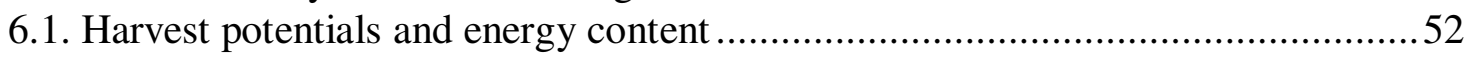

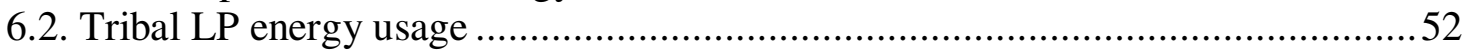

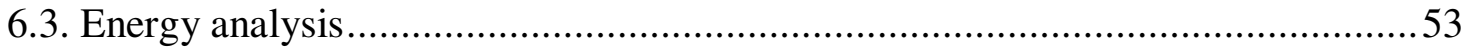

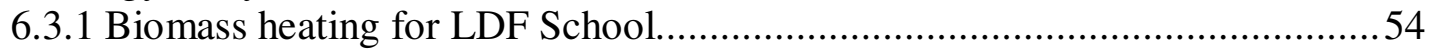

6.3.2 Biomass heating for natural resources facility ……...................................56

6.3.3 Biomass heating for the community center.....................................................57

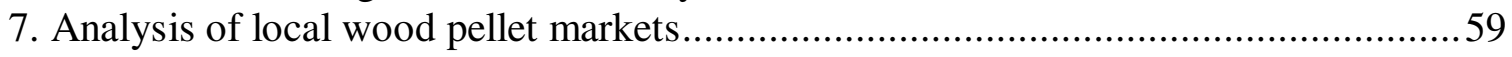

7.1. Pellet production in the United States and Wisconsin........................................59

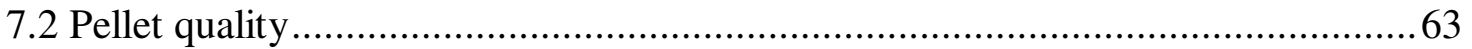

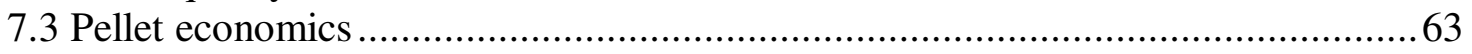

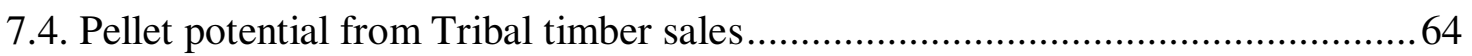

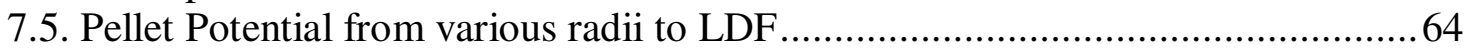

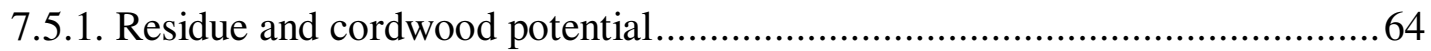

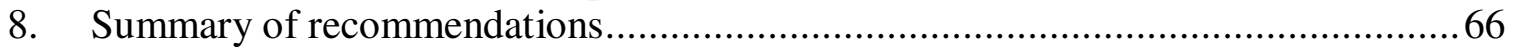

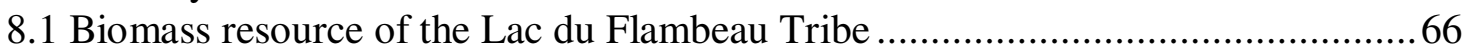

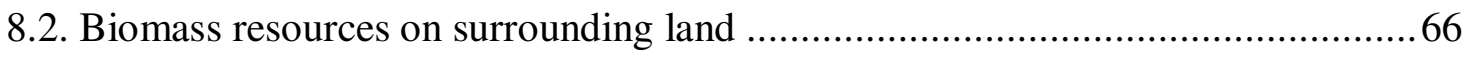

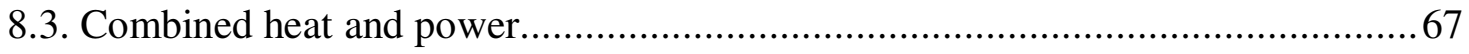

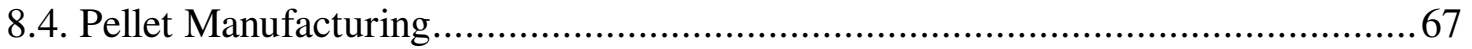

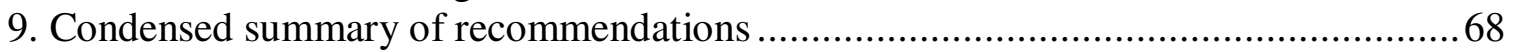

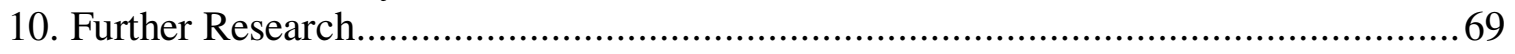

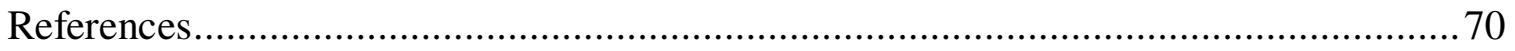




\section{List of Tables}

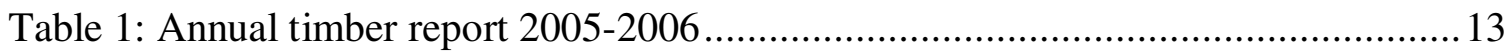

Table 2: Annual timber report 2006-2007 .................................................................. 14

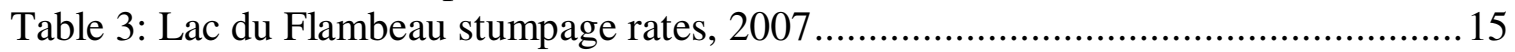

Table 4: Timber cut under contract from 2006-2007 annual report.................................15

Table 5: Cordwood and sawlog stumpage prices for surrounding areas..........................16

Table 6: Energy content and quantity of fuelwoods for 2006-2007 ……....................... 18

Table 7: Energy value of sawlog-cordwood for current use and LP offset......................20

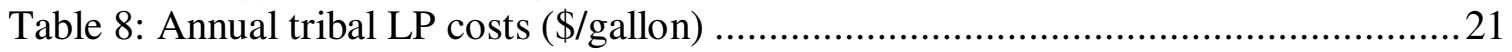

Table 9: Biomass offset savings under various scenarios ..........................................22

Table 10: Whole tree residue removal cost[from 2005 Don Peterson study]...................26

Table 11: Cost per delivered MMBtu of wood chips and cord wood ..............................2

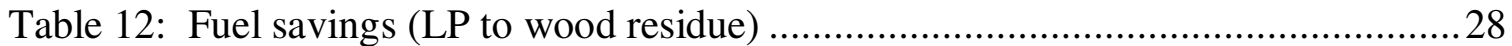

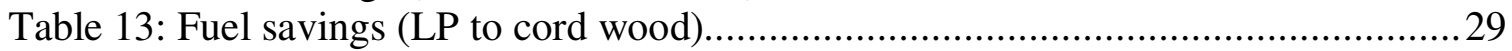

Table 14: Timberland ownership around Lac du Flambeau, WI ........................................32

Table 15: Area of timberland at various distances from Lac du Flambeau........................34

Table 16: Total mill residue with in 75 miles of Lac du Flambeau ..................................35

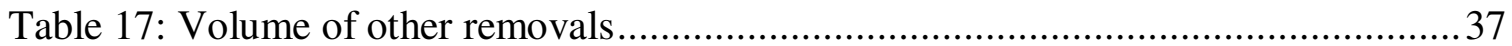

Table 18: Available Volume of Logging Residue within 75 miles of LDF ......................39

Table 19: Volume of logging residue by county (estimates).........................................41

Table 20: Volume of roundwood at various distances from LDF .................................41

Table 21: County and state harvest totals around LDF [Wisc. DNR: fiscal year 2008] .. 44

Table 22: Harvest and energy totals on LDF lands 2006-2007 ...................................52

Table 23: Top 10 Tribal LP consumers in 2007 .....................................................53

Table 24: Energy savings with pellet burner for LDF School........................................55

Table 25: Energy savings with wood chip burner for LDF School ................................56

Table 26: Energy savings with pellet burner for natural resources facility ......................57

Table 27: Energy Savings with biomass boiler for community center ............................58

Table 29: Pellet mills established and in the permitting stage for Wisconsin .................59

Table 29: Residue + cordwood totals in pellet equivalents for various radii from LDF.. 65 


\section{List of Figures}

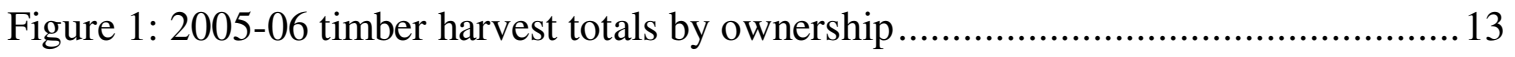

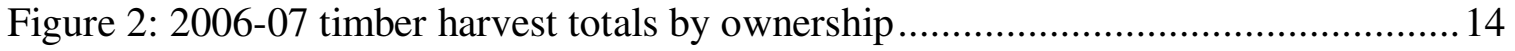

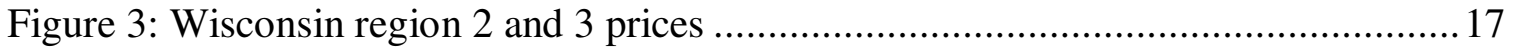

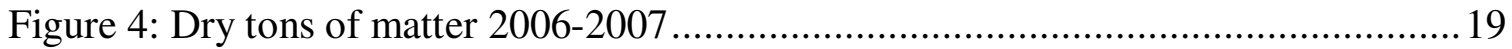

Figure 6: Historical LP cost with forecasted cost $(\$ 2.20$ gal. as the current rate) ............22

Figure 7: Historical LP cost with forecasted cost ( $\$ 1.75$ gal. as the current rate) ............22

Figure 8: Biomass forecasted savings under various scenarios ............................... 24

Figure 9: Historical stumpage values of cord wood for tax purposes [zone 7] ...............25

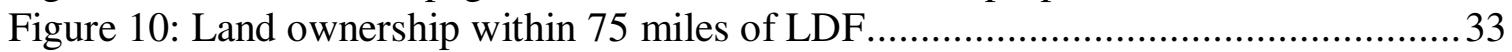

Figure 11: timberland acres within 75 miles of LDF ............................................ 34

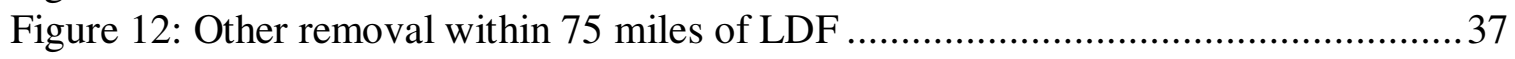

Figure 13: Residue totals within 75 miles of LDF ................................................ 40

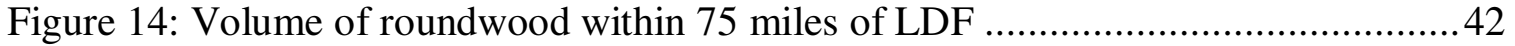

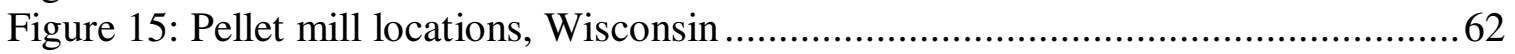




\section{Abstract}

Biomass resources are abundant in and around the Lac du Flambeau tribal area. Biomass has the potential to be an economical, sustainable alternative to the current petroleum fuels utilized for heating purposes by the Lac du Flambeau Tribe. Timber harvest resource quantity, value, and potential are unknown for tribal lands and surrounding areas. Of particular interest is the use of residues and cordwood for non-traditional purposes. To answer such questions, timber harvest totals for the tribal land were obtained through actual data obtained from the Bureau of Indian Affairs. Recorded biomass volumes for surrounding areas were obtained from the United States Forest Service and the Wisconsin Department of Natural Resources. Economic data was retrieved from Timber Mart North, the Wisconsin DNR, and the BIA. Results show that 11,929 dry tons of residue, cordwood, and sawtimber were available from the 2006-2007 harvest on Tribal land. Residue and cordwood volumes within a 25 mile radius of Lac du Flambeau total 79,270 and 307,021 dry-tons, respectively. Sawlog, cordwood, and residue prices are $\$ 9.60, \$ 4.18$, and $\$ 3.84$ per MMBtu delivered, respectively. LP prices are $\$ 19.02$ per MMBtu delivered. Biomass has the potential of saving the tribe over $\$ 600,000$ annually in heating fuel costs. Enough residues are available on tribal lands to offset casino and school heating loads. Furthermore, there are resources within a 25 mile radius of Lac du Flambeau to economically operate a large scale pellet mill facility. Biomass is a viable, cost competitive and abundant resource that should be utilized in a non-traditional manner by the Lac du Flambeau Indian Tribe. 


\section{Summary of recommendations actions}

1. Develop a timber harvest species and residue inventory. This will help determine current and future residue volumes available from harvest practices. A more thorough resource inventory will assist in redeveloping any new forestry expansion plans.

2. Reevaluate the priority, responsibility, and funding of Tribal forest practice. The potential to expand timber harvest practices exists within tribal land. However, additional staff, support, and resources must be allocated to fully expand operations and utilize these valued resources to their fullest potential.

3. Conduct a detailed feasibility study for a biomass boiler in the Lac du Flambeau school and community center. Preliminary numbers from both locations indicate that a biomass combustion system would result in a quick payback. Also, analyze the potential for a pellet heating system at the new natural resource facility.

4. Conduct a case study of chipping cordwood for thermal purposes. This will require weighing cordwood mass and comparing the value to cordwood prices. This should than be compared with residue and LP prices for an economic comparison.

5. Research residue prices in regard to local stumpage value and consider establishing a value price structure. Talk with local timber agents about residue removal, chipping, and transport cost for use at tribal facilities.

6. Continue to further analyze the Wisconsin wood pellet market and the potential use of residue and cordwood for pellet production on Tribal lands. Talk with current and future pellet plants within 75 miles of Lac du Flambeau about supplying residues for production. Conduct a more detailed feasibility study to determine pellet mill potentials in Lac du Flambeau. 


\section{Lac du Flambeau biomass resource assessment}

\subsection{Tribal forest overview in brief}

The Lac du Flambeau tribe's 108 square miles of land encompass an abundant biomass resource. The tribal region is comprised of many different forest covers. Some of the primary stands include aspen, red pine, white pine, jack pine, birch, and oak; with aspen and birch being the two most prevalent species. Many other northern hardwoods and sub-associates exist on the tribal lands as well. Sound silviculture practices have given way to healthy tree stands and forests in the tribal region.

Efforts are underway to convert the next generation of tree stands back to the native, longer lived tree species versus short rotational species such as aspen. The preferred vision of the future forest would include a higher percentage of white pine, red pine, and red oak. . Native tree species provide such benefits as a higher resilience to insects and disease attacks, a lowered susceptibility to stress induced by non-native species, the ability to provide superior habitat for native animal and plant species, and a higher adaptability to the regional climate and conditions. In addition, pines are also more resilient to fire.

\subsection{Wisconsin biomass overview in brief}

Biomass is an attractive renewable energy source for most of Northern Wisconsin and particularly for the Lac du Flambeau tribe. Wisconsin is comprised of 34.4 million acres, of which, 16 million acres are forested. Sixty-eight percent of the forested land is privately owned, where 20 percent of it is part of the Wisconsin Managed Forest Law (MFL).

Wisconsin is home to the Chequamegon-Nicolet National Forest, the only national forest in Wisconsin. In addition, Wisconsin is also home to twenty-nine county forests. Currently, Wisconsin's renewable energy use is dominated by biomass with most of the resource being used for wood burning for space and process heat, primarily in homes and industry. This is mostly attributed by the historical use induced by the cold climate along with wood being readily availability. Wood accounts for 47 percent of the renewable energy used in Wisconsin (Wisconsin DOA, 2007). In many instances, local trees are being harvested for pulp wood and saw timber. In many areas of Northern Wisconsin infrastructures are already developed for the biomass commodity. 


\subsection{Harvested Tree Components}

Biomass is defined as organic matter of recent biological origin. The vast majority of biomass consists of forests, crops, prairies, marshes, and fisheries. The chemical energy in biomass materials can be used as a resource for heat and stationary power, transportation fuels, commodity chemicals, and fibers (Brown, 2003). For this study the focus will be on biomass' use for thermal energy with a quick examination of combined heat and power.

\subsubsection{Sawlog}

A sawlog or saw timber is a log meeting minimum standards of diameter, length, and defect. This includes logs that are at least eight feet long, sound and straight, and have a minimum diameter inside bark of six inches for softwoods and eight inches for hardwoods, or meeting other combinations of size and defect specified by regional standards. LDF standards typically are 10 inches of diameter inside bark (DIB) at the small end. Sawlogs possess the highest value of all the timber harvested and are harvested and used in specific established markets. Unmerchantable sawlogs are produced from a harvest if issues such as rot, defect, or excessive curves render it unsawable. Sawlogs cut within the Lac du Flambeau area are taken to nearby saw mills and processed within the primary wood users industry. Once received at the saw mill, sawlogs will be debarked and trimmed to the desired size. The residues left over from this process can be sold to the paper industry as pulp wood or used to make lower end products such as pallets.

\subsubsection{Sawbolt}

Sawbolt, sometimes referred to as small wood, has the second highest value of harvestable timber. Sawbolt which is found between saw timber and cord wood, is in many cases the timber which is not long enough to be sawlogs but carries a higher value then traditional cord wood. In cases such as the US Forest Service, sawbolt is considered cordwood as many end users do not differentiate between sawbolt and cordwood. The diameter of this timber is generally between eight to ten inches. Sawbolt can be used to make plywood and is generally not handled by saw mills that deal with sawlogs. The value of sawbolt can be 1.25 to 1.33 times that of traditional cord wood. ${ }^{1}$

\footnotetext{
${ }^{1}$ Personal Communication, Scott McDougalll, Lac du Flambeau Tribe, June 13, 2008.
} 


\subsubsection{Cordwood}

Cordwood or pulpwood is wood which lacks the diameter or quality characteristics of sawlogs or boltwood. It is typically the upper portion of the tree which can be cut down into five inch diameters at eight foot lengths. In some cases, wood that is cut down to two inches diameter in eight foot lengths can be considered cordwood. ${ }^{1} \quad$ In Northern Wisconsin, cordwood is most notably used for residential space heat and used within the pulp and paper industry. Due

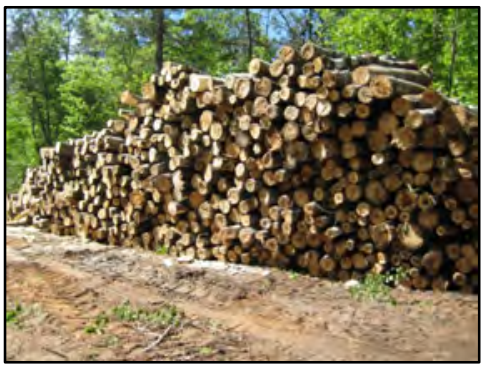

Picture 1: cordwood to cordwood's volume and over-estimated cost per MMBtu, it is one the best options for thermal heating at tribal facilities and will be discussed in more detail in further sections.

\subsubsection{Logging Residue}

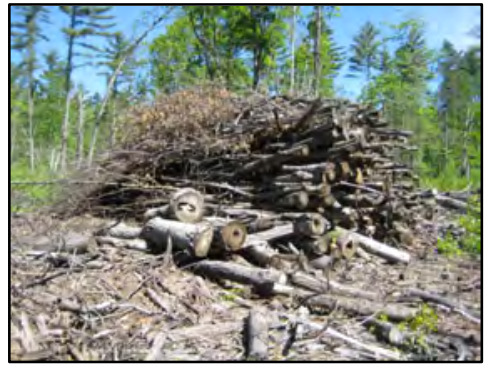

Picture 2: harvest residue

Logging residues are the tops and branches of the tree not used for traditional forest products. This generally includes the unused portion of the tree, trimmings-cut or tree portions that break during harvesting. Stumps, tops, limbs, cull sections of central stem, saplings, rough, and rotten trees can all be considered logging residue. ${ }^{2}$ Logging residues can also include unmerchantable whole trees or trees which are either too small or do not meet mill standards (Peterson, 2005). In many cases tree tops and branches are cut off at the site of harvest and are left in the woods as forest litter, thus having no immediate monetary value. Logging residue left in the forest provides nutrients to soil, and homes for birds and small game. Soil tests on tribal lands show high levels of phosphorus and potassium meaning removal of tops and branches beyond recommended thresholds may be an environmental and economical option.

\subsection{Harvesting}

\subsubsection{Assessing Resource Potential}

Timber value can be highly variable and can fluctuate significantly from year to year. Many factors including timber species, size, logging method, market price, market characteristics, and distance to market affect the overall value of timber (Niccolucci, Meneghin, McKinnon, n.d.). But before such factors are considered a forester must assess the tree volume and density on a given site. When a site has been picked for harvest, the forester will cruise the tree stand to determine the species of trees present, timber density, timber grade, and basal area of the stand (University of Florida, 2006). From this information the amount of timber and its value can be determined.

\footnotetext{
${ }^{2}$ Taken from the published definition by the US Forest Service.
} 


\subsubsection{Assessing Resource Value}

The Lac du Flambeau Tribe uses the Timber Sale Handbook for determining cordwood, sawbolt, and sawlog value. This handbook categorizes felling and bucking, skidding, road construction, hauling, marketability, and quality. These factors are labeled with a standing between poor to excellent with weighted averages for each. Using this rubric allows foresters to determine the stands multiplying factor. For example, the highest quality stand with the greatest ease of entry will receive a high factor. The quality of the tree stand is adjusted for the quantity and quality of sawbolts on-site and will affect the overall tree standing multiplier. The multiplying factor determined from the Timber Sale Handbook is weighed against the most current base stumpage rates for each tree species. ${ }^{3}$

Determining value of the timber resource can be difficult. The unique wood properties and characteristics of various tree species govern their suitability for specific uses. Size, structure, strength, appearance and workability can affect overall value. For example, red oak sawlogs command a higher price than weaker, plainer, less workable basswood. Red pine and jack pine, with their longer fibers, command a higher price for pulpwood than shorter fiber aspen.

Logging residues in Wisconsin are considered nonmerchantable. This means that a defined market for residue has not been developed in Wisconsin, thus in most cases loggers are not required to pay stumpage fees for the residue that is retrieved. As residue markets continue to develop in Wisconsin, loggers will be inclined to remove such residues. If residues become

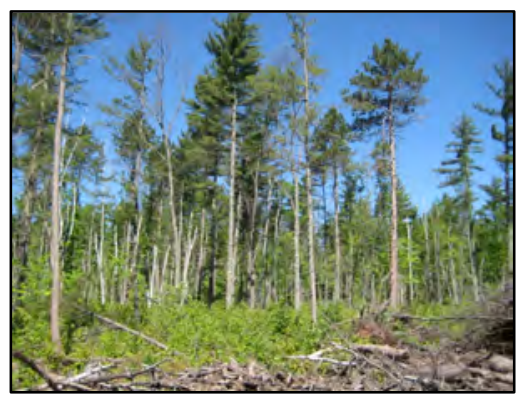

Picture 3 : harvested timber site "merchantable", then residue value will have to exceed stumpage fees. Currently, residue values do not exceed stumpage fees because of their lower quality, thus contracts for residue are site and customer specific. For example, if Midwest Timber company bid a tribal timber project where the stumpage rate for residue was $\$ 20 /$ ton and the cost of removal was $\$ 15 /$ ton, the market price for residue must than be over $\$ 35 /$ ton to generate a profit. In the case of Midwest Timber, the residue was being sold at $\$ 17.50 /$ ton and the initial stumpage rate was $\$ 0.50 /$ ton. The extremely low stumpage rate made residue collection profitable in this situation.

\subsubsection{Bidding}

The U.S. Department of Interior Bureau of Indian Affairs will bid out the forest resources for a specific harvest site. Within the bid, the tribe will specify how and where they want the forest road built. The bid will determine the forest management practice during the harvest, as well as describe the desired outcome of the harvest. Most contracts for the Lac du Flambeau tribe are two years in length. Bids from the BIA itemize the species and products of timber on the stand. A quantity will be determined for each of the itemized products and a bid price then accompanies each of these itemized products. The

\footnotetext{
${ }^{3}$ Personal Communication, Scott McDougall, Lac du Flambeau Tribe, June 13, 2008.
} 
minimum bid prices for each stand are tallied to determine a baseline value. The bid further describes a cord weight for each of the itemized products and includes a map of the area to be logged.

Forest products can be sold by estimated volume, as described earlier, or else they can be sold as a lump sum sale. Lump sum sales are used when the forest products have been previously measured to very accurate standards. Forest products can also be a scaled sale. In a scaled sale, the buyer submits a bid based on a unit of volume by species, product, and sometimes grade. In this scenario, the harvested products are paid for as they are removed by unit volume. This has been the methodology chosen for the residue that is removed from tribal land. All other pulpwood, sawlogs, and sawbolt are sold based on volume and stumpage value per unit volume.

\subsubsection{Harvest Practice}

The two most common harvesting practices in Wisconsin are whole tree removal and cut-to-length harvesting. Whole tree removal is the most economical way to remove logging residue and involves removal of the

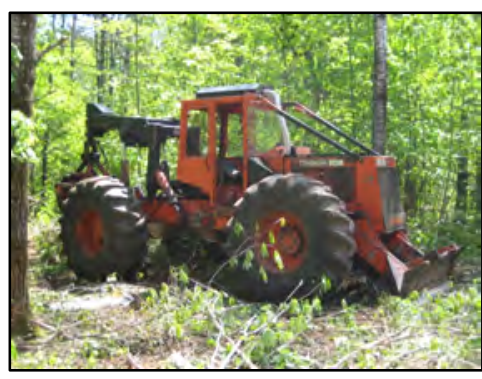

Picture 5: Forwarder entire tree to the landing for processing and loading. Midwest Timber used this practice when they bought

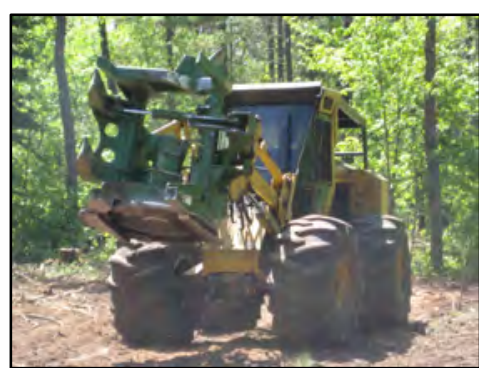

Picture 4: Feller-buncher and removed residue from tribal lands. In most cases of whole tree removal, trees designated for harvest are felled with a feller-buncher. The cut trees are positioned in a

bunch easily accessed by a skidder. The skidder then "skids" the bunch of trees to the landing. Traditionally, limbing of the cut trees is done at this stage or on the way to the landing. Felling and bucking costs are affected by volume per acre, average diameter, number of pulp sticks or logs per tree, thinning versus clearcut, limbiness, and slash control needs (Wisconsin, 2003). The product is then skid. Skidding of the product involves moving the cut products, limbs and tops from the stump to the landing or roadside for hauling. At the landing the tree will be cut to the appropriate lengths and sorted by end use category. Logging residue that is removed from the harvest site and centralized at the landing, can than be chipped and transported for further use. This type of harvest offers advantages to traditional harvest practice in that less damage is done to the harvested logs that are being removed. During removal, maintaining the tree branches and limbs helps cushion the impact on smaller standing trees from the skidding process. In addition, this practice aggregates the forest residue in a central location at the landing where it can be chipped and transported to its end use. Issues with whole tree harvesting include dirt build-up on tops and limbs as well as limited potential during tree thinning practices.

The second harvesting option is cut-to-length harvesting. In this practice, trees are delimbed at the site of the cut and residue is hauled out separately by the forwarder. This 
practice requires additional trips to be made with the forwarder or skidder thus lowering the economic benefit of such practice. Also, forwarders are then underutilized as tops only use roughly 20 to 25 percent of the machines weight capacity. However, most forwarders have open bunks which do not facilitate the transportation of small diameter products as these tend to fall out. In Europe, forwarders with special bunkers have been developed for this type of removal practice, however; this requires a specialized and dedicated forwarder to residue removal, thus lowering its economic potential.

\subsection{Tribal biomass quantity}

The Bureau of Indian Affairs develops an annual report for the Lac du Flambeau tribe which inventories the Tribe's total cut and contracted timber. The annual report determines the volume and value of timber harvested on tribal, allotted, and government owned lands. Tribal lands include lands where the tribal council determines the outcome of the land. Allotted land is parceled land owned by specific individuals and is considered private land. Table 1 shows the annual report from October 1, 2005 through September 30, 2006.

Table 2 shows the annual report from October 1, 2006 through September 30, 2007.

There is no government owned lands within the reservation where timber is harvested.

Table 1: Annual timber report 2005-2006

\begin{tabular}{|r|c|c|r|r|r|r|}
\hline & \multicolumn{2}{|c|}{ Total } & \multicolumn{2}{c|}{ Tribal } & \multicolumn{2}{c|}{ Allotted } \\
\hline & $\begin{array}{c}\text { Volume } \\
\text { MBF }\end{array}$ & $\begin{array}{c}\text { Value } \\
(\$)\end{array}$ & $\begin{array}{c}\text { Volume } \\
\text { MBF }\end{array}$ & $\begin{array}{c}\text { Value } \\
(\$)\end{array}$ & $\begin{array}{c}\text { Volume } \\
\text { MBF }\end{array}$ & $\begin{array}{c}\text { Value } \\
(\$)\end{array}$ \\
\hline $\begin{array}{r}\text { Total Indian } \\
\text { harvested }\end{array}$ & 1679 & 138,481 & 585 & 37,609 & 1093 & 100,872 \\
\hline $\begin{array}{r}\text { Total Non-Indian } \\
\text { harvested }\end{array}$ & 3277 & 239,167 & 55 & 1816 & 2979 & 223,196 \\
\hline Total & $\mathbf{4 9 5 5}$ & $\mathbf{3 7 7 , 6 4 7}$ & $\mathbf{6 4 1}$ & $\mathbf{3 9 , 4 2 6}$ & $\mathbf{4 0 7 2}$ & $\mathbf{3 2 4 , 0 6 8}$ \\
\hline
\end{tabular}

2005-2006 timber harvest totals by land

ownership (MBF)

641

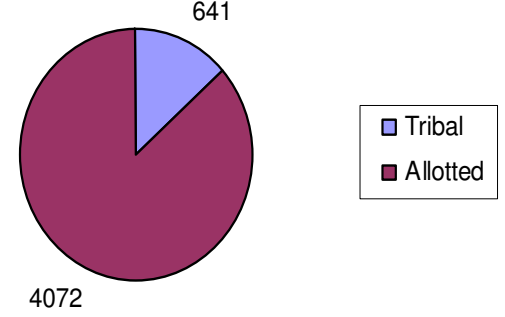

Figure 1: 2005-06 timber harvest totals by ownership 
Table 2: Annual timber report 2006-2007

\begin{tabular}{|r|r|r|r|r|r|r|}
\hline & \multicolumn{2}{|c|}{ Total } & \multicolumn{2}{c|}{ Tribal } & \multicolumn{2}{c|}{ Allotted } \\
\hline & $\begin{array}{c}\text { Volume } \\
\text { MBF }\end{array}$ & Value (\$) & $\begin{array}{c}\text { Volume } \\
\text { MBF }\end{array}$ & Value (\$) & $\begin{array}{c}\text { Volume } \\
\text { MBF }\end{array}$ & Value (\$) \\
\hline $\begin{array}{r}\text { Total Indian } \\
\text { harvested }\end{array}$ & 309 & 22,497 & 168 & 12,279 & 141 & 10,218 \\
\hline $\begin{array}{r}\text { Total Non-Indian } \\
\text { harvested }\end{array}$ & 6845 & 628,994 & 107 & 8578 & 6738 & 620,416 \\
\hline Total & $\mathbf{7 1 5 4}$ & $\mathbf{6 5 1 , 4 9 1}$ & $\mathbf{2 7 5}$ & $\mathbf{2 0 , 8 5 7}$ & $\mathbf{6 8 7 9}$ & $\mathbf{6 3 0 , 6 3 4}$ \\
\hline
\end{tabular}

2006-2007 timber harvest totals by land ownership (MBF)

275

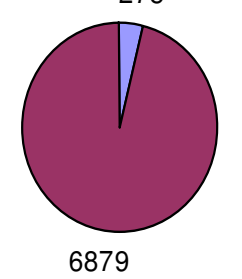

Figure 2: 2006-07 timber harvest totals by ownership

\subsection{Biomass Value}

\subsubsection{LDF stumpage values}

Table 3 shows the 2007 sawlog and cordwood base prices used by the tribe. Base price stumpage rates for sawlogs range from $\$ 70$ to $\$ 150$ per thousand board feet (MBF), with the exception being cedar at $\$ 35$ per $\mathrm{MBF}$ and hemlock being $\$ 40$ per MBF. Cordwood base prices range from $\$ 5$ to $\$ 33$ per cord. Base rates are used as a starting point for timber appraisal purposes and allow for a 15 percent leeway in bidding, profit, and risk for the loggers. All appraisal factors averaged for the reservation would result in the base rates as listed in Table 3. Table 3 can be used as a platform for land owners to determine the relative timber value on their property before accepting harvest bids.

As mentioned earlier, cordwood, sawbolt, and sawlog rates are variable based upon many different factors. Each specific harvest site will yield different stumpage rates for timber. For the economic analysis, the average rates above will be used. 
Table 3: Lac du Flambeau stumpage rates, 2007

\begin{tabular}{|r|r|r|}
\hline Species & $\begin{array}{c}\text { Cordwood } \\
\text { base price } \\
\text { (\$/cord) }\end{array}$ & $\begin{array}{c}\text { Sawlog base } \\
\text { price } \\
\text { (\$/MBF) }\end{array}$ \\
\hline Aspen & $\$ 25.00$ & $\$ 70.00$ \\
\hline Balsam-fir & $\$ 12.00$ & $\$ 50.00$ \\
\hline Basswood & $\$ 5.00$ & $\$ 90.00$ \\
\hline Birch White & $\$ 22.00$ & $\$ 110.00$ \\
\hline Birch Yellow & $\$ 20.00$ & $\$ 120.00$ \\
\hline Hedar & $\$ 6.00$ & $\$ 35.00$ \\
\hline Red Maple & $\$ 11.00$ & $\$ 40.00$ \\
\hline Sugar Maple & $\$ 20.00$ & $\$ 100.00$ \\
\hline Mixed Hardwood & $\$ 20.00$ & $\$ 125.00$ \\
\hline Red Oak & $\$ 12.50$ & $\$ 100.00$ \\
\hline Jack Pine & $\$ 33.00$ & $\$ 150.00$ \\
\hline Red Pine & $\$ 25.00$ & $\$ 110.00$ \\
\hline White Pine & $\$ 22.00$ & $\$ 110.00$ \\
\hline Spruce & $\$ 16.00$ & $\$ 70.00$ \\
\hline Tamarack & $\$ 12.00$ & $\$ 70.00$ \\
\hline
\end{tabular}

\subsubsection{LDF report values}

Timber costs are very dynamic and can differ substantially throughout the state. Timber prices are based upon many factors specific to the harvest site as well as external market dynamics. When examining the use of timber and residues for thermal heat, it is important to recognize the variance between individual tree species. Table 4 shows the timber cut by species for the Lac du Flambeau tribe for the 2006-2007 report. It is assumed that two cords of wood equals $1 \mathrm{MBF}$.

Table 4: Timber cut under contract from 2006-2007 annual report

\begin{tabular}{|c|c|c|c|c|c|c|}
\hline & \multicolumn{2}{|c|}{ Totals } & \multicolumn{2}{|c|}{ Sawlogs } & \multicolumn{2}{|c|}{$\begin{array}{c}\text { Other Products } \\
\text { (cordwood/sawbolt) }\end{array}$} \\
\hline & $\begin{array}{l}\text { Volume } \\
\text { MBF }\end{array}$ & $\$ / M B F$ & $\begin{array}{l}\text { Volume } \\
\text { MBF }\end{array}$ & $\$ / M B F$ & $\frac{\text { Volume }}{\text { Cords }}$ & Ave/Cord \\
\hline Softwoods & 23 & $\$ 31.21$ & 0 & $\$ 0.00$ & 45 & $\$ 15.61$ \\
\hline Hardwoods & 2621 & $\$ 85.39$ & 3 & $\$ 73.58$ & 5237 & $\$ 42.70$ \\
\hline Mix Hard-softwoods & 35 & $\$ 2.30$ & 0 & $\$ 0.00$ & 70 & $\$ 1.15$ \\
\hline Balsam Fir & 111 & $\$ 52.62$ & 0 & $\$ 0.00$ & 222 & $\$ 26.31$ \\
\hline Spruce & 110 & $\$ 76.05$ & 0 & $\$ 0.00$ & 221 & $\$ 38.03$ \\
\hline Jack Pine & 12 & $\$ 70.10$ & 0 & $\$ 0.00$ & 25 & $\$ 35.05$ \\
\hline Red Pine & 84 & $\$ 111.24$ & 48 & $\$ 142.46$ & 71 & $\$ 34.54$ \\
\hline White Pine & 123 & $\$ 120.80$ & 91 & $\$ 143.37$ & 64 & $\$ 28.71$ \\
\hline Hemlock & 193 & $\$ 32.91$ & 0 & $\$ 0.00$ & 386 & $\$ 16.46$ \\
\hline Red Maple & 2 & $\$ 150.00$ & 2 & $\$ 150.00$ & 0 & $\$ 0.00$ \\
\hline Sugar Maple & 11 & $\$ 200.07$ & 11 & $\$ 200.07$ & 0 & $\$ 0.00$ \\
\hline Tallow Birch & 20 & $\$ 185.00$ & 20 & $\$ 185.00$ & 0 & $\$ 0.00$ \\
\hline Paper Birch & 35 & $\$ 111.01$ & 35 & $\$ 111.01$ & 0 & $\$ 0.00$ \\
\hline Aspen & 3745 & $\$ 96.96$ & 0 & $\$ 0.00$ & 7489 & $\$ 48.48$ \\
\hline Red Oak & 30 & $\$ 53.14$ & 5 & $\$ 222.24$ & 50 & $\$ 10.00$ \\
\hline
\end{tabular}




\begin{tabular}{|r|r|r|r|r|r|r|}
\hline Totals \& ave. value & 7154 & $\$ 90.14$ & 214 & $\$ 145.42$ & 13880 & $\$ 44.22$ \\
\hline
\end{tabular}

Table 4 shows the various prices for sawlogs and other products. Other products include both cordwood and sawbolt. It is estimated that about $33 \%$ of the other product is sawbolt while the remainding is cordwood. A variation between $\$ 73$ and $\$ 222$ is noticed for sawlogs, while other products range between $\$ 2$ and $\$ 96$ depending on the species.

Hardwoods, such as aspen, are harvested as cordwood while white pine is harvested for both sawlogs and cordwood. This helps explain the differences in value between species.

Behind residues, cordwood is the next option of biomass to use for thermal heat. As seen below, different species will result in various volumes of cordwood. These variances will affect annual cordwood yields and make it more difficult to maintain steady cordwood volumes.

The average stumpage rate for the 2005-2006 year was $\$ 76.21$ while the average stumpage rate for 2006-2007 was \$90.14. This change does not reflect a higher overall stumpage value. As mentioned earlier, harvested tree species will affect this total. More aspen was harvested in 2006-2007, than in previous harvesting seasons.

\subsubsection{Timber Mart values}

Below is a breakdown of stumpage rates for forestry districts in Northern Wisconsin. Table 5 shows the stumpage prices for cordwood and sawlogs in Wisconsin Region 2 and 3 based upon data provided from the Timber Mart North Price Report. ${ }^{4}$ Prices are a result of surveys completed by timber buyers, sellers, and their agents. Lac du Flambeau is located in region 2 (Northeast Wisconsin), while region 3 encompasses Northwest Wisconsin. Prices in Table 5 represent timber delivered prices.

Table 5: Cordwood and sawlog stumpage prices for surrounding areas

\begin{tabular}{|c|c|c|}
\hline Cordwood & wlog stumpage ra & 007-2008] \\
\hline Cordwood (\$/cord) & & \\
\hline & Wisconsin Zone 2 & Wisconsin Zone 3 \\
\hline Aspen & $\$ 24.00$ & $\$ 24.00$ \\
\hline Yellow Birch & $\$ 106.00$ & $\$ 106.00$ \\
\hline White Pine & $\$ 90.00$ & $\$ 98.00$ \\
\hline Ave. & $\$ 73.33$ & $\$ 76.00$ \\
\hline Sawlogs (\$/MBF) & & \\
\hline & Wisconsin Zone 2 & Wisconsin Zone 3 \\
\hline Aspen & $\$ 70.00$ & $\$ 70.00$ \\
\hline Yellow Birch & $\$ 189.00$ & $\$ 189.00$ \\
\hline White Pine & $\$ 121.00$ & $\$ 125.00$ \\
\hline Ave. & $\$ 126.67$ & $\$ 128.00$ \\
\hline
\end{tabular}

\footnotetext{
${ }^{4}$ Prices taken from Timber Mart North Price Report, Wisconsin Edition. Vol. 14, \#1. 2007.
} 

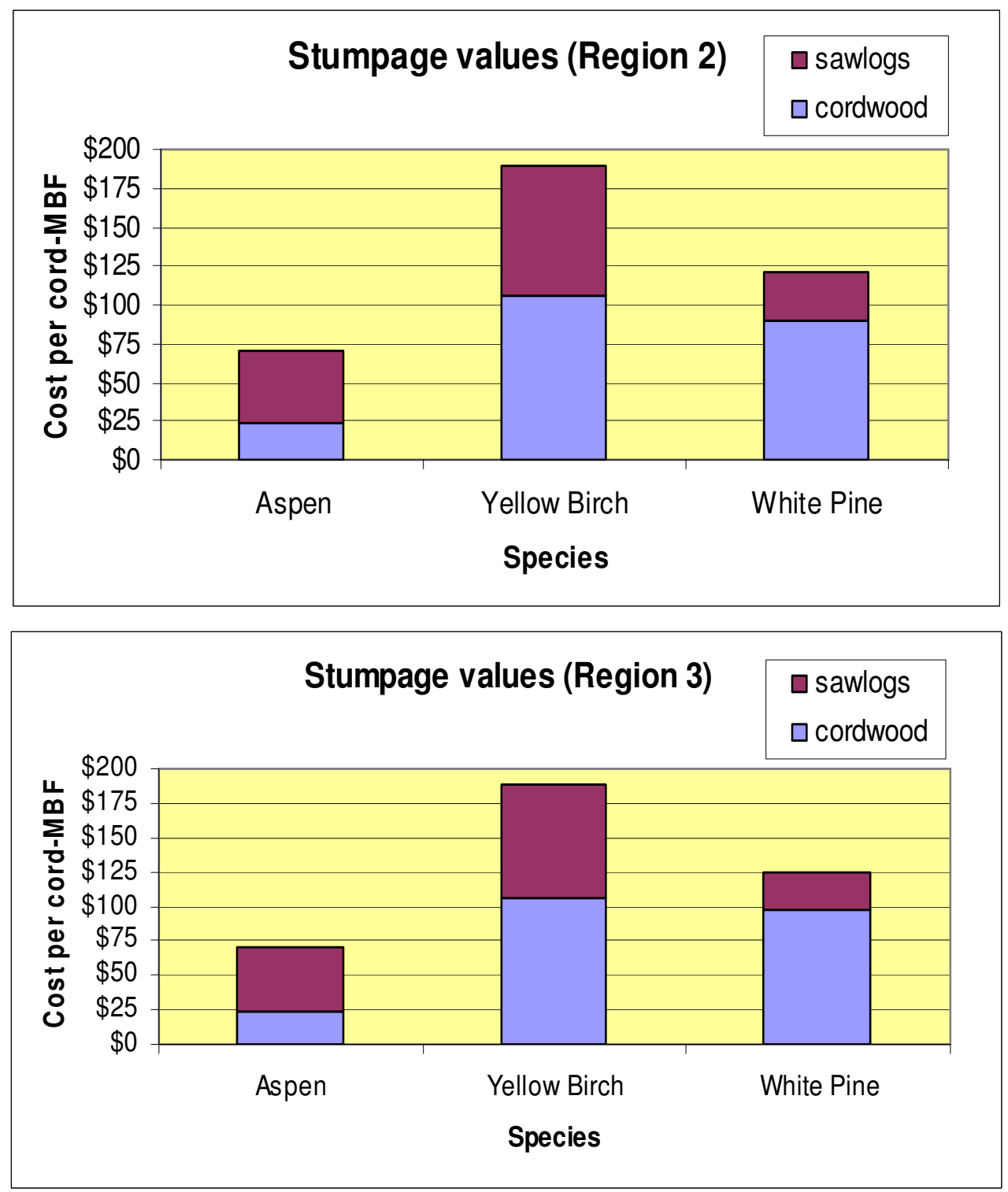

Figure 3: Wisconsin region 2 and 3 prices

The prices for sawlogs are nearly double that of cordwood in the same regions. However, as shown earlier, the mass of dry biomass product is not the same between a cord of wood and one-thousand board feet. Prices between zones appear to be similar with only minor variations in cordwood price. Yellow birch and white pine cordwood prices are substantially higher than the other species because sawbolt prices were used to determine their cordwood value.

\subsection{Energy and production volume analysis}

Two factors which dictate the end use of sawlogs, cord wood, and residues are 1) economic value of the feedstock compared to traditional fuels and 2) willingness to 
diversify the tribe's energy portfolio. Because economic value is the only quantifiable entity it will be discussed in depth while energy diversification, a more subjective matter, will be mentioned in brief later.

For this study it was assumed that harvested green wood has a moisture content of 50 percent. A higher heating value (HHV) of 8,600 BTU per pound for all wood species was used (Bioenergy Feedstock Information Network, n.d.). Estimates are used as it is difficult to determine exact energy contents of timber. Softwoods will generally have a higher energy content per pound than hardwoods but have a lower volumetric energy density. Timber species, needle/leaf content, and bark content all affect the overall residue energy values. Bark has a higher energy content, however, it contains more pollutants and results in higher ash contents when burned. Due to these variances, a general assumption was made for all residues and timber removed.

Total MMBtu was calculated by using a factor of 34.5 pounds of dry matter per cubic foot of timber. This is a weighted average of aspen, yellow birch, white and jack pine. For the calculations in Table 6, the 2007 tribal harvest annual report was used to determine amounts of cordwood and sawlogs. Data from the forest harvest inventory show that 3 percent of the harvest was sawlogs while 97 percent was cordwood. Residual totals in Table 6 were calculated by assuming that residue totaled 16 percent of total volume removed (Smith et.al., 2004). It is assumed that 90 percent of the total residue available is recoverable under whole tree harvest practice. This value will be closer to 60 percent under more traditional harvesting practices (Stokes, 1992). For the analysis report below we will examine the residue as if it were removed as merchantable timber. Table 6 displays the energy values and harvest totals as green tons for various removals.

Table 6: Energy content and quantity of fuelwoods for 2006-2007

\begin{tabular}{|l|c|c|c|c|c|c|}
\hline & \multicolumn{2}{|c|}{$\begin{array}{c}\text { Total from Indian } \\
\text { land }\end{array}$} & \multicolumn{2}{c|}{$\begin{array}{c}\text { Total from non- } \\
\text { Indian land }\end{array}$} & \multicolumn{2}{c|}{ Totals } \\
\hline & $\begin{array}{c}\text { dry tons } \\
\text { available }\end{array}$ & $\begin{array}{c}\text { MMBtu } \\
\text { (available) }\end{array}$ & $\begin{array}{c}\text { dry tons } \\
\text { available }\end{array}$ & $\begin{array}{c}\text { MMBtu } \\
\text { (available) }\end{array}$ & $\begin{array}{c}\text { dry tons } \\
\text { available }\end{array}$ & $\begin{array}{c}\text { MMBtu } \\
\text { (available) }\end{array}$ \\
\hline Residuals & 71 & 1,110 & 1,583 & 24,500 & 1,655 & 25,610 \\
\hline Cordwood & 433 & 7,450 & 9,600 & 165,100 & 10,033 & 172,550 \\
\hline sawlog & 13 & 231 & 297 & 5,100 & 310 & 5,331 \\
\hline Total & 518 & 8,791 & 11,480 & 194,700 & 11,998 & 203,491 \\
\hline
\end{tabular}




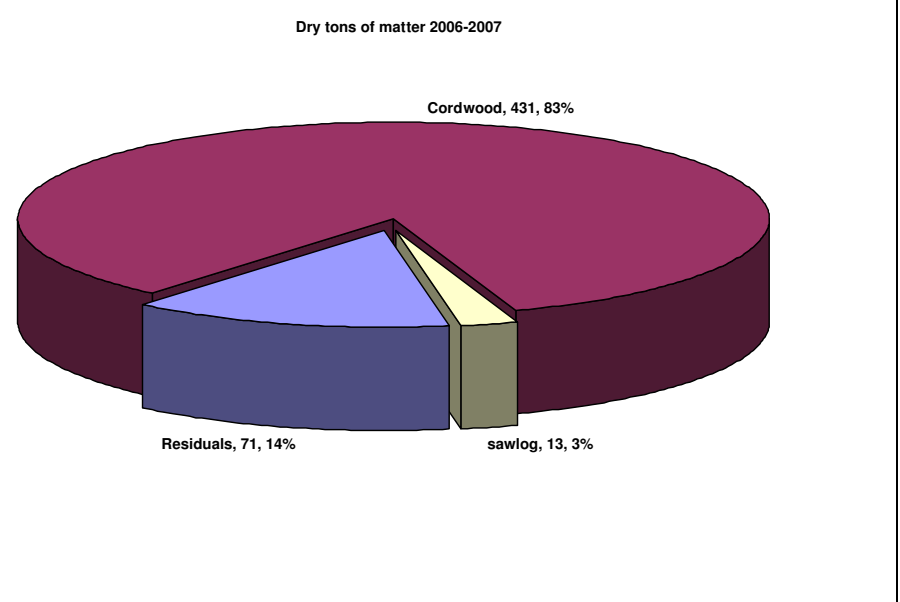

Figure 4: Dry tons of matter 2006-2007

Table 6 shows a total available energy content of 25,610 MMBtu available from residue alone. However, the majority of available biomass is in the form of cordwood. In 20062007, 52 percent of the harvested timber was cut from aspen which is predominantly a cordwood species. The above values are subject to change if more birch and pines are harvested in successive years as these species yield more sawlogs. Examining historical harvest values by species as well as projected values will be important in determining residue and cordwood resource potentials for tribal usage. The significance of this will be discussed later. It should be noted that the Lac du Flambeau tribe is not reaching their allowable cut limits, thus leaving room for the potential of increased production values in the future. ${ }^{5}$ In addition, the total energy value from all the timber harvested in the 20062007 season $(202,439 \mathrm{MMBtu})$ is more than enough to offset all of the LP used in 2007 (44,758 MMBtu).

\subsubsection{Energy value of current timber harvests}

In order to create a comparison between the current wood market established and the potential use of wood for thermal purposes for the Lac du Flambeau area, a standardized functional unit must be used. For this study we will use a functional unit of one million British thermal units (MMBtu). Analysis will be conducted on white pine, yellow birch, and aspen. Table 7 displays the various energy contents per MBF for sawlogs and per cord for cordwood. A value per MMBtu is established for traditional end use and for thermal use in tribal buildings. A cost of $\$ 1.75$ per gallon of LP was used in the example. All energy values of timber were obtained from the Forest Products Laboratory (U.S. Dept. of Ag, 1977). The cubic feet of each species of wood per cord was taken from the State of Wisconsin Timber Sale Handbook along with data from the University of Wisconsin Stevens Point (State of Wisconsin, 2006). Midwest Timber Mart prices were used to provide values for sawlogs and cordwood for each species.

\footnotetext{
${ }^{5}$ Personal Communication, Scott McDougall, Lac du Flambeau Tribe, June 13, 2008.
} 
Table 7: Energy value of sawlog-cordwood for current use and LP offset

\begin{tabular}{|r|r|r|r|r|r|r|}
\hline & \multicolumn{3}{|c|}{ Saw timber } & \multicolumn{3}{c|}{ Cord wood } \\
\cline { 2 - 7 } Species & $\begin{array}{c}\text { Cost per } \\
\text { MBF }\end{array}$ & $\begin{array}{c}\text { Price per } \\
\text { Green } \\
\text { Ton }\end{array}$ & $\$ /$ MMBtu & $\begin{array}{c}\text { Cost per } \\
\text { Cord }\end{array}$ & $\begin{array}{c}\text { Price per } \\
\text { Green Ton }\end{array}$ & \$/MMBtu \\
\hline Aspen & $\$ 200$ & $\$ 92$ & $\$ 10.73$ & $\$ 76$ & $\$ 34$ & $\$ 3.93$ \\
\hline $\begin{array}{r}\text { Yellow } \\
\text { Birch }\end{array}$ & $\$ 255$ & $\$ 70$ & $\$ 7.44$ & $\$ 106$ & $\$ 40$ & $\$ 4.24$ \\
\hline White Pine & $\$ 271$ & $\$ 96$ & $\$ 9.96$ & $\$ 90$ & $\$ 43$ & $\$ 4.46$ \\
\hline Average & $\$ 242$ & $\$ 86$ & $\$ 9.38$ & $\$ 91$ & $\$ 39$ & $\$ 4.21$ \\
\hline LP cost per MMBtu (HHV) at $\$ 1.75 /$ gal. $=\$ 19.02 / \mathrm{MMBtu}$ \\
\hline
\end{tabular}

Table 7 shows that there are economic potentials for utilizing both cordwood and sawtimber for biomass fuel when compared to current LP costs. Saw timber has an energy cost value of $\$ 9.38$ per MMBtu compared to cord wood which has an average cost-energy value of $\$ 4.121$ per MMBtu. These values assume moisture contents of 50 percent at the time of harvest. Saw timber dry matter values of 26, 44, and $34 \mathrm{lbs} / \mathrm{ft}^{3}$ were used for aspen, birch, and white pine respectively. ${ }^{6}$ Dry matter values for timber were estimated at $34.7 \mathrm{lbs}$. cu. $\mathrm{ft}$ with an average of $78 \mathrm{cu}$. ft. per cord. ${ }^{7}$ LP costs of 1.75/gal. and a high heating value of 92,000 btu/gal. were used in Table 7. Waste wood residue prices were assumed at $\$ 33 /$ ton. $^{8}$

Table 7 depicts the potential of using all portions of the tree for biomass energy, it is important to note that the highest value for cordwood and sawtimber is in the major

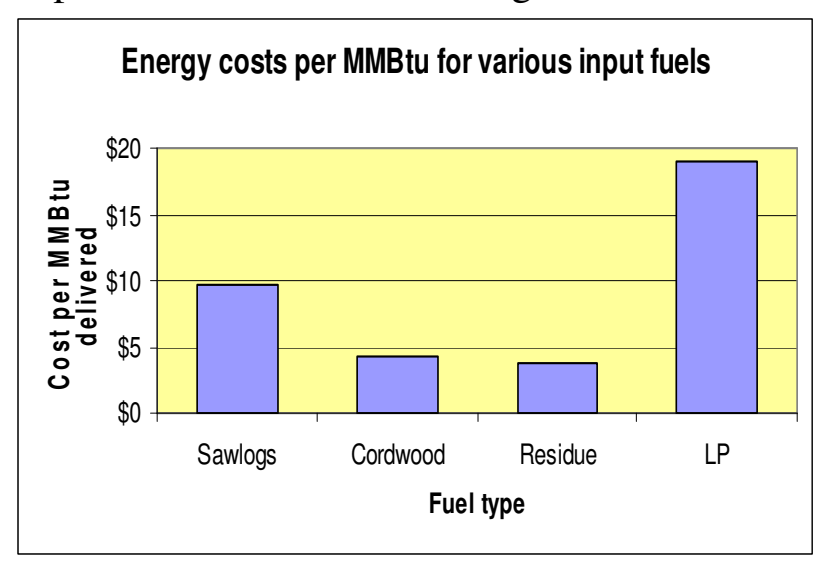

Figure 5: Energy cost per MMBtu delivered

markets of pulp wood and for lumber production. However, on an energycost level, residue values remain relatively close to cordwood values at $\$ 3.83$ per MMBtu. The majority of timber harvested and sold from the tribal land is cordwood. If waste wood prices climb to $\$ 36 /$ ton in the future and cord wood price are static, the use of cordwood for heating fuel becomes economically even. In regard to saw

timber, it would be advisable for the tribe to purchase residue from outside sources for biomass heat before utilizing cordwood or sawtimber resources.

\footnotetext{
${ }^{6}$ Dry matter values were taken from the website http://www.reade.com/Particle_Briefings/spec_gra2.html. Retrieved 10-13-2008.

${ }^{7}$ Cubic feet of cord wood values taken from the Wisconsin DNR website http://dnr.wi.gov/forestry/StateForests/2461/2461.pdf. Retrieved 10-13-2008.

8 The value of $\$ 33 /$ ton was obtained by averaging actually values obtained from the 2007 CleanTech Partners report , "Financial feasibility analysis for a wood pellet mill using roundwood feedstock", as well as values obtained from the document, "Report of biomass options available to the Menominee Tribal Enterprises", conducted in 2004 for the Menominee Tribe.
} 


\subsubsection{LP prices and forecasts}

Trends in tribal LP costs have shown dramatic increases over the past five years. An annual increase of over $\$ 0.17$ per gallon has been noticed since 2003. Despite the trend in rising LP costs, it is difficult to determine future LP prices. For example, during the drafting of this report, delivered LP prices for rural farm customers in southern Wisconsin fell from $\$ 2.29 /$ gal.to near $\$ 1.50 /$ gal. $^{9}$ The Energy Information Administration has also shown dramatic fluctuations for propane in Wisconsin as well. Wholesale propane prices have fallen from the high in March of $\$ 1.816 /$ gallon to a current price of $\$ 0.896 /$ gallon as of December $1,2008 .{ }^{10}$ In many cases, commercial propane will be priced at roughly $\$ 0.40$ higher than the wholesale price. The diary spot market price of propane determines the cost of LP for an area. In some cases, businesses will lock in propane rates before a heating season. Locking in rates can have a reverse affect, such as the 2008-2009 heating season, when rates where higher in the summer than in the winter. In these instances, the business must purchase fuel at the locked in rate. ${ }^{11}$ For these reasons, it is difficult to determine current and future costs of LP. However, historic data can be obtained with certainty. Table 8 contains cost data for tribal LP use over the past five years.

Table 8: Annual tribal LP costs (\$/gallon)

\begin{tabular}{|c|r|r|r|}
\hline Year & $\begin{array}{c}\text { Total annual } \\
\text { cost }\end{array}$ & $\begin{array}{c}\text { Total annual } \\
\text { gallons consumed }\end{array}$ & \multicolumn{1}{c|}{$\begin{array}{c}\text { Price per } \\
\text { gallon }\end{array}$} \\
\hline 2003 & 265,404 & 331,299 & $\$ 0.80$ \\
\hline 2004 & 463,438 & 472,483 & $\$ 0.98$ \\
\hline 2005 & 469,182 & 372,226 & $\$ 1.26$ \\
\hline 2006 & 659,468 & 476,721 & $\$ 1.38$ \\
\hline 2007 & 709,389 & 486,499 & $\$ 1.46$ \\
\hline 2008 & -- & -- & $\$ 2.20$ or $\$ 1.75^{*}$ \\
\hline
\end{tabular}

*it was estimated that LP rates would be between $\$ 2.10$ and $\$ 2.30 . \$ 1.75$ may

more accurately depict current prices

\footnotetext{
${ }^{9}$ Data taken from phone conversations with rural ag customers in Southern Wisconsin July 2008 and October 2008.

${ }^{10}$ Department of Energy, Energy Information Administration Retrieved December 9, 2008. http://tonto.eia.doe.gov/oog/ftparea/wogirs/xls/pswc6vwall.xls\#'Data 1'!A1

${ }^{11}$ Data taken from conversations with AmeriGas of Mercer, WI on December 9, 2008.
} 


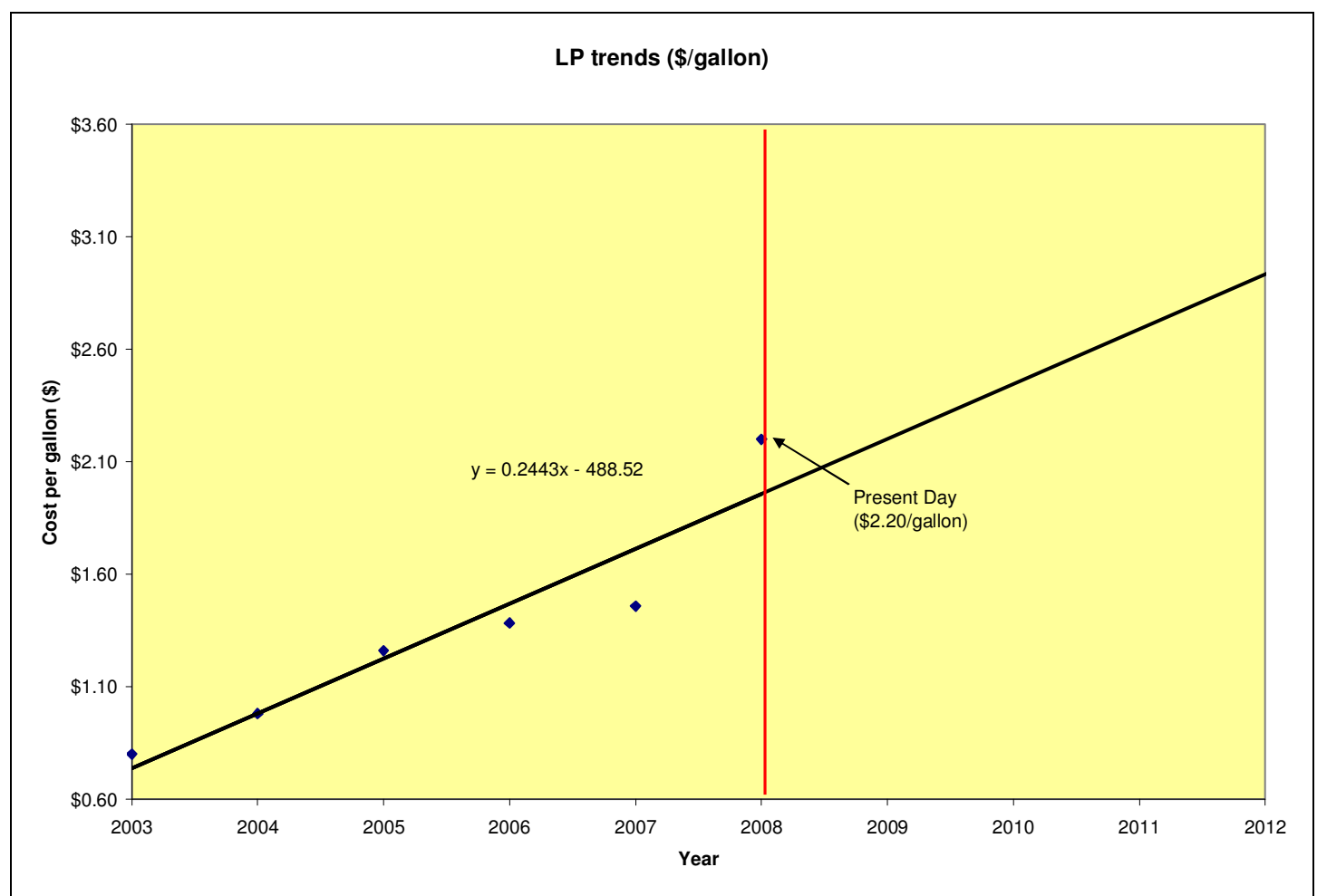

Figure 6: Historical LP cost with forecasted cost (\$2.20 gal. as the current rate)

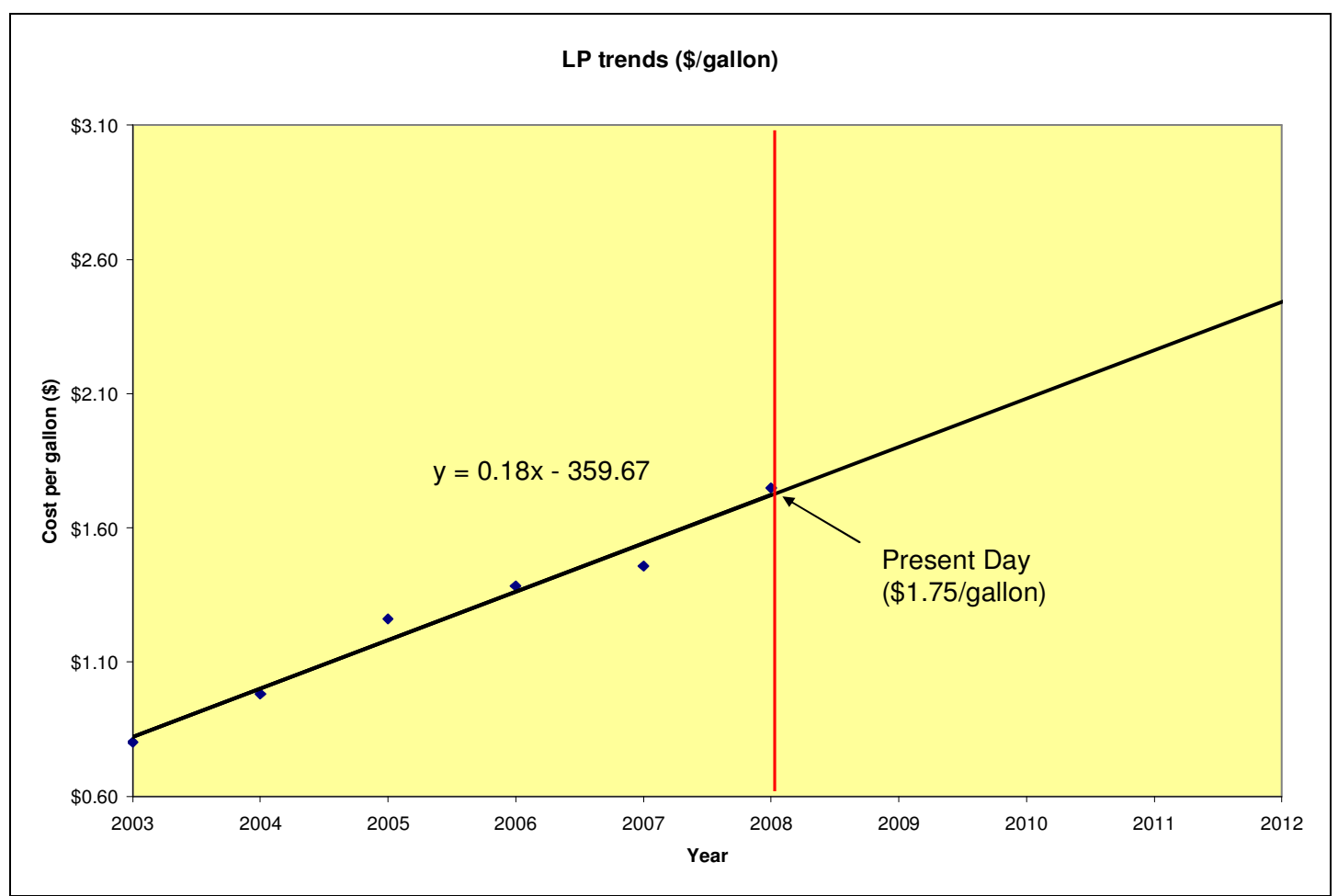

Figure 7: Historical LP cost with forecasted cost (\$1.75 gal. as the current rate)

Figure 6 and Figure 7 shows a steady projected increase in LP prices into the future. Figure 6 trends show an LP price of \$3.01 by the year 2012 while Figure 7 shows an LP 
cost of $\$ 2.49$ per gallon in 2012. The present day cost of LP was estimated at $\$ 2.20$ /gallon and \$1.75/gallon for Figure 6 and Figure 7 respectively. Later analysis of LP costs in the tribal region showed LP cost as low as \$1.38 in some part of northern Wisconsin by December of 2008. It is very difficult to forecast or speculate fuel costs as fluctuations can be drastic and quick.

\subsubsection{Biomass offset economic comparison}

Much of the Lac du Flambeau tribe utilizes LP gas for heating purposes. Heating options are limited as natural gas is not presently available to tribal buildings and a biomass infrastructure is not established. The following section examines the potential savings of a complete conversion from LP to biomass. Currently, there is not enough timber harvested on tribal lands to completely offset the tribes LP usage. However, this does not limit the tribe from purchasing residue and cord wood for thermal purposes from outside sources. Because of this potential, a cost per MMBtu of $\$ 4.18$ was used in the analysis. This value has been taken from current delivered cord wood prices. This value does not take into account the potential of purchasing and utilizing forest residue. Current residue costs are estimated at $\$ 3.83 / \mathrm{MMBtu}$. Savings noticed in Table 9 can be multiplied by 1.09 to determine savings using residue. Propane costs were assumed to be $\$ 1.75 /$ gallon.

The analysis below assumes a cord wood or residue price increase of $3.06 \%$ annually. LP price trends were determined using data obtained from the tribe . All data assumes $100 \%$ biomass offset.

Table 9: Biomass offset savings under various scenarios

\begin{tabular}{|c|c|c|c|c|}
\hline Scenario & & Scenario 1 & Scenario 2 & Scenario 3 \\
\hline Year & $\begin{array}{c}\text { Annual } \\
\text { biomass cost } \\
\text { with price } \\
\text { increases }\end{array}$ & $\begin{array}{c}\text { Annual saving with: } \\
\text { complete switch to } \\
\text { biomass, level LP } \\
\text { consumption, } \\
\text { increased LP and } \\
\text { biomass costs }\end{array}$ & $\begin{array}{c}\text { Annual savings } \\
\text { with } \% \text { annual } \\
\text { decrease in LP } \\
\text { usage, increased } \\
\text { LP and biomass } \\
\text { cost }\end{array}$ & $\begin{array}{c}\text { Annual savings } \\
\text { with stable LP } \\
\text { price, 2\% annual } \\
\text { reduction, and } \\
\text { biomass price } \\
\text { increase }\end{array}$ \\
\hline 2008 & $\$ 164,532$ & $\$ 584,197$ & $\$ 584,197$ & $\$ 584,197$ \\
\hline 2009 & $\$ 169,567$ & $\$ 664,732$ & $\$ 651,437$ & $\$ 584,623$ \\
\hline 2010 & $\$ 174,756$ & $\$ 736,555$ & $\$ 707,388$ & $\$ 581,187$ \\
\hline 2011 & $\$ 180,103$ & $\$ 808,220$ & $\$ 760,690$ & $\$ 576,280$ \\
\hline 2012 & $\$ 185,614$ & $\$ 879,721$ & $\$ 811,427$ & $\$ 570,280$ \\
\hline 2013 & $\$ 191,294$ & $\$ 951,053$ & $\$ 859,677$ & $\$ 563,459$ \\
\hline 2014 & $\$ 197,148$ & $\$ 1,022,212$ & $\$ 905,519$ & $\$ 556,020$ \\
\hline 2015 & $\$ 203,181$ & $\$ 1,093,192$ & $\$ 949,027$ & $\$ 548,118$ \\
\hline 2016 & $\$ 209,398$ & $\$ 1,163,986$ & $\$ 990,277$ & $\$ 539,870$ \\
\hline 2017 & $\$ 215,805$ & $\$ 1,234,591$ & $\$ 1,029,337$ & $\$ 531,369$ \\
\hline 2018 & $\$ 222,409$ & $\$ 1,305,000$ & $\$ 1,066,280$ & $\$ 522,686$ \\
\hline 2019 & $\$ 229,215$ & $\$ 1,375,206$ & $\$ 1,101,171$ & $\$ 513,880$ \\
\hline 2020 & $\$ 236,229$ & $\$ 1,445,204$ & $\$ 1,134,076$ & $\$ 504,996$ \\
\hline 2021 & $\$ 243,457$ & $\$ 1,514,988$ & $\$ 1,165,060$ & $\$ 496,072$ \\
\hline 2022 & $\$ 250,907$ & $\$ 1,584,550$ & $\$ 1,194,184$ & $\$ 487,138$ \\
\hline 2023 & $\$ 258,585$ & $\$ 1,653,885$ & $\$ 1,221,508$ & $\$ 478,219$ \\
\hline 2024 & $\$ 266,498$ & $\$ 1,722,984$ & $\$ 1,247,092$ & $\$ 469,336$ \\
\hline
\end{tabular}




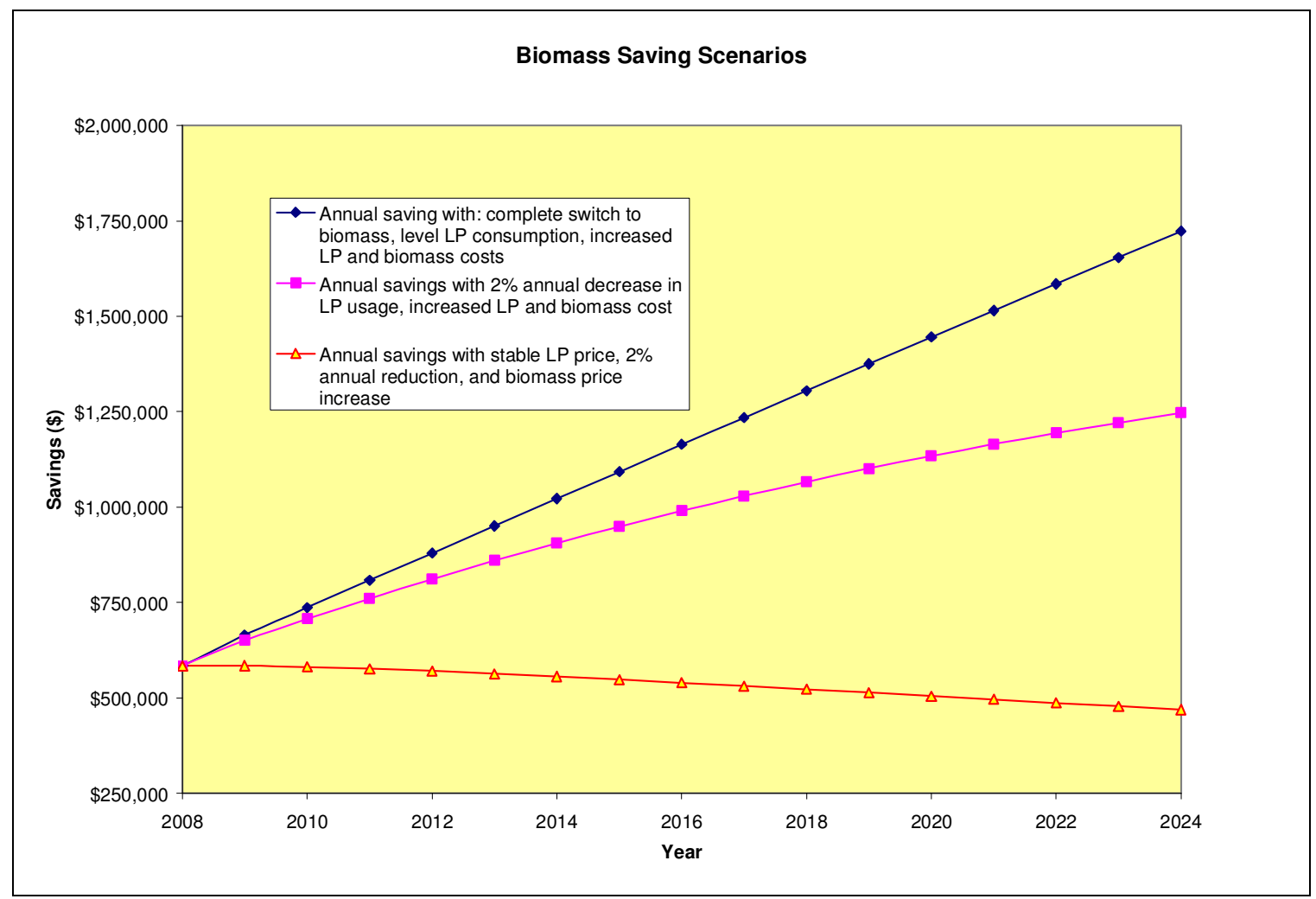

Figure 8: Biomass forecasted savings under various scenarios

In each of the scenarios presented in Figure 8 biomass as an LP energy offset is an economically feasible option. The greatest savings are noticed when LP trends from the previous five years are forecasted out. The focus of the tribe is to stabilize or reduce their energy consumption. Even if LP usage totals are stabilized or reduced by $2 \%$ annually, conversion to biomass is still a benefit as the cost per MMBtu is substantially less than LP.

Energy futures are dynamic, and speculating on such price trends is difficult. It is a fair assumption that biomass prices will continue to increase in Northern Wisconsin. Extensive research and development in underway in the Midwest to determine alternative uses for woody biomass materials. The U.S. Department of Agricultures Billion Ton Report, along with extensive research into fuel production from cellulosic materials, and the beginning of a Midwest biomass commodity exchange indicate a stronger movement towards utilizing woody biomass materials. As this transition occurs and stronger markets are established for cord wood and residue, prices will naturally increase.

\subsubsection{Historic cordwood prices}

Timber values fluctuate by season, sale, and location. As mentioned in the previous section, determining future prices is a difficult and subjective task. Plotting historic prices of common species of timber found on the tribal land shows that fuel wood prices are increasing in the Wisconsin Administrative zone 7. Such fluctuations can be attributed to an assortment of market changes. Most timber prices are dictated by lumber value. If lumber is in high demand than prices will increase. Related to the current state 
of the market, construction has steadily decreased which will ultimately drive prices down. However, if other markets such as cellulosic ethanol and the pellet industry begin to purchase timber for production and processing, than prices may begin trending heating fuel and transportation fuel prices.

The data used in Figure 9 was taken from the Wisconsin Administrative Code NR 46.30. The values seen in Figure 9 are not reflective of actual cord wood prices in the region; rather they demonstrate the states assessment of timber value in zone 7 . However, such trends are representative of timber price changes in the region. Market prices for the zone 7 can fluctuate up and down and are a product of macro and micro-economic conditions reflecting specific factors of each individual sale. ${ }^{12}$ The historical base prices for cord wood lack statistical significance when trended over time. However, it is evident from Figure 9 that there is a price increase occurring in Wisconsin zone 7 since 2002 for aspen, yellow birch, and jack pine, and white pine (Wisconsin Administrative Code, 2006).

\section{Figure 9: Historical stumpage values of cord wood for tax purposes [zone 7]}

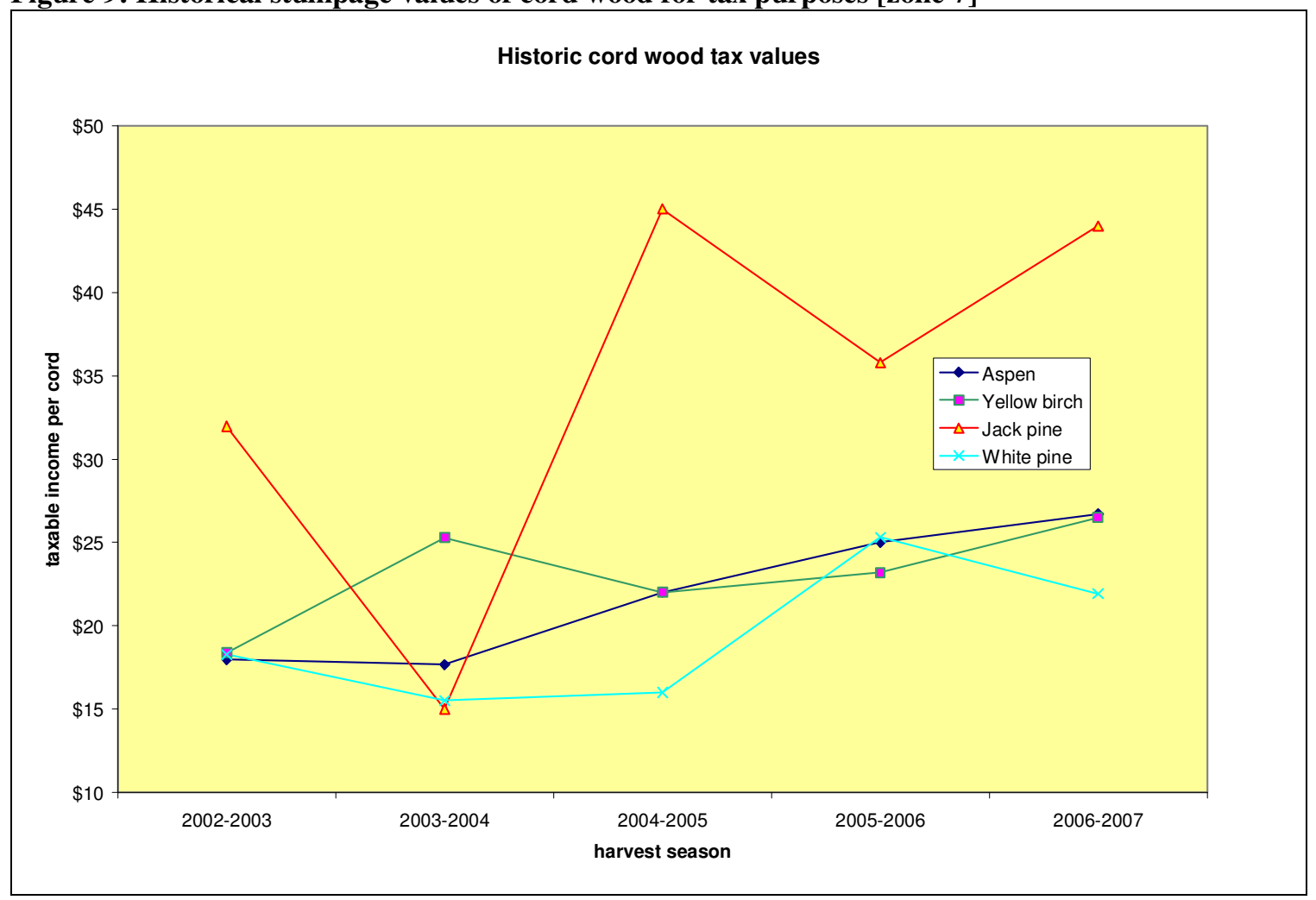

The United States Forest Service has experienced similar variances in prices throughout the past several years. In July 2004 aspen pulpwood prices were \$25 per cord, in 2005 aspen was $\$ 68$ per cord, in 2006 it was $\$ 60$ per cord, and finally slumped back down to $\$ 22$ per cord in 2007. Much of these changes were due to fiber shortages as the OSB market was consuming more products, pulling feedstock away from the pulp and paper

${ }^{12}$ This "note" was taken from the October 2006 Register, No. 610, NR 46.30 of the Wisconsin Administrative Code. 
industry. The OSB market has since slowed, lowering prices back to what they were in 2004. ${ }^{13}$

\subsubsection{LDF residue case study}

In 2007 Midwest Timber was given permission to chip the residuals brought from the harvest site to the landing. The stumpage charge for the chips was set at $\$ 0.50$ per ton. In a memorandum from Scott McDougalll, it was reported that 160 tons of chipped residue were taken from the site. The chips were comprised of aspen and other hardwoods (maple, oak, and birch). Seven truck loads were removed from the site and it was estimated that it took 450 cords of merchantable wood to make 160 tons of chips. This is equivalent to one ton of residue for every 6.44 tons of cordwood. This is equivalent to roughly 16 percent of the cordwood mass removed. The residue was chipped and sold by Midwest Timber as boiler fuel for $\$ 17.50$ per green-ton.

Harvesting and extraction costs of forest residues are dependent upon many variables including terrain, distance to landing, residue density, soil moisture content, economics of logging operations, and trucking distance. A 2005 study of logging residue extraction costs found that the freight on board (FOB) destination price for residue in the great lakes region for whole tree removal range from $\$ 13.41$ to $\$ 15.41$ [Table 10] (Peterson, 2005). Freight on board considered the costs of delivering the materials to the end user.

Table 10: Whole tree residue removal cost [from 2005 Don Peterson study]

\begin{tabular}{|c|c|c|c|c|c|c|c|c|}
\hline Tree Length & $\begin{array}{c}\text { Cords/Acre } \\
\text { Merchantable }\end{array}$ & $\begin{array}{c}\text { Tons/Acre } \\
\text { Biomass }\end{array}$ & Harvesting & Skidding & $\begin{array}{c}\$ \text { to } \\
\text { Chip/Ton }\end{array}$ & $\begin{array}{c}\text { Transport } \\
\text { to Mill }\end{array}$ & $\begin{array}{c}\$ / \text { Ton } \\
\text { Stumpage }\end{array}$ & $\begin{array}{c}\text { Total } \\
\text { Price/Ton }\end{array}$ \\
\hline $\begin{array}{c}\text { Northern } \\
\text { Hardwood } \\
(\mathrm{NH})\end{array}$ & 7 & 8.2 & $\$ 0 /$ ton & $\$ 0 /$ ton & $\$ 4.27 /$ ton & $\$ 8 /$ ton & $\$ 2.14$ & $\$ 14.41$ \\
\hline $\mathrm{NH}$ & 10 & 11.7 & $\$ 0 /$ ton & $\$ 0 /$ ton & $\$ 4.27 /$ ton & $\$ 7 /$ ton & $\$ 2.14$ & $\$ 13.41$ \\
\hline $\begin{array}{c}\mathrm{NH}(\text { Aspen } \\
\text { Removal) }\end{array}$ & 10 & 3.5 & $\$ 0 /$ ton & $\$ 0 /$ ton & $\$ 4.27 /$ ton & $\$ 9 /$ ton & $\$ 2.14$ & $\$ 15.41$ \\
\hline
\end{tabular}

In the case of the Lac du Flambeau sale with Midwest Timber, the "total price/ton" values seen in Table 10 could be lowered by $\$ 1.64$ per ton as the stumpage fee is $\$ 0.50$ per ton versus the listed price of $\$ 2.14 /$ ton seen in Table 10. In cut-to-length harvest practices which harvest, fell, and process the tree at the site, residue removal life cycle costs can be as high as $\$ 31.80$ per ton. Considering an average residue tonnage price of $\$ 33$ for Northern Wisconsin, profit margins for logging operations can be narrow. In some cases the landowner will take a reduced stumpage rate in return for residue removal. The reduced stumpage price actually subsidizes the chipping operation. To conclude, residue removals in whole-tree operations are economical while removals of residue during cut-to-length operations remain uneconomical unless residue removal costs are deducted from the stumpage value.

Treating residue like a merchantable timber product is vital in seizing the maximum value of the harvest. Residue pricing should be including in the bid price stumpage rate based upon current economic value of residue in Northern Wisconsin, \$33 ton.

\footnotetext{
${ }^{13}$ Information taken from conversation with US Forest Service, Northern Wisconsin Forester.
} 


\subsubsection{Wood chip energy-cost analysis}

In a survey conducted on 39 saw mills in Wisconsin, the Biomass Energy Resource Center found an average proximity cost of $\$ 30$ per ton for hardwoods in 2003 (Biomass Energy Resource Center, 2003). More recent data shows that residue values are near $\$ 33$, which depicts an increase in value in recent years. In the previous section we discovered that Midwest sold the residue for a FOB destination price of $\$ 17.50$ per green ton. From an interview with the manager of a soy bean roasting facility in Southeast Wisconsin, a FOB destination residue price of $\$ 60$ per green ton was quoted. In all the examples above, prices are determined for harvested green wood at roughly 30 percent moisture content. Moisture content directly affects the delivered energy content of the biomass on a weight bases. There are many calculations used to determine or explain moisture content. In the example below, moisture content is expressed as a weight basis (w.b.). A sensitivity analysis is performed to compare biomass energy-cost prices. A moisture content variation between 10 and 50 percent for delivered biomass chips are presented in Table 11 below. It can be estimated that harvested timber has a moisture content of 50 percent, while seasoned wood will have a moisture content near 30 percent. Wood pellets generally have a moisture content below 10 percent.

Table 11: Cost per delivered MMBtu of wood chips and cord wood

\begin{tabular}{|c|c|c|c|c|c|c|c|c|c|c|}
\hline \multicolumn{11}{|c|}{ Cost per delivered MMBtu at various moisture contents } \\
\hline \multicolumn{11}{|c|}{ Cost per MMBtu delivered residues } \\
\hline \multicolumn{11}{|c|}{ Cost per MMBtu delivered cordwood } \\
\hline Delivery & \multirow{4}{*}{\multicolumn{2}{|c|}{$10 \%$ m.c. }} & \multirow{4}{*}{\multicolumn{2}{|c|}{$20 \%$ m.c. }} & \multirow{4}{*}{\multicolumn{2}{|c|}{$30 \%$ m.c. }} & \multirow{4}{*}{\multicolumn{2}{|c|}{$40 \%$ m.c. }} & \multirow{4}{*}{\multicolumn{2}{|c|}{$50 \%$ m.c. }} \\
\hline ost & & & & & & & & & & \\
\hline (\$/ton or & & & & & & & & & & \\
\hline$\$ /$ cord) & & & & & & & & & & \\
\hline$\$ 10.00$ & $\$ 0.65$ & $\$ 0.51$ & $\$ 0.73$ & $\$ 0.51$ & $\$ 0.83$ & $\$ 0.51$ & $\$ 0.97$ & $\$ 0.51$ & $\$ 1.16$ & $\$ 0.51$ \\
\hline$\$ 17.50$ & $\$ 1.13$ & $\$ 0.89$ & $\$ 1.27$ & $\$ 0.89$ & $\$ 1.45$ & $\$ 0.89$ & $\$ 1.70$ & $\$ 0.89$ & $\$ 2.03$ & $\$ 0.89$ \\
\hline$\$ 25.00$ & $\$ 1.61$ & $\$ 1.27$ & $\$ 1.82$ & $\$ 1.27$ & $\$ 2.08$ & $\$ 1.27$ & $\$ 2.42$ & $\$ 1.27$ & $\$ 2.91$ & $\$ 1.27$ \\
\hline$\$ 32.50$ & $\$ 2.10$ & $\$ 1.65$ & $\$ 2.36$ & $\$ 1.65$ & $\$ 2.70$ & $\$ 1.65$ & $\$ 3.15$ & $\$ 1.65$ & $\$ 3.78$ & $\$ 1.65$ \\
\hline$\$ 40.00$ & $\$ 2.58$ & $\$ 2.03$ & $\$ 2.91$ & $\$ 2.03$ & $\$ 3.32$ & $\$ 2.03$ & $\$ 3.88$ & $\$ 2.03$ & $\$ 4.65$ & $\$ 2.03$ \\
\hline$\$ 47.50$ & $\$ 3.07$ & $\$ 2.41$ & $\$ 3.45$ & $\$ 2.41$ & $\$ 3.95$ & $\$ 2.41$ & $\$ 4.60$ & $\$ 2.41$ & $\$ 5.52$ & $\$ 2.41$ \\
\hline$\$ 55.00$ & $\$ 3.55$ & $\$ 2.80$ & $\$ 4.00$ & $\$ 2.80$ & $\$ 4.57$ & $\$ 2.80$ & $\$ 5.33$ & $\$ 2.80$ & $\$ 6.40$ & $\$ 2.80$ \\
\hline$\$ 62.50$ & $\$ 4.04$ & $\$ 3.18$ & $\$ 4.54$ & $\$ 3.18$ & $\$ 5.19$ & $\$ 3.18$ & $\$ 6.06$ & $\$ 3.18$ & $\$ 7.27$ & $\$ 3.18$ \\
\hline$\$ 70.00$ & $\$ 4.52$ & $\$ 3.56$ & $\$ 5.09$ & $\$ 3.56$ & $\$ 5.81$ & $\$ 3.56$ & $\$ 6.78$ & $\$ 3.56$ & $\$ 8.14$ & $\$ 3.56$ \\
\hline$\$ 77.50$ & $\$ 5.01$ & $\$ 3.94$ & $\$ 5.63$ & $\$ 3.94$ & $\$ 6.44$ & $\$ 3.94$ & $\$ 7.51$ & $\$ 3.94$ & $\$ 9.01$ & $\$ 3.94$ \\
\hline$\$ 85.00$ & $\$ 5.49$ & $\$ 4.32$ & $\$ 6.18$ & $\$ 4.32$ & $\$ 7.06$ & $\$ 4.32$ & $\$ 8.24$ & $\$ 4.32$ & $\$ 9.88$ & $\$ 4.32$ \\
\hline$\$ 92.50$ & $\$ 5.98$ & $\$ 4.70$ & $\$ 6.72$ & $\$ 4.70$ & $\$ 7.68$ & $\$ 4.70$ & $\$ 8.96$ & $\$ 4.70$ & $\$ 10.76$ & $\$ 4.70$ \\
\hline$\$ 100.00$ & $\$ 6.46$ & $\$ 5.08$ & $\$ 7.27$ & $\$ 5.08$ & $\$ 8.31$ & $\$ 5.08$ & $\$ 9.69$ & $\$ 5.08$ & $\$ 11.63$ & $\$ 5.08$ \\
\hline
\end{tabular}

Moisture content of the biomass has a significant bearing on overall delivered cost per MMBtu. When wood chips are purchased at $\$ 32.50$ per ton with a 30 percent moisture content, the delivered cost is $\$ 2.70 / \mathrm{MMBtu}$. At the same price with 50 percent moisture content, this cost is $\$ 3.78$ per MMBtu, a 40 percent increase in delivered fuel price. The delivered fuel cost for cordwood does not change in Table 11 because cordwood is sold on a volume basis and not on a weight basis. 
High moisture chips can be used in biomass boilers but results in lower combustion temperatures and efficiencies. This is because energy is stolen from the feedstock in order to vaporize existing moisture in the wood chips. High moisture fuels require more initial input energy as well as energy to maintain internal boiler temperatures. In many cases, the chips will have to be stored on-site until they are more suitable for boiler use.

In all scenarios shown in Table 11, the FOB delivered values are significantly lower than LP costs per MMBtu (\$19.02 at $\$ 1.75 /$ gal.). As shown earlier, biomass is a suitable option for boiler use on-site even if prices on biomass are inflated.

\subsubsection{Residue savings analysis}

The delivered cost of LP in 2008 was estimated to be $\$ 1.75$ per gallon. Assuming a cost of $\$ 1.75$ per gallon, a delivered cost of $\$ 19.02$ per MMBtu is noticed. One potential opportunity for the tribe is to use biomass residue from harvest practices to heat tribal buildings. Based upon Table 6, 25,500 MMBtu of potential residues are available for

Table 12: Fuel savings (LP to wood residue)

\begin{tabular}{|c|c|c|}
\hline \multicolumn{3}{|c|}{$\begin{array}{l}\text { Annual savings of converting from LP to } \\
\text { biomass with Tribal residue }\end{array}$} \\
\hline FOB destination & & \\
\hline Cost per ton & $30 \%$ m.c. & $50 \%$ m.c. \\
\hline$\$ 10.00$ & $\$ 464,000$ & $\$ 455,000$ \\
\hline$\$ 17.50$ & $\$ 448,000$ & $\$ 433,000$ \\
\hline$\$ 25.00$ & $\$ 432,000$ & $\$ 411,000$ \\
\hline$\$ 32.50$ & $\$ 416,000$ & $\$ 389,000$ \\
\hline$\$ 40.00$ & $\$ 400,000$ & $\$ 366,000$ \\
\hline$\$ 47.50$ & $\$ 384,000$ & $\$ 344,000$ \\
\hline$\$ 55.00$ & $\$ 369,000$ & $\$ 322,000$ \\
\hline$\$ 62.50$ & $\$ 353,000$ & $\$ 300,000$ \\
\hline$\$ 70.00$ & $\$ 337,000$ & $\$ 277,000$ \\
\hline$\$ 77.50$ & $\$ 321,000$ & $\$ 255,000$ \\
\hline
\end{tabular}

chipping and combustion.

Table 12 displays the savings if tribal residue was used for space heating purposes versus using LP. Residue costs quoted from Midwest Timber as well as state averages were used in the analysis.

Another potential opportunity is to utilize the harvested cord wood for internal heat uses. As displayed earlier, the cost of this fuel is more than residues but is still an economical option for the tribe. Table 13 displays the cost savings of using cord wood assuming various FOB destination prices.

Significant cost savings are noticed when residue or cord wood of various moisture contents are used to replace LP. It is evident from

Table 12 that purchasing wood that has been seasoned before chipping will yield higher savings. It can be assumed that harvested green wood will have a moisture content of near 50 percent while wood that has been air dried will have a moisture content of around 30 percent. 
Table 13: Fuel savings (LP to cord wood)

Annual savings of converting from LP to biomass with Tribal cordwood

\begin{tabular}{|c|c|}
\hline $\begin{array}{l}\text { FOB destination } \\
\text { Cost per cord }\end{array}$ & Total savings \\
\hline$\$ 32.50$ & $\$ 2,981,000$ \\
\hline$\$ 40.00$ & $\$ 2,915,000$ \\
\hline$\$ 47.50$ & $\$ 2,850,000$ \\
\hline$\$ 55.00$ & $\$ 2,784,000$ \\
\hline$\$ 62.50$ & $\$ 2,719,000$ \\
\hline$\$ 70.00$ & $\$ 2,654,000$ \\
\hline$\$ 77.50$ & $\$ 2,588,000$ \\
\hline$\$ 85.00$ & $\$ 2,523,000$ \\
\hline$\$ 92.50$ & $\$ 2,457,000$ \\
\hline$\$ 100.00$ & $\$ 2,392,000$ \\
\hline
\end{tabular}

The use of residue as an LP replacement is the more economical and sensible option. Cord wood results in substantial savings as an LP offset. However, the Tribe should consider purchasing residue from external sources before utilizing the higher value cord wood. Cord wood prices can be misleading when compared to tonnage prices of residue. It is vital to compare the dry matter totals of each cord of wood to that of residue before making a formal decision. 


\section{Biomass resource assessment}

\subsection{A national overview}

The abundance of biomass resources available in the United States supports the use of biomass as a space heating fuel (USDA, 2002). As more timber is harvested, substantial amounts of forest residue such as bark, limbs, and stumps accumulates. In addition, forest growth has continued to exceed mortality and harvest totals. This has resulted in a net accumulation of above ground woody biomass (USDA, 2002). In 2003, 2.9 quadrillion Btu of energy was produced from biomass in the United States. Biomass accounts for over three percent of the total energy consumed in the United States and makes up 47 percent of the renewable energy produced in the United States (U.S. Dept. of Energy, 2005).

Maintaining forest health is vital to proper forest growth. Developing sustainable harvesting practices is not only an important ecological management tool, but is also a key component of minimizing forest fires as well as ensuring that valuable timber is available into the future. The total forest land in the Unites States is estimated at 749 million acres, about one-third of the nation's total land area. Two-thirds of the forestland is classified as timberland or area of land capable of producing crops of industrial wood (US Dept. of Energy, 2005). The North Central part of the country is home to more than 80 million acres of forestland. Data from the United States Department of Agriculture shows that forest growth has exceeded removal by 33 percent since 1952 (Miles et al., 2004). Despite an anticipated loss of three percent of U.S. forestland by 2050 due to urban sprawl, forest inventories are expected to increase (US Dept. of Energy, 2005). A 2004 study found that 20.2 billion $\mathrm{ft}^{3}$ of forest inventory was removed. Of this volume, 78 percent was for roundwood products, 16 percent was logging residue, and about 6 percent was classified as other removals. This statistic clearly demonstrates the abundant biomass resource currently available in the United States. Utilizing harvested biomass from sustainable forests is an environmentally sustainable option for thermal energy purposes.

In 2005, the US Department of Energy and the US Department of Agriculture partnered to develop a national biomass assessment. The vision of the merger was to examine the potential of offsetting 30 percent of the countries petroleum supply with biofuels by 2030. The assessment examined both forest resource and agricultural resources to meet the goals. The study found over 1.3 billion dry tons of biomass per year of potential resources. It was estimated that the contiguous United States can produce 368 million dry tons of biomass annually. Of this, 145 million dry tons of residues were available for annual removal. 


\subsection{A state overview}

Wisconsin is a state that is greatly dependent upon imported fuel sources. Historically, Wisconsin has relied heavily on imported foreign energy resources to maintain a growing economy and population. Much of the energy used in Wisconsin's residential, industrial, commercial, and transportation sector comes from fossil energy. Energy expenditures for Wisconsin reached $\$ 19.5$ billion dollars in 2006, with two-thirds of this value leaving the state of Wisconsin to external entities (Wisconsin DOA, 2007). This value represents an out of state loss of \$5,800 per household in Wisconsin, for energy alone.

Wisconsin has witnessed a shift away from the use of heating oil and liquid petroleum gas (LPG), only to be substituted by a heavier reliance upon the use of natural gas. Since 1970, the amount of natural gas consumed per customer has declined by nearly 50 percent, yet a continued increase in residential natural gas usage in Wisconsin is noticed (Wisconsin DOA, 2007). The decline can be attributed to more energy efficient space heating products and appliances. Despite the increase in energy efficiency, a concern still arises from using natural gas, as it is a fossil fuel that must be imported completely into Wisconsin. Due to this energy dependence, Wisconsin is bound by external forces which dictate the price of these fuels.

It is evident that Wisconsin is heavily reliant upon fossil energy and continues to increase its fossil fuel usage. Price fluctuations experienced in Wisconsin are highly dictated by external factors as all fossil fuel energy is imported into Wisconsin. The result of this dynamic is a continual rise in fuel costs as well as a transfer of Wisconsin income to outside entities for this energy.

In Wisconsin, 16.1 of the 34.8 million acres are considered forestland. Of this total forestland, 15.9 million acres are considered timberland available for harvest. Forests cover 46 percent of the total land area of the state. In addition to the abundant amount of timber, like the rest of the United States, Wisconsin has a positive net timber growth rate (Brand and Perry, 2006). From 2000 to 2005, Wisconsin net growth of growing stock increased by 605.7 million $\mathrm{ft}^{3}$, which factors in harvest removal and mortality of trees (Brand and Perry, 2006). In addition, forest area has been steadily increasing since 1968, mostly due to the conversion of marginal agricultural land back into forests. Since 1983, forestland has increased by about four-percent, or 640,000 acres (Wisconsin, 2003).

Wisconsin's forestry industry is very important to the state's economy. Wisconsin's forests provide the raw materials for homes, offices, furniture, paper, medicines, paints, plastics, and other products. Over 1,400 businesses in Wisconsin are centered on forestry in Wisconsin. This accounts for nearly 15 percent of all manufacturing jobs in the state. Forestry in Wisconsin has a value-added benefit of $\$ 1.2$ billion annually. ${ }^{14}$ More than 1850 wood-using businesses produce nearly 20 billion dollars of forest products every year. More than 300,000 jobs rely on the forest products industry (Wisconsin, 2003).

\footnotetext{
${ }^{14}$ Information taken from the Wisconsin DNR Forestry website, October 14, 2008.
} 
The most abundant forest type in Wisconsin is hardwood forest types. 84 percent of Wisconsin's forests are hardwoods, though significant softwood stands such as red pine, jack pine, black spruce, northern white cedar, and tamarack exist. As of 1996, 34 percent of forests in Wisconsin were maple-basswood, 18 percent were aspen, 18 percent were oak-hickory, and 10 percent were elm-ash-cottonwood. This constitutes the great majority of forestland in Wisconsin. Aspen-birch stands have steadily declined over the past 70 years, while all other major species have increased (Wisconsin, 2003).

\subsection{Lac du Flambeau overview}

To determine the timberland resources around Lac du Flambeau, the United States Forest Service-Forestry Inventory Mapmaker program was used to determine volumes of residue, cordwood, and sawtimber from Lac du Flambeau. ${ }^{15}$ The counties in Michigan falling within a 75 mile radius of Lac du Flambeau are Baraga, Gogebic, Houghton, Iron and Ontonagon. The counties in Wisconsin are Ashland, Bayfield, Chippewa, Florence, Forest, Iron, Langlade, Lincoln, Marathon, Oneida, Price, Rusk, Sawyer, Taylor and Vilas. These are the counties that will encompass the detailed timber values in the following sections.

\subsubsection{Lac du Flambeau timber assessment by radii}

Wisconsin has about 16 million acres of timberland while Michigan has about 19 million total acres. The timberland resources within a 75 mile radius of Lac du Flambeau are estimated at 7.7 million acres. Total acres in the 75 mile radius are broken down by ownership in Table 14. In Table 14, ownership is seen as a percentage of total timberland in the 75 mile radius area.

Table 14: Timberland ownership around Lac du Flambeau, WI

\begin{tabular}{|l|c|c|c|c|c|}
\hline & \multicolumn{5}{|c|}{ Timberland by Ownership within a 75 Mile Radius of Lac du } \\
Flambeau (Acres)
\end{tabular}

${ }^{15}$ US Forest Service Inventory Mapmaker Version 2.1, 2005. 


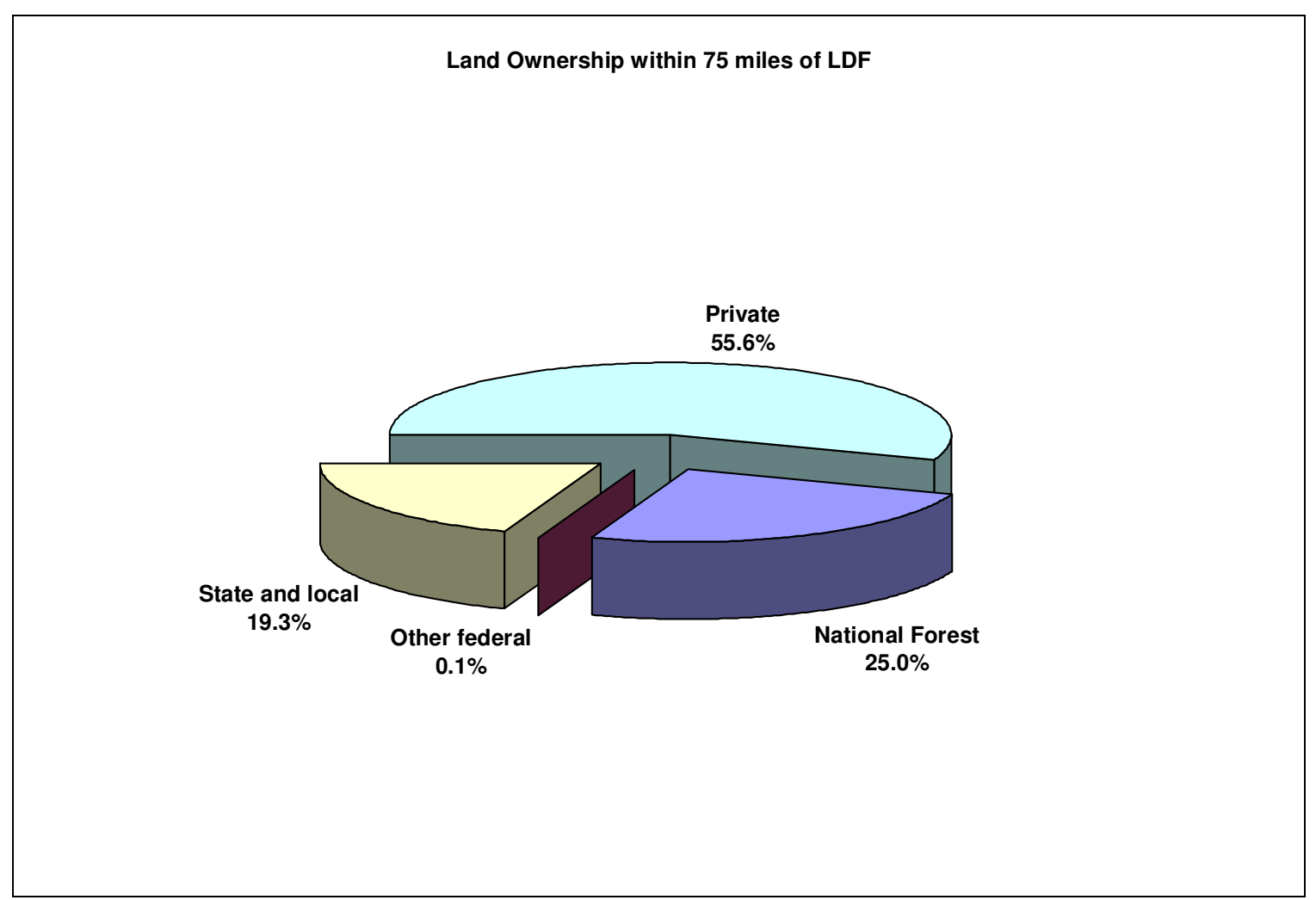

Figure 10: Land ownership within 75 miles of LDF

Private ownership accounts for 56 percent of the timberland acreage and public acreage accounts for just over 44 percent of the area. If timber resources are pursued in areas surrounding Lac du Flambeau, they will generally come from a mix of private and public lands. State and national contracts for biomass may be easier to shore up than pursuing many smaller contracts with private landowners.

Table 15 is a representation of timberland acreage from Lac du Flambeau at various distances. This is displayed by county for the surrounding areas. We would expect a four fold increase in timberland within a 50 mile radius versus 25 mile radius. We would expect a nine fold increase in timberland within a 75 mile radius versus 25 mile radius.

From Table 15 we notice a 7.7 fold increase in timber from 75 miles to 25 miles. This can be attributed to the loss of timber acres because of Lake Superior. In conclusion, we can determine that the timberland density is fairly even in Northern Wisconsin and Michigan and that pursuing resources in any direction of Lac du Flambeau would be appropriate. However, transportation routes may be more of a limiting factor than timber density that is currently being pursued. 
Table 15: Area of timberland at various distances from Lac du Flambeau

\begin{tabular}{|r|c|c|c|c|}
\hline & \multicolumn{2}{|c|}{ Area of Timberland at Different Distances from Lac du Flambeau (Acres) } \\
\hline County & $\begin{array}{c}\text { Total County } \\
\text { Acreage }\end{array}$ & $\begin{array}{c}\text { 25 Mile Radius } \\
\text { from LDF }\end{array}$ & $\begin{array}{c}\text { 50 Mile Radius } \\
\text { from LDF }\end{array}$ & $\begin{array}{c}\text { 75 Mile Radius } \\
\text { from LDF }\end{array}$ \\
\hline Baraga, MI & 517,515 & 0 & 0 & 46,165 \\
\hline Gogebic, MI & 612,283 & 38,105 & 606,395 & 612,283 \\
\hline Houghton, MI & 511,923 & 0 & 0 & 173,237 \\
\hline Iron, MI & 682,860 & 0 & 36,145 & 461,273 \\
\hline Ontonagon, MI & 683,075 & 0 & 209,789 & 632,187 \\
\hline Ashland & 439,510 & 36,842 & 341,633 & 439,510 \\
\hline Bayfield & 765,309 & 0 & 0 & 336,966 \\
\hline Chippewa & 239,788 & 0 & 0 & 16,303 \\
\hline Florence & 276,364 & 0 & 0 & 173,791 \\
\hline Forest & 552,316 & 0 & 97,343 & 521,994 \\
\hline Iron & 481,992 & 220,965 & 475,676 & 481,992 \\
\hline Langlade & 398,215 & 0 & 37,902 & 350,975 \\
\hline Lincoln & 392,657 & 0 & 287,355 & 392,657 \\
\hline Marathon & 415,865 & 0 & 0 & 173,807 \\
\hline Oneida & 570,374 & 249,109 & 562,192 & 570,374 \\
\hline Price & 625,469 & 153,715 & 605,732 & 625,469 \\
\hline Rusk & 401,143 & 0 & 13,320 & 250,718 \\
\hline Sawyer & 624,886 & 0 & 129,611 & 549,211 \\
\hline Taylor & 378,660 & 0 & 60,092 & 365,616 \\
\hline Vilas & 482,191 & 294,904 & 482,191 & 482,191 \\
\hline Acres & $\mathbf{1 0 , 0 5 2 , 3 9 5}$ & $\mathbf{9 9 3 , 6 4 0}$ & $\mathbf{3 , 9 4 5 , 3 7 6}$ & $\mathbf{7 , 6 5 6 , 7 1 9}$ \\
\hline
\end{tabular}

Acres of timberland at various radii

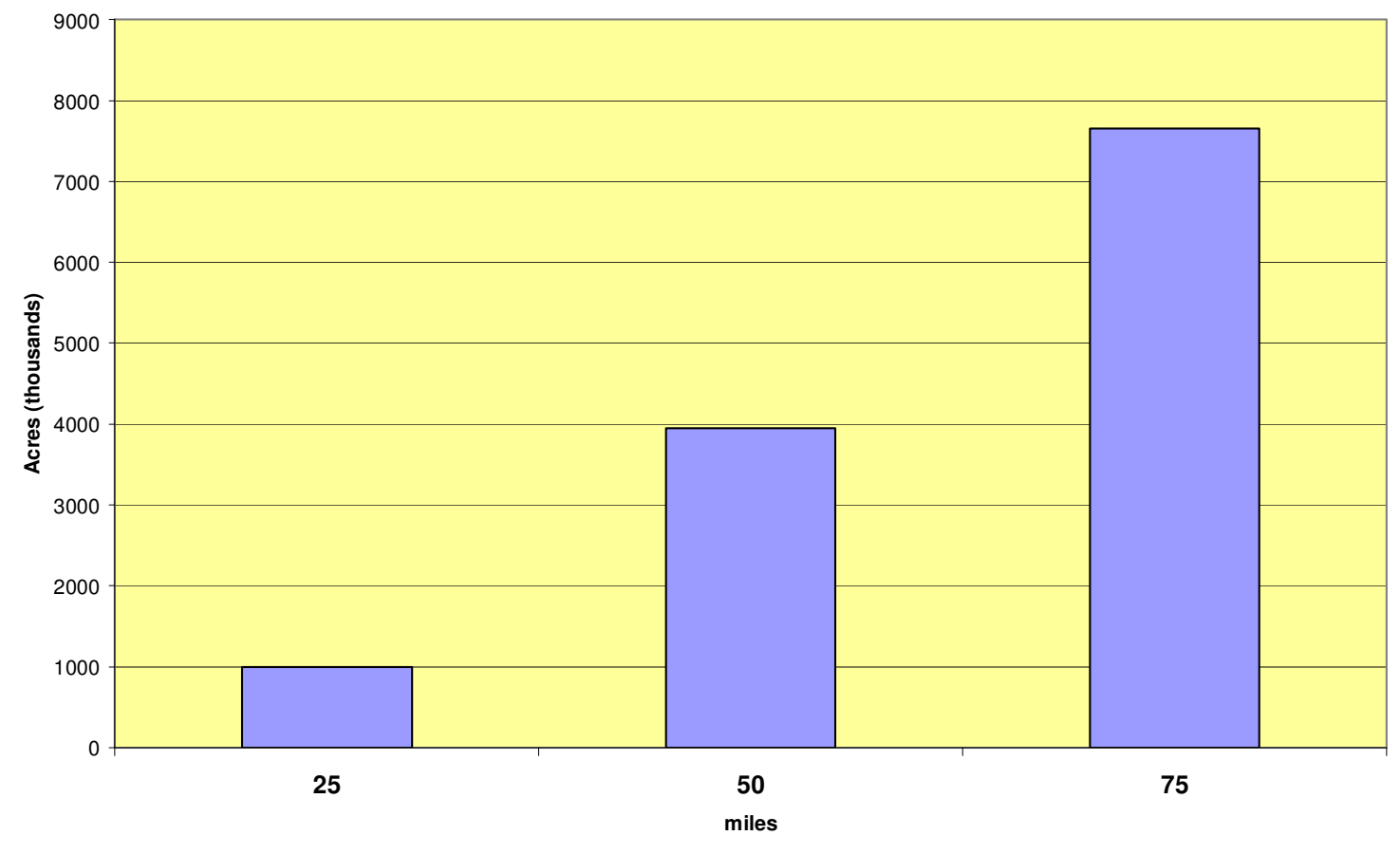

Figure 11: timberland acres within 75 miles of LDF 
The overall Forest Service analysis demonstrates the vast resource potential in areas surrounding Lac du Flambeau. A general rule in biomass resource aggregation is a limitation factor of 50 miles. Thus, it is not desirable to haul or deliver biomass materials over-the-road beyond a 50 mile radius. Traditionally this seem reasonable, however, given some of the higher value end products such as wood pellets or transportation fuels in the case of Flambeau River Biofuels, the resource aggregation radius may be expanded.

\subsubsection{Mill residue by radii}

There are a number of sources for residue, including mill residues, residues from primary logging operations, and residues from logging activities unrelated to harvesting such as thinning of trees and removal of trees on land that is undergoing development. Mill residue is the most desirable of these options as the biomass is generally seasoned or even dried, considered a waste product, and is more concentrated than logging residue. Until recently, mill residue has been viewed as a high value material to secondary users such as pellet mills and of little value to mill operators. A study by the U.S. Forest Products Laboratory discovered that about 98 percent of mill residue was reportedly being used for other products and energy (McKeever and Falk, 2004). With only two percent available for theoretical use, it would be difficult and costly to pursue the use of mill residues alone for energy purposes.

\section{Primary Mill Residue}

Primary mill residue is wood material and bark that is generated at manufacturing plants from round wood processed into principal products. These residues include wood products which are obtained incidentally when producing principal products and wood materials but are not utilized for some byproducts (Reading et al, 2007).

There are a total of 737,161 dry tons of mill residues produced within a 75 mile radius of Lac du Flambeau. However, the vast majority of this material currently has a use as shown in Table 16. There are 5,911 dry tons of unused mill residues. This value is less than one-percent of the total mill residues in this area.

Table 16: Total mill residue with in 75 miles of Lac du Flambeau

\begin{tabular}{|c|c|c|c|c|}
\hline \multicolumn{5}{|c|}{ Total mill residue within a 75 mile radius of Lac du Flambeau and How } \\
it is utilized (Dry Tons) \\
\hline $\begin{array}{c}\text { Total Mill } \\
\text { Residue } \\
\text { Produced }\end{array}$ & $\begin{array}{c}\text { Fiber } \\
\text { Byproducts }\end{array}$ & $\begin{array}{c}\text { Fuel } \\
\text { Byproducts }\end{array}$ & $\begin{array}{c}\text { Miscellaneous } \\
\text { Byproducts }\end{array}$ & $\begin{array}{c}\text { Unused } \\
\text { Mill } \\
\text { Residues }\end{array}$ \\
\hline 737,161 & 289,771 & 379,458 & 62,017 & 5,911 \\
\hline
\end{tabular}

Mill residues have economic value and are not readily available for new uses at this time. Examining the aggregation of mill residue would be a much larger task than focusing on residue closer to Lac du Flambeau. It is recommended to call saw mills within 75 of Lac du Flambeau to determine more updated and real-time estimates of residue totals and costs. 


\section{Secondary Mill Residue}

Secondary mill residue is residue generated by secondary mills producing pallets, furniture, flooring, paper and paper products. Residues include sawdust and sander dust, wood chips and shavings, board and cut-offs, and miscellaneous scrap wood (Perlack, 2005).

There is no data on the amount of secondary mill residue produced each year. The Billion Ton Report does reference a study from 1999 that suggests there are about 15.6 million dry tons produced per year for the entire country. About 60 percent of this is used for fuel and other products. The remaining unused 40 percent may be available for other purposes (Perlack, 2005).

\subsubsection{Other removals}

Other removals are the unutilized wood volume of trees cut or otherwise killed by cultural operations (e.g., precommercial thinnings), or land clearings to non-forest uses. Other removals can include trees removed from the inventory by cultural operations such as timber stand improvement, land clearing, and other changes in land use that result in the removal of the trees from timberland. Other removals do not include volumes removed from the inventory by reclassification of timberland to productive reserved forestland (Steltzer et al., 2008).

Other removals are another source of woody biomass that are presently underutilized. Table 17 shows the green-ton values of other removals for each county within 75 miles of Lac du Flambeau. 
Table 17: Volume of other removals

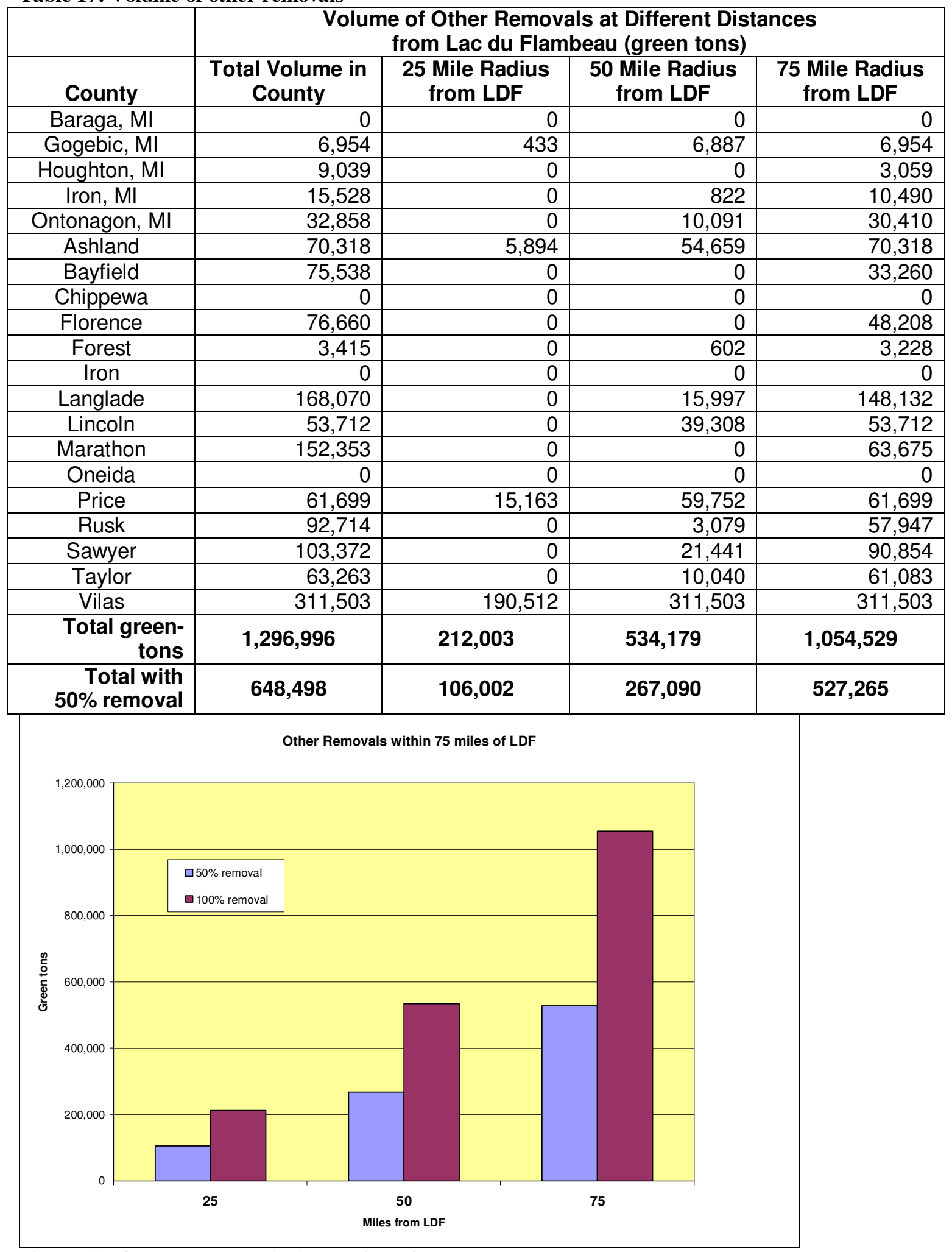

Figure 12: Other removal within 75 miles of LDF 
Similar to logging residue, not all the other removals are available for new uses. The Billion Ton Report suggests that about 50 percent of other removals are able to be harvested and utilized. This is mostly due to the difficulty in collecting the material from smaller more diversified areas of land and because other wood includes smaller portions of material (Perlack et al., 2005).

\subsubsection{Logging residues}

Logging residue is the unused portions of trees cut, or killed by logging, that is left in the woods (Shifley, 2002). These residues are currently under-utilized and there value is quite variable at the time of this report. As markets develop for residue, prices will tend to follow that of cordwood.

The data for logging residues come from the US Forest Service Timber Output Report where data is reported by county. It is difficult to assess the residue potentials for given areas as different harvest practices will result in different volumes of removable residue. In addition, maintaining a healthy forest requires that some residue be left on the ground after harvest. Brush and residue piles provide cover for small game and regional birds. Such materials can also be used for nesting and shelters for such animals. Land owners may desire to have residues removed to provide a more 'park like' appearance or for fire prevention.

In some areas including Northern Wisconsin, removal of residue translates to fire prevention. In a conversation with a Wisconsin DNR Forester Ranger for Northern Wisconsin, it was stated that 51 percent of his job has been devoted to fire control and education. ${ }^{16}$ Over the last ten years, federal agencies have spent more than $\$ 8.2$ billion in fighting forest fires which have consumed over 49 million acres (U.S. DOE, 2005). The Healthy Forest Restoration Act (HFRA) of 2003 was created to encourage the removal of hazardous fuels and to protect, restore, and enhance forest ecosystem components. HFRA was also created to overcome market barriers to greater utilization of the residue (U.S. DOE, 2005). During the writing of this report, the Wisconsin DNR developed a draft report outlining acceptable residue removal volumes for a timber harvest site. In the report, it is stated to retain a minimum of 5 oven-dry ton/acre of residue for even-aged rotations and a miminum of 1 ton/acre for even-aged intermediate treatments and unevenaged systems. $^{17}$

In most cases, logging residue is left in the forest. Table 18 summarizes the availability of residue at various radii from different timber harvests. A growing-stock tree at least 5.0 inches d.b.h. but smaller than sawtimber size (9.0 inches d.b.h. for softwoods, 11.0 inches d.b.h. for hardwoods). Nongrowing-stock is defined as the net volume removed from the nongrowing-stock portions of poletimber and sawtimber trees (stumps, tops, limbs, cull sections of central stem) and from any portion of a rough, rotten, sapling,

\footnotetext{
${ }^{16}$ Information taken from an interview on October 15, 2008 with Jed Kaurich, Wisconsin DNR Forester Ranger for Northern Wisconsin, Barnes, WI.

17 Taken from a draft report of "Wisconsin's Forestland Woody Biomass Harvesting Guidelines."

Wisconsin Council of Forestry and Wisconsin DNR. September 22, 2008.
} 
dead, or non-forest trees. It is timber which is not used for pulpwood or sawtimber purposes. Nongrowing stock removals can be greater in situations where whole trees are chipped for fuel. In such instances, non-forest land will be targeted and non-growing stock may be 50 percent and 30 percent of the total stand for softwood and hardwood stands, respectively.

Questions have been raised concerning the health of forest land if logging residue is removed. Concerns range from the impact on the soil, insect, animal, bird and plant life to damage to streams and lakes. Minnesota has worked on developing guidelines to preserve forest land, while also making use of logging residues. Guidelines recommend leaving slash, snags and other harvest remains from past years in the forest (Biomass Harvesting, 2007). For current harvests, it is suggested that 30 percent of the logging residue be left behind (Reading et al., 2007). In cases such as the Lac du Flambeau tribal area, soil conditions are above average and can support full removal of residue. However, it is unknown if this is best practice. Though the soil conditions may allow full removal of residue, this is not always possible. It should be noted that under conventional harvest practices, only 60 percent of residue is recoverable while up to 90 percent is recoverable under whole tree harvest practice (Stokes, 1992).

Currently, Wisconsin does not have residue removal recommendations in place. However, according to Terry Mace at the Department of Natural Resources, there will be research done soon, using Minnesota's research as a starting point. ${ }^{18}$

Based on the Minnesota guidelines, 30 percent of the logging residue for each radius was removed from the total. Table 18 shows residues totals at 70 percent removal (Biomass, 2007).

Table 18: Available Volume of Logging Residue within 75 miles of LDF

\begin{tabular}{|r|r|r|r|}
\hline \multicolumn{1}{|c|}{ Available volume of logging residue (Green Tons) } \\
\hline \multicolumn{1}{|c|}{$\begin{array}{c}\text { Source } \\
\text { 25 Mile Radius from } \\
\text { LDF }\end{array}$} & $\begin{array}{c}\text { 50 Mile Radius from } \\
\text { LDF }\end{array}$ & $\mathbf{7 5}$ Mile Radius from LDF \\
\hline $\begin{array}{r}\text { Non-growing Stock } \\
\text { Poletimber Growing } \\
\text { Stock }\end{array}$ & 199,561 & 852,371 & $1,753,237$ \\
\hline $\begin{array}{r}\text { Sawtimber Growing } \\
\text { Stock }\end{array}$ & 10,372 & 50,248 & 104,515 \\
\hline Total & 16,552 & 77,766 & 169,418 \\
\hline $\begin{array}{r}\text { with 70\% } \\
\text { removal }\end{array}$ & $\mathbf{2 2 6 , 4 8 6}$ & $\mathbf{9 8 0 , 3 8 5}$ & $\mathbf{2 , 0 2 7 , 1 7 0}$ \\
\hline
\end{tabular}

18 Mace, Terry, Department of Natural Resources, Forest Resource Analyst, interview on June 13, 2008. 


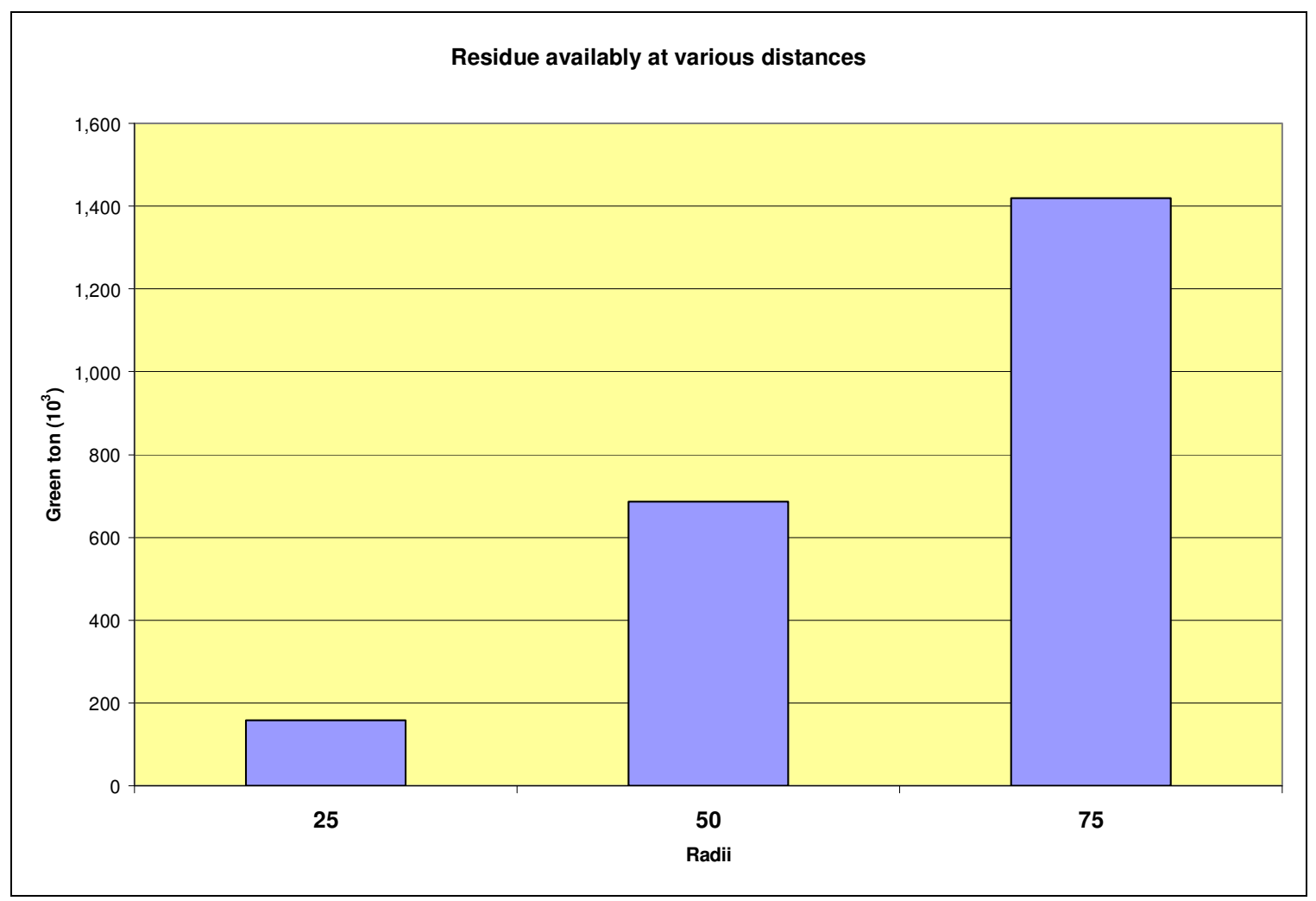

Figure 13: Residue totals within 75 miles of LDF

Figure 13 shows the volume of residues at 70 percent removal for various distances from Lac du Flambeau. Nearly 1.4 million green tons are available within a 75 mile radius of Lac du Flambeau while nearly 200,000 green-tons of residue are available within a 25 mile radius.

Logging residue totals for each county within 75 miles of Lac du Flambeau were calculated. If the entire county did not fall within the given radius, a percentage of the county residue total was used. These logging residues in green tons are shown in Table 19 for distances of 25, 50, and 75 miles. 
Table 19: Volume of logging residue by county (estimates)

\begin{tabular}{|c|c|c|c|}
\hline \multicolumn{4}{|c|}{$\begin{array}{l}\text { Volume of Logging Residue at Different Distances from } \\
\text { Lac du Flambeau (green tons) }\end{array}$} \\
\hline County & $\begin{array}{l}25 \text { Mile Radius } \\
\text { from LDF }\end{array}$ & $\begin{array}{l}50 \text { Mile Radius } \\
\text { from LDF }\end{array}$ & $\begin{array}{l}75 \text { Mile Radius } \\
\text { from LDF }\end{array}$ \\
\hline Baraga, Ml & 0 & 0 & 333,626 \\
\hline Gogebic, MI & 243,905 & $3,881,461$ & $3,919,149$ \\
\hline Houghton, MI & 0 & 0 & $1,413,620$ \\
\hline Iron, Ml & 0 & 225,177 & $2,873,647$ \\
\hline Ontonagon, MI & 0 & $1,064,948$ & $3,209,160$ \\
\hline Ashland & 680,183 & $6,307,281$ & $8,114,301$ \\
\hline Bayfield & 0 & 0 & $2,788,973$ \\
\hline Chippewa & 0 & 0 & 134,938 \\
\hline Florence & 0 & 0 & $2,577,940$ \\
\hline Forest & 0 & $1,288,782$ & $6,910,989$ \\
\hline Iron & $1,600,932$ & $3,446,359$ & $3,492,120$ \\
\hline Langlade & 0 & 769,545 & $7,126,033$ \\
\hline Lincoln & 0 & $4,042,174$ & $5,523,439$ \\
\hline Marathon & 0 & 0 & $2,237,566$ \\
\hline Oneida & $2,884,776$ & $6,510,395$ & $6,605,146$ \\
\hline Price & $1,329,077$ & $5,237,386$ & $5,408,039$ \\
\hline Rusk & 0 & 138,405 & $2,605,155$ \\
\hline Sawyer & 0 & $2,203,672$ & $9,337,794$ \\
\hline Taylor & 0 & 549,551 & $3,343,616$ \\
\hline Vilas & $2,411,154$ & $3,942,425$ & $3,942,425$ \\
\hline Total Green Tons & 226,486 & 980,385 & $2,027,170$ \\
\hline $\begin{array}{r}\text { Total Green Tons } \\
\text { ( } 70 \% \text { removal) }\end{array}$ & 158,540 & 686,270 & $1,419,019$ \\
\hline
\end{tabular}

Table 19 can be used as a quick reference for biomass residue availability by county. There is a total of around 2 million green tons of residue within a 75 mile radius of Lac du Flambeau. Recommended removal totals are estimated at just over 1.4 million green tons.

\subsubsection{Cordwood resource availability}

As shown earlier, residue and cordwood are two of the most viable options for thermal usage in offsetting LP due to their economic viability when compared to high priced LP. Cordwood from the three major timber sources is displayed in Table 20. Cord wood from poletimber, sawtimber, and non-growing stock values are shown below. Table 20 displays these values in green-tons.

Table 20: Volume of roundwood at various distances from LDF

\begin{tabular}{|l|r|r|r|}
\hline \multicolumn{4}{|c|}{ Volume of Roundwood at various distances from Lac du Flambeau (green tons) } \\
\hline \multicolumn{1}{|c|}{ Source } & $\begin{array}{r}\text { 25 Mile Radius from } \\
\text { LDF }\end{array}$ & $\begin{array}{c}\text { 50 Mile Radius from } \\
\text { LDF }\end{array}$ & $\begin{array}{c}\text { 75 Mile Radius from } \\
\text { LDF }\end{array}$ \\
\hline $\begin{array}{l}\text { Poletimber Growing } \\
\text { Stock }\end{array}$ & 204,932 & 885,709 & $1,722,303$ \\
\hline $\begin{array}{l}\text { Sawtimber Growing } \\
\text { Stock }\end{array}$ & 296,576 & $1,267,188$ & $2,597,449$ \\
\hline $\begin{array}{l}\text { Non-growing Stock } \\
\text { Portion of Poletimber } \\
\text { and Sawtimber }\end{array}$ & 112,535 & & \\
\hline Total & $\mathbf{6 1 4 , 0 4 2}$ & 516,117 & $1,063,440$ \\
\hline
\end{tabular}




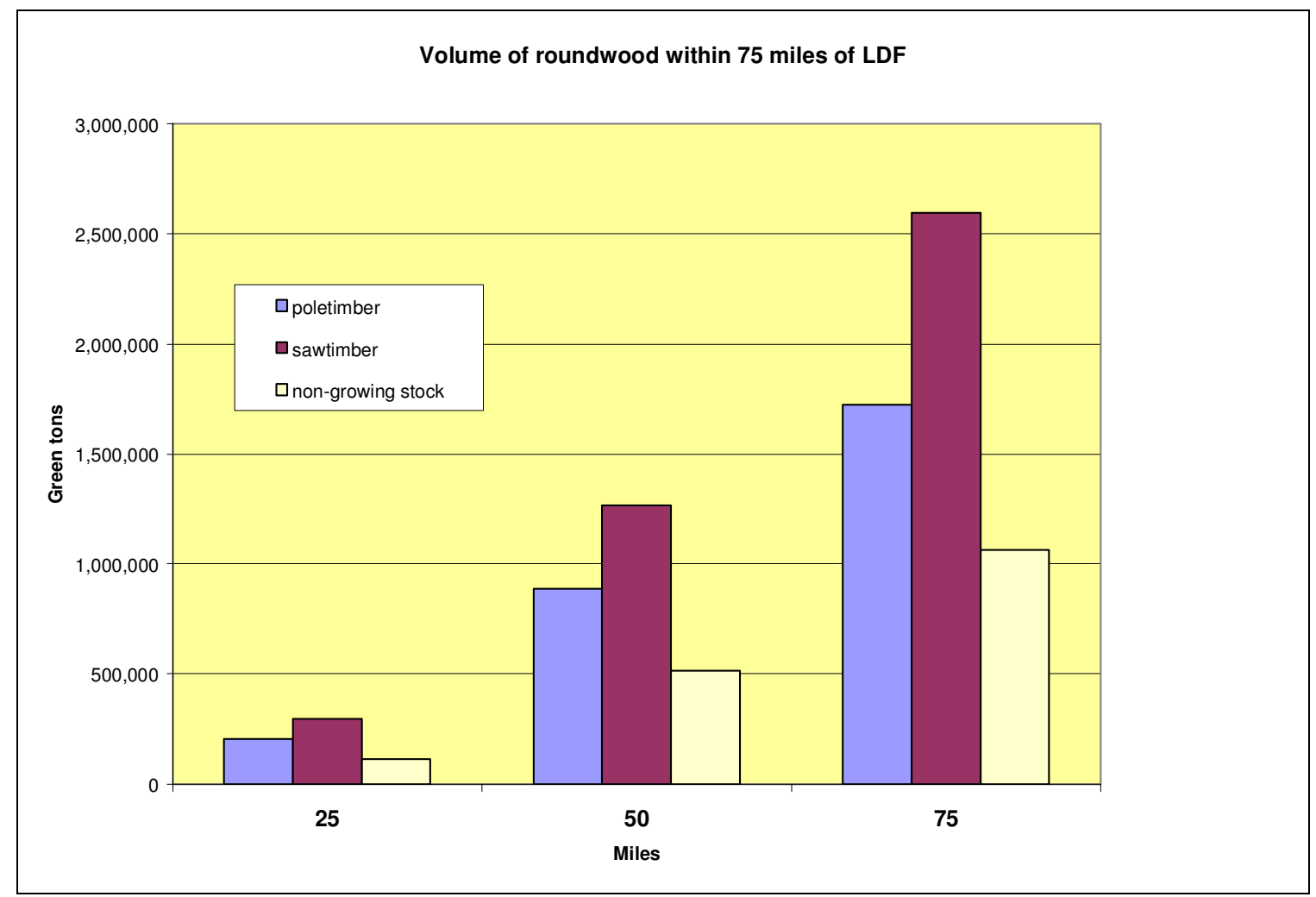

Figure 14: Volume of roundwood within 75 miles of LDF

Table 20 shows roundwood volumes from various sources. Poletimber growing stock would include trees such as aspen while sawtimber growing stock might include species such as pine and birch. When compared to Table 18 residue total for various radii, roundwood totals are nearly four-fold that of residue. This simplistic observation can be used as a tool to gauge residue potentials when cordwood is known. Figure 14 shows that the major source of roundwood comes from sawtimber operations and stand while the lowest values come from non-growing stock. 


\section{National and state opportunities}

\subsection{National Forests}

Northern Wisconsin and Upper Michigan have a vast biomass resource which is used in many different streams. The national, state, and non-industrial forest lands comprise 71 percent or the 16 million acres of forest land in Wisconsin. Chequamegon-Nicolet National Forest and Northern Highland American Legion State Forest are located in northern Wisconsin (Ahl et al., 2005). There are also many non-industrial private forests enrolled in the managed forest laws of Wisconsin.

In many cases timber is first managed by a forester land owner. The merchantable roundwood is harvested by a purchasing company, transported by truck or rail, and processed by a primary milling company. The product is then transported to a secondary milling company, distribution warehouse, and/or to the consumer (Ahl et al., 2005).

Much of the timber harvested from the Chequamegon-Nicolet National Forests is harvested for pulp wood and then sent to various locations, including Park Falls Paper Company, the Fox River Area, Wisconsin Rapids, Port Edwards, Neenah, Duluth, Tomahawk, and Upper Michigan. Timber is hauled via railcar and over-the-road trucks. Much of the sawlogs which are harvested in the national forest are processed locally at nearby sawmills.

\subsection{State and county forest removals}

The state forests of Wisconsin total over 490,000 acres and are made up of eight different forests. Timber contract areas are woven between the habitat locations of endangered and special concern species. Many considerations are given to harvest sites on state and county lands. Safety protection, fire prevention, and aesthetics are incorporated into the harvest bid wherever applicable (Wisconsin DNR, 2008).

Table 21 shows timber contracts on state and county forest land for various areas around Lac du Flambeau. ${ }^{19}$ Information is shown by number of sales, sawlog totals, cordwood totals, along with total sales from each area.

\footnotetext{
${ }^{19}$ Information provided by John Gritt of the Wisconsin DNR on July 29, 2008.
} 
Table 21: County and state harvest totals around LDF [Wisc. DNR: fiscal year 2008]

\begin{tabular}{|c|c|c|c|c|c|c|}
\hline \multicolumn{7}{|l|}{ County Forests } \\
\hline & $\begin{array}{l}\text { No. } \\
\text { Sales }\end{array}$ & $\begin{array}{c}\text { All } \\
\text { Sawlogs } \\
\text { (MBF) }\end{array}$ & $\begin{array}{l}\text { Total } \\
\text { Cordwood } \\
\text { (Cords) }\end{array}$ & $\%$ sawlogs & $\begin{array}{c}\% \\
\text { cordwood }\end{array}$ & $\begin{array}{c}\text { Total Sales } \\
\text { Value }\end{array}$ \\
\hline Ashland & 15 & 438 & 18,114 & $4.6 \%$ & $95.4 \%$ & $\$ 837,795$ \\
\hline Bayfield & 56 & 832 & 51,198 & $3.1 \%$ & $96.9 \%$ & $\$ 2,225,878$ \\
\hline Florence & 13 & 112 & 16,197 & $1.4 \%$ & $98.6 \%$ & $\$ 687,335$ \\
\hline Forest & 7 & 120 & 16,197 & $1.5 \%$ & $98.5 \%$ & $\$ 687,335$ \\
\hline Iron & 32 & 631 & 34,065 & $3.6 \%$ & $96.4 \%$ & $\$ 1,232,363$ \\
\hline Langlade & 53 & 996 & 49,094 & $3.9 \%$ & $96.1 \%$ & $\$ 1,834,340$ \\
\hline Lincoln & 45 & 425 & 33,126 & $2.5 \%$ & $97.5 \%$ & $\$ 1,508,339$ \\
\hline Oneida & 14 & 445 & 22,559 & $3.8 \%$ & $96.2 \%$ & $\$ 932,714$ \\
\hline Price & 25 & 717 & 25,253 & $5.4 \%$ & $94.6 \%$ & $\$ 1,063,542$ \\
\hline Sawyer & 45 & 2,581 & 71,350 & $6.7 \%$ & $93.3 \%$ & $\$ 2,693,648$ \\
\hline Taylor & 14 & 344 & 10,897 & $5.9 \%$ & $94.1 \%$ & $\$ 506,229$ \\
\hline Vilas & 15 & 197 & 12,814 & $3.0 \%$ & $97.0 \%$ & $\$ 478,145$ \\
\hline \multicolumn{7}{|l|}{ State Forests } \\
\hline & $\begin{array}{l}\text { No. } \\
\text { Sales }\end{array}$ & $\begin{array}{c}\text { All } \\
\text { Sawlogs } \\
\text { (MBF) }\end{array}$ & $\begin{array}{c}\text { Total } \\
\text { Cordwood } \\
\text { (Cords) }\end{array}$ & \% sawlogs & $\begin{array}{c}\% \\
\text { cordwood }\end{array}$ & $\begin{array}{c}\text { Total Sales } \\
\text { Value }\end{array}$ \\
\hline Brule River & 3 & 0 & 1,267 & $0.0 \%$ & $100.0 \%$ & $\$ 39,648$ \\
\hline Black River & 15 & 233 & 8,643 & $5.1 \%$ & $94.9 \%$ & $\$ 378,684$ \\
\hline $\begin{array}{r}\text { American } \\
\text { Legion }\end{array}$ & 8 & 130 & 10,278 & $2.5 \%$ & $97.5 \%$ & $\$ 392,656$ \\
\hline $\begin{array}{r}\text { Governor } \\
\text { Knowles }\end{array}$ & 4 & 0 & 7,218 & $0.0 \%$ & $100.0 \%$ & $\$ 136,636$ \\
\hline $\begin{array}{r}\text { Flambeau } \\
\text { River }\end{array}$ & 17 & 726 & 17,720 & $7.6 \%$ & $92.4 \%$ & $\$ 651,426$ \\
\hline $\begin{array}{r}\text { Nothern } \\
\text { Highland }\end{array}$ & 12 & 891 & 21,406 & $7.7 \%$ & $92.3 \%$ & $\$ 1,048,949$ \\
\hline $\begin{array}{r}\text { Kettle Moraine } \\
\text { - Southern } \\
\text { Unit }\end{array}$ & 3 & 0 & 1,988 & $0.0 \%$ & $100.0 \%$ & $\$ 56,031$ \\
\hline $\begin{array}{r}\text { Griffith } \\
\text { Nursery }\end{array}$ & 1 & 0 & 476 & $0.0 \%$ & $100.0 \%$ & $\$ 17,627$ \\
\hline
\end{tabular}

Table 21 shows that the harvested timber is dominated by cordwood sales. Cordwood values make up over 95 percent of the harvested timber by volume, while sawtimber makes up less then five percent. Currently, residues are not being harvested on state lands though there is a suspected potential in the near future. ${ }^{20}$ Utilizing state forest land around the Lac du Flambeau region for both cordwood and residue resources would be a viable option for energy related purposes. If a substantial shift toward biomass is considered on tribal land, low cost residues on state and county lands within 50 miles of Lac du Flambeau should be considered first.

It is clear by the percentage of cordwood removed from state and county lands in Northern Wisconsin, that the pulp and paper industry are the dominate sectors. It is unclear whether cordwood harvested on state land is distributed for other purposes.

\footnotetext{
${ }^{20}$ Personal Communication, Jim Halverson, Wisconsin DNR: Flambeau River State Forester, July 28, 2008.
} 
Much of the saw timber that is harvested is processed in local mills. The size of the contracts on state and county forests would be beneficial when contracting for residues as the aggregated resource would be more concentrated. In addition, fewer overall contracts would be necessary to achieve a complete biomass offset. Stricter guidelines are being developed for residue removal on public lands which can add to the costs of removals and potentially lower residue removal volumes.

Many concerns exist over the movement of timber from areas of Wisconsin which exists in quarantined counties to non-quarantined area. For example, emerald ash borer that has been found in trees in southeast Wisconsin might be used in boilers located in northern Wisconsin. Both federal and state guidelines exist for emerald ash borer. The Wisconsin Department of Agricultural Trade and Consumer Protection (DATCP) has noted that emerald ash borer may result in the further utilization of wood fired boilers to eliminate infected timber. This could result in excess biomass potential for various areas of Wisconsin. ${ }^{21}$

\subsection{Major landowner policies for Wisconsin residue ${ }^{22}$}

Federal: On the Chequamegon-Nicolet National Forest all timbersales are done on a lump sum bases with utilization requirement to four-inch tops. There is no residue removal system in place at the National Forest, thus there is no cost value of such residue on site. There is no policy currently in place which forbids removal of forest residue.

State: Timber sales are not limited to tree top diameter. Instead, contractors bid based on utilization standards. The total sale bid determines which contractor will get the sale.

County: Of the 29 county forests in Wisconsin, residue values and policies vary dramatically. In some counties, residue values have not been addressed, while in others estimated residue totals are added to the total biomass volume up for sale.

Private Non-industrial: Members of the Managed Forest Law (MFL) program have witnessed fuelwood prices of $\$ 5 /$ cord to $\$ 13.53 /$ cord. A $5 \%$ severance tax must be paid on fuelwood sold from the property. For individuals not in the MFL program, fuelwood retains no value or land owners may pay to have it removed from the property.

\footnotetext{
${ }^{21}$ Data taken from the website, http://emeraldashborer.wi.gov/pdf/quarantineIssuesWithEAB08062008.pdf on December 10, 2008.

${ }^{22}$ The following contract data was taken from CleanTech Partners, Resource Availability study conducted in 2007. Information was taken from Technical Section 1.
} 


\section{Resource markets and potentials}

\subsection{Pulp and paper industry}

Wisconsin has a vast infrastructure for handling forest resources. Wisconsin's abundant biomass resources account for the 11 million green tons of cordwood which were processed in 1999. Hardwood species account for approximately 75 percent of the species removed. Forest materials are harvested and handled by approximately 1,100 loggers throughout Wisconsin (P Squared Group, LLC et al., 2008). These materials are sent to the 355 saw mills in operation in Wisconsin or to one of the pulp and paper mills within the state.

Paper mills are the largest competitor of forest biomass. Wisconsin is the United States' top paper producer. Over 5.3 million tons of paper and 1.1 million tons of paperboard are produced in Wisconsin annually. It is estimated that one in every twelve manufacturing jobs belongs to the pulp and paper industry (Wisconsin Paper Council, n.d.). There are currently 17 active pulp mills in Wisconsin which consume both harvested pulpwood and mill residues. In 1999, 3 million cords (7.5 million green tons) of pulpwood were harvested. Pulpwood volumes which go to the papermills have not fluctuated much since the 1999 report (P Squared Group, LLC et al., 2008).

\subsection{Forest Residue Markets}

\section{Flambeau River Biofuels}

Currently, residue that is generated from the harvest of timber in the national forest is not sold or used for any specific purpose. ${ }^{23}$ It is anticipated that these residues will have value in the near future as companies such as Flambeau Rivers Biofuels seeks forest byproducts and residues to make an anticipated six million gallons of liquid fuels annually. The biorefinery is expected to be operational by 2010 (Federal grant, 2008). The project is expected to use 1,900 tons of bone dry forest residue biomass annually. Futurewood Corporation will be the biomass resource aggregator and transporter for their venture. Futurewood is expecting to pull residue from a 150 mile radius of Park Falls in order to collect the needed materials (Flambeau River Biofuels, n.d.).

In talks with a representative for Futurewood Corporation, wood products used for Flambeau Rivers Biofuels, LLC will be residues and roundwood. The wood that is harvested will be around 50 percent moisture content. Futurewood stated that the boilers used at Flambeau Rivers Biofuels run inefficiently on such high moisture feedstocks. The biomass resources obtained by Futurewood will be left to air-dry during the summer months which is expected to lower the moisture content to near 30 percent. On average, 17 to 22 tons of roundwood can be hauled per truckload, while 25 tons of chipped wood

\footnotetext{
${ }^{23}$ Personal Communication, Carl Welch, US Forest Service, July 23, 2008.
} 
can be transported per truck load. As it is more difficult to dry chipped wood then roundwood, much of the chipping is completed before entering the biomass boilers. ${ }^{24}$

\section{Fuel For Schools}

Increased attention has been given in the past few years to utilizing wood for heating Wisconsin schools. A 2003 study by the Biomass Energy Resource Center (BERC) found that Wisconsin schools which pay over $\$ 125,000$ annually for natural gas, $\$ 100,000$ for fuel oil, or $\$ 75,000$ for propane are good candidates for biomass heat. The study found about 100 schools in the northern two-thirds of the state which would be good candidates for biomass based upon the above criteria. Schools are good candidates for biomass heating as they have access to long-term (10-20 year), low interest financing. In some cases a positive cash flow will be noticed the first year of installation.

The study focused on utilizing green hardwood chips for biomass boilers for schools. Sawdust, shaving, and bark are poor fuels for boilers, and should be avoided. It is very possible for residue to be used in these instances. The study examined economic scenarios at FOB delivered prices of \$30/ton for chipped fuel (BERC, 2003).

As this study has examined prices at or near this value, residue from the tribal region could be used for the Lac du Flambeau School or for other nearby school as well. Lac du Flambeau school LP costs have exceeded $\$ 75,000$ since 2003, meeting the criteria set forth in the study.

\section{Xcel Energy Plant}

Xcel Energy's Bay Front generation plant in Ashland, Wisconsin has examined the potential of converting their remaining coal consumption for energy to 100 percent biomass. The report examined a radius of 50 miles for biomass resource availability. It was estimated that approximately 360,000 tons per year of green chipped wood would be needed to obtain this goal. The primary sources examined in the study were harvest residue, mill residue, and dedicated biomass crops such as planted short rotation wood crops.

The volume of residue in the 50 mile radius is estimated to be quite large and capable of providing the volume of green wood needed. One inhibitor is that residue is not regularly collected. Prices of residue would have to be negotiated with individual logging operations to encourage them to expand operations enabling them to collect, chip, and deliver the residue at a price competitive with other biomass resources (Kramer et. al., 2007).

\subsection{Biomass Commodity Exchange}

Efforts are underway to develop a biomass commodity exchange for Wisconsin. The exchange would boost efficiency of the supply chain that provides biomass to the existing biobased fuels industries, particularly for the emerging concept for biorefineries. In

\footnotetext{
${ }^{24}$ Personal Communication with TJ of Futurewoods Corporation.July 28, 2008.
} 
addition, the exchange will seek to leverage future trade of closed-loop energy crops, such as willow, poplar, and switchgrass and as an offset to $\mathrm{CO}_{2}$ emissions through other regulated exchanges (US Forest Service, 2007).

There are two main benefits for the Lac du Flambeau tribe in regards to the commodity exchange. First, the exchange will reduce the cost of trading biomass products as well as reduce the uncertainty of who is buying and selling timber, as the exchange will be on a membership basis and full company information will be disclosed. In addition, the exchange will act to resolve commodity disputes and handle arbitration agreements. There will be penalties for companies which do not harvest in ethical manners or who do not fulfill all requirements of the timber contracts. Secondly, the exchange will act as a trading point where businesses and land owners can find potential timber sellers and purchasers. In addition, an exchange member will be able to better determine cost potentials, gauge the demand for resources, and negotiate rates to move a sale. Ultimately, the exchange will expand the search for wood and set up a standard price structure for all forms of biomass based upon monthly average prices obtained from commodity exchanges. These values will be more accurate then traditional stumpage rates. $^{25}$

The exchange is an organic institute which will float resource potentials and their uses. Currently, woody biomass utilization is centered on the pulp and paper industry. These prices in many areas of Wisconsin are near $\$ 50$ per ton for cordwood. As biomass becomes a feedstock for ethanol and diesel fuel, prices of woody biomass will trend that of petroleum. ${ }^{25}$

\subsection{Cellulosic Ethanol Potentials}

The shift towards cellulosic ethanol and transportations fuels is underway. In February 2007 , the Department of Energy announced that they would provide $\$ 385$ million dollars in grant money to bolster six cellulosic ethanol facilities in the United States, with a plant is South Dakota being the closest to Wisconsin. When fully operational, the biorefineries are expected to produce more than 130 million gallons of cellulosic ethanol per year. Cellulosic ethanol is part of President Bush's plan to make such fuels cost-competitive with gasoline by 2012. The ultimate goal is to reduce America's gasoline consumption by 20 percent in ten years (Department of Energy, 2007). As more cellulosic ethanol facilities come on-line, Wisconsin can expect to be a central location for a facility based upon their current feedstock volumes. ${ }^{25}$

\footnotetext{
${ }^{25}$ Personal Communication, Stephen Dinehart, Project Manager: Biomass Commodity Exchange, July 28, 2008.
} 


\section{Combined Heat and Power}

\subsection{History of CHP}

Combined Heat and Power (CHP) systems were implemented as early as the nineteenth century. In the 1880's the first electric generators were powered by reciprocating steam engines. A large amount of waste steam was generated due to the inefficiency of these power stations. This waste steam was sent through pipelines for process use or building heat in a system called district heating. In 1884 the Del Coronado Hotel was the first to be implemented with district heating. Reciprocating steam engines were later replaced with larger, more efficient turbine generating systems. From 1902 to 1932 the efficiencies of the power stations improved from 3.7 percent to 16.5 percent. In the early $20^{\text {th }}$ century the fuel of choice became coal due to its availability and its affordability. The public's opposition to coal-fired power plants due to coal dust and flue gas particulate emissions caused the power plants to be moved out of the city. The capture and transmission of heat energy became uneconomical due to the new, more remote locations of the coal-fired power stations (University of Massachusetts, 2005).

CHP systems were in use in many areas during the mid $20^{\text {th }}$ century but the use of CHP systems became more feasible with the help of federal legislation. In 1978 the Public Utilities Regulatory Act (PURPA) was passed to promote greater use of renewable energy and to increase the thermal efficiency of the energy production process. PURPA helped overcome many of the market barriers the CHP systems faced. However, a competitive market created many new hurdles for CHP systems. Most of the legislative reform has been done at the state and not the federal level. Some states are adopting rules that discourage CHP systems while others are encouraging their development by exempting CHP facilities from fees and charges and passing legislation that opens electricity markets (Kaarsberg \& Elliot, 2001).

\subsection{Types of CHP systems}

There are three major technologies transforming biomass into useable energy: Anaerobic Digestion, Direct Combustion and Gasification. Anaerobic digestion uses biodegradable material and microorganisms to convert the material into methane. The methane that is produced is then used to produce power by means of an internal combustion engine, microturbine, gas turbine, fuel cell or Stirling engine. There are several different technologies utilizing biomass along with direct combustion, some of which include fixed bed boilers (stoker), fluidized bed boilers, cofiring and modular direct combustion technology. Each of these technologies use steam, hot water or hot air turbines to convert the heat produced from the biomass into electrical energy. Gasification is a biomass conversion process that creates useable fuel from woody biomass feedstocks. Biomass gasification creates a flammable gas by heating biomass in an oxygen deprived environment, thus breaking down the biomass but not burning it. Wood can be converted by means of fixed bed gasifiers, fluidized bed gasifiers, modular gasification technology and modular hybrid gasification/combustion. The hydrogen gas that is produced from the gasification process can then be used in gas turbines, internal combustion engines, fuel 
cell and Stirling engines to produce power (Energy and Environmental Analysis Inc., 2007).

New power turbines use recuperative technology. This systems does not function off of steam to produce power through a backpressure turbine, rather the unit utilizes refrigerants with lower boiling points to power a generator. This refrigerant is kept in a closed loop and is reused in the process. These systems are much more efficient and have just recently been installed in many locations. Hurst Boiler has coupled their technology with recuperative turbines in California. In talks with Hurst Boiler, the combined biomass boiler with turbine has performed well and many additional CHP ventures are underway. The refrigerant used in such waste-heat to power applications is an environmentally friendly refrigerant which can be tested and approved by the Environmental Protection Agency. This enables the system to be located in most any facility without restriction.

\subsection{Key Factors of Combined Heat and Power}

On a first cut basis, the initial item to be considered is the difference between electricity and natural gas. This is known as the "spark spread". The spark spread can be used as an economic estimator for combined heat and power. However, it should be noted that noneconomic issues such as emission restriction or utility interconnection issues can impede or halt a project completely. Overall, grid connected CHP evaluations are time intensive, and depend on the response time and cooperation of the electric utility. Such analysis can take over a month to complete.

Combined heat and power accounts for about 7 percent of the total electrical power in the United States (US Dept. of Energy: FEMP, 2004). Even with CHP's great potential, many facilities have not installed CHP because of the historical low tariff for electricity, high cost of CHP systems, limited capital budgets, custom engineering required during construction, lack of initial evaluation time, and interconnection and policy issues.

Ideal sites for combined heat and power will have a few of the following characteristics:

- High electric prices ( $>5$ cents $/ \mathrm{kWh}$ )

- Average electric load $>1 \mathrm{MW}$

- $\quad$ Ratio of average electric load to peak load $>0.7$

- A central or district heating and/or cooling system in place (or a need for process heat)

- $\quad$ Spark spread (difference in price per MBtu between gas and electricity) $>\$ 12$

- High annual operating hours (> 6000)

- Thermal demand closely matched to electric load

Prime CHP candidates are sites with a central boiler and chiller plant as well as a district heating and cooling plant. An increasing number of CHP applications are becoming feasible for single buildings as tariffs offer strong demand side management incentives through special rates structures and as CHP costs come down (US Dept. of Energy: FEMP, 2004). 


\subsection{Individualized analysis of CHP (LDF casino and hotel)}

The best opportunity for CHP in Lac du Flambeau is the casino and hotel facility. However, both places are heated with individualized personal heating and cooling units or individual rooftop units. Due to this HVAC set-up, no central chiller or boiler is in service. This would require a drastic overhaul of the heating system if $\mathrm{CHP}$ was to be implemented. A 399,000 btu/hr Munchkin boiler is being used to heat the hotel pool. Two 399,000 btu boilers and one 200,000 btu boiler are being used to heat domestic hot water for the hotel. In addition, casino domestic hot water is supplied by two 260,000 btu boilers along with seven other electric water heater units. ${ }^{26}$ Despite these restrictions, the casino and hotel will be examined for the CHP analysis below.

The electrical prices at the casino and hotel have averaged $\$ 0.052$ and $\$ 0.055$ per $\mathrm{kWh}$ respectively in the past year. These values fall just above the electric price standard of $\$ 0.05$ per $\mathrm{kWh}$. It should be noted that the bingo hall rate is $\$ 0.105$ per $\mathrm{kWh}$. This demonstrates the variance in rates between the larger tribal facility and some of the smaller outlier buildings.

The highest load value seen in the past four year at the casino was $0.974 \mathrm{MW}$. These record loads were seen in May 2007 and August of 2006. These values fall under the average electric load of $1 \mathrm{MW}$ needed for CHP. There is currently no peak load data for the casino and hotel.

The spark spread between gas and biomass per MMBtu is 11.93. This assumes a price of $\$ 4.18$ per MMBtu of biomass delivered and an electrical cost of $\$ 0.055 / \mathrm{kWh}$. FEMP suggests that a project have a spark spread greater than $\$ 12 / \mathrm{MMBtu}$.

The annual operation hours of the casino make it a good candidate for CHP as the building is occupied and operated throughout the year. The thermal demand does not correlate well with the electrical demand, as LP use decreases in summer months when electric demands are notably higher due to air conditioning.

Analysis of the casino and hotel shows that CHP would not be a viable option. Electric rates are too low while electrical and thermal demands do not correlate. In addition, electrical load is not high enough to make CHP justifiable. Finally, there is no central heating and cooling system in place which would require a capital intensive retrofit to switch to a central boiler system for heat.

\footnotetext{
${ }^{26}$ Personal Communication, Bobbi Rongstad, Focus on Energy, Energy Advisor, July 28, 2008.
} 


\section{Biomass feasibility for tribal building use}

Current timber harvested on tribal lands is sold to logging companies which sell the timber to local saw mills or to the pulp industry. As mentioned earlier, in one recent transaction, residue was sold to Midwest Timber Company for $\$ 0.50$ per ton. An option for the tribe is to utilize the timber harvested on tribal lands or surrounding lands for biomass heat.

Two potential resources exist for use in biomass combustion units for tribal buildings. Forest residues and cordwood appear to be the two most economical options available. Sawtimber is another potential energy source, however; sawtimber is much more cost effective when used in its current market versus being used for biomass heat.

\subsection{Harvest potentials and energy content}

Table 22 is a recap of harvested or potential harvetable resources on tribal lands in 2006 and 2007. Residue totals are expected to equal 16 percent of the above ground biomass harvested. As stated earlier, with whole tree removal 90 percent of the forest residue is obtainable, while 60 percent is obtainable with traditional practices. Table 22 shows a recap of energy content values for residue, cordwood, and sawlogs.

Table 22: Harvest and energy totals on LDF lands 2006-2007

\begin{tabular}{|r|r|r|}
\hline & \multicolumn{1}{|c|}{$\begin{array}{c}\text { Dry tons } \\
\text { Available }\end{array}$} & MMBtu Available \\
\hline Residuals & 1,655 & 25,610 \\
\hline Cordwood & 10,033 & 172,550 \\
\hline Sawlog & 310 & 5,331 \\
\hline Total & 11,998 & 203,491 \\
\hline
\end{tabular}

\subsection{Tribal LP energy usage}

Table 23 shows the top ten tribal LP users for the 2007 year. Table 23 also shows the gallons of LP used as well as a conversion to MMBtu. A high heating value of 92,000 Btu per gallon of LP was used in the calculations. It is important to understand that the total LP used does not necessarily reflect the demands of the facility. Inefficiencies for the heating unit must also be considered. In the following analysis, the AFUE of an LP boiler and biomass heating system were both considered to be 80 percent. Thus, both inefficiencies will offset and we can strictly examine delivered energy values on a high heating value level. 
Table 23: Top 10 Tribal LP consumers in 2007

\begin{tabular}{|r|r|r|r|}
\hline \multicolumn{1}{|c|}{ Facility } & $\begin{array}{c}\text { Gallons of } \\
\text { LP used }\end{array}$ & $\begin{array}{c}\text { MMBtu's } \\
\text { used }\end{array}$ & $\begin{array}{c}\text { Percentage } \\
\text { of total }\end{array}$ \\
\hline Casino & 163,200 & 15,014 & $33.60 \%$ \\
\hline Lac du Flambeau School & 90,000 & 8,280 & $18.53 \%$ \\
\hline Community Center/Clinic & 42,472 & 3,907 & $8.75 \%$ \\
\hline Simpson's Plastics Plant & 27,159 & 2,499 & $5.59 \%$ \\
\hline Simpson's Main Plant & 16,352 & 1,504 & $3.37 \%$ \\
\hline Fish Hatchery & 16,312 & 1,501 & $3.36 \%$ \\
\hline Roads Garage (Tribal & & & \\
garage) & 13,050 & 1,201 & $2.69 \%$ \\
\hline Bingo Hall & 11,534 & 1,061 & $2.38 \%$ \\
\hline Wellness Center & 11,228 & 1,033 & $2.31 \%$ \\
\hline Store (Ojibwe mall) & 9,550 & 879 & $1.97 \%$ \\
\hline Total & $\mathbf{4 0 0 , 8 5 7}$ & $\mathbf{3 6 , 8 7 9}$ & $\mathbf{1 0 0} \%$ \\
\hline
\end{tabular}

The total MMBtu of LP used for the top ten tribal energy users is $36,879 \mathrm{MMBtu}$. The greatest user of LP is the casino at 15,014 MMBtu followed by the school at 8,280 MMBtu. Table 22 shows that energy from residues total 25,500 MMBtu. This assumes 90 percent removal of all residues. From the preliminary analysis, biomass residue could be used to offset the heating demands of the top two LP energy users. This assumes that 2007 removal estimates can be used as a reference for future prediction. This is difficult to assume given that various tree species will result in various residue yields. In addition, it may be necessary in some areas to leave residue for the health of the forest.

Other concerns and issues might be the energy content or value of forest residue. Density of wood will affect the energy value per volume of timber harvested. In many cases, $8,600 \mathrm{Btu}$ per pound of residue was used as an estimator of energy content in per dry pound of wood though this value can vary by species of tree. It should also be noted that unseasoned residue might have a moisture content of 50 percent when harvested. An ideal moisture content for wood is zero, however, this is impractical and in most cases wood will be seasoned to 20 percent or 30 percent before combustion.

Residue could be removed and used as an LP offset, understanding that residue totals might not be large enough in some future years and that cordwood might have to be harvested and purchased to compensate. As shown earlier, this is also an economically prudent choice for the tribe as well.

\subsection{Energy analysis}

The MMBtu's of energy seen in Table 22 are totals of the energy stored in the dry harvested wood along with delivered energy totals for residue, cordwood, and saw timber. It is evident from Table 22 that there is enough energy available from residue to heat the casino alone. Utilizing 21.4 percent of the cordwood harvested on tribal lands in the 2006-2007 season would be enough to supply biomass heat for the top ten LP users. If 100 percent of the residue is harvested and used to offset LP, than only 6.6 percent of the cordwood would be needed to offset LP for the top ten users. 
As mentioned earlier, residue volumes will vary by tree species and by the amount of residue that can be pulled from the timber harvest without reducing soil quality. If only 30 percent of the available 2007 residue can be removed, there would still be enough energy in the removed residue to offset LP at the Lac du Flambeau School.

\subsubsection{Biomass heating for LDF School}

The school is an ideal location for a biomass boiler system as the building heat is provided from one central source and location and the school is one of the largest LP consumers in the area.

The school current has two LP boilers on-site which are used to heat water which is sent to the 24 air handling units throughout the facility. Both propane boilers are Kewanee Boilers rated each at $2.296 \mathrm{MMBtu} / \mathrm{hr}$. The boilers are never operated at the same time, rather each serves as the primary heater with the responsibility being altered between each unit. The current boilers have been in operation for fifteen years. No gas meter is present on the boilers to determine their run times or daily gas use.

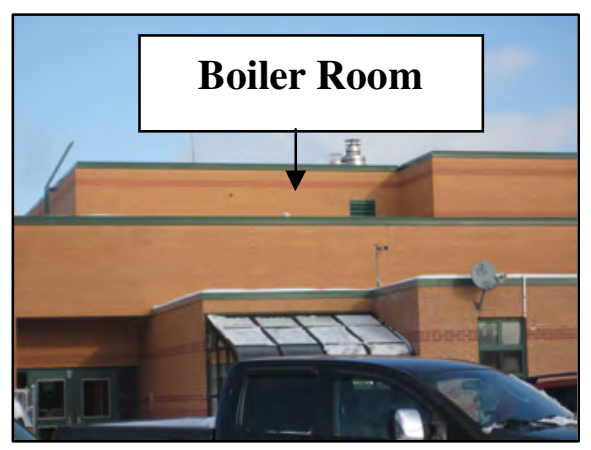

Picture 6: School boiler room
The room the boilers are housed in is $20^{\prime} \times 25^{\prime}$ with 14' side walls. There appears to be available space to the Northwest of the boiler room as this goes out onto the roof adjacent to the faculty parking lot. No structural information was gathered during the school site visit to determine whether a biomass unit could be housed within the boiler room or outside the boiler room on the roof.

In talking with custodial staff at the Lac du Flambeau School, there appears to be easy access to the boiler room from the outside along with available outdoor space for biomass storage bins which would be needed with a biomass boiler. In talking with Monte Lamer of Biomass Solutions, LLC of Middleton, Wisconsin, it was stated that the school would have two primary options to consider if they were to convert to a biomass boiler system. The first option would be to install a separate biomass system from the current boilers. In this scenario, the biomass system would be independent of the current LP boilers and the LP boilers would act as a back-up system or used as a peaking boiler during high demand. The second option would be to retrofit a biomass boiler

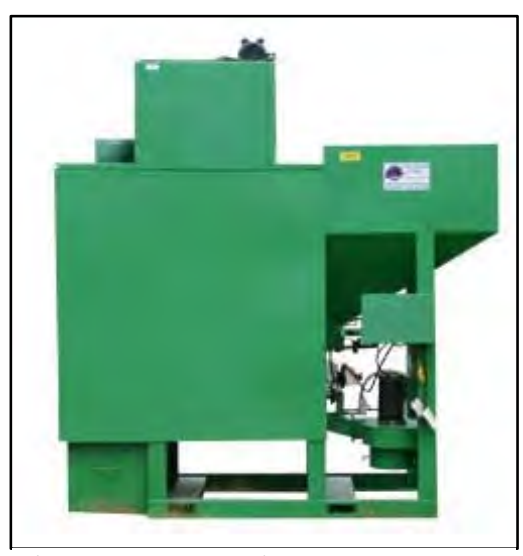

Picture 7: Year-A Round Wood pellet burner into the combustion box of the current boiler system. In this example, the wood boiler system would be inserted into the existing unit and the existing unit combustion chamber and heat exchanger would be used. 
A quote was provided for a Year-A Round wood pellet/corn burning system for the Lac du Flambeau School. The quote was provided by Merton Anderson, President and founder of Year-A Round Corporation. Merton recommended the installation of one CBF955-IB12 pellet burning unit for the school. This unit can operate between 140,000 and 950,000 Btu/hr. The cost of the burner was quoted at $\$ 16,300$ with an auger and storage system cost of $\$ 2000$. Installation cost was estimated at a 'few thousand dollars.' The Year-A Round burner will be used to heat water going to the air handling units within the school. If the wood pellet burner cannot meet the demand, then the LP boiler will assist. Merton recommended installing just one unit at first to determine how much LP is being offset. If it is found that the current LP boiler is still working the majority of the time, than he recommended the installation of a second pellet system.

Table 24 is a rough estimate of the savings seen from the installation of a single Year-A Round system. Estimates assume that the biomass boiler will be able to offset $50 \%$ of the heating load noticed by the school. The annual LP consumption for the school was estimated at 95,000 gallons, which is a five year average between 2003 and 2008. Table 24 shows the overall cost savings by switching to a Year-A Round pellet boiler system for the Lac du Flambeau School.

Table 24: Energy savings with pellet burner for LDF School

\begin{tabular}{|l|r|}
\hline Turnkey pellet boiler cost & $\$ 25,000$ \\
\hline Gallons of LP offset by pellet boiler & 47,500 \\
\hline Unit cost of LP (\$/gal.) & $\$ 1.75$ \\
\hline Value of LP that is offset & $\$ 83,125$ \\
\hline Unit cost of wood pellet (\$/ton) & $\$ 163$ \\
\hline Annual biomass fuel cost & $\$ 45,196$ \\
\hline Annual savings & $\$ 37,929$ \\
\hline Simple Payback & 0.66 years \\
\hline
\end{tabular}

These values from in Table 24 are speculative and preliminary at best. It is highly recommended that a detailed study be performed for the Lac du Flambeau public school to determine closer savings estimates. In addition, a detailed study will help determine the proper number of combustion units to install for the school.

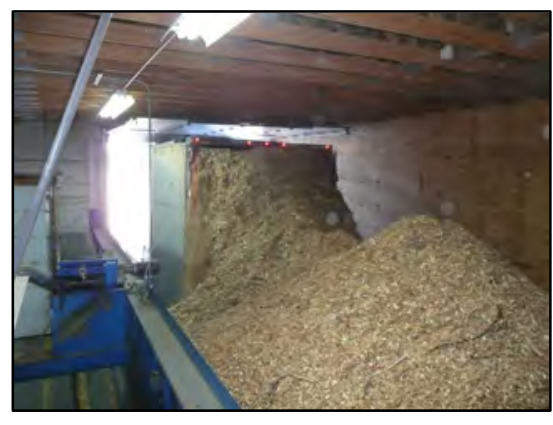

Picture 8: fuel storage for Messersmith boiler
Another option for the school is the installation of a wood chip boiler unit. The school could than utilize the residues of the Tribal Timber sales. Wood chip burning systems have greater costs associated with them as the burners, combustion chamber, and fuel handling systems are more sophisticated than those of a pellet system. An over-the-phone estimate was provided for a Messersmith wood chip system. The estimated was provided by Gerry Guard of Messersmith Manufacturing. The estimated cost of a 2 MMBtu system was $\$ 230,000$. This price includes steel wall and beam as the fourth wall of the 
chip storage bin, traveling auger, belt conveyor with chip screen to remove over sized fuel, metering bin and metering auger, stoker auger, combustor, Hurst boiler with automatic tube cleaner and air compressor, all breeching, multi-cyclone particulate removal device, induced draft fan, insulated sectional stack and control panel. ${ }^{27}$ It is difficult to provide a turn-key cost for such systems without a complete audit of the facility. In some instances more specialized retrofits are required such as a new exhaust stack. $^{28}$ A new stack may be installed to meet local air emissions or requirements. Messersmith estimated that a new free standing stack would cost $\$ 48,000$. For the calculations below, a turn-key cost of $\$ 230,000$ was used. Savings were based upon a per ton wood chip cost of $\$ 17.50$ for residue and $\$ 39$ for cord wood. Data provided from Messersmith shows that a similar install in a similar sized school in Vermont yielded a 92\% energy offset. This value will be used in the economic estimate seen in Table 25.

Table 25: Energy savings with wood chip burner for LDF School

\begin{tabular}{|c|c|c|}
\hline Turnkey boiler cost & $\$ 230,000$ & \\
\hline Gallons of LP offset by pellet boiler & 87,400 & \\
\hline Unit cost of LP (\$/gal.) & $\$ 1.75$ & \\
\hline Value of LP that is offset & $\$ 152,950$ & \\
\hline & residue & cordwood \\
\hline Unit cost (\$/ton) & $\$ 17.50$ & $\$ 39$ \\
\hline Annual biomass fuel cost & $\$ 13,330$ & $\$ 38,740$ \\
\hline Annual savings & $\$ 139,620$ & $\$ 114,210$ \\
\hline Simple Payback & 1.65 years & 2.01 years \\
\hline
\end{tabular}

It is evident from

Table 25 that the installation of a wood chip boiler system would result in extended savings for the school. A lower payback of 1.65 versus 2.01 years can be seen when residue is chipped and used versus cordwood. It would be recommended to use residue before cordwood due to its lower cost of purchase.

The school could also consider the retrofit of a wood chip boiler system which inserts into the current boiler units. In talking with Biomass Solution, LLC, it was highly recommended that a boiler contractor visit the site to fully determine the potential of using a biomass boiler insert. It is undetermined whether such an insert would result in a lower system cost. ${ }^{29}$

\subsubsection{Biomass heating for natural resources facility}

The new natural resources facility is expected to be built and constructed in 2009. The facility is estimated to be 7,000 sq ft. It is unknown whether the facility will be heated via forced air or hot water. It is estimated that a forced air system will save roughly $15 \%$

\footnotetext{
${ }^{27}$ Information provided by Gerry Guard of Messersmith Manufacturing, Inc [12-10-2008].

${ }^{28}$ Information provided by Monte Lamer of Biomass Solutions, LLC. [12-09-2008]

${ }^{29}$ Information provided by Monte Lamer of Biomass Solutions, LLC. [12-09-2008]
} 
in heating costs versus a hot water system. In addition, hot water biomass systems tend to be about $10 \%$ more expensive than forced air units. ${ }^{30}$

The natural resources facility will be roughly three to four times the size of a standard home. A biomass wood chip burning system should not be examined due to both its smaller size, and its lack of economic viability. The other option for this facility is the installation of a biomass pellet burner similar to the Year-A Round unit mentioned earlier. A Year-A Round pellet burner, model 500-FA was quoted for this facility. This particular unit is capable of producing heat output between 50,000 and 500,000 btu/hr. Merton Anderson of Year-A Round quoted this unit with a cost of $\$ 12,000$ for a forced air unit and \$13,650 for hot water heat. A storage vessel and augers will result in an additional cost of $\$ 2000$. A turn-key cost of $\$ 17,000$ was used in the economic analysis seen in Table 26.

Table 26: Energy savings with pellet burner for natural resources facility

\begin{tabular}{|l|r|}
\hline Turnkey pellet boiler cost & $\$ 17,000$ \\
\hline Gallons of LP offset by pellet boiler & 2090 \\
\hline Unit cost of LP (\$/gal.) & $\$ 1.75$ \\
\hline Value of LP that is offset & $\$ 3660$ \\
\hline Unit cost of wood pellet (\$/ton) & $\$ 163$ \\
\hline Annual biomass fuel cost & $\$ 2130$ \\
\hline Annual savings & $\$ 1530$ \\
\hline Simple Payback & 11.11 years \\
\hline
\end{tabular}

Table 26 demonstrates that pellet fuel will provide a financial advantage over an LP heating system at current fuel prices. A payback over eleven years can be seen when switching from an LP heating system to a wood pellet system. This would be the case if the tribe chose to replace the LP heating system with wood. Since the natural resource facility has not been developed yet, the incremental cost of installing a wood pellet unit versus a standard LP heating system should be used in determining overall payback. A detailed analysis of biomass for heat in the natural resources building should be conducted before construction.

\subsubsection{Biomass heating for the community center}

The community center houses an assortment of various businesses and administrative sectors for the tribe. The building is an older facility and is the third largest consumer of LP. The community center used 42,472 gallons of LP in the 2006-2007 heating season. This value accounted for $8.75 \%$ of the total LP purchased for tribal use.

The community center has four boilers on site for space heating. One of the boilers is an old wood heating system which is no longer used. Two of the boilers which heat one side of the facility are each 1.35 MMBtu in size. It appears that only one unit operates at a time while the other serves as a backup. Both of these units operate at $30 \mathrm{psi}$. The third

${ }^{30}$ Information provided by Merton Anderson of Year-A Round Corporation. [12-09-2008] 
boiler which handles the other side of the facility is $0.936 \mathrm{MMBtu}$ in size and operates at $30 \mathrm{psi}$. There are two boiler rooms each located next to the back parking lot and drive through. This setup allows for easy placement and access to fuel storage if a biomass boiler is considered.

Table 27: Energy Savings with biomass boiler for community center

\begin{tabular}{|l|l|l|}
\hline Turnkey boiler cost & $\$ 230,000$ & \multirow{2}{*}{} \\
\cline { 1 - 2 } $\begin{array}{l}\text { Gallons of LP offset by } \\
\text { pellet boiler }\end{array}$ & 38,225 & \\
\cline { 1 - 2 } Unit cost of LP (\$/gal.) & $\$ 1.75$ & \\
\hline Value of LP that is offset & $\$ 66,893$ & \\
\hline & residue & cordwood \\
\hline Unit cost (\$/ton) & $\$ 17.50$ & $\$ 39$ \\
\hline Annual biomass fuel cost & $\$ 5830$ & $\$ 16,943$ \\
\hline Annual savings & $\$ 61,063$ & $\$ 49,950$ \\
\hline Simple Payback & 3.76 years & 4.60 years \\
\hline
\end{tabular}

A 2 MMBtu Messersmith biomass boiler was used to run the simple economic analysis in Table 27. Costs of the system are similar to the Lac du Flambeau School. A 2 MMBtu system will have the capacity to heat the entire community center. It is unknown whether both boiler rooms could be set up to one central biomass boiler. A full feasibility study would be needed to determine the implications and potential. It is assumed that the biomass boiler can offset $90 \%$ of the facilities LP.

The simple payback is best with using residue as the feedstock. However, utilization of cordwood as feedstock provides a shorter payback as well. The greatest factor dictating payback in this scenario is the cost of LP. Residue costs along with cordwood prices should remain fairly stable as the feedstock is from harvest sites on tribal lands and private lands near Lac du Flambeau. 


\section{Analysis of local wood pellet markets}

\subsection{Pellet production in the United States and Wisconsin}

Wood pellet popularity has dramatically increased over the past several years in Wisconsin due to rising heating oil, LP, and natural gas prices. Pellets are viewed as a renewable domestic resource to Wisconsin due to Wisconsin's abundant forests and sawmills. Typically, biomass is delivered to the pellet mill or end users by truck or railcar. The density of this transported material is low, which raises the overall costs. Densifying the biomass into bales, pellets, cubes, or briquettes reduces the bulk volume and raises the density of the material. Pellets main disadvantage is the cost of production, which will be discussed later. However, pellets are easier to store, transport, and have a higher combustion efficiency due to their lower moisture content.

In the United States and Canada, approximately two million tons of pellets are sold annually (Porter et al., 2008). This value is expected to increase as biomass is studied more closely as a domestic alternative to natural gas and LP and as more pellet mill facilities come on-line in the near future. Currently, there are fifteen pellet mills in operation in Wisconsin, with another four mills in the permitting stage. Table 28 shows the various operational and proposed pellets mills in Wisconsin. Locations and production values are provided. Those facilities marked as 'NA' would either not reveal their totals or the information was not available. ${ }^{31}$

Table 28: Pellet mills established and in the permitting stage for Wisconsin

\begin{tabular}{|r|r|r|}
\hline Existing Pellet Mills & Location & $\begin{array}{c}\text { Tons/ } \\
\text { year }\end{array}$ \\
\hline American Wood Fibers & Schofield & NA \\
\hline Bay Lakes Companies, LLC & Oconto Falls & 20,000 \\
\hline Dejno's Inc. & Kenosha and Antigo & 20,000 \\
\hline Earth Sense Energy Systems & Dale & NA \\
\hline Elkhorn Industries, Inc. & Superior & 36,000 \\
\hline Fiber Recovery Inc & Wausau & NA \\
\hline Marth Wood Shaving Supply & Marathon and & 100,000 \\
\hline Pellet America Corp & Peshtigo & Appleton \\
\hline Pj Murphy & Ladysmith & 5,000 \\
\hline Performance Wood & Seymour & 5,000 \\
\hline Agrecol & Viroqua & NA \\
\hline Great Lakes Renewable Energy, & Evansville & 15,000 \\
\hline Inc. & Hayward & 80,000 \\
\hline Badger Pellet & Sheboygan & 1,000 \\
\hline
\end{tabular}

${ }^{31}$ Information taken from an email provided by Don Wichert of WECC USA. Email sent on July 14, 2008. 


\begin{tabular}{|c|c|c|}
\hline \multicolumn{3}{|l|}{ Burned Plant) } \\
\hline & Totals & 282,000 \\
\hline \multicolumn{3}{|l|}{ Proposed Mills } \\
\hline Forest Source & Crandon & 100,000 \\
\hline Indeck Ladysmith, LLC & Ladysmith & 60,000 \\
\hline $\begin{array}{r}\text { Wisconsin Wood Energy } \\
\text { Products }\end{array}$ & Goodman & 70,000 \\
\hline Superior wood products & Ino & 100,000 \\
\hline & Totals & 330,000 \\
\hline \multicolumn{2}{|c|}{ Total production if all plants occur. } & 612,000 \\
\hline \multicolumn{2}{|c|}{ Estimated cords need if produced from Roundwood. } & 544,000 \\
\hline
\end{tabular}

With the new proposed mills, pellet manufacturing is expected to over double its production. This would require 544,000 cords of timber. These values assume that one cord of wood will make 1.125 tons of pellets. ${ }^{32}$

\footnotetext{
${ }^{32}$ Information taken from an email provided by Don Wichert of WECC USA. Email sent on July 14, 2008.
} 
Figure 15 shows the locations of current pellet mill operations along with those mills in the permitting process. The star represents Lac du Flambeau while the red dots represent existing mills. Green dots represent mills in the permitting stage. A 75 mile radius around Lac du Flambeau is shown on the map. Six existing mills and two proposed mills fall within 75 miles of Lac du Flambeau. 75 miles is an arbitrary value on the map and is simply used as a reference distance. 


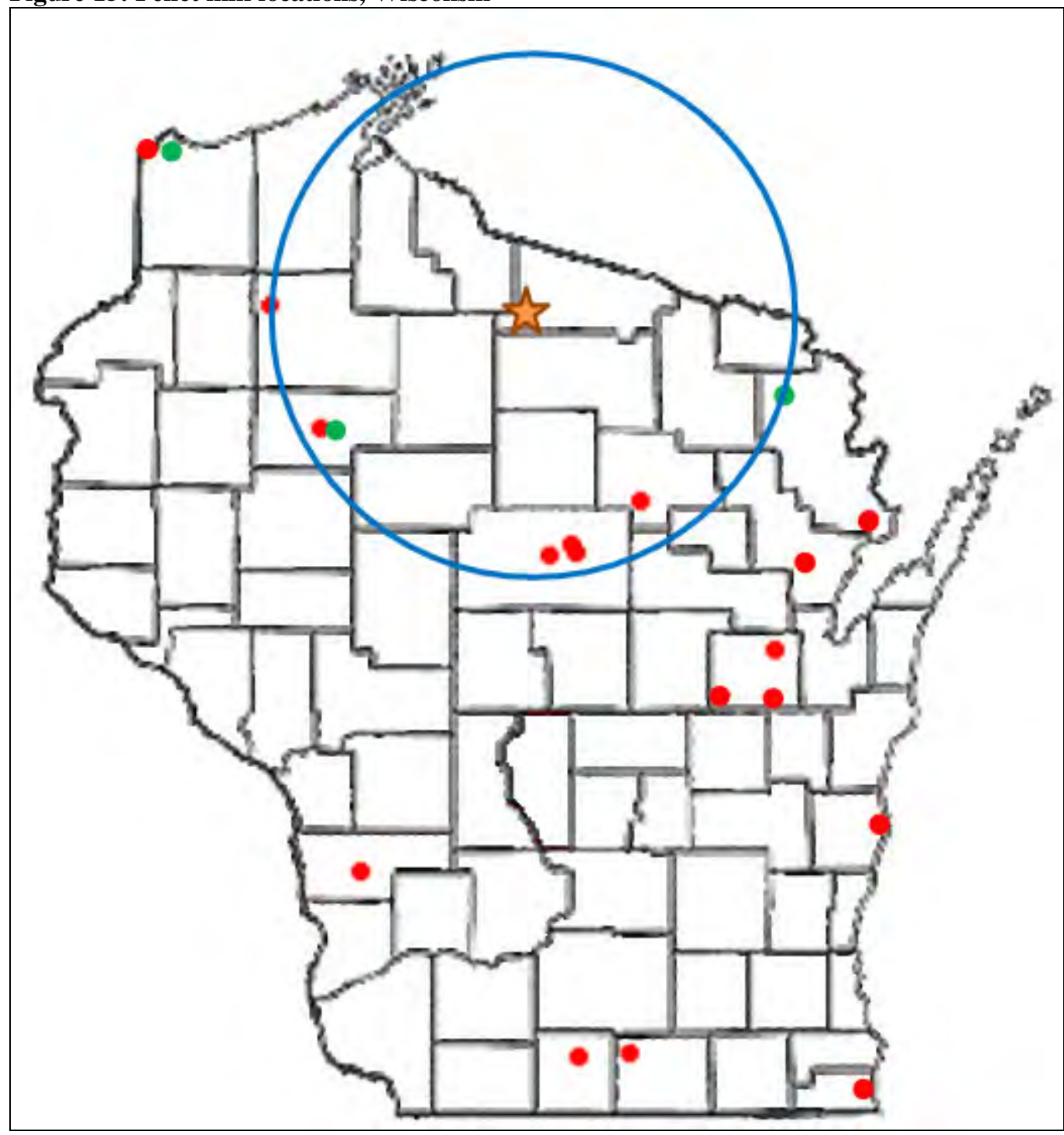

Most of the pellet mills in Wisconsin exist in the northeast region. Pellet mills can pull feedstocks from over 100 miles away. Wood fuel pellets produced in Wisconsin can be manufactured from either dry wood waste or green wood waste. It is assumed that most pellets produced in Wisconsin are made from dry wood waste or saw mill waste, as this does not require drying of the feedstock prior to manufacturing the pellet. Dry wood feedstock generally has a moisture content of approximately 5 to 15 percent. The most likely source of this dry feedstock is from saw mills or other similar industries that utilize kiln dried wood. The kiln dried sawdust used in wood pellets is a waste product from saw mills. 


\subsection{Pellet quality}

Pellet quality is primarily based upon the biomass materials chosen as the feedstock. The Pellet Fuel Institute (PFI) helped lead the way towards industry pellet standards in 1995. The standards in 1995 resulted in two standards for pellets, premium and standard. The standards were based upon ash content, fines, and diameter, and had a recommendation for sodium content. Though standards were set, no specific testing method was laid out.

Poor pellet standards led to problem with pellet stoves and in many instances, pellets were the cause of the problem, not the stove itself. Due to these issues and others, the PFI is close to releasing revised quality standards. The new standard will recognize four grades of pellets: super premium, premium, standard and utility. Each grade has both physical and chemical specifications. The new pellet grades will be based upon an ASTM format for testing. Currently no testing parameters exist for pellets, thus a new methodology aligned with ASTM standard was formed. ${ }^{34}$

It is unknown how pellets from northern hardwood or softwood residue and cordwood will perform in these tests. Softwood pellets tend to perform better and are of higher quality standards than hardwoods. Residues will be of a lower grade as their inputs are not as uniform and contain more bark and leaves, resulting in lower energy density and higher ash contents.

\subsection{Pellet economics}

The average pellet mill in Wisconsin produces 25,000 tons annually, with costs of production ranging from $\$ 40-60 /$ ton (Porter et al., 2008). Larger plants will have lower capital and operating costs than smaller facilities. These values can range from $\$ 100$ per ton for 2 ton/hr production rate facilities to $\$ 40 /$ ton for plants producing 150,000 tons annually (Peterson, 2007). Pellet production facilities are sized by throughput per hour. A 25,000 ton per year facility will produce 2.9 tons per hour while a 150,000 ton per year facility will produce nearly 17 tons per hour. An average Wisconsin plant producing 25,000 tons per year will have capital and operating costs of nearly $\$ 85 /$ ton on average. A larger 150,000 ton facility can lower these costs to under $\$ 30 /$ ton. $^{35}$

Pelletizing facilities require large capital expenditures. In many cases, a pellet mill will need a raw material receiver, chipper, separator, hammer mill, belt dryer, sand separator, conveyers, dry material storage, pellet manufacturing equipment line, storage system, boiler system, and pollution control system. The Pellet-Ex Corporation estimates a facility cost of $\$ 28.7$ million dollars for a $20 \mathrm{ton} / \mathrm{hr}$ facility. These costs include equipment and installation, with no building (Porter et al., 2008). A 2007 study by CleanTec Partners showed a turnkey pellet mill cost of $\$ 7.66$ million dollars for an 8

\footnotetext{
${ }^{34}$ Information taken from Biomass Magazine, July 2008 article on "Pellet Properties". Pg. 46.

${ }^{35}$ This information was taken from a graph presented by Sudhagar Mani, Ph.D., of the University of British Columbia. The graph was presented in the 2008 study by Agrecol titled "Growing Wisconsin Energy: a native grass pellet bio-heat roadmap for Wisconsin", page 32
} 
ton/hr facility. Pellet mill costs appear proportional to volume produced. For example, recently a \$6 million dollar wood pellet mill was approved for Hayward which is expected to produce 36,000 tons of pellets per year.

\subsection{Pellet potential from Tribal timber sales}

In the 2006-2007 tribal harvest year, 1,645 dry tons of residue were available. In addition, 9,975 dry tons of biomass were available from cordwood harvest. It can be estimated that each ton of dry biomass removed could be used to produce 1 ton of pellets. In many cases, biomass will be used to dry the feedstock that will be used to produce pellets. It is estimated that 1500 Btu's of energy are needed to remove one pound of water from wood. To dry enough green wood to produce 1-ton of pellets consumes 0.25 tons of seasoned wood..

The total pellet production from tribal timber harvests are 11,929 tons. Pellet production totals assume a steady state operation which operates 7446 hours per year. In addition, this analysis covers the 2006-2007 year and does not forecast for changes in the future. However, it should be noted that the tribe might be able to boost their harvest production totals as they are not hitting their annual allowable cuts. ${ }^{36}$ However, boosting production

Table 29: Timber volume removed and pellet equivalents from harvest totals 2006-2007

\begin{tabular}{|r|r|r|}
\hline Source & $\begin{array}{l}\text { Dry tons } \\
\text { available }\end{array}$ & $\begin{array}{c}\text { Pellet production } \\
\text { totals @ 15\% } \\
\text { downtime } \\
\text { (tons/hour) }\end{array}$ \\
\hline Sawlogs & 1,645 & 0.2 \\
\hline Cordwood & 9,975 & 1.1 \\
\hline Residue & 309 & 0.0 \\
\hline Totals & $\mathbf{1 1 , 9 2 9}$ & $\mathbf{1 . 4}$ \\
\hline
\end{tabular}

totals would require a larger forestry budget along with more resources to accomplish such an increase. In addition, the department responsibilities would have to be modified as the current forest staff conducts forest development, works on NRCS projects, and prescribed control burns. Logistics to accomplish a boost would have to include other departments involved in sale reviews

along with reestablishing tribal forestry priorities. If changes were to be made in regards to forestry production increases, the local community would have to accept such changes. Resistance to timber cut increases has existed in the past. At the current volumes, it would not be economical to pelletize their biomass resources alone for sale. At such low throughputs, production costs would out-weight the financial gains.

\subsection{Pellet Potential from various radii to LDF}

\subsubsection{Residue and cordwood potential}

An analysis of cordwood and residue volume for various radii from Lac du Flambeau were studied. Table 30 shows the pellet equivalents for residue volumes in area the surrounding Lac du Flambeau. It is estimated that two green tons of wood would equal one ton of finished pellets.

\footnotetext{
${ }^{36}$ Personal Communication, Scott McDougalll, Lac du Flambeau Tribe, June 13, 2008.
} 
Table 30: Residue + cordwood totals in pellet equivalents for various radii from LDF

\begin{tabular}{|r|r|r|r|r|r|}
\hline \multicolumn{1}{|c|}{ Radius } & $\begin{array}{c}\text { Logging } \\
\text { Residue @ } \\
70 \% \text { removal } \\
\text { (green tons) }\end{array}$ & $\begin{array}{c}\text { cordwood } \\
\text { (green tons) }\end{array}$ & $\begin{array}{c}\text { Pellets from } \\
\text { residue } \\
\text { (ton/hr) }\end{array}$ & $\begin{array}{c}\text { Pellets from } \\
\text { cordwood } \\
\text { (tons/hr) }\end{array}$ & \multicolumn{1}{|c|}{ Totals } \\
\hline 25 & 158,540 & 614,067 & 10.6 & 41.2 & 51.9 \\
\hline 50 & 686,270 & $2,669,064$ & 46.1 & 179.2 & 225.3 \\
\hline 75 & $1,419,019$ & $5,383,267$ & 95.3 & 361.5 & 456.8 \\
\hline
\end{tabular}

Table 30 shows that a resource potential for a pellet mill located in Lac du Flambeau exists. If 70 percent of the residue from a 25 mile radius of Lac du Flambeau is taken, a $10.6 \mathrm{ton} / \mathrm{hr}$ pellet facility is possible. If 27 percent of the residue in a 25 mile radius is retrieved, a 2.9 tons/hr facility is possible, which is the current Wisconsin average. Utilizing cordwood for pellet production is another option examined in Table 30. If cordwood was utilized, pellet production in Lac du Flambeau is very feasible. If 7 percent of the cordwood in a 25 mile radius is retrieved, a $2.9 \mathrm{tons} / \mathrm{hr}$ facility is possible. The issue with using cordwood is the higher feedstock costs compared to low value residue. Operational margins for pellet facilities can vary from 23 percent, for 30 percent moisture feedstocks, to near 8 percent for green wood. Increased feedstock costs may significantly lower this margin to the point of diminishing returns.

Mill residue for use in pellet manufacturing is another potential feedstock option for making pellets. As mentioned earlier, 99 percent of the mill waste is used for other purposes. The estimated volume of unused mill residue in a 75 mile radius of Lac du Flambeau is 5,911 dry tons. This equals 2,462 cords of wood. Converted to tons of pellets, this value equals 2770 tons of pellets or a production rate of 0.3 tons $/ \mathrm{hr}$. If further studies were to be conducted, mill residue or mill waste should be examined. 


\section{Summary of recommendations}

\subsection{Biomass resource of the Lac du Flambeau Tribe}

The tribe has a vast biomass resource. This resource is the second greatest income for the tribe so it is important that it be used in the most cost effectively and environmentally sound manner. These are the parameters for the recommendations that follow.

Sawlogs should continue to be used in the traditional manner of lumber production. Its higher value does not warrant it to be used as a biomass heat fuel. Cordwood has a great potential for being used for offsetting LP. Current cordwood prices warrant its use as an LP offset. Cordwood markets are well established and stand volumes are well known from current cruising practices. Thus, determining the amount of cordwood resource on a given area of land is much more accurate than that of determining residue values. Enough cordwood is available on tribal land to offset the tribe's LP consumption.

Cordwood is a middle value timber resource and should be used only after residue use has been ruled out. Residue appears to have the greatest short term potential and advantage for the tribe. Enough residue volumes appear to be harvested annually to offset the equivalent energy usage of the casino and school. Though this may not be practical, it does provide a baseline of available resource energy to help us understand other applications. The tribe is anticipating the construction of a Natural Resources building in the next year or two and has envisioned that this building be a demonstration site for renewable and sustainable energy systems. While the building size and energy loads are unknown, it can be assumed that the facility will not have the demands of the school or casino. This concludes that biomass for space heat at this facility is a very feasible opportunity.

\subsection{Biomass resources on surrounding land}

Biomass resources are abundant within Lac du Flambeau tribal property as well as in surrounding areas. Over 95 percent of the timber harvested around Lac du Flambeau on state, federal, and county lands is cordwood. Much of this cordwood is used for the pulp and paper industry. Cordwood surrounding the Lac du Flambeau has a potential of being utilized for the wood pellet industry or for thermal energy purposes. There is easily enough cordwood in a 25 mile radius to supply enough feedstock for an average sized Wisconsin pellet mill to be located in Lac du Flambeau. Cordwood from surrounding lands would be a great potential to examine for offsetting LP if resources are limited on the tribal lands. Transportation costs and cordwood costs may inhibit this opportunity, but should be revisited in the future as prices fluctuate.

Residue utilization is an unexplored and underestimated resource in surrounding areas. In conversations with many state and national foresters, residues are underutilized and have little or no value to the seller. Removal of 70 percent of the forest residue would leave enough forest litter for soil and plant health, and would leave sufficient habitat for birds and game. Enough residues are available within a 25 mile radius to operate an 
average sized Wisconsin pellet mill or offset the tribes LP use. Determining how and where the tribe would obtain residue in surrounding areas may be a formidable task but is certainly feasible as others in northern Wisconsin have taken on the challenge.

\subsection{Combined heat and power}

Combined heat and power does not appear to be a viable option for the tribe. The casino and hotel facility does not have the proper HVAC system to fully utilize CHP. A completely new HVAC system would have to be installed rendering the project impractical. In addition, a CHP system utilizes pressures over $15 \mathrm{psi}$, thus requiring a full time boiler operator to be present during operation. More significantly, utility prices cross examined with the Federal Energy Management Program for CHP show that tribal buildings do not meet the preliminary requirements set up by FEMP. This is attributed to low electrical costs.

\subsection{Pellet Manufacturing}

There are currently fifteen pellet mills in operation in Wisconsin with another four in the permit process. The market for pellets continues to increase but the potential for easy resource aggregation becomes limited. This may appear as a paradox to the amount of residue mentioned in previous sections, however, ideal feedstock is already dried and of a similar consistency, such as what is seen from saw mills. As mentioned earlier, most of the waste from saw mills is already utilized. The tribe has a potential for development of a pellet mill as residue volumes within a 25 mile radius are enough to supply an average Wisconsin pellet plant. A further analysis will have to be performed to examine overall economics of pellet production for the Lac du Flambeau area as well as potential markets for the pellet products. 


\section{Condensed summary of recommendations}

Below is a summary of recommendations from this report.

1. Develop a timber harvest species and residue inventory. Such a measure will help determine current and future residue volumes available from harvest practices. A more thorough resource inventory will assist in redeveloping any new forestry expansion plans.

2. Reevaluate the priority, responsibility, and funding of tribal forest practice. The potential to expand timber harvest practices exists within tribal land. However, additional staff, support, and resources must be allocated to fully expand operations and utilize these value resources to their fullest potential.

3. Conduct a detailed feasibility study for a biomass boiler in the Lac du Flambeau School and community center. In both locations, preliminary numbers indicate that a biomass combustion system would result in a quick payback. Also, analyze the potential for a pellet heating system at the new natural resource facility .

4. Conduct a case study of chipping cordwood for thermal purposes. This will require weighing cordwood mass and comparing the value to cordwood prices. This should than be compared with residue and LP prices for an economic comparison.

5. Research residue prices in regard to local stumpage value and consider establishing a value price structure. Talk with local timber agents about residue removal, chipping, and transport cost for use at tribal facilities.

6. Continue to further analyze the Wisconsin wood pellet market and the potential use of residue and cordwood for pellet production on tribal lands. Talk with current and future pellet plants within 75 miles of Lac du Flambeau about supplying residues for production. Conduct a more detailed feasibility study to determine pellet mill potentials in Lac du Flambeau. 


\section{Further Research}

Further research should be conducted on the amount of residue available within different tree species harvested on tribal lands. Residues values were assumed to be sixteen percent of above ground biomass, however; this will vary by species and calendar harvest time. Further research should examine historical trends in harvest totals on tribal lands and attempt to evaluate future sales or anticipated sales total based upon annual allowable cut. With the newly explored area of cellulosic fuels, such as the Flambeau River Biofuels, it would be prudent to examine current or future plans for biofuel facilities in northern Wisconsin. As discussed earlier, a biomass commodity exchange in conjunction with an expanded cellulosic biofuels market could drive timber prices up and open up extended and more diverse market potentials. 


\section{References}

Ahl, D., Gower, S., White, M. (2005). Life cycle inventories of roundwood production in northern Wisconsin: Inputs into an industrial forest carbon budget. Forest Ecology and Management, 219, 13-28.

Bioenergy Feedstock Information Network. (n.d.). Biomass Energy. Retrieved on November 28, 2006, from http://bioenergy.ornl.gov/papers/misc/energy_conv.html

Biomass Energy Resource Center (2003). Feasibility Study: Wisconsin school wood energy program. Retrieved July 23, 2008 from http://www.biomasscenter.org/reports/wisconsin-school-wood-energy-study.html

"Biomass Harvesting on Forest Management Sites in Minnesota" (draft), prepared by the Minnesota Forest Resources Council, Biomass Harvesting Guideline Development Committee, May 1, 2007, developed as an additional chapter in "Sustaining Minnesota forest Resources: Voluntary site-Level Forest Management Guidelines".

Brand, G., Perry, C. (2006). Wisconsin's forest resources, 2005. United States Department of Agriculture, Resource Bulletin-NRS-2, Newtown Square, PA.

Brown, R. (2003). Biorenewable resources: engineering new products from agriculture. Ames, IA: Iowa State Press.

Department of Agriculture, Forest Service, Northern Research Station, Resource Bulletin NRS-19.

Department of Energy (2007). DOE Selects Six Cellulosic Ethanol Plants for Up to $\$ 385$ Million in Federal Funding. Retrieved July 28, 2008, from http://www.doe.gov/news/4827.htm

Energy and Environmental Analysis Inc. (2007). Biomass Combined Heat and Power Catalog of Tecgnologies. Wahington, DC: U.S. Environmental Protection Agency.

Engineering Toolbox (2005). Weight of wood species at various moisture contents. Retrieved August 18, 2008, from http://www.engineeringtoolbox.com/weigtwood-d_821.html

Federal grant approved for Park Falls biodiesel plant (2008). The Business Journal of Milwaukee. Retrieved July 25, 2008, from http://www.liu.edu/cwis/cwp/library/workshop/citapa.htm 
Flambeau River Biofuels, LLC (n.d.). Retrieved July 25, 2008 from http://www.fpl.fs.fed.us/resources-products/documents/bioenergy/flambeau-riverbiofuels.pdf

Kaarsberg, T., \& Elliot, R. N. (2001, April 01). Combined Heat \& Power: Saving Energy and the Environment. Retrieved July 23, 2008, from Northeast Midest Inctitute: http://www.nemw.org/ERheatpower.htm

Kramer, Joseph M., Weitner, Sean, “Assessment of Biomass Resources for Energy Generation at Xcel Energy's Bay Front Generation Station in Ashland, Wisconsin”, April 2007, Energy Center of Wisconsin report number 240-1. http://www.ecw.org/prod/240-1.pdf

McKeever D., Falk R. (2002). "Woody residue and solid waste wood availability for recovery in the United States" in management of recovered wood recycling, bioenergy and other options, Christos Gallis (editor), Thessaloniki, April 22-24, 2004.

Michigan Department of Natural Resources-Forest, Mineral, and Fire Management Timber Sales Management System (2006). Average stumpage price report. Retrieved July 24, 2008 from http://www.michigandnr.com/ftp/forestry/tsreports/StumpagePriceReports/

Miles, P., Pugh, S. Visaje, J., Smith, B. (2004). Forest resources of the United States 2002. U.S. Department of Agriculture Forest Service, General Technical Report NC-241, St. Paul, MN

Niccolucci, M., Meneghin, B., McKinnon, D. (n.d.). Estimating Standing Timber Valuesfor SPECTRUM and Similar Land Management Planning Models. Retrieved July 22, 2008 from http://www.fs.fed.us/

P Squared Group, LLC., Biomass Energy Resource Center (2008). Heating with biomass: a feasibility study of Wisconsin schools heating with wood. Retrieved July 25, 2008 from www.focusonenergy.com

Perlack, Robert D., Wright, Lynn L., Turhollow, Anthony F., Graham, Robin L., Stokes, Bryce J., Erbach, Donald C., "Biomass as Feedstock for a Bioenergy and Bioproducts Industry: The Technical Feasibility of a Billion-Ton Annual Supply", April 2005, a joint study sponsored by the US Department of Energy and the US Department of Agriculture. www1.eere.energy.gov/biomass/pdfs/final_billionton_vision_report2.pdf

Peterson, D. (2005). The cost of extracting logging residues for biomass fuels. Lumberjack Resource Conservation and Development Council, Inc. Retrieved November 8, 2006, from http://www.dnr.wisconsin.gov/ 
Reading, IV, William H., Whipple, James W., Wisconsin Timber Industry: An Assessment of Timber Product Output and Use in 2003, 2007, United States Department of Agriculture, Forest Service, Northern Research Station, Resource Bulletin NRS-19.

Shifley, Stephen R., Sullivan, Neal, H., "The Status of Timber Resources in the North Central United States", General Technical Report NC-228, 2002, St. Paul, MN: US Department of Agriculture, Forest Service, North Central Research Station. http://www.ncrs.fs.fed.us/pubs/2319.

Smith, W.B., 2004. Forest Resources of the United States, 2002. General Technical Report NC-241. U.S. Department of Agriculture, Forest Services, North Central Research Station, St. Paul, MN., April.

State of Wisconsin, Department of Natural Resources (2006). Timber sale handbook. Retrieved July 23, 2008, from http://dnr.wi.gov/forestry/StateForests/2461/2461.pdf, pg A-19.

Stelzer, Henry E., Barnett, Chris, Bensen, Verel W., "Sustainable Bioenergy Production from Missouri's Ozark Forests", April 8-9, 2008, Proceedings of the $16^{\text {th }}$ Central Hardwood Forest Conference held at Purdue University West Lafayette, IN, published by the US Forest Service, Northern Research Station, Newtown Square, PA. http://www.fs.fed.us/nrs/pubs/gtr/gtr_nrs-p-24.pdf

Stokes, B.J., 1992. "Harvesting small trees and residues." Biomass and Bioenergy 2(1):131-147.

The Engineering Toolbox (2005). Wood and combustion heat values. Retrieved July 22, 2008, from http://www.engineeringtoolbox.com/wood-combustion-heatd_372.html

University of Massachusetts. (2005, Oct 14). Combined Heat \& Power. Retrieved July 23, 2008, from Industrial Assessment Center: http://www.ceere.org/iac/iac_combined.html

US Department of Agriculture Forest Service (1977). Estimating effective heating value of wood or bark fuels at various moisture contents. USDA Forest Service General Technical Report FPL (1977): 2.

US Department of Agriculture (2002). 2002 Census of Agriculture State Profile. Retrieved October 25, 2008 from http://www.nass.usda.gov/census/census02/profiles/wi/index.htm

US Department of Agriculture - Forestry Service (n.d.), Forestry Inventory Mapmaker, version 3.0, Retrieved July 10, 2008 from http://www.ncrs2.fs.fed.us/4801/fiadb/fim30/wcfim30.asp. 
US Department of Energy (2005). Biomass and feestock for a bioenergy and bioproducts industry: the technical feasibility of a billion-ton annual supply. Retreived October 14, 2008 from http://feedstockreview.ornl.gov/pdf/billion_ton_vision.pdf

US Department of Energy: Federal Energy Management Program (2004). FEMP CHP program overview. Retrieved July 28, 2008, from http://www1.eere.energy.gov/femp/pdfs/chp_prog_overvw.pdf

US Forest Service (2007). Forest Service announces grants for state wood energy programs. Retrieved July 28, 2008, from http://www.fpl.fs.fed.us/pressroom/newsreleases/nrtmu-2007aug06-fs-announcesgrant-state-wood-energy-programs.html

University of Florida: IFAS Extension (2006). Site quality \& stand density. Retrieved July 22, 2008, from http://www.sfrc.ufl.edu

Wisconsin Administrative Code (2006). Department of Natural Resources, Forest tax program. NR-46.02. Retrieved July 23, 2008 from http://www.legis.state.wi.us/rsb/code/register/

Wisconsin Department of Administration. (2007). Wisconsin energy statistics. Retrieved July 24, 2008, from http://www.doa.state.wi.us/

Wisconsin Department of Natural Resources (2008). State Forests History. Retrieved July 28, 2008, from http://dnr.wi.gov/Forestry/history/history_state.htm

Wisconsin forest management guidelines. (2003). Wisconsin Department of Natural Resources Division of Forestry. PUB-FR-226 2003.

Wisconsin Paper Council (n.d.). Paper Facts. Retrieved July 25, 2008, from http://www.wipapercouncil.org/industry.html. 


\section{Task Seven: Micro-hydro}

\section{Table of Contents}

\begin{tabular}{|c|c|}
\hline 1.1 & ................................ 2 \\
\hline 1.2 & АРPROACH \\
\hline 1.3 & 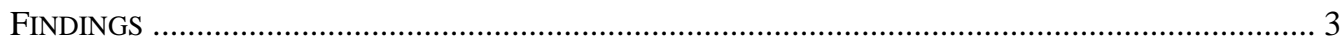 \\
\hline 1.3.1 & Summary \\
\hline 1.3.2 & 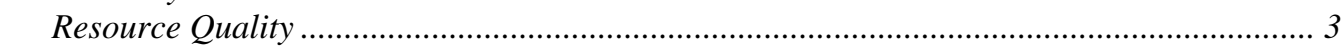 \\
\hline 1.3.3 & 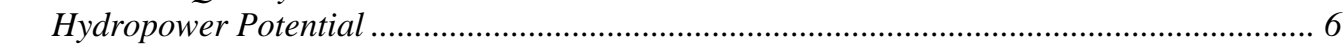 \\
\hline 1.3.4 & 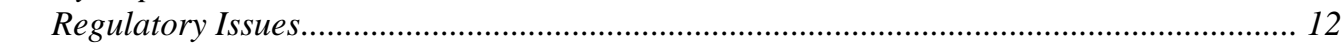 \\
\hline 1.4 & CONCLUSION \\
\hline
\end{tabular}

\section{List of Figures}

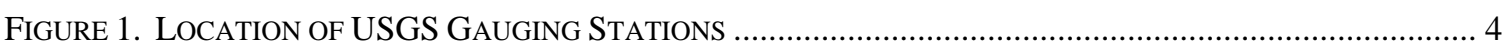

Figure 2. TROUT RIVER GAUGING STATION LOOKING WEST AND NORTH .................................................. 4

Figure 3. TROUT River GaUging StATION LOOKING WeSt AND SOUTH.................................................... 5

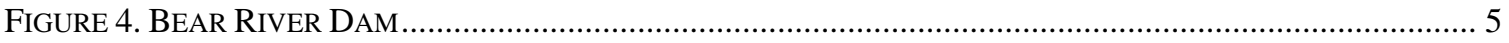

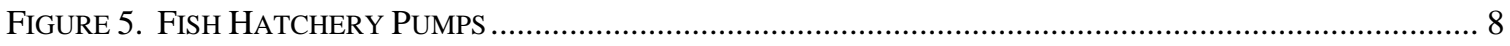

Figure 6. TROut Pond (Retaining AND Pollution Prevention Pond) .................................................... 9

\section{List of Tables}

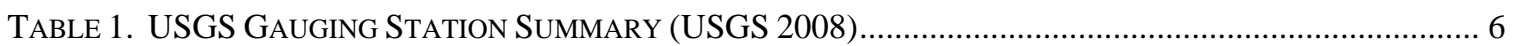

TABLE 2. HYDROELECTRIC POWER AND ENERGY ESTIMATES..................................................................... 7

TABLE 3. UTILIZATION RATES OF FISH HATCHERY RACEWAYS ................................................................... 8 


\subsection{Objective}

The objective of the micro-hydro study is to determine if the Tribe's water resources can be harnessed to produce electricity economically and without significant environmental consequences.

The study focuses on three water resources on the Lac du Flambeau reservation.

1. Trout River

2. Bear River Dam

3. Lac du Flambeau Hatchery

These locations were selected by Tribal staff. SGES concurs that these are the logical primary water resources of interest.

\subsection{Approach}

SGES employed a multi-faceted approach to evaluate the micro-hydro potential of Tribal water resources. The approach is outlined below:

1. Access existing stream flow data.

The United States Geological Service (USGS) installs gauging stations on rivers throughout the country. These stations obtain information about the river in terms of water flow rates and the drainage area. This is one critical component to estimate the hydro-power production potential. ${ }^{1}$

2. Evaluate topographic maps.

USGS topographical maps were evaluated to determine river elevation drops, land use and siting considerations for hydroelectric development.

3. Review regulatory framework.

State agencies such as the Wisconsin Department of Natural Resources (DNR) and Federal agencies, including the Federal Energy Regulatory Commission (FERC), U.S. Fish and Wildlife Service (USFWS) and Army Corps of Engineers (ACC); typically have jurisdictional authority over any activity on "navigable" waterways. The standards of these agencies were reviewed for this study. However, as a sovereign nation, it is not readily clear whether or not the state would be involved or

\footnotetext{
${ }^{1}$ USGS Water Data for Wisconsin: http://waterdata.usgs.gov/wi/nwis/nwis
} 
if all permitting would be through the Federal agencies. It is likely that the federal agencies would bring the DNR in as a consulting agency regardless.

\section{Screen hydro power technologies}

There are multiple hydro electric power generation technologies available, the selection of which depends on project size, water resource characteristics and budgets. SGES screened these technologies to identify the right options to meet the Tribe's objectives.

\section{Match resource to needs}

The final step is to identify preliminary micro-hydro system options based on the available water resource and the Tribe's development objectives.

\subsection{Findings}

\subsubsection{Summary}

In general the Lac du Flambeau water resources on the Trout and Bear Rivers are not well suited for hydropower development if the primary goal is to provide the community with an economical source of clean power. However, the fish hatchery may be able to construct a very small hydro electric generator for the primary purpose of community education and demonstration of the Tribe's commitment to renewable energy.

The rationale for this conclusion is presented in the following sections.

\subsubsection{Resource quality}

SGES reviewed publically available USGS gauge station records for the Trout River and Bear River. The locations and photos of the USGS stations are provided in the Figures below and the data for the USGS stations are provide in Table 1. 
Figure 1. Location of USGS Gauging Stations

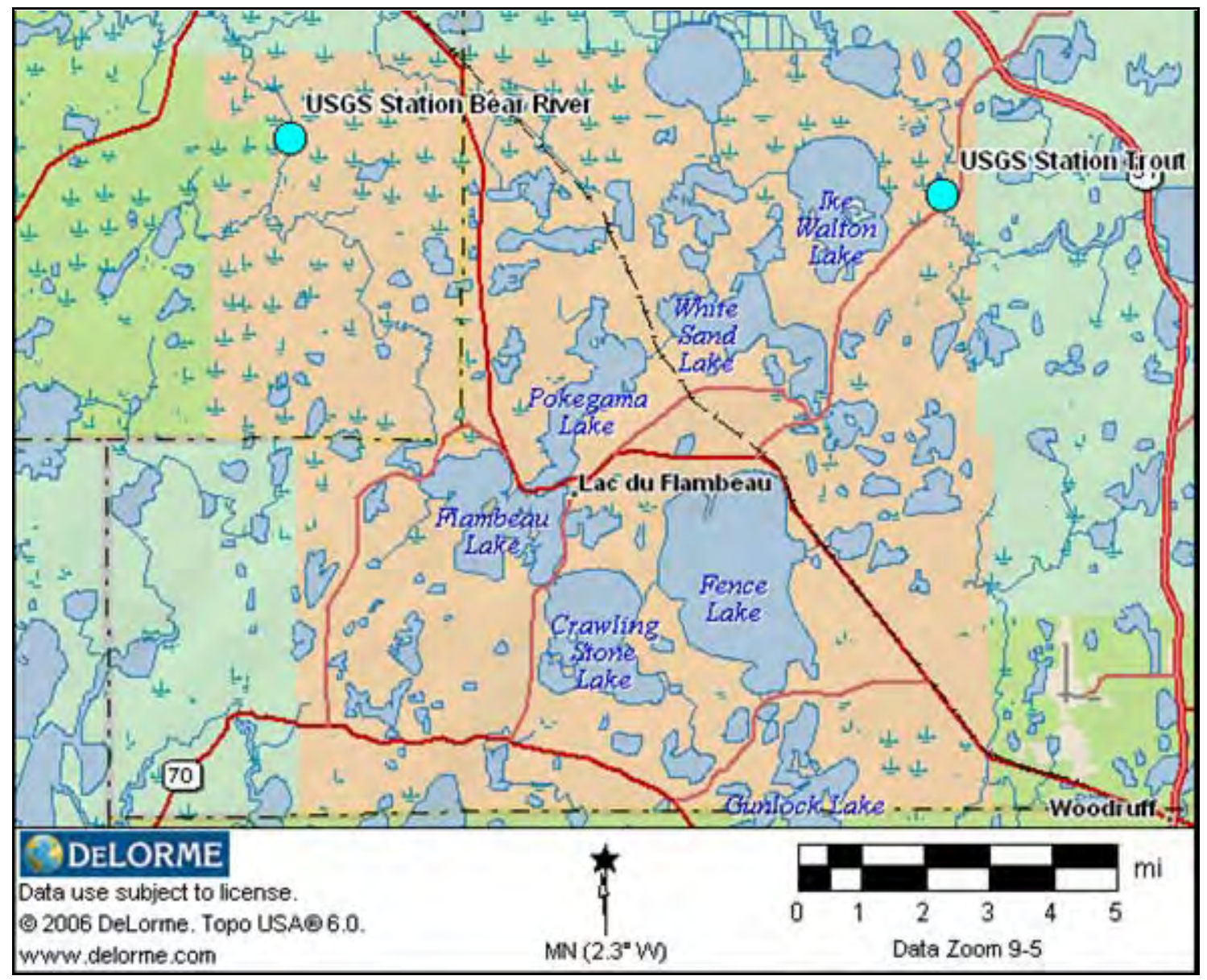

Figure 2. Trout River Gauging Station looking West and North

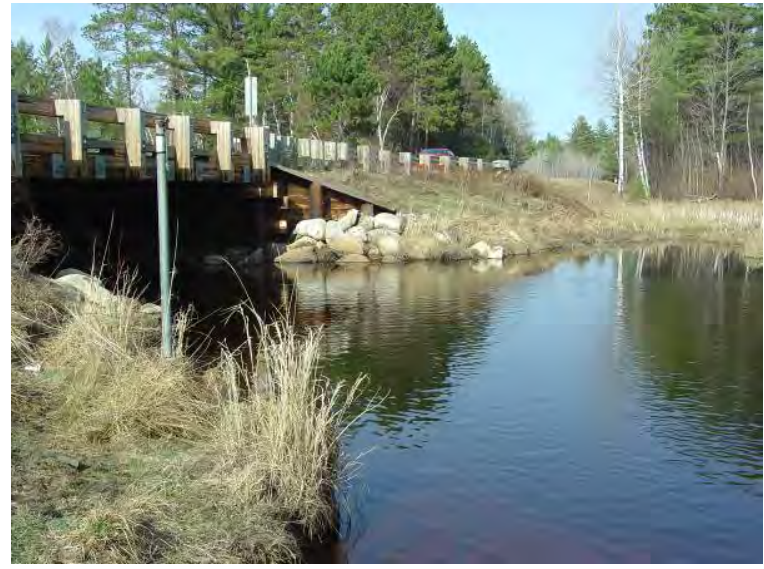

WEST

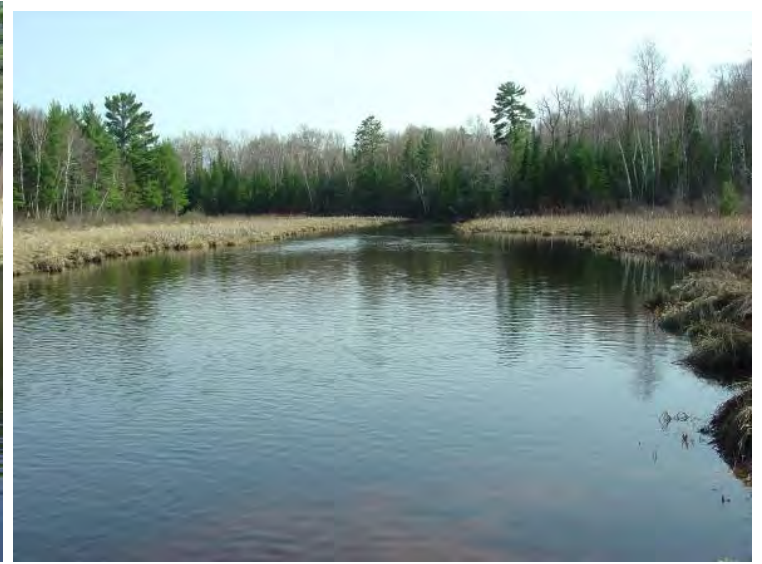

NORTH 
Figure 3. Trout River Gauging Station looking West and South
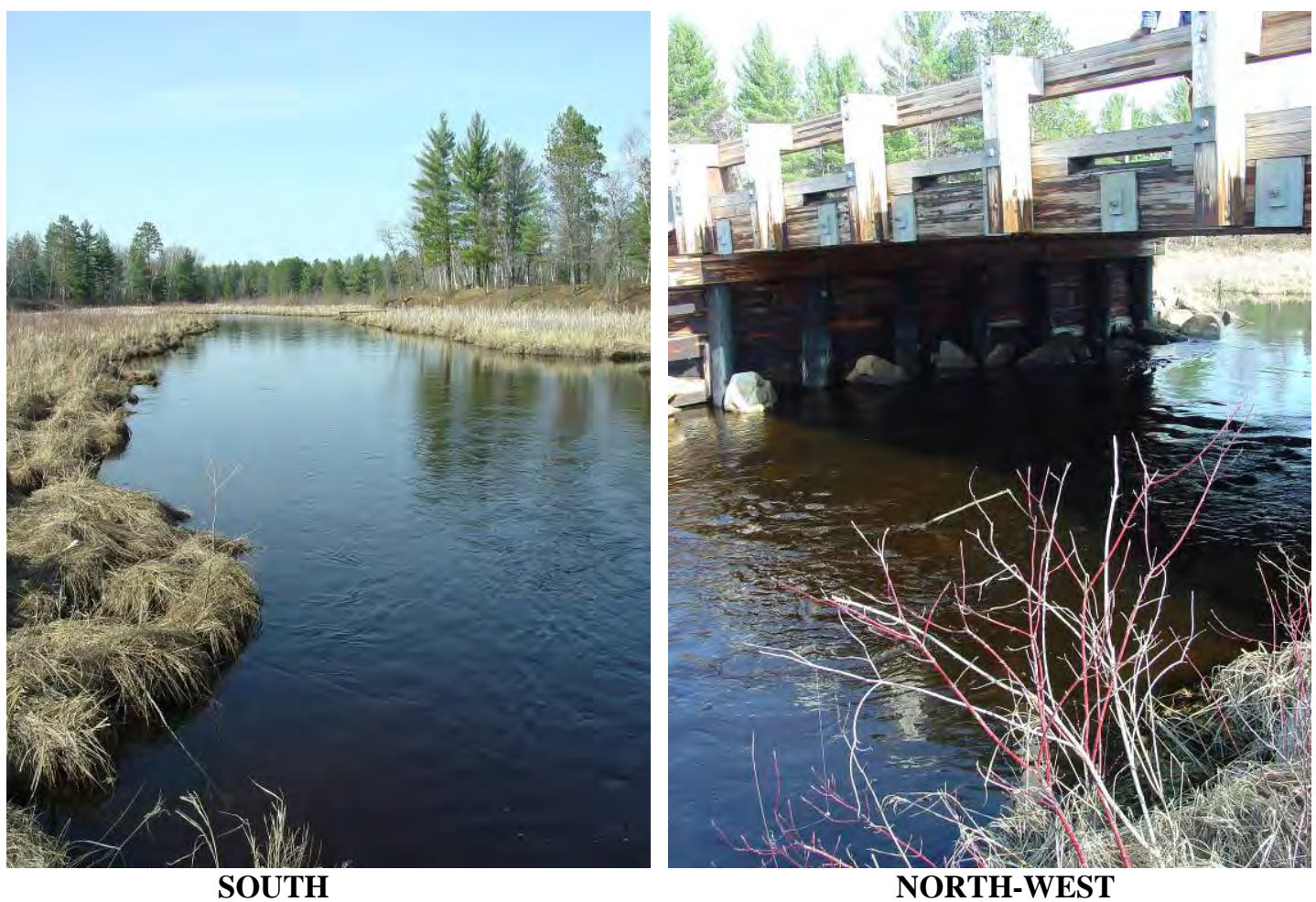

Figure 4. Bear River Dam

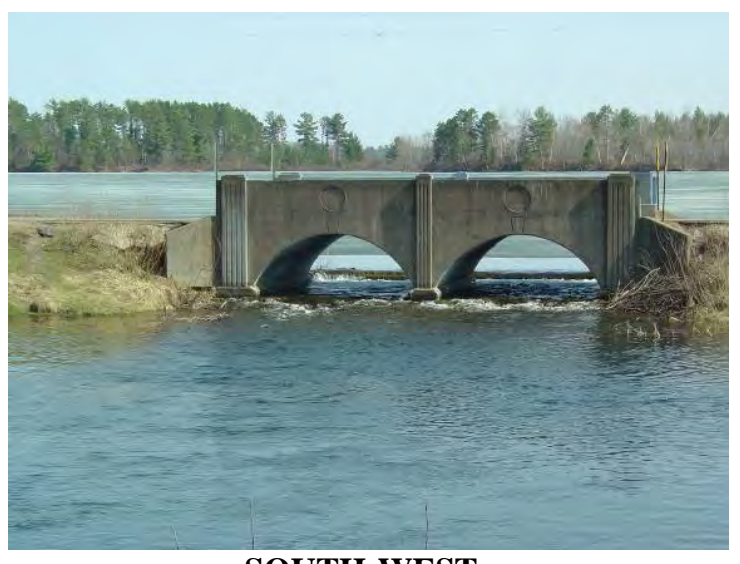

SOUTH-WEST

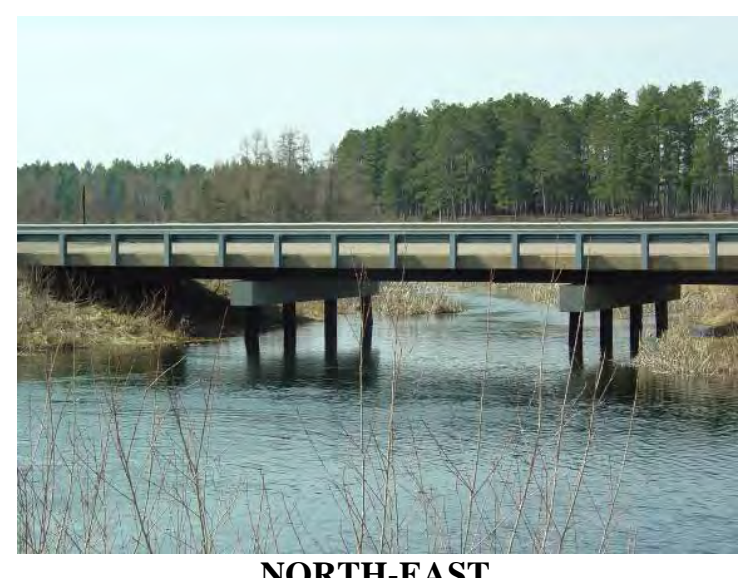

NORTH-EAST 
Table 1. USGS Gauging Station Summary (USGS 2008)

\begin{tabular}{|l|l|l|}
\hline Characteristics & Trout River & Bear River \\
\hline Station ID & 05357254 & 05357335 \\
\hline Location & $\begin{array}{l}\text { County Road H } \\
\text { Vilas County } \\
\text { NE Corner of LdF } \\
\text { Reservation }\end{array}$ & $\begin{array}{l}\text { East River Trail Bridge } \\
\text { Iron County } \\
\text { NW Corner of LdF } \\
\text { Reservation }\end{array}$ \\
\hline Latitude & $46^{\circ} 02^{\prime} 02^{\prime \prime}$ & $46^{\circ} 02^{\prime} 56^{\prime}$ \\
\hline Longitude & $89^{\circ} 46^{\prime} 21^{\prime \prime}$ & $89^{\circ} 59^{\prime} 04^{\prime \prime}$ \\
\hline Elevation & 1610 feet & 1580 feet \\
\hline Period of Record & $10 / 98-$ Current & $5 / 91-$ Current \\
\hline Drainage Area & 58.9 sq miles & 81.3 sq miles \\
\hline $\begin{array}{l}\text { Long-term Median Flow } \\
\text { (cubic ft / sec) }\end{array}$ & 43.0 & 63.1 \\
\hline
\end{tabular}

The critical data are the long-term median flow rates expressed in cubic feet per second. This is one of the two primary variables used to calculate the potential size of a hydroelectric generator.

\subsubsection{Hydropower potential}

The power available from flowing water is determined by the following formula:

$$
\mathrm{P}=\underline{\mathrm{Q} \times \mathrm{H} \times 0.85}
$$

Where:

$\mathrm{P}=\quad$ power in kilowatts

$\mathrm{Q}=$ water flow rate in cubic feet per second

$\mathrm{H}=$ head or vertical distance the water can fall expressed in feet

$0.85=$ de-rate for pipe friction losses

The power formula shows that in order to generate large amounts of power, a site needs either high flow rates, large elevation changes or both.

\section{Bear and Trout Rivers}

Unfortunately, this is not the case for the Lac du Flambeau water resources. Inspection of the topographic maps shows that the Trout River and Bear Rivers run at nearly the same elevation throughout the reservation. The Bear River Dam only provides a modest drop of approximately two feet. Even if a small elevation change could be created through construction of a larger dam, the low flow rates still result in low power levels. 
The average power output for the Bear River and Trout River is shown in Table 2. Hydroelectric Power and Energy Estimates. The expected Annual Energy Output, in kilowatt-hours per year is given by:

$$
\mathrm{AEO}=\mathrm{P} \times 8760 \times 80 \% * 90 \%
$$

Where:

$\mathrm{P}=$ average power output in kilowatts

$8760=$ number of hours per year

$80 \%=$ expected capacity factor or percent of theoretical maximum energy production to account for low flow periods and outages for maintenance

$90 \%=$ adjustment for electrical conversion inefficiencies and distribution line losses

Table 2. Hydroelectric Power and Energy Estimates

\begin{tabular}{|l|l|l|}
\hline Characteristics & Trout River & Bear River \\
\hline Average Flow Rate $\left(\mathrm{ft}^{3} / \mathrm{sec}\right)$ & 43.0 & 63.1 \\
\hline Head $(\mathrm{ft})$ & 2 & 2 \\
\hline Average Power $(\mathrm{kW})$ & $6.2 \mathrm{~kW}$ & $9.1 \mathrm{~kW}$ \\
\hline Annual Energy Output $(\mathrm{kWh})$ & 39,104 & 57,396 \\
\hline
\end{tabular}

At first glance, the energy production estimates may seem favorable, especially as a source of energy for smaller Tribal electrical loads. However, any effort to construct and operate a hydroelectric unit on the Trout or Bear Rivers will be an expensive proposition. While the capital costs of the technology are relatively modest, the costs to obtain construction and operating permits will quickly increase the total project cost.

In addition, the development of small-scale hydro power projects is only feasible when the generator is located directly adjacent to the electrical load. If the end-user is more than several hundred feet away, the cost to transmit the power will quickly outweigh any potential benefits.

For these reasons, micro-hydro is not considered a viable renewable energy technology option for the Trout or Bear Rivers on the Lac du Flambeau Reservation.

\section{Fish Hatchery}

SGES evaluated the Tribal Fish Hatchery as a potential micro-hydroelectric development site. A small generator may make sense for this location but its primary purpose would be education and demonstration of the Tribe's commitment to clean energy. In addition, the power produced at the hatchery may be useful as a battery charging "source" for the local community's fishing boat batteries. In this case, the batteries would be charged at the hatchery and the energy to charge the batteries would be "supplied" by the hydropower generator. In application, the hydropower would connect to the electrical service equipment at the site thereby displacing energy purchases from WPS as with any 
customer-owned renewable energy project. As long as the amount of hydro-electric power produced equals or exceeds the amount of energy used to charge fishing boat batteries, the battery charging could be legitimately described as being powered by $100 \%$ clean energy. Appropriate signage, along with other means of communication can inform and educate the fisherman and Tribal membership about this initiative.

To estimate the power and energy production available at the Fish Hatchery, SGES consulted with Hatchery staff to better understand the facility and its operation.

The Fish Hatchery has five, 3-phase pumps on site: (1) 15 horsepower (HP) deep well; (1) 20 HP deep well; (3) 15 HP lake pumps.

\section{Figure 5. Fish Hatchery Pumps}

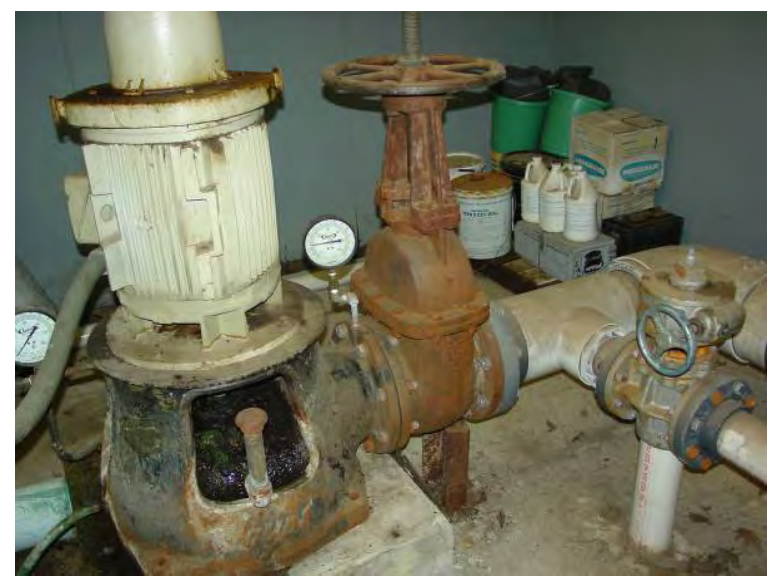

1 x 15 HP Deep Well Pump in Water Resources Office

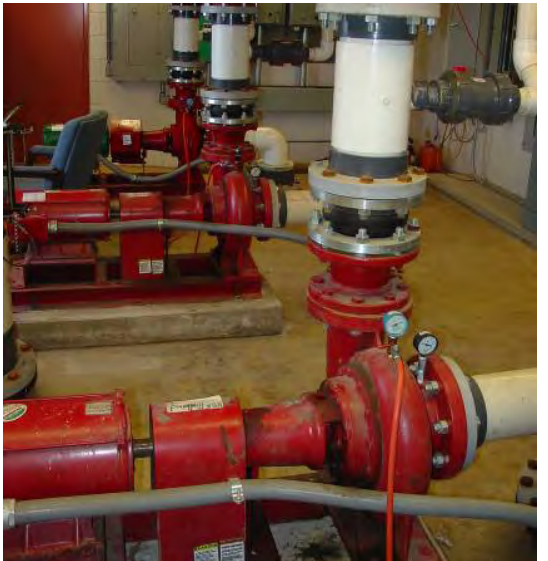

3 x 15 HP Lake Pump in New Hatchery

The raceways receive a mix of deep well and lake fed water. When in use, each hatchery raceway has 1000 gallons per minute of water flowing through it. Not all raceways are in use at all times and all five raceways are never used simultaneously. Utilization rates are as follows in Table 3.

Table 3. Utilization Rates of Fish Hatchery Raceways

\begin{tabular}{|l|l|l|l|}
\hline $\begin{array}{l}\text { No. of Pumps } \\
\text { Running }\end{array}$ & Flow Rate (gal/min) & $\begin{array}{l}\text { Percent of Time in } \\
\text { Use (Annually) }\end{array}$ & $\begin{array}{l}\text { Effective Flow Rate } \\
\text { (gal/min) }\end{array}$ \\
\hline 1 & 1000 & $20 \%$ & 200 \\
\hline 2 & 2000 & $40 \%$ & 800 \\
\hline 3 & 3000 & $20 \%$ & 600 \\
\hline 4 & 4000 & $10 \%$ & 400 \\
\hline 5 & 5000 & $0 \%$ & 0 \\
\hline Total & -- & -- & 2000 \\
\hline
\end{tabular}

Therefore, the average effective annual water flow rate at the Fish Hatchery is 2000 gallons per minute. 
Preliminary assessment of the outflow pipe system indicates that the vertical distance from the top of the raceway overflow drain to the water return pipe with empties into Trout Pond could be as much as eight feet.

Figure 6 shows the raceways in the upper-right hand corner of the photo and the common draining spout in the upper left hand side of the photo, info Trout Pond.

Figure 6. Trout Pond (Retaining and Pollution Prevention Pond)

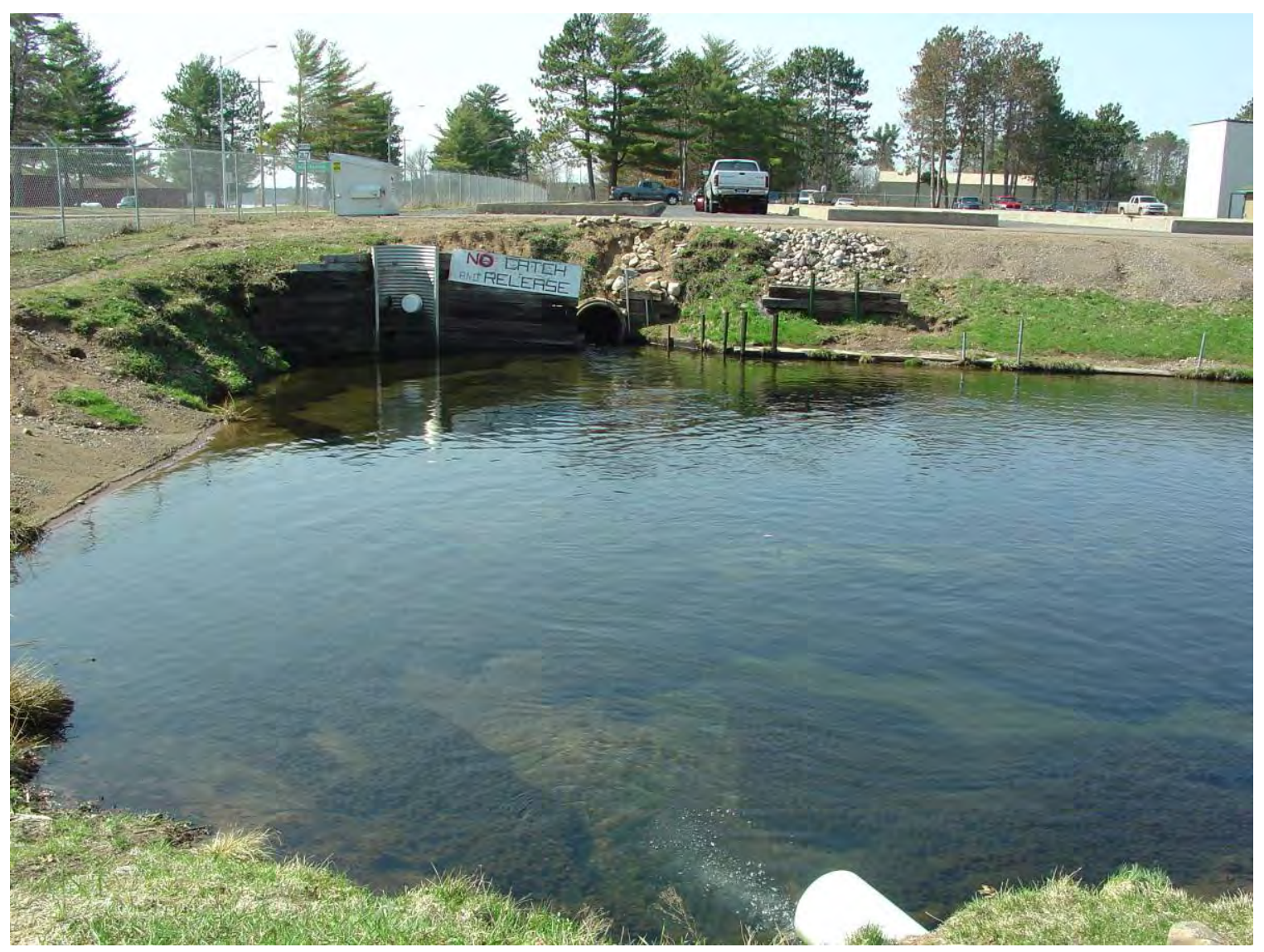

Based on the average water flow and the low head, the maximum output from a low-head micro-hydro turbine would be 1000 watts. However, since water flow is doubled during high volume hatchery operations to $4000 \mathrm{gal} / \mathrm{min}$ flow rates, another micro-hydro turbine could be added to work from this added flow for peak power output of 2000 watts. But with one turbine, using the above Average Energy Output formula, the average yearly energy production from a 1000 watt generator would be $6,307 \mathrm{kWh}$. If $100 \%$ of the hydropower was used by the hatchery, the Tribe would enjoy energy bill savings of almost $\$ 687$ per year.

Assuming a standard $12 \mathrm{~V}$ marine lead-acid battery with 300 amp-hours of capacity is $50 \%$ discharged, then this hydropower system could recharge approximately 6,300 
batteries per year, which is more than enough to legitimately claim “ $100 \%$ renewable energy” battery charging.

\section{Design Considerations}

Building this system would not be without challenges, and would be best undertaken as part of the planned renovation work at the Hatchery. The most significant question is how to modify the existing raceway overflow/drain pipe network to divert a steady amount of flow (900 gal/min or $2060 \mathrm{gal} / \mathrm{min}$ depending on the turbine) through a channel to the hydro unit located at the right height above the top of the Trout Pond's water level. Another consideration is the diameter of the return pipe with respect to the size of the hydropower unit.

Assuming the existing physical plant can be readily modified for a hydropower unit, the Tribe will need to decide if an AC or DC generator best meets its needs. Historically, most micro-hydro generators were designed to produce direct current electricity. Current levels vary with seasonal water flow. The DC output is used to charge a bank of batteries at $12 \mathrm{~V} ; 24 \mathrm{~V}$ or higher voltage levels. If DC loads are available, they are run directly from the batteries. If AC is required, a DC to AC inverter is installed which will produce $120 \mathrm{~V}$ or $240 \mathrm{~V}$ power with either a modified or pure 60 hertz sine wave.

The Energy Systems and Design LH-1000 turbine is one such system ${ }^{2}$. It can produce power from as little as two feet of head, but needs a full 10 feet of head to produce 1000 watts at a flow rate of 1000 gallons/minute. With only 8 feet of head, this generator could produce 800 watts with a maximum flow rate of 900 gal/minute. However, an additional 2 feet of head could be created during the renovation work by making the pond deeper/wider.

\section{LH1000 INSTALLATION}

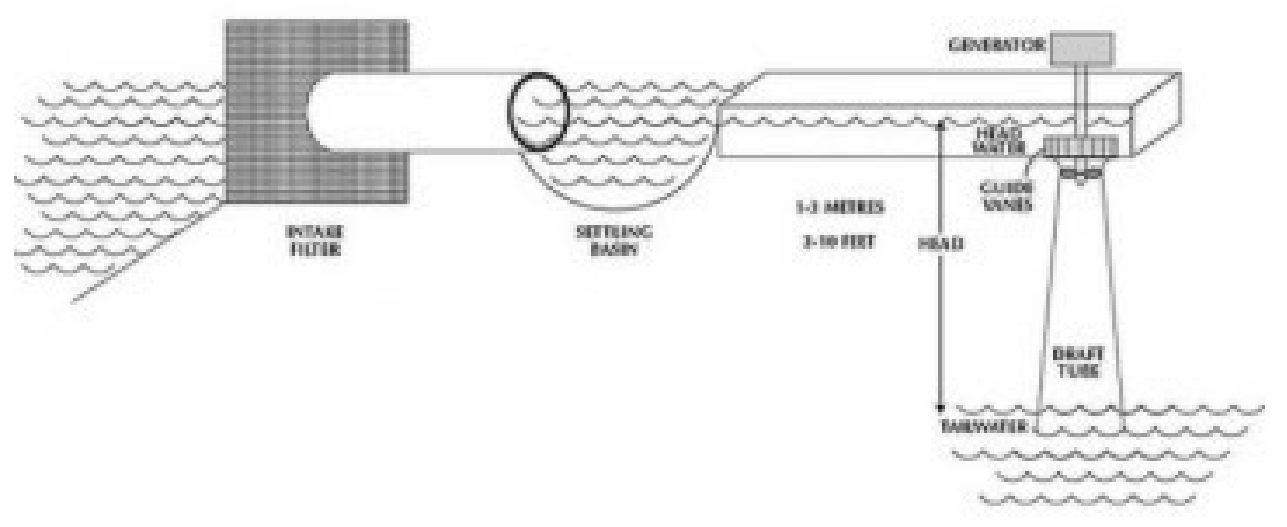

${ }^{2}$ Energy Systems and Design LH-1000: www.microhydropower.com 
AC systems have several advantages over DC systems. Since no batteries are required, system efficiency is increased. Also, AC hydro-generators produce $110 \mathrm{~V}$ or $240 \mathrm{~V}$ pure sine wave outputs making them perfectly compatible for all typical AC loads. However, AC hydro-turbines do require a sophisticated controller to maintain frequency at 60 hertz. Uncontrolled, the output frequency will vary with different flow rates.

Asian Phoenix Resources Power Pal MHG-1000 turbine is a good candidate ${ }^{3}$. It can produce up to 1000 watts and works best with head between 4.6 and 5.25 feet, and a flow rate of $2060 \mathrm{gal} / \mathrm{min}$. In addition to the draft tube, it comes with its own fiberglass canal intake.

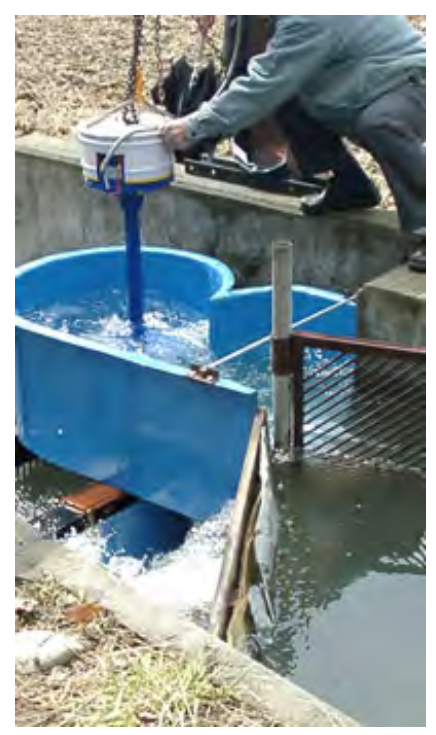

Given the existing electrical infrastructure at the Fish Hatchery and recognizing the goal of a micro-hydro project is to provide for fishing boat battery charging and limited on-site use, the Power Pal turbine will likely be the best candidate.

\section{Pricing for Turbine/Controller}

The ES\&D LH-1000 is available in a 12, 24, or 48V DC version for about \$2550. It comes with a 10' draft tube that can be cut to size, however it does not include cabling, inverter, dump load, pipes, etc, which would add another $\$ 1000$. Shipping from Canada through a direct freight forwarder costs about $\$ 150$.

The PowerPal MHG 1000LH is available in 110V AC for \$1089. This turbine is supplied with an electronic load controller and produces $50-65 \mathrm{~Hz}$. Custom-made fiberglass canal intake and draft tube are available for \$215. This product is manufactured in Vietnam, and the shipping costs between $\$ 400-500$, potentially less if the canal intake and draft tube are made locally.

\footnotetext{
${ }^{3}$ Asian Phoenix Resources Power Pal MHG-1000: www.powerpal.com
} 


\subsubsection{Regulatory issues}

As mentioned, permitting hydroelectric power plants of any size, on a navigable waterway automatically triggers a lengthy and costly process involving state and federal agencies. Since the Bear and Trout Rivers are not technically viable for hydropower, the details of the permitting process will not be discussed in this report although interested parties may refer to Wisconsin Department of Natural Resources website: Waterway and Wetland Permitting for Power Plants ${ }^{4}$ or contact the DNR at (608) 264 - 6048 for more information.

Installing a micro-hydro turbine at the Fish Hatchery, in our opinion, would not require state or federal permits since the turbine would simply be a modification to an existing water use and would not:

a. Create an obstruction to navigation;

b. Reduce the flood flow capacity of a stream; or

c. Adversely affect public rights and interest.

This is yet another factor favoring hydropower at the Fish Hatchery.

\subsection{Conclusion}

SGES's assessment of hydropower development options in the Lac du Flambeau Reservation makes the following conclusions:

1. The Bear and Trout Rivers are not suitable for development due to:

a. Low stream flows;

b. Low head;

c. Distance from the river to load centers; and

d. Complex and expensive permitting requirements

2. The Tribe should further investigate the option to install a $1 \mathrm{~kW}$ commercially available micro-hydro turbine at the Fish Hatchery. The primary purpose of such a project would be for fishing boat battery charging, public education, demonstration of Tribal commitment to clean energy and minimal power bill savings.

\footnotetext{
${ }^{4}$ WNDR Waterway Permitting for Power Plants: dnr.wi.gov/org/es/science/energy/pplants/wwet.html
} 
Task Seven: Micro-hydro Seventh Generation Energy Systems 


\section{Task Eight: Integration of Renewables into Existing Facilities}

\section{Table of Contents}

\begin{tabular}{|c|c|}
\hline & EXECUTIVE SUMMARY ...... \\
\hline 1.1.1 & 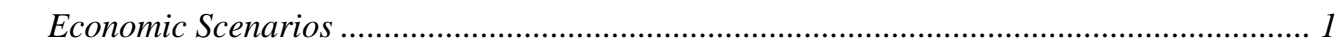 \\
\hline 1.1.2 & 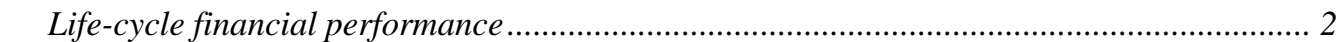 \\
\hline 1.1.3 & Renewable Energy Potential........... \\
\hline & INTRODUCTION AND METHODOLOGY..... \\
\hline 1.2.1 & Facility Selection And Renewable Energy System Sizing \\
\hline 1.2 .2 & Economic Scenarios \\
\hline 1.2 .3 & System Installed Costs ... \\
\hline & RESULTS \\
\hline SULTS & CONTINUED \\
\hline 1.3.1 & Facility Energy \\
\hline 1.3.2 & Renewable Energy 1 \\
\hline
\end{tabular}

\subsection{Executive Summary}

Nearly every facility on the Lac du Flambeau Reservation is a good candidate to utilize one or more types of renewable energy technology. However, the economic performance of a renewable energy system can vary greatly depending on current and predicted future fossil fuel prices, availability of financial incentives, and costs of equipment.

\subsubsection{Economic Scenarios}

Our financial analysis looks at two economic scenarios (baseline scenario vs. optimistic scenario). Each scenario uses different values for the key variables that affect financial performance. The optimistic scenario assumes that more incentives will be available to fund renewable energy installations, and that fossil fuel prices will increase more rapidly than in the baseline scenario.

The financial performance in the optimistic scenario is often two or three times greater than the baseline scenario, meaning that payback periods are cut in half and return on investment may double or triple. This difference in economic performance between the two economic scenarios is most significant for solar PV and least for geothermal and wind. 


\subsubsection{Life-cycle financial performance}

Our analysis of 30-year life-cycle costs shows:

- In both scenarios, solar hot water systems provide the greatest return on investment due to the relatively low equipment cost, minor maintenance costs and the significant savings that can be achieved by offsetting a high-cost fuel such as propane.

- In both scenarios, geothermal heat pump systems show favorable economic returns. In the baseline scenario, the benefits of geothermal appear greater, relative to other technologies, because the systems are cost effective without major financial incentives. A geothermal system would completely take the place of a building's conventional heating system, therefore the potential for energy savings and the upfront investment are significant.

- Solar photovoltaic systems have a high installation cost and, as a result, return on investment for a PV system is largely dependent on upfront incentives. PV systems perform significantly better in the optimistic scenario when federal tax benefits can be taken advantage of and when the system is connected to a facility that pays higher electric rates. Solar PV is scalable and can supply as large of a share of the Tribe's electricity consumption as is economically feasible.

- Opportunities for small to medium scale wind turbine installations are limited. However, two of the four locations analyzed show that wind speeds and electric rates are high enough that a wind turbine would provide a moderate return on investment in both economic scenarios.

In Task Six, biomass options were reviewed for the Lac du Flambeau School and Casino heating. It was determined that the heating loads of both facilities could be met with biomass combustion systems and preliminary results indicate that such a system at both locations would result in a quick payback. Due to the uniqueness and complexity of biomass systems and feed stock availability, further economic feasibility studies will be required to determine actual financial performance.

\subsubsection{Renewable Energy Potential}

In an idealized situation, it is interesting to see how much energy could be produced by all of the renewable energy systems that were evaluated in this report. If all of these systems were implemented, the energy production and savings potential would be $1,375,784 \mathrm{kWhs}$ of electricity and 174,804 gallons of propane. In other words, implementing all of these systems would provide $11.6 \%$ of the Tribe's 2007 electricity use and $29.4 \%$ of the Tribe's 2007 propane use.

It is encouraging to know that through the implementation of current renewable energy technologies the Lac du Flambeau Tribe could meet Wisconsin's renewable energy goals of $25 \%$ by 2025 . Of course the costs of such a goal need to be considered, but along with low-cost energy efficiency improvements and a future that will make renewable energy options even more affordable, the Tribe has many viable options today as it begins to make investments in renewable energy. 
Introduction and Methodology

\subsubsection{Facility Selection And Renewable Energy System Sizing}

Out of the 92 facilities included in this report, 29 of these were evaluated to determine which renewable energy technologies would be suitable and how an appropriately sized system would perform. The 29 facilities were chosen based on the following criteria.

Solar PV criteria - Selected facilities must have good access to the solar resource. Two locations were chosen that would provide high visibility for educational purposes. Generally, systems were sized based on the available roof space. Several very large systems were included to show the difference in economic performance between large and small solar PV arrays.

Solar hot water criteria - Selected facilities must have good access to the solar resource and a consistent hot water load. Systems were sized to meet 40 to $70 \%$ of the building's hot water load.

Wind criteria - Selected locations must have good access to the wind resource. The best locations were on the north or northeastern shores of the larger Tribal lakes and situated within 1,000 feet of a facility for electric interconnection. Wind turbines were selected that would perform best in the Reservation's modest wind regime.

Geothermal - Selected facilities must have balanced annual heating and cooling loads and high occupancy rates. Systems were sized to provide $100 \%$ of a facility or group of facilities' heating and cooling needs.

\subsubsection{Economic Scenarios}

Our financial analysis looks at two economic scenarios (baseline scenario vs. optimistic scenario). Each scenario uses different values for the key variables that affect financial performance. The optimistic scenario assumes that more incentives will be available to fund renewable energy installations, and that fossil fuel prices will increase more rapidly than in the baseline scenario. Table 1 presents each of the economic variables that were included in our analysis. 
Table 1. Economic Variables Affecting the Financial Performance of Renewable Energy Technologies

\begin{tabular}{|c|c|c|c|c|c|c|c|c|}
\hline & \multicolumn{2}{|c|}{ Solar Hot Water } & \multicolumn{2}{|c|}{ Geothermal } & \multicolumn{2}{|c|}{ Solar PV } & \multicolumn{2}{|c|}{ Wind } \\
\hline $\begin{array}{l}\text { Economic } \\
\text { Scenarios } \longrightarrow\end{array}$ & Baseline & Optimistic & Baseline & Optimistic & Baseline & Optimistic & Baseline & Optimistic \\
\hline Variables 凸 & & & & & & & & \\
\hline $\begin{array}{l}\text { Focus on Energy } \\
\text { Incentive }\end{array}$ & $\begin{array}{c}25-35 \% \text { of } \\
\text { installed cost } \\
(\$ 50 \mathrm{k} \mathrm{max})^{*} \\
\end{array}$ & $\begin{array}{l}25-35 \% \text { of } \\
\text { installed cost } \\
(\$ 50 \mathrm{k} \mathrm{max})^{*}\end{array}$ & $\begin{array}{l}\sim 1 \% \text { of } \\
\text { installed } \\
\text { cost }\end{array}$ & $\begin{array}{l}\sim 1 \% \text { of } \\
\text { installed cost }\end{array}$ & $\begin{array}{c}25-35 \% \text { of } \\
\text { installed cost } \\
(\$ 50 \mathrm{k} \text { max }) \\
\end{array}$ & $\begin{array}{l}25-35 \% \text { of } \\
\text { installed cost } \\
(\$ 50 \mathrm{k} \text { max }) \\
\end{array}$ & $\begin{array}{c}25-35 \% \text { of } \\
\text { installed cost } \\
(\$ 100 \mathrm{k} \text { max }) \\
\end{array}$ & $\begin{array}{l}25-35 \% \text { of } \\
\text { installed cost } \\
(\$ 100 \mathrm{k} \text { max }) \\
\end{array}$ \\
\hline $\begin{array}{l}\text { MACRS } \\
\text { (Depreciation Rate: } \\
\text { 5-year Schedule) }\end{array}$ & NA & $\begin{array}{l}\sim 20 \% \text { of } \\
\text { installed cost }\end{array}$ & NA & $\begin{array}{l}\sim 20 \% \text { of } \\
\text { installed cost }\end{array}$ & NA & $\begin{array}{c}\sim 20 \% \text { of } \\
\text { installed cost }\end{array}$ & NA & $\begin{array}{l}\sim 20 \% \text { of } \\
\text { installed cost }\end{array}$ \\
\hline $\begin{array}{l}\text { Federal Investment } \\
\text { Tax Credit } \\
\text { (Business) }\end{array}$ & NA & $\begin{array}{c}30 \% \\
\text { (no limit) }\end{array}$ & NA & $\begin{array}{c}10 \% \\
\text { (no limit) }\end{array}$ & NA & $\begin{array}{c}30 \% \\
\text { (no limit) }\end{array}$ & NA & $\begin{array}{c}5-10 \% \\
(\$ 4 k \text { max })\end{array}$ \\
\hline $\begin{array}{l}\text { Renewable Energy } \\
\text { Credits** }\end{array}$ & $\begin{array}{c}5 \% \text { of } \\
\text { installed cost } \\
\end{array}$ & $\begin{array}{c}10 \% \text { of } \\
\text { installed cost }\end{array}$ & NA & NA & $\mathrm{NA}^{* * *}$ & $\mathrm{NA} * * *$ & $\begin{array}{c}\text { 7\% of } \\
\text { installed cost } \\
\end{array}$ & $\begin{array}{c}15 \% \text { of } \\
\text { installed cost }\end{array}$ \\
\hline $\begin{array}{l}\text { Advanced } \\
\text { Renewable Tariff }\end{array}$ & NA & NA & NA & NA & $\begin{array}{c}\$ 0.25 \text { per } \\
\text { kWh for } 10 \\
\text { years } \\
\text { (up to } 20 \mathrm{~kW} \text { ) }\end{array}$ & $\begin{array}{c}\$ 0.25 \text { per } \\
\mathrm{kWh} \text { for } 10 \\
\text { years } \\
\text { (up to } 20 \mathrm{~kW} \text { ) } \\
\end{array}$ & NA & NA \\
\hline $\begin{array}{l}\text { 15-year Loan } \\
\text { Interest Rate }\end{array}$ & $3 \%$ & $1.5 \%$ & $3 \%$ & $1.5 \%$ & $3 \%$ & $1.5 \%$ & $3 \%$ & $1.5 \%$ \\
\hline $\begin{array}{l}\text { Annual Electricity } \\
\text { Rate Increase }\end{array}$ & $3.7 \%$ & $7 \%$ & $3.7 \%$ & $7 \%$ & $3.7 \%$ & $7 \%$ & $3.7 \%$ & $7 \%$ \\
\hline $\begin{array}{l}\text { Annual Propane } \\
\text { Rate Increase }\end{array}$ & $8 \%$ & $14.5 \%$ & $8 \%$ & $14.5 \%$ & NA & NA & NA & NA \\
\hline
\end{tabular}

* Focus on Energy Incentives are only available to Solar Hot Water systems that displace electric heating loads.

** Estimated value of RECs were obtained from Native Energy, Inc in Sep. 2008. Figures should be expected to vary based on current carbon market values.

*** If a utility purchases energy from a solar system through an advanced renewable tariff the RECs are owned by the utility. 


\subsubsection{System Installed Costs}

The financial performance of renewable energy systems is dependent on the cost of each technology. The following cost estimates were used in our financial analysis.

Solar PV - Projected initial costs for solar PV systems were obtained from typical 2008 solar system project costs (using silicon-based modules).

Table 2. Solar PV Estimated Installation Cost

\begin{tabular}{|l|c|}
\hline System Size & Cost per kW \\
\hline $1-3 \mathrm{~kW}$ & $\$ 10,000$ \\
\hline $4-10 \mathrm{~kW}$ & $\$ 9,000$ \\
\hline$>11 \mathrm{~kW}$ & $\$ 8,000$ \\
\hline
\end{tabular}

Solar Hot Water - Solar hot water cost estimates were based on the average cost of installations on existing commercial facilities in Wisconsin in 2008.

Table 3. Solar Hot Water Estimated Installation Cost

\begin{tabular}{|l|c|}
\hline System Size & Cost per square foot of collector \\
\hline All sizes & $\$ 120$ \\
\hline
\end{tabular}

Wind - Estimated project costs were based on recently completed and upcoming projects.

Table 4. Wind Turbine Estimated Installation Cost

\begin{tabular}{|l|l|c|}
\hline System Type (Size) & Site Locations & Turnkey Installed Cost \\
\hline Vestas V15 $(35 \mathrm{~kW})$ & $\begin{array}{l}\text { Elks Point Elder Housing } \\
\text { and Casino Hotel }\end{array}$ & $\$ 180,000$ \\
\hline Energie PGE $(35 \mathrm{~kW})$ & Casino & $\$ 300,000$ \\
\hline Proven 15000 $(15 \mathrm{~kW})$ & Natural Resources (Planned) & $\$ 120,000$ \\
\hline
\end{tabular}

${ }^{\star}$ Annual maintenance costs are estimated at $1 \%$ of installed cost for systems under $20 \mathrm{~kW}$ and $0.5 \%$ of installed cost for systems larger than $20 \mathrm{~kW}$.

Geothermal - Projected initial costs for both the conventional CAV systems and the geothermal heat pump systems were based on an analysis of recently completed projects of similar size.

Table 5. Geothermal and Conventional CAV Estimated Installation Cost

\begin{tabular}{|l|c|}
\hline System Type & $\begin{array}{l}\text { Installation cost per square foot of } \\
\text { space to be heated/cooled }\end{array}$ \\
\hline Conventional CAV furnace & $\$ 16$ \\
\hline Geothermal heatpump & $\$ 22$ to $\$ 23$ \\
\hline
\end{tabular}

${ }^{\star}$ Annual maintenance costs are estimated at $0.89 \%$ of installed cost for geothermal systems and $1.88 \%$ of installed cost for conventional CAV systems. 


\subsection{Results}

Table 6 and Table 7 show the 29 sites that were analyzed for renewable energy installations and how each site performs based on the selected renewable energy technology.

The financial performance of renewable energy systems in the optimistic scenario is often two or three times greater than the baseline scenario, meaning that payback periods are cut in half and return on investment may double or triple. This difference in economic performance between the two economic scenarios is most significant for solar PV and least significant for geothermal and wind.

As described above, key findings from the life-cycle cost analysis include:

- In both scenarios, solar hot water systems provide the greatest return on investment due to the relatively low equipment cost, minor maintenance costs and the significant savings that can be achieved by offsetting a high-cost fuel such as propane.

- In both scenarios, geothermal heat pump systems show favorable economic returns. In the baseline scenario, the benefits of geothermal appear greater, relative to other technologies, because the systems are cost effective without major financial incentives. Because a geothermal system would completely take the place of a building's conventional heating system, both the potential for energy savings and the upfront investment are significant.

- Solar photovoltaic systems have a high installation cost and, as a result, return on investment for a PV system is largely dependent on upfront incentives. PV systems perform significantly better in the optimistic scenario when federal tax benefits can be utilized and when the system is connected to a facility that pays higher electric rates. Solar PV is scalable and can supply as large of a share of the Tribe's electricity consumption as is economically feasible.

- Opportunities for small to medium scale wind turbine installations are limited. However, two of the four locations analyzed show that wind speeds and electric rates are high enough that a wind turbine would provide a moderate return on investment in both economic scenarios. 
Table 6. Baseline Scenario Summary of Renewable Energy Projects by 30-year Cost, Return on Investment, and Energy Savings

\begin{tabular}{|c|c|c|c|c|c|}
\hline & PV & SHW & Wind & Geo & Legend \\
\hline Adaawe Place & - & - & - & $\$ 479,133$ & \\
\hline Bingo Hall & $\$ 764,453$ & $\$ 16,877$ & - & $\$ 1,389,726$ & Return on Investment \\
\hline Casino & $\$ 262,930$ & $\$ 69,010$ & $\$ 195,159$ & - & greater than $100 \%$ \\
\hline Casino Billboard (47) & $\$ 18,194$ & - & - & - & $20 \%$ to $100 \%$ \\
\hline Casino Billboard $(47 / \mathrm{H})$ & $\$ 18,194$ & - & - & - & $0 \%$ to $20 \%$ \\
\hline Casino Billboard (70) & - & - & - & - & less than $0 \%$ \\
\hline Casino Engineering Building & $\$ 17,064$ & - & - & - & \\
\hline Casino Hotel & - & $\$ 136,138$ & $\$ 277,613$ & - & Energy Savings (in kBtu) \\
\hline Casino Human Resources / Education Building & $\$ 16,678$ & $\$ 20,252$ & - & $\$ 1,137,878$ & greater than 20 million \\
\hline Community Center / Clinic & $\$ 753,776$ & $\$ 23,628$ & - & $\$ 3,008,720$ & 5 million to 20 million \\
\hline Elks Point Elder Housing & $\$ 231,874$ & $\$ 16,877$ & $\$ 277,421$ & - & 1 million to 5 million \\
\hline Family Resource Center & $\$ 17,064$ & - & - & - & less than 1 million \\
\hline Food Distribution Building & $\$ 17,064$ & - & - & - & \\
\hline Gas Station & $\$ 72,756$ & - & - & - & \\
\hline Indian Bowl & $\$ 17,064$ & - & - & $\$ 457,467$ & \\
\hline Judicial building & $\$ 200,818$ & - & - & $\$ 615,872$ & \\
\hline Lac du Flambeau School & $\$ 1,892,124$ & $\$ 138,021$ & - & - & \\
\hline Museum & $\$ 34,128$ & $\$ 4,929$ & - & $\$ 780,754$ & \\
\hline Natural Resources (PLANNED) & $\$ 134,908$ & - & $\$ 147,033$ & $\$ 583,245$ & \\
\hline Planning / Bank Building & $\$ 17,064$ & - & - & $\$ 382,589$ & \\
\hline Post Office (Tribal Office, Library) & $\$ 17,064$ & - & - & $\$ 669,315$ & \\
\hline Roads Garage (Tribal garage) & $\$ 17,064$ & $\$ 9,859$ & - & - & \\
\hline Simpson's Main Plant & $\$ 464,245$ & $\$ 6,481$ & - & $\$ 2,626,730$ & \\
\hline Simpsons Plastics Plant & $\$ 72,756$ & $\$ 23,628$ & - & - & \\
\hline Smoke Shop & $\$ 17,064$ & - & - & $\$ 1,348,477$ & \\
\hline Store (Ojibwe mall) & $\$ 16,678$ & $\$ 43,880$ & - & - & \\
\hline Water Resource office & $\$ 87,307$ & - & - & - & \\
\hline Wellness Center & $\$ 16,678$ & - & - & - & \\
\hline Youth Center (Abinoojiiyag Center) & $\$ 84,268$ & $\$ 20,252$ & - & $\$ 582,376$ & \\
\hline
\end{tabular}


Table 7. Optimistic Scenario Summary of Renewable Energy Projects by 30-year Cost, Return on Investment, and Energy Savings

\section{Adaawe Place \\ Bingo Hall \\ Casino}

Casino Billboard (47)

Casino Billboard $(47 / \mathrm{H})$

Casino Billboard (70)

Casino Engineering Building

Casino Hotel

Casino Human Resources / Education Building

Community Center / Clinic

Elks Point Elder Housing

Family Resource Center

Food Distribution Building

Gas Station

Indian Bowl

Judicial building

Lac du Flambeau School

Museum

Natural Resources (PLANNED)

Planning / Bank Building

Post Office (Tribal Office, Library)

Roads Garage (Tribal garage)

Simpson's Main Plant

Simpsons Plastics Plant

Smoke Shop

Store (Ojibwe mall)

Water Resource office

Wellness Center

Youth Center (Abinoojiïyag Center)

\begin{tabular}{|c|c|c|c|}
\hline PV & SHW & Wind & Geo \\
\hline - & - & - & $\$ 462,402$ \\
\hline$\$ 336,425$ & $\$ 6,109$ & - & $\$ 2,371,014$ \\
\hline$\$ 83,512$ & $\$ 26,189$ & $\$ 136,135$ & - \\
\hline$\$ 6,284$ & - & - & - \\
\hline$\$ 6,284$ & - & - & - \\
\hline- & - & - & - \\
\hline$\$ 5,153$ & - & - & - \\
\hline- & $\$ 51,362$ & $\$ 199,545$ & - \\
\hline$\$ 4,768$ & $\$ 7,331$ & - & $\$ 1,979,861$ \\
\hline$\$ 708,054$ & $\$ 8,553$ & - & $\$ 4,310,878$ \\
\hline$\$ 73,220$ & $\$ 6,109$ & $\$ 199,425$ & - \\
\hline$\$ 5,153$ & - & - & - \\
\hline$\$ 5,153$ & - & - & - \\
\hline$\$ 20,709$ & - & - & - \\
\hline$\$ 5,153$ & - & - & $\$ 657,919$ \\
\hline$\$ 62,927$ & - & - & $\$ 950,608$ \\
\hline$\$ 816,722$ & $\$ 52,378$ & - & - \\
\hline$\$ 10,307$ & $\$ 1,871$ & - & $\$ 1,088,400$ \\
\hline$\$ 31,301$ & - & $\$ 88,835$ & $\$ 837,812$ \\
\hline$\$ 5,153$ & - & - & $\$ 528,159$ \\
\hline$\$ 5,153$ & - & - & $\$ 896,395$ \\
\hline$\$ 5,153$ & $\$ 3,741$ & - & - \\
\hline$\$ 223,574$ & $\$ 2,230$ & - & $\$ 4,450,974$ \\
\hline$\$ 20,709$ & $\$ 8,553$ & - & - \\
\hline$\$ 5,153$ & - & - & $\$ 2,139,489$ \\
\hline$\$ 4,768$ & $\$ 15,884$ & - & - \\
\hline$\$ 24,851$ & - & - & - \\
\hline$\$ 4,768$ & - & - & - \\
\hline$\$ 21,911$ & $\$ 7,331$ & - & $\$ 769,588$ \\
\hline
\end{tabular}

\section{Return on Investment}

greater than $1000 \%$ $300 \%$ to $1000 \%$ $100 \%$ to $300 \%$

$0 \%$ to $100 \%$

\section{Energy Savings (in kBtu)}

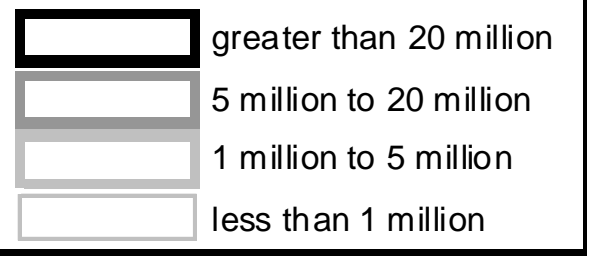




\section{Results Continued...}

\subsubsection{Facility Energy Profiles}

In addition to the performance comparison of renewable technologies, we present profiles of each facility that describe key building characteristics, 2007 energy use, electric account information, energy efficiency recommendations and detailed summaries of renewable energy system performance. A collection of these profiles is contained in Appendix 2.

\subsubsection{Renewable Energy Potential}

In an idealized situation, it is interesting to see how much energy could be produced by all of the renewable energy systems that were evaluated in this report. If all of these systems were implemented, the energy production and savings potential would be $1,375,784 \mathrm{kWh}$ of electricity and 174,804 gallons of propane. This would provide 11.6\% of the Tribe’s 2007 electricity use and 29.4\% of the Tribe’s 2007 propane use.

Table 8. Energy Production and Savings from All Renewable Energy Systems

\begin{tabular}{|c|c|c|c|c|}
\hline $\begin{array}{l}\text { Renewable } \\
\text { Energy Type }\end{array}$ & $\begin{array}{l}\text { Electricity } \\
\text { Production/Savings } \\
\text { (kWh) }\end{array}$ & $\begin{array}{l}\text { Percent of } \\
\text { Tribal } \\
\text { Electricity Use } \\
(2007)\end{array}$ & $\begin{array}{l}\text { Propane } \\
\text { Production/Savings } \\
\text { (gallons) }\end{array}$ & $\begin{array}{l}\text { Percent of } \\
\text { Tribal } \\
\text { Propane Use } \\
(2007)\end{array}$ \\
\hline Solar PV & 847,392 & $7.1 \%$ & - & - \\
\hline Solar Hot Water & 128,119 & $1.1 \%$ & 96,939 & $16.3 \%$ \\
\hline Wind & 214,863 & $1.8 \%$ & - & - \\
\hline Geothermal & 185,410 & $1.6 \%$ & 77,865 & $13.1 \%$ \\
\hline Total & $1,375,784$ & $11.6 \%$ & 174,804 & $29.4 \%$ \\
\hline
\end{tabular}




\subsection{Conclusions and Recommendations}

Many renewable energy systems are a sound investment given current energy prices and financial incentives. Investments in certain renewable energy options may not be as financially compelling today, but as energy prices increase, equipment costs decline and the Tribe investigates the availability of federal tax benefits all options will need to be considered.

In the near term, as the Tribe moves forward with their strategic energy plan, we offer the following recommendations:

- Energy efficiency first. Efficiency improvements will reduce the amount of renewable energy that is needed. For every dollar spent on energy efficiency, three to five dollars can be saved on renewable energy systems.

- "Bite sized” investments in renewable energy can begin immediately and solar hot water systems provide a range of options that offer the quickest payback and high return on investment.

- Geothermal heat pumps are a cost-effective solution to provide a facility's entire heating and cooling needs. Their large upfront cost will require more careful planning and a more detailed economic feasibility study.

- Solar PV systems are a scalable technology and small systems on high-profile buildings or stand-alone structures should be considered immediately. If the Tribe finds a way to receive federal solar tax benefits, larger scale systems will become quite appealing. Also, while solar PV may be a relatively expensive technology today, we expect its cost to decline quickly over the next five years.

- The Tribe should begin researching the availability of federal tax credits. Federal business tax credits and accelerated depreciation can reduce the cost of solar hot water and solar PV by up to 50\%. If the Lac du Flambeau government isn't eligible directly, the Tribe may look into forming or partnering with other legal entities that do qualify for a desired incentive.

- Once a direction is decided by the Tribe, current pricing and performance of smaller systems can be obtained through low-cost site assessments or by requesting bids from installers. As larger systems are pursued, economic feasibility studies may be necessary to obtain accurate equipment pricing, negotiate power purchase rates, and determine financing costs, applicable grants and tax benefits.

Through the implementation of current renewable energy technologies the Lac du Flambeau Tribe could meet Wisconsin's renewable energy goals of $25 \%$ by 2025 . Along with low-cost energy efficiency improvements and a future that will make renewable energy options even more affordable, the Tribe has many viable options today as it begins to make investments in renewable energy. 


\subsection{Appendices}

\begin{tabular}{|c|c|c|c|c|c|c|}
\hline $\begin{array}{c}\text { Project } \\
\text { Type }\end{array}$ & Building & Size of System & \begin{tabular}{|l|}
$\begin{array}{l}\text { Cost to Intall } \\
\text { (after Focus) }\end{array}$ \\
\end{tabular} & \begin{tabular}{|l|} 
30-Year Energy \\
Savings (kBtu)
\end{tabular} & \begin{tabular}{|l} 
Baseline 30- \\
Year ROI
\end{tabular} & $\begin{array}{l}\text { Optimistic 30- } \\
\text { Year RO }\end{array}$ \\
\hline PV & Casino Billboard (47) & $2 \mathrm{~kW}$ & $\$ 15,344$ & \begin{tabular}{r|}
238,294 \\
\end{tabular} & $2 \%$ & $454 \%$ \\
\hline $\mathrm{PV}$ & Casino Billboard (47/H) & $2 \mathrm{~kW}$ & $\$ 15,344$ & 238,294 & $2 \%$ & $454 \%$ \\
\hline $\mathrm{PV}$ & Casino Engineering Building & $2 \mathrm{~kW}$ & $\$ 15,344$ & 238,294 & $-21 \%$ & $391 \%$ \\
\hline $\mathrm{PV}$ & Casino Human Resources/Education Bldg & $2 \mathrm{~kW}$ & $\$ 15,344$ & 238,294 & $-29 \%$ & $363 \%$ \\
\hline $\mathrm{PV}$ & Family Resource Center & $2 \mathrm{~kW}$ & $\$ 15,344$ & 238,294 & $-21 \%$ & $391 \%$ \\
\hline $\mathrm{PV}$ & Food Distribution Building & $2 \mathrm{~kW}$ & $\$ 15,344$ & 238,294 & $-21 \%$ & $391 \%$ \\
\hline PV & Indian Bowl & $2 \mathrm{~kW}$ & $\$ 15,344$ & 238,294 & $-21 \%$ & $391 \%$ \\
\hline $\mathrm{PV}$ & Planning / Bank Building & $2 \mathrm{~kW}$ & $\$ 15,344$ & 238,294 & $-21 \%$ & $391 \%$ \\
\hline PV & Post Office (Tribal Office, Library) & $2 \mathrm{~kW}$ & $\$ 15,344$ & 238,294 & $-21 \%$ & $391 \%$ \\
\hline $\mathrm{PV}$ & Roads Garage (Tribal garage) & $2 \mathrm{~kW}$ & $\$ 15,344$ & 238,294 & $-21 \%$ & $391 \%$ \\
\hline $\mathrm{PV}$ & Smoke Shop & $2 \mathrm{~kW}$ & $\$ 15,344$ & 238,294 & $-21 \%$ & $391 \%$ \\
\hline $\mathrm{PV}$ & Store (Ojibwe mall) & $2 \mathrm{~kW}$ & $\$ 15,344$ & 238,294 & $-29 \%$ & $363 \%$ \\
\hline $\mathrm{PV}$ & Wellness Center & $2 \mathrm{~kW}$ & $\$ 15,344$ & 238,294 & $-29 \%$ & $363 \%$ \\
\hline $\mathrm{PV}$ & Museum & $4 \mathrm{~kW}$ & $\$ 30,688$ & 476,588 & $-21 \%$ & $391 \%$ \\
\hline $\mathrm{PV}$ & Youth Center (Abinoojiiyag Center) & $14 \mathrm{~kW}$ & $\$ 53,956$ & $1,668,059$ & $12 \%$ & $708 \%$ \\
\hline $\mathrm{PV}$ & Gas Station & $10 \mathrm{~kW}$ & $\$ 66,720$ & $1,191,470$ & $-7 \%$ & $511 \%$ \\
\hline $\mathrm{PV}$ & Simpsons Plastics Plant & $10 \mathrm{~kW}$ & $\$ 66,720$ & $1,191,470$ & $-7 \%$ & $511 \%$ \\
\hline PV & Water Resource office & $12 \mathrm{~kW}$ & $\$ 68,064$ & $1,429,764$ & $-7 \%$ & $511 \%$ \\
\hline $\mathrm{PV}$ & Natural Resources (PLANNED) & $20 \mathrm{~kW}$ & $\$ 125,000$ & $2,382,941$ & $0 \%$ & $708 \%$ \\
\hline $\mathrm{PV}$ & Judicial building & $29 \mathrm{~kW}$ & $\$ 182,000$ & $3,455,264$ & $-2 \%$ & $483 \%$ \\
\hline $\mathrm{PV}$ & Elks Point Eder Housing & $32 \mathrm{~kW}$ & $\$ 206,000$ & $3,812,705$ & $-7 \%$ & $453 \%$ \\
\hline $\mathrm{PV}$ & Casino & $35 \mathrm{~kW}$ & $\$ 209,500$ & $4,170,146$ & $-10 \%$ & $430 \%$ \\
\hline $\mathrm{PV}$ & Simpson's Main Plant & $61 \mathrm{~kW}$ & $\$ 388,000$ & $7,267,969$ & $-22 \%$ & $201 \%$ \\
\hline $\mathrm{PV}$ & Bingo Hall & $90 \mathrm{~kW}$ & $\$ 620,000$ & $10,723,234$ & $-31 \%$ & $195 \%$ \\
\hline $\mathrm{PV}$ & Community Center / Clinic & $175 \mathrm{~kW}$ & $\$ 1,300,000$ & $20,850,732$ & $-8 \%$ & $84 \%$ \\
\hline $\mathrm{PV}$ & Lac du Flambeau School & $200 \mathrm{~kW}$ & $\$ 1,600,000$ & $23,829,408$ & $-58 \%$ & $82 \%$ \\
\hline SHW & Museum & $32 \mathrm{sqft}$ & $\$ 3,648$ & 309,243 & $419 \%$ & $4652 \%$ \\
\hline SHW & Simpsons Plastics Plant & $64 \mathrm{sqft}$ & $\$ 4,608$ & $1,732,078$ & $263 \%$ & $1774 \%$ \\
\hline SHW & Roads Garage (Tribal garage) & $64 \mathrm{sqft}$ & $\$ 7,296$ & 618,578 & $419 \%$ & $4653 \%$ \\
\hline SHW & Bingo Hall & $160 \mathrm{sq} \mathrm{ft}$ & $\$ 12,056$ & $1,237,198$ & $263 \%$ & $1774 \%$ \\
\hline SHW & Casino Human Resources/ Education Bldg & $192 \mathrm{sq} \mathrm{ft}$ & $\$ 14,468$ & $1,484,640$ & $263 \%$ & $1774 \%$ \\
\hline SHW & Youth Center (Abinoojiilyag Center) & $192 \mathrm{sq} \mathrm{ft}$ & $\$ 14,468$ & $1,484,640$ & $317 \%$ & $2050 \%$ \\
\hline SHW & Community Center / Clinic & $224 \mathrm{sq} \mathrm{ft}$ & $\$ 16,879$ & $1,732,078$ & $145 \%$ & $1163 \%$ \\
\hline SHW & Simpson's Main Plant & $224 \mathrm{sq} \mathrm{ft}$ & $\$ 16,879$ & 494,880 & $155 \%$ & $1284 \%$ \\
\hline SHW & Elks Point Eder Housing & $160 \mathrm{sq} \mathrm{ft}$ & $\$ 18,240$ & $1,237,198$ & $263 \%$ & $1774 \%$ \\
\hline SHW & Store (Ojibwe mall) & $416 \mathrm{sq} \mathrm{ft}$ & $\$ 31,347$ & $3,216,718$ & $145 \%$ & $1163 \%$ \\
\hline SHW & Casino & $448 \mathrm{sq} \mathrm{ft}$ & $\$ 51,072$ & $4,330,047$ & $419 \%$ & $4653 \%$ \\
\hline SHW & Casino Hotel & $1216 \mathrm{sqft}$ & $\$ 97,895$ & $251,685,022$ & $130 \%$ & $1041 \%$ \\
\hline SHW & Lac du Flambeau School & $896 \mathrm{sq} f \mathrm{ft}$ & $\$ 102,144$ & $6,181,762$ & $419 \%$ & $4653 \%$ \\
\hline Wind & Natural Resources (PLANNED) & $15 \mathrm{~kW}$ & $\$ 88,367$ & $1,587,863$ & $-19 \%$ & $149 \%$ \\
\hline Wind & Elks Point Eder Housing & $35 \mathrm{~kW}$ & $\$ 184,977$ & $7,867,591$ & $61 \%$ & $319 \%$ \\
\hline Wind & Casino Hotel & $35 \mathrm{~kW}$ & $\$ 185,130$ & $7,854,799$ & $-6 \%$ & $145 \%$ \\
\hline Wind & Casino & $35 \mathrm{~kW}$ & $\$ 202,637$ & $4,683,042$ & $36 \%$ & $266 \%$ \\
\hline Geo & Judicial building & 10 cooling tons & $\$ 109,032$ & $5,650,426$ & $85 \%$ & $195 \%$ \\
\hline Geo & Indian Bowl & 11 cooling tons & $\$ 114,633$ & $7,211,630$ & $150 \%$ & $373 \%$ \\
\hline Geo & Planning / Bank Building & 7 bores & $\$ 127,956$ & $9,760,560$ & $249 \%$ & $640 \%$ \\
\hline Geo & Casino Human Resources/ Education Bldg & 8 bores & $\$ 136,472$ & $18,073,452$ & $151 \%$ & $300 \%$ \\
\hline Geo & Natural Resources (PLANNED) & 13 cooling tons & $\$ 146,546$ & $9,241,579$ & $151 \%$ & $375 \%$ \\
\hline Geo & Youth Center (Abinoojiilyag Center) & 8 bores & $\$ 170,515$ & $5,839,901$ & $94 \%$ & $259 \%$ \\
\hline Geo & Smoke Shop & 11 bores & $\$ 182,010$ & $1,941,428$ & $8 \%$ & $14 \%$ \\
\hline Geo & Post Office (Tribal Office, Library) & 11 bores & $\$ 187,243$ & $4,924,582$ & $68 \%$ & $186 \%$ \\
\hline Geo & Museum & 18 cooling tons & $\$ 196,501$ & $8,495,774$ & $102 \%$ & $264 \%$ \\
\hline Geo & Bingo Hall & 10 bores & $\$ 204,062$ & $26,701,051$ & $184 \%$ & $375 \%$ \\
\hline Geo & Adaawe Place & 11 bores & $\$ 229,718$ & $6,792,241$ & $134 \%$ & $522 \%$ \\
\hline Geo & Simpson's Main Plant & 17 bores & $\$ 353,480$ & $38,871,134$ & $140 \%$ & $287 \%$ \\
\hline Geo & Community Center / Clinic & 37 bores & $\$ 794,752$ & $50,096,976$ & $154 \%$ & $382 \%$ \\
\hline
\end{tabular}




\section{Appendix 2. Building Profiles}

In addition to the performance comparison of renewable technologies, we present profiles of each facility that describe key building characteristics, 2007 energy use, electric account information, energy efficiency recommendations and detailed summaries of renewable energy system performance. 
Task Eight: Integration of Renewables into Existing Facilities Seventh Generation Energy Systems 


\begin{tabular}{|llll|}
\hline Facility - Youth Center (Abinoojiiyag Center) & Space Heating System & Furnace \\
Area $\left(\mathrm{ft}^{2}\right)$ & 7,568 & Space Cooling System & DX \\
Occupany Schedule & M-Sat $8 \mathrm{am}-8 \mathrm{pm}$ & Water Heating System & Electric \\
\hline
\end{tabular}

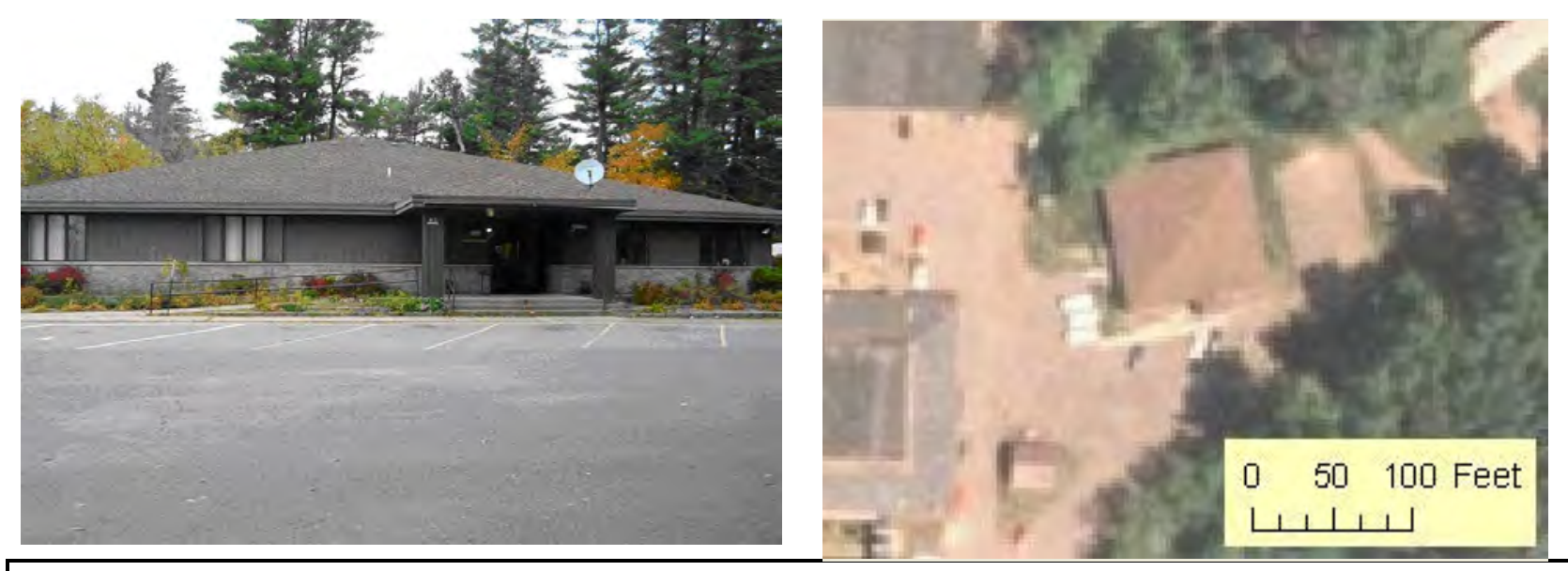

Energy Profile (2007)

\begin{tabular}{|c|c|c|c|}
\hline Electricity & Total & Rank & $\begin{array}{l}\text { Percent } \\
\text { of Tribe }\end{array}$ \\
\hline $\begin{array}{c}\text { Consumption kWh } \\
\text { (Cost) }\end{array}$ & $\begin{array}{l}\mathbf{4 8 , 6 3 8} \\
\$ 6,335\end{array}$ & 17 & $0.4 \%$ \\
\hline $\begin{array}{c}\text { Electricity Intensity } \\
\left(\mathrm{Cost} / \mathrm{ft}^{2}\right)\end{array}$ & $\begin{array}{r}21.9 \\
\$ 0.84\end{array}$ & 21 & \\
\hline \begin{tabular}{|l} 
Energy Charge $(\mathrm{kWh})$ \\
Demand Charge $(\mathrm{kW})$
\end{tabular} & \begin{tabular}{r|}
$\$ 0.109$ \\
$\$ 0.00$
\end{tabular} & & \\
\hline
\end{tabular}

\begin{tabular}{|c|c|c|c|}
\hline Propane & Total & Rank & $\begin{array}{l}\text { Percent } \\
\text { of Tribe }\end{array}$ \\
\hline $\begin{array}{c}\text { Consumption gal } \\
\text { (Cost) }\end{array}$ & $\begin{array}{r}\mathbf{2 , 5 0 1} \\
\$ 3,652 \\
\end{array}$ & 17 & $0.6 \%$ \\
\hline $\begin{array}{c}\text { Propane Intensity } \\
\left(\text { Cost } / \mathbf{f t}^{2}\right)\end{array}$ & $\begin{array}{r}30.2 \\
\$ 0.48 \\
\end{array}$ & 19 & \\
\hline Propane Cost (gal) & & $\$ 1.46$ & \\
\hline
\end{tabular}
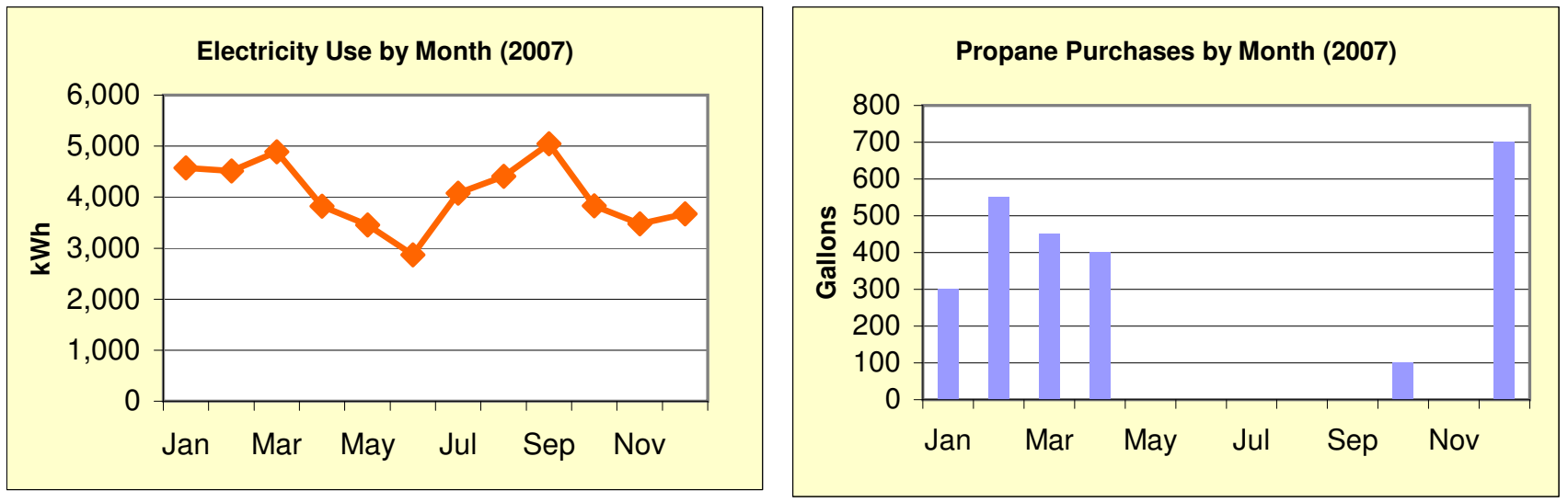

\section{WPS Electric Accounts}

\section{Energy Efficiency Recommendations}

\begin{tabular}{|l|l|r|r|}
\hline \multicolumn{1}{|c|}{ Type } & Rate & $\begin{array}{c}\text { 2007 Use } \\
\text { (kWh) }\end{array}$ & 2007 Cost \\
\hline Main & CG-1 & 48,638 & $\$ 5,346$ \\
\hline Outdoor lighting & GY-3 & & $\$ 989$ \\
\hline & & & \\
\hline & & & \\
\hline & & & \\
\hline & & & \\
\hline & & & \\
\hline
\end{tabular}

\begin{tabular}{|l|l|l|l|}
\hline Recommendation & $\begin{array}{c}\text { Cost to } \\
\text { Install }\end{array}$ & $\begin{array}{c}\text { Annual } \\
\text { kWh } \\
\text { Savings }\end{array}$ & $\begin{array}{c}\text { Simple Payback } \\
\text { (yrs) }\end{array}$ \\
\hline & & & \\
\hline Monitor damper vents \\
\hline Install programmable set-back thermostats \\
\hline Turn gym lights off when not in use \\
\hline \multicolumn{2}{|l|}{} \\
\hline
\end{tabular}




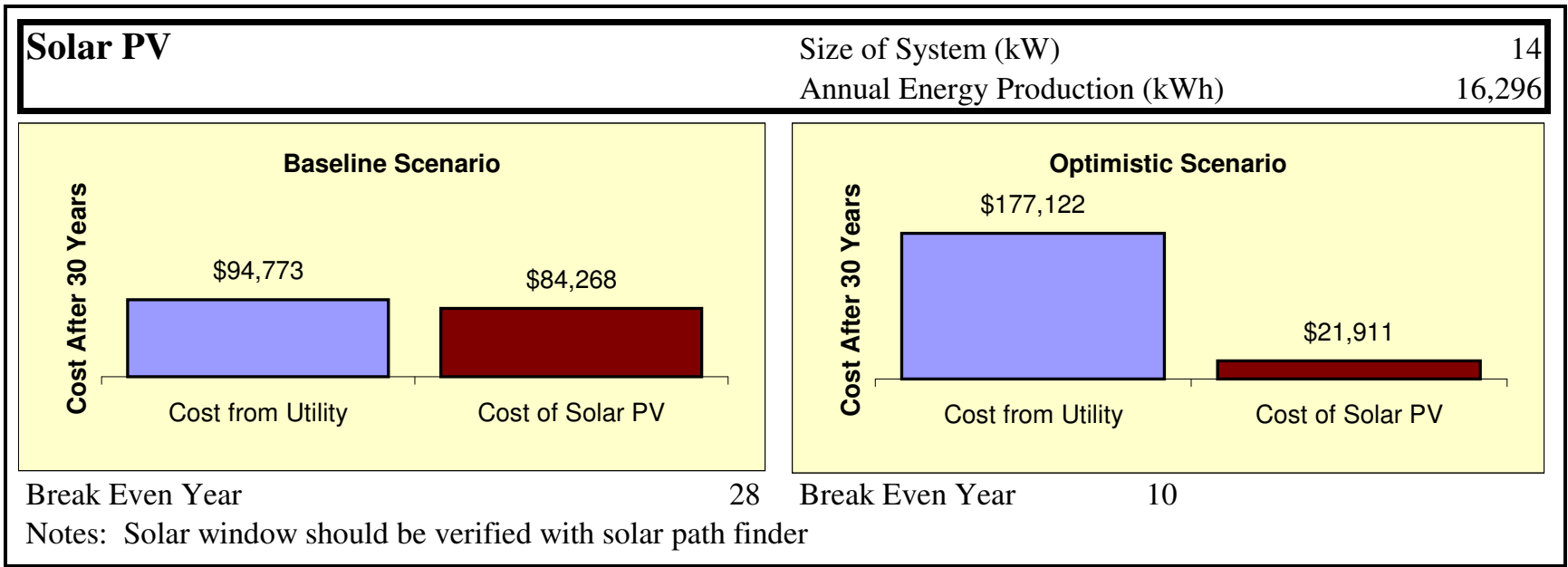

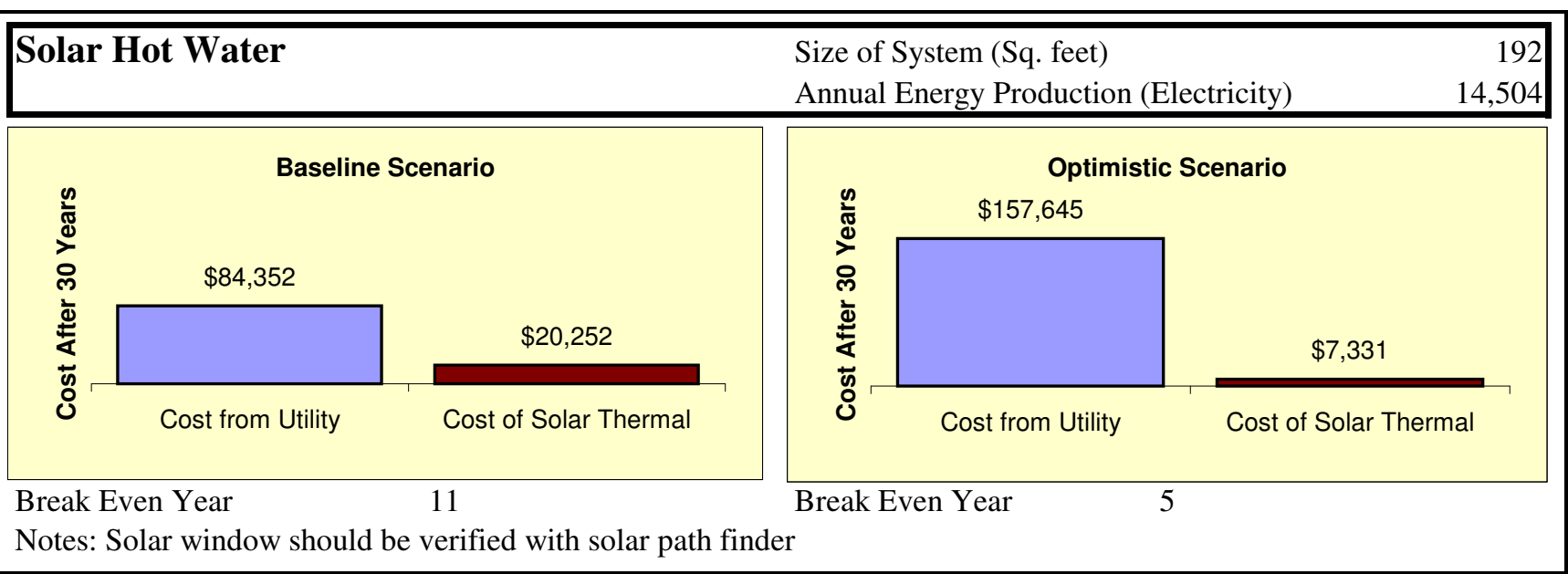

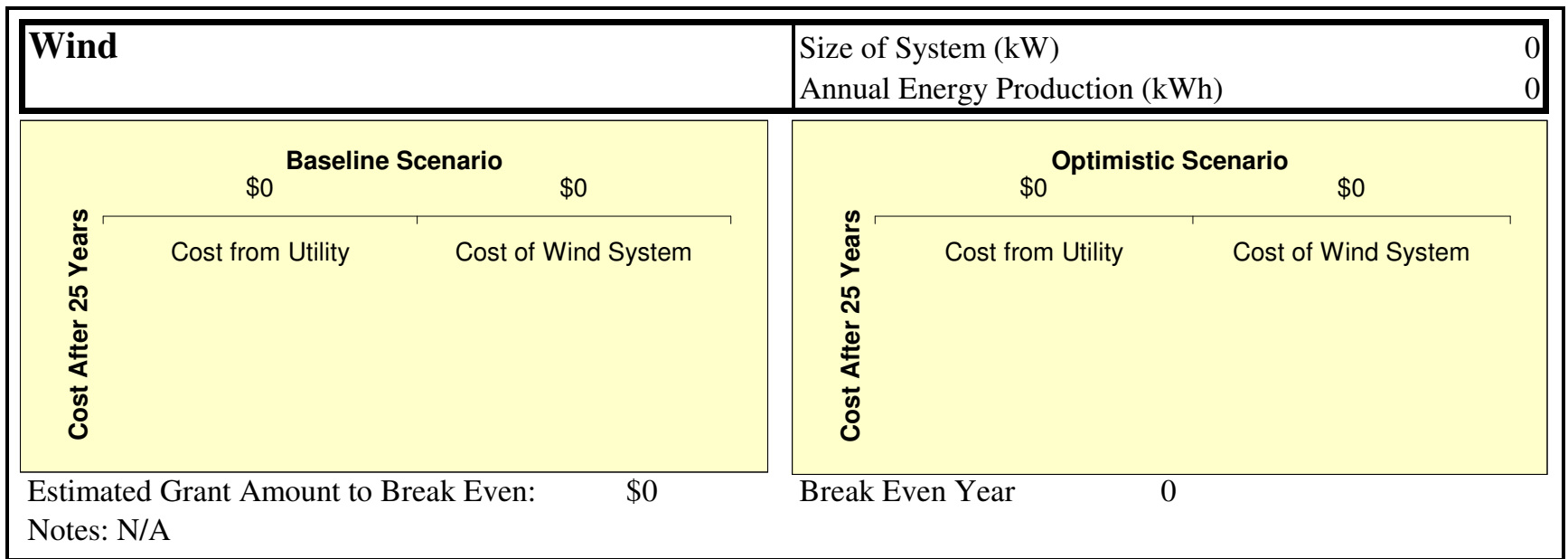

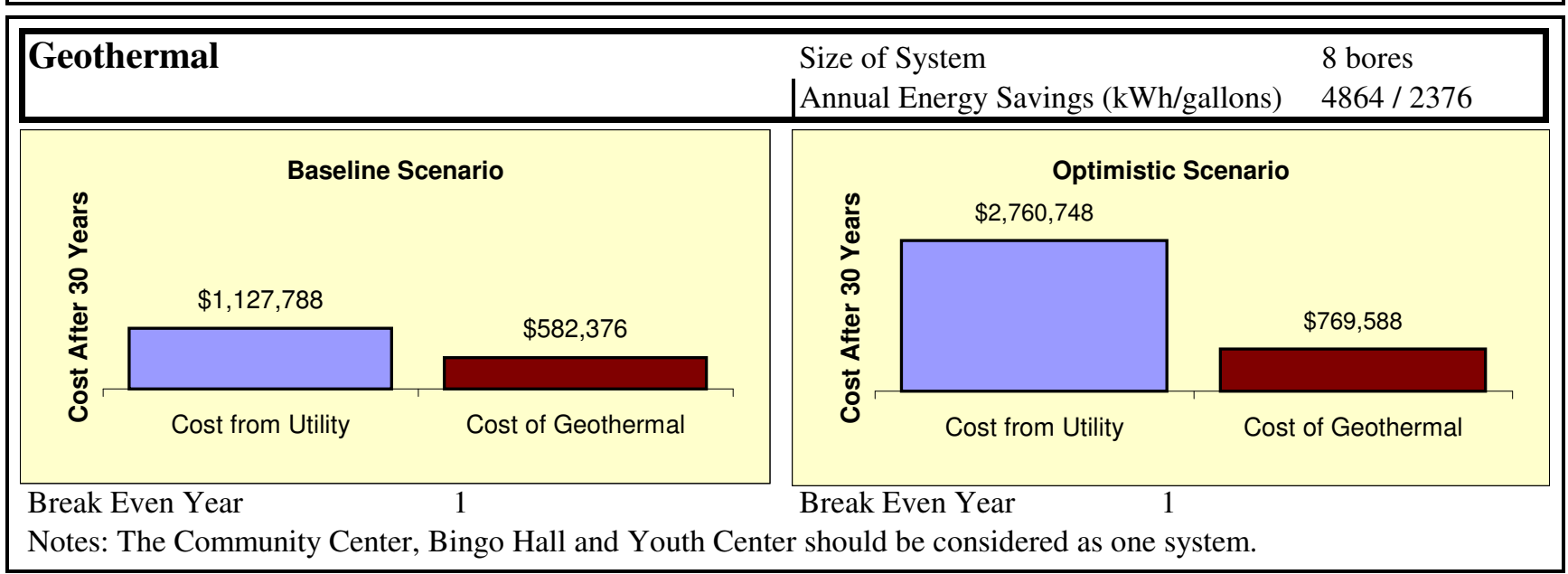




\begin{tabular}{|llll|}
\hline \multicolumn{2}{|l|}{ Facility - Wellness Center } & Space Heating System & unknown \\
Area $\left(\mathrm{ft}^{2}\right)$ & 20,000 & Space Cooling System & unknown \\
Occupany Schedule & $6 \mathrm{am}-6: 30 \mathrm{pm}$ & Water Heating System & Propane \\
\hline
\end{tabular}

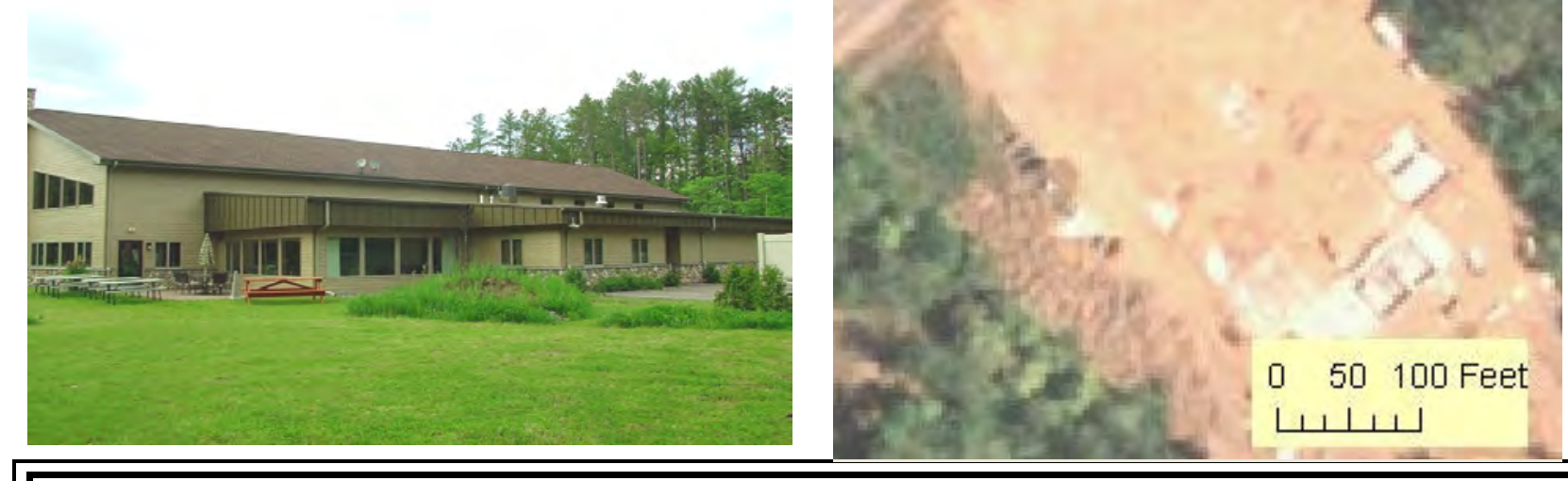

Energy Profile (2007)

\begin{tabular}{|c|c|c|c|}
\hline Electricity & Total & Rank & $\begin{array}{l}\text { Percent } \\
\text { of Tribe }\end{array}$ \\
\hline $\begin{array}{c}\text { Consumption kWh } \\
\text { (Cost) }\end{array}$ & $\begin{array}{l}\mathbf{1 9 1 , 7 2 0} \\
\$ 17,682\end{array}$ & 10 & $1.6 \%$ \\
\hline $\begin{array}{c}\text { Electricity Intensity } \\
\left(\text { Cost } / \mathrm{ft}^{2}\right)\end{array}$ & $\begin{array}{r}32.7 \\
\$ 0.88\end{array}$ & 14 & \\
\hline $\begin{array}{l}\text { Energy Charge }(\mathrm{kWh}) \\
\text { Demand Charge }(\mathrm{kW})\end{array}$ & \begin{tabular}{r|}
$\$ 0.095$ \\
$\$ 0.00$
\end{tabular} & & \\
\hline
\end{tabular}

\begin{tabular}{|c|c|c|c|}
\hline Propane & Total & Rank & $\begin{array}{l}\text { Percent } \\
\text { of Tribe }\end{array}$ \\
\hline $\begin{array}{c}\text { Consumption gal } \\
\text { (Cost) }\end{array}$ & $\begin{array}{r}\mathbf{5 , 6 1 4} \\
\$ 8,196 \\
\end{array}$ & 10 & $1.4 \%$ \\
\hline $\begin{array}{c}\text { Propane Intensity } \\
\left(\text { Cost } / \mathbf{f t}^{2}\right)\end{array}$ & $\begin{array}{r}25.6 \\
\$ 0.41\end{array}$ & 21 & \\
\hline Propane Cost (gal) & & $\$ 1.46$ & \\
\hline
\end{tabular}
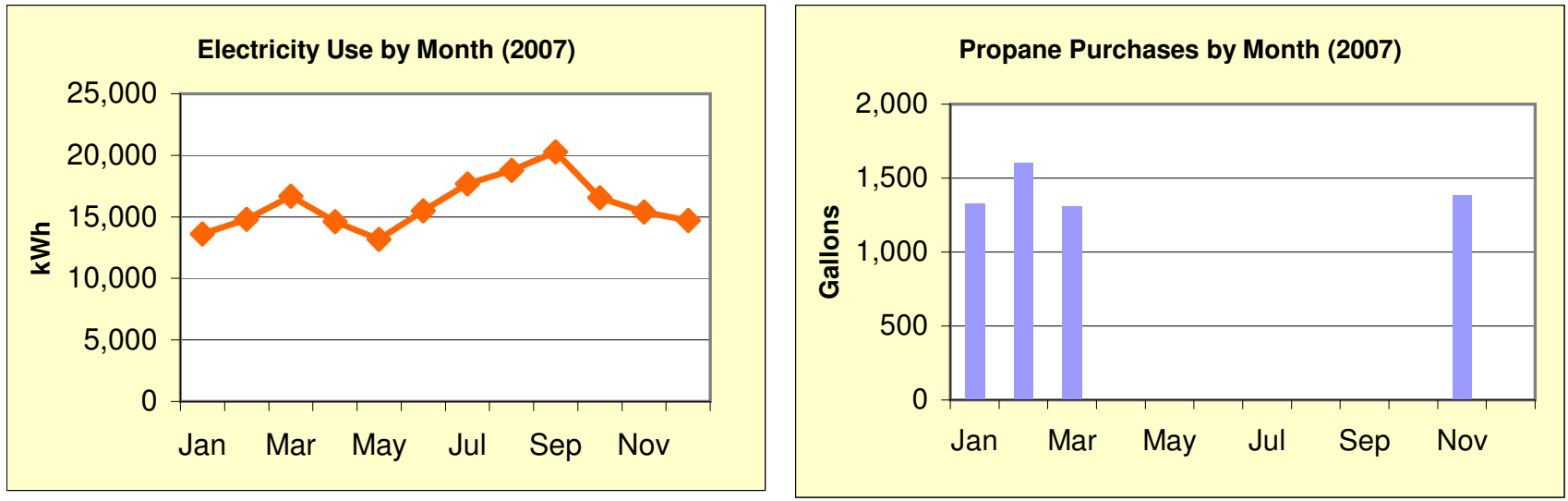

\section{WPS Electric Accounts}

\section{Energy Efficiency Recommendations}

\begin{tabular}{|l|l|c|r|}
\hline Type & Rate & $\begin{array}{c}\text { 2007 Use } \\
\text { (kWh) }\end{array}$ & 2007 Cost \\
\hline Main & CG-5 & 191,720 & $\$ 17,682$ \\
\hline & & & \\
\hline & & & \\
\hline & & & \\
\hline & & & \\
\hline & & & \\
\hline & & & \\
\hline
\end{tabular}

\begin{tabular}{|l|l|c|c|}
\hline Recommendation & $\begin{array}{c}\text { Cost to } \\
\text { Install }\end{array}$ & $\begin{array}{c}\text { Annual } \\
\text { therm } \\
\text { Savings }\end{array}$ & $\begin{array}{c}\text { Simple Payback } \\
\text { (yrs) }\end{array}$ \\
\hline & & & \\
\hline Energy audit recommended \\
\hline \multicolumn{3}{|l}{} \\
\hline
\end{tabular}




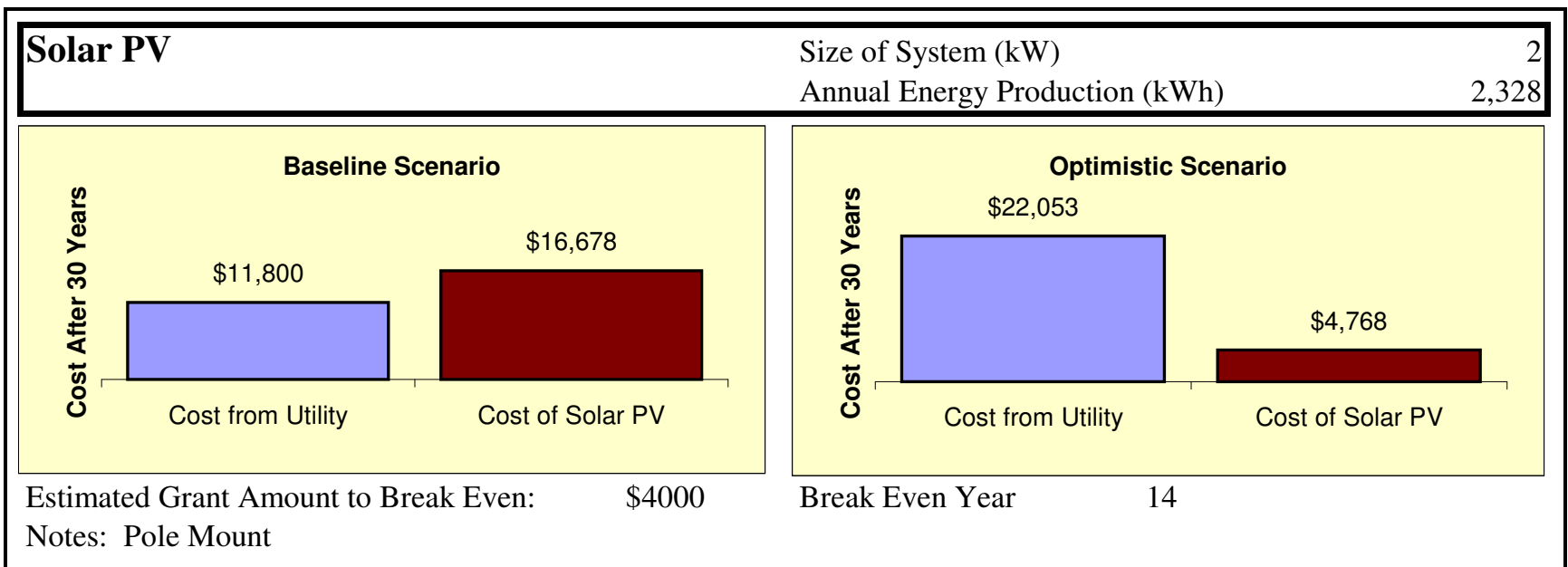

\begin{tabular}{|c|c|c|}
\hline \multicolumn{3}{|c|}{ Solar Hot Water } \\
\hline \multirow[b]{2}{*}{ 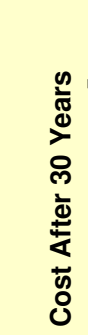 } & $\$ 0$ Basel & nario \\
\hline & Cost from Utility & Cost of Solar Thermal \\
\hline
\end{tabular}

Break Even Year

0

Size of System (Sq. feet)

Annual Energy Production (Propane)

Notes: Recommended future review

\begin{tabular}{|c|c|c|c|c|c|}
\hline \multicolumn{3}{|c|}{ Wind } & \multicolumn{3}{|c|}{$\begin{array}{l}\text { Size of System (kW) } \\
\text { Annual Energy Production }(\mathrm{kWh})\end{array}$} \\
\hline \multicolumn{3}{|c|}{ Baseline Scenario } & \multicolumn{3}{|c|}{$\$ 0$ Optimistic Scenario } \\
\hline 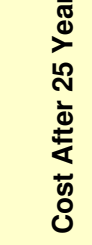 & Cost from Utility & Cost of Wind System & 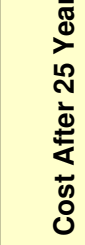 & Cost from Utility & Cost of Wind System \\
\hline $\begin{array}{l}\text { Estim } \\
\text { Notes }\end{array}$ & Grant Amount t & k Even: & Break & Year & \\
\hline
\end{tabular}

\begin{tabular}{|c|c|c|}
\hline \multicolumn{3}{|c|}{ Geothermal } \\
\hline \multicolumn{3}{|c|}{$\$ 0$ Baseline Scenario } \\
\hline 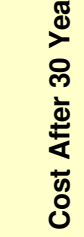 & Cost from Utility & Cost of Geothermal \\
\hline
\end{tabular}

Break Even Year

Size of System

0

Annual Energy Savings (kWh/gallons)

$0 / 0$

$\$ 0$ Optimistic Scenario $\$ 0$

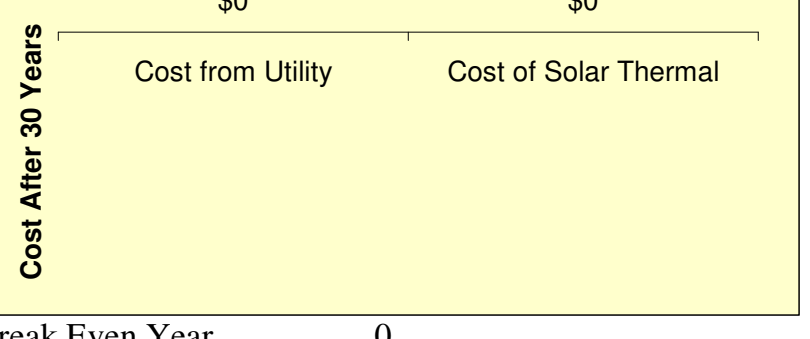

Break Even Year 0 


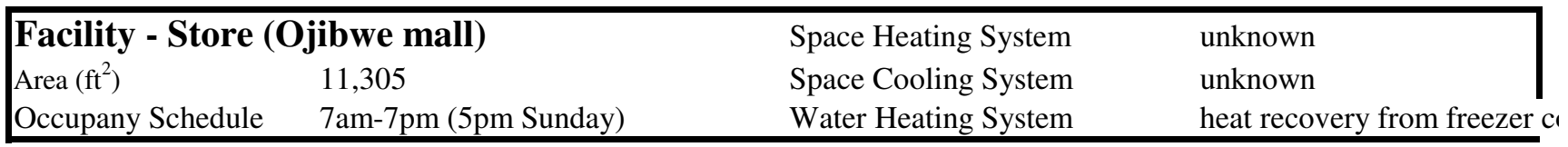
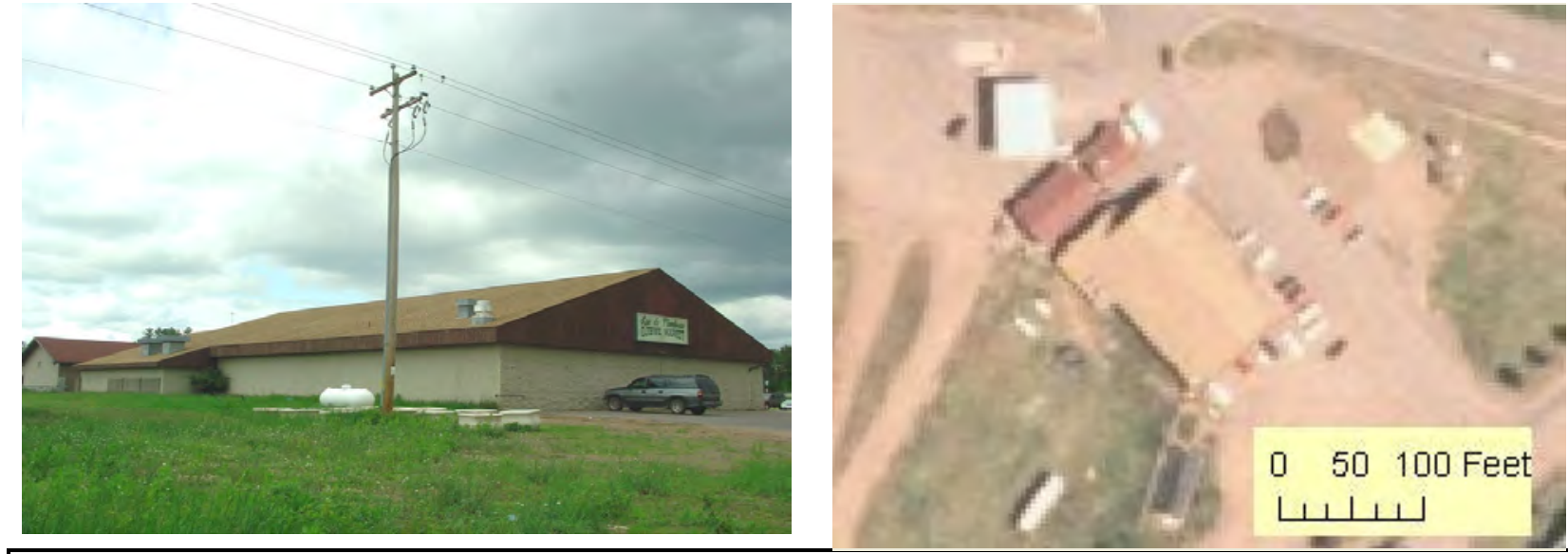

Energy Profile (2007)

\begin{tabular}{|c|c|c|c|}
\hline Electricity & Total & Rank & $\begin{array}{l}\text { Percent } \\
\text { of Tribe }\end{array}$ \\
\hline $\begin{array}{c}\text { Consumption kWh } \\
\text { (Cost) }\end{array}$ & $\begin{array}{l}\mathbf{6 3 8 , 4 7 5} \\
\$ 39,861\end{array}$ & 4 & $5.4 \%$ \\
\hline $\begin{array}{c}\text { Electricity Intensity } \\
\left(\mathrm{Cost} / \mathrm{ft}^{2}\right)\end{array}$ & $\begin{array}{l}192.7 \\
\$ 3.53\end{array}$ & 3 & \\
\hline $\begin{array}{l}\text { Energy Charge }(\mathrm{kWh}) \\
\text { Demand Charge }(\mathrm{kW})\end{array}$ & \begin{tabular}{r|}
$\$ 0.095$ \\
$\$ 0.00$
\end{tabular} & & \\
\hline
\end{tabular}

\begin{tabular}{|c|c|c|c|}
\hline Propane & Total & Rank & $\begin{array}{l}\text { Percent } \\
\text { of Tribe }\end{array}$ \\
\hline $\begin{array}{c}\text { Consumption gal } \\
\text { (Cost) }\end{array}$ & $\begin{array}{r}\mathbf{4 , 7 7 5} \\
\$ 6,972\end{array}$ & 11 & $1.2 \%$ \\
\hline $\begin{array}{c}\text { Propane Intensity } \\
\left(\text { Cost } / \mathbf{f t}^{2}\right)\end{array}$ & $\begin{array}{r}38.6 \\
\$ 0.62\end{array}$ & 15 & \\
\hline Propane Cost (gal) & & $\$ 1.46$ & \\
\hline
\end{tabular}
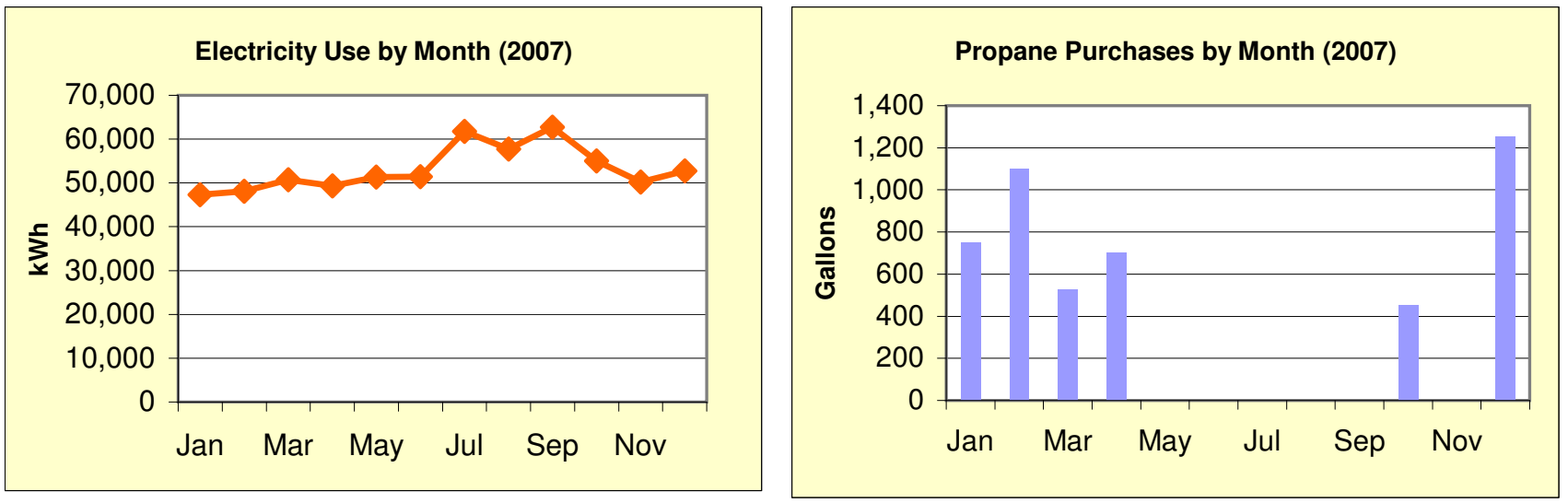

\section{WPS Electric Accounts}

\section{Energy Efficiency Recommendations}

\begin{tabular}{|l|l|r|r|}
\hline \multicolumn{1}{|c|}{ Type } & \multicolumn{1}{c|}{ Rate } & $\begin{array}{c}\text { 2007 Use } \\
\text { (kWh) }\end{array}$ & 2007 Cost \\
\hline Main & CG-5 & 631,600 & $\$ 38,327$ \\
\hline Road sign & CG-1 & 6,875 & $\$ 864$ \\
\hline Outdoor lighting & GY-3 & & $\$ 364$ \\
\hline Outdoor lighting & GY-1 & & $\$ 306$ \\
\hline & & & \\
\hline & & & \\
\hline & & & \\
\hline
\end{tabular}

\begin{tabular}{|l|c|c|c|}
\hline Recommendation & $\begin{array}{c}\text { Cost to } \\
\text { Install }\end{array}$ & $\begin{array}{c}\text { Annual } \\
\text { therm } \\
\text { Savings }\end{array}$ & $\begin{array}{c}\text { Simple Payback } \\
\text { (yrs) }\end{array}$ \\
\hline T8 lighting upgrade & 3648 & 28343 & \\
\hline Add curtains to refriderators \\
\hline Insulate hot water piping \\
\hline Upgrade to Energy Star kitchen equipment \\
\hline Add sweep to backdoor room \\
\hline \multicolumn{2}{|l|}{ Recommend a more detailed energy audit } \\
\hline
\end{tabular}




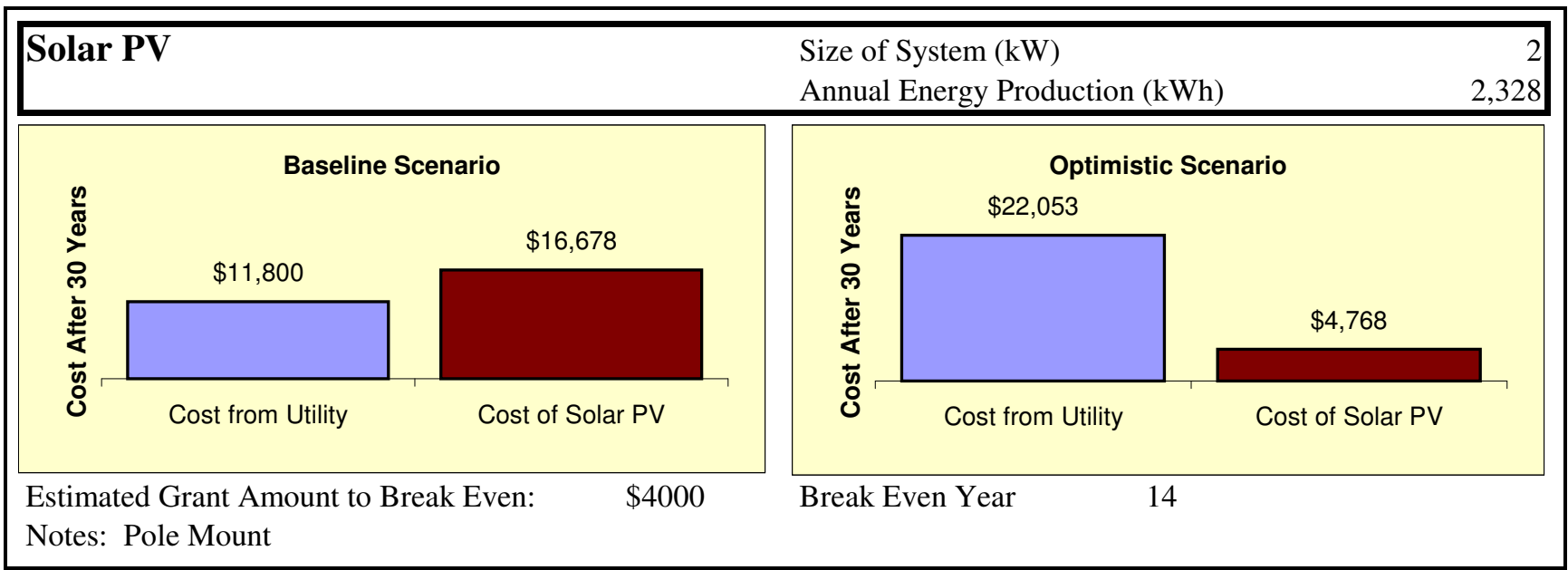

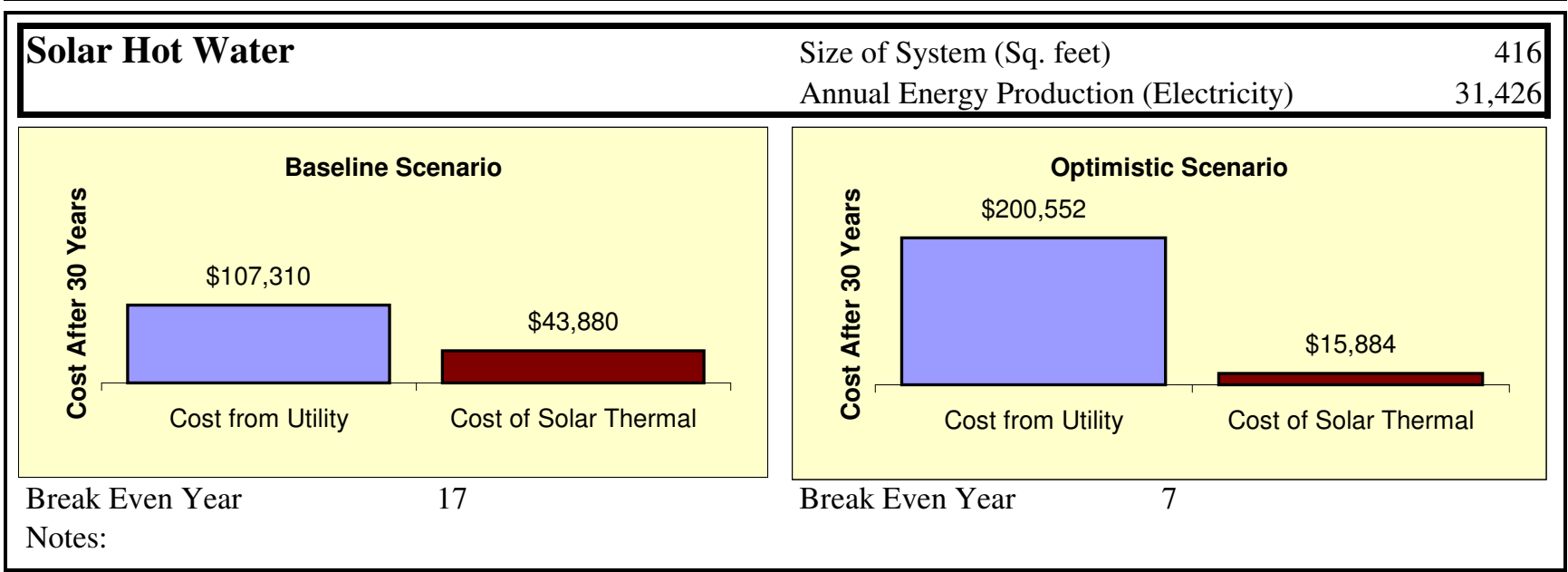

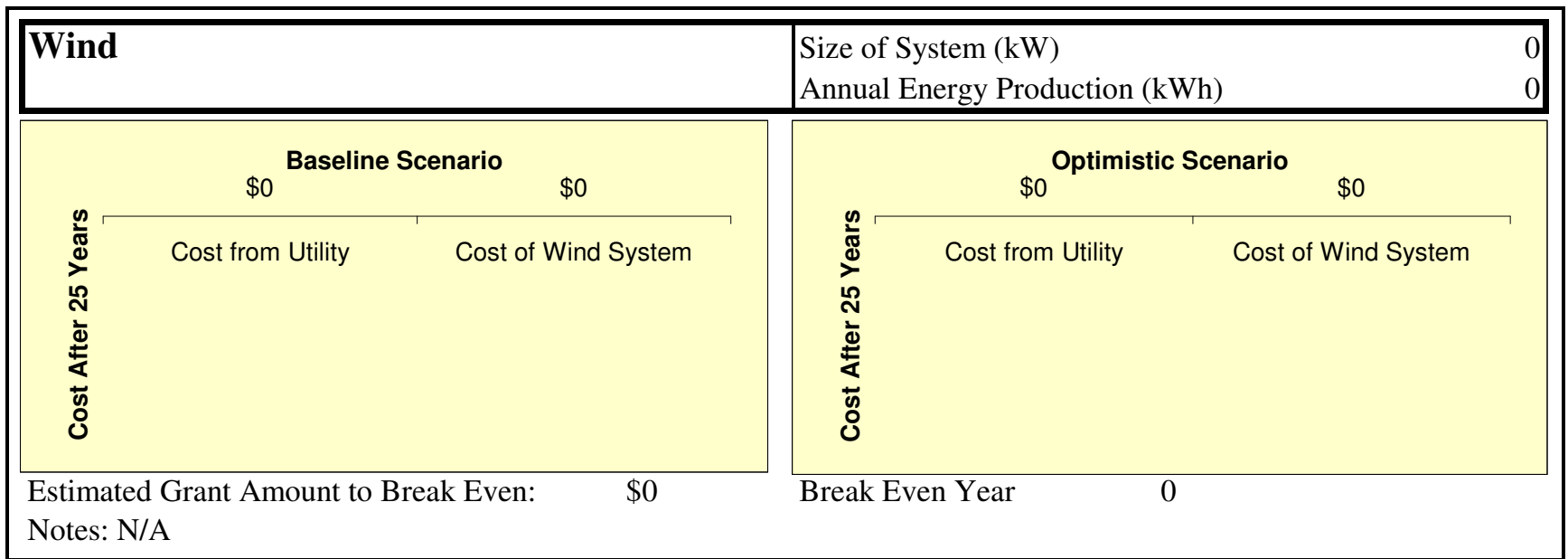

\begin{tabular}{|c|c|c|c|c|c|c|}
\hline \multicolumn{3}{|c|}{ Geothermal } & \multicolumn{3}{|c|}{$\begin{array}{l}\text { Size of System } \\
\text { |Annual Energy Savings (kWh/gallons) }\end{array}$} & $\begin{array}{l}0 \\
0 / 0\end{array}$ \\
\hline \multicolumn{3}{|c|}{$\$ 0$ Baseline Scenario } & \multicolumn{4}{|c|}{ Optimistic Scenario } \\
\hline 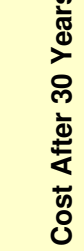 & Cost from Utility & Cost of Geothermal & 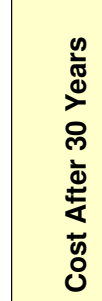 & Cost from Utility & \multicolumn{2}{|c|}{ Cost of Geothermal } \\
\hline $\begin{array}{l}\text { Break } \\
\text { Notes }\end{array}$ & $\begin{array}{l}\text { n Year } \\
\text { quires further res }\end{array}$ & 0 & Break & n Year & & \\
\hline
\end{tabular}




\begin{tabular}{|llll|}
\hline Facility - Smoke Shop & Space Heating System & Furnace \\
Area $\left(\mathrm{ft}^{2}\right)$ & 8,000 & Space Cooling System & DX \\
Occupany Schedule & 7 days/week 10am -12am & Water Heating System & Propane \\
\hline
\end{tabular}

\section{Image not available}

Energy Profile (2007)

\begin{tabular}{|c|c|c|c|}
\hline Electricity & Total & Rank & $\begin{array}{l}\text { Percent } \\
\text { of Tribe }\end{array}$ \\
\hline $\begin{array}{c}\text { Consumption kWh } \\
\text { (Cost) }\end{array}$ & $\begin{array}{l}\mathbf{2 2 7 , 5 9 8} \\
\$ 21,818\end{array}$ & 8 & $1.9 \%$ \\
\hline $\begin{array}{l}\text { Electricity Intensity } \\
\left(\mathbf{C o s t} / \mathrm{ft}^{2}\right)\end{array}$ & $\begin{array}{r}97.1 \\
\$ 2.73\end{array}$ & 4 & \\
\hline Energy Charge (kWh) & $\$ 0.095$ & & \\
\hline Demand Charge $(\mathrm{kW})$ & $\$ 0.00$ & & \\
\hline
\end{tabular}

\begin{tabular}{|c|c|c|c|}
\hline Propane & Total & Rank & $\begin{array}{l}\text { Percent } \\
\text { of Tribe }\end{array}$ \\
\hline $\begin{array}{c}\text { Consumption gal } \\
\text { (Cost) }\end{array}$ & $\begin{array}{r}\mathbf{0} \\
\$ 0 \\
\end{array}$ & 0 & $0.0 \%$ \\
\hline $\begin{array}{c}\text { Propane Intensity } \\
\left(\text { Cost } / \mathrm{ft}^{2}\right)\end{array}$ & $\begin{array}{r}0.0 \\
\$ 0.00\end{array}$ & 0 & \\
\hline Propane Cost (gal) & \multicolumn{2}{|c|}{ \#DIV/0! } & \\
\hline
\end{tabular}
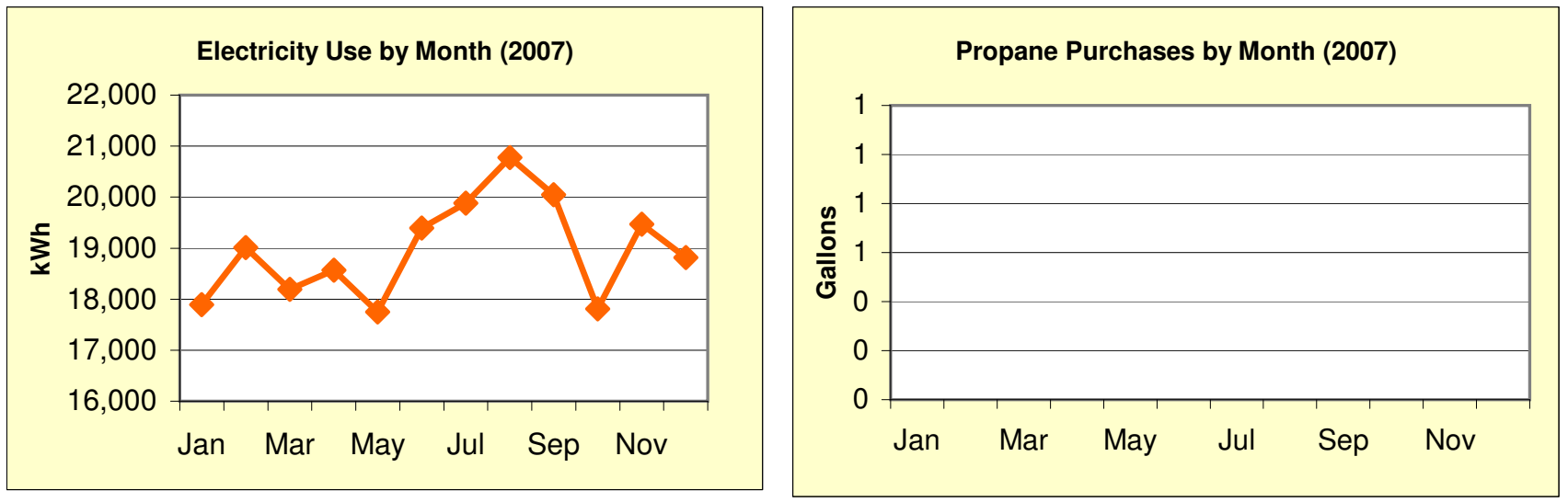

\section{WPS Electric Accounts}

\section{Energy Efficiency Recommendations}

\begin{tabular}{|l|l|r|r|}
\hline \multicolumn{1}{|c|}{ Type } & Rate & $\begin{array}{c}\text { 2007 Use } \\
\text { (kWh) }\end{array}$ & 2007 Cost \\
\hline Main & CG-5 & 190,409 & $\$ 17,662$ \\
\hline Main & CG-1 & 37,189 & $\$ 4,156$ \\
\hline & & & \\
\hline & & & \\
\hline & & & \\
\hline & & & \\
\hline & & & \\
\hline
\end{tabular}

\begin{tabular}{|l|l|c|c|}
\hline Recommendation & $\begin{array}{c}\text { Cost to } \\
\text { Install }\end{array}$ & $\begin{array}{c}\text { Annual } \\
\text { therm } \\
\text { Savings }\end{array}$ & $\begin{array}{c}\text { Simple Payback } \\
\text { (yrs) }\end{array}$ \\
\hline & & & \\
\hline Energy audit recommended \\
\hline \multicolumn{3}{|l|}{} \\
\hline
\end{tabular}




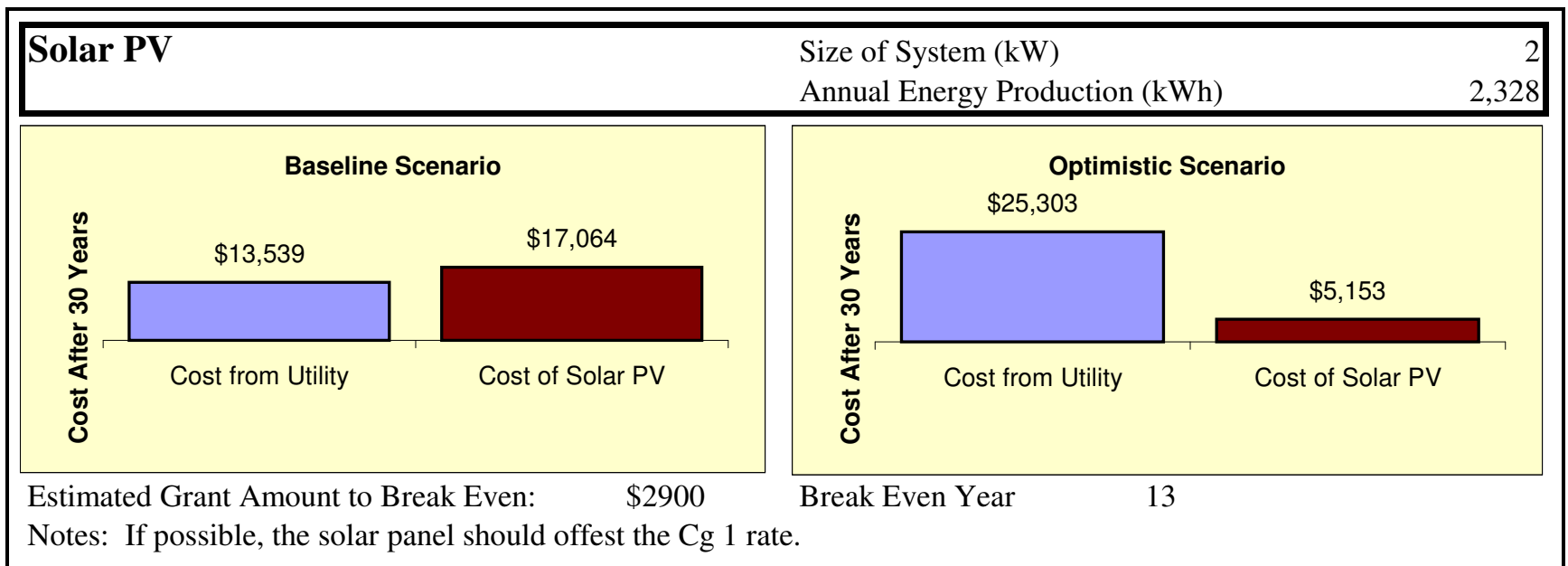

\begin{tabular}{|c|c|c|}
\hline \multicolumn{3}{|c|}{ Solar Hot Water } \\
\hline \multirow[b]{2}{*}{ 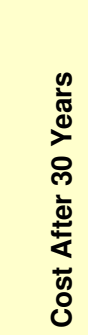 } & $\$ 0{ }^{\text {Basel }}$ & nario \\
\hline & Cost from Utility & Cost of Solar Therma \\
\hline
\end{tabular}

Break Even Year

0

Size of System (Sq. feet)

Annual Energy Production (Propane)

Notes: Recommended future review

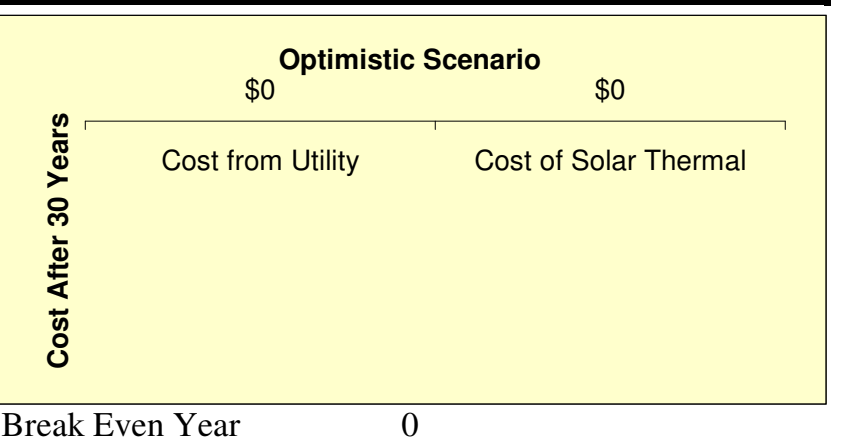

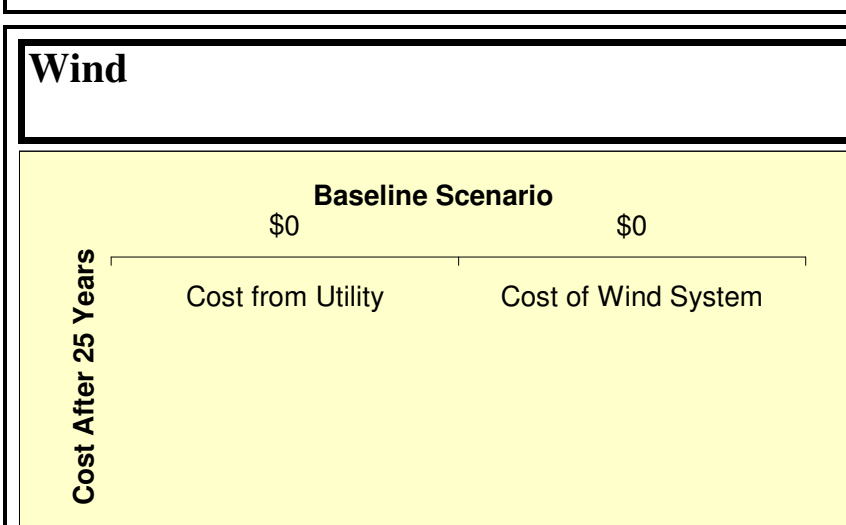

Estimated Grant Amount to Break Even:

$\$ 0$

Size of System $(\mathrm{kW})$

Annual Energy Production (kWh)

Notes: N/A

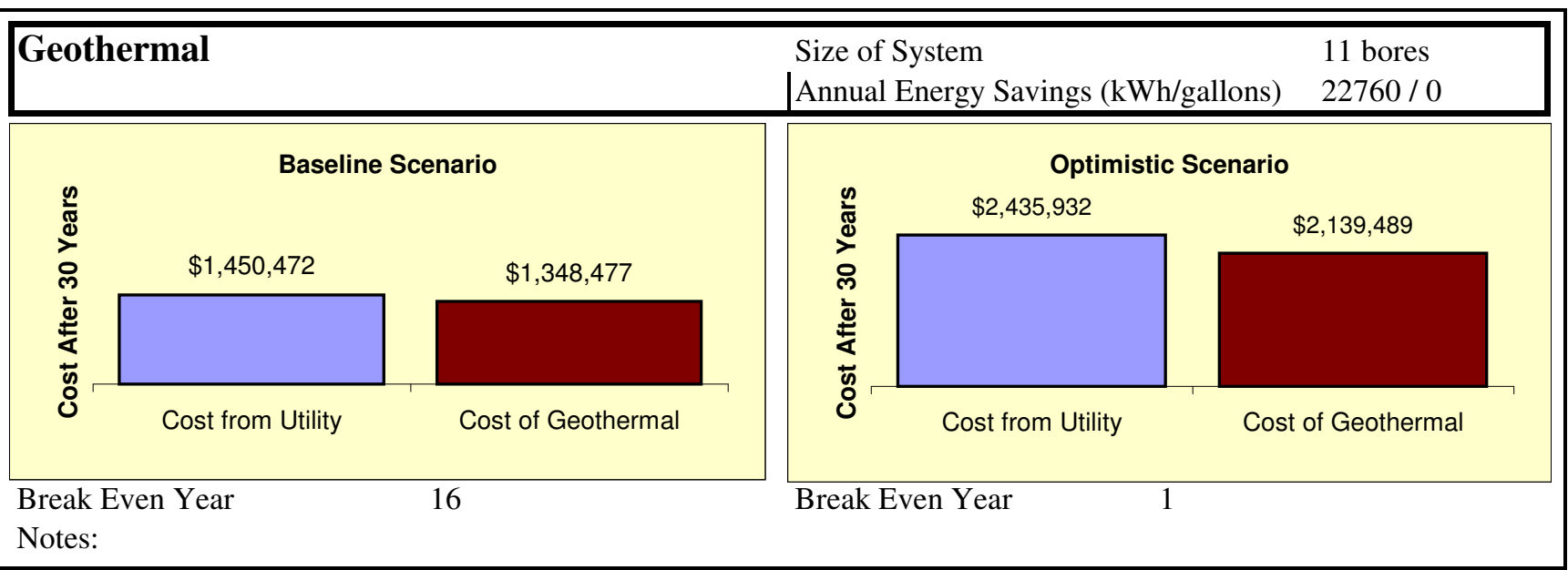




\begin{tabular}{|llll|}
\hline \multicolumn{2}{|l|}{ Facility - Simpsons Plastics Plant } & Space Heating System & unknown \\
Area $\left(\mathrm{ft}^{2}\right)$ & 14,780 & Space Cooling System & unknown \\
Occupany Schedule & $\mathrm{M}-\mathrm{Th} 6 \mathrm{am}-4 \mathrm{pm}$ & Water Heating System & Electric \\
\hline
\end{tabular}

Image not available

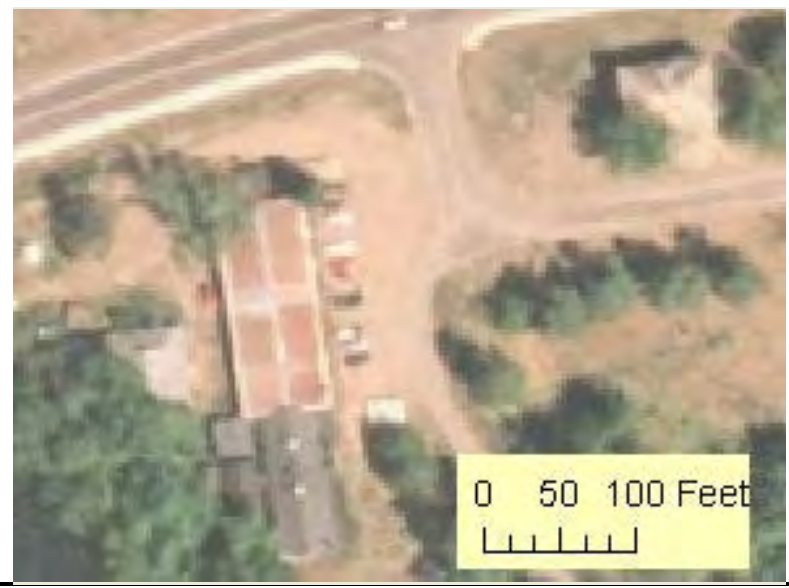

\begin{tabular}{|c|c|c|c|}
\hline \multicolumn{4}{|c|}{ Energy Profile (2007) } \\
\hline Electricity & Total & Rank & $\begin{array}{l}\text { Percent } \\
\text { of Tribe }\end{array}$ \\
\hline $\begin{array}{c}\text { Consumption kWh } \\
\text { (Cost) }\end{array}$ & $\begin{array}{l}\mathbf{4 1 5}, 967 \\
\$ 40,174\end{array}$ & 6 & $3.5 \%$ \\
\hline 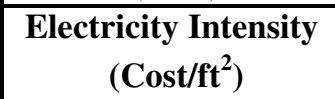 & $\begin{array}{r}96.0 \\
\$ 2.72\end{array}$ & 5 & \\
\hline \begin{tabular}{|l} 
Energy Charge $(\mathrm{kWh})$ \\
Demand Charge $(\mathrm{kW})$
\end{tabular} & \begin{tabular}{|l|}
0.060 \\
$\$ 10.67$ \\
\end{tabular} & & \\
\hline
\end{tabular}

\begin{tabular}{|c|c|c|c|}
\hline Propane & Total & Rank & $\begin{array}{l}\text { Percent } \\
\text { of Tribe }\end{array}$ \\
\hline $\begin{array}{c}\text { Consumption gal } \\
\text { (Cost) }\end{array}$ & $\begin{array}{r}\mathbf{2 7 , 1 5 9} \\
\$ 39,652 \\
\end{array}$ & 3 & $6.7 \%$ \\
\hline $\begin{array}{c}\text { Propane Intensity } \\
\left(\text { Cost } / \mathbf{f t}^{2}\right)\end{array}$ & $\begin{array}{l}167.8 \\
\$ 2.68\end{array}$ & 2 & \\
\hline Propane Cost (gal) & & $\$ 1.46$ & \\
\hline
\end{tabular}
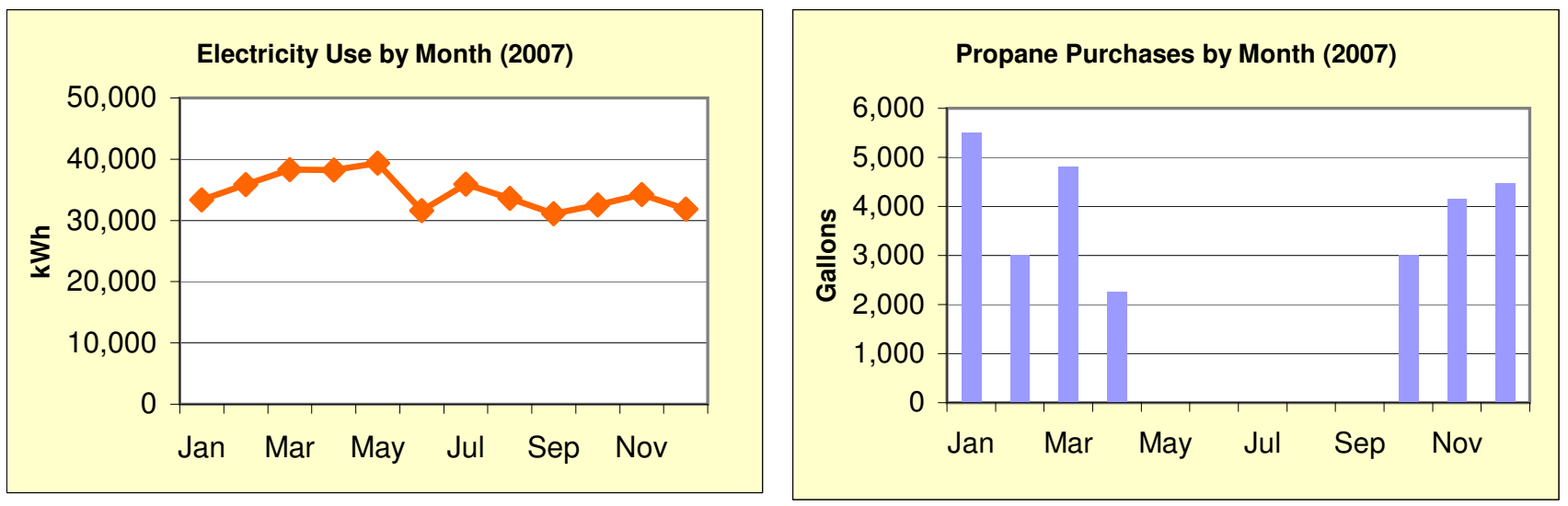

\section{WPS Electric Accounts}

\section{Energy Efficiency Recommendations}

\begin{tabular}{|l|l|r|r|}
\hline \multicolumn{1}{|c|}{ Type } & \multicolumn{1}{|c|}{ Rate } & $\begin{array}{c}\text { 2007 Use } \\
\text { (kWh) }\end{array}$ & 2007 Cost \\
\hline Main & CG-20 & 333,120 & $\$ 30,804$ \\
\hline Main & CG-1 & 82,847 & $\$ 8,874$ \\
\hline Outdoor lighting & GY-1 & & $\$ 497$ \\
\hline & & & \\
\hline & & & \\
\hline & & & \\
\hline & & & \\
\hline
\end{tabular}

\begin{tabular}{|l|l|l|l|}
\hline Recommendation & $\begin{array}{c}\text { Cost to } \\
\text { Install }\end{array}$ & $\begin{array}{c}\text { Annual } \\
\text { therm } \\
\text { Savings }\end{array}$ & $\begin{array}{c}\text { Simple Payback } \\
\text { (yrs) }\end{array}$ \\
\hline T8 lighting upgrade & & & \\
\hline Add insulation to roof & \\
\hline Seal cracks and holes \\
\hline Winterize exhaust fans \\
\hline Double pane windows \\
\hline Turn heat down on nights and weekends \\
\hline Compressed Air Audit \\
\hline
\end{tabular}




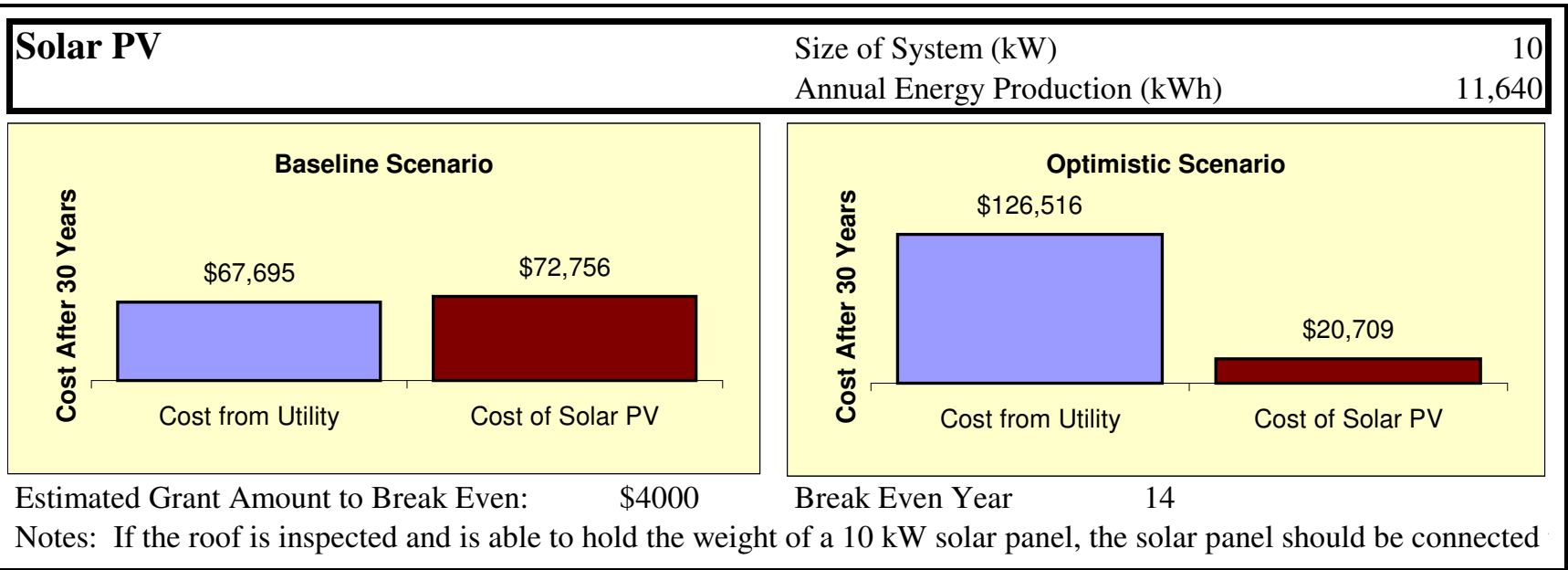

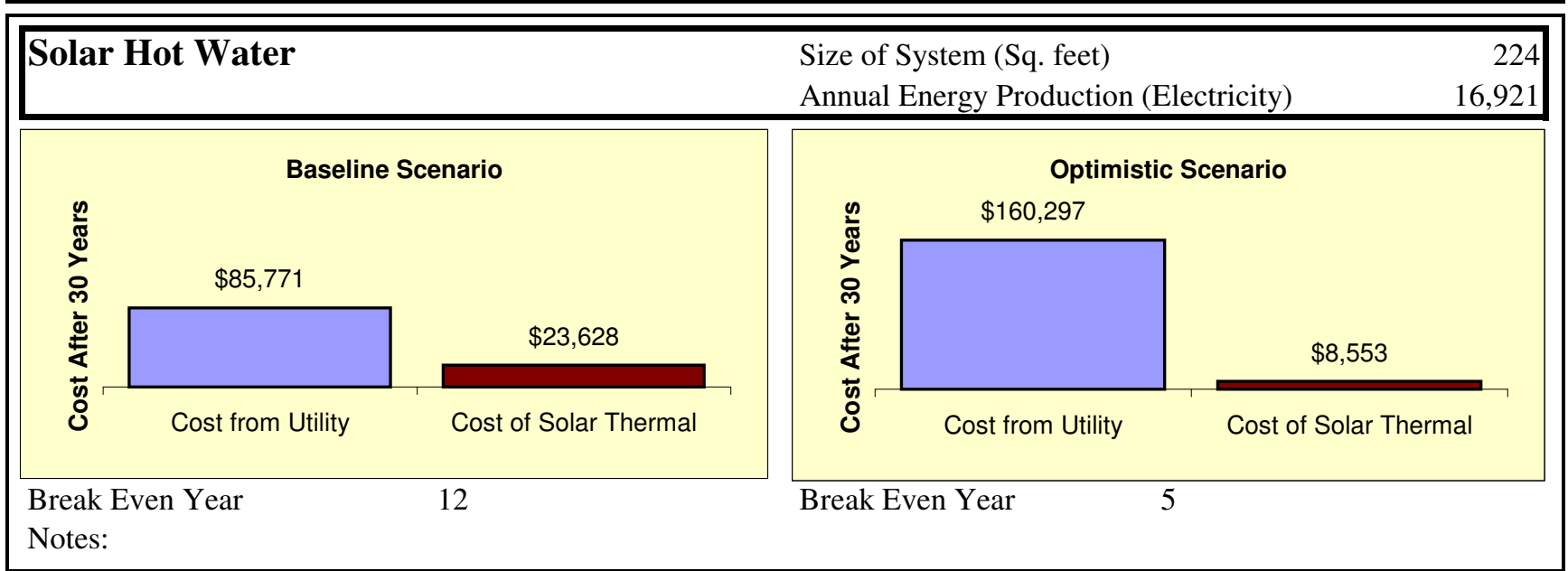

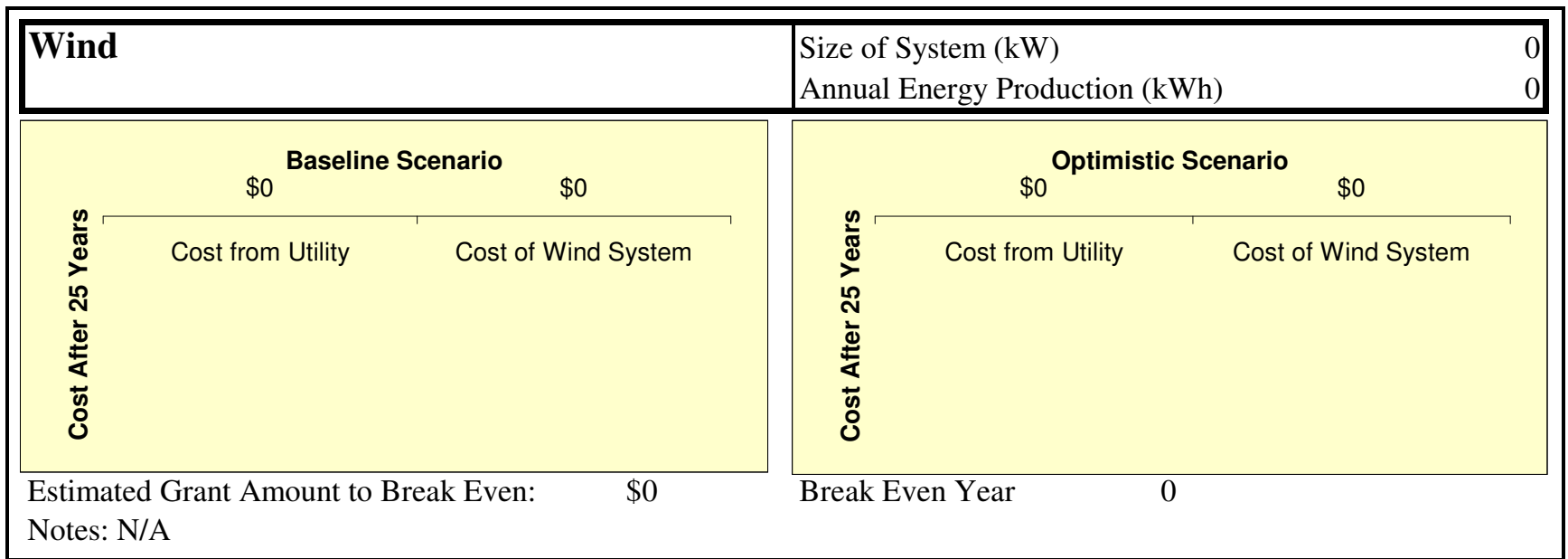

\begin{tabular}{|c|c|c|c|c|c|c|}
\hline \multicolumn{3}{|c|}{ Geothermal } & $\begin{array}{r}\text { Size o } \\
\lfloor\text { Annua } \\
\end{array}$ & $\begin{array}{l}\text { tem } \\
\text { ergy Savings ( } k\end{array}$ & ons) & $\begin{array}{l}0 \\
0 / 0\end{array}$ \\
\hline \multirow[b]{2}{*}{ 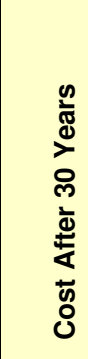 } & \multicolumn{2}{|c|}{$\$ 0$ Baseline Scenario } & \multicolumn{4}{|c|}{$\$ 0$ Optimistic Scenario } \\
\hline & Cost from Utility & Cost of Geothermal & 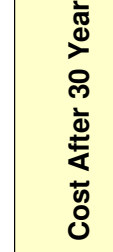 & Cost from Utility & Cos & f Geothermal \\
\hline $\begin{array}{l}\text { Break } \\
\text { Notes }\end{array}$ & $\begin{array}{l}\text { n Year } \\
t \text { a priority }\end{array}$ & 0 & Break & n Year & & \\
\hline
\end{tabular}




\begin{tabular}{|llll|}
\hline Facility - Simpson's Main Plant & Space Heating System & Boiler \\
Area $\left(\mathrm{ft}^{2}\right)$ & 27,280 & Space Cooling System & DX \\
Occupany Schedule & M-Th 7am-5pm & Water Heating System & Electric \\
\hline
\end{tabular}
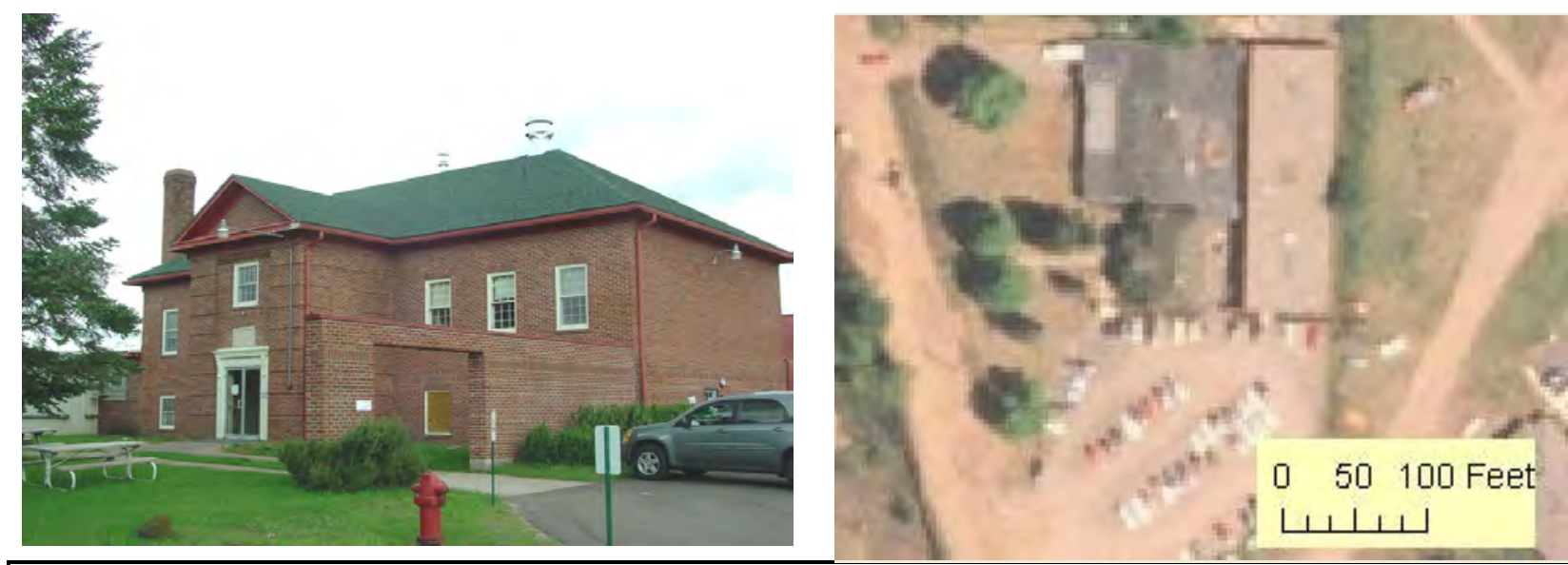

Energy Profile (2007)

\begin{tabular}{|c|c|c|c|}
\hline Electricity & Total & Rank & $\begin{array}{l}\text { Percent } \\
\text { of Tribe }\end{array}$ \\
\hline $\begin{array}{c}\text { Consumption kWh } \\
\text { (Cost) }\end{array}$ & $\begin{array}{l}\mathbf{3 9 8 , 9 6 0} \\
\$ 36,904\end{array}$ & 7 & $3.4 \%$ \\
\hline $\begin{array}{c}\text { Electricity Intensity } \\
\left(\text { Cost } / \mathrm{ft}^{2}\right)\end{array}$ & $\begin{array}{r}49.9 \\
\$ 1.35\end{array}$ & 8 & \\
\hline Energy Charge $(\mathrm{kWh})$ & $\$ 0.095$ & & \\
\hline Demand Charge $(\mathrm{kW})$ & $\$ 0.00$ & & \\
\hline
\end{tabular}

\begin{tabular}{|c|c|c|c|}
\hline Propane & Total & Rank & $\begin{array}{l}\text { Percent } \\
\text { of Tribe }\end{array}$ \\
\hline $\begin{array}{c}\text { Consumption gal } \\
\text { (Cost) }\end{array}$ & $\begin{array}{r}\mathbf{1 6 , 3 5 2} \\
\$ 23,874\end{array}$ & 5 & $4.0 \%$ \\
\hline $\begin{array}{c}\text { Propane Intensity } \\
\left(\text { Cost } / \mathbf{f t}^{2}\right)\end{array}$ & $\begin{array}{r}54.7 \\
\$ 0.88 \\
\end{array}$ & 10 & \\
\hline Propane Cost (gal) & & $\$ 1.46$ & \\
\hline
\end{tabular}
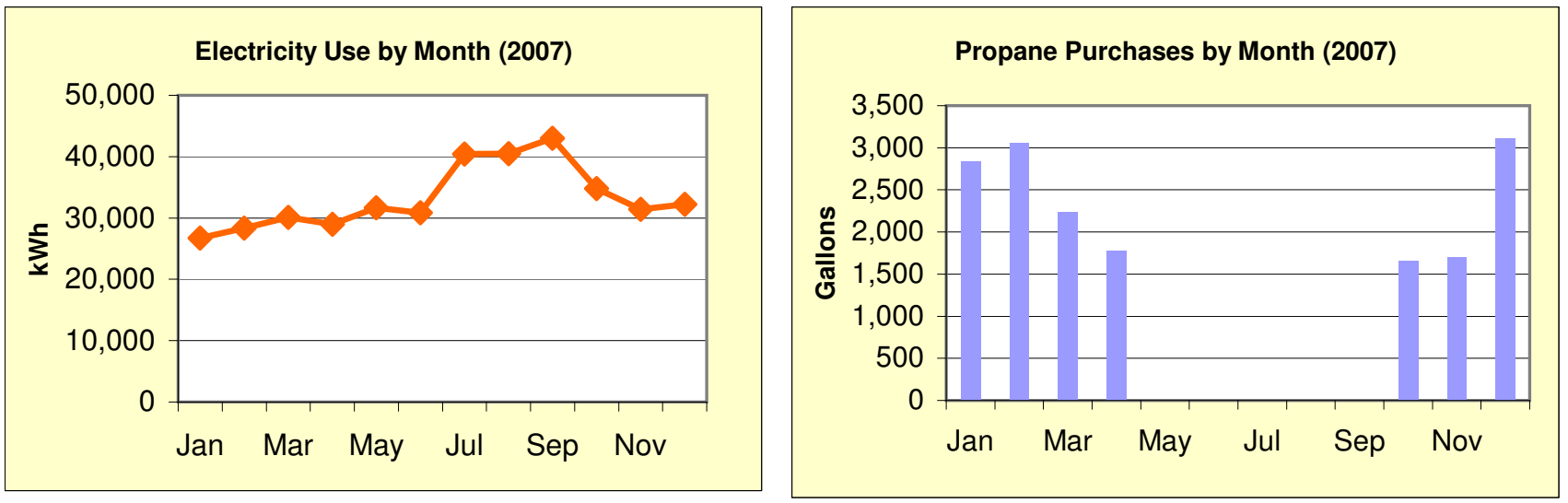

\section{WPS Electric Accounts}

\section{Energy Efficiency Recommendations}

\begin{tabular}{|l|l|c|r|}
\hline \multicolumn{1}{|c|}{ Type } & \multicolumn{1}{c|}{ Rate } & $\begin{array}{c}\text { 2007 Use } \\
\text { (kWh) }\end{array}$ & 2007 Cost \\
\hline Main & CG-5 & 218,880 & $\$ 20,213$ \\
\hline Main & CG-5 & 180,080 & $\$ 16,691$ \\
\hline Outdoor lighting & GY-1 & & \\
\hline & & & \\
\hline & & & \\
\hline & & & \\
\hline & & & \\
\hline
\end{tabular}

\begin{tabular}{|l|c|c|c|}
\hline Recommendation & $\begin{array}{c}\text { Cost to } \\
\text { Install }\end{array}$ & $\begin{array}{c}\text { Annual } \\
\text { therm } \\
\text { Savings }\end{array}$ & $\begin{array}{c}\text { Simple Payback } \\
\text { (yrs) }\end{array}$ \\
\hline Insulate heat pipes & 60 & 538 & 0.1 \\
\hline Improve insulation \\
\hline Install programmable temp controls \\
\hline Allow HVAC to use free "cool" outside air \\
\hline Close air dampers when building is not occupied \\
\hline
\end{tabular}




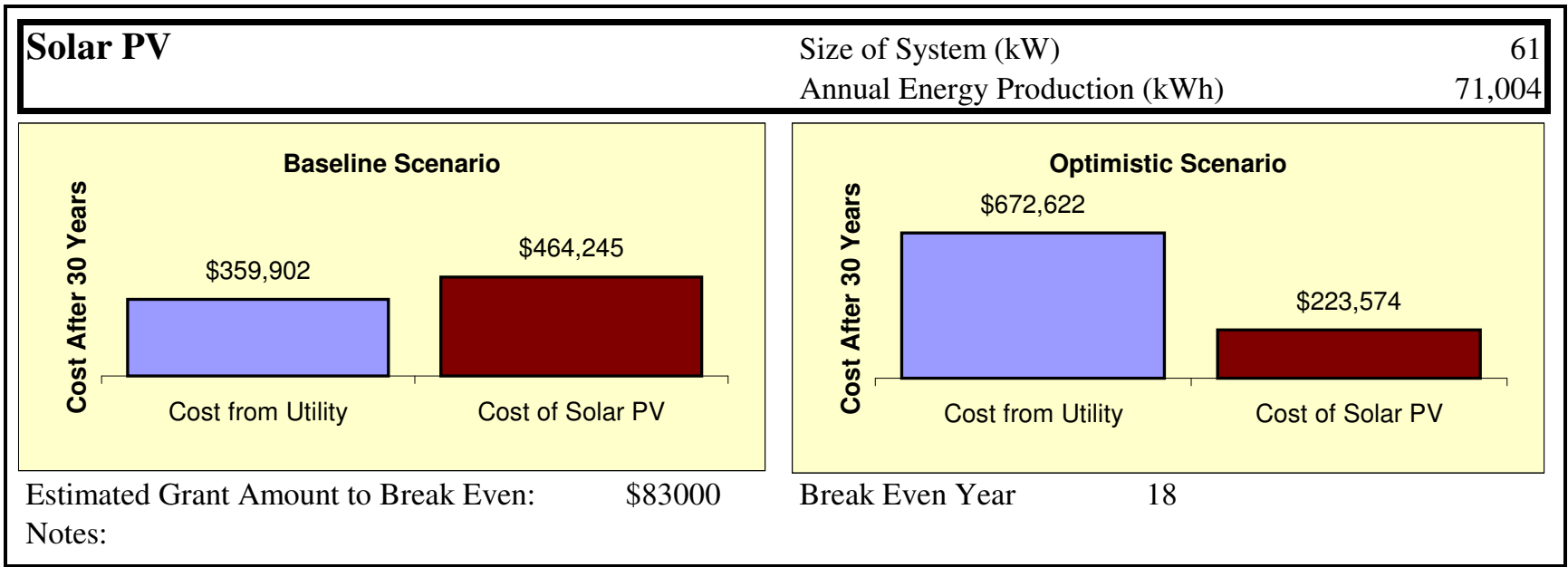

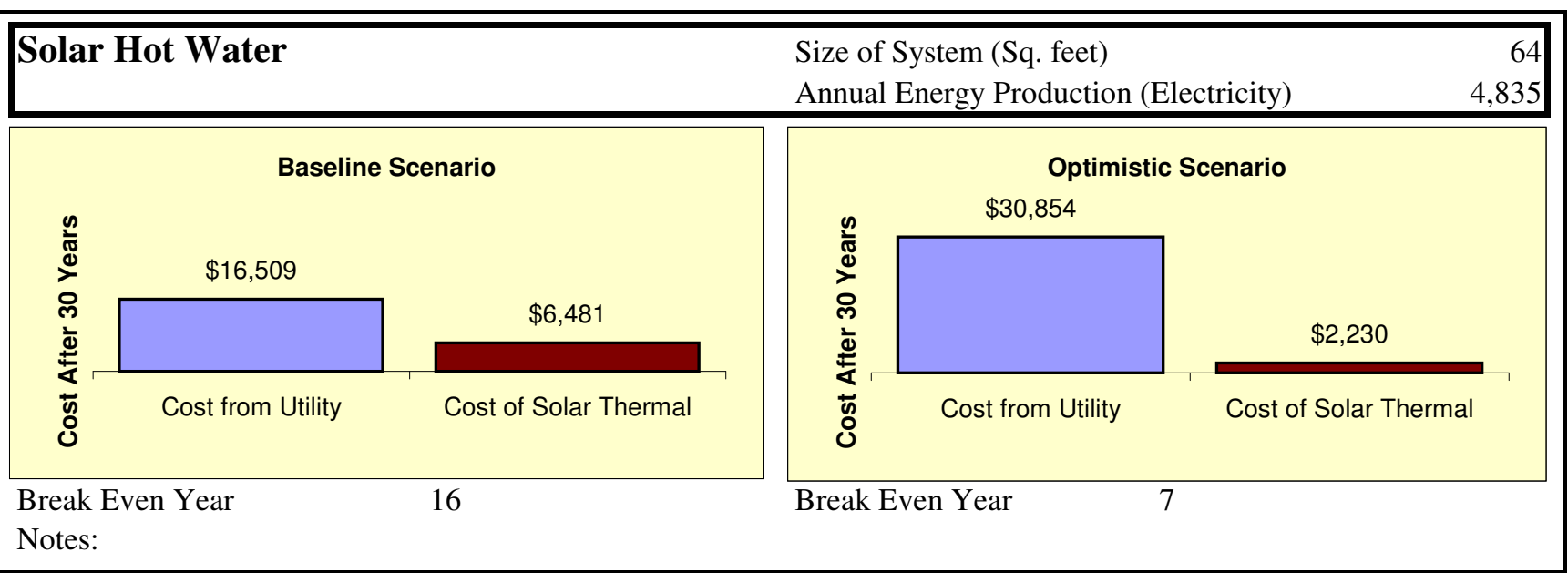

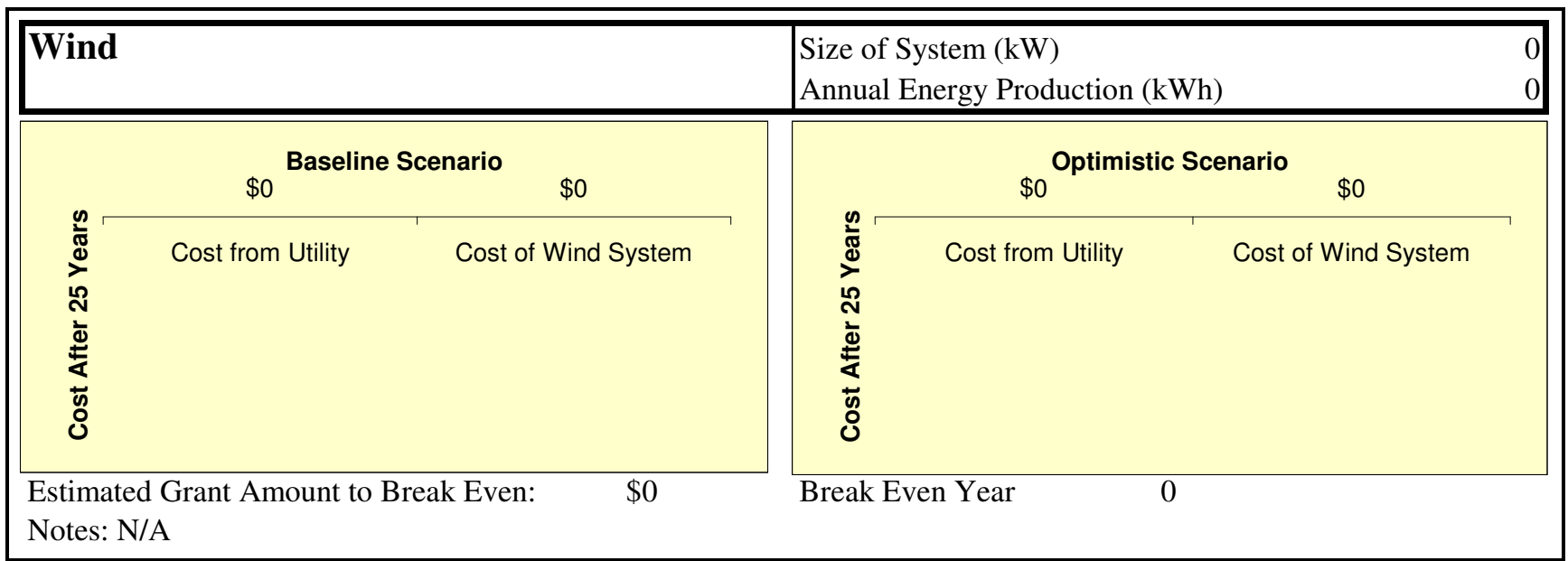

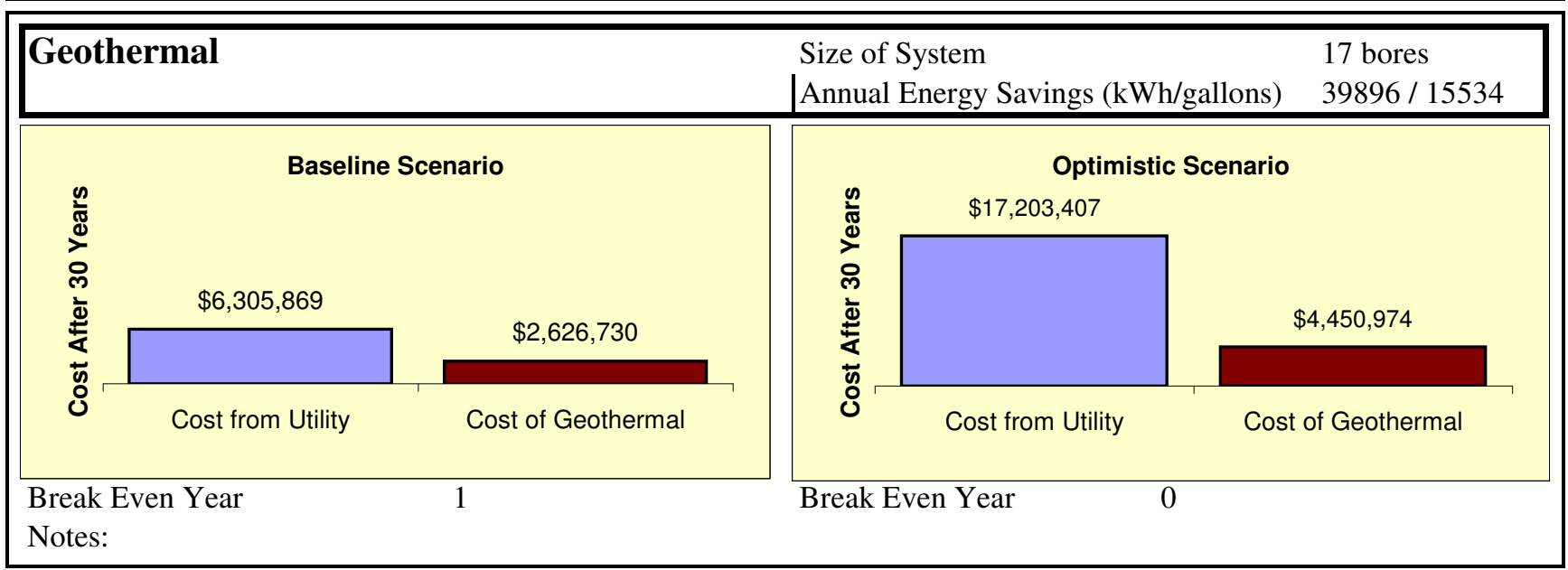




\begin{tabular}{|c|c|c|}
\hline Facility - Lac du Flambeau School & Space Heating System & Boiler \\
\hline Area $\left(\mathrm{ft}^{2}\right) \quad 100,000$ & Space Cooling System & $\mathrm{DX}$ \\
\hline Occupany Schedule & Water Heating System & Propane \\
\hline
\end{tabular}

Image not available

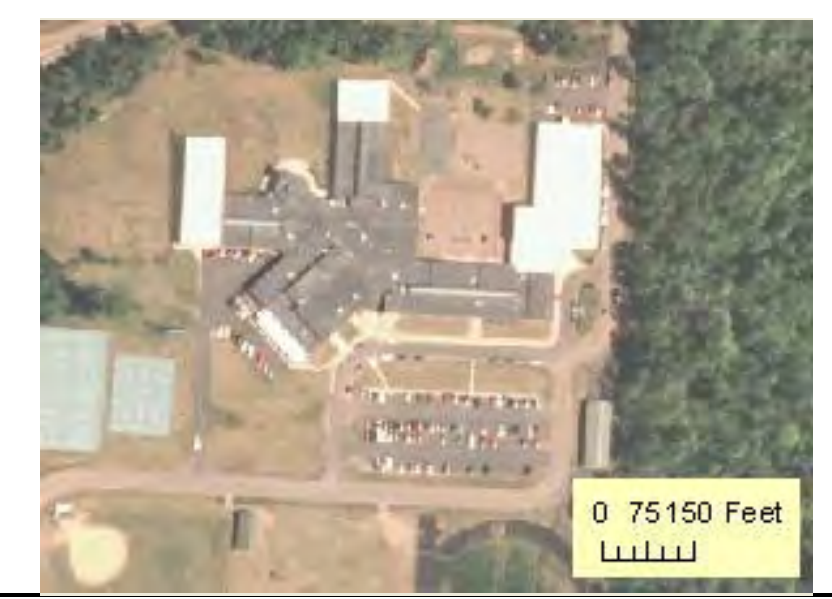

\begin{tabular}{|c|c|c|c|}
\hline \multicolumn{4}{|c|}{ Energy Profile (2007) } \\
\hline Electricity & Total & Rank & $\begin{array}{l}\text { Percent } \\
\text { of Tribe }\end{array}$ \\
\hline $\begin{array}{c}\text { Consumption kWh } \\
\text { (Cost) } \\
\end{array}$ & $\begin{array}{r}\mathbf{1 , 2 4 2 , 2 0 0} \\
\$ 91,079 \\
\end{array}$ & 3 & $10.5 \%$ \\
\hline $\begin{array}{c}\text { Electricity Intensity } \\
\left(\mathrm{Cost} / \mathrm{ft}^{2}\right)\end{array}$ & $\begin{array}{r}42.4 \\
\$ 0.91 \\
\end{array}$ & 11 & \\
\hline Energy Charge $(\mathrm{kWh})$ & $\$ 0.060$ & & \\
\hline Demand Charge $(\mathrm{kW})$ & $\$ 10.67$ & & \\
\hline
\end{tabular}

\begin{tabular}{|c|c|c|c|}
\hline Propane & Total & Rank & $\begin{array}{l}\text { Percent } \\
\text { of Tribe }\end{array}$ \\
\hline $\begin{array}{c}\text { Consumption gal } \\
\text { (Cost) }\end{array}$ & $\begin{array}{r}\mathbf{9 0 , 0 0 0} \\
\$ 130,500\end{array}$ & 2 & $22.1 \%$ \\
\hline $\begin{array}{c}\text { Propane Intensity } \\
\left(\text { Cost } / \mathrm{ft}^{2}\right)\end{array}$ & $\begin{array}{r}82.2 \\
\$ 1.31\end{array}$ & 4 & \\
\hline Propane Cost (gal) & & $\$ 1.45$ & \\
\hline
\end{tabular}
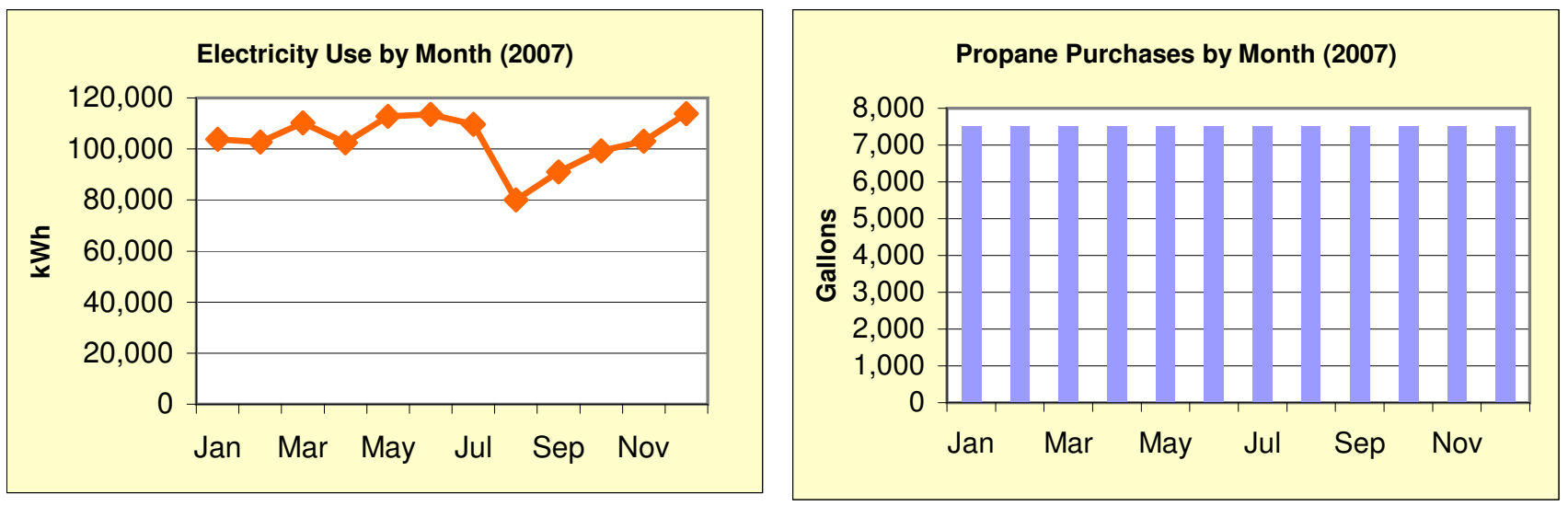

\section{WPS Electric Accounts}

\section{Energy Efficiency Recommendations}

\begin{tabular}{|l|l|l|r|}
\hline Type & Rate & $\begin{array}{c}\text { 2007 Use } \\
\text { (kWh) }\end{array}$ & 2007 Cost \\
\hline Main & CG-20 & $1,242,200$ & $\$ 91,079$ \\
\hline & & & \\
\hline & & & \\
\hline & & & \\
\hline & & & \\
\hline & & & \\
\hline & & & \\
\hline
\end{tabular}

\begin{tabular}{|l|c|c|c|}
\hline Recommendation & $\begin{array}{c}\text { Cost to } \\
\text { Install }\end{array}$ & $\begin{array}{c}\text { Annual } \\
\mathbf{k W h} \\
\text { Savings }\end{array}$ & $\begin{array}{c}\text { Simple Payback } \\
\text { (yrs) }\end{array}$ \\
\hline Occupancy sensors & 2550 & 76950 & 0.4 \\
\hline Consider variable speed drives for air handlers \\
\hline \multicolumn{4}{|l|}{} \\
\hline
\end{tabular}




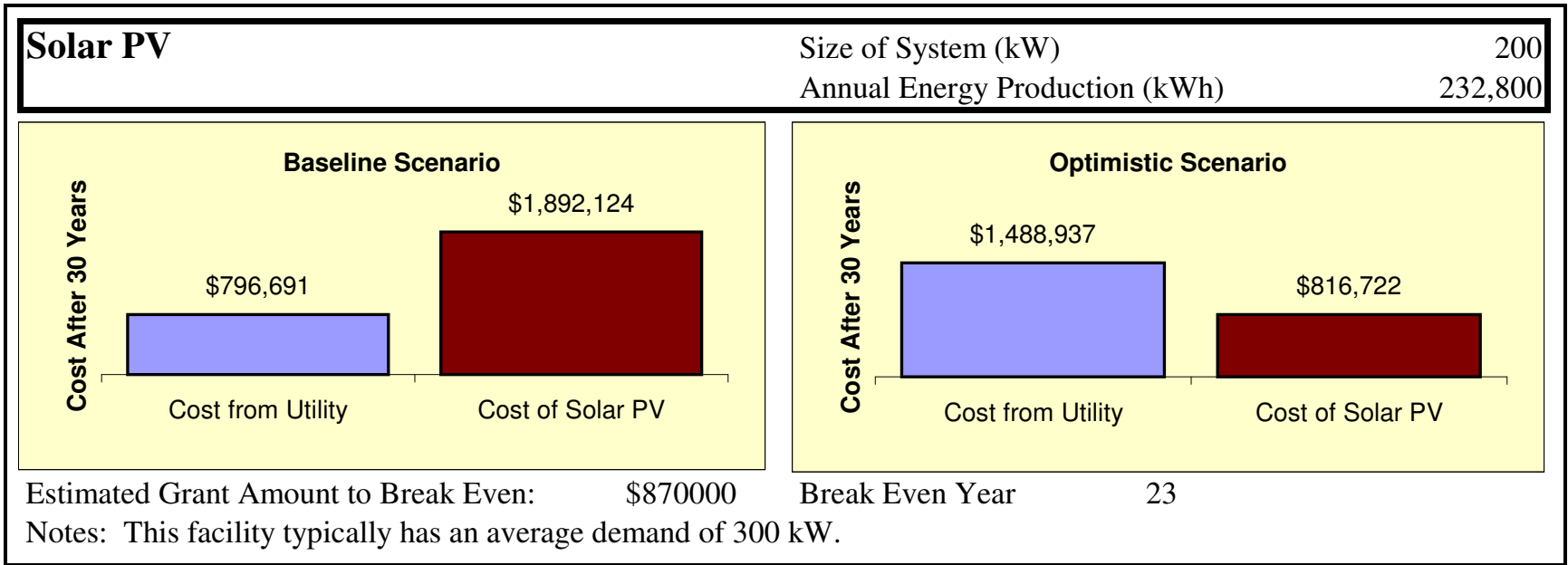

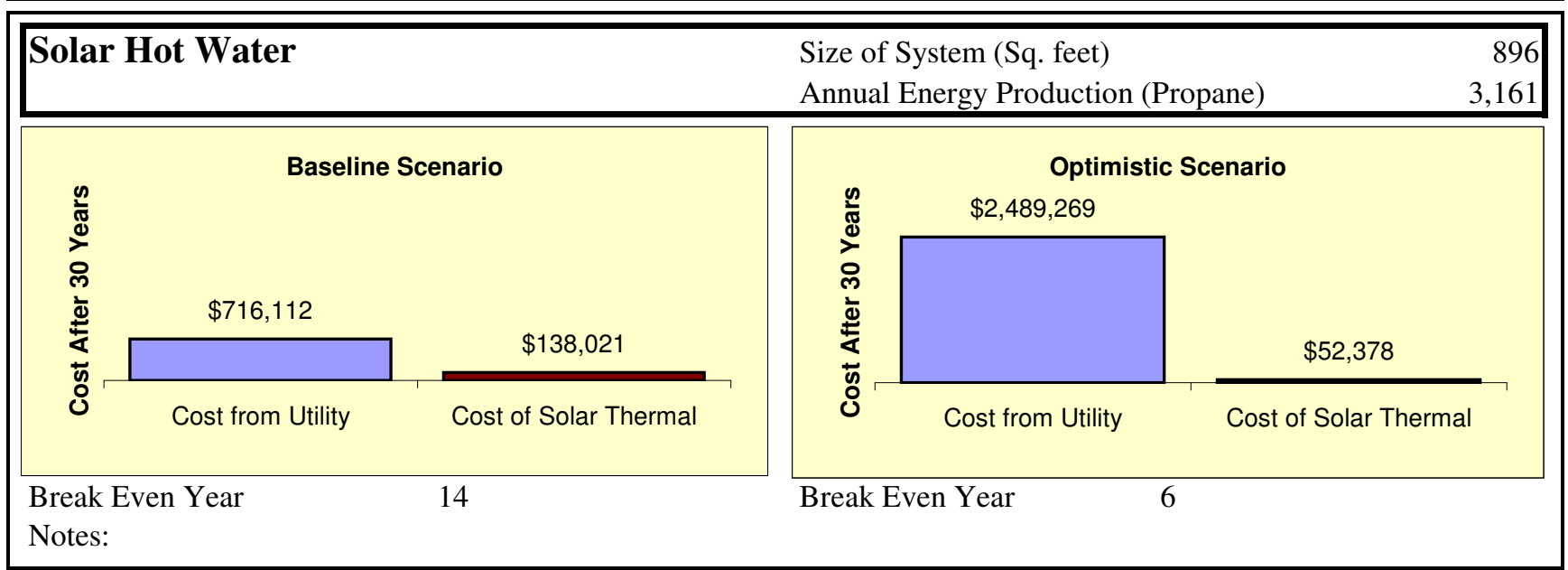

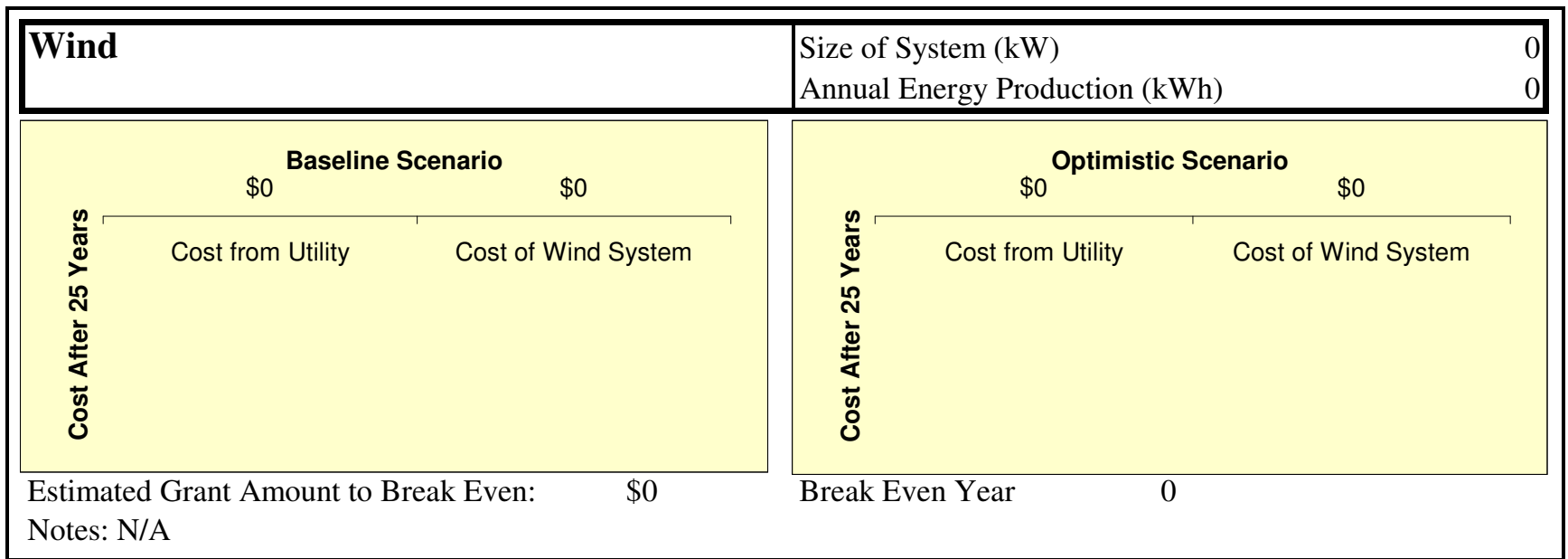

\begin{tabular}{|c|c|c|c|c|c|c|}
\hline \multicolumn{3}{|c|}{ Geothermal } & \multicolumn{3}{|c|}{$\begin{array}{l}\text { Size of System } \\
\text { |Annual Energy Savings (kWh/gallons) }\end{array}$} & $\begin{array}{l}0 \\
0 / 0\end{array}$ \\
\hline \multicolumn{3}{|c|}{$\$ 0$ Baseline Scenario } & \multicolumn{4}{|c|}{ Optimistic Scenario } \\
\hline 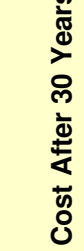 & Cost from Utility & Cost of Geothermal & 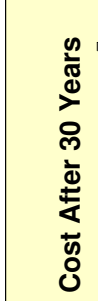 & Cost from Utility & \multicolumn{2}{|c|}{ Cost of Geothermal } \\
\hline $\begin{array}{l}\text { Break } \\
\text { Notes }\end{array}$ & $\begin{array}{l}n \text { Year } \\
\text { a priority at thi }\end{array}$ & 0 & Break & Year & & \\
\hline
\end{tabular}




\begin{tabular}{|llll|}
\hline Facility - Roads Garage (Tribal garage) & Space Heating System & unknown \\
Area $\left(\mathrm{ft}^{2}\right)$ & 9,800 & Space Cooling System & unknown \\
Occupany Schedule & M-Th $7 \mathrm{am}-5 \mathrm{pm}$ & Water Heating System & Propane \\
\hline
\end{tabular}
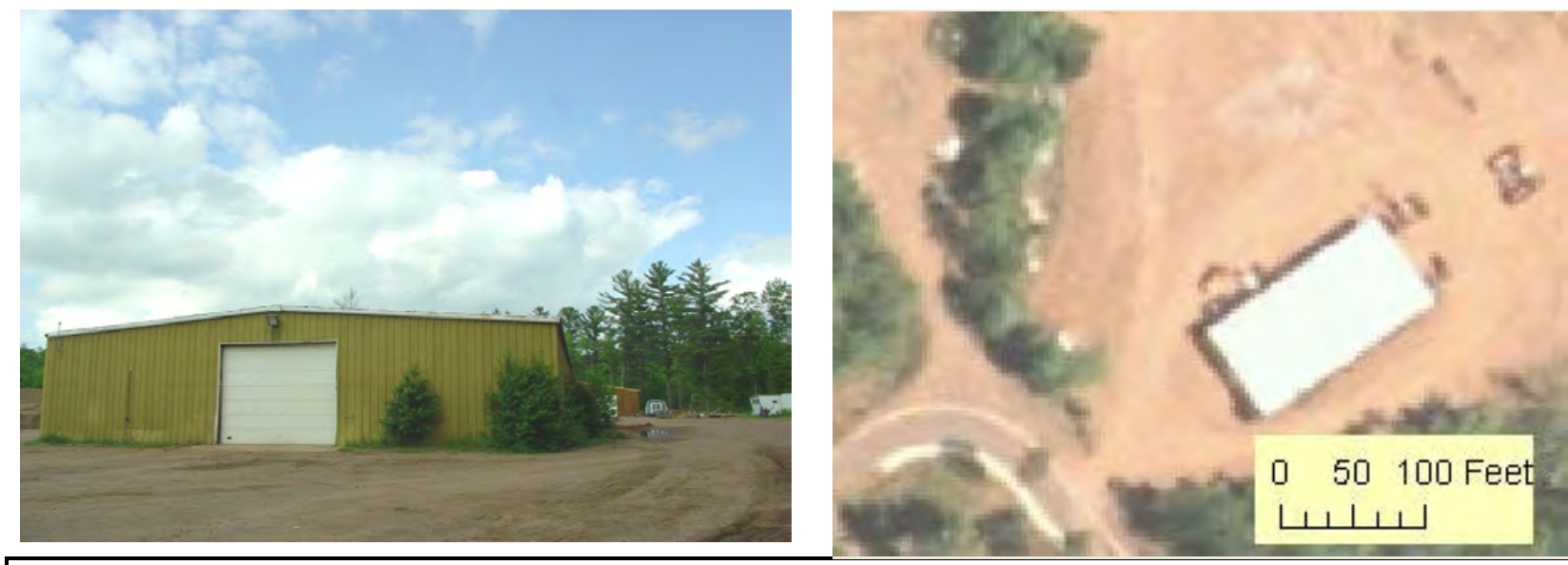

Energy Profile (2007)

\begin{tabular}{|c|c|c|c|}
\hline Electricity & Total & Rank & $\begin{array}{l}\text { Percent } \\
\text { of Tribe }\end{array}$ \\
\hline $\begin{array}{c}\text { Consumption kWh } \\
\text { (Cost) }\end{array}$ & $\begin{array}{l}\mathbf{7 8 , 1 7 6} \\
\$ 8,394\end{array}$ & 13 & $0.7 \%$ \\
\hline $\begin{array}{c}\text { Electricity Intensity } \\
\left(\mathrm{Cost} / \mathrm{ft}^{2}\right)\end{array}$ & $\begin{array}{r}27.2 \\
\$ 0.86\end{array}$ & 17 & \\
\hline \begin{tabular}{|l} 
Energy Charge $(\mathrm{kWh})$ \\
Demand Charge $(\mathrm{kW})$
\end{tabular} & \begin{tabular}{r|}
$\$ 0.109$ \\
$\$ 0.00$
\end{tabular} & & \\
\hline
\end{tabular}

\begin{tabular}{|c|c|c|c|}
\hline Propane & Total & Rank & $\begin{array}{l}\text { Percent } \\
\text { of Tribe }\end{array}$ \\
\hline $\begin{array}{c}\text { Consumption gal } \\
\text { (Cost) }\end{array}$ & $\begin{array}{r}\mathbf{6 , 5 2 5} \\
\$ 9,527\end{array}$ & 9 & $1.6 \%$ \\
\hline $\begin{array}{l}\text { Propane Intensity } \\
\left(\text { Cost } / \mathrm{ft}^{2}\right)\end{array}$ & $\begin{array}{r}60.8 \\
\$ 0.97\end{array}$ & 7 & \\
\hline Propane Cost (gal) & & $\$ 1.46$ & \\
\hline
\end{tabular}
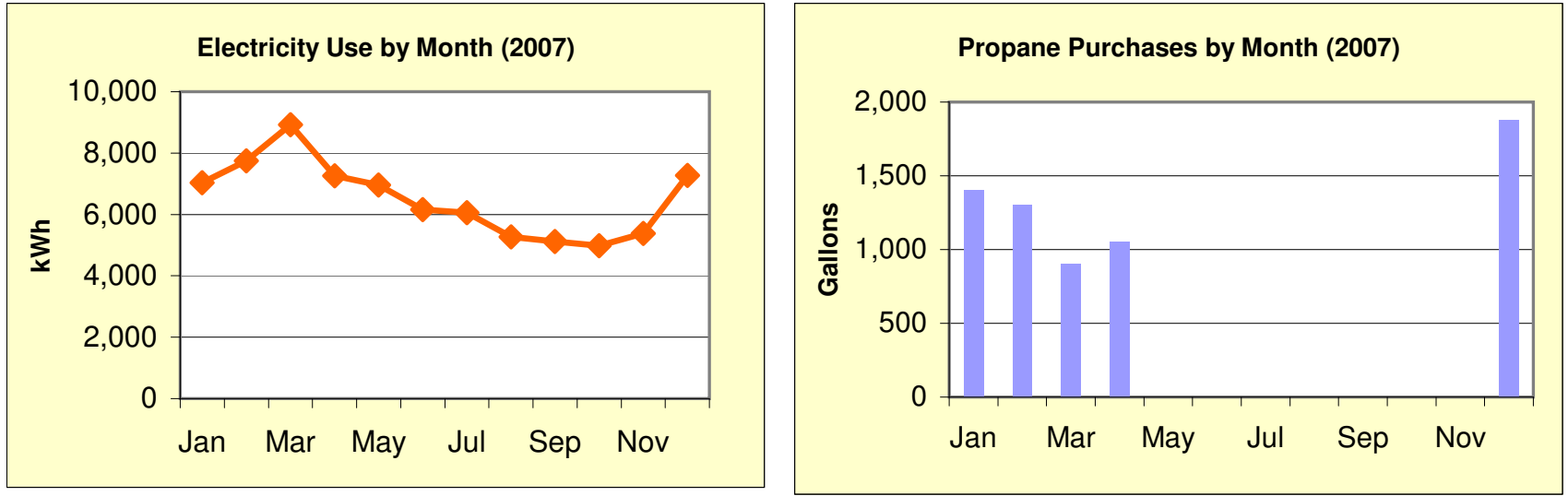

\section{WPS Electric Accounts}

\section{Energy Efficiency Recommendations}

\begin{tabular}{|l|l|c|r|}
\hline Type & Rate & $\begin{array}{c}\text { 2007 Use } \\
\text { (kWh) }\end{array}$ & 2007 Cost \\
\hline Main & CG-1 & 78,176 & $\$ 8,394$ \\
\hline & & & \\
\hline & & & \\
\hline & & & \\
\hline & & & \\
\hline & & & \\
\hline & & & \\
\hline
\end{tabular}

\begin{tabular}{|l|c|c|c|}
\hline Recommendation & $\begin{array}{c}\text { Cost to } \\
\text { Install }\end{array}$ & $\begin{array}{c}\text { Annual } \\
\mathbf{k W h} \\
\text { Savings }\end{array}$ & $\begin{array}{c}\text { Simple Payback } \\
\text { (yrs) }\end{array}$ \\
\hline 6LT8 lighting upgrad & 2760 & 15869 & \\
\hline Install sweeps on doors \\
\hline Heat building only to 50 degrees \\
\hline \multicolumn{2}{|l}{} \\
\hline \\
\hline
\end{tabular}




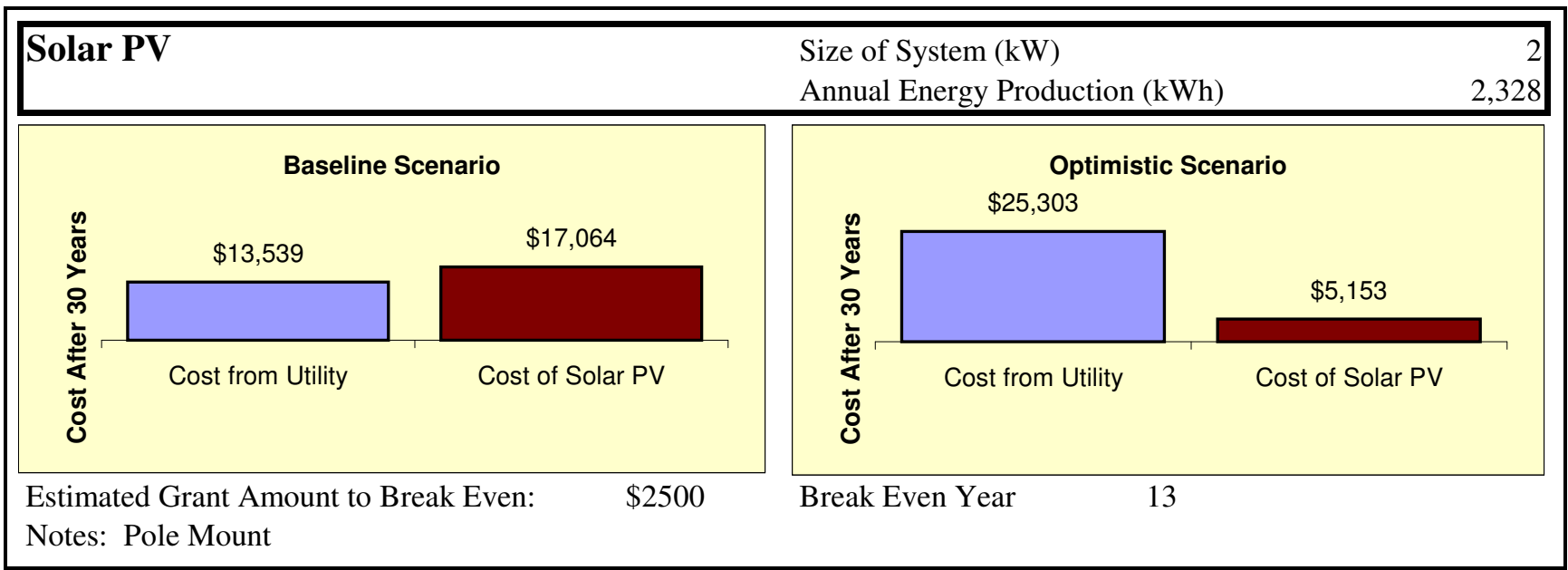

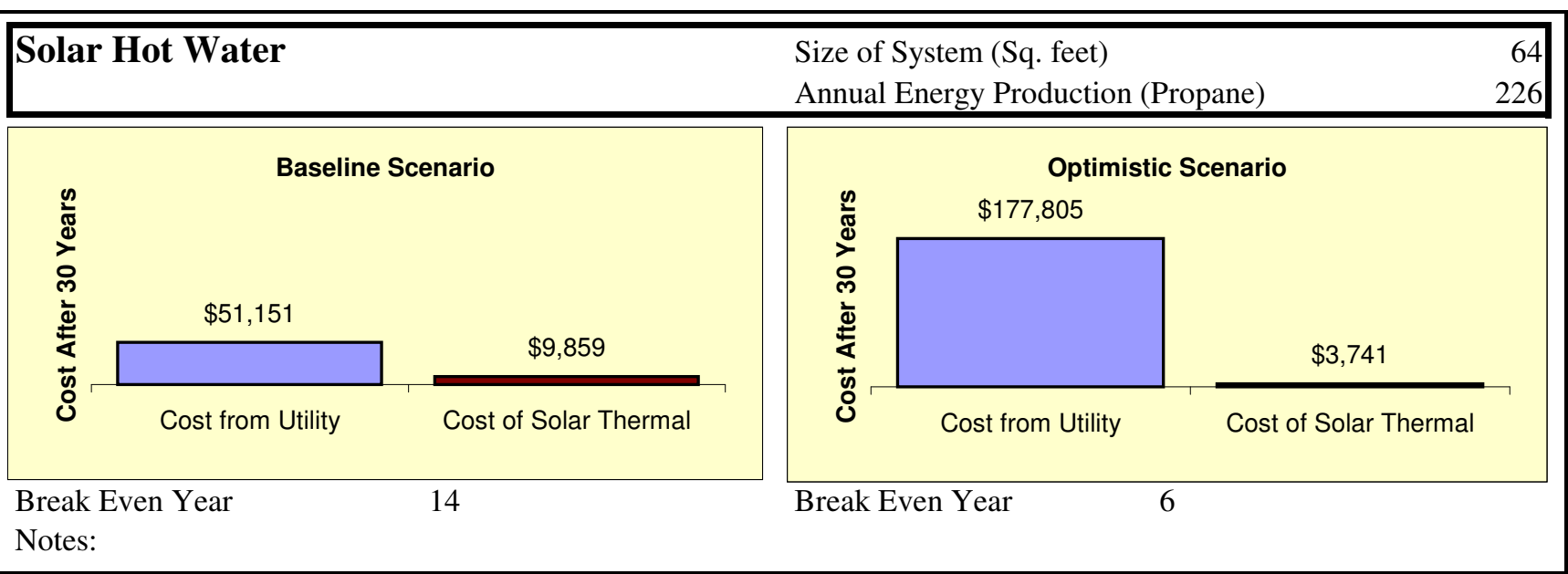

\begin{tabular}{|c|c|c|c|c|c|}
\hline \multicolumn{3}{|c|}{ Wind } & \multicolumn{3}{|c|}{$\begin{array}{l}\text { Size of System }(\mathrm{kW}) \\
\text { Annual Energy Production }(\mathrm{kWh})\end{array}$} \\
\hline \multirow[b]{2}{*}{ 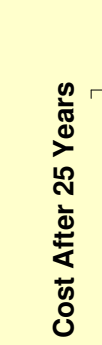 } & $\$ 0{ }^{\text {Basel }}$ & nario & \multirow[b]{2}{*}{ 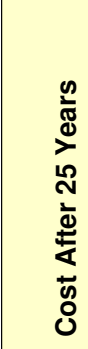 } & \multicolumn{2}{|c|}{ Optimistic Scenario } \\
\hline & Cost from Utility & Cost of Wind System & & Cost from Utility & Cost of Wind System \\
\hline $\begin{array}{l}\text { Estima } \\
\text { Notes: }\end{array}$ & Grant Amount & k Even: & Break & Year & \\
\hline
\end{tabular}

\begin{tabular}{|c|c|c|c|c|c|c|}
\hline \multicolumn{3}{|c|}{ Geothermal } & $\begin{array}{l}\text { Size o } \\
\text { Annua }\end{array}$ & $\begin{array}{l}\text { tem } \\
\text { ergy Savings }(k\end{array}$ & ons) & $\begin{array}{l}0 \\
0 / 0\end{array}$ \\
\hline \multicolumn{3}{|c|}{$\$ 0$ Baseline Scenario } & \multicolumn{4}{|c|}{ Optimistic Scenario } \\
\hline 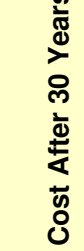 & Cost from Utility & Cost of Geothermal & 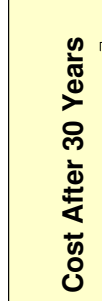 & Cost from Utility & \multicolumn{2}{|c|}{ Cost of Geothermal } \\
\hline \multicolumn{3}{|c|}{$\begin{array}{l}\text { Break Even Year } \\
\text { Notes: Not a priority }\end{array}$} & \multicolumn{2}{|c|}{ Break Even Year } & & \\
\hline
\end{tabular}




\begin{tabular}{|llll|}
\hline Facility - Post Office (Tribal Office, Library) & Space Heating System & Furnace \\
Area $\left(\mathrm{ft}^{2}\right)$ & 8,176 & Space Cooling System & DX \\
Occupany Schedule & M-F 7am-5pm Sat 8am-12pm & Water Heating System & unknown \\
\hline
\end{tabular}
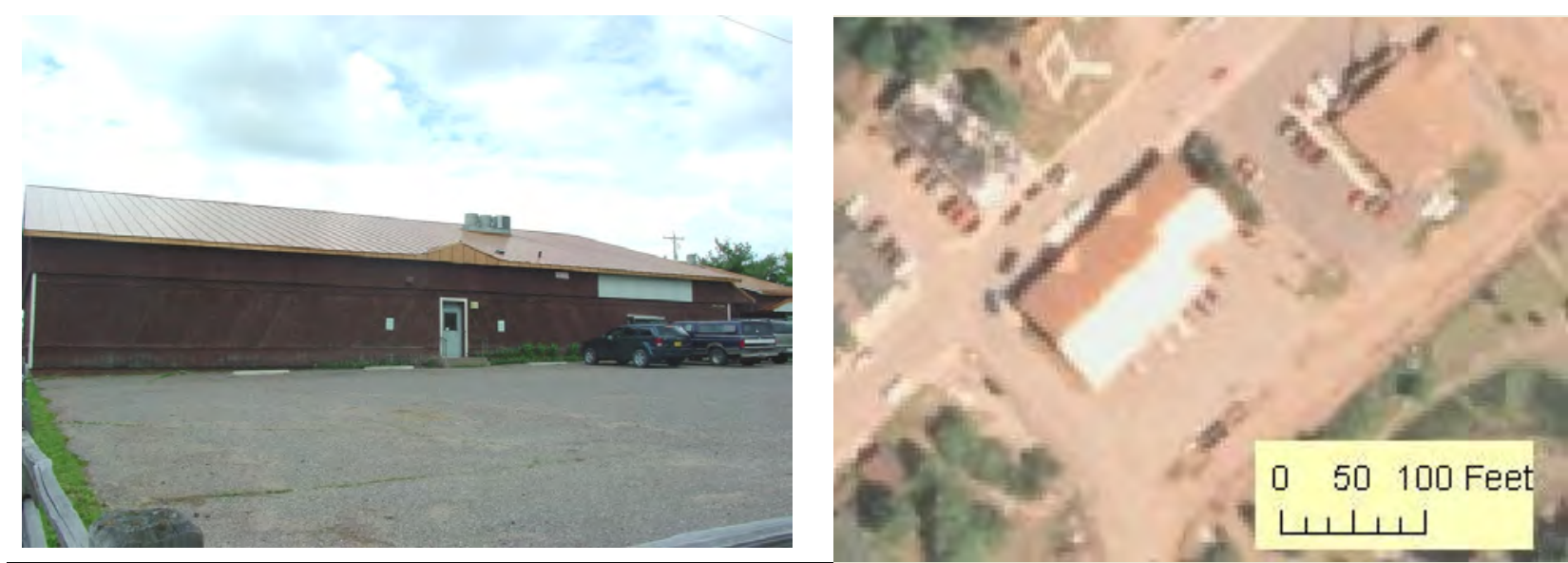

Energy Profile (2007)

\begin{tabular}{|c|c|c|c|}
\hline Electricity & Total & Rank & $\begin{array}{l}\text { Percent } \\
\text { of Tribe }\end{array}$ \\
\hline $\begin{array}{c}\text { Consumption kWh } \\
\text { (Cost) }\end{array}$ & $\begin{array}{l}\mathbf{2 1 , 9 1 1} \\
\$ 2,521\end{array}$ & 22 & $0.2 \%$ \\
\hline $\begin{array}{c}\text { Electricity Intensity } \\
\left(\text { Cost } / \mathbf{f t}^{2}\right)\end{array}$ & $\begin{array}{r}9.1 \\
\$ 0.31 \\
\end{array}$ & 22 & \\
\hline Energy Charge $(\mathrm{kWh})$ & $\$ 0.109$ & & \\
\hline Demand Charge $(\mathrm{kW})$ & $\$ 0.00$ & & \\
\hline
\end{tabular}

\begin{tabular}{|c|c|c|c|}
\hline Propane & Total & Rank & $\begin{array}{l}\text { Percent } \\
\text { of Tribe }\end{array}$ \\
\hline $\begin{array}{c}\text { Consumption gal } \\
\text { (Cost) }\end{array}$ & $\begin{array}{r}\mathbf{4 , 4 1 4} \\
\$ 6,445 \\
\end{array}$ & 12 & $1.1 \%$ \\
\hline $\begin{array}{c}\text { Propane Intensity } \\
\left(\text { Cost } / \mathrm{ft}^{2}\right)\end{array}$ & $\begin{array}{r}49.3 \\
\$ 0.79 \\
\end{array}$ & 11 & \\
\hline Propane Cost (gal) & & $\$ 1.46$ & \\
\hline
\end{tabular}
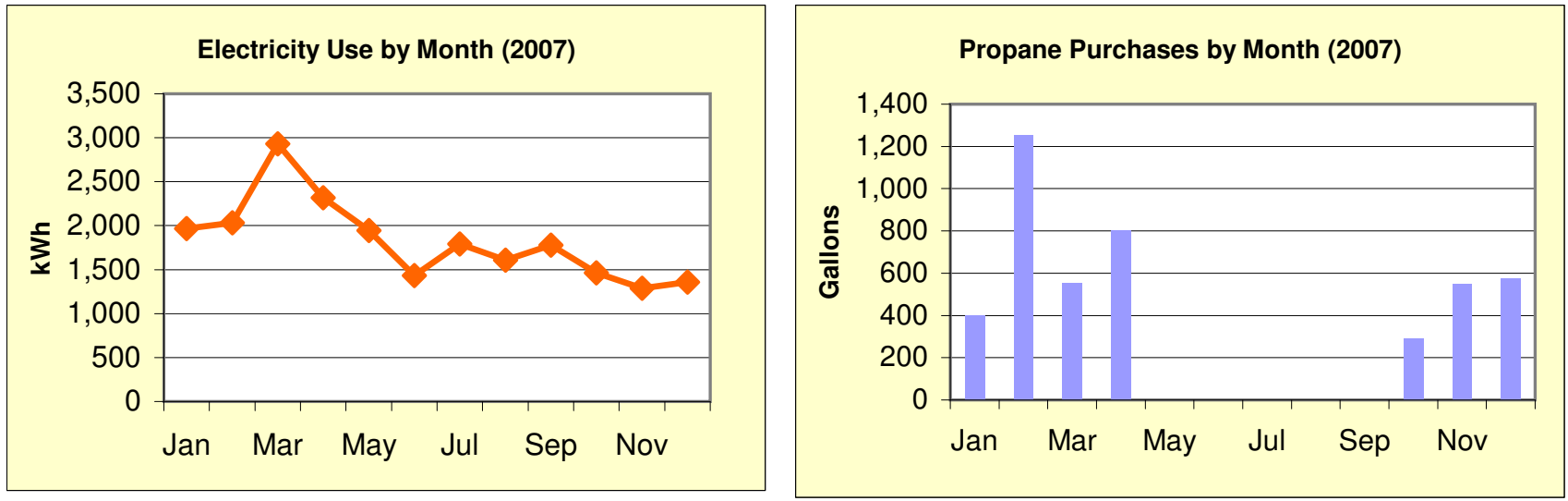

\section{WPS Electric Accounts}

\section{Energy Efficiency Recommendations}

\begin{tabular}{|l|l|c|r|}
\hline Type & Rate & $\begin{array}{c}\text { 2007 Use } \\
(\mathbf{k W h})\end{array}$ & 2007 Cost \\
\hline Main & CG-1 & 21,911 & $\$ 2,521$ \\
\hline & & & \\
\hline & & & \\
\hline & & & \\
\hline & & & \\
\hline & & & \\
\hline & & & \\
\hline
\end{tabular}

\begin{tabular}{|l|c|c|c|}
\hline Recommendation & $\begin{array}{c}\text { Cost to } \\
\text { Install }\end{array}$ & $\begin{array}{c}\text { knnual } \\
\text { Savings }\end{array}$ & $\begin{array}{c}\text { Simple Payback } \\
\text { (yrs) }\end{array}$ \\
\hline & & & \\
\hline Energy audit recommended \\
\hline \multicolumn{2}{|l|}{} \\
\hline
\end{tabular}




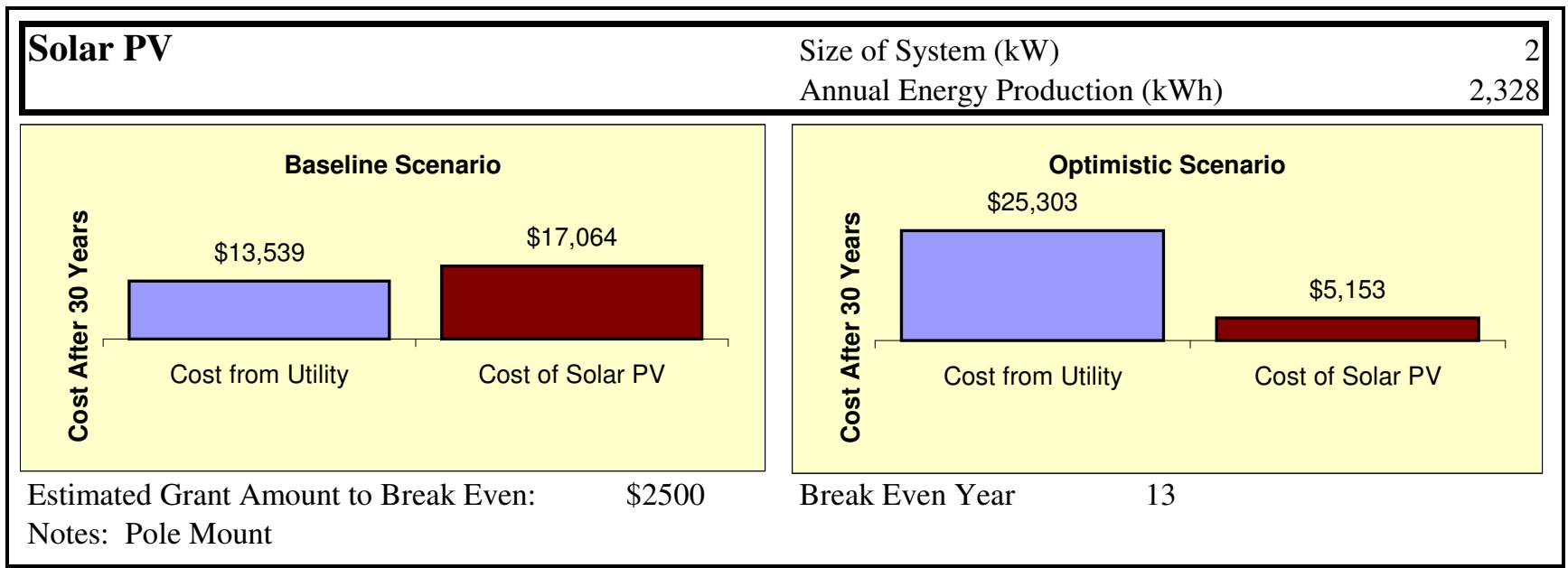

\begin{tabular}{|c|c|c|c|c|c|c|}
\hline \multicolumn{3}{|c|}{ Solar Hot Water } & \multicolumn{3}{|c|}{$\begin{array}{l}\text { Size of System (Sq. feet) } \\
\text { Annual Energy Production () }\end{array}$} & 0 \\
\hline \multicolumn{3}{|c|}{$\$ 0$ Baseline Scenario } & \multicolumn{3}{|c|}{$\$ 0$ Optimistic Scenario } & \\
\hline 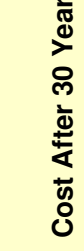 & Cost from Utility & Cost of Solar Thermal & 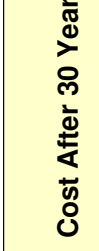 & Cost from Utility & Cost of Solar Thermal & \\
\hline $\begin{array}{l}\text { Break } \\
\text { Notes }\end{array}$ & $\begin{array}{l}n \text { Year } \\
\text { a priority }\end{array}$ & 0 & Break & Year & & \\
\hline
\end{tabular}

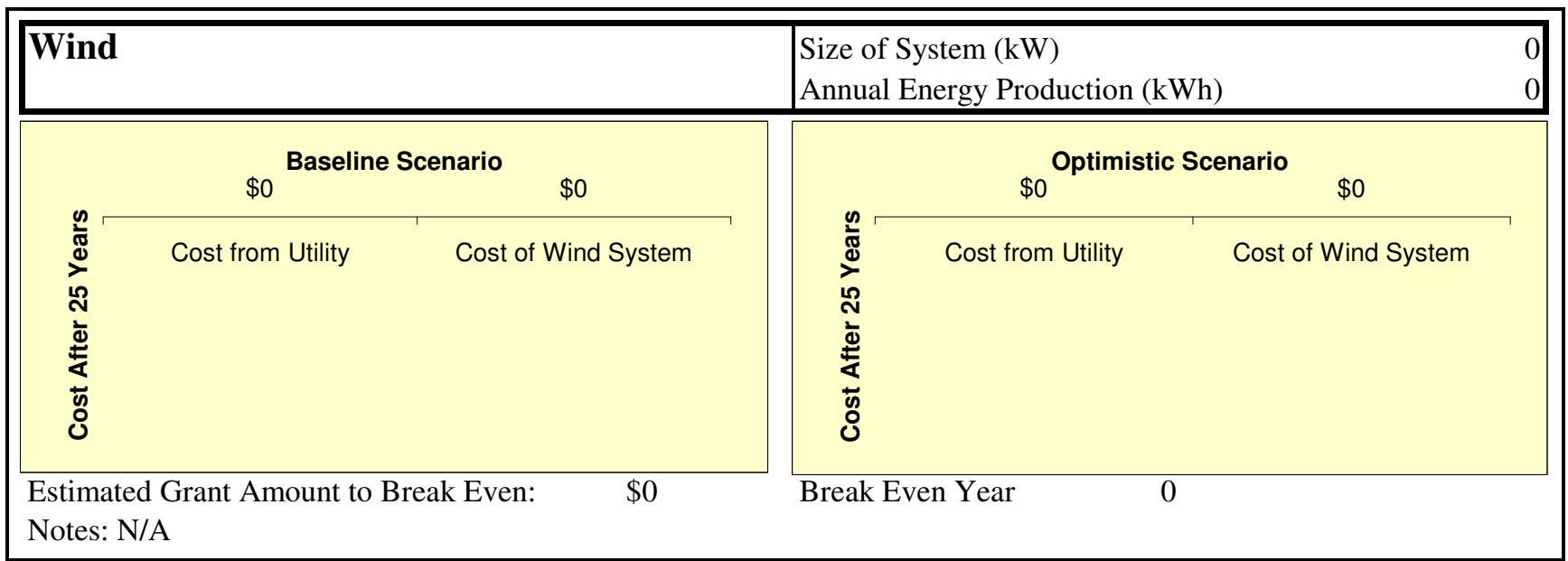

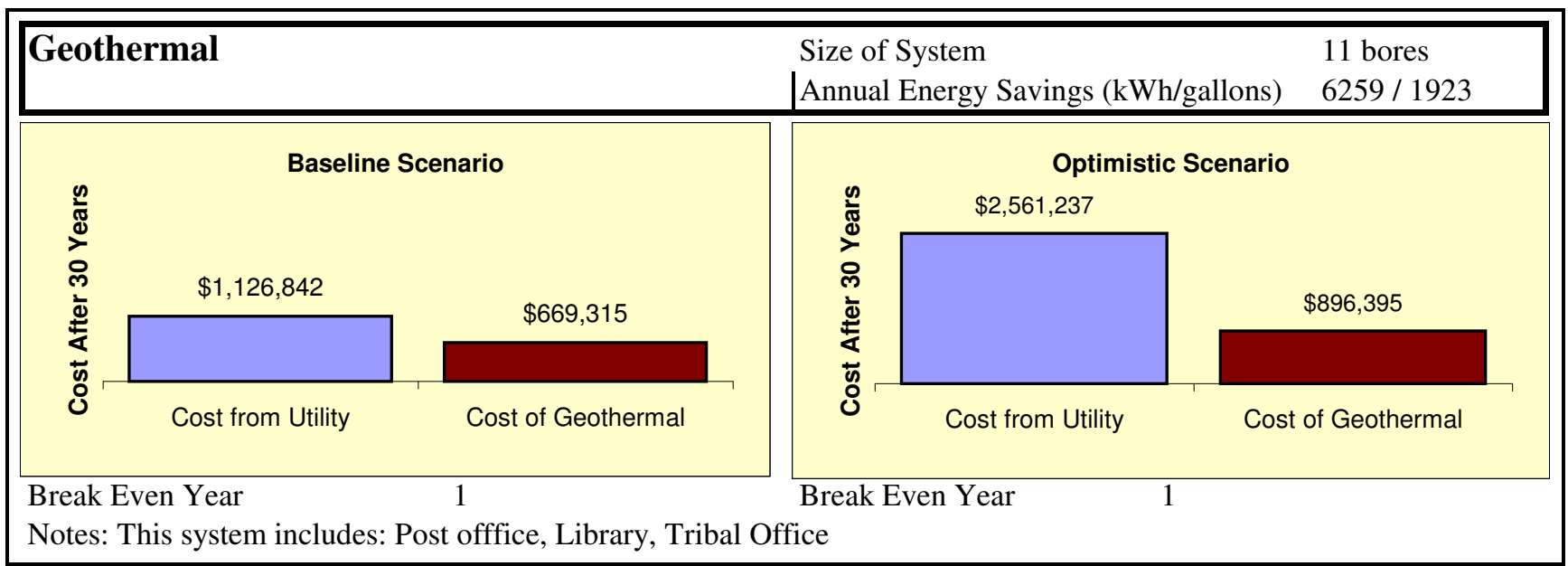




\begin{tabular}{|llll|}
\hline Facility - Planning / Bank Building & Space Heating System & Furnace \\
Area $\left(\mathrm{ft}^{2}\right)$ & 5,620 & Space Cooling System & DX \\
Occupany Schedule & M-F 7am-5pm (Bank Sat 7:30-12) & Water Heating System & unknown \\
\hline
\end{tabular}

Image not available

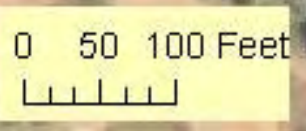

\section{Energy Profile (2007)}

\begin{tabular}{|c|c|c|c|}
\hline Electricity & Total & Rank & $\begin{array}{l}\text { Percent } \\
\text { of Tribe }\end{array}$ \\
\hline $\begin{array}{c}\text { Consumption kWh } \\
\text { (Cost) }\end{array}$ & $\begin{array}{l}\mathbf{6 2 , 5 9 2} \\
\$ 6,753\end{array}$ & 16 & $0.5 \%$ \\
\hline $\begin{array}{c}\text { Electricity Intensity } \\
\left(\text { Cost } / \mathrm{ft}^{2}\right)\end{array}$ & $\begin{array}{r}38.0 \\
\$ 1.20\end{array}$ & 13 & \\
\hline Energy Charge $(\mathrm{kWh})$ & $\$ 0.109$ & & \\
\hline Demand Charge $(\mathrm{kW})$ & $\$ 0.00$ & & \\
\hline
\end{tabular}

\begin{tabular}{|c|c|c|c|}
\hline Propane & Total & Rank & $\begin{array}{l}\text { Percent } \\
\text { of Tribe }\end{array}$ \\
\hline $\begin{array}{c}\text { Consumption gal } \\
\text { (Cost) }\end{array}$ & $\begin{array}{r}\mathbf{2 , 0 2 4} \\
\$ 2,955\end{array}$ & 19 & $0.5 \%$ \\
\hline $\begin{array}{l}\text { Propane Intensity } \\
\left(\text { Cost } / \mathrm{ft}^{2}\right)\end{array}$ & $\begin{array}{r}32.9 \\
\$ 0.53\end{array}$ & 18 & \\
\hline Propane Cost (gal) & & $\$ 1.46$ & \\
\hline
\end{tabular}
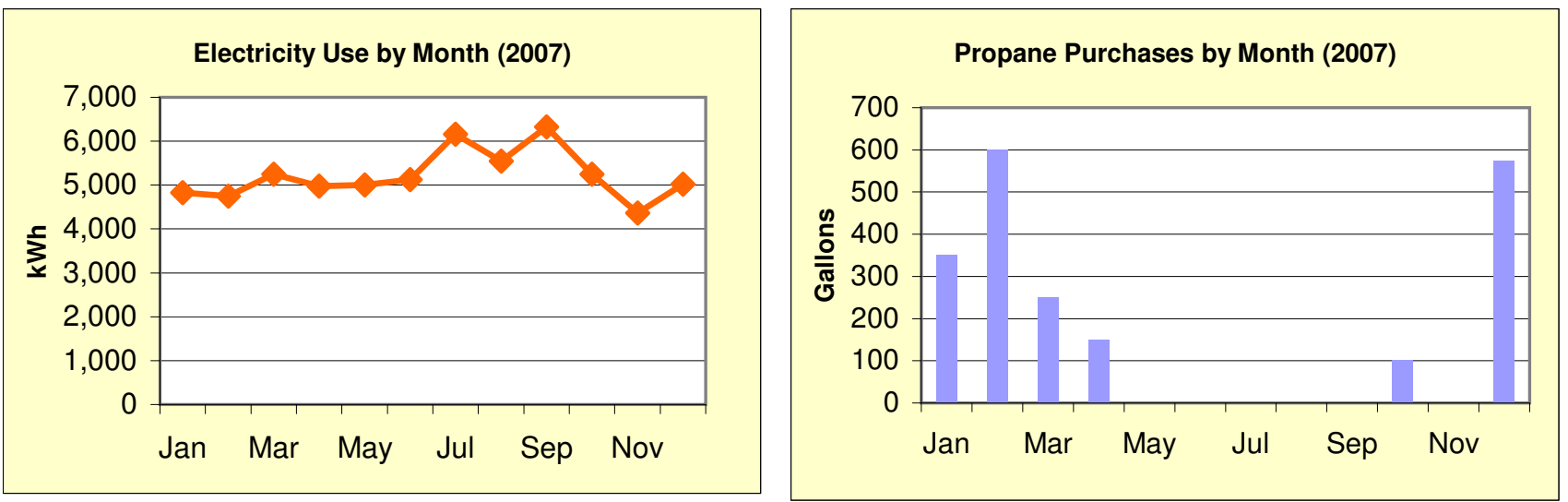

\section{WPS Electric Accounts}

\section{Energy Efficiency Recommendations}

\begin{tabular}{|l|l|c|r|}
\hline Type & Rate & $\begin{array}{c}\text { 2007 Use } \\
\text { (kWh) }\end{array}$ & 2007 Cost \\
\hline Main & CG-1 & 62,592 & $\$ 6,753$ \\
\hline & & & \\
\hline & & & \\
\hline & & & \\
\hline & & & \\
\hline & & & \\
\hline & & & \\
\hline
\end{tabular}

\begin{tabular}{|l|l|l|l|}
\hline Recommendation & $\begin{array}{c}\text { Cost to } \\
\text { Install }\end{array}$ & $\begin{array}{c}\text { Annual } \\
\mathbf{k W h} \\
\text { Savings }\end{array}$ & $\begin{array}{c}\text { Simple Payback } \\
\text { (yrs) }\end{array}$ \\
\hline & & & \\
\hline Continue to seal building shell and doors \\
\hline Install programmable set-back thermostats \\
\hline Change HVAC filters monthly \\
\hline Insulate hot water piping \\
\hline Set water heater to lowest setting \\
\hline Install lighting occupancy sensors \\
\hline
\end{tabular}




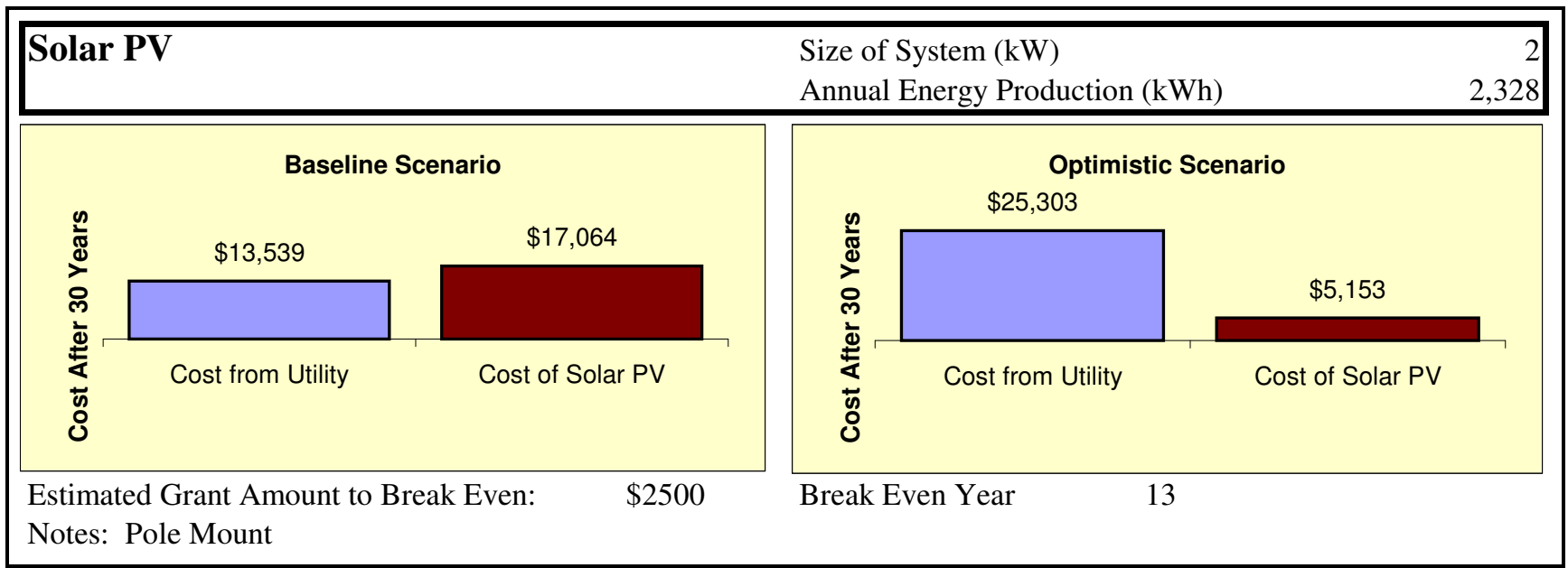

\begin{tabular}{|c|c|c|}
\hline Solai & ot Water & \\
\hline & $\$ 0$ Baseli & nario \\
\hline 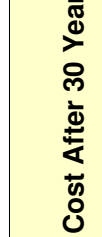 & Cost from Utility & Cost of Solar Thermal \\
\hline
\end{tabular}

Break Even Year

0

Size of System (Sq. feet)

Annual Energy Production ()

Notes: Recommended future review

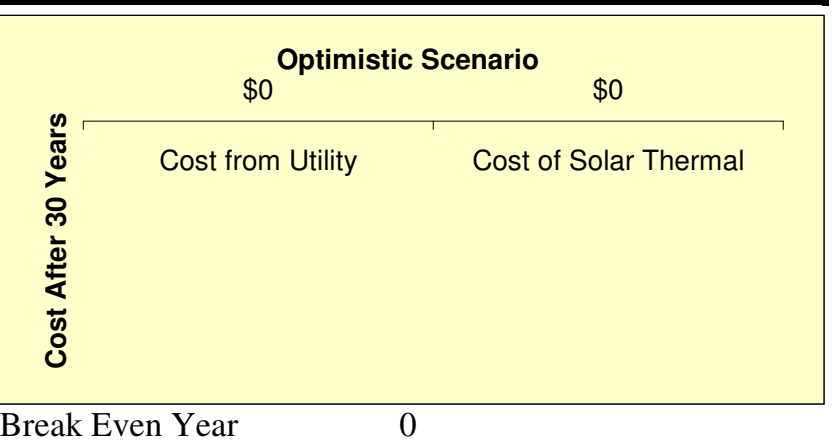

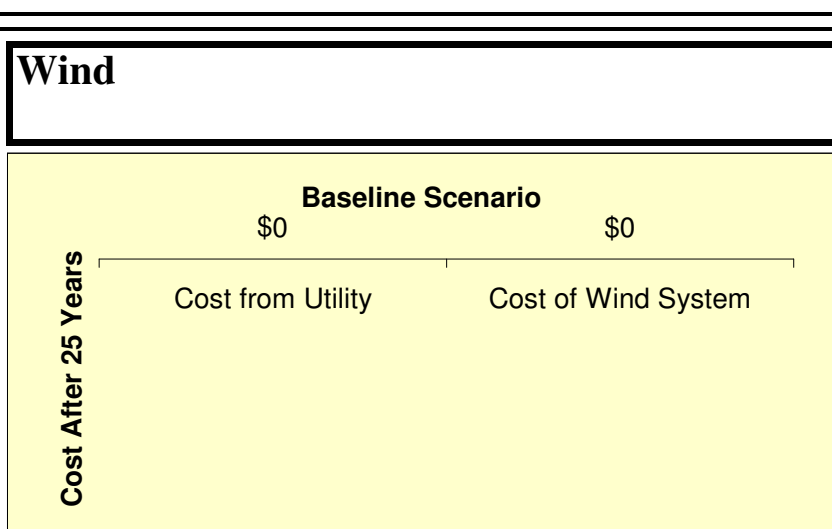

Estimated Grant Amount to Break Even:

$\$ 0$

Size of System $(\mathrm{kW})$

Annual Energy Production (kWh)

Notes: N/A

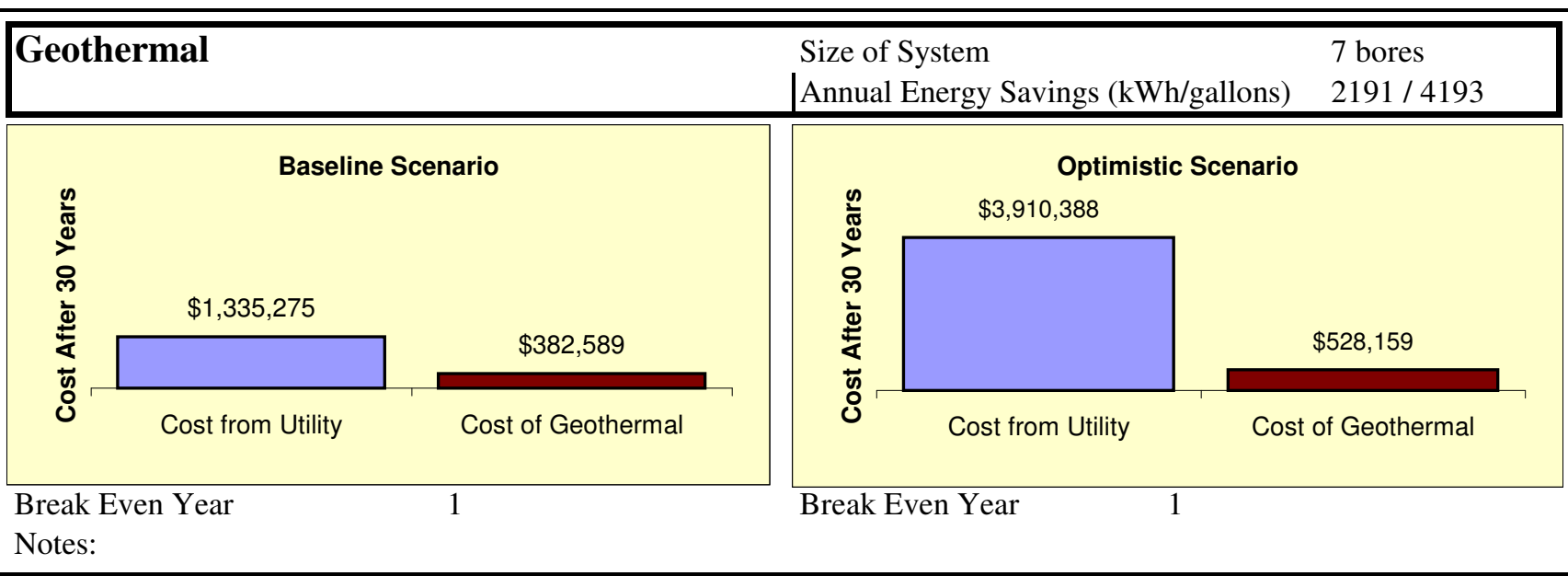




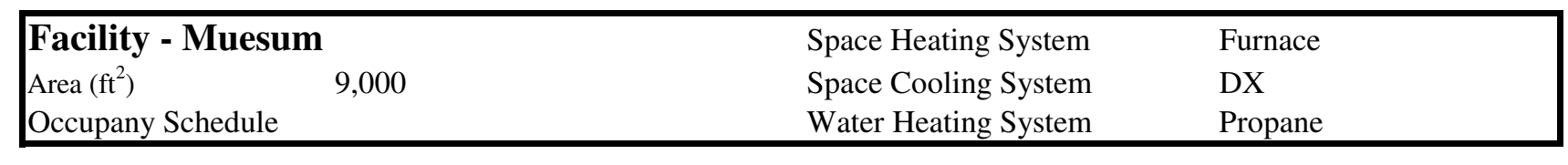
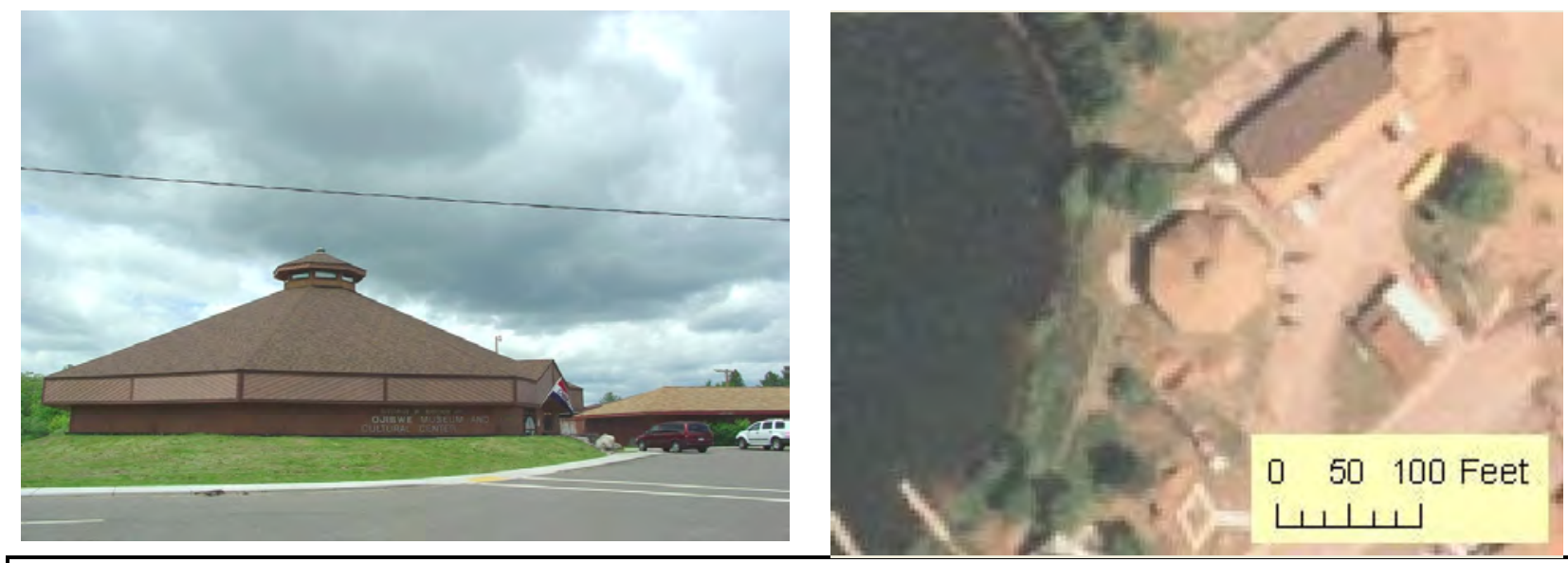

Energy Profile (2007)

\begin{tabular}{|c|c|c|c|}
\hline Electricity & Total & Rank & $\begin{array}{l}\text { Percent } \\
\text { of Tribe }\end{array}$ \\
\hline $\begin{array}{c}\text { Consumption kWh } \\
\text { (Cost) }\end{array}$ & $\begin{array}{l}\mathbf{7 0 , 9 0 9} \\
\$ 8,032\end{array}$ & 15 & $0.6 \%$ \\
\hline $\begin{array}{c}\text { Electricity Intensity } \\
\left(\text { Cost } / \mathbf{f t}^{2}\right)\end{array}$ & $\begin{array}{r}26.9 \\
\$ 0.89\end{array}$ & 19 & \\
\hline \begin{tabular}{|l} 
Energy Charge $(\mathrm{kWh})$ \\
Demand Charge $(\mathrm{kW})$
\end{tabular} & \begin{tabular}{r|}
$\$ 0.109$ \\
$\$ 0.00$
\end{tabular} & & \\
\hline
\end{tabular}

\begin{tabular}{|c|c|c|c|}
\hline Propane & Total & Rank & $\begin{array}{l}\text { Percent } \\
\text { of Tribe }\end{array}$ \\
\hline $\begin{array}{c}\text { Consumption gal } \\
\text { (Cost) }\end{array}$ & $\begin{array}{r}\mathbf{3 , 6 3 8} \\
\$ 5,311\end{array}$ & 13 & $0.9 \%$ \\
\hline $\begin{array}{l}\text { Propane Intensity } \\
\left(\text { Cost } / \mathrm{ft}^{2}\right)\end{array}$ & $\begin{array}{r}36.9 \\
\$ 0.59\end{array}$ & 16 & \\
\hline Propane Cost (gal) & & $\$ 1.46$ & \\
\hline
\end{tabular}
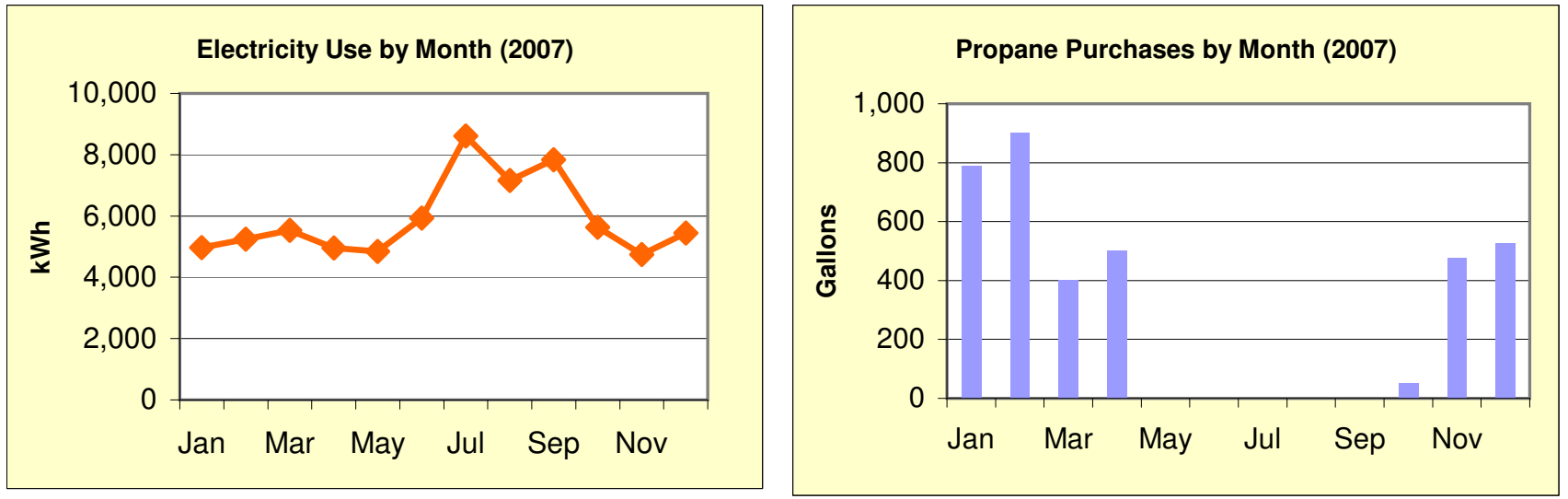

\section{WPS Electric Accounts}

\section{Energy Efficiency Recommendations}

\begin{tabular}{|l|l|c|r|}
\hline \multicolumn{1}{|c|}{ Type } & \multicolumn{1}{c|}{ Rate } & $\begin{array}{c}\text { 2007 Use } \\
(\mathbf{k W h})\end{array}$ & 2007 Cost \\
\hline Main & CG-1 & 70,909 & $\$ 7,693$ \\
\hline Outdoor lighting & GY-3 & & $\$ 339$ \\
\hline Outdoor lighting & GY-3 & & \\
\hline & & & \\
\hline & & & \\
\hline & & & \\
\hline & & & \\
\hline
\end{tabular}

\begin{tabular}{|l|l|c|c|}
\hline Recommendation & $\begin{array}{c}\text { Cost to } \\
\text { Install }\end{array}$ & $\begin{array}{c}\text { Annual } \\
\mathbf{k W h} \\
\text { Savings }\end{array}$ & $\begin{array}{c}\text { Simple Payback } \\
\text { (yrs) }\end{array}$ \\
\hline & & & \\
\hline Energy audit recommended \\
\hline \multicolumn{3}{|l}{} \\
\hline
\end{tabular}




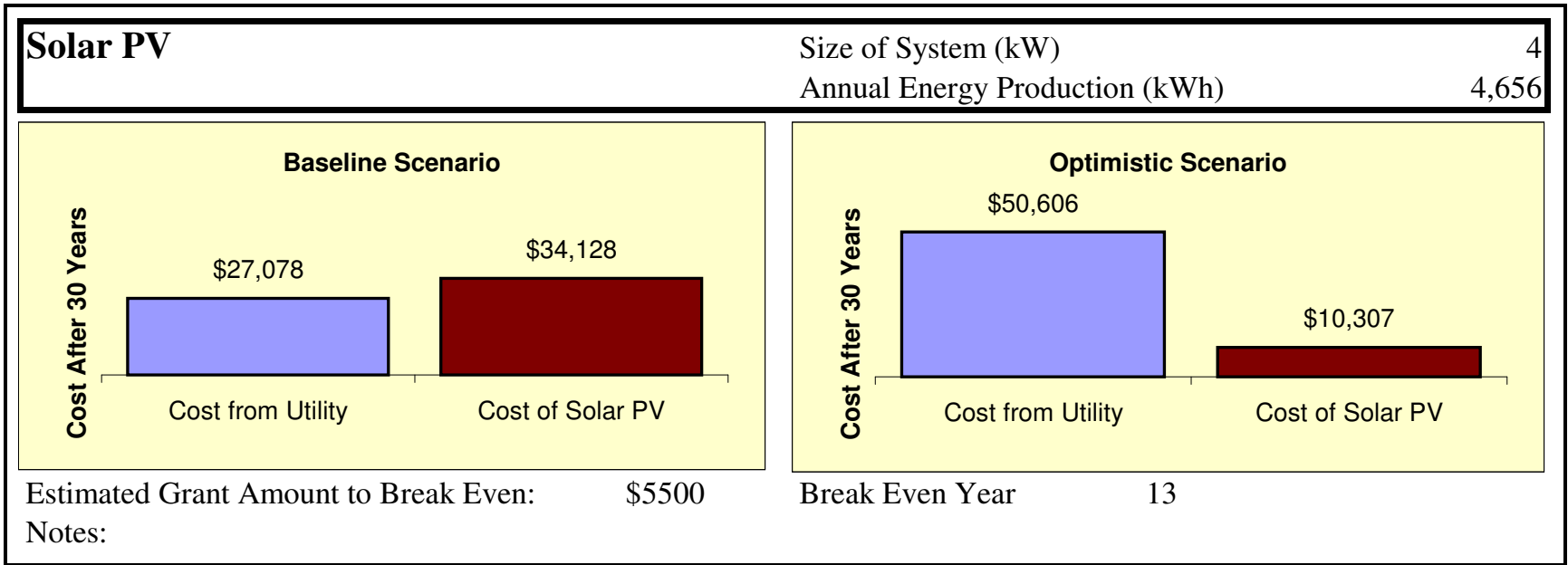

\section{Solar Hot Water}

Size of System (Sq. feet)

Annual Energy Production (Propane)
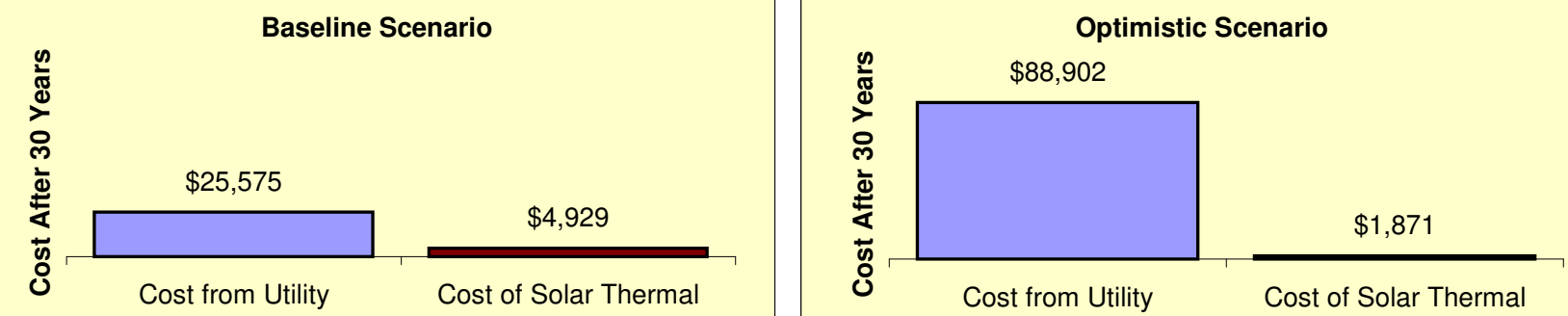

Break Even Year

14

Break Even Year

6

Notes: A hot water system should only be considered after exact amount of hot water use is verified.

\begin{tabular}{|c|c|c|c|c|c|}
\hline \multicolumn{3}{|c|}{ Wind } & \multicolumn{3}{|c|}{$\begin{array}{l}\text { Size of System }(\mathrm{kW}) \\
\text { Annual Energy Production }(\mathrm{kWh})\end{array}$} \\
\hline \multicolumn{3}{|c|}{$\$ 0$ Baseline Scenario } & \multicolumn{3}{|c|}{ Optimistic Scenario } \\
\hline 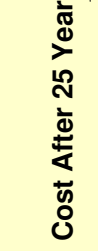 & Cost from Utility & Cost of Wind System & 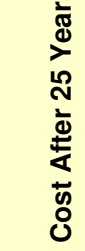 & Cost from Utility & Cost of Wind System \\
\hline $\begin{array}{l}\text { Estima } \\
\text { Notes: }\end{array}$ & Grant Amount & Even: & Break & n Year & \\
\hline
\end{tabular}

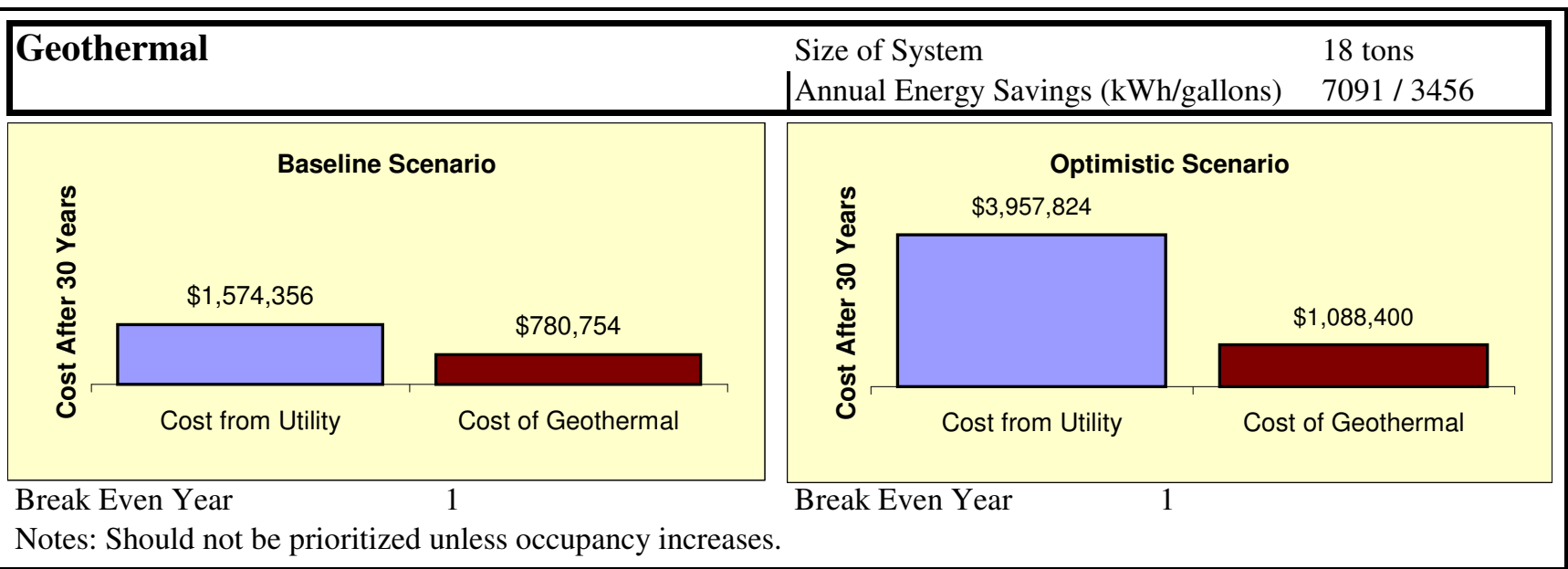




\begin{tabular}{|lcll|}
\hline \multicolumn{2}{|l}{ Facility - Judicial building } & Space Heating System & furnace \\
Area $\left(\mathrm{ft}^{2}\right)$ & 5,000 & Space Cooling System & DX \\
Occupany Schedule & & Water Heating System & unknown \\
\hline
\end{tabular}

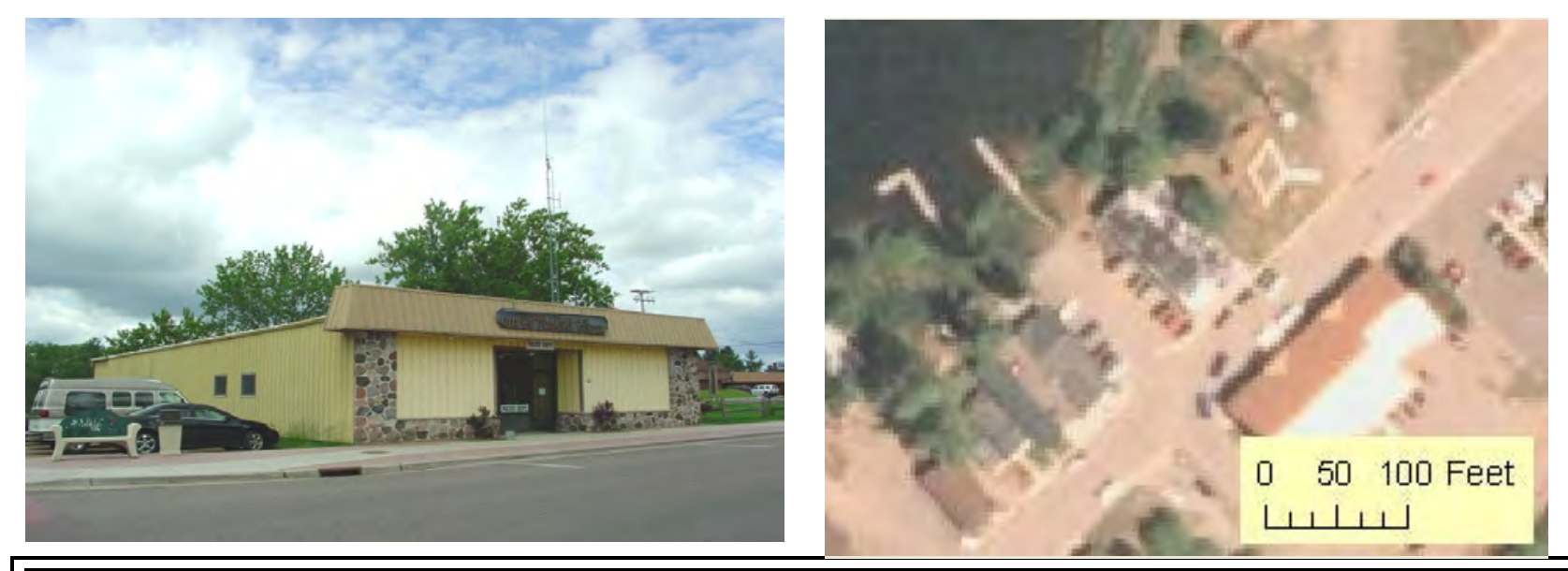

Energy Profile (2007)

\begin{tabular}{|c|c|c|c|}
\hline Electricity & Total & Rank & $\begin{array}{l}\text { Percent } \\
\text { of Tribe }\end{array}$ \\
\hline $\begin{array}{c}\text { Consumption kWh } \\
\text { (Cost) }\end{array}$ & $\begin{array}{l}\mathbf{7 3 , 2 7 2} \\
\$ 8,300 \\
\end{array}$ & 14 & $0.6 \%$ \\
\hline $\begin{array}{c}\text { Electricity Intensity } \\
\left(\text { Cost } / \mathrm{ft}^{2}\right)\end{array}$ & $\begin{array}{r}50.0 \\
\$ 1.66\end{array}$ & 7 & \\
\hline Energy Charge (kWh) & $\$ 0.109$ & & \\
\hline Demand Charge $(\mathrm{kW})$ & $\$ 0.00$ & & \\
\hline
\end{tabular}

\begin{tabular}{|c|c|c|c|}
\hline Propane & Total & Rank & $\begin{array}{l}\text { Percent } \\
\text { of Tribe }\end{array}$ \\
\hline $\begin{array}{c}\text { Consumption gal } \\
\text { (Cost) }\end{array}$ & $\begin{array}{r}\mathbf{2 , 3 1 7} \\
\$ 3,383 \\
\end{array}$ & 18 & $0.6 \%$ \\
\hline $\begin{array}{c}\text { Propane Intensity } \\
\left(\text { Cost } / \mathbf{f t}^{2}\right)\end{array}$ & $\begin{array}{r}42.3 \\
\$ 0.68 \\
\end{array}$ & 14 & \\
\hline Propane Cost (gal) & & $\$ 1.46$ & \\
\hline
\end{tabular}
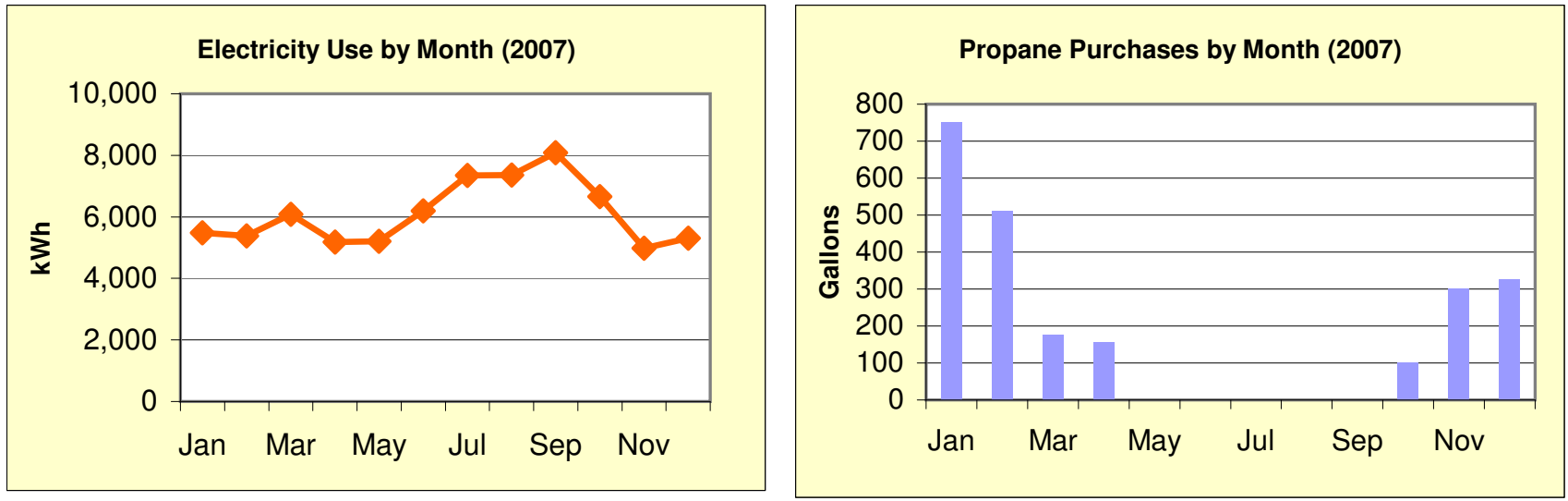

\section{WPS Electric Accounts}

\section{Energy Efficiency Recommendations}

\begin{tabular}{|l|l|r|r|}
\hline \multicolumn{1}{|c|}{ Type } & Rate & $\begin{array}{c}\text { 2007 Use } \\
\text { (kWh) }\end{array}$ & 2007 Cost \\
\hline Main & CG-1 & 73,272 & $\$ 7,878$ \\
\hline Outdoor lighting & GY-3 & & $\$ 421$ \\
\hline & & & \\
\hline & & & \\
\hline & & & \\
\hline & & & \\
\hline & & & \\
\hline
\end{tabular}

\begin{tabular}{|l|l|l|l|}
\hline Recommendation & $\begin{array}{c}\text { Cost to } \\
\text { Install }\end{array}$ & $\begin{array}{c}\text { Annual } \\
\text { kWh } \\
\text { Savings }\end{array}$ & $\begin{array}{c}\text { Simple Payback } \\
\text { (yrs) }\end{array}$ \\
\hline & & & \\
\hline Install lighting occupancy sensors \\
\hline Seal building shell leaks \\
\hline Change HVAC filters monthly \\
\hline Install programmable set-back thermostat \\
\hline Turn off vending machine lights \\
\hline Upgrade Lamps and Ballasts to T8 \\
\hline
\end{tabular}




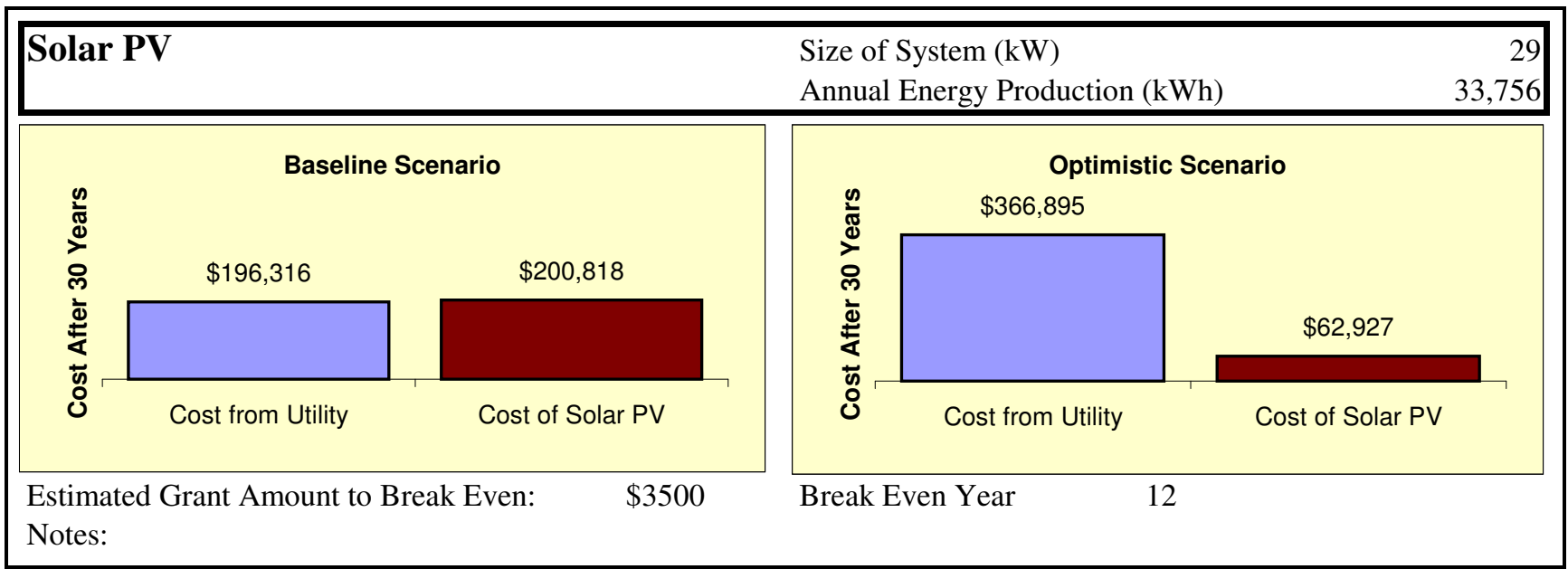

\begin{tabular}{|c|c|c|}
\hline \multicolumn{3}{|c|}{ Solar Hot Water } \\
\hline \multicolumn{3}{|c|}{$\$ 0$ Baseline Scenario } \\
\hline 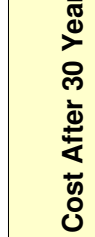 & Cost from Utility & Cost of Solar Thermal \\
\hline
\end{tabular}

Break Even Year

0

Size of System (Sq. feet)

Annual Energy Production ()

Notes: Recommended future review

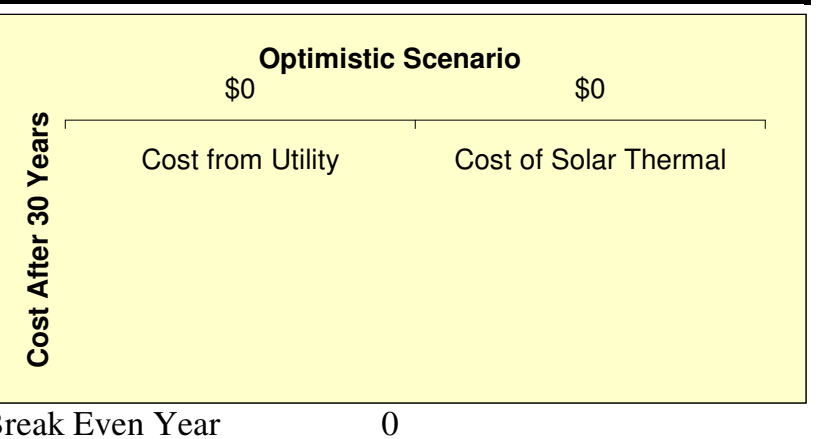

Notes: Recommended future review

\begin{tabular}{|c|c|c|c|c|c|}
\hline \multicolumn{3}{|c|}{ Wind } & \multicolumn{3}{|c|}{$\begin{array}{l}\text { Size of System (kW) } \\
\text { Annual Energy Production (kWh) }\end{array}$} \\
\hline \multicolumn{3}{|c|}{ Baseline Scenario } & \multicolumn{3}{|c|}{$\$ 0$ Optimistic Scenario } \\
\hline 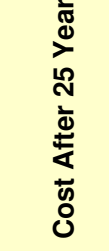 & Cost from Utility & Cost of Wind System & 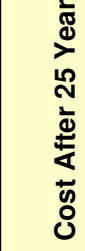 & Cost from Utility & Cost of Wind System \\
\hline $\begin{array}{l}\text { Estimat } \\
\text { Notes: }\end{array}$ & Grant Amount & Even: & Break & Year & \\
\hline
\end{tabular}

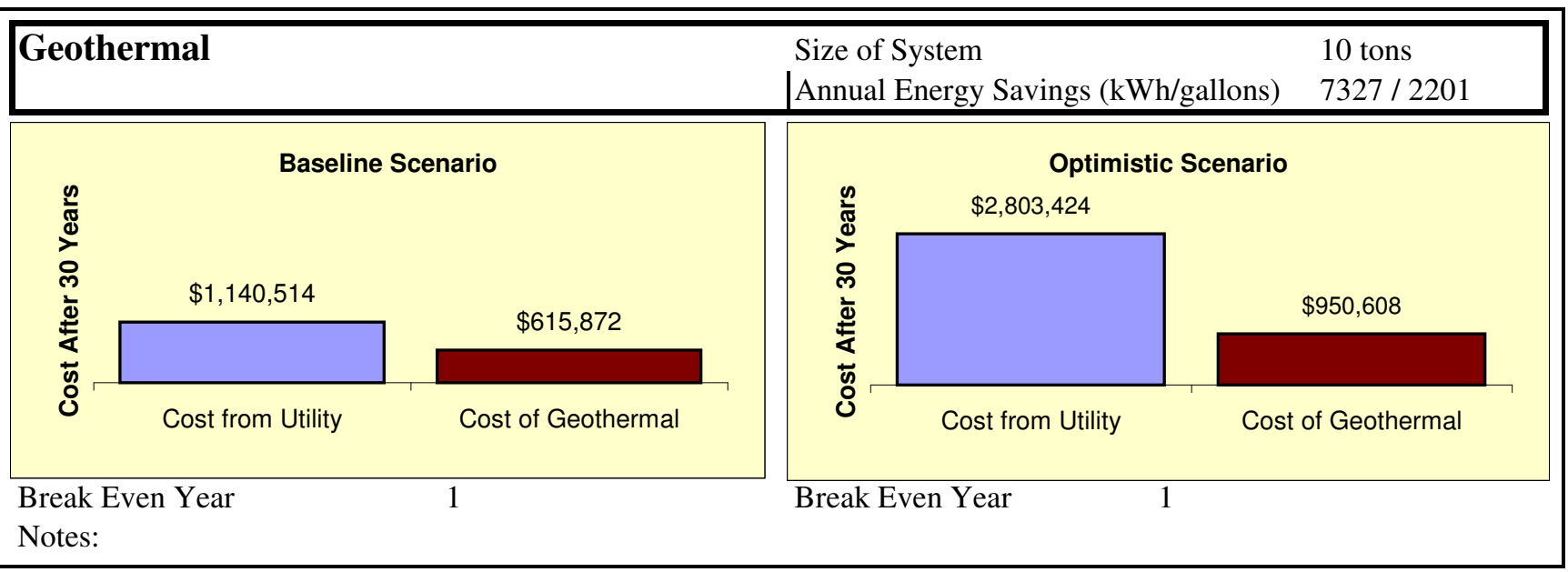




\begin{tabular}{|lcll|}
\hline Facility - Indian Bowl & Space Heating System & Furnace \\
Area $\left(\mathrm{ft}^{2}\right)$ & 5,250 & Space Cooling System & DX \\
Occupany Schedule & Water Heating System & unknown \\
\hline
\end{tabular}

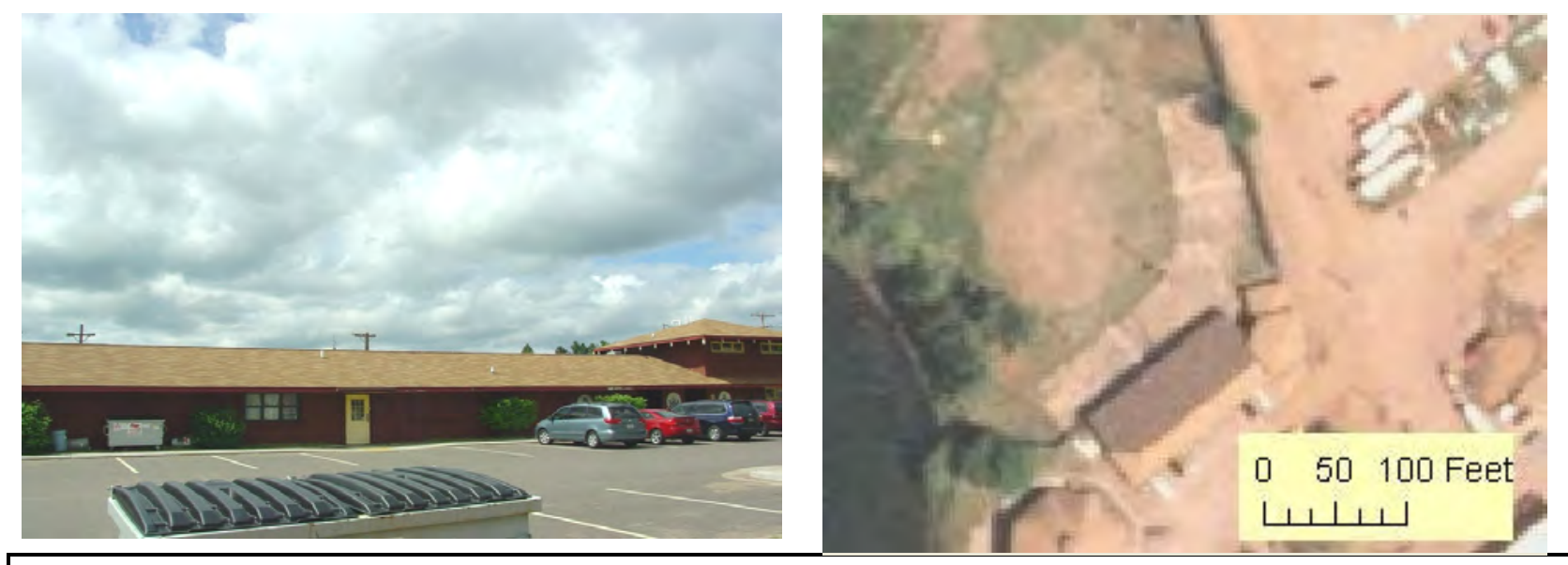

Energy Profile (2007)

\begin{tabular}{|c|c|c|c|}
\hline Electricity & Total & Rank & $\begin{array}{l}\text { Percent } \\
\text { of Tribe }\end{array}$ \\
\hline $\begin{array}{c}\text { Consumption kWh } \\
\text { (Cost) }\end{array}$ & $\begin{array}{l}\mathbf{3 9 , 4 8 0} \\
\$ 4,407\end{array}$ & 20 & $0.3 \%$ \\
\hline $\begin{array}{c}\text { Electricity Intensity } \\
\left(\operatorname{Cost} / \mathrm{ft}^{2}\right)\end{array}$ & $\begin{array}{r}25.7 \\
\$ 0.84\end{array}$ & 20 & \\
\hline $\begin{array}{l}\text { Energy Charge }(\mathrm{kWh}) \\
\text { Demand Charge }(\mathrm{kW})\end{array}$ & \begin{tabular}{r|}
$\$ 0.109$ \\
$\$ 0.00$
\end{tabular} & & \\
\hline
\end{tabular}

\begin{tabular}{|c|c|c|c|}
\hline Propane & Total & Rank & $\begin{array}{l}\text { Percent } \\
\text { of Tribe }\end{array}$ \\
\hline $\begin{array}{c}\text { Consumption gal } \\
\text { (Cost) }\end{array}$ & $\begin{array}{r}\mathbf{3 , 1 7 0} \\
\$ 4,628 \\
\end{array}$ & 14 & $0.8 \%$ \\
\hline $\begin{array}{c}\text { Propane Intensity } \\
\left(\text { Cost } / \mathbf{f t}^{2}\right)\end{array}$ & $\begin{array}{r}55.1 \\
\$ 0.88 \\
\end{array}$ & 9 & \\
\hline Propane Cost (gal) & & $\$ 1.46$ & \\
\hline
\end{tabular}
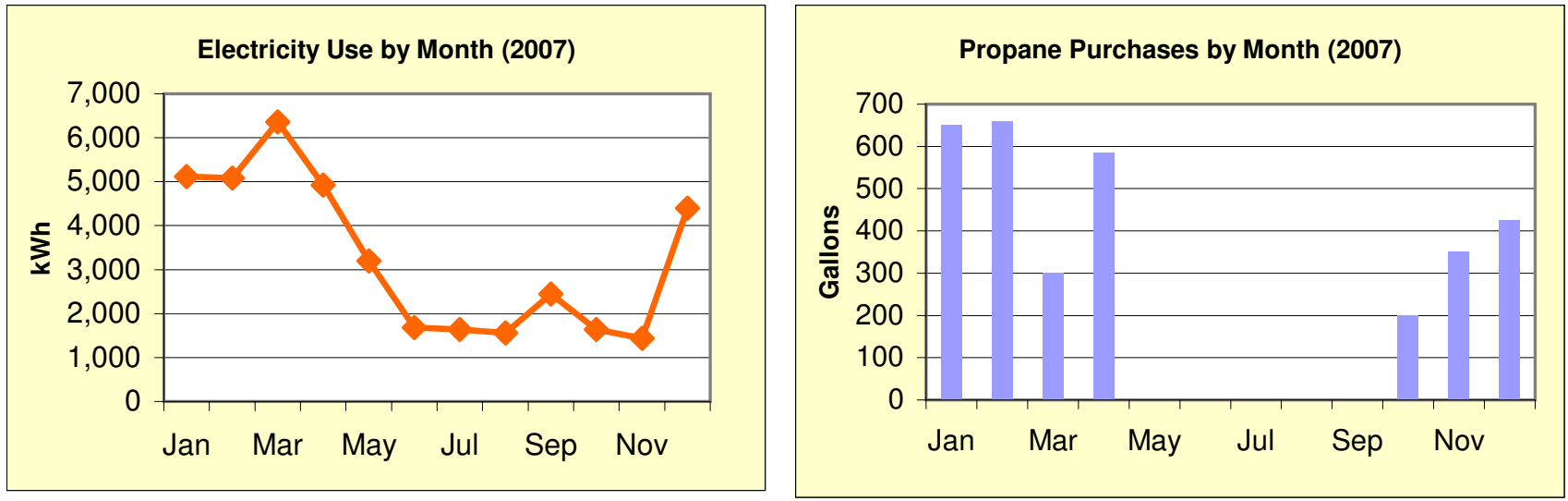

\section{WPS Electric Accounts}

\section{Energy Efficiency Recommendations}

\begin{tabular}{|l|l|r|r|}
\hline \multicolumn{1}{|c|}{ Type } & \multicolumn{1}{c|}{ Rate } & $\begin{array}{c}\text { 2007 Use } \\
\text { (kWh) }\end{array}$ & 2007 Cost \\
\hline Main & CG-1 & 39,480 & $\$ 4,278$ \\
\hline Main & CG-1 & & $\$ 129$ \\
\hline Outdoor lighting & CG-1 & & \\
\hline Outdoor lighting & CG-1 & & \\
\hline Outdoor lighting & GY-3 & & \\
\hline & & & \\
\hline & & & \\
\hline
\end{tabular}

\begin{tabular}{|l|c|c|c|}
\hline Recommendation & $\begin{array}{c}\text { Cost to } \\
\text { Install }\end{array}$ & $\begin{array}{c}\text { Annual } \\
\mathbf{k W h} \\
\text { Savings }\end{array}$ & $\begin{array}{c}\text { Simple Payback } \\
\text { (yrs) }\end{array}$ \\
\hline & & & \\
\hline Energy audit recommended \\
\hline \multicolumn{3}{|l|}{} \\
\hline
\end{tabular}




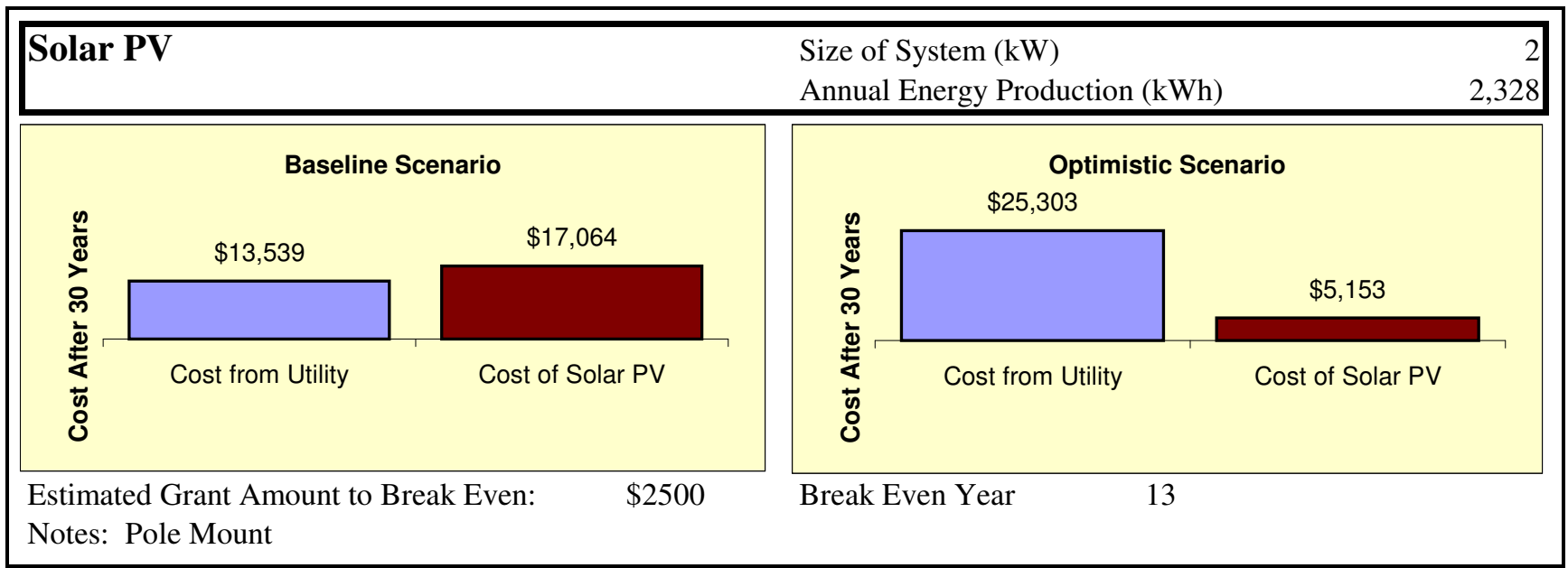

\begin{tabular}{|c|c|c|}
\hline Solai & ot Water & \\
\hline & $\$ 0$ Baseli & nario \\
\hline 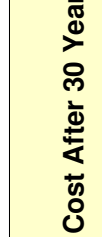 & Cost from Utility & Cost of Solar Thermal \\
\hline
\end{tabular}

Break Even Year

0

Size of System (Sq. feet)

Annual Energy Production ()

Notes: Recommended future review

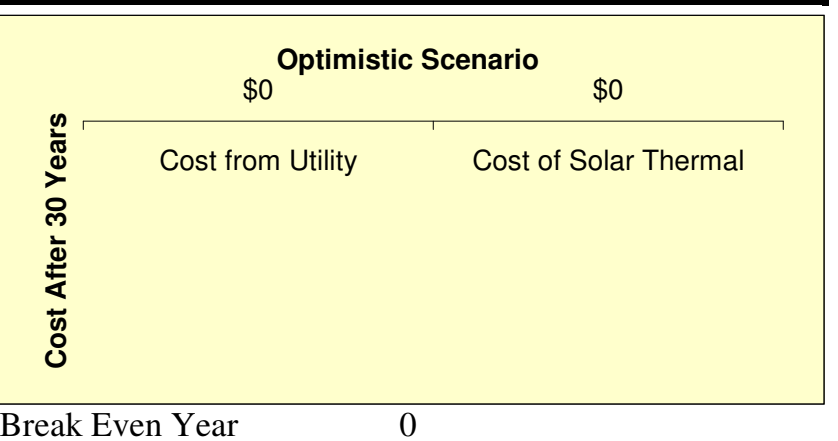

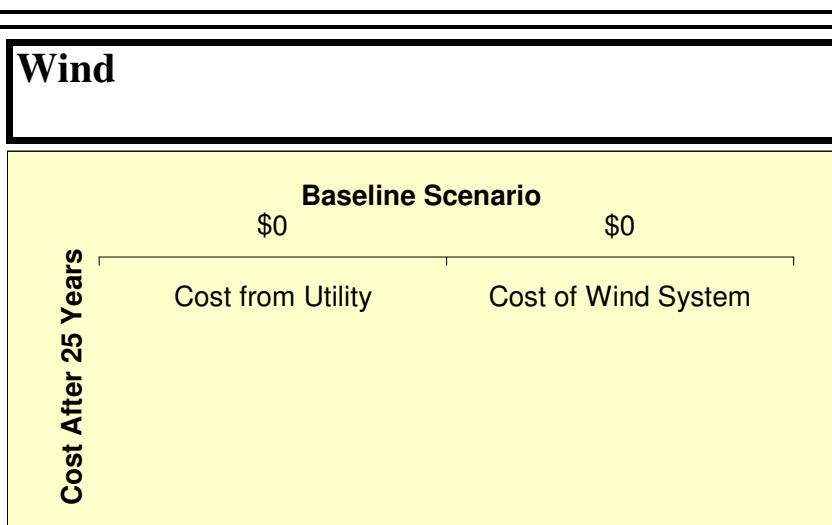

Estimated Grant Amount to Break Even:

$\$ 0$

Size of System $(\mathrm{kW})$

Annual Energy Production (kWh)

Notes: N/A

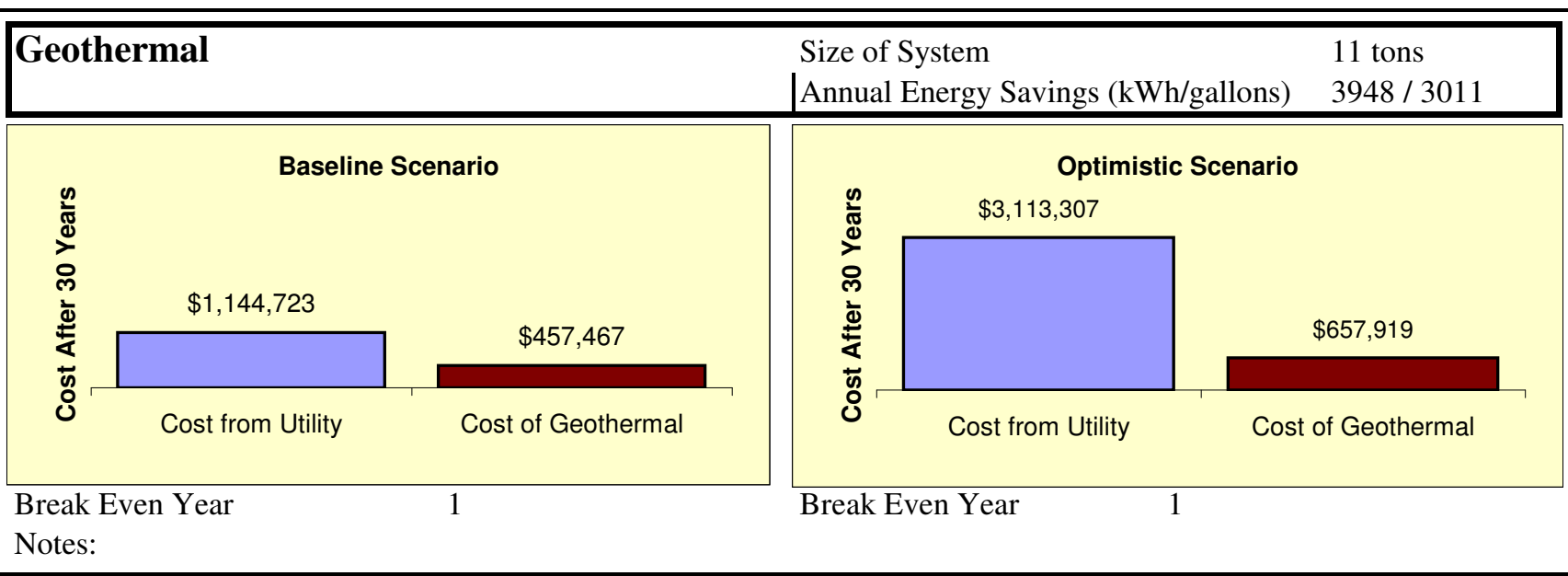




\begin{tabular}{|llll|}
\hline Facility - Gas Station & Space Heating System & unknown \\
Area $\left(\mathrm{ft}^{2}\right)$ & 768 & Space Cooling System & unknown \\
Occupany Schedule & $7 \mathrm{am}-7 \mathrm{pm}$ & Water Heating System & unknown \\
\hline
\end{tabular}

Image not available

050100 Feet

لــــــ

\begin{tabular}{|c|c|c|c|}
\hline \multicolumn{4}{|c|}{ Energy Profile (2007) } \\
\hline Electricity & Total & Rank & $\begin{array}{l}\text { Percent } \\
\text { of Tribe }\end{array}$ \\
\hline $\begin{array}{c}\text { Consumption kWh } \\
\text { (Cost) }\end{array}$ & $\begin{array}{r}\mathbf{9 3 , 1 8 3} \\
\$ 10,139\end{array}$ & 12 & $0.8 \%$ \\
\hline $\begin{array}{c}\text { Electricity Intensity } \\
\left(\text { Cost } / \mathrm{ft}^{2}\right)\end{array}$ & $\begin{array}{r}414.0 \\
\$ 13.20\end{array}$ & 1 & \\
\hline $\begin{array}{l}\text { Energy Charge }(\mathrm{kWh}) \\
\text { Demand Charge }(\mathrm{kW})\end{array}$ & $\begin{array}{r}\$ 0.109 \\
\$ 0.00 \\
\end{array}$ & & \\
\hline
\end{tabular}

\begin{tabular}{|c|c|c|c|}
\hline Propane & Total & Rank & $\begin{array}{l}\text { Percent } \\
\text { of Tribe }\end{array}$ \\
\hline $\begin{array}{c}\text { Consumption gal } \\
\text { (Cost) }\end{array}$ & $\begin{array}{r}\mathbf{5 2 5} \\
\$ 767\end{array}$ & 21 & $0.1 \%$ \\
\hline $\begin{array}{c}\text { Propane Intensity } \\
\left(\text { Cost } / \mathrm{ft}^{2}\right)\end{array}$ & $\begin{array}{r}62.4 \\
\$ 1.00\end{array}$ & 6 & \\
\hline Propane Cost (gal) & & $\$ 1.46$ & \\
\hline
\end{tabular}
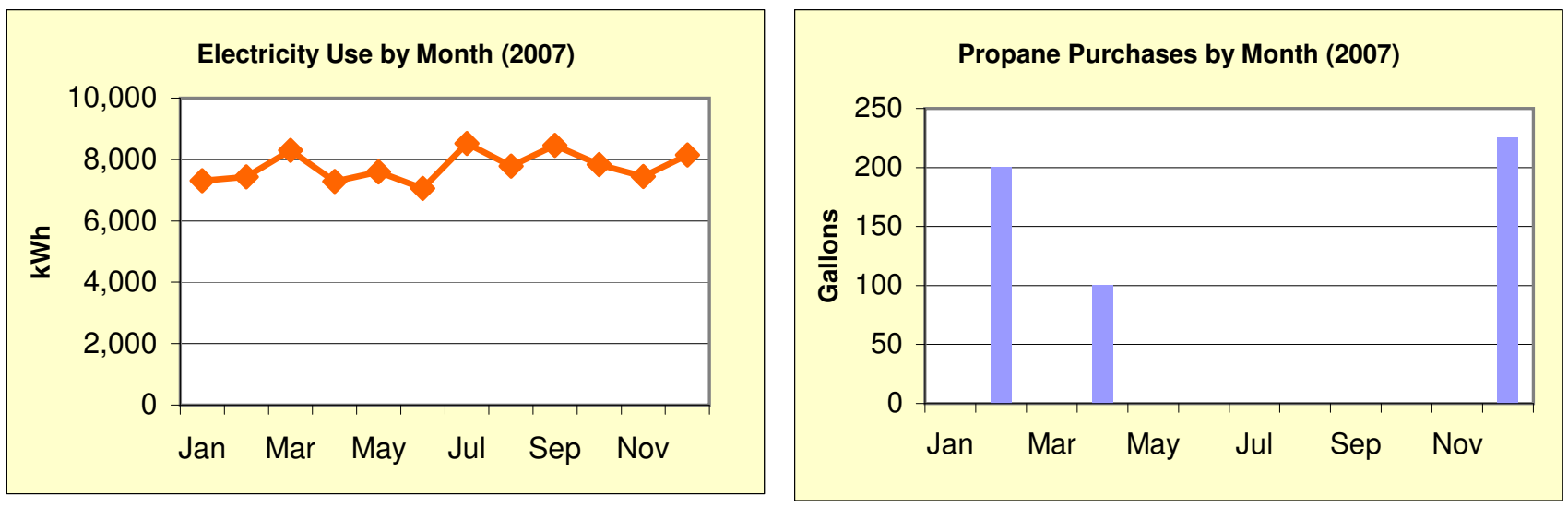

\section{WPS Electric Accounts}

\section{Energy Efficiency Recommendations}

\begin{tabular}{|l|l|r|r|}
\hline \multicolumn{1}{|c|}{ Type } & \multicolumn{1}{c|}{ Rate } & $\begin{array}{c}\text { 2007 Use } \\
\text { (kWh) }\end{array}$ & 2007 Cost \\
\hline Main & CG-1 & 85,674 & $\$ 9,201$ \\
\hline Road sign & CG-1 & 7,509 & $\$ 938$ \\
\hline & & & \\
\hline & & & \\
\hline & & & \\
\hline & & & \\
\hline & & & \\
\hline
\end{tabular}

\begin{tabular}{|l|c|c|c|}
\hline Recommendation & $\begin{array}{c}\text { Cost to } \\
\text { Install }\end{array}$ & $\begin{array}{c}\text { Annual } \\
\mathbf{k W h} \\
\text { Savings }\end{array}$ & $\begin{array}{c}\text { Simple Payback } \\
\text { (yrs) }\end{array}$ \\
\hline Decrease light use & & 36474 & \\
\hline T8 Lighting upgrade \\
\hline Install programmable, set-back thermostat \\
\hline Clean HVAC system \\
\hline Insulate exposed piping \\
\hline Occupancy light sensors \\
\hline
\end{tabular}




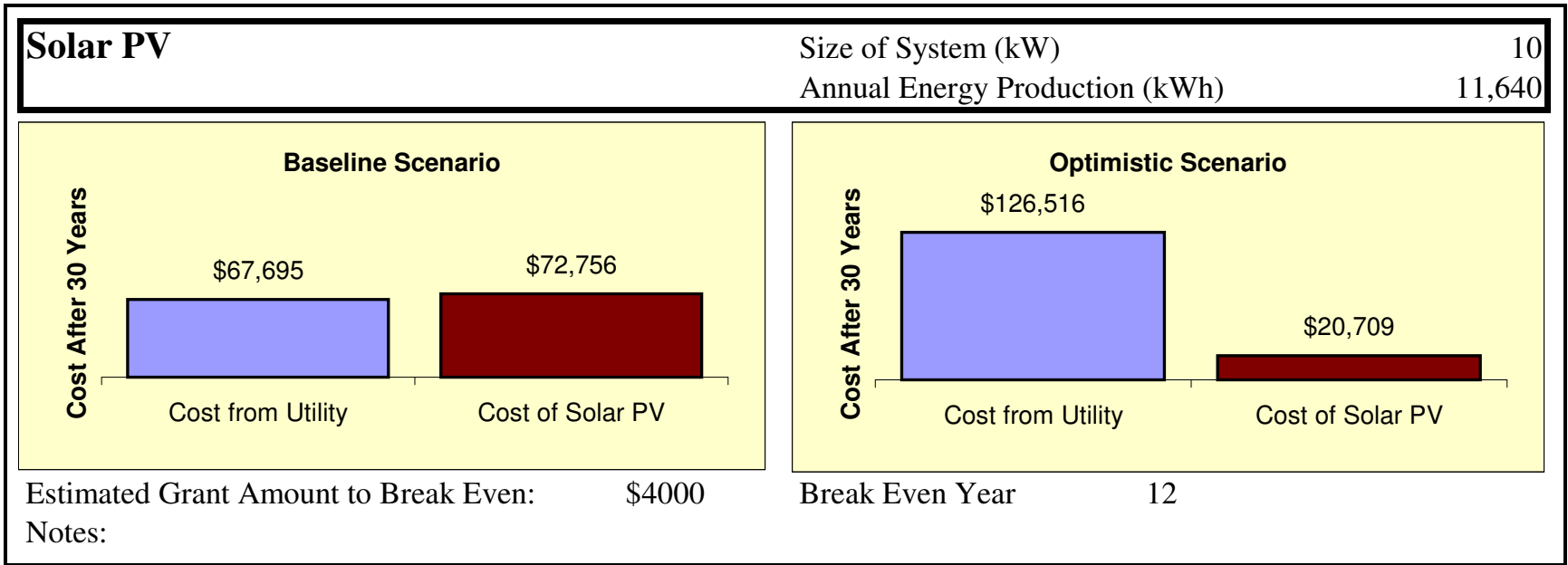

\begin{tabular}{|c|c|c|}
\hline \multicolumn{3}{|c|}{ Solar Hot Water } \\
\hline \multirow[b]{2}{*}{ 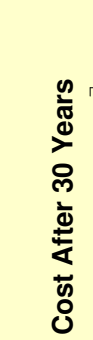 } & $\$ 0{ }^{\text {Basel }}$ & nario \\
\hline & Cost from Utility & Cost of Solar Thermal \\
\hline
\end{tabular}

Break Even Year

0

Size of System (Sq. feet)

Annual Energy Production ()

Notes: Recommended future review

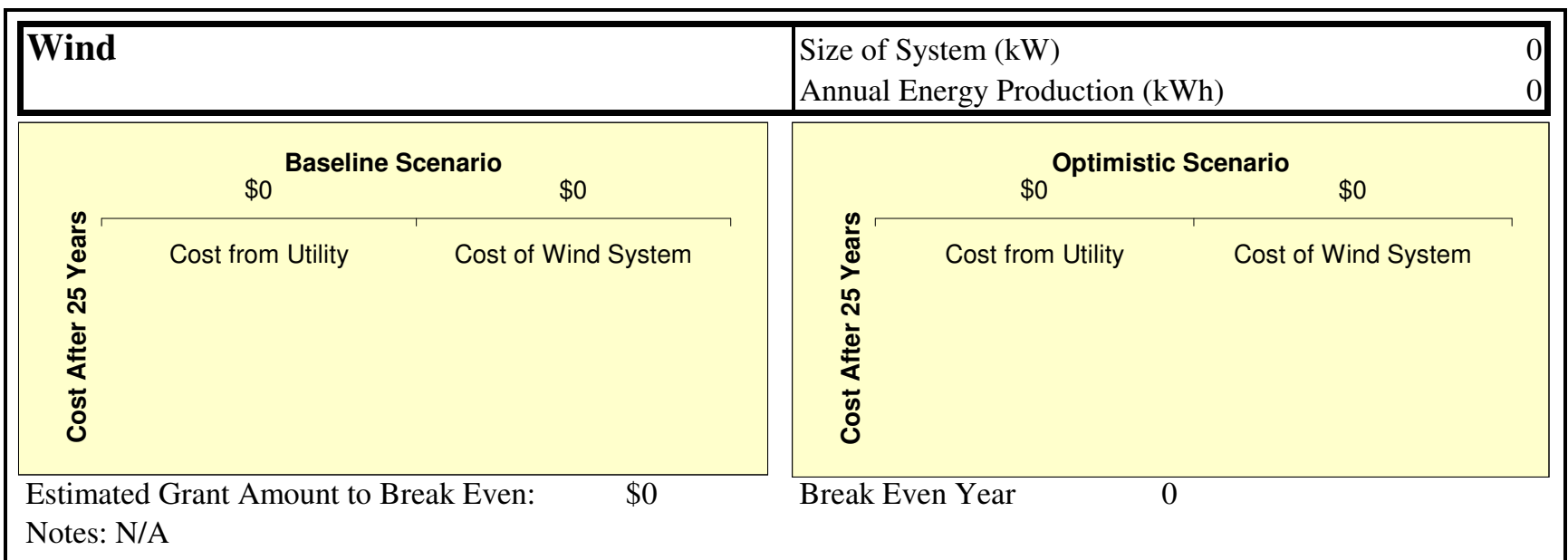

\begin{tabular}{|c|c|c|c|c|c|c|}
\hline \multicolumn{3}{|c|}{ Geothermal } & \multicolumn{3}{|c|}{$\begin{array}{l}\text { Size of System } \\
\text { Annual Energy Savings (kWh/gallons) }\end{array}$} & $\begin{array}{l}0 \\
0 / 0\end{array}$ \\
\hline \multicolumn{3}{|c|}{$\$ 0$ Baseline Scenario } & \multicolumn{4}{|c|}{ Optimistic Scenario } \\
\hline 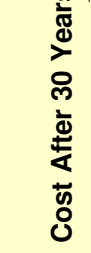 & Cost from Utility & Cost of Geothermal & 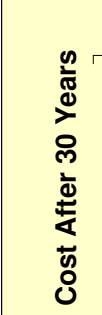 & Cost from Utility & \multicolumn{2}{|c|}{ Cost of Geothermal } \\
\hline $\begin{array}{l}\text { Break } \\
\text { Notes }\end{array}$ & $\begin{array}{l}\text { Year } \\
\text { a priority }\end{array}$ & 0 & \multicolumn{4}{|c|}{ Break Even Year $\quad 0$} \\
\hline
\end{tabular}




\begin{tabular}{|c|c|c|}
\hline Facility - Food Distribution Building & Space Heating System & unknown \\
\hline $\begin{array}{ll}\text { Area }\left(\mathrm{ft}^{2}\right) & 3,800 \\
\text { Occupany Schedule }\end{array}$ & $\begin{array}{l}\text { Space Cooling System } \\
\text { Water Heating System }\end{array}$ & $\begin{array}{l}\text { unknown } \\
\text { unknown }\end{array}$ \\
\hline
\end{tabular}

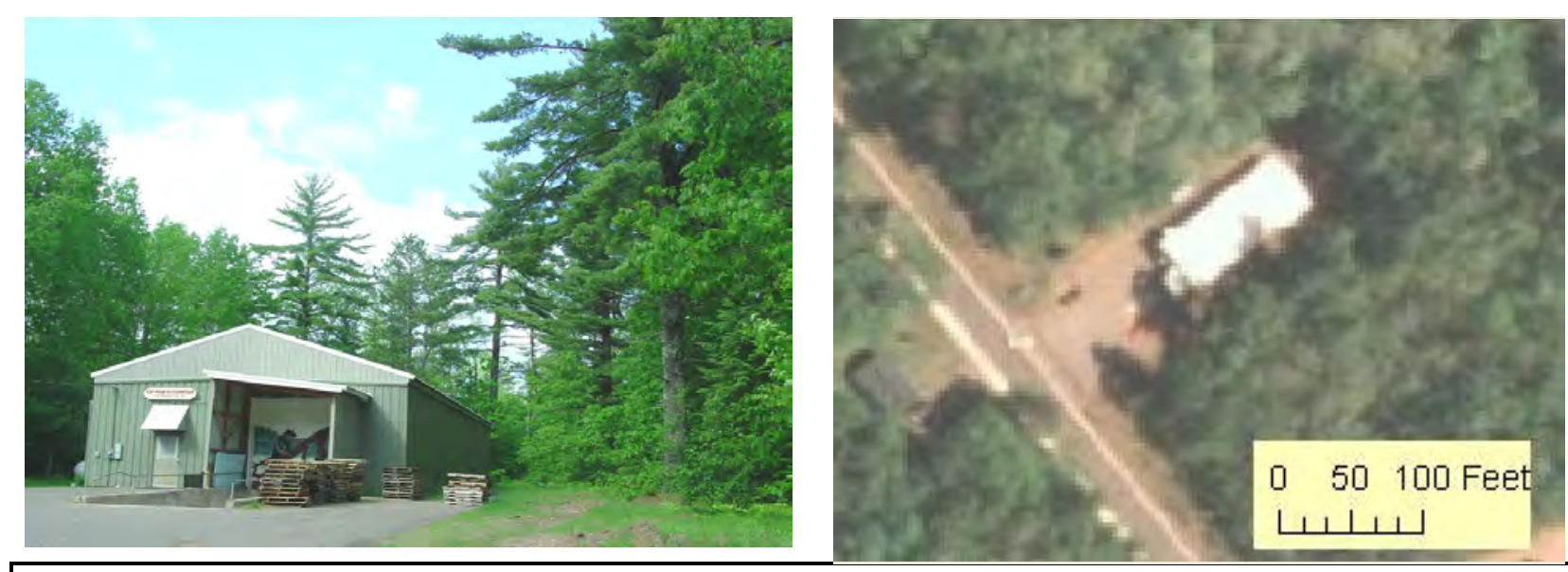

Energy Profile (2007)

\begin{tabular}{|c|c|c|c|}
\hline Electricity & Total & Rank & $\begin{array}{l}\text { Percent } \\
\text { of Tribe }\end{array}$ \\
\hline $\begin{array}{c}\text { Consumption kWh } \\
\text { (Cost) }\end{array}$ & $\begin{array}{l}\mathbf{3 1 , 9 7 2} \\
\$ 3,552\end{array}$ & 21 & $0.3 \%$ \\
\hline $\begin{array}{c}\text { Electricity Intensity } \\
\left(\text { Cost } / \mathbf{f t}^{2}\right)\end{array}$ & $\begin{array}{r}28.7 \\
\$ 0.93\end{array}$ & 16 & \\
\hline \begin{tabular}{|l} 
Energy Charge $(\mathrm{kWh})$ \\
Demand Charge $(\mathrm{kW})$
\end{tabular} & \begin{tabular}{r|}
$\$ 0.109$ \\
$\$ 0.00$
\end{tabular} & & \\
\hline
\end{tabular}

\begin{tabular}{|c|r|c|c|}
\hline Propane & Total & Rank & $\begin{array}{c}\text { Percent } \\
\text { of Tribe }\end{array}$ \\
\hline $\begin{array}{c}\text { Consumption gal } \\
\text { (Cost) }\end{array}$ & $\begin{array}{r}\mathbf{1 , 5 3 5} \\
\$ 2,241\end{array}$ & 20 & $0.4 \%$ \\
\hline $\begin{array}{c}\text { Propane Intensity } \\
\left.\text { (Cost/ft }^{2}\right)\end{array}$ & $\begin{array}{r}36.9 \\
\$ 0.59\end{array}$ & 17 & \multirow{2}{|c|}{$\$ 1.46$} \\
\cline { 1 - 2 } Propane Cost (gal) & \multicolumn{3}{|c|}{} \\
\cline { 1 - 2 }
\end{tabular}
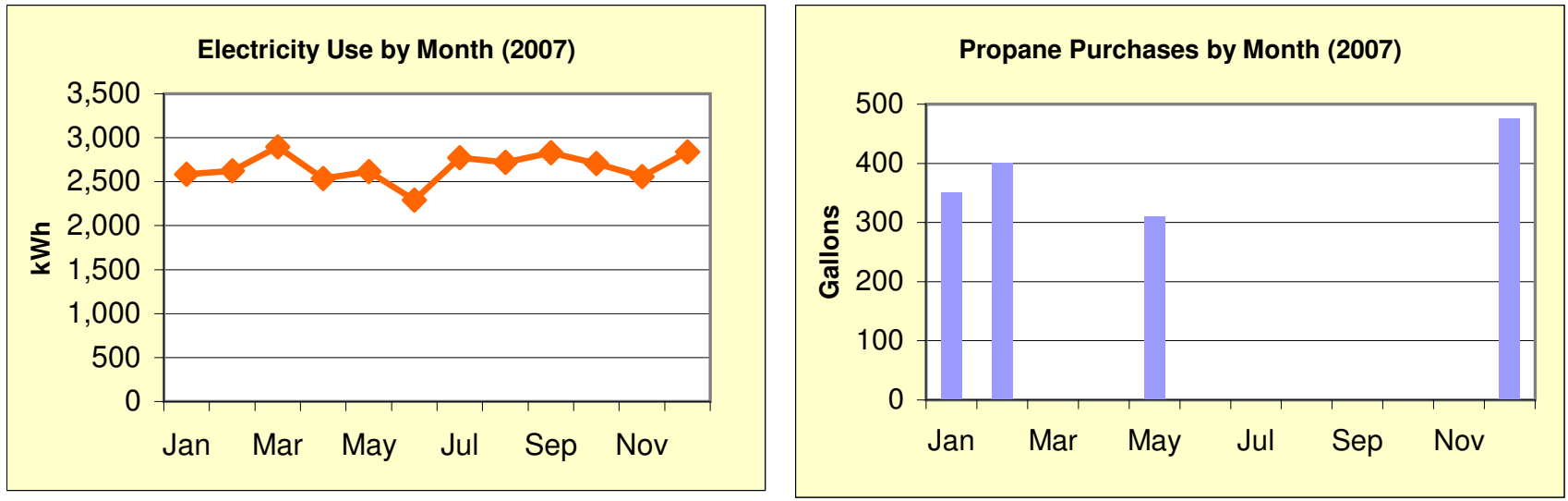

\section{WPS Electric Accounts}

\section{Energy Efficiency Recommendations}

\begin{tabular}{|l|l|c|r|}
\hline Type & Rate & $\begin{array}{c}\text { 2007 Use } \\
\text { (kWh) }\end{array}$ & 2007 Cost \\
\hline Main & CG-1 & 31,972 & $\$ 3,552$ \\
\hline & & & \\
\hline & & & \\
\hline & & & \\
\hline & & & \\
\hline & & & \\
\hline & & & \\
\hline
\end{tabular}

\begin{tabular}{|c|c|c|c|}
\hline Recommendation & $\begin{array}{l}\text { Cost to } \\
\text { Install }\end{array}$ & $\begin{array}{c}\text { Annual } \\
\text { kWh } \\
\text { Savings }\end{array}$ & $\begin{array}{c}\text { Simple Payback } \\
(\text { yrs })\end{array}$ \\
\hline \multicolumn{4}{|c|}{ Energy audit recommended } \\
\hline & & & \\
\hline & & & \\
\hline & & & \\
\hline & & & \\
\hline
\end{tabular}




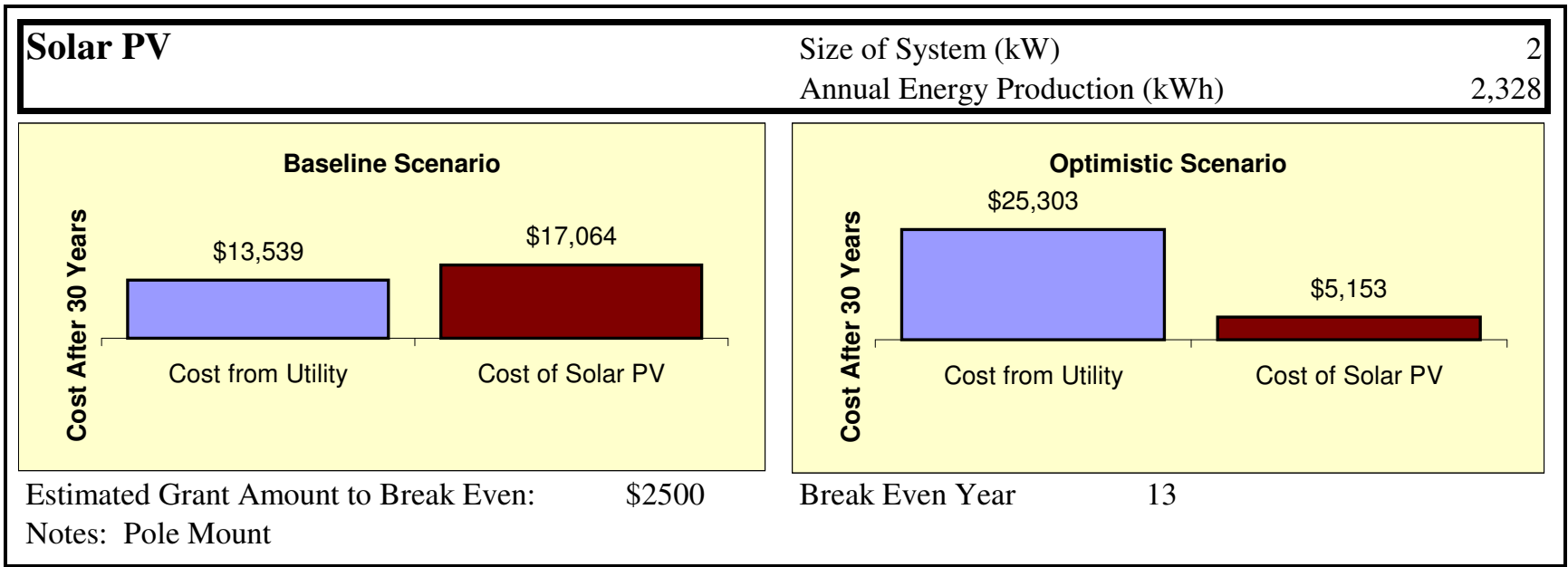

\begin{tabular}{|c|c|c|c|c|c|}
\hline \multicolumn{3}{|c|}{ Solar Hot Water } & \multicolumn{3}{|c|}{$\begin{array}{l}\text { Size of System (Sq. feet) } \\
\text { Annual Energy Production () }\end{array}$} \\
\hline \multicolumn{3}{|c|}{$\$ 0$ Baseline Scenario } & \multicolumn{3}{|c|}{$\$ 0$ Optimistic Scenario } \\
\hline 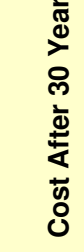 & Cost from Utility & Cost of Solar Thermal & 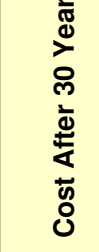 & Cost from Utility & Cost of Solar Thermal \\
\hline $\begin{array}{l}\text { Break } \\
\text { Notes }\end{array}$ & $\begin{array}{l}n \text { Year } \\
\text { a priority }\end{array}$ & 0 & Break & Year & \\
\hline
\end{tabular}

\begin{tabular}{|c|c|c|c|c|c|}
\hline \multicolumn{3}{|c|}{ Wind } & \multicolumn{3}{|c|}{$\begin{array}{l}\text { Size of System }(\mathrm{kW}) \\
\text { Annual Energy Production }(\mathrm{kWh})\end{array}$} \\
\hline \multirow[b]{2}{*}{ 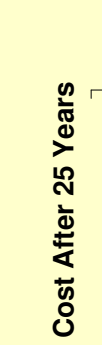 } & $\$ 0{ }^{\text {Basel }}$ & nario & \multirow[b]{2}{*}{ 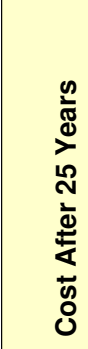 } & \multicolumn{2}{|c|}{ Optimistic Scenario } \\
\hline & Cost from Utility & Cost of Wind System & & Cost from Utility & Cost of Wind System \\
\hline $\begin{array}{l}\text { Estima } \\
\text { Notes: }\end{array}$ & Grant Amount & k Even: & Break & Year & \\
\hline
\end{tabular}

\begin{tabular}{|c|c|c|c|c|c|c|}
\hline \multicolumn{3}{|c|}{ Geothermal } & $\begin{array}{l}\text { Size o } \\
\text { Annua }\end{array}$ & $\begin{array}{l}\text { tem } \\
\text { ergy Savings }(k\end{array}$ & ons) & $\begin{array}{l}0 \\
0 / 0\end{array}$ \\
\hline \multicolumn{3}{|c|}{$\$ 0$ Baseline Scenario } & \multicolumn{4}{|c|}{ Optimistic Scenario } \\
\hline 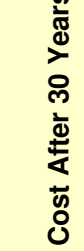 & Cost from Utility & Cost of Geothermal & 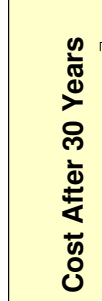 & Cost from Utility & \multicolumn{2}{|c|}{ Cost of Geothermal } \\
\hline \multicolumn{3}{|c|}{$\begin{array}{l}\text { Break Even Year } \\
\text { Notes: Not a priority }\end{array}$} & \multicolumn{2}{|c|}{ Break Even Year } & & \\
\hline
\end{tabular}




\begin{tabular}{|llll|}
\hline Facility - Family Resource Center & Space Heating System & unknown \\
Area $\left(\mathrm{ft}^{2}\right)$ & 5,988 & Space Cooling System & unknown \\
Occupany Schedule & M-F 7am-9pm & Water Heating System & unknown \\
\hline
\end{tabular}

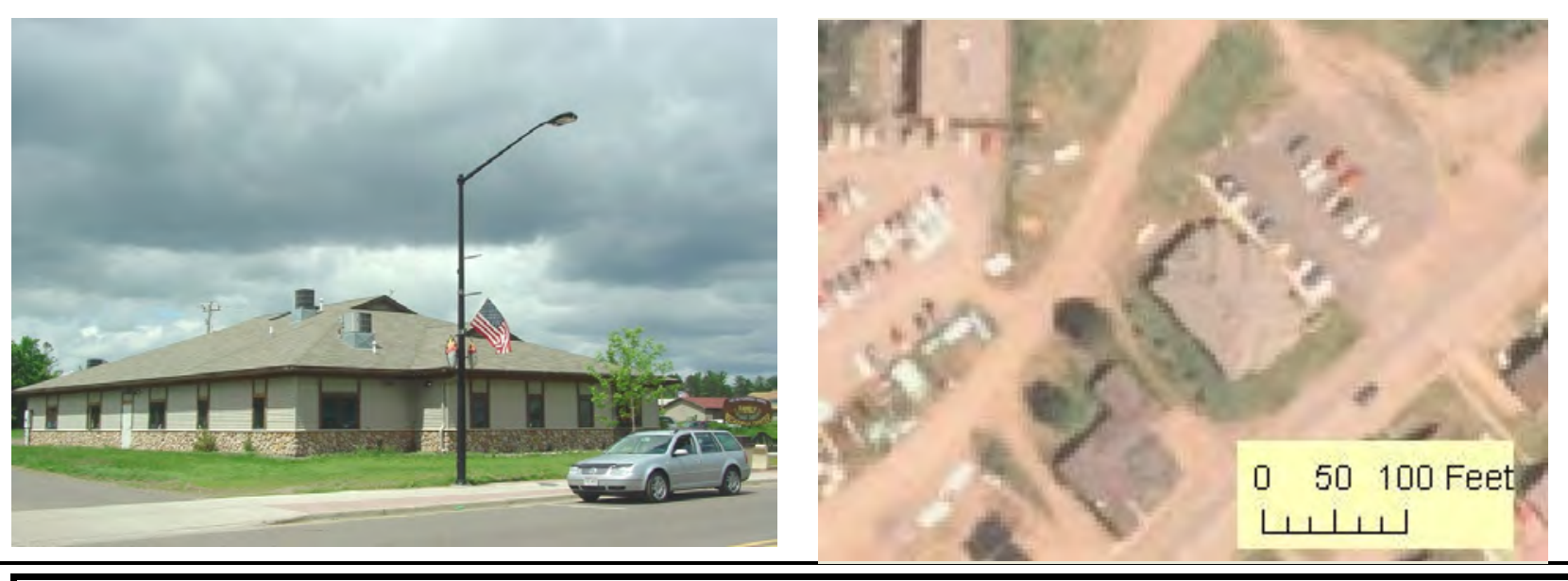

Energy Profile (2007)

\begin{tabular}{|c|c|c|c|}
\hline Electricity & Total & Rank & $\begin{array}{l}\text { Percent } \\
\text { of Tribe }\end{array}$ \\
\hline $\begin{array}{c}\text { Consumption kWh } \\
\text { (Cost) }\end{array}$ & $\begin{array}{l}\mathbf{4 7 , 4 6 6} \\
\$ 5,485 \\
\end{array}$ & 18 & $0.4 \%$ \\
\hline $\begin{array}{c}\text { Electricity Intensity } \\
\left(\text { Cost } / \mathrm{ft}^{2}\right)\end{array}$ & $\begin{array}{r}27.0 \\
\$ 0.92\end{array}$ & 18 & \\
\hline \begin{tabular}{|l} 
Energy Charge $(\mathrm{kWh})$ \\
Demand Charge $(\mathrm{kW})$
\end{tabular} & \begin{tabular}{r|}
$\$ 0.109$ \\
$\$ 0.00$
\end{tabular} & & \\
\hline
\end{tabular}

\begin{tabular}{|c|c|c|c|}
\hline Propane & Total & Rank & $\begin{array}{l}\text { Percent } \\
\text { of Tribe }\end{array}$ \\
\hline $\begin{array}{c}\text { Consumption gal } \\
\text { (Cost) }\end{array}$ & $\begin{array}{r}\mathbf{2 , 8 0 0} \\
\$ 4,088 \\
\end{array}$ & 16 & $0.7 \%$ \\
\hline $\begin{array}{c}\text { Propane Intensity } \\
\left(\text { Cost } / \mathrm{ft}^{2}\right)\end{array}$ & $\begin{array}{r}42.7 \\
\$ 0.68 \\
\end{array}$ & 13 & \\
\hline Propane Cost (gal) & & $\$ 1.46$ & \\
\hline
\end{tabular}
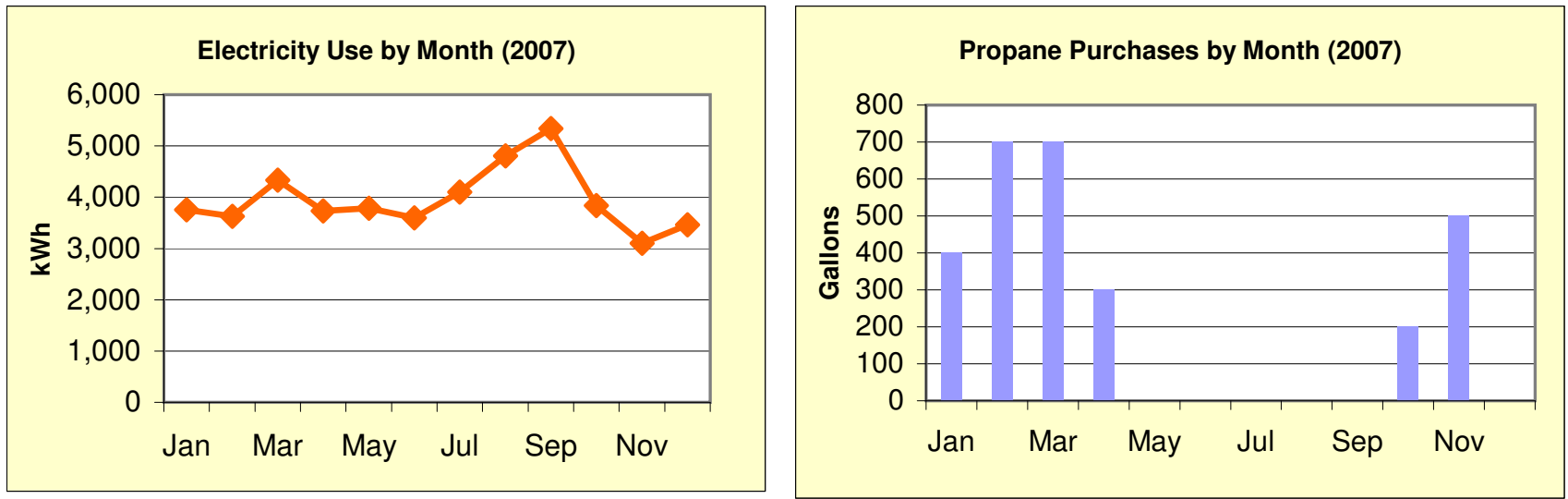

\section{WPS Electric Accounts}

\section{Energy Efficiency Recommendations}

\begin{tabular}{|l|l|r|r|}
\hline \multicolumn{1}{|c|}{ Type } & Rate & $\begin{array}{c}\text { 2007 Use } \\
\text { (kWh) }\end{array}$ & 2007 Cost \\
\hline Main & CG-1 & 47,466 & $\$ 5,179$ \\
\hline Outdoor lighting & GY-1 & & $\$ 306$ \\
\hline & & & \\
\hline & & & \\
\hline & & & \\
\hline & & & \\
\hline & & & \\
\hline
\end{tabular}

\begin{tabular}{|c|c|c|c|}
\hline Recommendation & $\begin{array}{l}\text { Cost to } \\
\text { Install }\end{array}$ & $\begin{array}{c}\text { Annual } \\
\text { kWh } \\
\text { Savings }\end{array}$ & $\begin{array}{c}\text { Simple Payback } \\
\text { (yrs) }\end{array}$ \\
\hline \multicolumn{4}{|l|}{ Occupancy sensors } \\
\hline \multicolumn{4}{|c|}{ Seal building shell and doors } \\
\hline \multicolumn{4}{|c|}{ Correctly program thermostat } \\
\hline \multicolumn{4}{|c|}{ Change furnace filters regularly } \\
\hline \multicolumn{4}{|c|}{ Insulate hot water pipes } \\
\hline \multicolumn{4}{|c|}{ Set water heater to lowest setting } \\
\hline \multicolumn{4}{|c|}{ Turn off vending machine light } \\
\hline
\end{tabular}




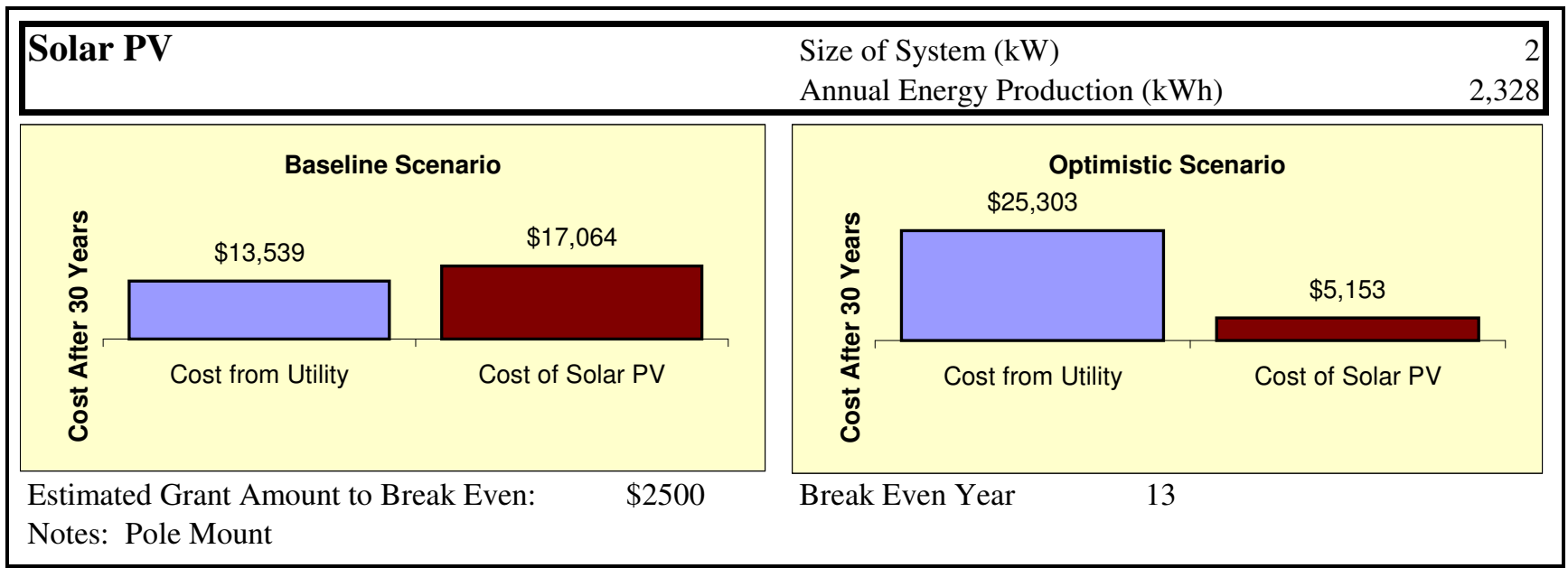

Solar Hot Water

Size of System (Sq. feet)

Annual Energy Production ()

\begin{tabular}{|c|c|c|}
\hline \multicolumn{3}{|c|}{ Baseline Scenario } \\
\hline 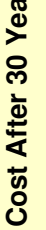 & Cost from Utility & Cost of Solar Thermal \\
\hline
\end{tabular}

Break Even Year

0

Break Even Year Optimistic Scenario $\$ 0$

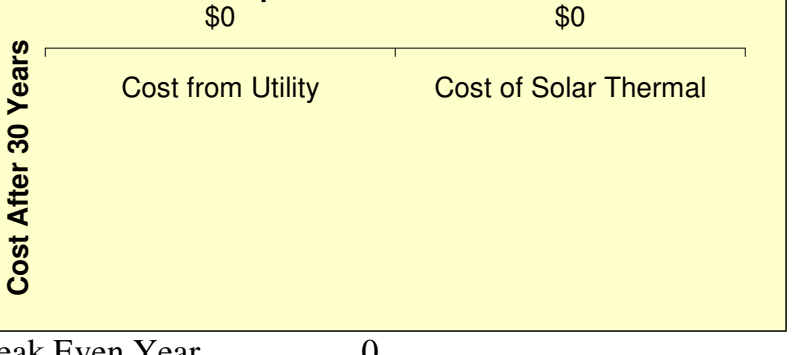

Notes: Recommended future review

\begin{tabular}{|c|c|c|c|c|c|}
\hline \multicolumn{3}{|c|}{ Wind } & \multicolumn{3}{|c|}{$\begin{array}{l}\text { Size of System (kW) } \\
\text { Annual Energy Production }(\mathrm{kWh})\end{array}$} \\
\hline \multicolumn{3}{|c|}{ Baseline Scenario } & \multicolumn{3}{|c|}{$\$ 0$ Optimistic Scenario } \\
\hline 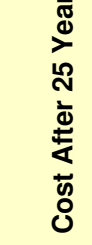 & Cost from Utility & Cost of Wind System & 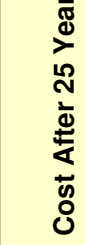 & Cost from Utility & Cost of Wind System \\
\hline $\begin{array}{l}\text { Estim } \\
\text { Notes }\end{array}$ & Grant Amount t & k Even: & Break & Year & \\
\hline
\end{tabular}

\begin{tabular}{|c|c|c|c|c|c|c|}
\hline \multicolumn{3}{|c|}{ Geothermal } & $\begin{array}{r}\text { Size o } \\
\text { |Annu: }\end{array}$ & $\begin{array}{l}\text { tem } \\
\text { ergy Savings }(k\end{array}$ & ons) & $\begin{array}{l}0 \\
0 / 0 \\
\end{array}$ \\
\hline \multicolumn{3}{|c|}{$\$ 0$ Baseline Scenario } & \multicolumn{4}{|c|}{$\$ 0$ Optimistic Scenario } \\
\hline 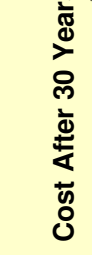 & Cost from Utility & Cost of Geothermal & 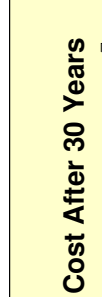 & Cost from Utility & \multicolumn{2}{|c|}{ Cost of Geotherma } \\
\hline $\begin{array}{l}\text { Break } \\
\text { Notes }\end{array}$ & $\begin{array}{l}\text { Year } \\
\text { a priority }\end{array}$ & 0 & Break & Year & & \\
\hline
\end{tabular}




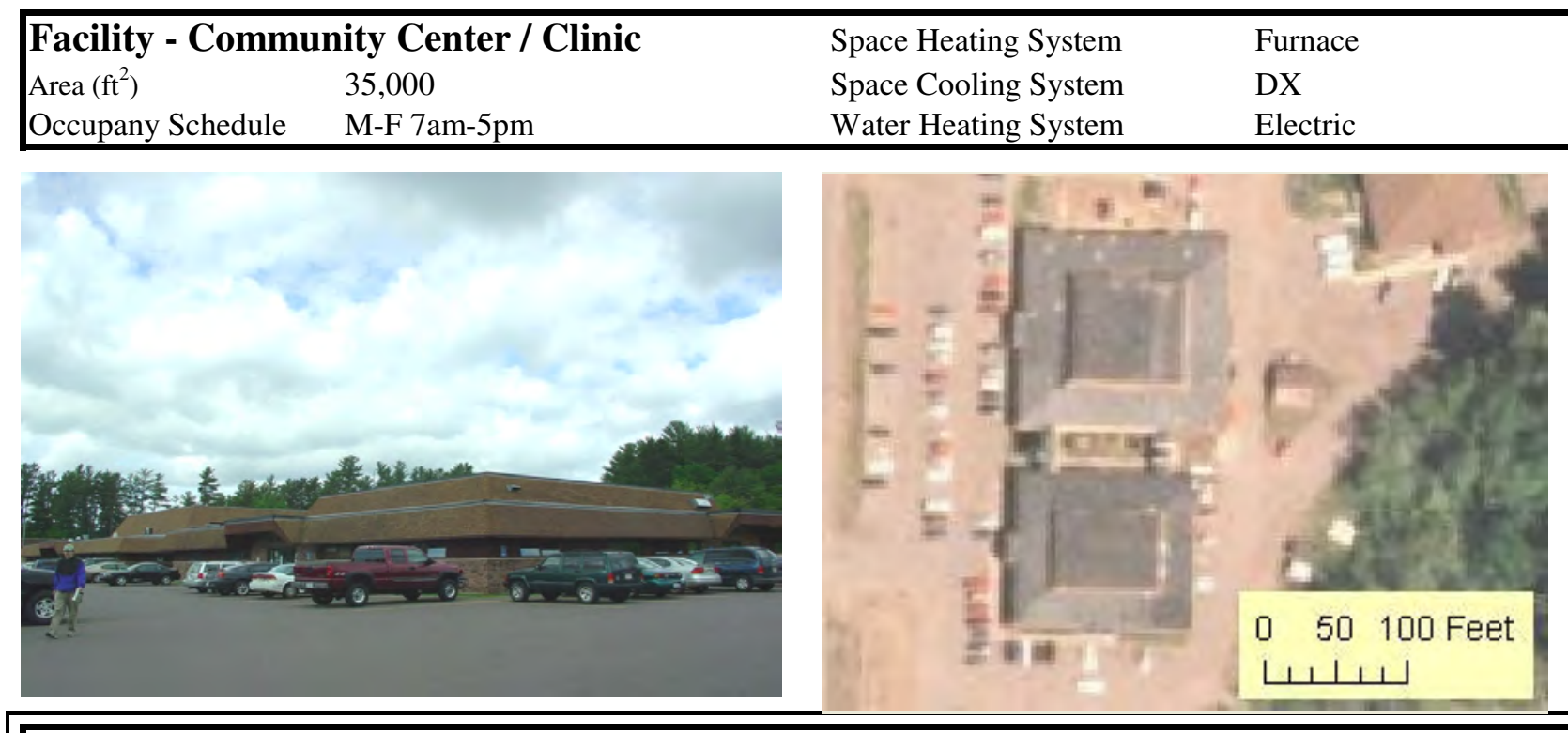

Energy Profile (2007)

\begin{tabular}{|c|c|c|c|}
\hline Electricity & Total & Rank & $\begin{array}{l}\text { Percent } \\
\text { of Tribe }\end{array}$ \\
\hline $\begin{array}{c}\text { Consumption kWh } \\
\text { (Cost) }\end{array}$ & $\begin{array}{l}\mathbf{4 7 3 , 0 0 0} \\
\$ 33,660\end{array}$ & 5 & $4.0 \%$ \\
\hline $\begin{array}{c}\text { Electricity Intensity } \\
\left(\mathrm{Cost} / \mathrm{ft}^{2}\right)\end{array}$ & $\begin{array}{r}46.1 \\
\$ 0.96 \\
\end{array}$ & 10 & \\
\hline Energy Charge (kWh) & $\$ 0.060$ & & \\
\hline Demand Charge $(\mathrm{kW})$ & $\$ 10.67$ & & \\
\hline
\end{tabular}

\begin{tabular}{|c|c|c|c|}
\hline Propane & Total & Rank & $\begin{array}{c}\text { Percent } \\
\text { of Tribe }\end{array}$ \\
\hline $\begin{array}{c}\text { Consumption gal } \\
\text { (Cost) }\end{array}$ & $\begin{array}{r}\mathbf{2 1 , 2 3 6} \\
\$ 31,004\end{array}$ & 4 & $5.2 \%$ \\
\hline $\begin{array}{c}\text { Propane Intensity } \\
\text { (Cost/ft }^{\mathbf{2}} \text { ) }\end{array}$ & $\begin{array}{r}55.4 \\
\$ 0.89\end{array}$ & 8 & \multirow{2}{|c|}{$\$ 1.46$} \\
\cline { 1 - 2 } Propane Cost (gal) & \multicolumn{2}{|c|}{} \\
\cline { 1 - 2 } & &
\end{tabular}
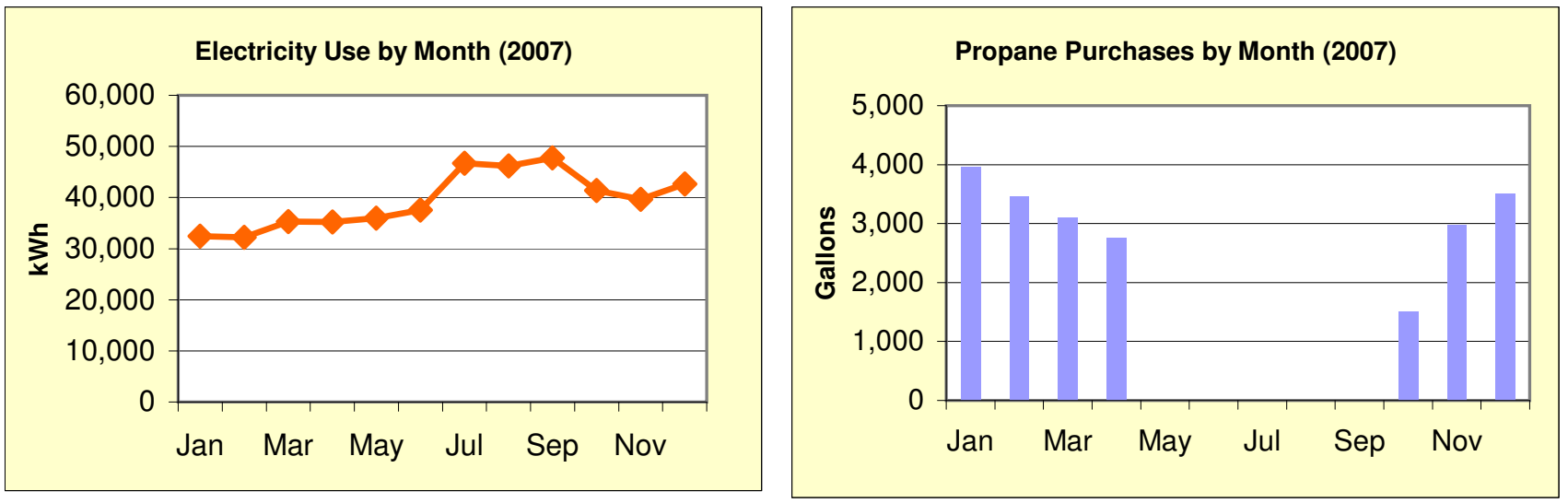

\section{WPS Electric Accounts}

\section{Energy Efficiency Recommendations}

\begin{tabular}{|l|l|r|r|}
\hline \multicolumn{1}{|c|}{ Type } & \multicolumn{1}{c|}{ Rate } & $\begin{array}{c}\text { 2007 Use } \\
\text { (kWh) }\end{array}$ & 2007 Cost \\
\hline Main & CG-20 & 445,520 & $\$ 33,281$ \\
\hline Main & CG-1 & 27,480 & $\$ 1,556$ \\
\hline Outdoor lighting & GY-3 & & $\$ 495$ \\
\hline DLC & DLC & & \\
\hline & & & \\
\hline & & & \\
\hline & & & \\
\hline
\end{tabular}

\begin{tabular}{|c|c|c|c|}
\hline Recommendation & $\begin{array}{c}\text { Cost to } \\
\text { Install }\end{array}$ & $\begin{array}{c}\text { Annual } \\
\text { kWh } \\
\text { Savings }\end{array}$ & $\begin{array}{c}\text { Simple Payback } \\
\text { (yrs) }\end{array}$ \\
\hline T8 lighting upgrade & & & \\
\hline \multicolumn{4}{|c|}{ Install lighting occupancy sensors } \\
\hline \multicolumn{4}{|l|}{ Install LED exit lights } \\
\hline \multicolumn{4}{|l|}{ Seal building shell } \\
\hline \multicolumn{4}{|c|}{ Work with Johsnson Controls to optmize HVAC system } \\
\hline \multicolumn{4}{|c|}{ Install programmable thermostat } \\
\hline \multicolumn{4}{|c|}{ Clean and tune-up boiler } \\
\hline
\end{tabular}




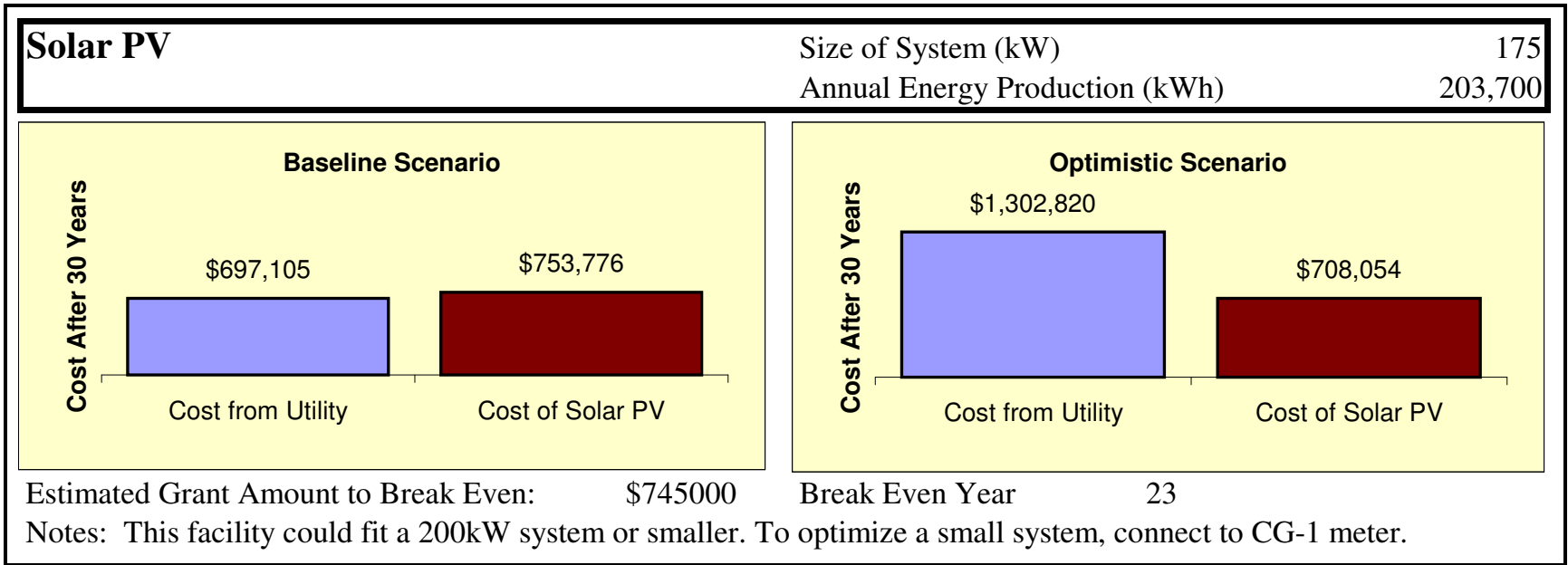

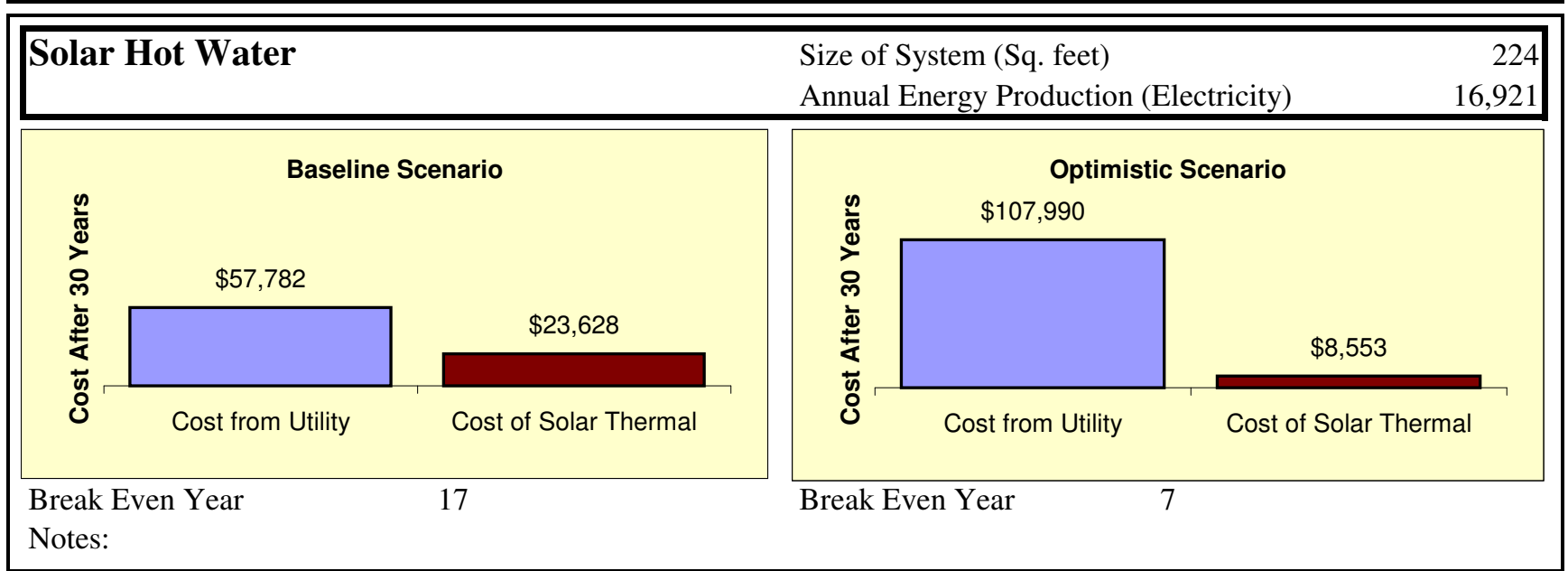

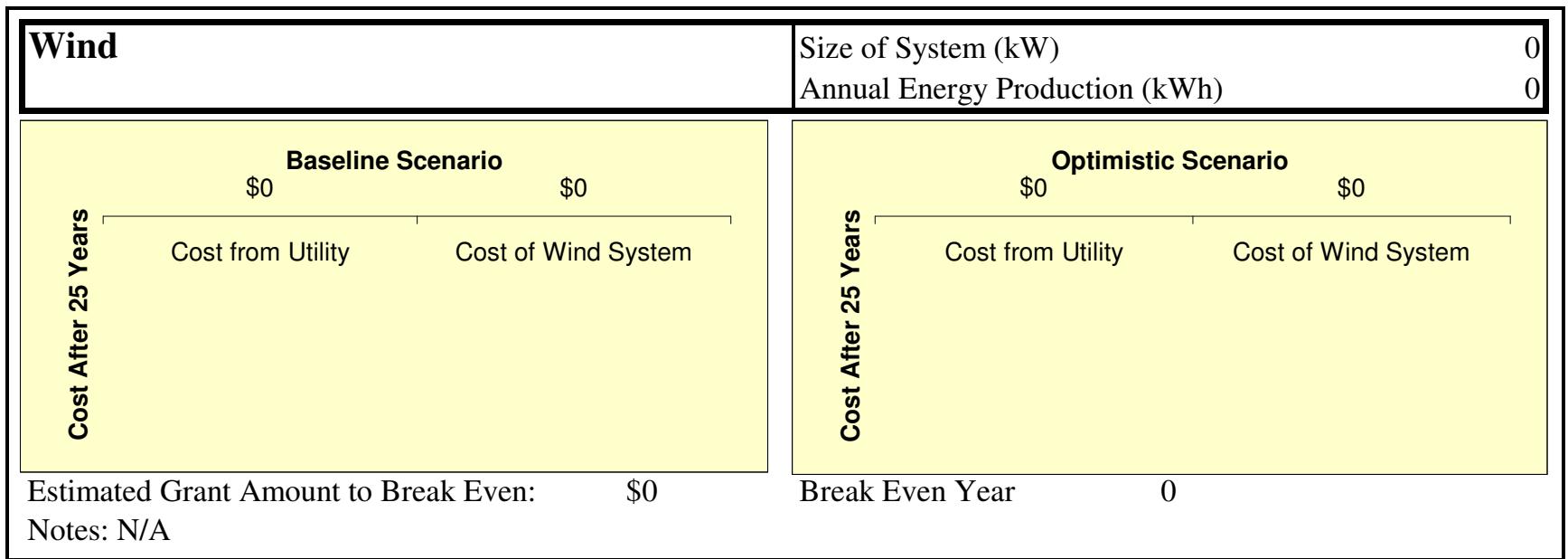

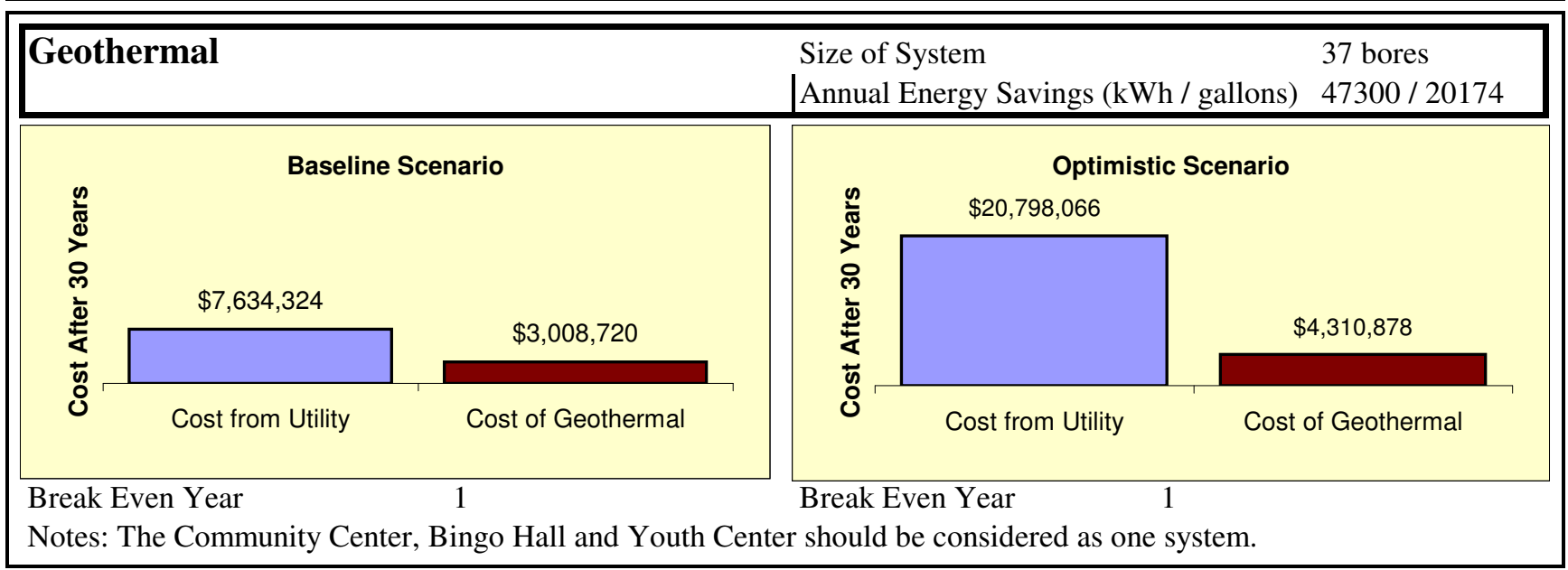




\begin{tabular}{|llll|}
\hline Facility - Casino & & Space Heating System & RTU \\
Area $\left(\mathrm{ft}^{2}\right)$ & 75,340 & Space Cooling System & DX RTU \\
Occupany Schedule & 24 hours & Water Heating System & Propane \\
\hline
\end{tabular}

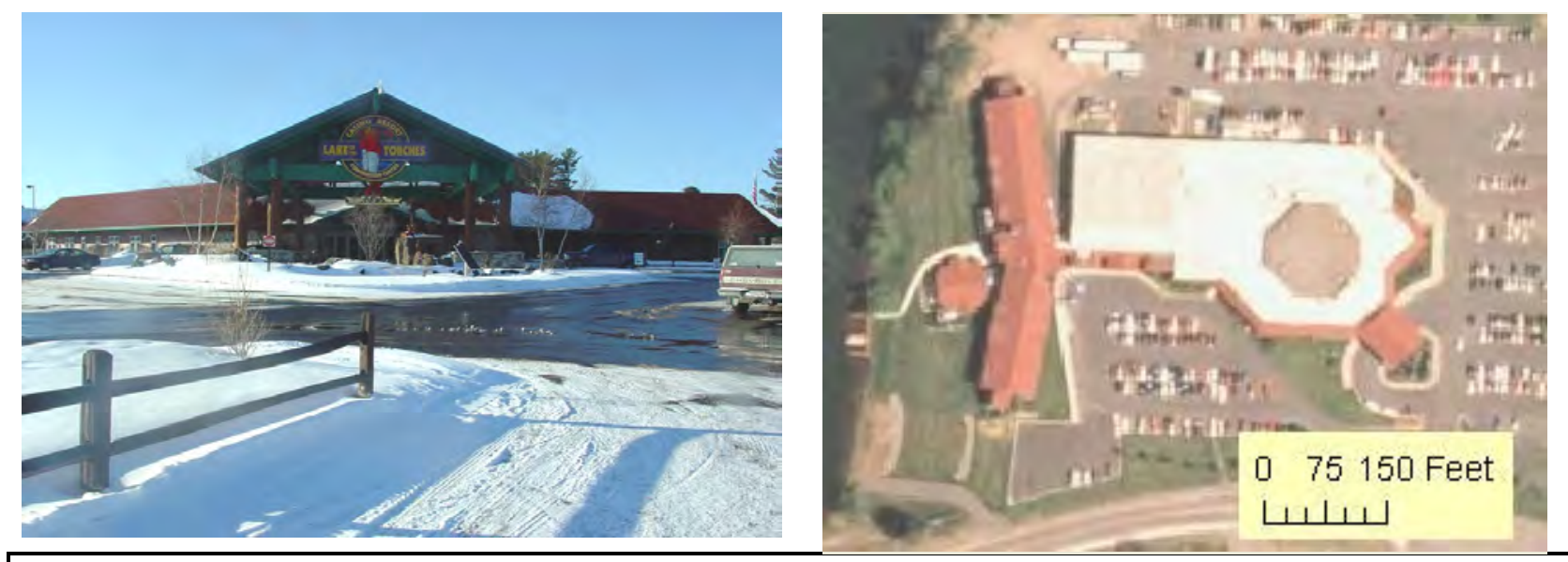

Energy Profile (2007)

\begin{tabular}{|c|c|c|c|}
\hline Electricity & Total & Rank & $\begin{array}{l}\text { Percent } \\
\text { of Tribe }\end{array}$ \\
\hline $\begin{array}{c}\text { Consumption kWh } \\
\text { (Cost) }\end{array}$ & $\begin{array}{r}\mathbf{5 , 0 4 3 , 7 9 3} \\
\$ 264,076\end{array}$ & 1 & $42.5 \%$ \\
\hline $\begin{array}{c}\text { Electricity Intensity } \\
\left(\mathrm{Cost} / \mathrm{ft}^{2}\right)\end{array}$ & $\begin{array}{l}228.4 \\
\$ 3.51\end{array}$ & 2 & \\
\hline \begin{tabular}{|l} 
Energy Charge $(\mathrm{kWh})$ \\
Demand Charge $(\mathrm{kW})$
\end{tabular} & $\begin{array}{l}\$ 0.060 \\
\$ 10.67\end{array}$ & & \\
\hline
\end{tabular}

\begin{tabular}{|c|c|c|c|}
\hline Propane & Total & Rank & $\begin{array}{l}\text { Percent } \\
\text { of Tribe }\end{array}$ \\
\hline $\begin{array}{c}\text { Consumption gal } \\
\text { (Cost) }\end{array}$ & \begin{tabular}{r|}
$\mathbf{1 6 3 , 2 0 0}$ \\
$\$ 238,272$
\end{tabular} & 1 & $40.1 \%$ \\
\hline $\begin{array}{c}\text { Propane Intensity } \\
\left(\text { Cost } / \mathbf{f t}^{2}\right)\end{array}$ & $\begin{array}{l}197.8 \\
\$ 3.16 \\
\end{array}$ & 1 & \\
\hline Propane Cost (gal) & & $\$ 1.46$ & \\
\hline
\end{tabular}
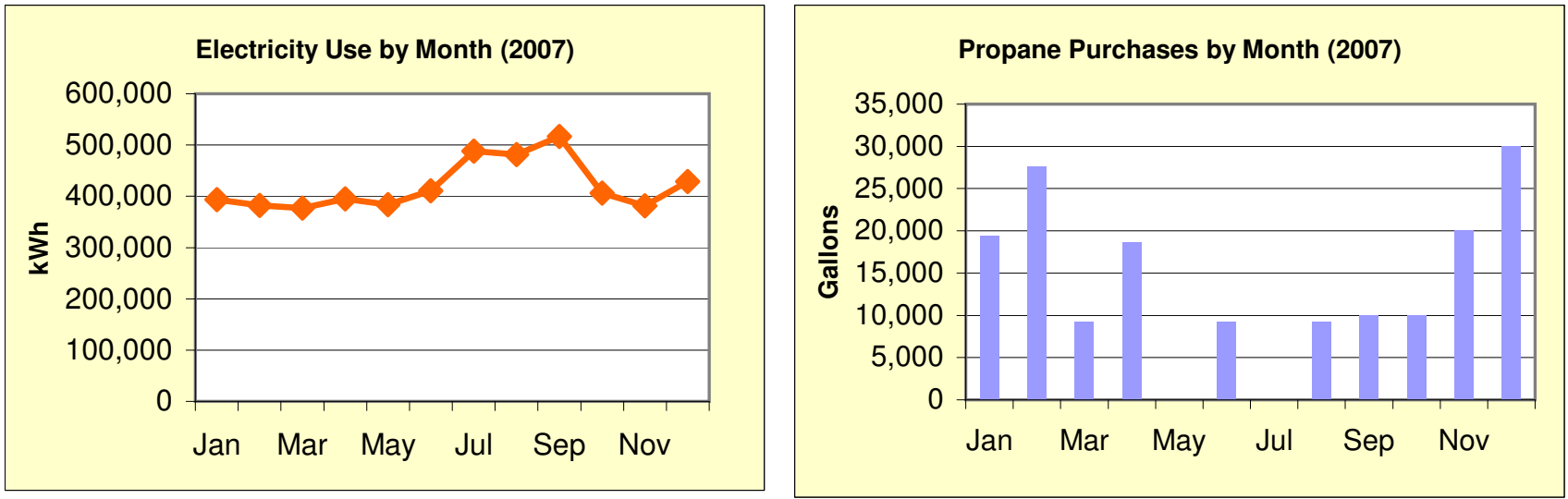

\section{Facility Accounts}

\section{Energy Efficiency Recommendations}

\begin{tabular}{|l|l|r|r|}
\hline \multicolumn{1}{|c|}{ Type } & \multicolumn{1}{c|}{ Rate } & $\begin{array}{c}\text { 2007 Use } \\
\text { (kWh) }\end{array}$ & 2007 Cost \\
\hline Main & CG -20 & $4,995,040$ & $\$ 293,217$ \\
\hline Main & CG-1 & 44,098 & $\$ 4,751$ \\
\hline Outdoor lighting & $3 \times$ GY & & $\$ 3,548$ \\
\hline Main & CG-1 & 3,726 & $\$ 595$ \\
\hline Main & CG-1 & 929 & $\$ 229$ \\
\hline & CG-1 & & \\
\hline & DLC & & \\
\hline
\end{tabular}

\begin{tabular}{|l|l|c|c|}
\hline Recommendation & $\begin{array}{c}\text { Cost to } \\
\text { Install }\end{array}$ & $\begin{array}{c}\text { Annual } \\
\mathbf{k W h} \\
\text { Savings }\end{array}$ & $\begin{array}{c}\text { Simple Payback } \\
(\mathbf{y r s})\end{array}$ \\
\hline & & & \\
\hline Energy audit recommended \\
\hline \multicolumn{3}{|l|}{} \\
\hline \multicolumn{2}{|l}{} \\
\hline
\end{tabular}




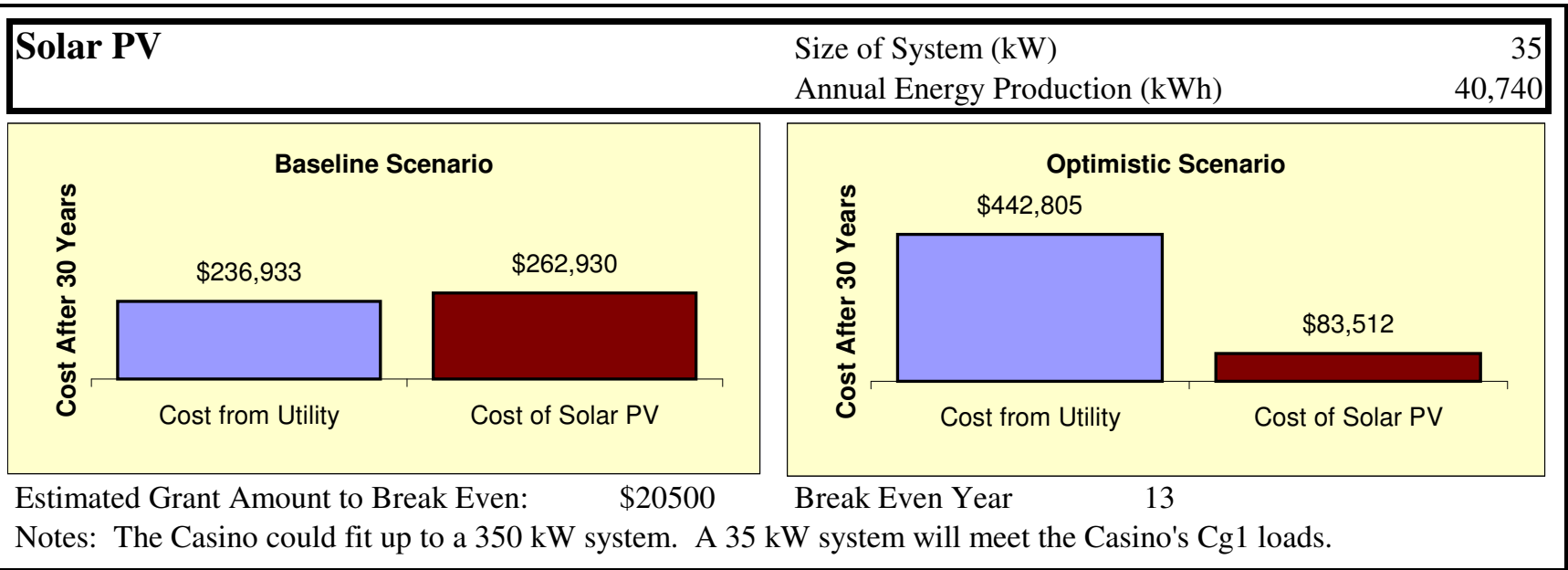

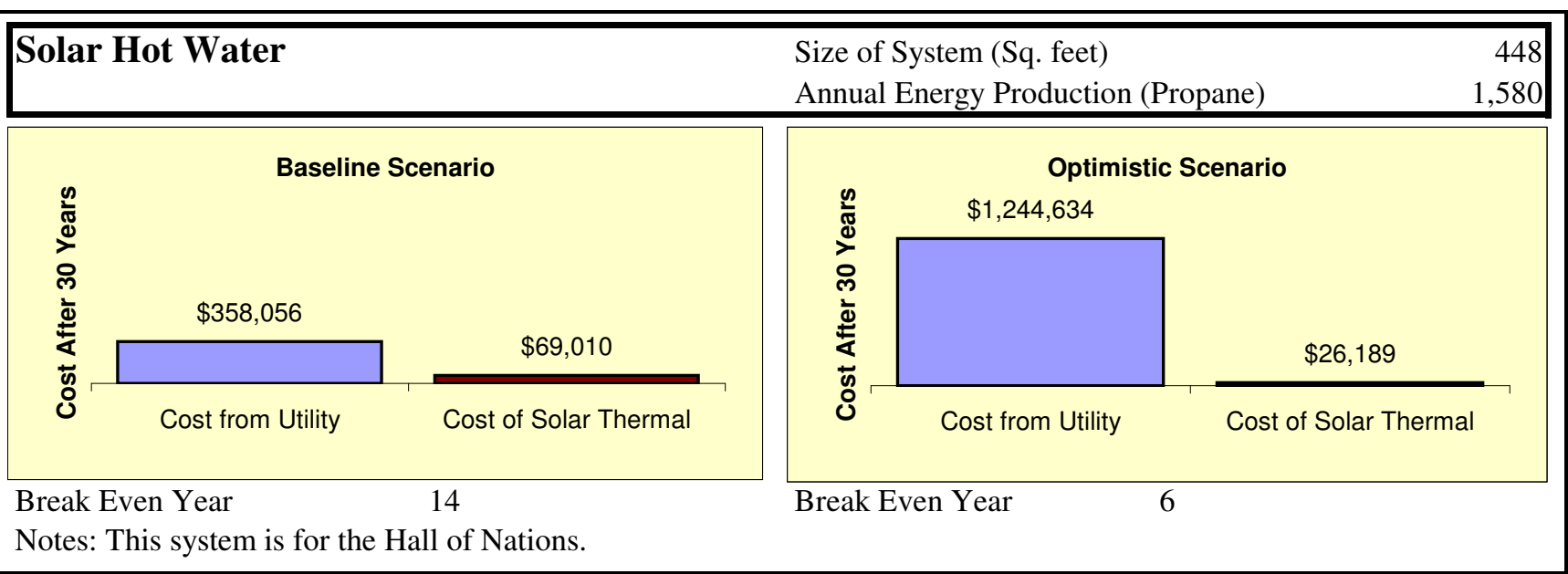

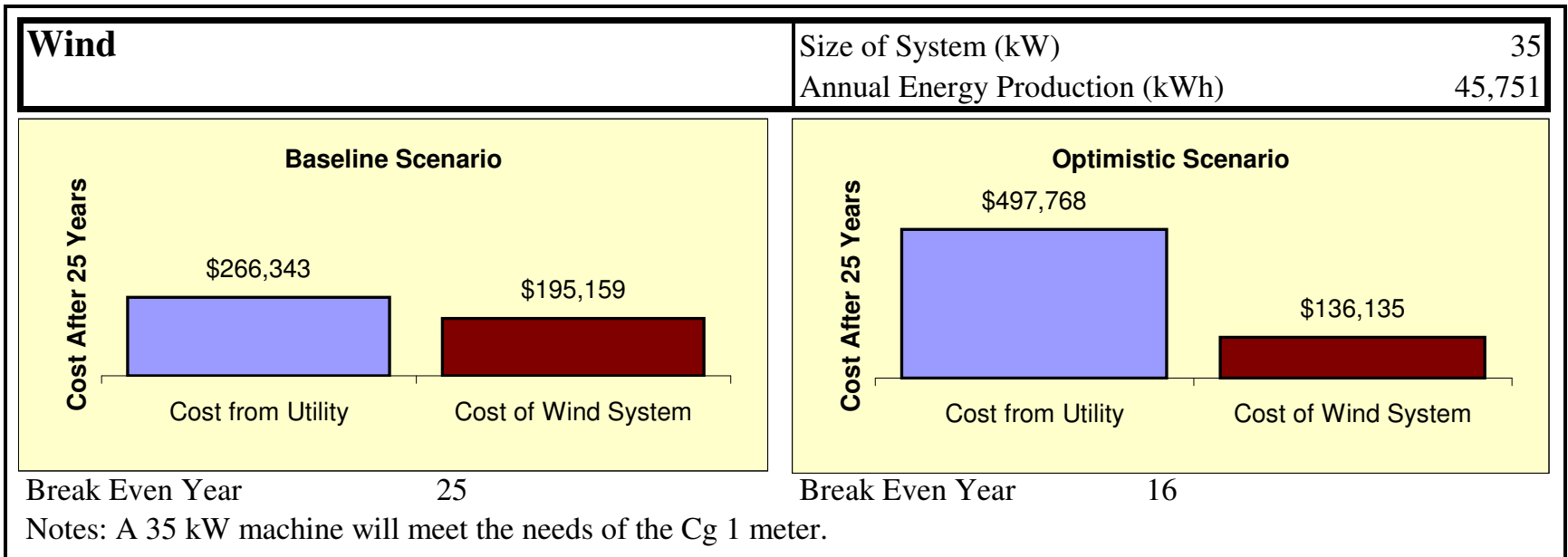

\begin{tabular}{|c|c|c|c|c|c|c|}
\hline \multicolumn{3}{|c|}{ Geothermal } & \multicolumn{3}{|c|}{$\begin{array}{l}\text { Size of System } \\
\text { Annual Energy Savings (kWh / gallons) }\end{array}$} & $\begin{array}{l}0 \\
0 / 0\end{array}$ \\
\hline \multicolumn{3}{|c|}{$\$ 0 \quad$ Baseline Scenario } & \multicolumn{4}{|c|}{$\$ 0 \bigcirc$ Optimistic Scenario } \\
\hline 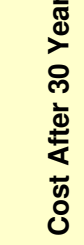 & Cost from Utility & Cost of Geothermal & 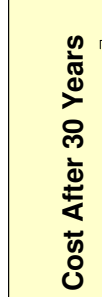 & Cost from Utility & \multicolumn{2}{|c|}{ Cost of Geothermal } \\
\hline $\begin{array}{l}\text { Break } \\
\text { Notes }\end{array}$ & $\begin{array}{l}\text { n Year } \\
\text { a priority at thi }\end{array}$ & 0 & Break & Year & & \\
\hline
\end{tabular}




\begin{tabular}{|llll|}
\hline \multicolumn{2}{|l|}{ Facility - Casino Human Resources / Education } & Space Heating System & RTU \\
Area $\left(\mathrm{ft}^{2}\right)$ & Space Cooling System & DX RTU \\
Occupany Schedule & M-F 7am-4pm (classes untill 7pm) & Water Heating System & Electric \\
\hline
\end{tabular}

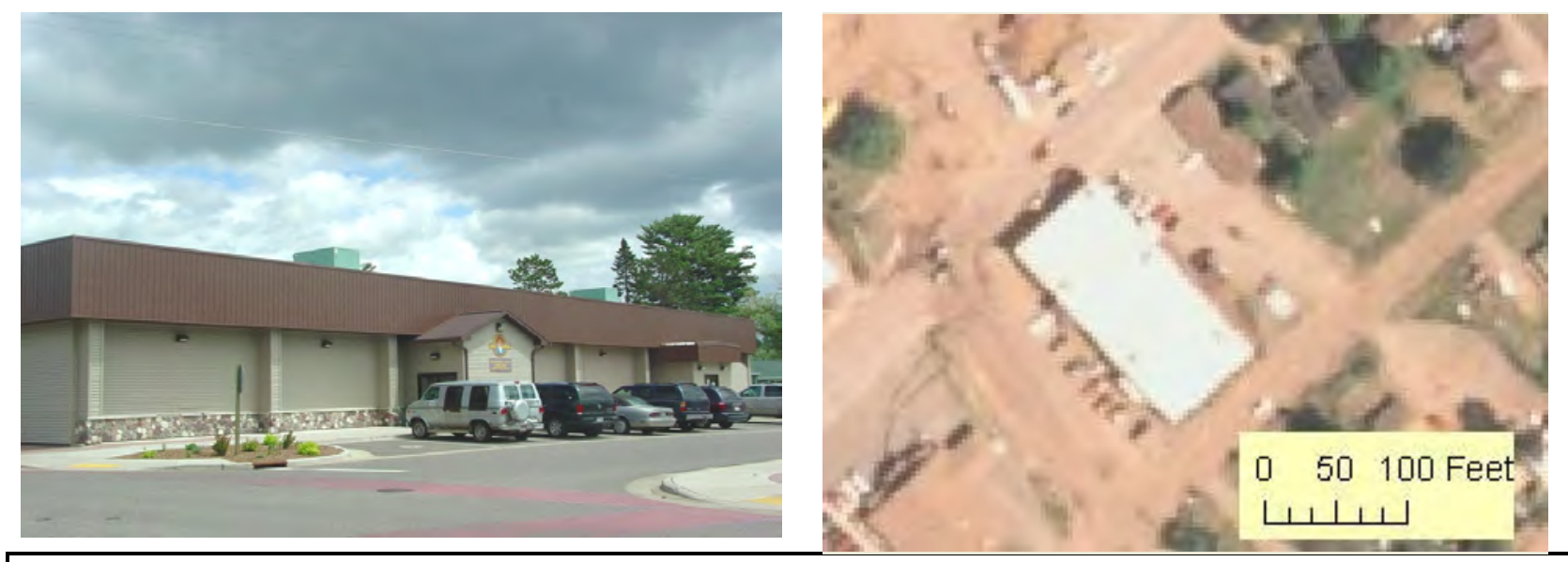

Energy Profile (2007)

\begin{tabular}{|c|c|c|c|}
\hline Electricity & Total & Rank & $\begin{array}{l}\text { Percent } \\
\text { of Tribe }\end{array}$ \\
\hline $\begin{array}{c}\text { Consumption kWh } \\
\text { (Cost) }\end{array}$ & $\begin{array}{l}\mathbf{1 7 9 , 5 2 0} \\
\$ 16,054\end{array}$ & 11 & $1.5 \%$ \\
\hline $\begin{array}{c}\text { Electricity Intensity } \\
\left(\text { Cost }^{\prime} \mathrm{ft}^{2}\right)\end{array}$ & $\begin{array}{r}41.2 \\
\$ 1.08\end{array}$ & 12 & \\
\hline Energy Charge (kWh) & $\$ 0.095$ & & \\
\hline Demand Charge $(\mathrm{kW})$ & $\$ 0.00$ & & \\
\hline
\end{tabular}

\begin{tabular}{|c|c|c|c|}
\hline Propane & Total & Rank & $\begin{array}{l}\text { Percent } \\
\text { of Tribe }\end{array}$ \\
\hline $\begin{array}{c}\text { Consumption gal } \\
\text { (Cost) }\end{array}$ & $\begin{array}{r}\mathbf{7 , 6 2 6} \\
\$ 11,133 \\
\end{array}$ & 7 & $1.9 \%$ \\
\hline $\begin{array}{c}\text { Propane Intensity } \\
\left(\text { Cost } / \mathbf{f t}^{2}\right)\end{array}$ & $\begin{array}{r}46.9 \\
\$ 0.75 \\
\end{array}$ & 12 & \\
\hline Propane Cost (gal) & & $\$ 1.46$ & \\
\hline
\end{tabular}
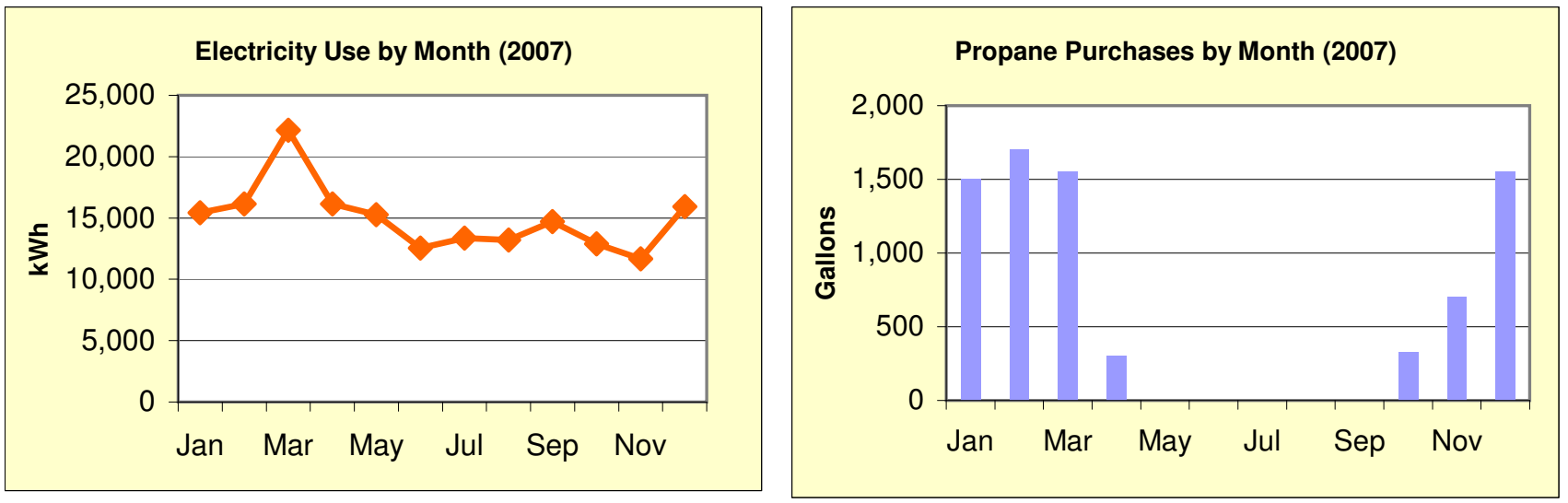

\section{WPS Electric Accounts}

\section{Energy Efficiency Recommendations}

\begin{tabular}{|l|l|c|r|}
\hline \multicolumn{1}{|c|}{ Type } & Rate & $\begin{array}{c}\text { 2007 Use } \\
\text { (kWh) }\end{array}$ & 2007 Cost \\
\hline Main & CG-5 & 179,520 & $\$ 15,268$ \\
\hline Outdoor lighting & GY-3 & & $\$ 785$ \\
\hline & & & \\
\hline & & & \\
\hline & & & \\
\hline & & & \\
\hline & & & \\
\hline
\end{tabular}

\begin{tabular}{|l|l|c|c|}
\hline Recommendation & $\begin{array}{c}\text { Cost to } \\
\text { Install }\end{array}$ & $\begin{array}{c}\text { Annual } \\
\mathbf{k W h} \\
\text { Savings }\end{array}$ & $\begin{array}{c}\text { Simple Payback } \\
\text { (yrs) }\end{array}$ \\
\hline & & & \\
\hline Energy audit recommended \\
\hline \multicolumn{3}{|l}{} \\
\hline
\end{tabular}




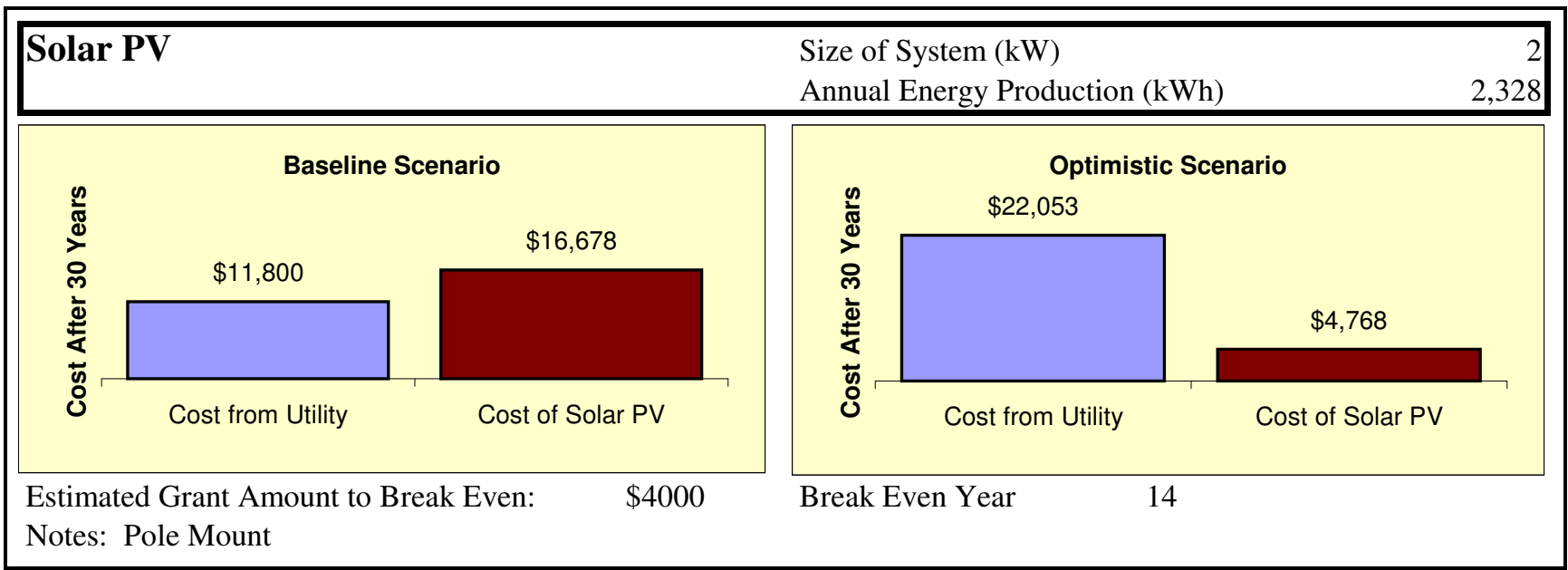

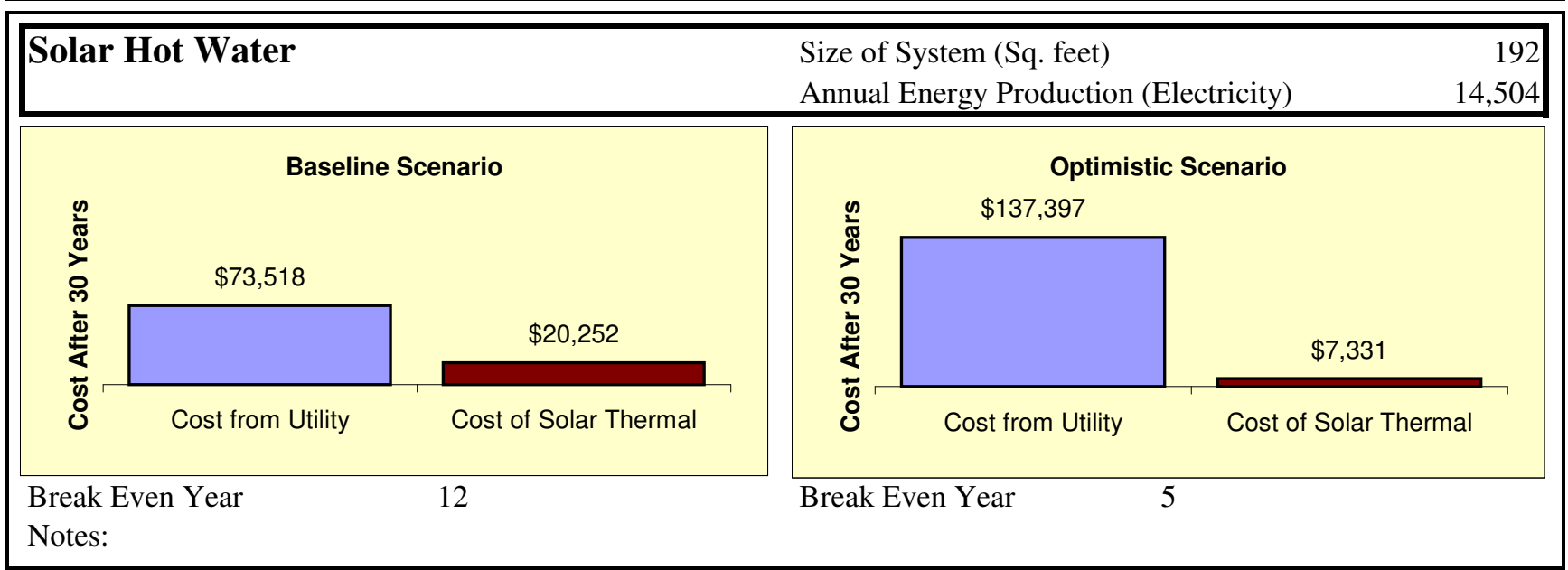

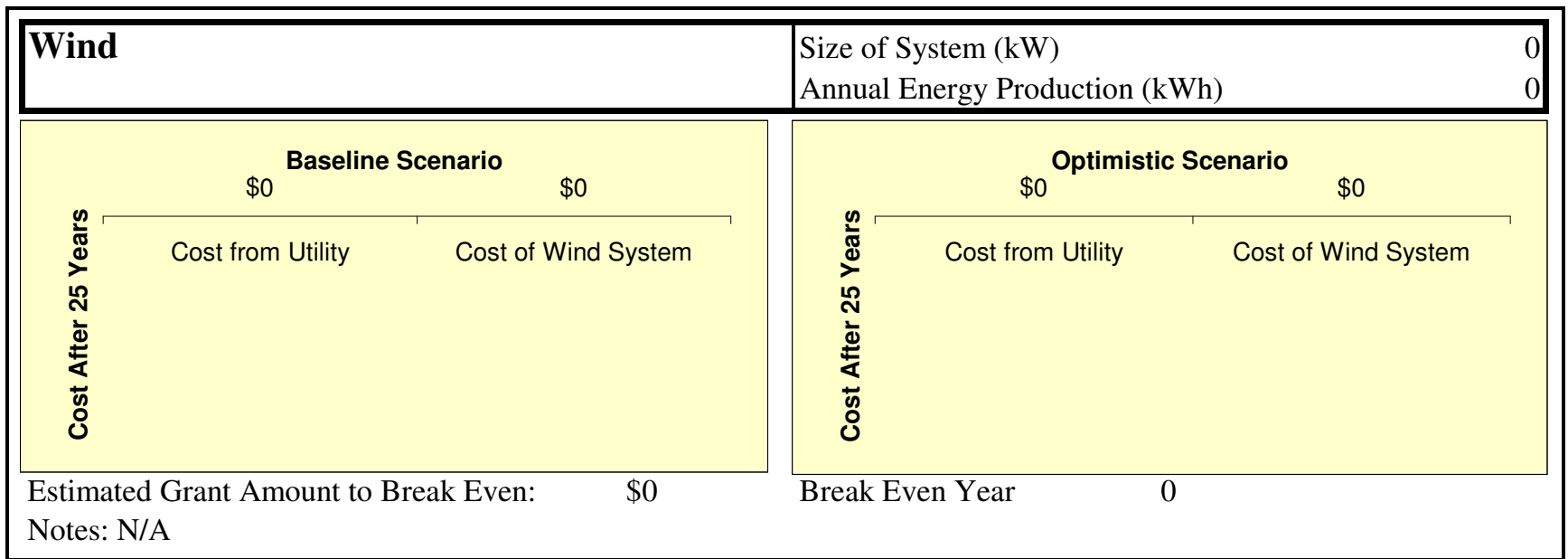

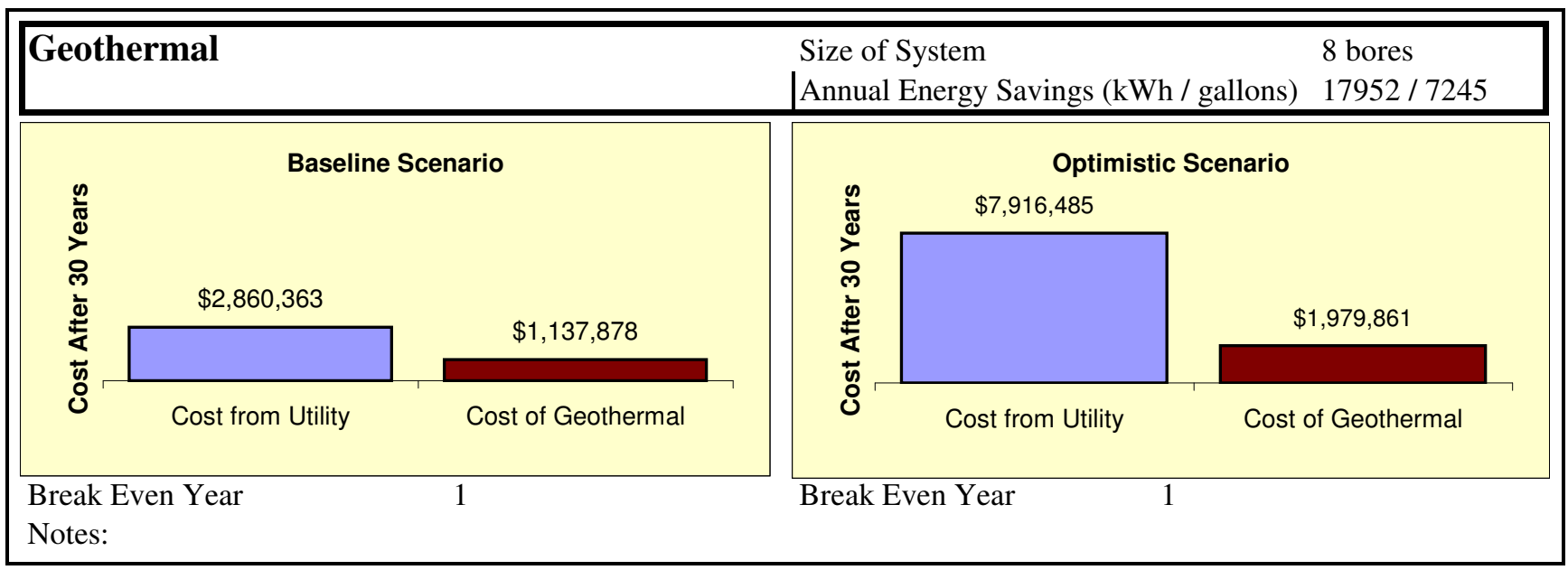




\begin{tabular}{|llll|}
\hline \multicolumn{2}{|l|}{ Facility - Casino Hotel } & Space Heating System & PTAC \\
Area $\left(\mathrm{ft}^{2}\right)$ & 74,400 & Space Cooling System & DX \\
Occupany Schedule & 24 hours & Water Heating System & Propane \\
\hline
\end{tabular}

Image not available

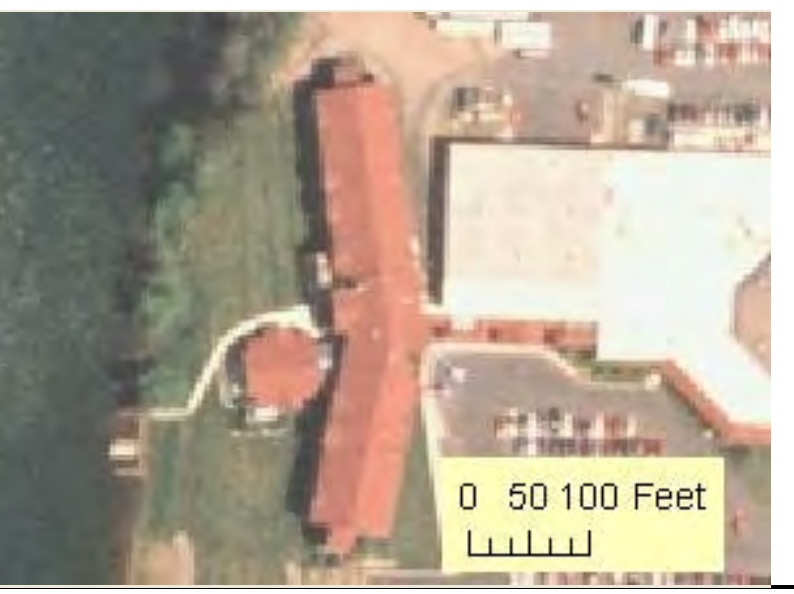

\section{Energy Profile (2007)}

\begin{tabular}{|c|c|c|c|}
\hline Electricity & Total & Rank & $\begin{array}{l}\text { Percent } \\
\text { of Tribe }\end{array}$ \\
\hline $\begin{array}{c}\text { Consumption kWh } \\
\text { (Cost) }\end{array}$ & $\begin{array}{r}\mathbf{1 , 3 8 0 , 3 6 0} \\
\$ 76,009\end{array}$ & 2 & $11.6 \%$ \\
\hline $\begin{array}{c}\text { Electricity Intensity } \\
\left(\text { Cost }_{\mathbf{f} t^{2}}\right)^{2}\end{array}$ & $\begin{array}{r}63.3 \\
\$ 1.02\end{array}$ & 6 & \\
\hline Energy Charge (kWh) & $\$ 0.060$ & & \\
\hline Demand Charge $(\mathrm{kW})$ & $\$ 10.67$ & & \\
\hline
\end{tabular}

\begin{tabular}{|c|c|c|c|}
\hline Propane & Total & Rank & $\begin{array}{l}\text { Percent } \\
\text { of Tribe }\end{array}$ \\
\hline $\begin{array}{c}\text { Consumption gal } \\
\text { (Cost) }\end{array}$ & $\begin{array}{r}\mathbf{0} \\
\$ 0\end{array}$ & 0 & $0.0 \%$ \\
\hline $\begin{array}{l}\text { Propane Intensity } \\
\left(\text { Cost } / \mathrm{ft}^{2}\right)\end{array}$ & $\begin{array}{r}0.0 \\
\$ 0.00\end{array}$ & 0 & \\
\hline Propane Cost (gal) & \multicolumn{2}{|c|}{ \#DIV/0! } & \\
\hline
\end{tabular}
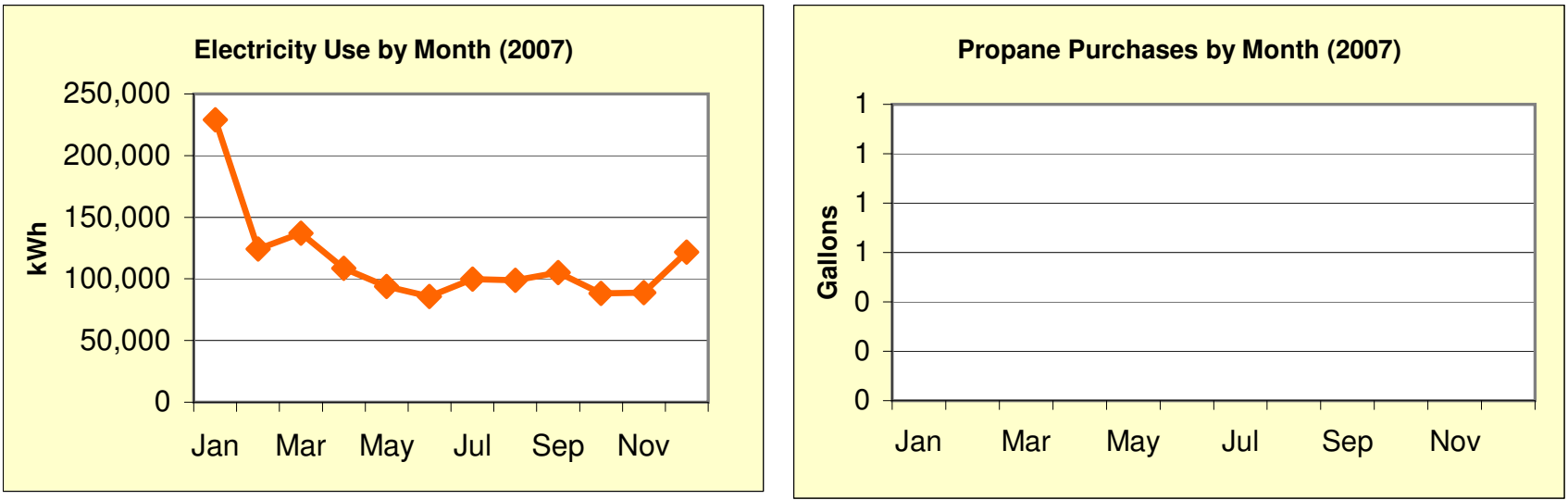

\section{WPS Electric Accounts}

\section{Energy Efficiency Recommendations}

\begin{tabular}{|l|l|l|l|}
\hline \multicolumn{1}{|c|}{ Type } & Rate & $\begin{array}{c}\text { 2007 Use } \\
\text { (kWh) }\end{array}$ & 2007 Cost \\
\hline Main & CG-20 & $1,380,360$ & $\$ 87,108$ \\
\hline DLC & DLC & & \\
\hline & & & \\
\hline & & & \\
\hline & & & \\
\hline & & & \\
\hline & & & \\
\hline
\end{tabular}

\begin{tabular}{|l|l|c|c|}
\hline Recommendation & $\begin{array}{c}\text { Cost to } \\
\text { Install }\end{array}$ & $\begin{array}{c}\text { Annual } \\
\text { Savings }\end{array}$ & $\begin{array}{c}\text { Simple Payback } \\
\text { (yrs) }\end{array}$ \\
\hline & & & \\
\hline Energy audit recommended \\
\hline \multicolumn{3}{|l|}{} \\
\hline
\end{tabular}




\begin{tabular}{|c|c|c|c|c|c|}
\hline \multicolumn{3}{|c|}{ Solar PV } & \multicolumn{3}{|c|}{$\begin{array}{l}\text { Size of System }(\mathrm{kW}) \\
\text { Annual Energy Production }(\mathrm{kWh})\end{array}$} \\
\hline \multicolumn{3}{|c|}{$\$ 0$ Baseline Scenario } & \multicolumn{3}{|c|}{$\$ 0$ Optimistic Scenario } \\
\hline 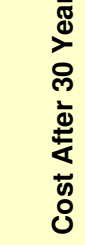 & Cost from Utility & Cost of Solar PV & 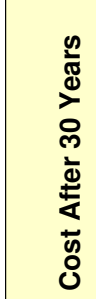 & Cost from Utility & Cost of Solar PV \\
\hline $\begin{array}{l}\text { Estim } \\
\text { Notes }\end{array}$ & $\begin{array}{l}\text { Grant Amount } t \\
t \text { a priority }\end{array}$ & Even: $\quad \$ 0$ & Break & Year & \\
\hline
\end{tabular}

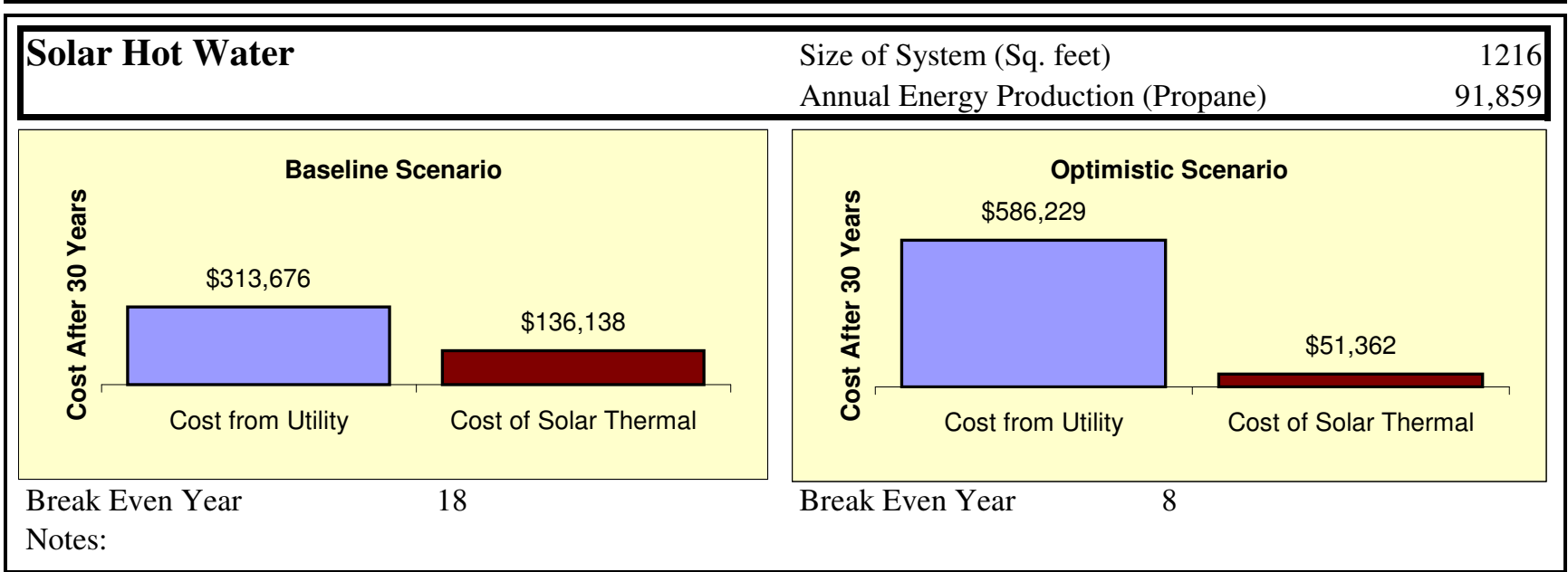

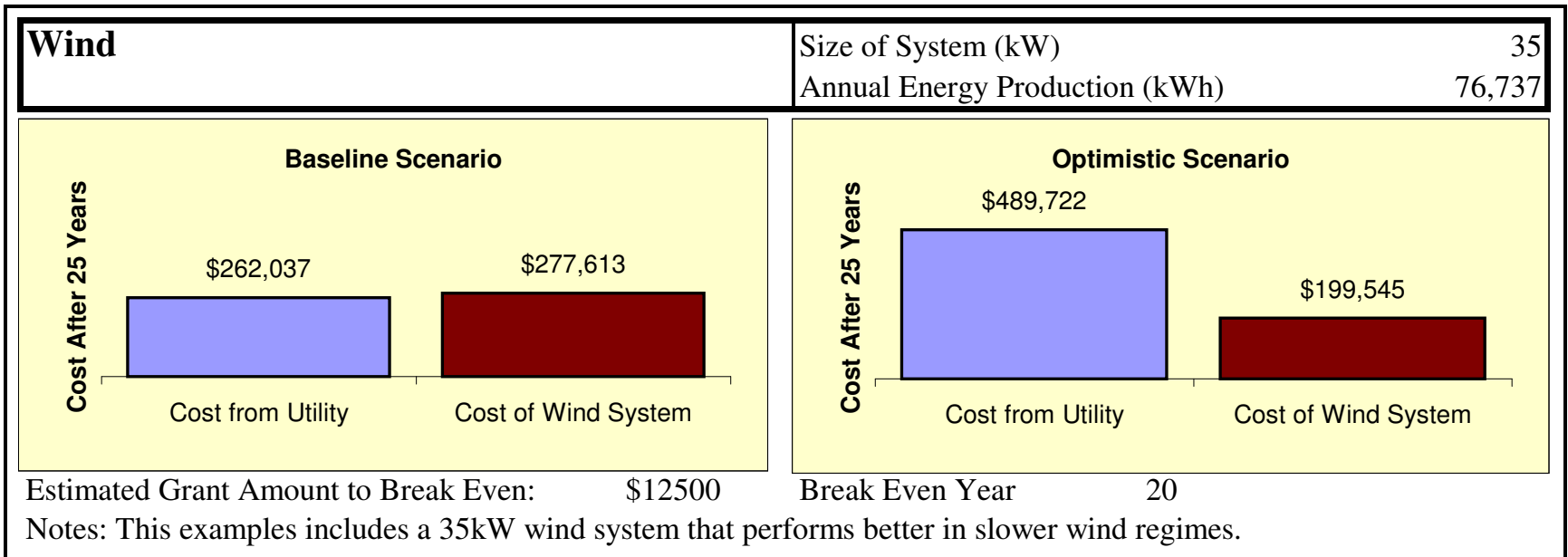

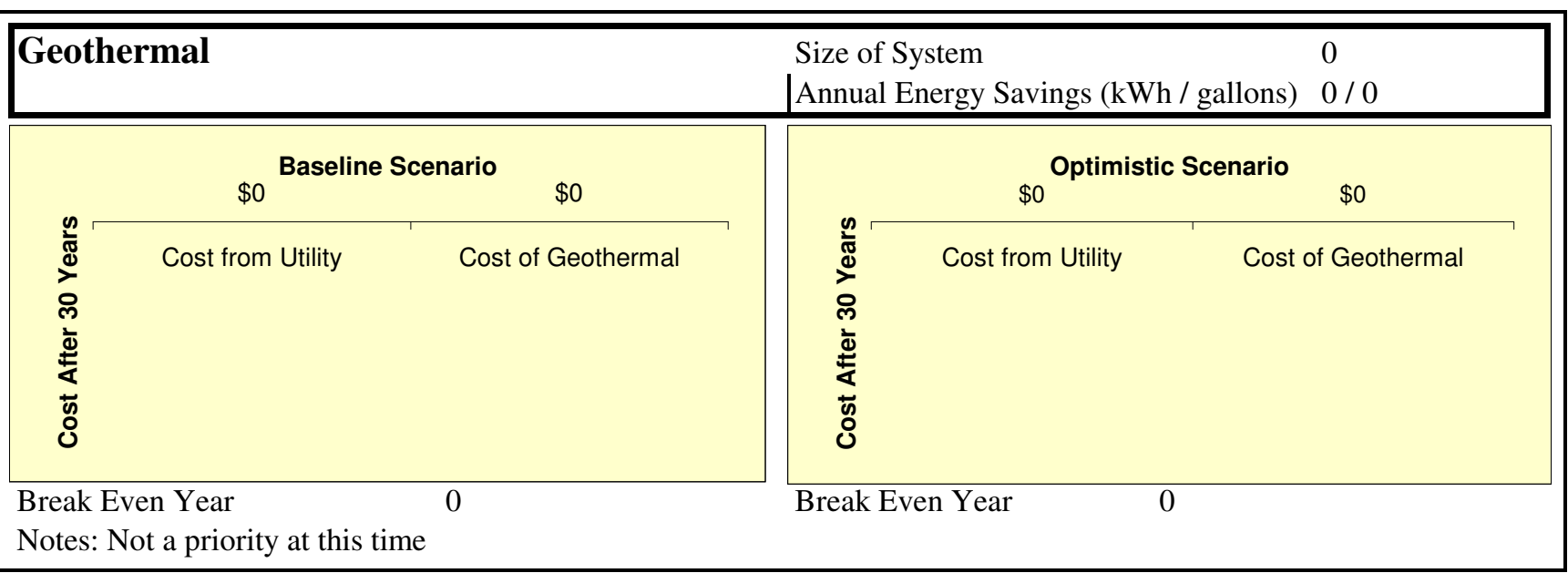




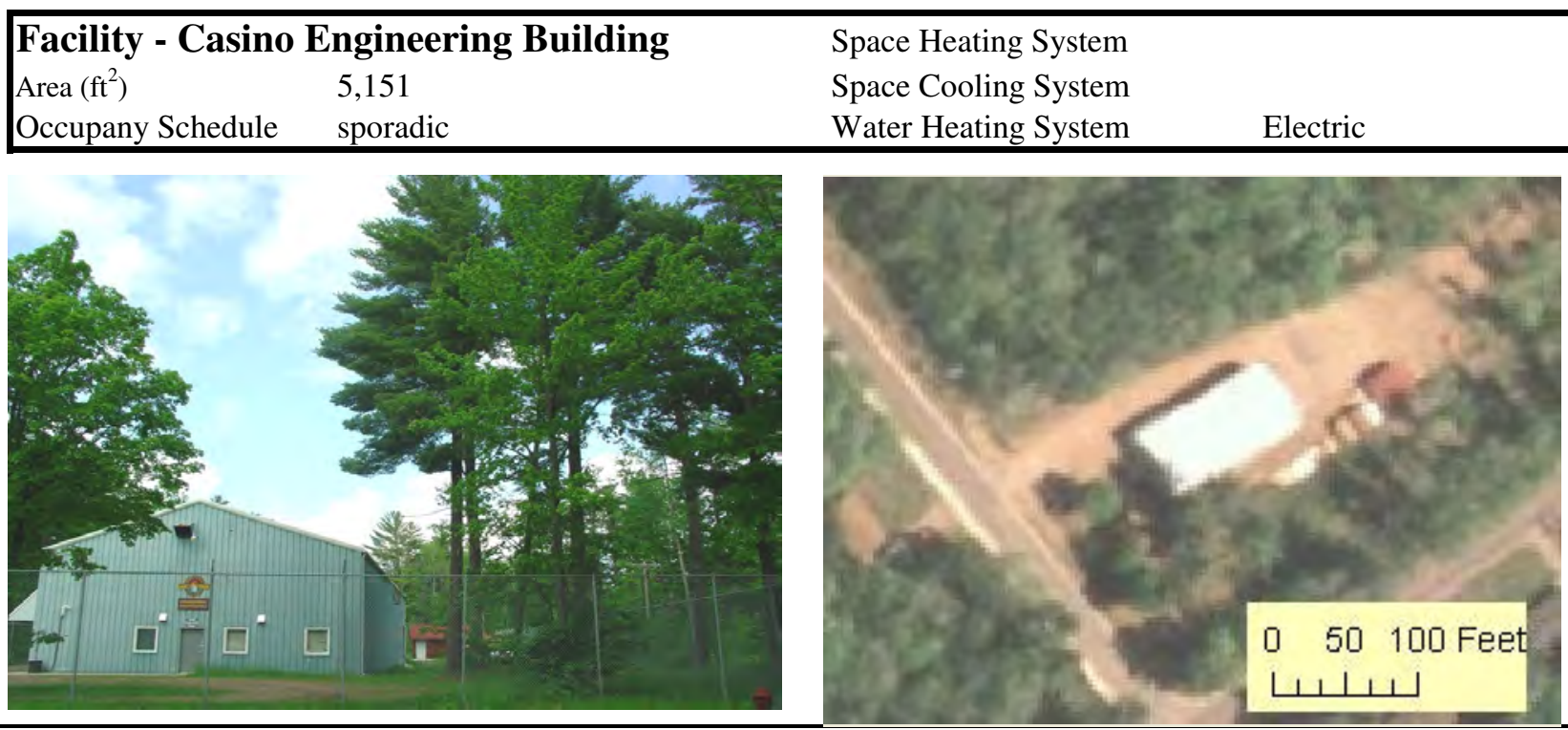

Energy Profile (2007)

\begin{tabular}{|c|c|c|c|}
\hline Electricity & Total & Rank & $\begin{array}{l}\text { Percent } \\
\text { of Tribe }\end{array}$ \\
\hline $\begin{array}{l}\text { Consumption kWh } \\
\text { (Cost) }\end{array}$ & $\begin{array}{l}\mathbf{4 5 , 4 6 7} \\
\$ 5,011\end{array}$ & 19 & $0.4 \%$ \\
\hline $\begin{array}{c}\text { Electricity Intensity } \\
\left(\mathrm{Cost} / \mathrm{ft}^{2}\right)\end{array}$ & $\begin{array}{r}30.1 \\
\$ 0.97\end{array}$ & 15 & \\
\hline Energy Charge (kWh) & $\$ 0.109$ & & \\
\hline
\end{tabular}

\begin{tabular}{|c|c|c|c|}
\hline Propane & Total & Rank & $\begin{array}{l}\text { Percent } \\
\text { of Tribe }\end{array}$ \\
\hline $\begin{array}{c}\text { Consumption gal } \\
\text { (Cost) }\end{array}$ & $\begin{array}{r}\mathbf{6 , 5 5 0} \\
\$ 9,564\end{array}$ & 8 & $1.6 \%$ \\
\hline $\begin{array}{l}\text { Propane Intensity } \\
\left(\text { Cost } / \mathrm{ft}^{2}\right)\end{array}$ & $\begin{array}{l}116.1 \\
\$ 1.86\end{array}$ & 3 & \\
\hline Propane Cost (gal) & & $\$ 1.46$ & \\
\hline
\end{tabular}
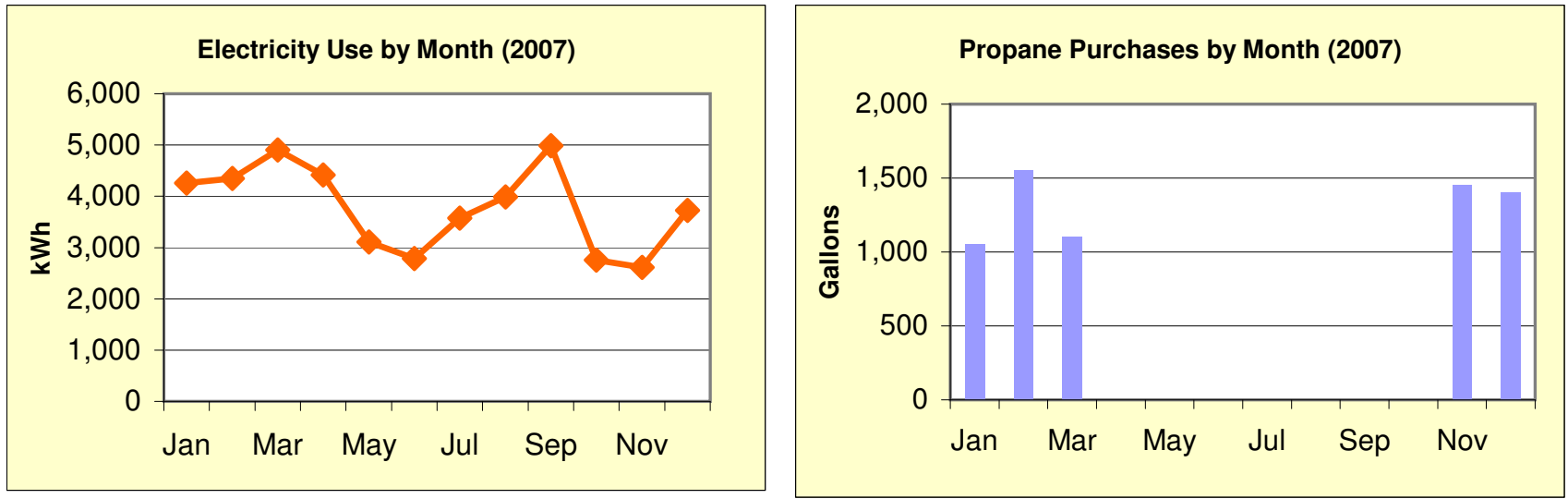

\section{WPS Electric Accounts}

\section{Energy Efficiency Recommendations}

\begin{tabular}{|l|l|r|r|}
\hline Type & Rate & $\begin{array}{c}\text { 2007 Use } \\
\text { (kWh) }\end{array}$ & 2007 Cost \\
\hline Main & CG-1 & 45,467 & $\$ 5,011$ \\
\hline & & & \\
\hline & & & \\
\hline & & & \\
\hline & & & \\
\hline & & & \\
\hline & & & \\
\hline
\end{tabular}

\begin{tabular}{|c|c|c|c|}
\hline Recommendation & $\begin{array}{l}\text { Cost to } \\
\text { Install }\end{array}$ & $\begin{array}{c}\text { Annual } \\
\text { kWh } \\
\text { Savings }\end{array}$ & $\begin{array}{c}\text { Simple Payback } \\
(\text { yrs })\end{array}$ \\
\hline \multicolumn{4}{|c|}{ Energy audit recommended } \\
\hline & & & \\
\hline & & & \\
\hline & & & \\
\hline & & & \\
\hline
\end{tabular}




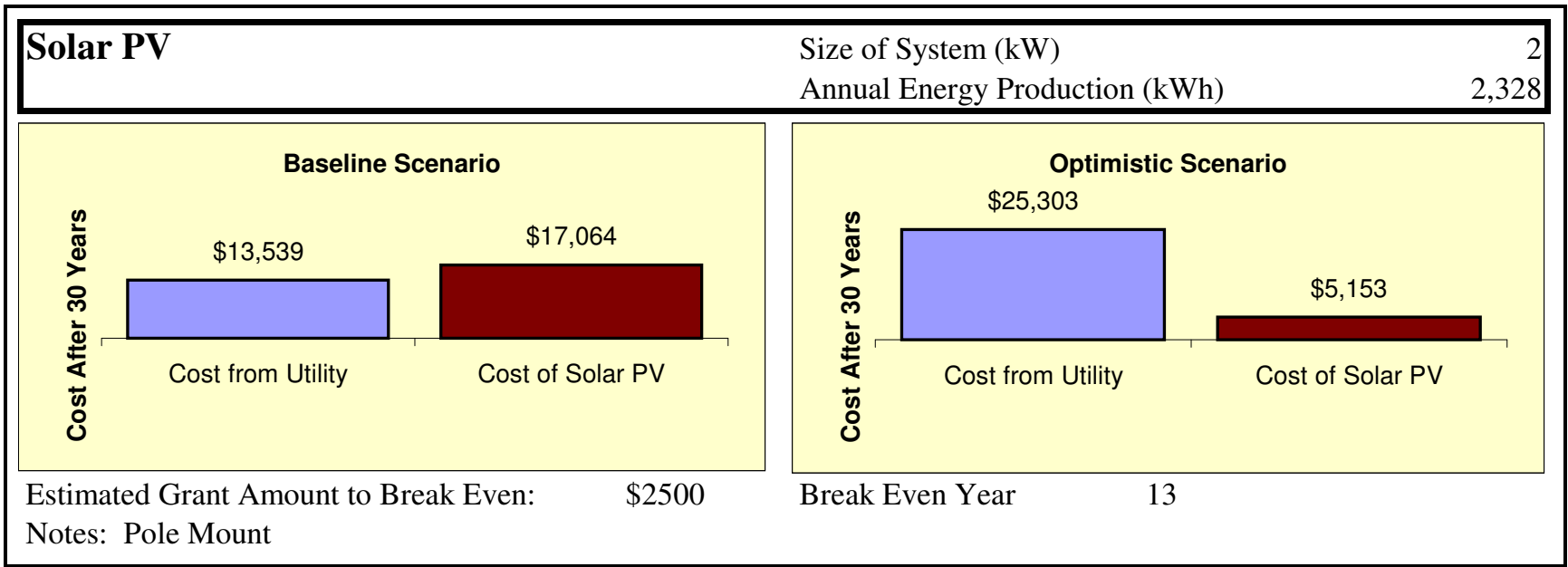

\begin{tabular}{|c|c|c|c|c|c|}
\hline \multicolumn{3}{|c|}{ Solar Hot Water } & \multicolumn{3}{|c|}{$\begin{array}{l}\text { Size of System (Sq. feet) } \\
\text { Annual Energy Production () }\end{array}$} \\
\hline \multicolumn{3}{|c|}{$\$ 0$ Baseline Scenario } & \multicolumn{3}{|c|}{$\$ 0$ Optimistic Scenario } \\
\hline 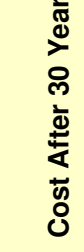 & Cost from Utility & Cost of Solar Thermal & 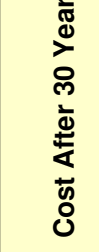 & Cost from Utility & Cost of Solar Thermal \\
\hline $\begin{array}{l}\text { Break } \\
\text { Notes }\end{array}$ & $\begin{array}{l}n \text { Year } \\
\text { a priority }\end{array}$ & 0 & Break & Year & \\
\hline
\end{tabular}

\begin{tabular}{|c|c|c|c|c|c|}
\hline \multicolumn{3}{|c|}{ Wind } & \multicolumn{3}{|c|}{$\begin{array}{l}\text { Size of System (kW) } \\
\text { Annual Energy Production (kWh) }\end{array}$} \\
\hline \multicolumn{3}{|c|}{$\$ 0$ Baseline Scenario } & \multicolumn{3}{|c|}{$\$ 0$ Optimistic Scenario } \\
\hline 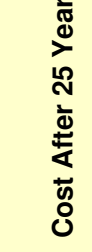 & Cost from Utility & Cost of Wind System & 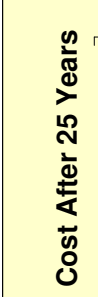 & Cost from Utility & Cost of Wind System \\
\hline $\begin{array}{l}\text { Estim: } \\
\text { Notes: }\end{array}$ & Grant Amour \$ & & Break & Year & \\
\hline
\end{tabular}

\begin{tabular}{|c|c|c|c|c|c|c|}
\hline \multicolumn{3}{|c|}{ Geothermal } & \multicolumn{3}{|c|}{$\begin{array}{l}\text { Size of System } \\
\text { |Annual Energy Savings (kWh / gallons) }\end{array}$} & $\begin{array}{l}0 \\
0 / 0\end{array}$ \\
\hline \multicolumn{3}{|c|}{$\$ 0$ Baseline Scenario } & \multicolumn{4}{|c|}{$\$ 0$ Optimistic Scenario } \\
\hline 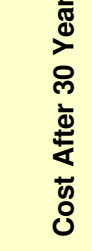 & Cost from Utility & Cost of Geothermal & 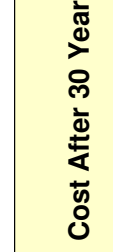 & Cost from Utility & Cost c & f Geothermal \\
\hline $\begin{array}{l}\text { Break } \\
\text { Notes }\end{array}$ & $\begin{array}{l}\text { n Year } \\
t \text { a priority }\end{array}$ & 0 & Break & n Year & & \\
\hline
\end{tabular}




\begin{tabular}{|llll|}
\hline \multicolumn{2}{|l}{ Facility - Bingo Hall } & Space Heating System & Furnace \\
Area $\left(\mathrm{ft}^{2}\right)$ & 13,741 & Space Cooling System & DX \\
Occupany Schedule & w,Th,Sat 6-11 pm/Fri 10am-11pm/Sun 12-6pm & Water Heating System & Electric \\
\hline
\end{tabular}
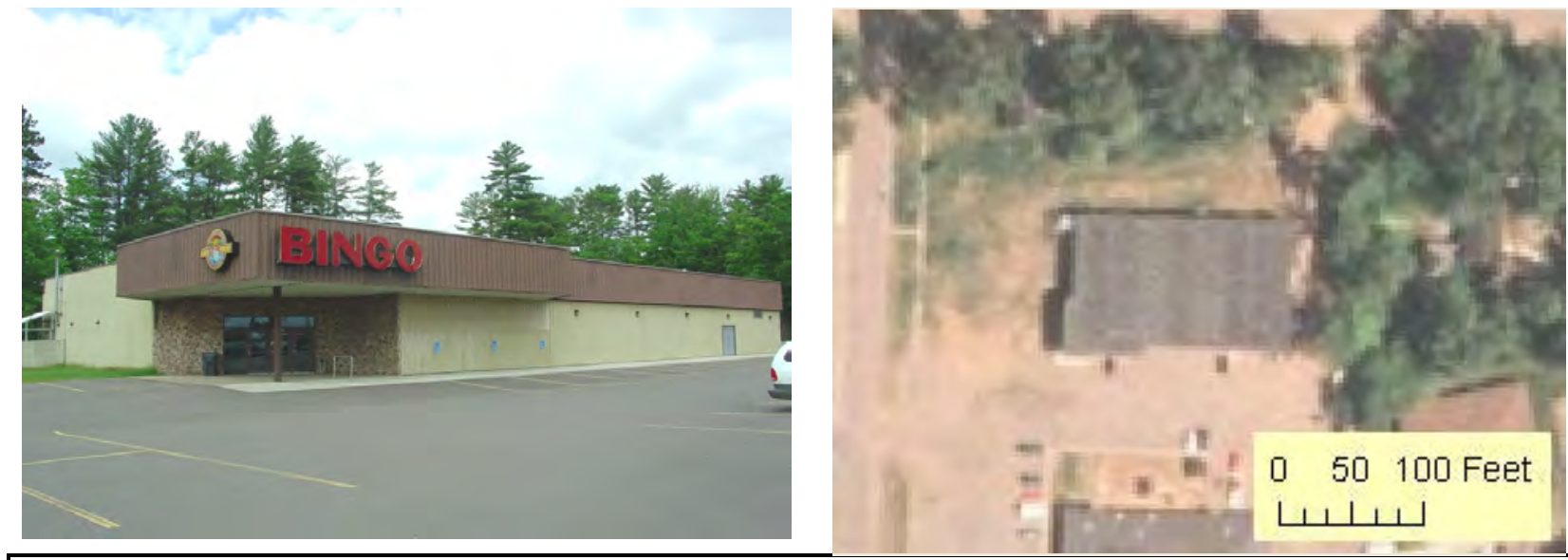

Energy Profile (2007)

\begin{tabular}{|c|c|c|c|}
\hline Electricity & Total & Rank & $\begin{array}{l}\text { Percent } \\
\text { of Tribe }\end{array}$ \\
\hline Consumption kWh & 197,361 & \multirow{2}{*}{9} & \multirow{2}{*}{$1.7 \%$} \\
\hline$($ Cost $)$ & $\$ 20,672$ & & \\
\hline Electricity Intensity & 49.0 & \multirow{2}{*}{9} & \\
\hline$\left(\operatorname{Cost} / \mathbf{f t}^{2}\right)$ & $\$ 1.50$ & & \\
\hline Energy Charge (kWh) & $\$ 0.096$ & & \\
\hline Demand Charge $(\mathrm{kW})$ & $\$ 0.00$ & & \\
\hline
\end{tabular}

\begin{tabular}{|c|c|c|c|}
\hline Propane & Total & Rank & $\begin{array}{l}\text { Percent } \\
\text { of Tribe }\end{array}$ \\
\hline $\begin{array}{c}\text { Consumption gal } \\
\text { (Cost) }\end{array}$ & $\begin{array}{r}\mathbf{1 1 , 5 3 4} \\
\$ 16,840\end{array}$ & 6 & $2.8 \%$ \\
\hline $\begin{array}{c}\text { Propane Intensity } \\
\left(\text { Cost } / \mathbf{f t}^{2}\right)\end{array}$ & $\begin{array}{r}76.7 \\
\$ 1.23 \\
\end{array}$ & 5 & \\
\hline Propane Cost (gal) & & $\$ 1.46$ & \\
\hline
\end{tabular}
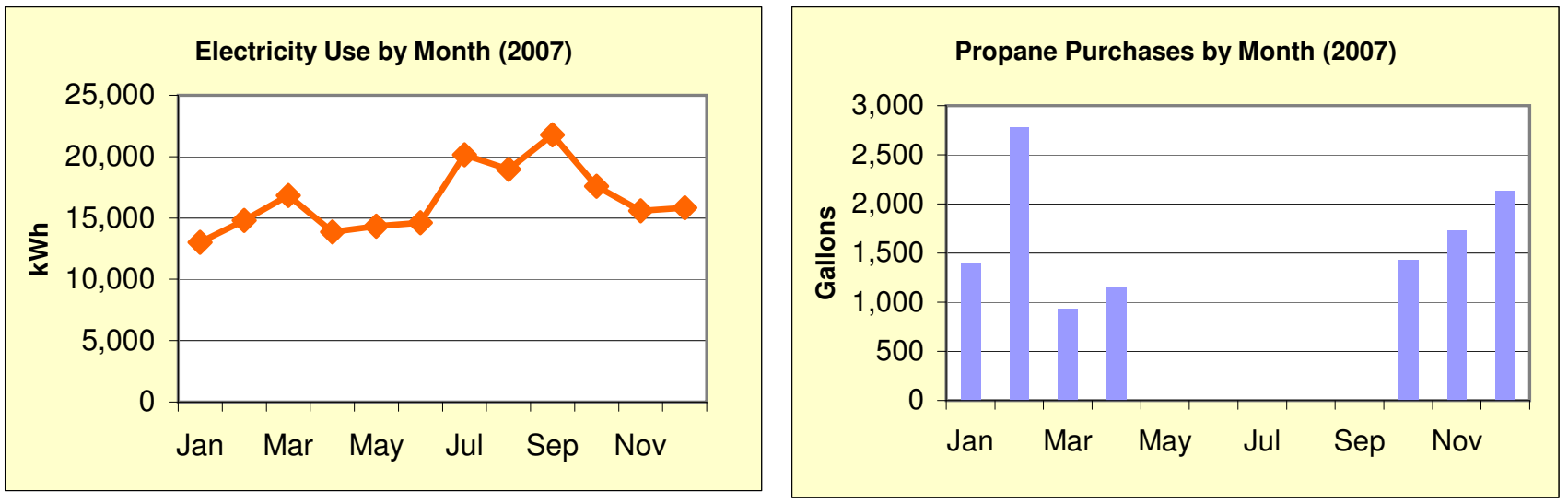

\section{Facility Accounts}

\section{Energy Efficiency Recommendations}

\begin{tabular}{|l|l|r|r|}
\hline \multicolumn{1}{|c|}{ Type } & \multicolumn{1}{c|}{ Rate } & $\begin{array}{c}\text { 2007 Use } \\
\text { (kWh) }\end{array}$ & 2007 Cost \\
\hline Main & Cg 5 & 197,361 & $\$ 18,279$ \\
\hline Outdoor lighting & GY-3 & 0 & $\$ 1,484$ \\
\hline Outdoor lighting & GY-1 & & $\$ 554$ \\
\hline Outdoor lighting & GY-1 & & $\$ 355$ \\
\hline & & & \\
\hline & & & \\
\hline & & & \\
\hline
\end{tabular}

\begin{tabular}{|l|c|c|c|}
\hline Recommendation & $\begin{array}{c}\text { Cost to } \\
\text { Install }\end{array}$ & $\begin{array}{c}\text { Annual } \\
\mathbf{k W h} \\
\text { Savings }\end{array}$ & $\begin{array}{c}\text { Simple Payback } \\
\text { (yrs) }\end{array}$ \\
\hline T8 lighting upgrade & 2000 & 5808 & \\
\hline Install Motion Sensors \\
\hline Tune-ups and filters for heating system \\
\hline Programmable, set-back thermostat \\
\hline Close vents when unoccupied \\
\hline Leave vestible doors closed when heat is on \\
\hline Turn kitchen equipment on only when necessary \\
\hline
\end{tabular}




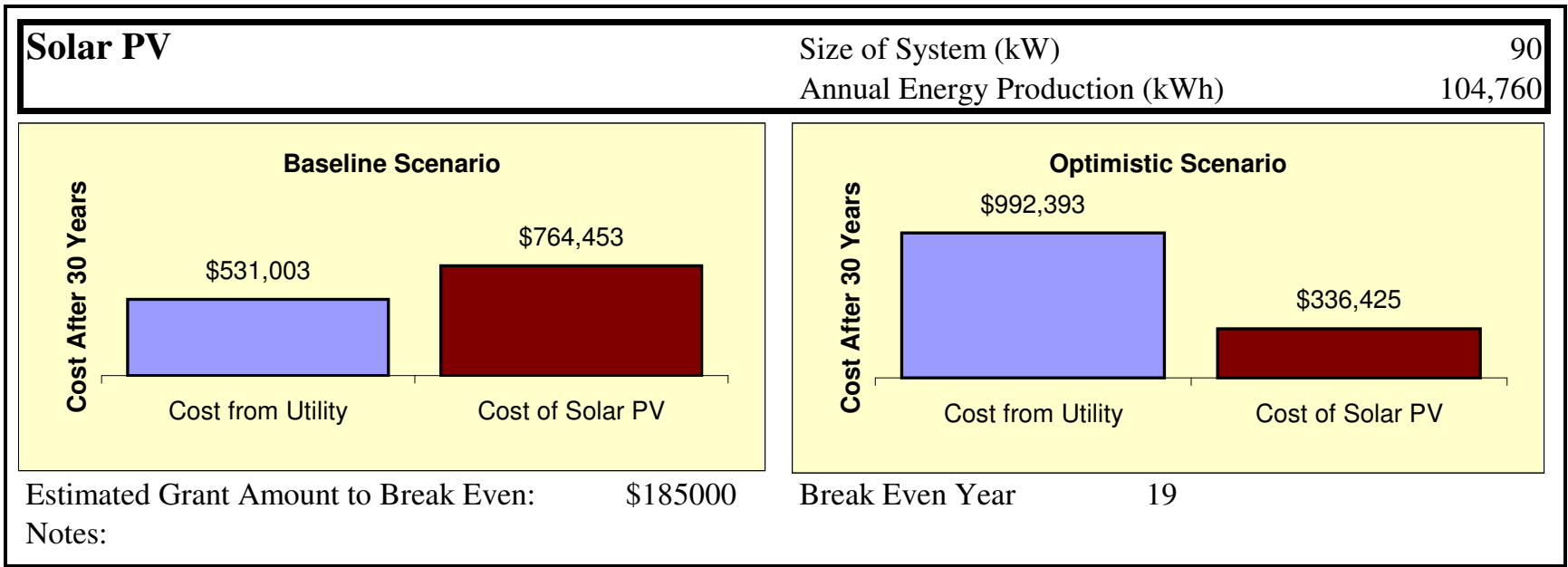

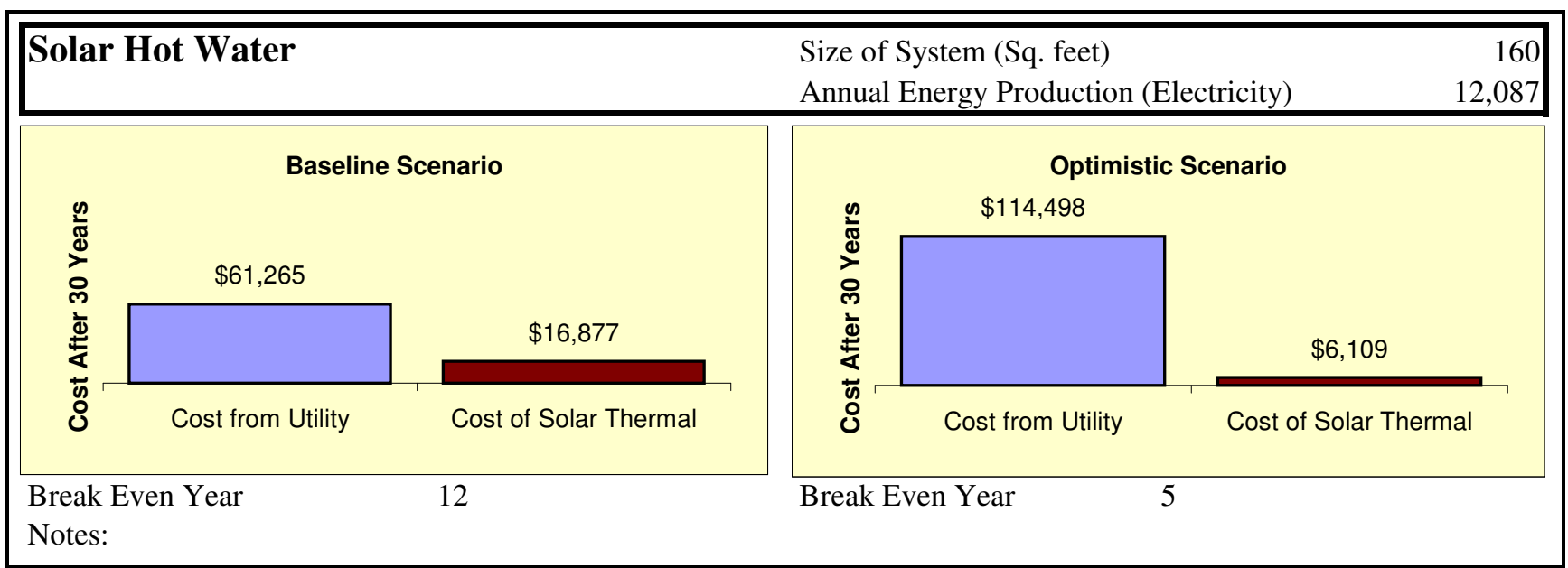

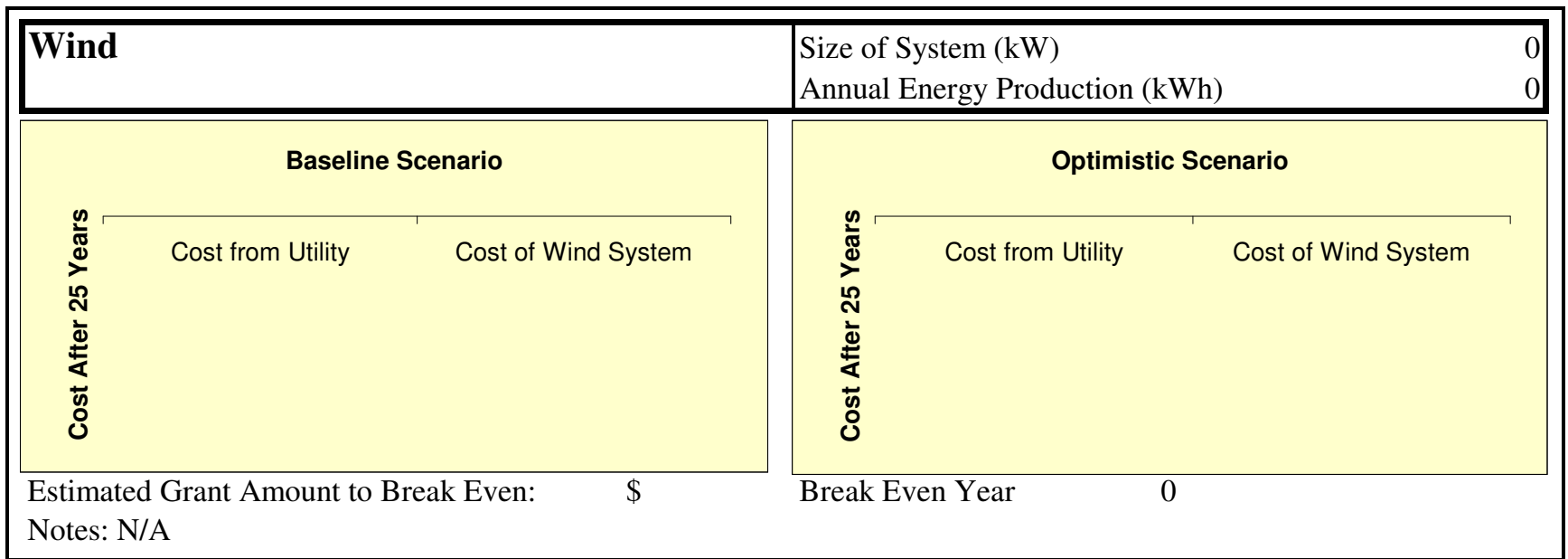

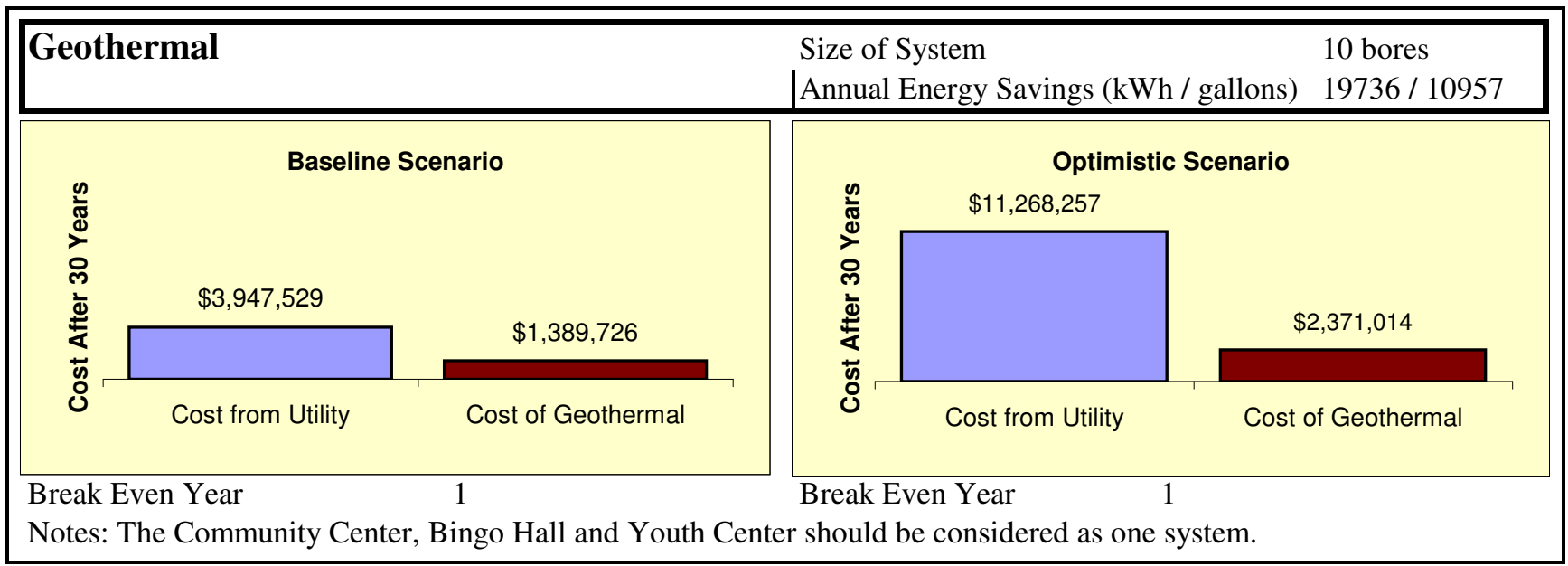

